\title{
TRINCHEIRAS DE INIFILTRAÇÃO COMO TECNOLOGIA ALTERNATIVA EM DRENAGEM URBANA: MODELAGEM EXPERIMENTAL E NUMÉRICA
}

Melissa Cristina Pereira Graciosa

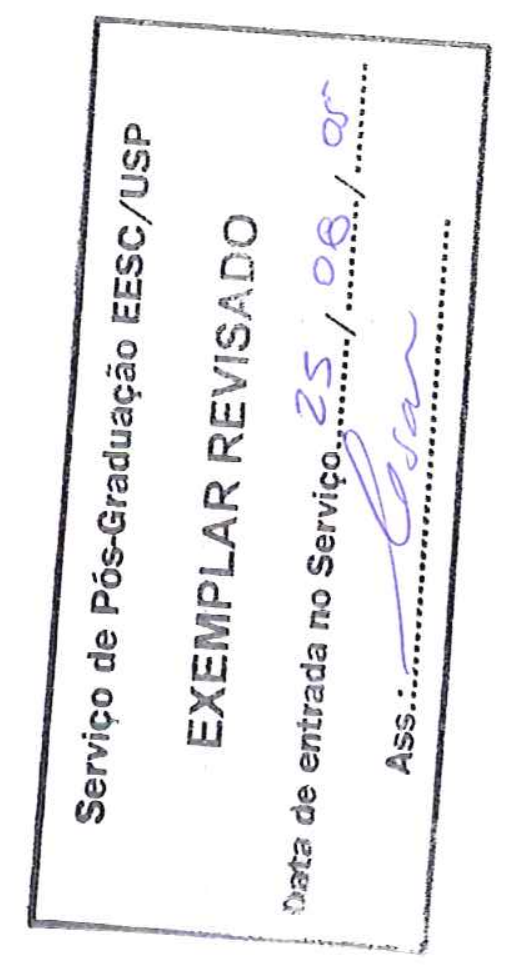

Dissertação apresentada à Escola de Engenharia de São Carlos da Universidade de São Paulo, como parte dos requisitos para a obtenção do título de Mestre em Engenharia Hidráulica e Sanitária.

ORIENTADOR:

Prof. Dr. Eduardo Mario Mendiondo

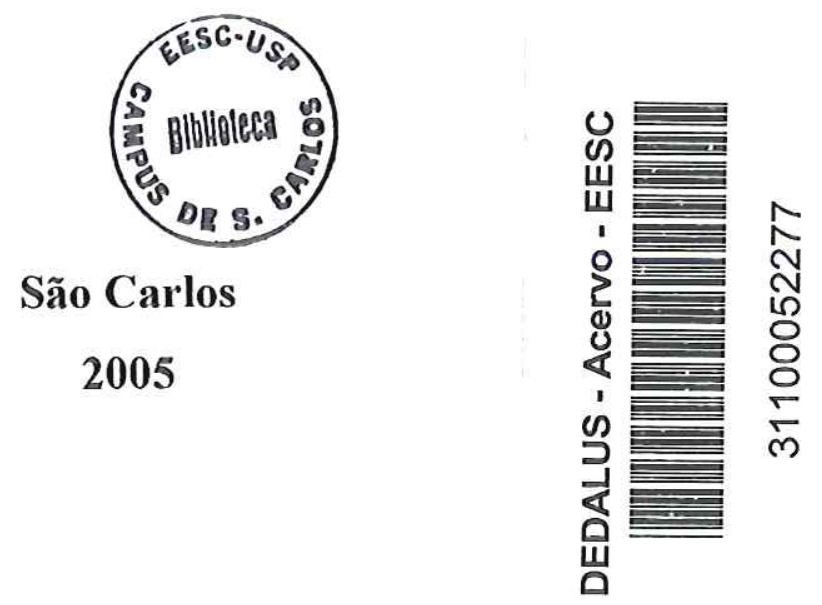


FOLHA DE JULGAMENTO

Candidato: Engenheira MELISSA CRISTINA PEREIRA GRACIOSA

Dissertação defendida e julgada em 17-06-2005 perante a Comissão Julgadora:

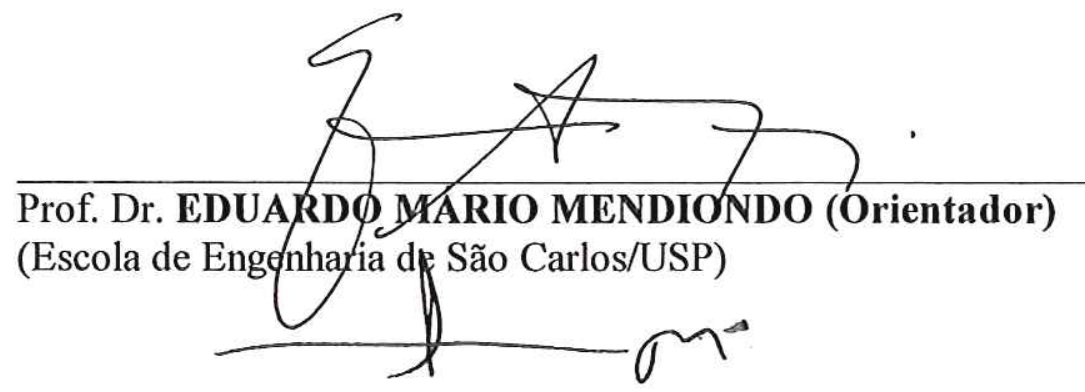

APROVADA

Prof. Dr. EDUARD 9 MARIO MENDIONDO (Orientador)

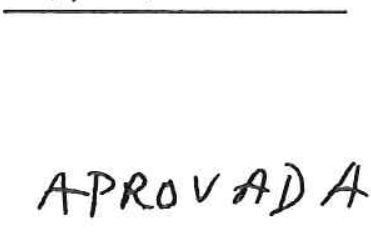

Prof. Titular FAZAL HUSSAIN CHAUDHRY

(Escola de Engenharia de São Carlos/USP)

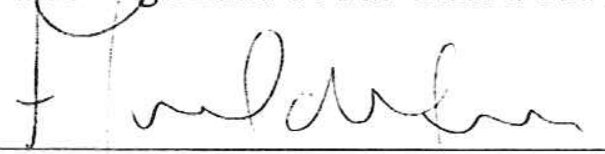

$$
\text { APRIVAA }
$$

Prof. Dr. JOEL AVRUCH GOLDENFUM

(Universidade Federal do Rio Grande do Sul/UFRGS)

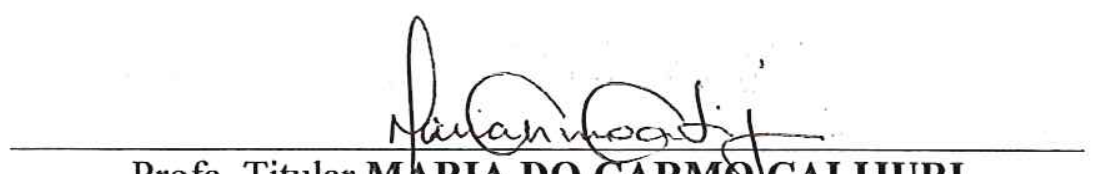

Profa. Titular MARIA DO CARMQ CALIJURI

Coordenadora do Programa de Pós-Graduação em

Engenharia (Hidráulica e Saneamento) e

Presidente da Comissão de Pós-Graduação 
Ao Paulo Roberto. Por ter sido meu primeiro incentivador e, ainda que em memória, sua presença em minha vida me impulsionar sempre em frente. Obrigada, pai. 


\section{AGRADECIMENTOS}

Agradeço, por este trabalho, primeiramente, a Deus. Por ser a origem de toda a ciência e de mim própria; por se fazer presente em cada momento de minha vida, e por ter me dado absolutamente tudo o que foi preciso para chegar até aqui.

Ao Rodrigo Roque, pelo companheirismo e incentivo, pelas horas boas e más, e por ter feito parte desta e de toda a minha história.

À minha família, por todo o apoio e incentivo, especialmente à minha irmã Aline, pela colaboração na etapa final de redação.

Ao professor Fazal Hussain Chaudhry pela orientação, por ter me ensinado o que eu sei sobre ciência, e por ter me proporcionado um modelo de disciplina, ética e profissionalismo, que eu pretendo seguir durante toda a minha carreira;

Ao amigo Fazal, por todo o incentivo, amizade, pelas conversas, pelo apoio nas horas dificeis, especialmente naquelas em que pensei em desistir, e por me dar um exemplo de vida e humanidade, no qual eu quero me espelhar ao longo de toda esta jornada;

Ao professor Eduardo Mario Mendiondo, por ter assumido, com responsabilidade e dedicação, a orientação deste trabalho, quando da aposentadoria de nosso amigo Fazal, me acompanhando até a sua conclusão.

Às amigas Liliane Albertin e Adelena Maia, pelo apoio nas dificuldades, por me ensinar a extrair delas aprendizado e crescimento; pelo exemplo de perseverança e fé, e também por me proporcionar bons momentos de amizade e companheirismo;

Ao amigo Cristiano Almeida, pelo auxílio na etapa de simulação numérica; pelo modelo de dedicação e esforço; e por ter, através do seu exemplo de postura profissional, me fortalecido na certeza de que, em ciência, compartilhar o conhecimento auxilia quem recebe, mas, sobretudo, engrandece quem doa;

Ao Físico Walter Siqueira Paes, do Serviço de Engenharia de Segurança e Medicina do Trabalho da USP, por todo o auxílio prestado nas questões relacionadas à sonda de nêutrons, sem a qual não seria possível o trabalho de campo, e por fazer a "ponte" que liga nós, engenheiros de campo, aos conceitos da Física e da proteção radiológica.

Ao amigo Walter, por tudo. Pelas conversas, pela dedicação, por me mostrar que "pode ser mais simples", por me conhecer tão bem e me ajudar a lidar com as situações limite por que passei, e por ter enfim, me ajudado a fechar este ciclo.

A todos os meus amigos e colegas de departamento: Marcelo "Minduim", Fernando Colombo, Luciana Peixoto, Roberta Bonini, Fernando Braga, Zé Eduardo Alamy, Alexandre Kepler, Klebber Formiga, J. Eduardo Quaresma e tantos outros que, em várias ocasiões, sempre estiveram prontos a me prestar auxílio, confirmando, que todos dependemos uns dos outros, e que é essa constante troca que nos faz crescer como pessoas e profissionais; 
Aos professores do Departamento de Hidráulica e Saneamento, Rodrigo de Melo Porto, Harry Edmar Schulz, Edson Wendland, Luiza Fernanda Ribeiro Reis e outros, que, com empenho e dedicação, se prontificaram a me ajudar em diferentes e importantes ocasiões;

Ao professor e amigo Swami Marcondes Vilela, pela amizade e oportunidades de crescimento profissional que me proporcionou;

À professora, Silvia Claudia Semensato Povinelli, pelo incentivo e apoio ao meu ingresso no meio acadêmico, quando ainda estava na graduação;

Ao professor Ademir Pacelli Barbassa, da UFSCar, pelo incentivo e sugestões;

Ao professor Rubem La Laina Porto, da Escola Politécnica, por participar da avaliação do trabalho, incorporando importantes sugestões e ensinamentos sobre drenagem urbana;

Aos professores Orencio Vilar e Lazaro Zuquetti, do Departamento de Geotecnia da EESC, que disponibilizaram as instalações de seus laboratórios, possibilitando os ensaios de solos;

Ao professor Paulo Leonel Libardi, da Escola Superior de Agricultura Luiz de Queiroz da USP, por todos os ensinamentos sobre Física dos Solos e trabalhos de campo;

Ao professor Manuel Tabuada, do Departamento de Engenharia Rural da Universidade Técnica de Lisboa, por ter disponibilizado seu modelo computacional para sulcos de irrigação, e participado do processo de adaptação do programa para as trincheiras de infiltração;

Ao professor Jackson Röhrig, do Institut für Technologie in den Tropen, da Fachhochschule Köln, pela ótima recepção que tive na Alemanha, e por ter disponibilizado suas instalações e recursos para o meu aprimoramento acadêmico, sobretudo na área de simulação numérica;

Ao Departamento de Pavimentação da Escola Politécnica e ao Instituto de Geociências, pelos equipamentos de campo cedidos;

A todos os técnicos do Departamento de Geotecnia, especialmente ao Oscar, pela prestatividade e dedicação em me auxiliar na condução dos ensaios;

Aos técnicos do Departamento de Hidráulica e Saneamento, que contribuíram para a execução dos trabalhos de campo, especialmente ao Roberto Maramark, o "Betão do Broa", pelas exaustivas e descontraídas horas de campo em que trabalhamos juntos;

Às funcionárias do Departamento de Hidráulica e Saneamento, Sá, Pavi, Rose, Raquel, Flavia, Fernanda, Cecília, Marcia e Valderez, com cuja dedicação sempre pude contar para solucionar as diversas situações cotidianas do trabalho acadêmico;

À Fundação de Amparo à Pesquisa do Estado de São Paulo - FAPESP, pelo fínanciamento deste projeto.

Ao CT-HIDRO-FINEP / EESC/USP / FIPAI / DAEE-SP, pelo convênio "Experimento Piloto de Gerenciamento Integrado de Bacias Urbanas para o Plano Diretor de São Carlos". 


\section{SUMÁRIO}

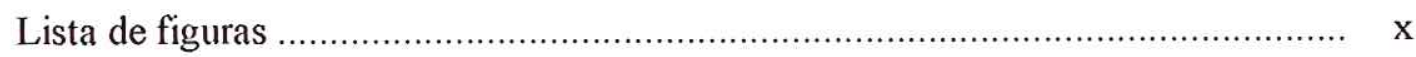

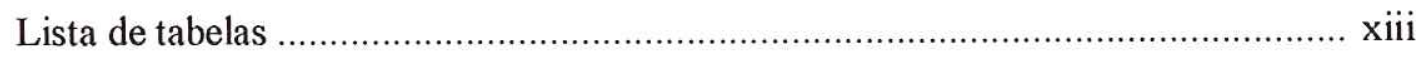

Lista de abreviaturas e siglas ............................................................................... xiv

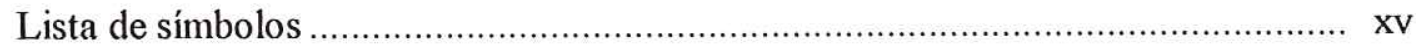

Lista de variáveis do modelo computacional .................................................... xviii

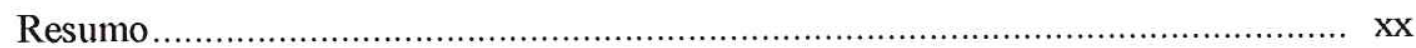

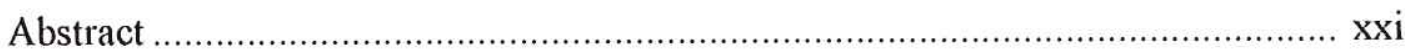

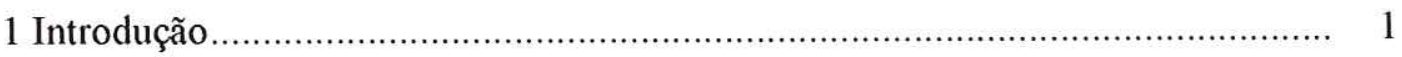

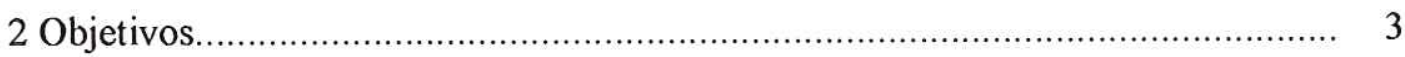

3 Revisão Bibliográfica........................................................................... 4

3.1. Histórico e panorama atual da drenagem urbana ........................................ 4

3.2. Tecnologias alternativas em drenagem urbana ........................................ 8

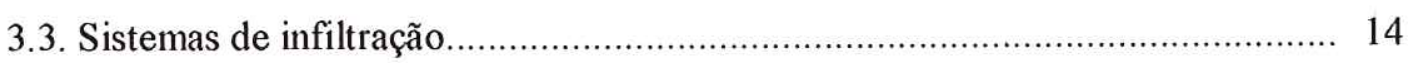

3.3.1. Exemplos de aplicação e simulação de infiltração...................................... 20

3.3.2. Planejamento de sistemas de infiltração ................................................... 24

3.3.3. Dimensionamento de estruturas de infiltração............................................ 27

3.4. Dinâmica da água no solo................................................................ 30

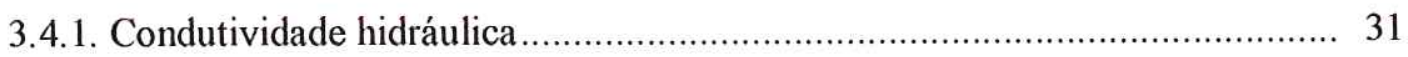

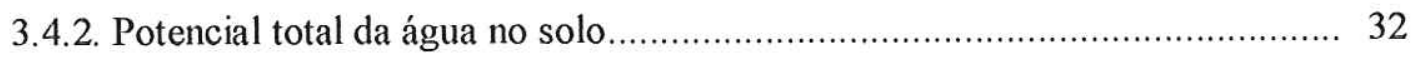

3.4.2.1. Potencial de pressão ............................................................................ 33

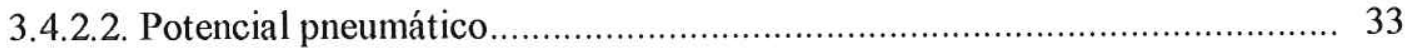

3.4.2.3. Potencial de temperatura .................................................................. 34

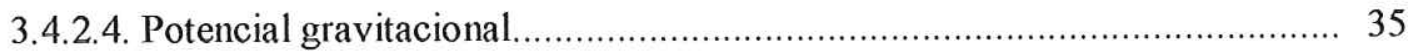

3.4.2.5. Potencial osmótico ............................................................................... 35

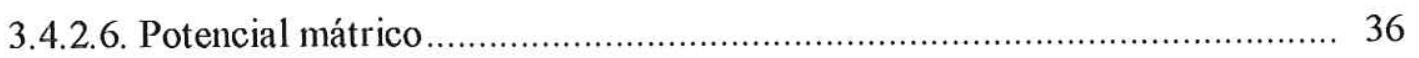

3.4.3. Curva de retenção ............................................................................ 36

Modelo de Brooks e Corey .............................................................. 36

Modelo de Van Genuchten ............................................................... 37

Modelo de Fredlund........................................................................ 37

Fenômeno de histerese ................................................................... 37 


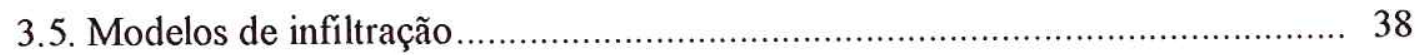

3.5.1. Equação de Green \& Ampt ..................................................................... 39

3.5.2. Equação de Kostiakov ……………….................................................... 39

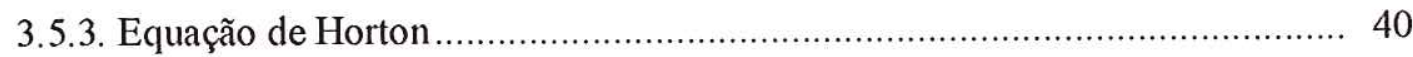

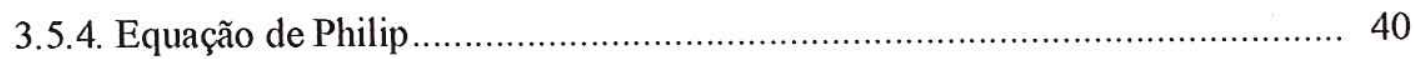

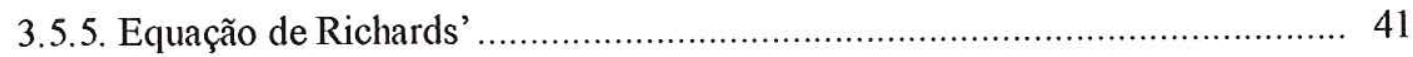

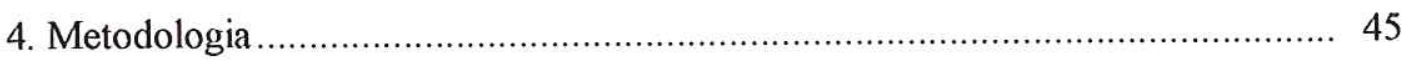

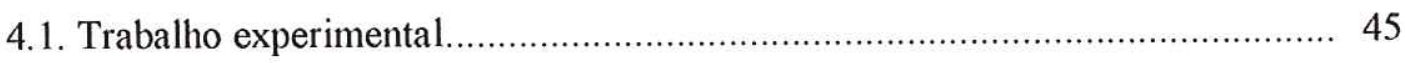

4.1.1. Escolha e classificação dos solos ........................................................ 45

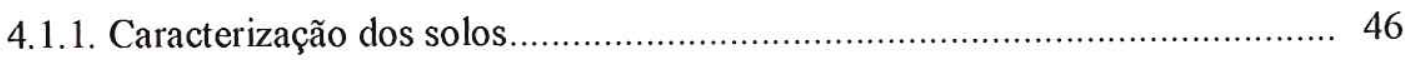

4.1.2.1. Determinação da curva de retenção....................................................... 46

4.1.2.2. Determinação da condutividade hidráulica saturada ............................. 53

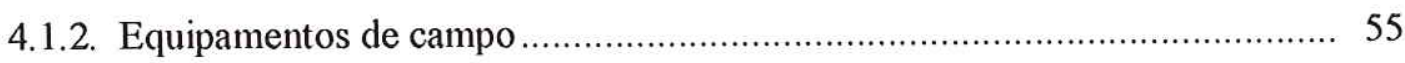

Sonda de nêutrons......................................................................... 55

Calibração da sonda de nêutrons .......................................................... 57

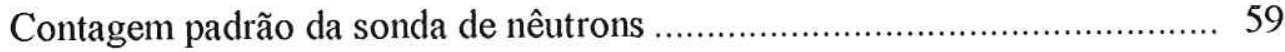

Proteção radiológica no uso da sonda de nêutrons .................................... 59

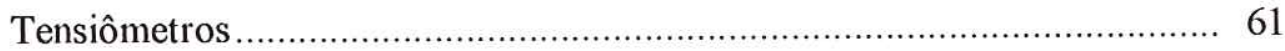

4.1.3. Determinação da condutividade hidráulica não saturada ............................ 62

4.1.4. Ensaios com trincheiras experimentais.................................................... 64

Transdutores de pressão........................................................................... 65

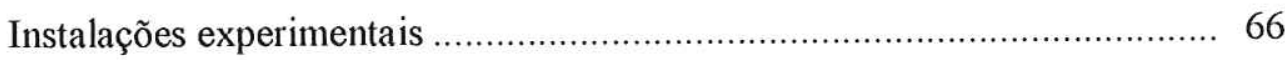

Condução dos ensaios e processamento dos dados ................................... 69

4.2. Modelagem numérica ..................................................................... 71

4.2.1. Simulação numérica - procedimento …….......................................... 79

5. Resultados e discussões ........................................................................ 80

5.1. Caracterização dos solos.................................................................... 80

5.1.1. Análise granulométrica conjunta...................................................... 80

5.1.2. Curva de retenção........................................................................... 81

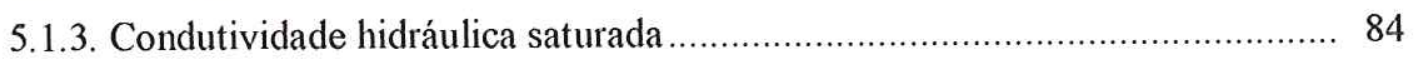

5.1.4. Calibração da sonda de nêutrons........................................................ 86 


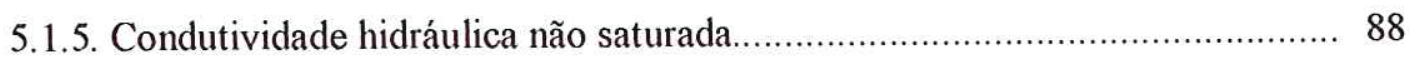

5.2. Ensaios com trincheiras de infiltração.......................................................... 95

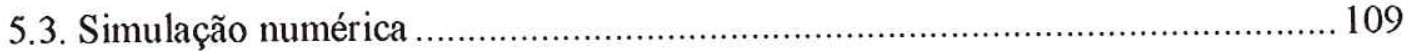

6. Modelo computacional - estrutura e manual de instruções .................................. 136

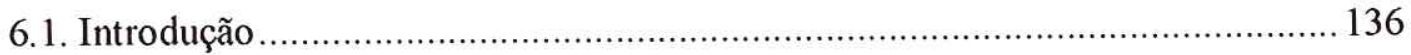

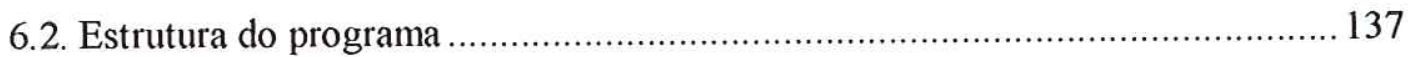

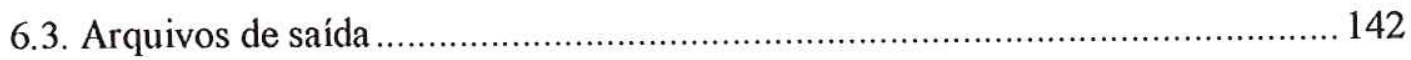

6.4. Informações necessárias para a simulação da infiltração em trincheiras ............ 143

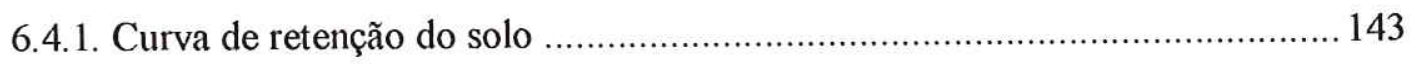

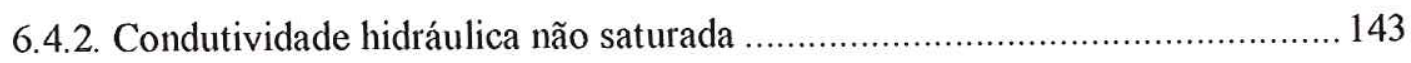

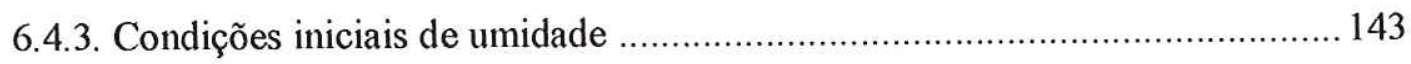

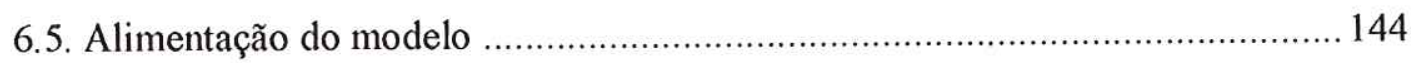

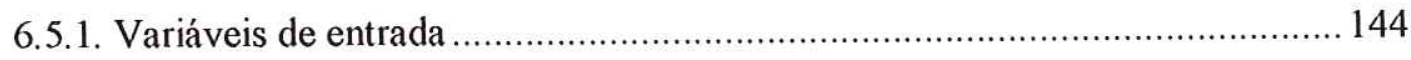

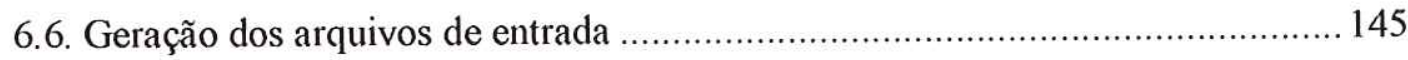

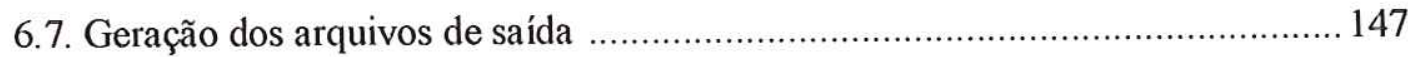

7. Dimensionamento de trincheiras de infiltração .............................................. 149

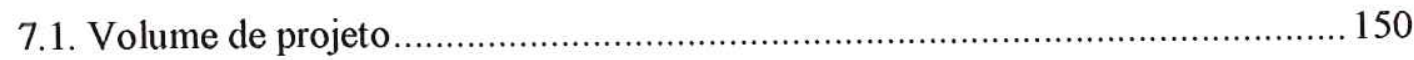

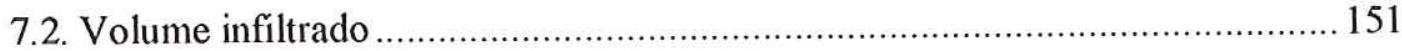

7.2.1. Método A - Baseado no modelo horizontal de Philip.................................. 151

7.2.2. Método B - Baseado no modelo bidimensional de Richards' ...................... 152

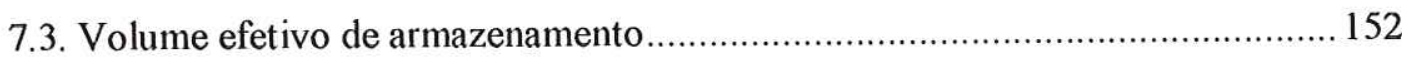

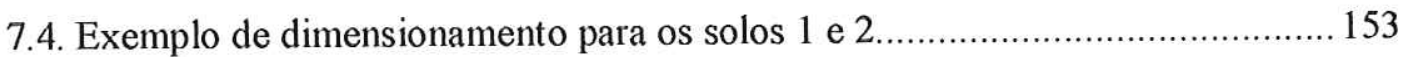

7.5. Estimativa de custos de implantação................................................................ 154

8. Estimativa da redução do escoamento superfícial em uma micro bacia pelo uso de trincheiras de infiltração ..................................................................... 155

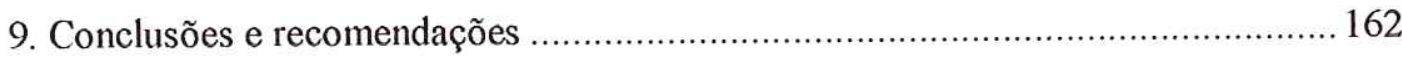

9.1. Escolha de dois solos de propriedades hidráulicas distintas e realização de ensaios de campo e laboratório para sua caracterização 162

9.2. Realização de experimentos de infiltração em trincheiras para quantificar a variação do volume infiltrado e do desenvolvimento do campo de umidade ... 163

9.3. Modelagem do fenômeno bidimensional de infiltração em torno de trincheiras 
e comparação entre os resultados experimentais e numéricos .......................... 164

9.4. Proposta de uma metodologia de dimensionamento de trincheiras .................... 165

9.5. Estimativa simplificada da redução no hidrograma da bacia proporcionada

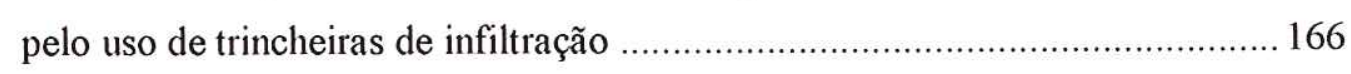

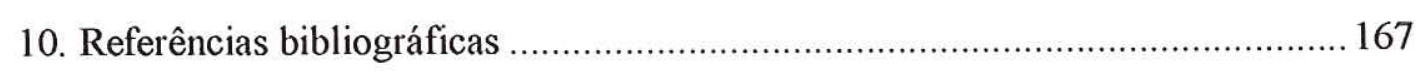

ANEXO I - Relatório de análise de segurança radiológica.................................... 171

ANEXO II - Registros na Comissão Nacional de Energia Nuclear ......................... 183

ANEXO III - Código fonte do modelo de infiltração .............................................. 186 


\section{LISTA DE FIGURAS}

Figura 3.1 - Efeitos da urbanização sobre a distribuição das águas na bacia hidrográfica 5

Figura 3.2 - Aumento da vazão dos rios Tamanduateí e Tietê, na RMSP …................................... 7

Figura 3.3 - Fases da degradação da drenagem natural ................................................................. 7

Figura 3.4 - Esquema de funcionamento de um piscinão "off line" . ............................................. 11

Figura 3.5 - Esquema de funcionamento de um reservatório de detenção no lote ............................. 13

Figura 3.6 - Esquema de pavimento poroso .............................................................................. 15

Figura 3.7 - Exemplos de modelos de trincheiras de infiltração ....................................................... 16

Figura 3.8 - Exemplo de trabalho conjunto entre vala gramada de percolação e trincheira subterrânea de infíltração ...................................................................................... 18

Figura 3.9 - Proposta de sistema de trincheiras de infiltração implantado em loteamentos ............... 19

Figura 3.10 - Sistema de gerenciamento de águas de chuva implantado em Figtree Place, New

Castle, Australia ................................................................................................ 22

Figura 3.11 - Hidrogramas de entrada dos sistemas de infiltração on-line e off-line ....................... 29

Figura 3.12 - Exemplo da influência dos processos de secagem e umdedecimento na forma da curva de retenção .................................................................................................. 37

Figura 4.1 - Bloco de solo indeformado, envolto em parafina e preso por chapas de metal ............. 46

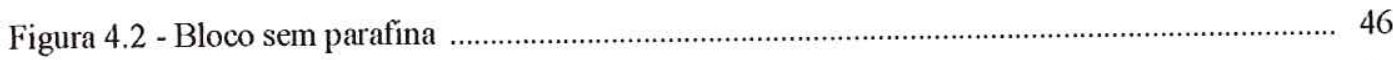

Figura 4.3 - Retirada da amostra cilíndrica ................................................................................. 47

Figura 4.4 - Processo de saturação das amostras de solo................................................................ 47

Figura 4.5 - Esquema da câmara de pressão de Richards ................................................................. 48

Figura 4.6 - Câmara de pressão de Ridhards' ................................................................................... 49

Figura 4.7 - Câmaras de pressão conectadas a um sistema de injeção e medição de pressão.............. 49

Figura 4.8 - Tela de inicialização do CurvaRet ............................................................................. 50

Figura 4.9 - Tela de entrada de dados do CurvaRet ......................................................................... 50

Figura 4.10 - Tela de saída de dados do CurvaRet ........................................................................ 51

Figura 4.11 - Ambiente de trabalho do Systat .............................................................................. 51

Figura 4.12 - Tela de inserção do modelo no Systat ......................................................................... 52

Figura 4.13 - Tela de saída de dados do Systat ............................................................................ 52

Figura 4.14 - Permeâmetro de carga constante ................................................................................. 53

Figura 4.15 - Esquema de funcionamento da sonda de nêutrons ..................................................... 55

Figura 4.16 - Sonda de nêutrons utilizada neste trabalho ............................................................... 56

Figura 4.17 - Monitoramento das doses de radiação com detetor Geiger-Muller ................................ 60

Figura 4.18 - Ensaio de condutividade hidráulica em campo........................................................... 62

Figura 4.19 - Esquema de funcionamento do sistema de transdutores ............................................. 64

Figura 4.20 - Transdutor de pressão e amplificador de sinais .............................................................. 65

Figura 4.21 - Tela do software da placa de aquisição de dados do sistema de transdutores ............... 65 
Figura 4.22 - Esquema da instalação experimental............................................................................ 67

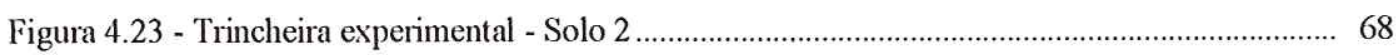

Figura 4.24 - Esquema do sulco de irrigação ……........................................................................... 73

Figura 4.25 - Esquema da trincheira de infiltração .......................................................................... 73

Figura 4.26 - Discretizção do domínio para a solução do sulco de irrigação ...................................... 73

Figura 4.27 - Discretização do domínio para a solução da trincheira de infilitração........................... 74

Figura 4.28 - Fluxograma do modelo BidiSul..................................................................................... 77

Figura 5.1 - Curva granulométrica do Solo 1 …......................................................................... 79

Figura 5.2 - Curva granulométrica do Solo 2 …....................................................................... 80

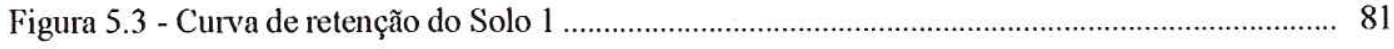

Figura 5.4 - Curva de retenção do Solo 2 …...................................................................................... 82

Figura 5.5 - Curva de retenção do Solo 2 - escalonada ................................................................ 82

Figura 5.6 - Curva de retenção do Solo 2 - escalonada …............................................................... 83

Figura 5.7 - Calibração da sonda de nêutrons ................................................................................. 86

Figura 5.8 - Perfís de umidade volumétrica do Solo 1, ao longo de 15 dias de irrigação, até z=1,50. 88

Figura 5.9 - Perfis de umidade volumétrica do Solo 2, ao longo de 15 dias de irrigação, até z=1,50. 88

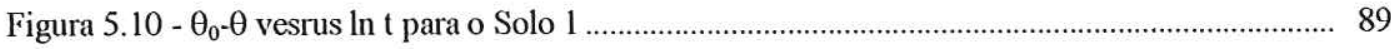

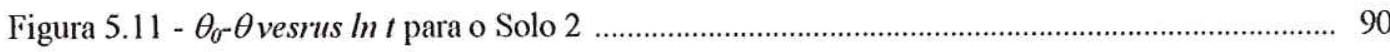

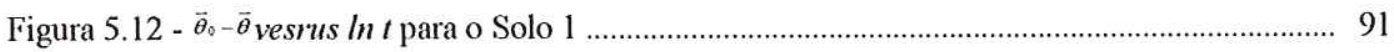

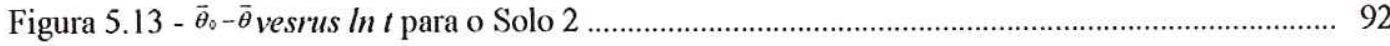

Figura 5.14 - Ajuste dos dados de infiltração ao modelo de infíltração horizontal de Philip - Solo 197

Figura 5.15 - Ajuste dos dados de infiltração ao modelo de infíltração horizontal de Philip - Solo 297

Figura 5.16 - Volumes de entrada, armazenamento e infiltração - Solo 1 .......................................... 98

Figura 5.17 - Volumes de entrada, armazenamento e infiltração - Solo 2 …..................................... 98

Figura 5.18 - Perfil de umidade observado - Solo 1 ........................................................................ 100

Figura 5.19 - Perfil de umidade observado - Solo 2 ..................................................................... 102

Figura 5.20 - Campo de umidade interpolado ................................................................................ 104

Figura 5.21 - Arquivo de entrada da simulação A para o Solo 1 - valores iniciais de h..................... 109

Figura 5.22 - Arquivo de entrada da simulação A para o Solo 1 - dados de entrada........................... 109

Figura 5.23 - Arquivo de entrada da simulação A para o Solo 2 - valores iniciais de h...................... 110

Figura 5.24 - Arquivo de entrada da simulação A para o Solo 2 - valores iniciais de h...................... 110

Figura 5.25 - Evolução do nível d'água na tricheira Solo 1 - simulados e observados....................... 113

Figura 5.26 - Evolução do nível d'água na tricheira Solo 1 - simulados e observados....................... 114

Figura 5.27 - Simulação A - Solo 1 - Perfil de umidade simulado ...................................................... 115

Figura 5.28 - Simulação A - Solo 2 - Perfil de umidade simulado ..................................................... 118

Figura 5.29 - Arquivo com os valores iniciais de h para a simulação B - Solo 1 ................................ 122

Figura 5.30 - Arquivo com os valores iniciais de h para a simulação B - Solo 2 ............................... 122 
Figura 5.31 - Evolução do nível d'água na trincheira, Solo 1, Simulações A e B

Figura 5.32 - Evolução do nível d'água na trincheira, Solo 2, Simulações A e B................................ 126

Figura 5.23 - Simulação B - Solo 1 - Perfil de umidade simulado ..................................................... 128

Figura 5.24 - Simulação B - Solo 2 - Perfil de umidade simulado ..................................................... 131

Figura 6.1 - Arquivo de entrada com os valores iniciais de sucção matricial ......................................... 145

Figura 6.2 - Arquivo de dados com as variáveis de entrada do modelo ............................................. 145

Figura 6.3 - Exemplo de arquivo de saída - SoilMoist.dat ............................................................. 146

Figura 6.4 - Exemplo de arquivo de saída - WaterLevel.dat ...................................................... 147

Figura 8.1 - Esquema representativo do escoamento superficial em uma microbacia urbana............. 155 


\section{LISTA DE TABELAS}

Tabela 4.1 - Condições de contorno do modelo de infilttração bidimensional ................................... 75

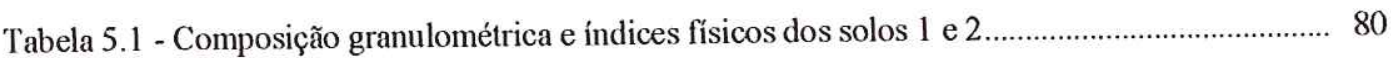

Tabela 5.2 - Resultados do ajuste da curva de retenção modelo de Van Genuchten ........................... 81

Tabela 5.3 - Ensaio de condutividade hidráulica saturada para o Solo 1 ........................................... 84

Tabela 5.4 - Ensaio de condutividade hidráulica saturada para o Solo 2 ......................................... 85

Tabela 5.5 - Parâmetros da equação de condutividade hidráulica não saturada ................................. 93

Tabela 5.6 - Variação do volume na trincheira durante a alimentação e recessão - Solo 1 ................. 95

Tabela 5.7 - Variação do volume na trincheira durante a alimentação e recessão - Solo 2 ................. 96

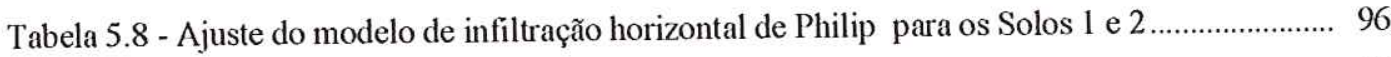

Tabela 5.9 - Acompanhamento da redistribuição - Solo 1 - Valores de umidade................................ 99

Tabela 5.10 - Acompanhamento da redistribuição - Solo 2 - Valores de umidade................................ 100

Tabela 5.11 - Fases de alimentação e recessão: Simulação A - valores de lâmina d'água e volume infiltrado, simulados e observados, Solos 1 e 2 ............................................ 111

Tabela 5.12 - Fases de alimentação e recessão: Simulação B - valores de lâmina d'água e volume infiltrado, Solos 1 e 2 .................................................................................. 123

Tabela 7.1 - Estimativa de custos diretos de implantação de uma trincheira de infíltração................. 153

Tabela 8.1 - Valores do coefíciente de escoamento superficial C adotados pela Prefeitura Municipal de São Paulo

Tabela 8.2 - Valores do coeficiente k (SCS, 1975). 157 


\section{LISTA DE ABREVIATURAS E SIGLAS}

$\begin{array}{lll}\text { ABNT } & - & \text { Associação Brasileira de Normas Técnicas } \\ \text { BIDISUL } & - & \text { Sulcos Bidimensionais de Infiltração } \\ \text { CNEN } & - & \text { Comissão Nacional de Energia Nuclear } \\ \text { CRHEA } & - & \text { Centro de Recursos Hídricos e Ecologia Aplicada } \\ \text { EESC } & - & \text { Escola de Engenharia de São Carlos } \\ \text { ESALQ } & - & \text { Escola Superior de Agricultura Luiz de Queiroz } \\ \text { FAPESP } & - & \text { Fundação de Amparo à Pesquisa do Estado de São Paulo } \\ \text { IDF } & - & \text { Intensidade Duração Freqüência } \\ \text { NBR } & - & \text { Norma Brasileira Registrada } \\ \text { PVC } & - & \text { Poli Cloreto de Vinila } \\ \text { SCS } & - & \text { Soil Conservation Service } \\ \text { USP } & - & \text { Universidade de São Paulo }\end{array}$




\section{LISTA DE SÍMBOLOS}

\begin{tabular}{|c|c|c|}
\hline a & - & Parâmetro de ajuste da curva idf \\
\hline$A_{1}$ & - & Área Lateral da trincheira de infiltração, $\mathrm{m}^{2}$ \\
\hline$A_{i, j}$ & - & Coeficiente de linearização da equação do modelo de infiltração \\
\hline$A_{\text {inf }}$ & - & Área efetiva de infiltração, $\mathrm{m}^{2}$ \\
\hline $\mathrm{b}$ & - & Parâmetro de ajuste da curva idf \\
\hline B & - & Largura da trincheira, $\mathrm{m}$ \\
\hline c & - & Parâmetro de ajuste da curva idf \\
\hline $\mathrm{C}$ & - & Sortividade, parâmetro de ajuste da Equação de Philip \\
\hline $\mathrm{C}$ & - & Contagem da sonda de nêutrons \\
\hline $\mathrm{C}_{\mathrm{p}}$ & - & Contagem padrão da sonda de nêutrons \\
\hline g & - & Aceleração da gravidade, $\mathrm{m} / \mathrm{s}^{2}$ \\
\hline $\mathrm{G}_{\mathrm{i}, \mathrm{j}}$ & - & Coeficiente de linearização da equação do modelo de infiltração \\
\hline $\mathrm{h}$ & - & Profundidade da trincheira, $\mathrm{m}$ \\
\hline $\mathrm{H}$ & - & Deslocamento da coluna de mercúrio, $\mathrm{mm}$ \\
\hline$h_{c}$ & - & Distância entre o nível de mercúrio, na cuba, e a superficie do solo, m \\
\hline $\mathrm{H}_{0}$ & - & Potencial de pressão constante na superfície do solo, $\mathrm{mH} 2 \mathrm{O}$ \\
\hline Hf & - & Potencial mátrico constante na frente de molhamento, $\mathrm{mH} 2 \mathrm{O}$ \\
\hline $\mathrm{i}$ & - & Intensidade de precipitação, $\mathrm{mm} / \mathrm{h}$ \\
\hline $\mathrm{i}$ & - & Taxa de infiltração, $\mathrm{m}^{3} / \mathrm{s} \cdot \mathrm{m}^{2}$ \\
\hline I & - & Infiltração acumulada até o instante $\mathrm{t}, \mathrm{m}^{3} / \mathrm{m}^{2}$ \\
\hline $\mathrm{i}_{\mathrm{i}}$ & - & Taxa de infiltração em $\mathrm{t}=0, \mathrm{~m}^{3} / \mathrm{s} \cdot \mathrm{m}^{2}$ \\
\hline $\mathrm{i}_{\mathrm{f}}$ & - & Taxa de infiltração constante em $\mathrm{t} \rightarrow \infty, \mathrm{m}^{3} / \mathrm{s} . \mathrm{m}^{2}$ \\
\hline $\mathrm{k}_{\mathrm{f}}$ & - & Fator de forma da bacia hidrográfica, $\mathrm{m} / \mathrm{m}$ \\
\hline $\mathrm{k}(\theta)$ & - & Condutividade hidráulica não saturada, m/s \\
\hline $\mathrm{K}$ & - & Condutividade hidráulica saturada, $\mathrm{m} / \mathrm{s}$ \\
\hline 1 & - & Comprimento da trincheira, $\mathrm{m}$ \\
\hline $\mathrm{L}$ & - & Comprimento da coluna saturada, $\mathrm{m}$ \\
\hline $\mathrm{m}$ & - & Coefíciente de ajuste da equação de Van Genuchten \\
\hline $\mathrm{m}_{\mathrm{a}}$ & - & Massa de água, $\mathrm{g}$ \\
\hline
\end{tabular}




\begin{tabular}{|c|c|c|}
\hline$m_{0}$ & - & Massa da cápsula, g \\
\hline $\mathrm{m}_{\mathrm{s}}$ & - & Massa de solo, $\mathrm{g}$ \\
\hline n & - & Coeficiente de ajuste da equação de Van Genuchten \\
\hline q & - & Densidade de fluxo, $\mathrm{m} / \mathrm{s}$ \\
\hline $\mathrm{q}_{\mathrm{a}}$ & - & Vazão de descarga específica, $\mathrm{m}^{3} / \mathrm{s} \cdot \mathrm{m}^{2}$ \\
\hline $\mathrm{q}_{\mathrm{fr}}$ & - & Taxa média de infiltração, m/s \\
\hline$Q_{\text {fr }}$ & - & Vazão de infiltração, $\mathrm{m}^{3} / \mathrm{s}$ \\
\hline Qout & - & Vazão vertida, m³/s \\
\hline $\mathrm{q}_{\mathrm{p}}$ & - & Vazão de pico do hidrograma unitário, $\mathrm{m}^{3} / \mathrm{s}$ \\
\hline $\mathrm{P}$ & - & Pressão externa atuante na fase sólidos-água-ar no solo, $\mathrm{kg} / \mathrm{m} \cdot \mathrm{s}^{2}$ \\
\hline $\mathrm{P}_{0}$ & - & Pressão atuante na fase estado padrão, $\mathrm{kg} / \mathrm{m} \cdot \mathrm{s}^{2}$ \\
\hline $\mathrm{P}_{\mathrm{ar}}$ & - & Pressão de ar na fase sólidos-água-ar, $\mathrm{kg} / \mathrm{m} \cdot \mathrm{s}^{2}$ \\
\hline $\mathrm{P}_{\mathrm{ar} 0}$ & - & Pressão de ar na fase estado padrão, $\mathrm{kg} / \mathrm{m} \cdot \mathrm{s}^{2}$ \\
\hline $\mathrm{P}_{\mathrm{osm}}$ & - & Pressão osmótica, $\mathrm{kg} / \mathrm{m} . \mathrm{s}^{2}$ \\
\hline$P_{1}$ & - & Pressão de líquido, $\mathrm{kg} / \mathrm{m} . \mathrm{s}^{2}$ \\
\hline $\mathrm{P}_{\mathrm{atm}}$ & - & Pressão atmosférica, $\mathrm{kg} / \mathrm{m} \cdot \mathrm{s}^{2}$ \\
\hline $\mathrm{t}$ & - & Tempo de precipitação, minutos \\
\hline t & - & Tempo, s \\
\hline $\mathrm{T}$ & - & Período de retorno, anos \\
\hline $\mathrm{T}$ & - & Temperatura da fase sólidos-água-ar no solo, ${ }^{\circ} \mathrm{C}$ \\
\hline $\mathrm{T}_{0}$ & - & Temperatura da fase estado padrão, ${ }^{\circ} \mathrm{C}$ \\
\hline$t_{e}$ & - & Tempo de esvaziamento, min \\
\hline$t_{p}$ & - & Tempo para atingir o pico do hidrograma, min \\
\hline $\mathrm{U}$ & - & Umidade gravimétrica, g/g \\
\hline $\mathrm{V}$ & - & Volume do sistema, $\mathrm{m}^{3}$ \\
\hline $\mathrm{V}_{\text {aef }}$ & - & Volume efetivo de armazenamento, $\mathrm{m}^{3}$ \\
\hline $\mathrm{V}, \mathrm{V}_{\mathrm{s}}$ & - & Volume útil de armazenamento, $\mathrm{m}^{3}$ \\
\hline $\mathrm{V}_{\mathrm{af}}$ & - & Volume afluente, $\mathrm{m}^{3}$ \\
\hline $\mathrm{V}_{\mathrm{ef}}$ & - & Volume efluente, $\mathrm{m}^{3}$ \\
\hline $\mathrm{V}_{\mathrm{p}}$ & - & Volume de projeto, $\mathrm{m}^{3}$ \\
\hline
\end{tabular}


$\mathrm{V}_{\text {prec }} \quad$ - Volume de água precipitado sobre a área de contribuição, no intervalo de tempo considerado, $\mathrm{m}^{3}$

$\mathrm{V}_{\text {inf }} \quad$ Volume de água infiltrado, no intervalo de tempo considerado, $\mathrm{m}^{3}$

$\mathrm{V}_{\mathrm{t}} \quad$ - Volume de armazenamento da trincheira, $\mathrm{m}^{3}$

z $\quad$ - Distância entre a superfície do solo e o centro da cápsula porosa do tensiômetro

Z - Distância vertical, em relação a um dado referencial, da fase sólidos-água-ar

$Z_{0} \quad$ - Distância vertical, em relação a um dado referencial, da fase estado padrão

$\alpha \quad$ - Parâmetro de ajuste da equação de Van Genuchten

$\Delta \mathrm{h} \quad$ - $\quad$ Diferença de carga total, $\mathrm{mH}_{2} \mathrm{O}$

$\phi \quad$ - $\quad$ Porosidade da brita, $\%$

$\phi_{\mathrm{g}} \quad$ - Potencial gravitacional da água no solo, $\mathrm{cmH}_{2} \mathrm{O}$

$\phi_{\mathrm{m}} \quad$ - Potencial mátrico da água no solo, $\mathrm{cmH}_{2} \mathrm{O}$

$\phi_{m a} \quad$ - Potencial mátrico que corresponde à entrada de $\mathrm{ar}, \mathrm{cmH}_{2} \mathrm{O}$

$\phi_{\mathrm{mr}} \quad$ - Potencial mátrico que corresponde à umidade volumétrica residual, em $\mathrm{cm}_{\mathrm{H} 2 \mathrm{O}}$;

$\phi_{\mathrm{n}} \quad$ - Potencial pneumático da água no solo, $\mathrm{cmH}_{2} \mathrm{O}$

$\phi_{0} \quad$ - Potencial osmótico da água no solo, $\mathrm{cmH}_{2} \mathrm{O}$

$\phi_{\mathrm{p}} \quad$ - $\quad$ Potencial de pressão da água no solo, $\mathrm{cmH}_{2} \mathrm{O}$

$\phi_{\mathrm{t}} \quad$ - Potencial total da água no solo, $\mathrm{cmH}_{2} \mathrm{O}$

$\phi_{\mathrm{T}} \quad$ - Potencial de temperatura da água no solo, $\mathrm{cmH}_{2} \mathrm{O}$

$\gamma \quad$ - Parâmetro da equação que define a função matemática para $\mathrm{k}(\theta)$

$\gamma_{\mathrm{w}} \quad$ - Peso específico da água, $\mathrm{kg} / \mathrm{m}^{3}$

$\mu_{a} \quad$ - Potencial químico da água no solo, $\mathrm{J} / \mathrm{m}^{3}$

$\theta \quad$ - Umidade volumétrica, $\mathrm{cm}^{3} / \mathrm{cm}^{3}$;

$\theta_{0} \quad$ - Umidade volumétrica inicial, $\mathrm{cm}^{3} / \mathrm{cm}^{3}$

$\theta_{\mathrm{r}} \quad$ - Umidade volumétrica residual, $\mathrm{cm}^{3} / \mathrm{cm}^{3}$

$\theta_{\mathrm{s}} \quad$ - Umidade volumétrica de saturação, $\mathrm{cm}^{3} / \mathrm{cm}^{3}$

$\rho_{\mathrm{a}} \quad$ - Densidade da água, $1000 \mathrm{~kg} / \mathrm{m}^{3}$

$\rho_{\mathrm{Hg}} \quad$ - Densidade do mercúrio, $13600 \mathrm{~kg} / \mathrm{m}^{3}$

$\rho_{r} \quad$ - Densidade aparente, ou densidade relativa do solo, $\mathrm{g} / \mathrm{cm}^{3}$

$v \quad$ - Volume específico de armazenamento, $\mathrm{m}^{3}$ 


\section{LISTA DE VARIÁVEIS DO MODELO COMPUTACIONAL}

\begin{tabular}{|c|c|c|}
\hline $\operatorname{AIJ}(i, j)$ & - & Coeficiente de linearização da equação do modelo \\
\hline ACTIV & - & Diferença de potencial para ativar o aumento do perfil \\
\hline ALFA & - & Parâmetro da equação de Van Genuchten \\
\hline $\operatorname{BIJ}(\mathrm{i}, \mathrm{j})$ & - & Coeficiente de linearização da equação do modelo \\
\hline BETA & - & Coeficiente $\mathrm{n}$ da equação de Van Genuchten \\
\hline BETA11 & - & Coeficiente $m$ da equação de Van Genuchten \\
\hline $\mathrm{C}(\mathrm{i}, \mathrm{j})$ & - & Derivada da função de umidade volumétrica em relação ao tempo \\
\hline CANG & - & Tangente do ângulo de inclinação do talude da trincheira \\
\hline DELTAT & - & Discretização do tempo, segundos \\
\hline DELTAX & - & Discretização do espaço na direção horizontal, $\mathrm{cm}$ \\
\hline DELTAZ & - & Discretização do espaço na direção vertical, $\mathrm{cm}$ \\
\hline $\operatorname{DIJ}(\mathrm{i}, \mathrm{j})$ & - & Coeficiente de linearização da equação do modelo \\
\hline $\operatorname{EIJ}(i, j)$ & - & Coefíciente de linearização da equação do modelo \\
\hline $\operatorname{FIJ}(i, j)$ & - & Coeficiente de linearização da equação do modelo \\
\hline$H(i, j)$ & - & Potencial mátrico, $\mathrm{cmH}_{2} \mathrm{O}$ \\
\hline $\operatorname{HM}(\mathrm{i}, \mathrm{j})$ & - & Matriz de incidência \\
\hline H1(i) & - & Vetor com as incógnitas \\
\hline $\mathrm{HI}(\mathrm{i}, \mathrm{j})$ & - & Potencial mátrico inicial, $\mathrm{cmH}_{2} \mathrm{O}$ \\
\hline HTEMPALI & - & Altura da lâmina d'água durante o tempo de alimentação, $\mathrm{cm}$ \\
\hline INCR & - & Incremento de linhas do perfil \\
\hline $\operatorname{KAPA}(i, j)$ & - & Condutividade hidráulica, $\mathrm{cm} / \mathrm{s}$ \\
\hline LAG & - & Altura da lâmina d'água, $\mathrm{cm}$ \\
\hline LCOMP & - & Comprimento da trincheira, $\mathrm{cm}$ \\
\hline NCS & - & Número de colunas à superfície \\
\hline NCF & - & Número de colunas no fundo da trincheira \\
\hline NLS & - & Número de linhas da trincheira \\
\hline NLSCA & - & Número de linhas da trincheira com água \\
\hline NLSSA & - & Número de linhas da trincheira sem água \\
\hline NTC & - & Número total de colunas \\
\hline NTL & - & Número total de linhas \\
\hline
\end{tabular}




\begin{tabular}{|c|c|c|}
\hline NVEZES & - & Número de vezes para aumentar o perfil \\
\hline NZDREN & - & Profundidade de drenagem, $\mathrm{cm}$ \\
\hline NPN1 & - & Número de linhas da matriz de incidência \\
\hline NPN2 & - & Número de colunas da matriz de incidência \\
\hline Q & - & Vazão fornecida à trincheira, $\mathrm{cm}^{3} / \mathrm{s}$ \\
\hline $\mathrm{T}$ & - & Tempo decorrido desde o início da simulação, $\mathrm{s}$ \\
\hline TEMPO & - & Intervalo de tempo para o traçado das eqüipotenciais, $\mathrm{s}$ \\
\hline TTREG & - & Tempo total de irrigação, s \\
\hline $\operatorname{TETA}(i, j)$ & - & Umidade volumétrica, $\mathrm{cm}^{3} / \mathrm{cm}^{3}$ \\
\hline $\operatorname{TETAI}(\mathrm{i}, \mathrm{j})$ & $\overline{-}$ & Umidade volumétrica inicial, $\mathrm{cm}^{3} / \mathrm{cm}^{3}$ \\
\hline $\operatorname{TETAR}(i, j)$ & - & Umidade volumétrica residual, $\mathrm{cm}^{3} / \mathrm{cm}^{3}$ \\
\hline $\operatorname{TETAS}(\mathrm{i}, \mathrm{j})$ & - & Umidade volumétrica de saturação, $\mathrm{cm}^{3} / \mathrm{cm}^{3}$ \\
\hline VOL1 & - & Volume total infiltrado, $\mathrm{cm}^{3}$ \\
\hline
\end{tabular}




\section{RESUMO}

A infiltração das águas de chuva dentro dos lotes urbanos é uma possível forma de promover o controle descentralizado do escoamento superficial na origem, com vistas ao gerenciamento das águas pluviais urbanas e conseqüente atenuação das cheias. Neste trabalho, foram conduzidos ensaios de campo com trincheiras de infiltração, em dois solos distintos, um arenoso e outro argiloso, com o objetivo de avaliar quantitativamente o comportamento hidráulico das estruturas de infiltração em resposta a volumes de escoamento. As trincheiras foram alimentadas com volumes de água controlados, e o campo de umidade do experimento foi monitorado com sonda de nêutrons, durante o processo de redistribuição da água no solo. Foi realizada a modelagem matemática do fenômeno bidimensional de infiltração em torno de trincheiras de seção retangular, em resposta à entrada de águas pluviais provenientes de áreas impermeabilizadas contíguas. A comparação entre os resultados experimentais e simulados pela equação bidimensional de Richards' indica uma pequena defasagem dos valores de volume infiltrado e umidade do solo nos processos de infiltração e drenagem interna simulados em relação aos observados. A capacidade de infiltração da trincheira mostrou-se maior nos dados observados, possivelmente devido à simplificação de distribuição unimodal dos diâmetros dos poros adotada na modelagem numérica, uma vez que, experimentalmente, observou-se multimodalidade nos dois solos estudados. A curva de van Genuchten é, juntamente com a equação de Richards', a base do modelo computacional, e divergências no seu ajuste em relação aos dados observados podem conduzir a pequenas divergências dos volumes infiltrados e perfis de umidade ao longo do processo de infiltração simulado, em relação ao observado. São apresentadas algumas considerações de dimensionamento sobre a implantação de trincheiras de infiltração em lotes residenciais, bem como discussões com respeito aos planos diretores urbanos. É apresentado um estudo simplificado, baseado no método racional, sobre a redução no hidrograma de cheia proporcionada pelo uso de trincheiras em uma micro bacia urbana, o qual revelou reduções da ordem de até $94 \%$ do deflúvio superficial direto gerado pelo lote .

\section{Palavras-chave}

Trincheiras de infiltração; controle do escoamento superficial na origem; ensaios de infiltração; gerenciamento de águas pluviais urbanas; sistemas descentralizados de drenagem urbana, plano diretor de drenagem urbana. 


\begin{abstract}
Stormwater infiltration process at the scale of housing is a possible way to promote the decentralized runoff control in order to manage the urban water and to attenuate flood peaks. In this work, field essays with infiltration devices at two different soils, either sandy and clayloam soils, are assessed in order to study the hydraulic behavior of infiltration trenches to attenuate incoming runoff volume inputs. The infiltration trench experiments set a controlled water supply for specific boundary conditions, and the experimental moisture field were monitored with neutron probe during the water redistribution process at soil core. Bidimensional (2D) mathematical modeling is depicted at specific boundary conditions with a rectangular-trench layout, thereby mimicking a potential situation of runoff incoming from adjacent impervious areas. The comparison between experimental and numerical results, simulated by two-dimensional Richards' Equation, shows a small lag-time difference of both infiltrated volumes and soil moisture contents during infiltration and drainage periods. The trench infiltration capacity of observed data appears to be greater than simulated results, possibly due to an overall simplification of a uni-modal, homogeneous pore diameter distribution adopted by the modeling scheme. Experimental retention curves outline indirect evidences of multi-modal, heterogeneous behavior of pore structure. Bon van Genutchen-type retention curve and Richards-momentum equations represent the baseline approach to the computational model of non-saturated soils. Some fitting discrepancies between observed and simulated results could lead to negligible different estimations of infiltrated volumes and moisture profiles. Finally, further discussions on project design and best management practices (BMPs) of infiltration trenches at housing scale as well discussions on Urban Master Plan are outlined herewith. A simplified study, based on rational method, is presented on the reduction of incoming hydrograph with the use of infiltration trenches. Preliminary results perform volume reductions of approximately $94 \%$ from incoming runoff generated at housing lots.
\end{abstract}

\title{
Key-words
}

Infiltration trenches; source control of the runoff; field infiltration experiments; urban rainwater management and control; decentralized urban drainage systems; urban stormwater planning. 


\section{INTRODUÇÃO}

O problema das cheias urbanas vem sendo tratado com freqüência como um dos principais desafios a serem vencidos pela Engenharia atual, tendo em vista os inúmeros transtornos causados à população dos municípios atingidos por enchentes periódicas.

A princípio, o que determina a propensão de uma bacia hidrográfica à ocorrência de enchentes é o seu fator de forma $\mathrm{k}_{f}$, expresso pela relação entre a largura média e o comprimento da bacia. Quanto menor o valor de $\mathrm{k}_{\mathrm{f}}$, maior a propensão ao armazenamento de águas pluviais, ou seja, bacias de forma achatada tendem a acumular mais água que as de geometria longa e estreita.

No entanto, com o processo de urbanização, especialmente quando este ocorre sem o planejamento adequado, surgem novos fatores que influenciam a ocorrência de enchentes. O principal deles é a impermeabilização das áreas por pavimentos, pátios e telhados. Sem a atenuação, a interceptação e a infiltração do escoamento proporcionados pela cobertura vegetal, aumentam os volumes de cheia e vazões de pico do hidrograma da bacia. Com a continuidade do processo de ocupação desordenada de toda a área da bacia, e, principalmente, das baixadas e áreas de várzea, as redes de micro e macro drenagem tornam-se subdimensionadas, incapazes de veicular a vazão adicional.

Os sistemas de drenagem urbana, da forma como têm sido concebidos, têm por objetivo conduzir o escoamento o mais rápido possível para os cursos d'água próximos, agravando o quadro de enchentes à jusante das áreas onde é gerado o escoamento superficial.

Tradicionalmente, a problemática das cheias urbanas é vista pela ótica da construção ou ampliação de obras hidráulicas que possam contê-las. No entanto, os órgãos públicos responsáveis nem sempre possuem recursos suficientes para materializar soluções estruturais, ou estas são fisicamente inviáveis por uma série de razões, de modo que os problemas de enchentes permanecem sem solução, ou com soluções pouco duradouras. 
A ineficiência dos sistemas de drenagem urbana causa impactos negativos principalmente no setor econômico e na saúde pública dos municípios atingidos, devido às muitas perdas materiais associadas às enchentes e à natureza de veiculação hídrica da maior parte das doenças atendidas em postos de saúde públicos.

Recentemente tem havido, por parte dos órgãos tomadores de decisão em recursos hídricos, a busca de soluções para tais problemas que focalizem as razões fundamentais dos mesmos, e venham ao encontro do conceito de desenvolvimento urbano sustentado. As soluções buscadas consistem na tentativa de restabelecer as condições naturais de regularização das cheias na bacia, ou atender à vazões de restrições pré-determinadas. Uma possível forma de recuperar tais condições é recorrer à infiltração ou à retenção das águas de chuva no lote urbano onde são geradas, promovendo o retardamento e diminuição do escoamento superficial, e a conseqüente redução dos volumes e picos do hidrograma.

Estes sistemas de controle do escoamento, chamados sistemas de controle na origem, vêm sendo objeto de pesquisa e têm sido implementados com êxito em diversas bacias hidrográficas em todo o mundo. No entanto, ainda existem lacunas a serem preenchidas, com relação aos aspectos de dimensionamento, construtivos e de eficácia de tais soluções.

Neste trabalho, estudou-se um sistema de controle do escoamento superficial na origem, baseado na infiltração das águas pluviais por meio de trincheiras de infiltração. $O$ aspecto estudado foi o comportamento hidráulico de tais estruturas, em resposta a eventos de chuva simulados. Foram realizados experimentos com trincheiras instaladas em dois tipos distintos de solo, e os resultados obtidos foram confrontados com os dados fornecidos por um modelo numérico de simulação, baseado nas equações de Richards' e Philip para o escoamento em solo não saturado, desenvolvida em sua forma bidimensional. 


\section{OBJETIVOS}

O objetivo deste trabalho é estudar o comportamento hidráulico de trincheiras de infiltração como dispositivos alternativos no gerenciamento de águas pluviais urbanas, para o controle do escoamento superficial e o auxílio à recarga do aqüífero subterrâneo. Especificamente, pode-se delinear os seguintes objetivos:

i. Escolha de dois solos de propriedades hidráulicas distintas e realização de ensaios de campo e laboratório para sua caracterização;

ii. Realização de experimentos de infiltração em trincheiras para quantificar a variação do volume infiltrado e o desenvolvimento do campo de umidade;

iii. Modelagem do fenômeno bidimensional de infiltração em torno de trincheiras de seção retangular, em resposta à entrada de águas pluviais provenientes de áreas impermeabilizadas contíguas;

iv. Comparação entre os resultados experimentais e numéricos;

v. Proposta de uma metodologia de dimensionamento de trincheiras de infiltração;

vi. Apresentar, de forma simplificada, a redução no hidrograma da bacia proporcionada pelo uso do sistema de trincheiras. 


\section{REVISÃO BIBLIOGRÁFICA}

Na presente síntese, são apresentados os tópicos gerais relacionados à problemática das enchentes em bacias hidrográficas urbanas, bem como as possíveis soluções, baseadas em técnicas convencionais e alternativas em engenharia de drenagem de águas pluviais.

\subsection{Histórico e panorama atual da drenagem urbana}

O sistema natural de drenagem em uma bacia hidrográfica é composto pelos caminhos percorridos pelo escoamento superficial, quando as características físicas da bacia ainda não foram afetadas pela intervenção humana (Makropoulos et al., 1999). O relevo e a vegetação naturais contribuem para a atenuação do escoamento superficial, retardando sua chegada aos cursos d'água receptores (Andoh e Declerck, 1997). O processo natural de interceptação pela vegetação e infiltração das águas de chuva favorece que os volumes e picos de cheia sejam condizentes com a capacidade de veiculação de vazão das calhas dos rios (Makropoulos et al., 1999).

Com a urbanização da bacia, as construções e pavimentações diminuem a permeabilidade da área, e, conseqüentemente, o volume de água infiltrado no subsolo (Makropoulos et al., 1999; Andoh e Declerck, 1997). A urbanização introduz, na bacia hidrográfica, grandes áreas de superficies impermeáveis, alterando a vegetação e as características do solo, e, portanto, as condições de drenagem (Lawrence et al., 1996).

Em decorrência disto, aumenta-se o escoamento superficial ou deflúvio direto, e medidas devem ser tomadas de modo a encaminhar convenientemente as águas pluviais.

As Figuras 3.1a e 3.1b ilustram o processo de aumento do escoamento superficial devido à urbanização de uma bacia hidrográfica. 


\section{Bacia em Estado Natural}

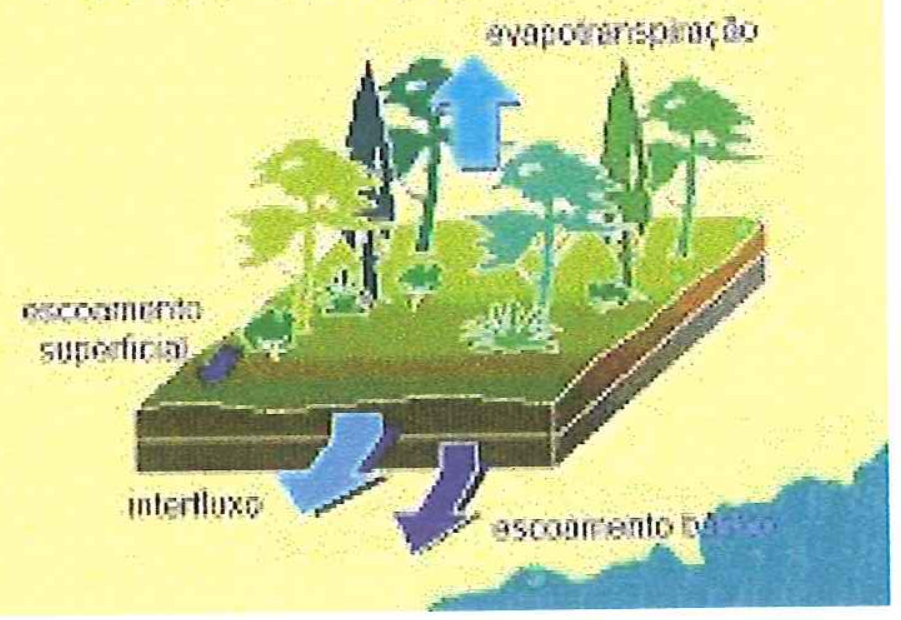

(a)

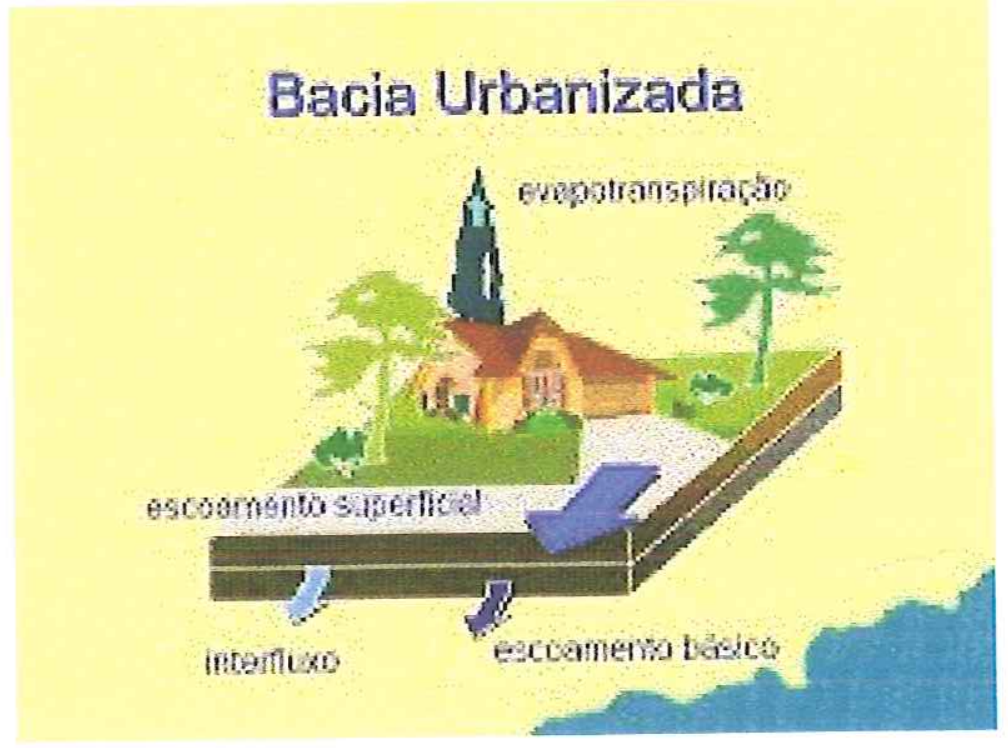

(b)

Figura 3.1 - Efeitos da urbanização sobre a distribuição das águas na bacia hidrográfica. Fonte: Domingues, A. F., 2004. ${ }^{1}$

Ao longo da história, a drenagem urbana desenvolveu-se com o único objetivo de promover o transporte hidráulica e economicamente eficaz do escoamento superficial de áreas urbanas para os cursos d'água próximos (Sieker,F.,1998). De fato, até mesmo a bibliografia que se tinha disponível no Brasil sobre drenagem urbana, até poucos anos atrás, consistia, basicamente, de manuais de projeto de galerias, sarjetas e bueiros. Nos

\footnotetext{
1 Apresentação da palestra "Conservação e Reuso de Água" de Antônio Felix Domingues, Superintendente de Conservação de Água e Solo da Agência Nacional de Águas - Ana, em 7/10/04, no 76 ENIC - Encontro Nacional da Indústria da Construção, Vitória-ES.
} 
últimos anos, tem-se observado que tal postura em relação às águas pluviais causa impactos significativos na macrodrenagem (Ellis e Marsalek, 1996).

A tendência da urbanização é ocorrer no sentido de jusante para montante, devido às características de relevo (Tucci, C. E. M., 1995). Os municípios exigem, de novos loteamentos, projetos de drenagem urbana eficientes apenas no sentido de escoar as águas pluviais, sem se preocupar com o acréscimo da vazão sobre o restante da bacia.

O aumento da freqüência de enchentes a jusante ocorre pela sobrecarga da microdrenagem sobre a macrodrenagem, e, as áreas mais afetadas, devido à construção das novas habitações a montante são as mais antigas, localizadas à jusante.

De fato, há exemplos de cursos d'água cuja vazão de pico aumentou mais de quinze vezes durante um século de urbanização da bacia contribuinte, como é o caso ilustrado na Figura 3.2, de dois importantes rios da Região Metropolitana de São Paulo - RMSP, o Tietê e um de seus principais afluentes, o Tamanduateí. Segundo o Departamento de Águas e Energia Elétrica do Estado de São Paulo - DAEE, em sua Revista Águas e Energia Elétrica - RAEE, de outubro/98, em 1893, a vazão máxima do Tamanduateí, na Várzea do Carmo, era de $30 \mathrm{~m}^{3} / \mathrm{s}$. Depois de passar por índices de $120 \mathrm{~m}^{3} / \mathrm{s}$ (1930) e de $484 \mathrm{~m}^{3} / \mathrm{s}$ (1977), a estimativa, em 1998, era de $800 \mathrm{~m}^{3} / \mathrm{s}$. A calha atual foi projetada para $480 \mathrm{~m}^{3} / \mathrm{s}$ nesse trecho. Na edição da RAEE de abril/99, é apresentado o caso do rio Tietê. No trecho compreendido entre a foz do Tamanduateí e Osasco, a vazão de projeto do plano de 1894 era de $174 \mathrm{~m}^{3} / \mathrm{s}$, passando a $400 \mathrm{~m}^{3} / \mathrm{s}$ no projeto de Saturnino Brito (1925); 650 $\mathrm{m}^{3} / \mathrm{s}$ no Plano HIBRACE (1968) e $1.188 \mathrm{~m}^{3} / \mathrm{s}$ no Projeto PROMON, de 1986 . Os estudos de enchentes elaborados pelo Consórcio HIDROPLAN (1995) já indicaram valores cerca de $20 \%$ superiores aos obtidos no Projeto PROMON (1). Esta mesma defasagem entre capacidades e demandas hidrológicas também é verificada em diversos rios e córregos que sofreram intervenções na RMSP. 


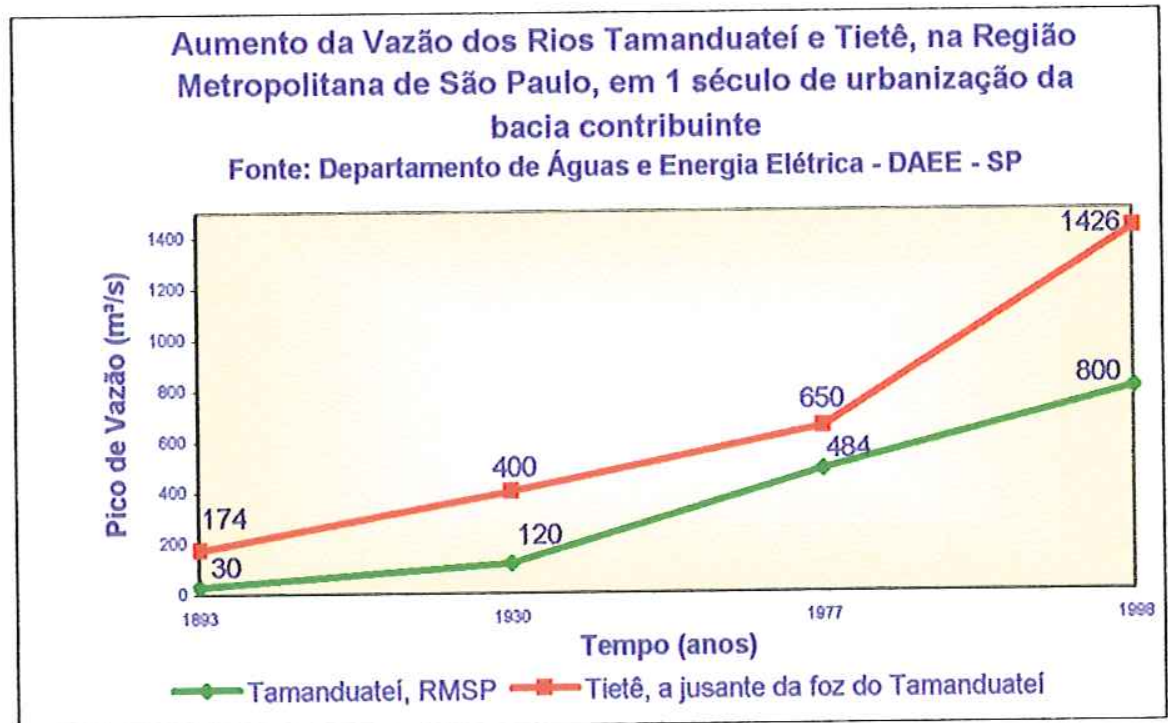

Figura 3.2 - Aumento da vazão dos rios Tamanduateí e Tietê, na RMSP. Fonte: Revista Águas e Energia Elétrica, publicação do Departamento de Águas e Energia Elétrica do Estado de São Paulo - DAEE-SP, edições de outubro/98 e abril/99.

Quando os leitos dos rios, muitas vezes canalizados, tornam-se incapazes de veicular a vazão adicional proveniente da impermeabilização, e/ou quando as margens estão urbanizadas, instala-se o quadro de enchentes periódicas nos meses de chuva. A Figura 3.3 ilustra a situação típica da calha de um canal da macrodrenagem antes e após a urbanização.
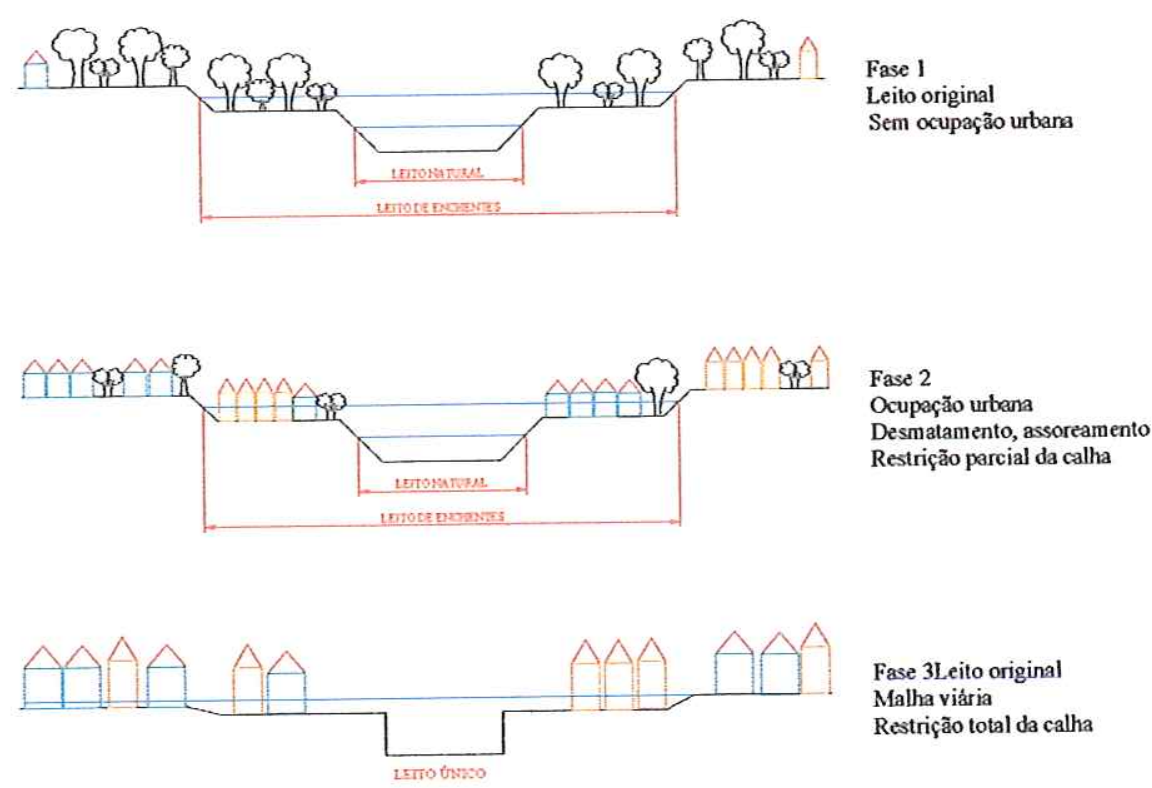

Fase 3Leito original Malha viária Restrição total da calha

Figura 3.3 - Fases da degradação da drenagem natural. Fonte: Martins, José Rodolfo S., 1995. ${ }^{2}$ (modificado)

${ }^{2}$ Drenagem Urbana, ed. ABRH, 428p. 
Como o escoamento das águas é mais complexo no ambiente urbano que no rural, a hidrologia urbana tem evoluído como uma ramificação importante da hidrologia (Ellis $e$ Marsalek, 1996), e cada vez mais sente-se a necessidade de implantar tecnologias sustentáveis em drenagem urbana, por meio de sistemas mais eficientes que os atuais conjuntos de sarjetas, galerias e canais.

\subsection{Tecnologias alternativas em drenagem urbana}

Atualmente, muito se tem falado, no meio acadêmico, sobre gerenciamento otimizado em drenagem urbana. Por meio de soluções estruturais ou não, o objetivo deste gerenciamento é limitar as mudanças impostas pela urbanização a patamares hidrologicamente sustentáveis, ou minimizar os impactos destas mudanças, uma vez que elas já estejam estabelecidas. Em geral não é viável recuperar as condições de escoamento anteriores à urbanização, e a limitação dos impactos a níveis aceitáveis deve ser a meta dos programas de gestão das águas pluviais (Lawrence et al., 1996).

As medidas de controle de inundações podem ser classificadas em estruturais, quando o homem modifica o rio, e não estruturais, quando o homem convive com o rio (Tucci, $C$. E. M., 1995).

As medidas não estruturais consistem em:

- Mapeamento de áreas de inundação: a partir de registros históricos de chuvas e curvas chave dos canais da macrodrenagem, estabelece-se cotas máximas de inundação para chuvas de diversos períodos de retorno, delimitando as áreas críticas.

- Leis de zoneamento e plano diretor de drenagem urbana: integrado a outros planos setoriais do município, deve prever alteração da ocupação urbana e conter um prognóstico dos conseqüentes impactos em áreas críticas, e, com horizonte de projeto suficientemente longo, estabelecer restrições quanto ao loteamento de áreas de risco de inundação. A unidade geográfica a ser adotada no planejamento é a bacia hidrográfica.

- Princípio de não ampliação da cheia natural em bacias em urbanização: manter as águas pluviais em seu ciclo hidrológico natural deve ser o fundamento básico do controle de inundações urbanas (Huhn e Stecker, 1997). Este conceito deve ser aplicado em todo novo empreendimento realizado na bacia, desde um simples aterro até a construção de pontes, rodovias e impermeabilização dos espaços urbanos (Tucci e Genz, 1995). Pode-se fixar, por exemplo, um índice máximo de impermeabilização do terreno a ser construído 
(Tucci, C.E.M., 1995). Este índice seria semelhante ao coeficiente máximo de aproveitamento do terreno e à taxa máxima de ocupação do lote, fiscalizados pela prefeitura por ocasião da aprovação do projeto. No entanto, este tipo de índice é de difícil fiscalização, uma vez que a realidade da obra pode não condizer com o projeto apresentado. A solução mais efetiva para este problema é a orientação e educação permanente da sociedade.

- Fiscalização efíciente: uma seqüência de anos sem enchentes costuma ocasionar uma pressão da sociedade para que haja ocupação do leito maior do rio, o que ocorre principalmente pela população de mais baixa renda, processo que somente poderá ser contido por uma fiscalização rígida, alicerçada em um bom plano diretor. Outro aspecto que requer fiscalização intensiva é o que envolve as ligações clandestinas de esgotos domésticos nas redes de águas pluviais, e vice versa. No primeiro caso, tem-se uma sobrecarga do sistema de drenagem, com risco de extravasamento durante os picos de chuva; no segundo, tem-se a diluição dos efluentes domésticos por águas pluviais, ocasionando maior dificuldade de tratamento.

- Sistemas de alerta ligados à defesa civil: para minimizar os impactos das ondas de cheia, prevenindo a população e evacuando áreas, quando for o caso.

- Manutenção adequada de canais, galerias e pavimentos: para que não haja diminuição das seções devido à presença de lixo ou entulho, reduzindo a capacidade do sistema;

- Programas de informação e educação da comunidade: a população tende a reclamar obras hidráulicas para a contenção de enchentes, o que provoca um certo desgaste no poder público, no sentido de implantar medidas não estruturais em drenagem urbana. $\mathrm{O}$ bom funcionamento de um sistema preventivo de enchentes urbanas fundamenta-se num triângulo que tem como vértices a legislação, a fiscalização e a educação ambiental. Esta última envolve os aspectos de preservação do sistema de drenagem, redução da geração do deflúvio e adesão às práticas de prevenção.

Quando a ocupação das áreas de risco é um quadro já instalado, a solução usualmente adotada consiste em implantar medidas estruturais ou ações, como relocação, populacional para o controle das cheias urbanas, o que, freqüentemente, não soluciona o problema, mas o transfere para jusante, como veremos a seguir.

Entre as medidas de controle na macrodrenagem a mais comumente praticada é a canalização de trecos críticos (Tucci, C.E.M. in Drenagem Urbana). Num primeiro estágio esta solução funciona bem, pois, apesar do aumento do hidrograma a jusante, há a 
contenção pelas áreas a montante, ainda não urbanizadas. Com o aumento da ocupação urbana, o poder público prossegue com a canalização a montante. Desta forma, à medida em que o escoamento se desloca para jusante, é acrescido de novos aumentos de volume devido à urbanização, resultando em acréscimos significativos na vazão máxima (Cruz et al., 1998), e as enchentes retornam a jusante. Neste estágio, em geral, já não há possibilidade de aumento lateral da calha, devido à ocupação urbana das margens, e as alternativas para promover o aumento da capacidade do canal recaem em soluções como: o aprofundamento da calha, a alteração da geometria da seção transversal, ou ainda a redução da rugosidade do canal, por meio de revestimento, a custos, muitas vezes, incompatíveis com a disponibilidade do poder público.

Surge então um outro tipo de medida de controle na macrodrenagem, baseado no retardamento artificial dos picos de cheia. Uma das estruturas utilizadas para o controle e atenuação da vazão de pico de um hidrograma, em projetos de drenagem urbana, ou mesmo em bacias rurais, é a implantação de uma bacia de detenção que propicie o armazenamento temporário do volume de água que chega a uma determinada seção (Porto, R.M., 1989).

Trata-se de reservatórios de armazenamento, instalados ao longo (in line) ou às margens (off line) dos cursos d'água, com a função de absorver o excesso de vazão durante precipitações críticas e, posteriormente, liberar a água retida em condições condizentes com a capacidade dos canais de jusante. As bacias de detenção, ou piscinões, permitem o retardo do escoamento, atenuando o pico dos hidrogramas e possibilitando a recuperação da capacidade de amortecimento perdida devido à impermeabilização (Cruz et al., 1998).

A Figura 3.4 apresenta o esquema de funcionamento típico de uma bacia de detenção, implantado em dois piscinões na região do $\mathrm{ABCD}$, em São Paulo. 


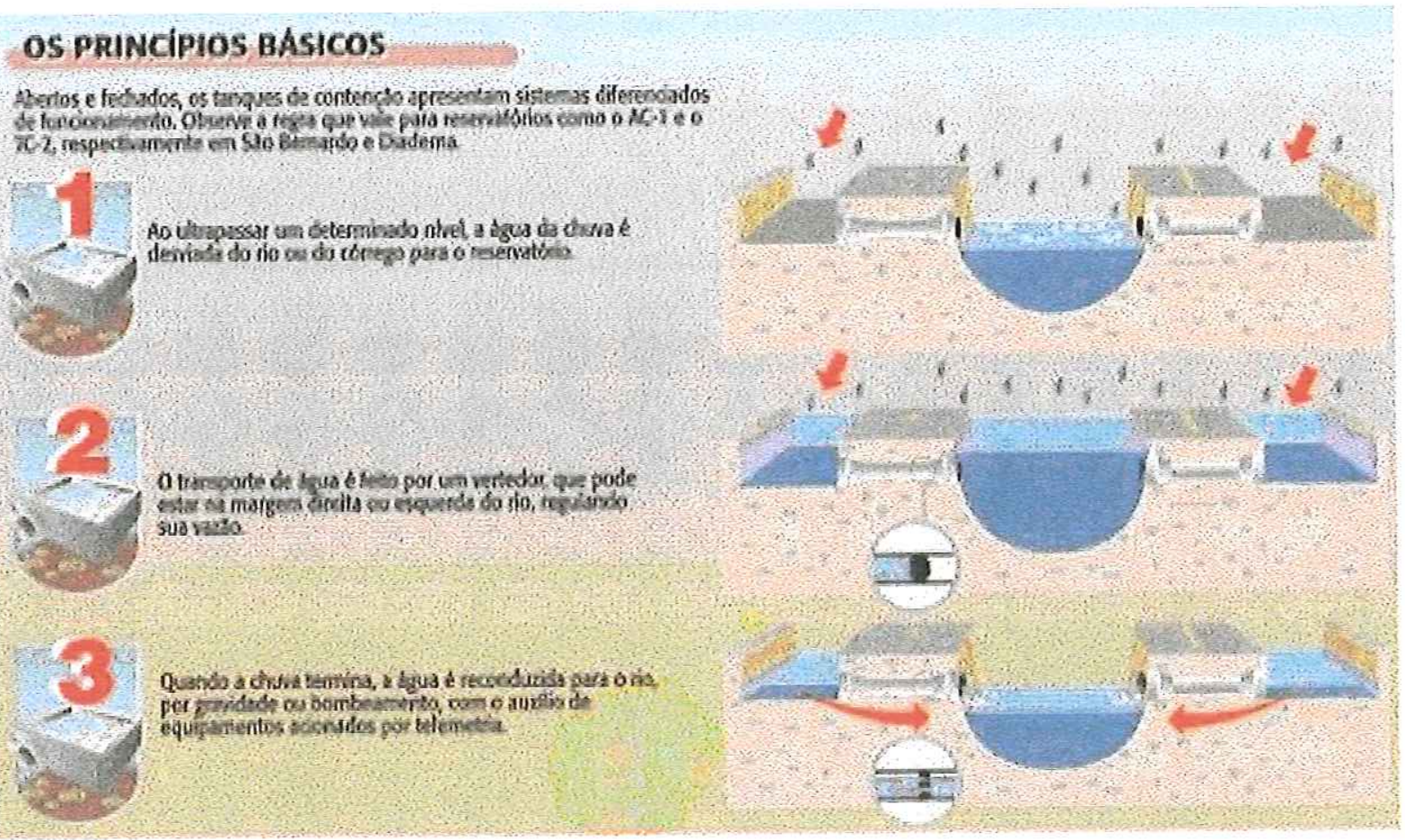

Figura 3.4 - Esquema de funcionamento de um piscinão "off line". Fonte: Revista Águas e Energia Elétrica, outubro/98, DAEE-SP

Estudos recentes comprovam a eficiência das bacias de detenção na redução dos picos nos hidrogramas de cheia. Entretanto, os custos de implantação deste tipo de estrutura são altos, pois envolvem a aquisição de extensas áreas urbanas e operações de grande porte, com movimento de terra, interrupção do tráfego local, instalação de vertedouros para a entrada da vazão excedente na bacia e sistemas de bombeamento para o retorno das águas ao curso d'água. Muitas vezes as bacias ou reservatórios de detenção são física ou economicamente inviáveis, devido a inexistência de áreas para sua implantação, conflitos com outras instalações urbanas ou falta de recursos financeiros para sua construção. $\mathrm{O}$ controle na macrodrenagem envolve também problemas ambientais, devido à carga de lixo transportada e às interligações clandestinas entre as redes de drenagem e esgoto (Cruz et al., 1998). Além disso, há também problemas com relação à operação e manutenção dos piscinões, que nem sempre cabem às mesmas entidades que os construíram, o que gera conflitos com relação às responsabilidades de cada órgão quando surgem problemas operacionais.

Para reduzir o número de cheias em uma bacia hidrográfica há duas possibilidades: aumentar sua capacidade de drenagem ou reduzir seu hidrograma afluente (Gedolf et al., 1994). Embora a segunda opção seja mais condizente com o conceito de desenvolvimento urbano sustentável, a maior parte das soluções em drenagem urbana recai sobre a primeira 
alternativa, e, apenas quando esta já não é possível, as soluções convergem para a redução do escoamento superficial. Estas soluções consistem em evitar o acréscimo de vazão nos hidrogramas urbanos, uma vez que a contenção das águas pluviais pode ser econômica ou fisicamente inviável. Nas bacias hidrográficas urbanas, o deflúvio se forma nos lotes residenciais, comerciais e industriais, bem como nas áreas de estacionamentos e pavimentos, e é nestes locais, ou seja, na origem da formação do problema que ele deve ser combatido.

As técnicas de controle na origem podem ser adotadas como soluções complementares ou alternativas aos sistemas de drenagem convencionais (Mikkelsen et al., 1996). Elas podem atuar no sentido de retardar o escoamento superficial, por meio de pequenos reservatórios de detenção instalados nos lotes, ou de infiltrar as águas de chuva, por meio de estruturas destinadas a este fim, tais como pavimentos permeáveis e trincheiras ou valas de infiltração. Estas soluções tendem a apresentar bons resultados no controle de enchentes, uma vez que, num lote urbano, a parcela do pátio impermeabilizada representa um fator significativo no hidrograma do terreno (Tucci, C.E.M., 1995, in Drenagem Urbana).

Muitas são as medidas estruturais passíveis de ser utilizadas dentro do conceito alternativo de drenagem urbana (Hun e Stecker, 1997), entre as quais pode-se destacar:

- Reservatórios de detenção nos lotes urbanos;

- Superfícies gramadas de percolação e infiltração;

- Trincheiras de infiltração como elementos isolados, nos lotes, ou como componentes de um sistema integrado de estruturas de infiltração em grandes áreas;

- Valas e canaletas gramadas de infiltração;

- Galerias permeáveis;

Embora não existam limites claros entre o controle na origem e o de jusante, para fins de classificação, pode-se identificar como dispositivos de controle na origem, os reservatórios de detenção nos lotes, telhados e estacionamentos, bem como os pavimentos permeáveis e as demais técnicas de infiltração (Makropoulos et al., 1999). Estas últimas são o foco principal deste trabalho, e serão abordadas com maiores detalhes mais adiante.

O armazenamento em lotes pode ser obtido por meio dos telhados, pequenos reservatórios residenciais, estacionamentos e áreas esportivas (Tucci et al., 1998). No Brasil, já foram realizados trabalhos de simulação do armazenamento em lotes urbanos (Tucci, 1998; Cruz et al., 1998), para condições preestabelecidas de chuva e permeabilidade, chegando-se à conclusão de que, para lotes com dimensões entre $300 \mathrm{e}$ 
$600 \mathrm{~m}^{2}$ seriam suficientes reservatórios com volume de armazenamento entre 1,50 e 3,00 $\mathrm{m}^{3}$.

Este tipo de estrutura requer um investimento para a sua implantação. Entretanto, uma vantagem adicional pode ser obtida de tais construções, considerando que as mesmas podem reter as águas de chuva para o posterior aproveitamento em atividades que não requeiram água potável (Pratt, 1999). A principal desvantagem destas estruturas residenciais, em comparação com as bacias de detenção na macrodrenagem, está na dificuldade que se tem em gerenciar um grande número de pequenos equipamentos de controle descentralizados (Makropoulos et al., 1999). Neste aspecto, cabe um comentário específico para a situação no Brasil. Nas grandes cidades, é comum a não observância às leis de uso e ocupação do solo, e ainda mais comum a pouca fiscalização em relação a este aspecto da expansão urbana. Neste cenário, o gerenciamento (que inclui a fiscalização) de equipamentos descentralizados de drenagem torna-se ainda mais problemático.

A Figura 3.5 apresenta um modelo de reservatório de detenção de águas pluviais no lote.
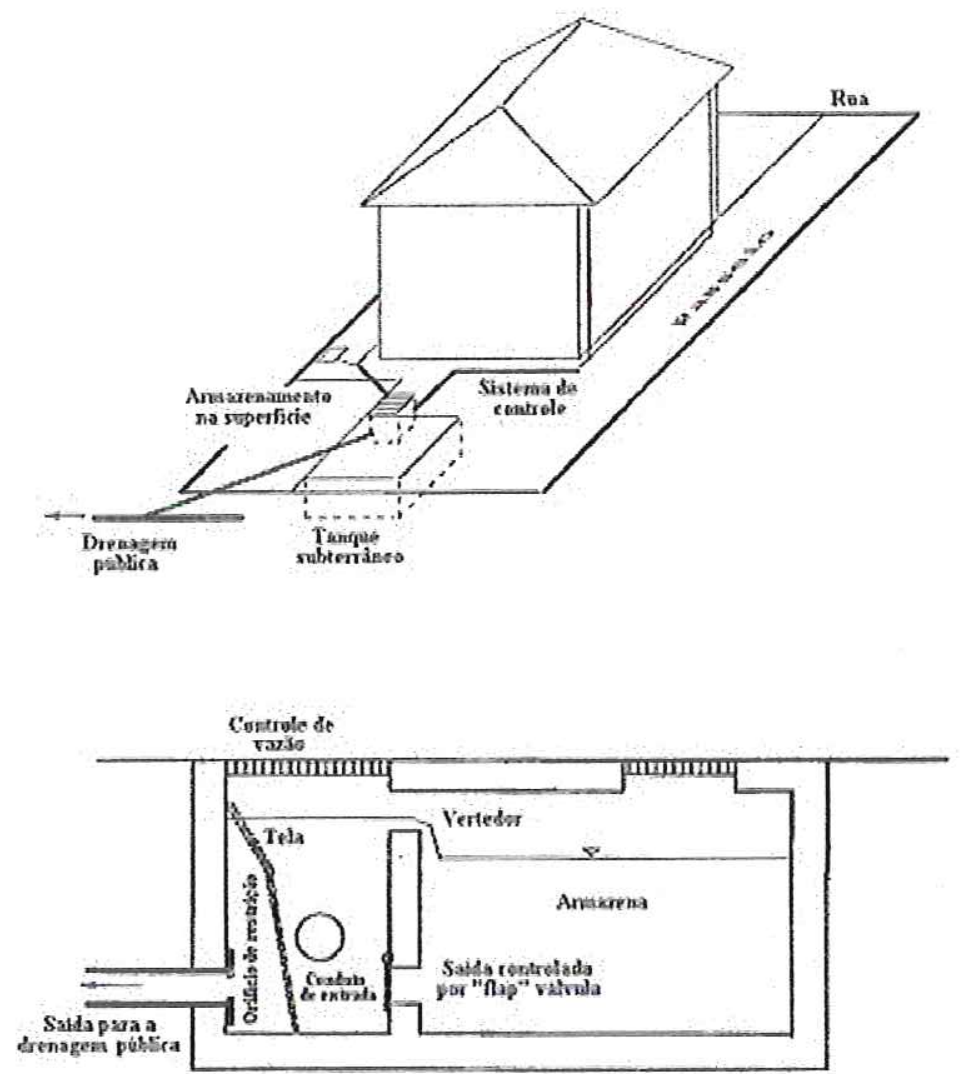

Figura 3.5 - Esquema de funcionamento de um reservatório de detenção no lote. Fonte: Cordeiro Netto, O. M, $2004^{3}$

\footnotetext{
${ }^{3}$ Gerenciamento do saneamento em comunidades organizadas, Técnicas de minimização da drenagem de águas pluviais, notas de aula. Universidade de Brasília.
} 


\subsection{Sistemas de infiltração}

Os sistemas de infilttração de águas de chuva têm a finalidade de interceptar o escoamento superficial e encaminhá-lo ao aqüífero, de modo a reduzir os picos de cheia e possibilitar a recarga do lençol freático (Lawrence et al., 1999).

A variável mais diretamente relacionada a esta prática é a taxa de infilttração do solo, definida como a vazão por unidade de área que o solo é capaz de infiltrar (Alfakih et al., 1999). Esta taxa depende, principalmente, da condutividade hidráulica do solo, da relação ente o potencial matricial e a umidade, e da posição do aqüífero subterrâneo. Segundo Alfakih et al. (1999), solos com condutividade hidráulica entre $10^{-6}$ e $10^{-3} \mathrm{~m} / \mathrm{s}$ apresentam boa resposta à infiltração. No entanto, Mikkelsen et al. (1996) ressaltam que a baixa condutividade hidráulica do solo não representa restrição técnica à implantação de estruturas de infiltração, e sim, econômica, uma vez que os volumes de armazenamento de tais estruturas são inversamente proporcionais esta propriedade do solo. Os parâmetros e variáveis de projeto envolvidos, qualquer que seja a estrutura de infiltração a implantar, são:

- As propriedades físicas e hidráulicas do solo;

- O período de retorno a ser considerado;

- As características de chuva locais (curva idf);

- O volume de armazenamento das estruturas;

- A qualidade das águas a serem infiltradas, devido ao risco de contaminação do aqüífero e do solo;

- A granulometria da camada superficial de solo;

- O teor de sólidos suspensos na água.

Estes dois últimos itens, em especial o teor de sólidos, interferem diretamente no processo de colmatação. Este fenômeno, cujo risco de ocorrência atinge todos os tipos de estrutura de infiltração, consiste na obstrução dos poros do solo, devido à presença de partículas sólidas na água infiltrada (Saripalli et al., 1999).

Diversas são as possibilidades de se promover a infiltração das águas pluviais. Uma delas é a percolação através de pavimentos permeáveis e o uso da subbase para o armazenamento, que têm se revelado eficientes em estacionamentos, calçadas e vias de tráfego pouco intenso (Mikkelsen et al., 1996). A implantação deste tipo de sistema é viável, do ponto de vista hidráulico, em locais planos ou com declividades suaves, e cujo 
solo possua boa capacidade de infiltração, com lençol freático relativamente profundo (Araújo et al., 1999). São recomendados em estacionamentos, calçadas e vias de tráfego pouco intenso, devido à menor resistência em relação aos pavimentos convencionais.

Os pavimentos permeáveis podem ser de concreto ou asfalto, e são construídos da mesma forma que os pavimentos tradicionais, com a diferença de que o material fino é retirado da mistura (Tucci e Genz, 1995). Sob o pavimento poroso, são construídas duas camadas de base: uma de agregado médio, com espessura de aproximadamente $3 \mathrm{~cm}$, e outra de agregado graúdo, também conhecida por "reservatório de pedras" (Araújo et al., 1999). Neste reservatório, que será tão profundo quanto for desejável sua capacidade de armazenamento, a água advinda da superfície é armazenada e posteriormente infiltrada para o subsolo, ou coletada por tubos de drenagem e transportada para uma saída.

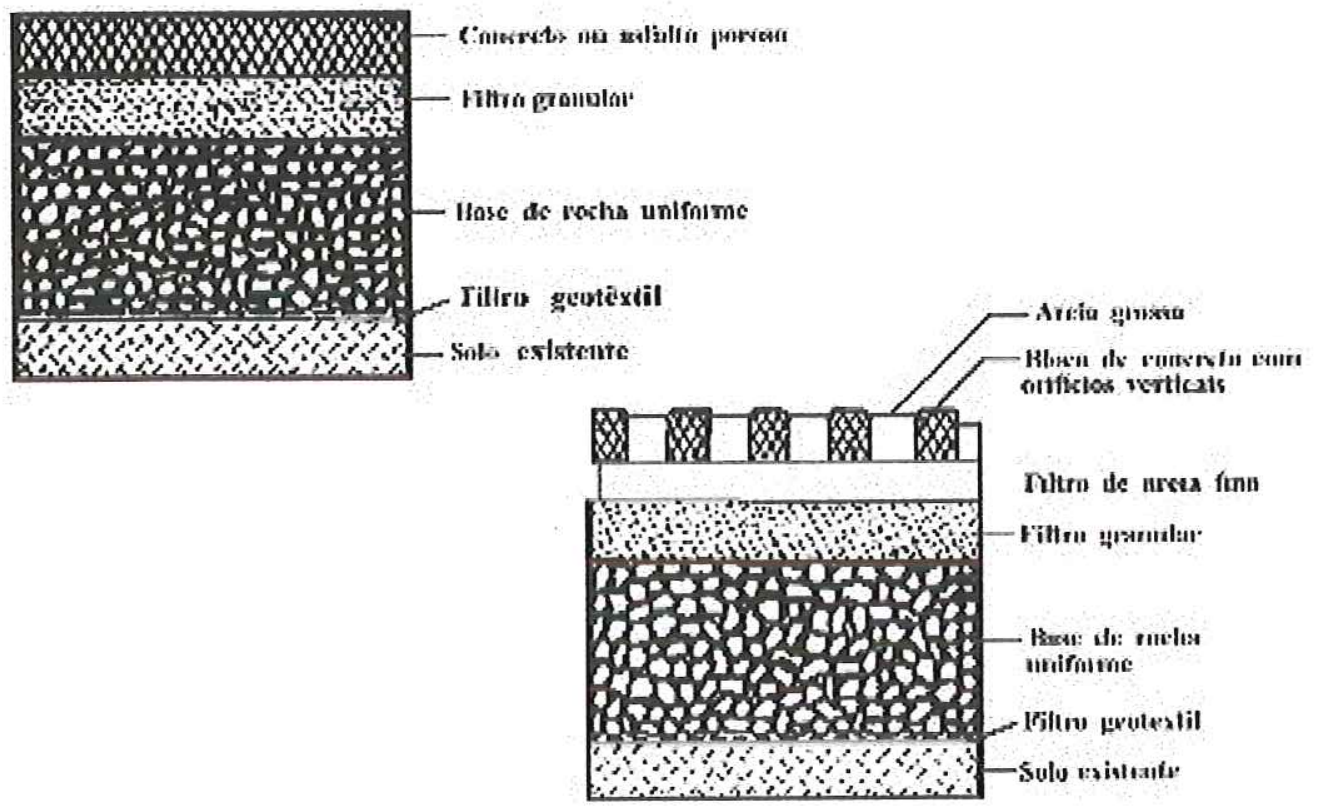

Figura 3.6 - Esquema de pavimento poroso. Fonte: Cordeiro Netto, O. M., 2004.

Segundo Araújo et al. (1999), as principais vantagens da utilização de pavimentos permeáveis, e de estruturas de infiltração de um modo geral, são: a redução ou eliminação da rede de drenagem, a preservação do equilíbrio da água no local, o controle das descargas de pico e do volume de escoamento superficial, a remoção de poluentes e uma superficie mais segura para dirigir. Em contrapartida, o sistema possui desvantagens que, de acordo com as circunstâncias, podem inviabilizar sua implantação, tais como: risco de entupimento, necessidade de inspeções regulares e um possível risco de contaminação das águas subterrâneas. A manutenção regular com equipamentos especiais, que aplicam ao 
pavimento altas pressões de "sopro" ou sucção, é requerida para preservar o seu bom funcionamento (Lawrence et al., 1996).

- Outra alternativa de sistema de infiltração são as trincheiras, como elementos isolados em lotes residenciais ou como parte de um sistema que integre toda a bacia contribuinte. Este tipo de estrutura constitui-se basicamente de frestas no solo preenchidas ou não com brita. Uma vez que as águas pluviais são drenadas de uma superfície conectada à trincheira de infiltração, estas são temporariamente armazenadas na porosidade da brita e, em seguida, infiltradas no solo (Mikkelsen e Jacobsen, 1993).

As trincheiras são tipicamente longas e estreitas, para reduzir a área superficial da base, que é supostamente obstruída por partículas finas após algum tempo de operação do sistema, e aumentar a relação entre a área efetiva de infiltração (os lados) e o volume de armazenamento (Mikkelsen et al., 1996). A geometria longa e estreita é também adequada à otimização da área em planta ocupada pelo equipamento de drenagem no lote urbano. As trincheiras atendem, geralmente, a pequenas áreas de drenagem (Lawrence et al., 1996), e requerem um pré-tratamento da água para reduzir o influxo de sólidos e a colmatação prematura. Este tratamento primário pode ser feito por meio do revestimento da estrutura com uma manta geotêxtil removível e lavável.

As Figuras 3.7 a, b e c ilustram diferentes exemplos de trincheiras de infiltração, propostos por Lawrence et al. (1996), Mikkelsen et al. (1996) e Tucci e Genz (1995).

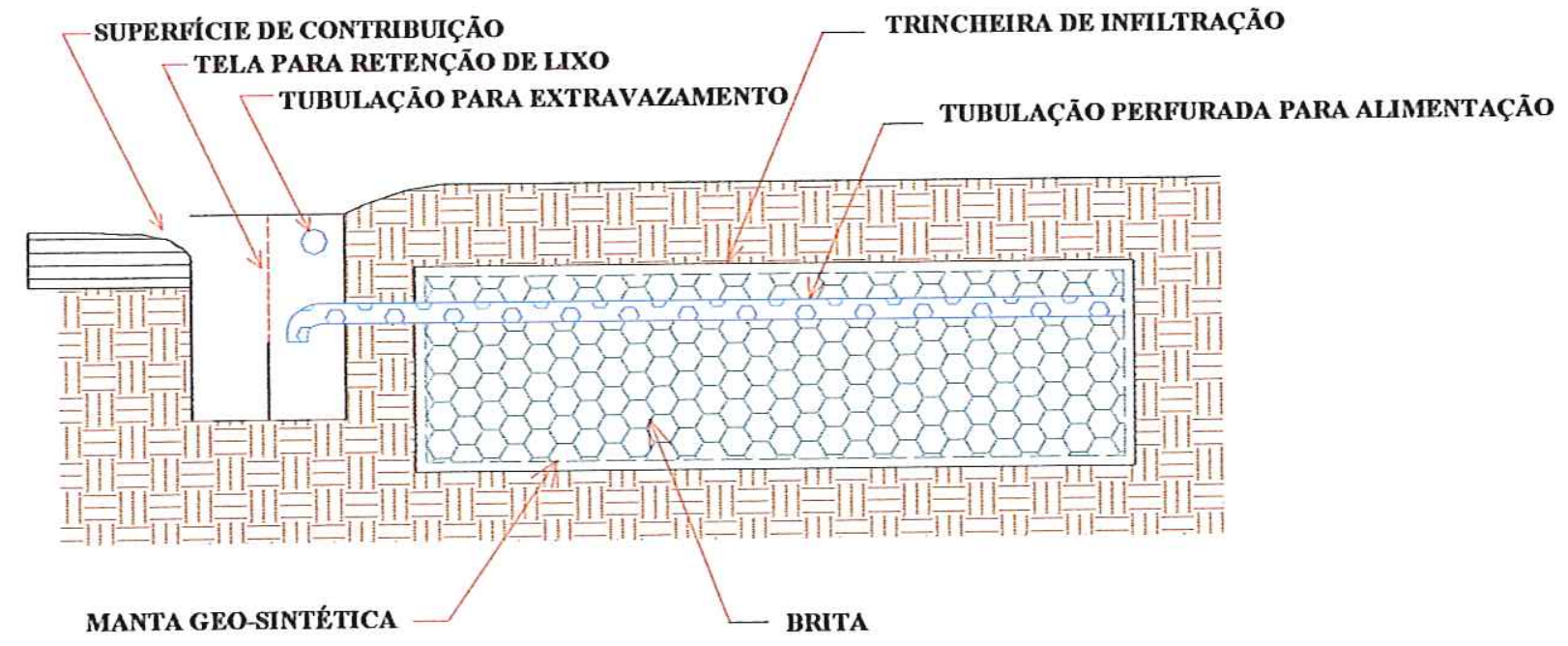

Figura 3.7 (a) - Exemplo de modelo de trincheira de infiltração. Fonte: Lawrence et. al., 1996, modificado. 


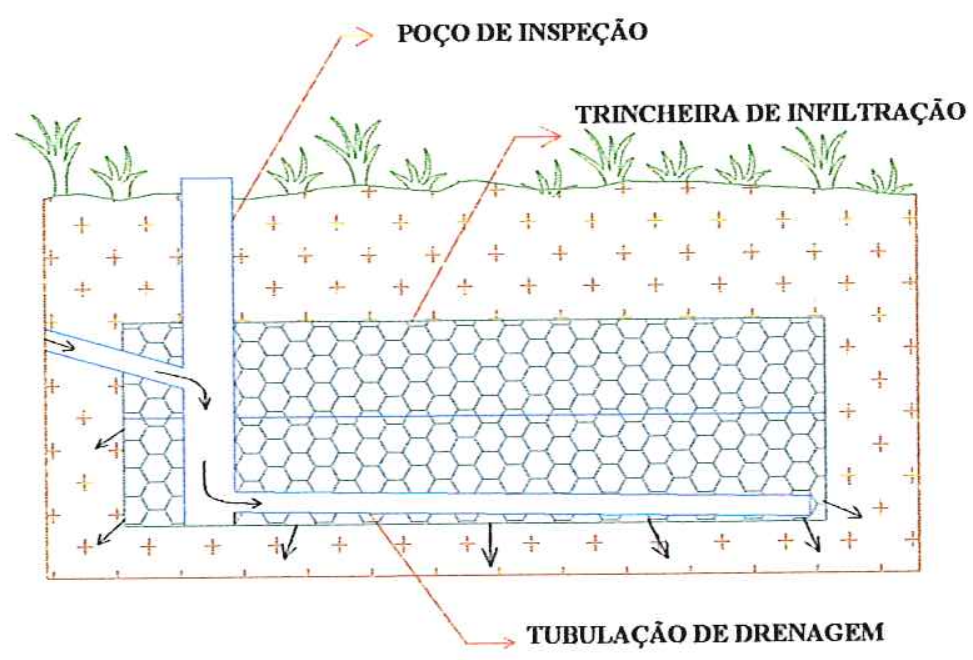

Figura 3.7 (b) - Exemplo de modelo de trincheira de infiltração. Fonte: Mikkelsen et al., 1996

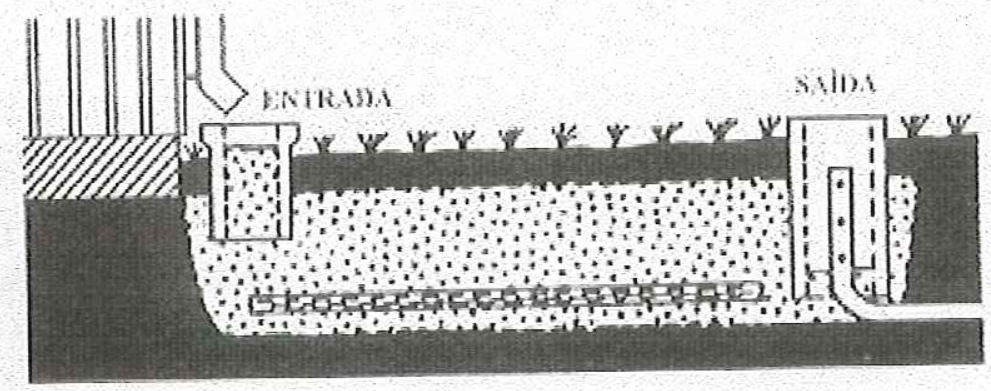

Figura 3.7 (c) - Exemplo de modelo de trincheira de infiltração. Fonte: Tucci e Genz, 1995.

Como todas as demais estruturas de infiltração, as trincheiras são viáveis em solos com boa capacidade de percolação. É importante que o sistema seja planejado e que haja manutenção adequada, pois a principal causa de falha deste tipo de dispositivo é a colmatação precoce. Sua eficiência também é diminuída para longos períodos chuvosos, devido à possibilidade de saturação do solo (Lawrence et al., 1996).

- É possível promover o trabalho conjunto entre duas ou mais estruturas de infiltração e detenção do deflúvio. Uma delas é o sistema proposto por Mikkelsen et al. (1996), no qual a água é drenada para uma bacia de retenção equipada com membrana de fundo, para evitar a infiltração direta; uma tubulação de descarga de fundo é conectada a um poço de infiltração com caixa separadora de óleos e graxas, para prevenir a colmatação. Desta forma, de toda a água desviada para a bacia, somente uma parte volta ao curso d'água, sendo que a outra é lentamente infíltrada no solo ao redor do poço.

Outra possibilidade de trabalho conjunto de duas estruturas alternativas de drenagem é o sistema proposto por Sieker (1998), ilustrado na Figura 3.8a e 3.8b, constituído por uma vala de infiltração gramada e aberta para a atmosfera, sob a qual se instala uma trincheira 
subterrânea de infiltração, preenchida com brita. Os elementos são dimensionados com o propósito de permitir a máxima infiltração possível do escoamento superficial. Isto é obtido por meio do armazenamento das águas de chuva na vala por um curto período de tempo, e seu posterior encaminhamento à trincheira, por meio da infiltração direta no solo. Na trincheira, a água é armazenada por um determinado tempo, até que haja total infiltração no entorno da estrutura.

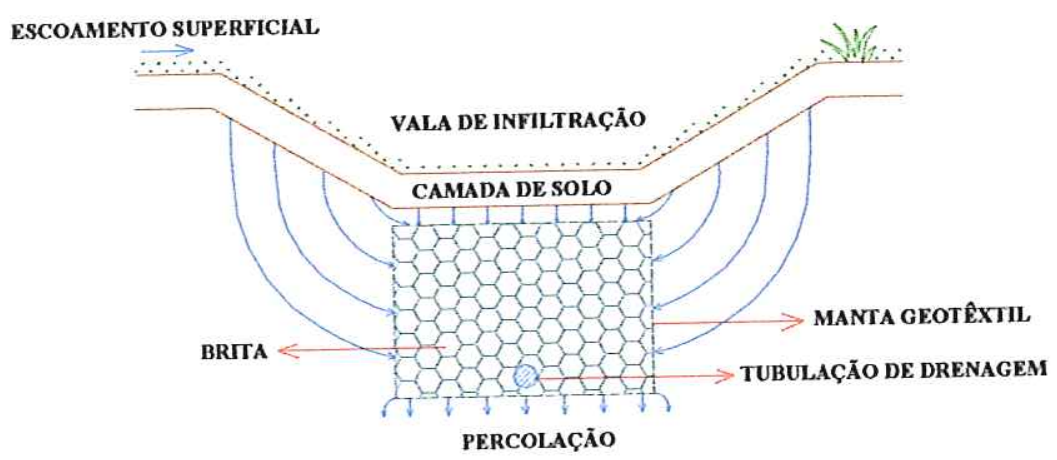

(a)

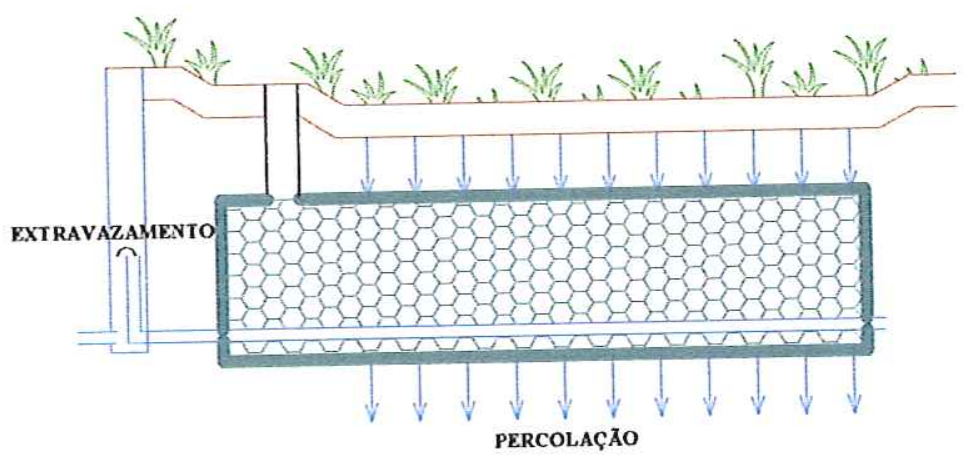

(b)

Figura 3.8 - Exemplo de trabalho conjunto entre vala gramada de percolação e trincheira subterrânea de infiltração. Fonte: Sieker, 1998, modificado.

Grotehuemann et. al (1994) propõem um sistema semelhante, em que valas de infiltração a céu aberto são construídas sobre trincheiras de infiltração subterrâneas, preenchidas com brita, ambas instaladas nas calçadas, em frente os lotes residenciais a elas conectados, conforme ilustra a Figura 3.9. As estruturas de cada lote são interligadas por meio de uma tubulação perfurada localizada no centro da seção transversal das trincheiras, que, além de conectar as estruturas, tem a função de encaminhar a vazão excedente ao sistema convencional de drenagem. Grotehuemann et. al (1994) observam que o sistema tem melhor efíciência para eventos isolados, pois necessita de um determinado tempo de 
esvaziamento e infiltração das trincheiras. Em eventos de chuva consecutivos, dentro de um curto período de tempo, as estruturas podem falhar por sobrecarga, e somente simulações de longo período podem avaliar a viabilidade do sistema em garantir as vazões de projeto.

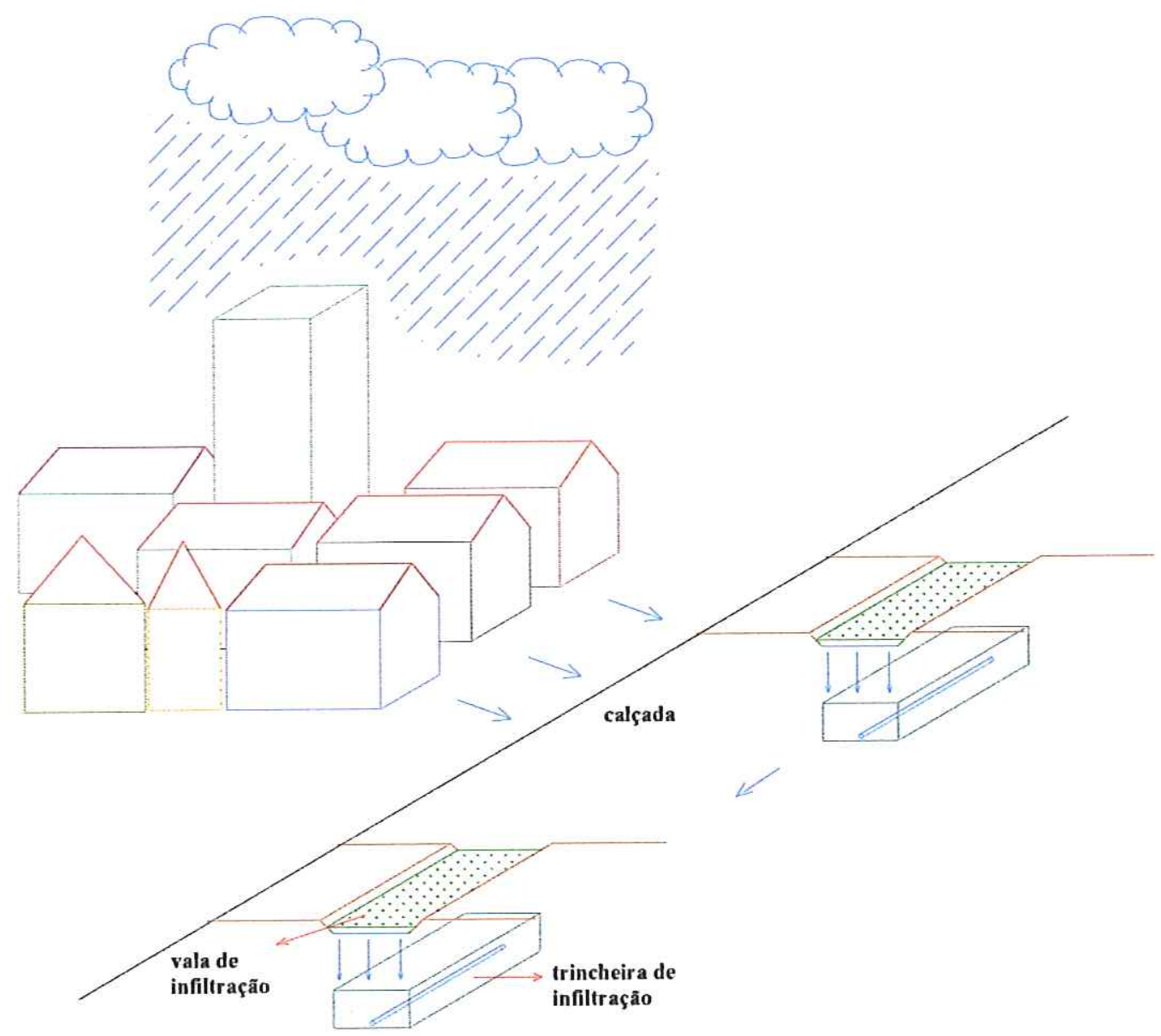

Figura 3.9 - Proposta de sistema de trincheiras de infiltração implantado em loteamentos. Fonte: Grotehuemann et. al , 1994, modificado.

$\rightarrow$ As vantagens e desvantagens das trincheiras e poços de infiltração são praticamente as mesmas dos pavimentos permeáveis. Os maiores riscos são a colmatação da superfície do solo e a contaminação deste e do aquífero, devido à carga de poluição presente nas águas pluviais (Mikkelsen et al., 1996).

$\rightarrow$ Com relação à colmatação, pode-se estudar diversas formas de se promover o prétratamento da água para reduzir o influxo de partículas sólidas no solo, como, por exemplo, o uso de mantas geotêxteis.

Alguns estudos vêm sendo feitos sobre a possibilidade de contaminação do solo e do aqüífero em resposta à infiltração de águas pluviais. Mikkelsen et al. (1996) avaliam que 
não há evidências de alto risco de contaminação das águas subterrâneas, mas ressalta que a qualidade do solo superficial tende a diminuir após longos períodos de operação dos sistemas, devido às camadas superiores de solo funcionarem como um filtro microbiológico e químico dos poluentes presentes nas águas pluviais.

Barraud et al. (1999) monitoraram, durante um ano, duas estruturas de infiltração em Valence, França, situadas em solo de alta condutividade hidráulica (aproximadamente $10^{-2}$ $\mathrm{m} / \mathrm{s}$ ), e conectadas a áreas impermeáveis de 300 e $1300 \mathrm{~m}^{2}$. Eles encontraram no solo ao redor das estruturas altas concentrações de metais pesados e hidrocarbonetos, e notaram redução significativa desses poluentes alguns centímetros abaixo das estruturas, registrando baixíssimo impacto nas águas subterrâneas.

No Brasil, há o atenuante de que as redes de drenagem são independentes das de esgoto, embora saiba-se que existem ligações clandestinas entre ambas. De qualquer forma, a maior parte dos contaminantes fica retida na região subsuperficial do solo, onde há a presença de substâncias húmicas, que retêm poluentes orgânicos por meio de reações hidrofóbicas. Desta forma, Ellis e Marsalek (1996) afirmam que, na maioria dos casos, o controle do escoamento superficial por meio da infiltração das águas de chuva pode ser praticado em áreas urbanas, tanto nos sistemas combinados quanto nos separados.

\subsubsection{Exemplos de aplicação e simulação de sistemas de infiltração}

- Embora as técnicas de infiltração ainda requeiram maiores constatações de seu desempenho a longo prazo, elas têm sido vistas amplamente como componentes viáveis do desenvolvimento urbano sustentado (Makropoulos et al., 1999; Mikkelsen et al., 1996). A despeito de toda a deficiência ainda existente de informações e estudos detalhados sobre seu funcionamento, estruturas de infiltração vêm sendo implementadas com êxito em vários lugares do mundo.

Segundo Fujita (1997) e Mikkelsen et al., 1996, no Japão, entre os anos de 1983 e 1995, o governo da região metropolitana de Tókio implantou mais de 30.000 poços de infiltração, $285 \mathrm{~km}$ de trincheiras de infiltração e $495.000 \mathrm{~km}^{2}$ de pavimentos permeáveis, em áreas públicas e privadas. A manutenção e limpeza das estruturas é feita com periodicidade que varia de bimestral a anual, dependendo localidade. Outras cidades japonesas, tais como Yokohama, Amagasaki, Sapporo, Chiba e outras têm adotado sistematicamente a prática da infiltração das águas de chuva. Os objetivos das estruturas de infiltração implementadas no Japão vão além do controle do escoamento superficial. Segundo Fujita (1997), elas visam restaurar o ciclo hidrológico perdido com a 
urbanização, promovendo a recarga dos aqüíferos subterrâneos e prevenindo, assim, a intrusão marinha, problema comum no país.

Segundo Warnaars et al. (1999), na cidade de Copenhagen, Dinamarca, dispositivos de infiltração existem e operam bem há mais de cem anos. Esta informação, contudo, somente é trazida à luz em discussões informais, sendo raramente reportada em publicações científicas.

Em 1994, Warnaars et al. avaliaram o funcionamento de duas trincheiras de infiltração subterrâneas, com volume útil de $4 \mathrm{~m}^{3}$ cada, conectadas a $600 \mathrm{~m}^{2}$ de telhados, na região central de Copenhagen, próximo à estação de trens Norrebro, área densamente urbanizada, cujo solo possui condutividade hidráulica de $2 \times 10^{-6} \mathrm{~m} / \mathrm{s}$. Ao longo dos dois anos e nove meses de observações, ocorreram 89 eventos de chuva, em 7 dos quais as estruturas sofreram sobrecarga, sendo acionado o sistema de extravasamento e encaminhada a vazão excedente à rede de drenagem local. A maior sobrecarga foi registrada durante um evento de $26,2 \mathrm{~mm}$ em 5 dias, ao longo dos quais as estruturas receberam um volume de 14,6 $\mathrm{m}^{3}$. O maior volume sem que houvesse sobrecarga do sistema ocorreu durante um evento de $63,6 \mathrm{~mm}$ em 20 dias, ao longo dos quais as trincheiras receberam um volume de $27,4 \mathrm{~m}^{3}$.

Coombes et al. (1999) monitoraram por dois anos o funcionamento de um sistema de retenção e infiltração de águas de chuva implantado em Figtree Place, subúrbio de New Castle, Australia, $160 \mathrm{~km}$ ao norte de Sidney. O sistema é resumidamente esquematizado na Figura 3.10, e foi instalado em uma área que compreende 27 unidades residenciais. Foram monitorados os aspectos quantitativos e qualitativos do sistema, tais como a qualidade das águas de chuva provenientes dos telhados e a porcentagem de redução do abastecimento doméstico e do volume encaminhado ao sistema de drenagem. A redução no abastecimento de água foi da ordem de $60 \%$. 


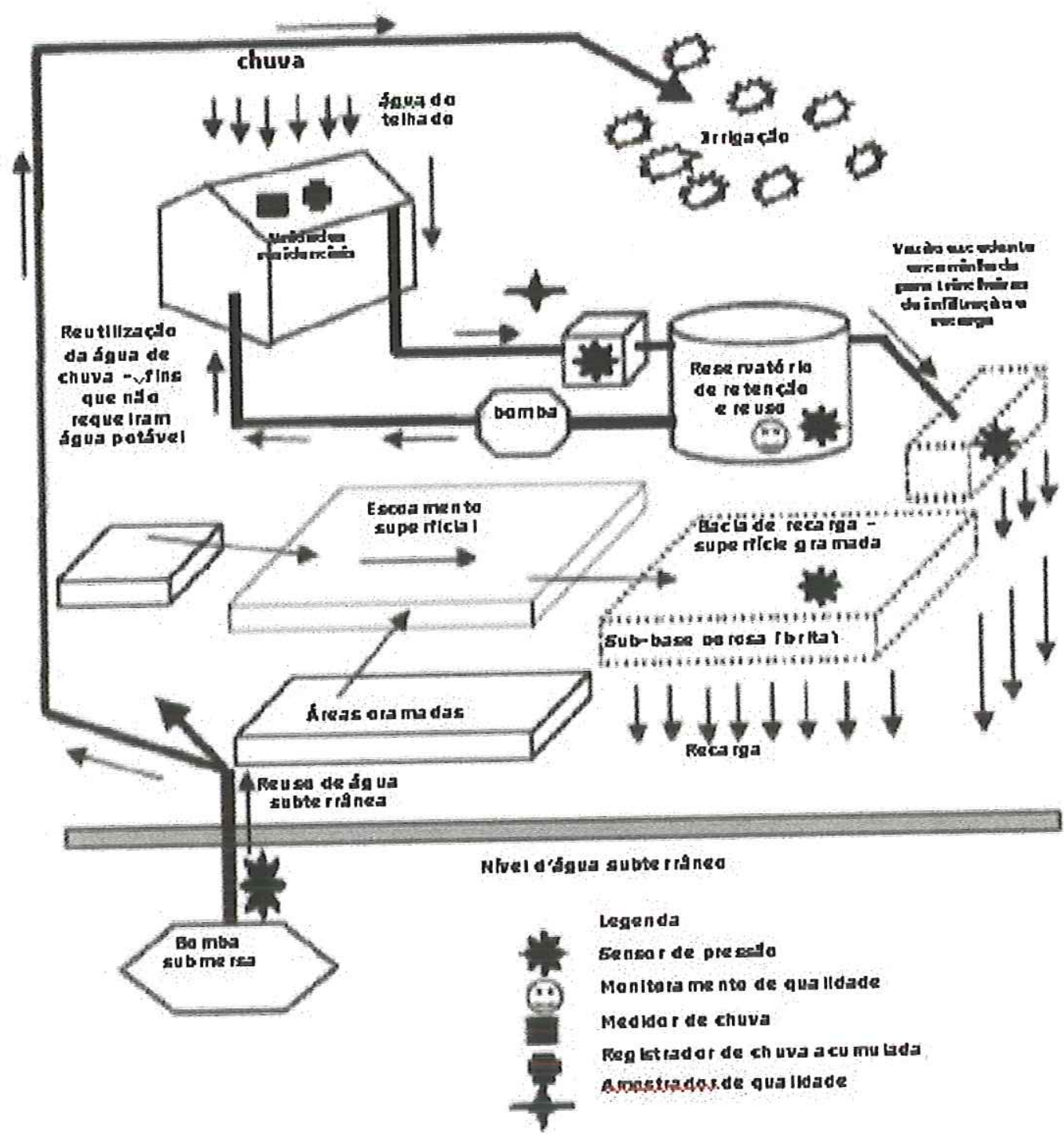

Figura 3.10 - Sistema de gerenciamento de águas de chuva implantado em Figtree Place, New Castle, Australia. Fonte: Combes et. al, 1999, modificado.

Em 2002, Coombes et al. apresentaram uma metodologia de avaliação dos benefícios econômicos devidos à implantação de sistemas de controle na origem em loteamentos urbanos, em duas diferentes regiões de New South Wales, Australia, Lower Hunter, com 450.000 habitantes, e Central Coast, com 289.000 habitantes. O trabalho, baseado na simulação de cenários, foi direcionado no sentido de avaliar o quanto o volume necessário para o abastecimento público de água potável pode ser aliviado por sistemas alternativos de abastecimento, tais como o reuso de águas de chuva. $\mathrm{O}$ estudo demonstrou que o uso de reservatórios de retenção de águas de chuva, instalados em lotes residenciais, com o objetivo de abastecer os usos domésticos de água que não requerem água potável, tais como banheiros e áreas externas, pode reduzir em até $50 \%$ a demanda de água para o abastecimento público urbano, e em até $40 \%$ o volume de águas de chuva encaminhadas 
para o sistema de drenagem urbana. A simulação para a região de Lower Hunter revelou um retardamento de 34 anos na implantação de novas fontes de abastecimento em relação ao cenário sem os reservatórios de retenção.

Grotehismann et al. (1994) simularam a operação de um sistema de 38 valas e 56 trincheiras de infiltração interconectadas, no distrito de Beckeradsdelle, na cidade de Gelsenkirchen, Alemanha, em uma área de 75 ha drenada por um sistema convencional de galerias e canais, cujo solo possui baixa condutividade hidráulica $\left(<10^{-7} \mathrm{~m} / \mathrm{s}\right)$ e a topografia apresenta declividade alta, com camada impermeável a $2 \mathrm{~m}$ de profundidade média. Nestas condições, a simulação mostrou que, com a instalação do sistema de infiltração proposto, com capacidade de armazenamento de $4.140 \mathrm{~m}^{3}$, haveria uma redução superior a $40 \%$ das áreas conectadas ao sistema de drenagem convencional.

Estudo semelhante foi realizado por Sieker e Klein (1998), para uma bacia de $22 \mathrm{~km}^{2}$, densamente urbanizada (aproximadamente 300.000 habitantes) na região leste da cidade de Berlin, Alemanha, drenada por $220 \mathrm{~km}$ de canais e galerias, com seis bacias de detenção com capacidade de $200.000 \mathrm{~m}^{3}$. As simulações da implantação de um sistema descentralizado de estruturas de armazenamento e infiltração conduziram a uma redução de $30 \%$ das áreas impermeáveis conectadas ao sistema existente de drenagem.

Simulações de mesma natureza realizadas por Gedolf et al. (1994) para a bacia do rio Shirako, que drena uma área de $10 \mathrm{~km}^{2}$ na região noroeste de Tókio, Japão, trouxeram outra conclusão importante a respeito da implantação de sistemas descentralizados de infiltração: em uma região que opera com sistemas combinados de esgotos pluviais e cloacais, a redução nas vazões de pico proporciona redução nos custos de tratamento de esgotos. Isso porque é economicamente mais viável tratar um certo volume de esgoto altamente concentrado, do que um volume maior de efluentes diluídos em águas pluviais. Além disso, a própria qualidade das águas pluviais é melhorada, uma vez que, ao reduzir a formação do escoamento superficial, reduz-se também sua contaminação por poluentes depositados nas áreas impermeáveis das regiões urbanizadas.

Medidas de infiltração podem ser realizadas também na macrodrenagem, como mostra Ferguson (1995), em seu estudo para a cidade de Athens, Georgia. Em uma bacia urbana de 2 ha, ele simulou o comportamento de três diferentes estruturas de contenção de cheias na macrodrenagem da bacia:

a. um reservatório de detenção ao longo do curso do rio (on-line), com orifício de fundo;

b. um reservatório de infiltração on-line, com vertedor sem comportas, e 
c. um reservatório de infiltração às margens do canal (off-line), com entrada e saída por vertedor.

Ferguson (1995) estimou a vazão afluente pelo método do Soil Conservation Service, do hidrograma unitário triangular. A condutividade hidráulica do solo é de $7,2 \times 10^{-7} \mathrm{~m} / \mathrm{s}, 0$ curve number (CN) adotado foi de 79,5 , e o hietograma de $24 \mathrm{~h}$ com precipitação total de $165 \mathrm{~mm}$, para um período de retorno $\mathrm{Tr}=25$ anos. Ele obteve os seguintes volumes de armazenamento: (a) reservatório de detenção on-line: $786 \mathrm{~m}^{3}$; (b) reservatório de infiltração on-line: $1.747 \mathrm{~m}^{3}$, com restrição de profundidade máxima igual a $15,5 \mathrm{~cm}$, o que implica numa área de 1.14 ha, inviável para a bacia; (c) reservatório de infiltração off-line: $781 \mathrm{~m}^{3}$, correspondente a uma área de 0,51 ha, disponível na bacia.

Segundo Mikkelsen et al. (1996), a diferença mais significativa entre reservatórios de detenção e de infiltração é que, no primeiro caso, o volume de armazenamento é determinado considerando que a saída ocorre por um sistema hidráulico, tal como orifício de fundo ou vertedor, e, no segundo, a saída se dá por infiltração no solo, e depende da sua condutividade hidráulica, bem como da geometria e do nível d'água na estrutura.

No Brasil, alguns estudos já foram realizados com sistemas de infiltração de águas pluviais, como o trabalho experimental de Souza (2002), em que foi monitorado, durante 33 meses, o funcionamento de trincheiras de infiltração instaladas no Instituto de Pesquisas Hidráulicas da Universidade Federal do Rio Grande do Sul. O estudo levou em conta critérios de dimensionamento, avaliação do desempenho, efeitos de colmatação e análise de custos, para as condições brasileiras. Durante o período de observação, não foram registradas vazões excedentes à capacidade de infiltração das trincheiras, embora tenham sido observados eventos de chuva de períodos de retorno superiores aos de projeto. Os dados observados revelaram eficiência total dos dispositivos de infiltração, durante os três anos hidrológicos monitorados.

\subsubsection{Planejamento de sistemas de infiltração}

Tendo em vista que a tecnologia relacionada à prática de infiltração é ainda específica para determinadas condições locais, e não aplicável de um modo geral, não existem na literatura muitos estudos comparativos entre os custos da infiltração de águas pluviais e das técnicas convencionais de drenagem urbana (Mikkelsen et al., 1996).

A primeira questão a ser respondida para a elaboração de qualquer projeto de drenagem urbana é "qual o período de retorno que se deseja atender?", ou para uma determinada obra hidráulica existente, "a que período de retorno esta obra pode atender?". 
'O período de retorno de um determinado evento é o inverso da probabilidade de ele ser igualado ou superado em um ano qualquer (Porto, R. L. L., 1995).

Ao se decidir, portanto, que uma obra será projetada para uma vazão com período de retorno $T$ anos, automaticamente, decide-se o grau de proteção conferido à população (Porto, R. L. L.,1995). A escolha do período de retorno de uma obra hidráulica para o controle de enchentes deve ser definida em âmbito político e econômico, uma vez que cabe aos representantes da comunidade decidir o grau de proteção desejável, e o quanto se dispõe a pagar por ele.

- Encontrar o ponto ótimo entre a proteção ideal e o custo aceitável é uma tarefa complexa, uma vez que, em geral, os benefícios advindos de um projeto de drenagem são de natureza qualitativa, e dificilmente podem ser quantificados.

- No entanto, alguns valores são aceitos de forma mais ou menos ampla no meio técnico, e eles variam em torno de 2 a 10 anos para projetos de micro drenagem, e a partir de 25 anos para projetos de macro drenagem.

- Quando não se dispõe de registros de precipitações, para a estimativa do período de retorno, ou quando estes estão incompletos para uma determinada região, pode-se lançar mão das curvas de intensidade-duração-freqüência (curvas idf).

- Estas curvas relacionam as três variáveis citadas por meio de parâmetros previamente ajustados, e, geralmente, têm a forma da Equação 3.1:

$$
i=\frac{a \cdot T^{b}}{(t+c)^{d}}
$$

Em que:

$i=$ intensidade de precipitação, $\mathrm{em} \mathrm{mm} / \mathrm{h}$;

$T=$ periodo de retorno, em anos;

$t=t e m p o$ de precipitação,ou duração da chuva, em mimutos

$a, b, c$ e d são parâmetros ajustados empiricamente.

A curva idf para a cidade de São Carlos, proposta por Barbassa (1991) é dada pela equação 3.2 :

$$
i=\frac{1519 \cdot T^{0,236}}{(t+16)^{0,935}}
$$

Determinado o período de retorno a ser atendido, deve-se proceder aos demais critérios de projeto pertinentes a cada tipo de obra em particular. Fujita (1997) enumera algumas 
observações pertinentes à implementação de sistemas de infiltração em uma bacia hidrográfica:

- Avaliação quantitativa dos benefícios. A eficiência desta etapa depende fundamentalmente da quantidade e qualidade de informações disponíveis e das ferramentas de que se dispõe para manipulá-las e analisá-las.

- Planejamento da manutenção das estruturas, seja preventiva ou corretiva;

- Programas de incentivo à cooperação da população, por meio de auxílio no projeto das estruturas residenciais, leis de incentivo tributário, trabalhos de divulgação e educação;

- Disponibilização de informações sobre experiências em outros países;

- Incentivo à fabricação de equipamentos, produtos e peças hidráulicas apropriadas à implantação de estruturas de infiltração, em escala industrial, com padronização comercial;

- Construção de modelos físicos que permitam a visualização e o estudo detalhado do funcionamento das estruturas;

- Normatização de técnicas construtivas e elaboração de manuais de projeto;

- Inclusão dos projetos de infiltração no planejamento urbano;

- Avaliar os riscos de falha das estruturas por colmatação, bem como os riscos de contaminação do solo e do aqüífero.

Coombes et al. (1999), num estudo de caso para a cidade costeira de New Castle, Australia, enumera os seguintes aspectos avaliados pela agência de licenciamento e fiscalização ambiental local quanto à implantação de sistemas de reuso e infiltração de águas de chuva em grande escala:

- A possibilidade de contaminantes não detectados serem infiltrados nas águas subterrâneas;

- A possibilidade das práticas de retenção e infiltração comprometerem a integridade estrutural das construções existentes;

- Os possíveis problemas de saúde pública pelo mau uso das águas de chuva armazenadas para reaproveitamento;

- O risco de secas severas produzirem reduções significativas no abastecimento público, uma vez que os sistemas de abastecimento seriam projetados contando com o fornecimento adicional proveniente das águas pluviais;

- O risco de eventos de chuva extremos produzirem enchentes em unidades residenciais, pela sobrecarga dos sistemas locais de infiltração e armazenamento. 
Coombes et al. (1999) identificaram uma relação de questões a serem respondidas para uma avaliação concreta destes itens:

- Qual a manutenção requerida para o sistema, e quanto custa?

- Qual a economia possível de águas de abastecimento para uso residencial interno e externo?

- Qual a redução possível na capacidade das redes de micro e macrodrenagem?

Na prática de gerenciamento sustentado de águas urbanas, a escolha da melhor técnica, ou combinação de técnicas viáveis para a solução de cada caso pode ser bastante complexa.

Veldkamp et al. (1997) desenvolveram um método de escolha constituído de cinco etapas:

- Definição do problema;

- Escolha das tecnologias viáveis e/ou disponíveis;

- Processo interativo de seleção das alternativas, com base em critérios preestabelecidos, dados referentes ao solo e à quantidade e qualidade da água, e com o auxílio de ferramentas apropriadas de simulação e dimensionamento;

- Combinação de técnicas;

- Organização das possíveis soluções encontradas em um ranking de custo e sustentabilidade.

Outras metodologias de escolha semelhantes a esta vêm sendo desenvolvidas atualmente (Barraud et. al., 1999) com o propósito de auxiliar os projetistas a definir a solução mais adequada a ser utilizada em cada situação, uma vez que trata-se de uma forma alternativa de se promover a drenagem das águas pluviais e que, portanto, deve ser introduzida de maneira eficiente e otimizada, a fim de evitar erros que possam provocar problemas futuros.

\subsubsection{Dimensionamento de estruturas de infiltração}

Para comparar a eficiência de estruturas de infiltração com a de outros métodos de drenagem de águas pluviais é necessário ter em mãos uma metodologia de projeto (Mikkelsen e Jacobsen, 1993). A literatura apresenta alguns métodos, que serão discutidos a seguir. 
Jonasson (1984, apud Mikkelsen e Jacobsen, 1993; Mikkelsen et al., 1996) propôs o rain envelope method, descrito por dois parâmetros, dados pelas Equações 3.3 e 3.4:

$$
v=\frac{V}{A_{r}}
$$

e

$$
q_{f r}=\frac{Q_{f r}}{A_{r}}
$$

em que:

$\nu=$ volume especifico de armazenamento $(L)$;

$V=$ volume útil de armazenamento $\left(L^{3}\right)$;

$q_{f r}=$ taxa média de infiltração, constante no tempo $\left(L T^{\underline{l}}\right)$;

$Q_{f r}=$ vazão de infiltração da estrutura $\left(L^{3} T^{-1}\right)$;

$A_{r}=$ área impermeável de drenagem conectada à trincheira $\left(L^{2}\right)$.

Jonasson (1984, apud Mikkelsen et al. 1996) propõe que $Q_{f r}$ seja obtida a partir da formulação de Darcy para escoamento em solo saturado, considerando que a infiltração ocorre somente em metade da área lateral da estrutura, supondo a colmatação total da área da base após algum tempo de operação do sistema, considerando que o nível d'água esteja localizado na seção média entre a base e o topo da trincheira, de modo que:

$$
Q_{f r}=K \frac{A_{1}}{2}
$$

em que:

$K=$ condutividade hidráulica saturada do solo $\left(L T^{1}\right)$;

$A_{l}=$ área lateral da estrutura de infiltração $\left(L^{2}\right)$;

O volume de armazenamento é obtido por balanço de massa, conforme a Equação 3.6:

$$
V=V_{a f}=V_{e f}
$$

em que:

$V_{a f}=$ volume afluente à estrutura $\left(L^{3}\right)$;

$V_{\text {ef }}=$ volume de saida da estrutura $\left(L^{3}\right)$.

Sendo que o volume afluente é estimado com base na curva IDF.

A principal desvantagem do rain envelope method, segundo Mikkelsen et al. (1996) é que, ao calcular o volume de entrada com base na curva IDF, o método negligencia o efeito

\footnotetext{
${ }^{4}$ Jonasson, S.A. (1984). Dimensioning methods for stormwater infiltration systems. Proc. Third Int. Conf. on Urban Storm Drainage, Göteborg, Sweden, June 4-8, 1984, 3, 1037-1046.
} 
de chuvas sucessivas, o que representa o principal risco de sobrecarga das estruturas de infiltração.

É importante ressaltar também que o processo de infiltração das águas pluviais se dá, em parte do tempo de operação do sistema, durante uma tormenta, em meio não saturado. Considerar que todo o processo ocorre em solo saturado significa subdimensionar a estrutura.

Mikkelsen e Jacobsen (1993) apresentaram um método de dimensionamento de estruturas de infiltração que leva em conta o efeito de chuvas sucessivas negligenciado pelo uso das curvas IDF no cálculo do volume de armazenamento. Uma vez que a taxa de infiltração $q_{f r}$ é constante, o tempo de esvaziamento total da estrutura de infiltração é dado pela Equação 3.7:

$$
t_{e}=\frac{v}{q_{f r}}
$$

O método proposto utiliza séries históricas como entrada de um modelo de simulação do escoamento superficial e armazenamento, a partir do qual elabora-se um ábaco que fornece o volume específico de armazenamento em função do tempo de esvaziamento $t_{e}$, para vários períodos de retorno. Com base na geometria da estrutura de infiltração, e considerando escoamento bidimensional, calcula-se, a partir das equações 3.8 a 3.10 , o tempo de esvaziamento $t_{e}$, com o qual obtém-se, no ábaco, o volume específico de armazenamento.

$$
\begin{aligned}
& q_{f r}=\frac{Q_{f r}}{A_{r}}=\frac{K \frac{A_{l}}{2}}{A_{r}}=\frac{K \cdot 2 \cdot l \cdot h / 2}{A_{r}}=\frac{K l h}{A_{r}} \\
& v=\frac{V}{A_{r}}=\frac{l \cdot h \cdot w \cdot \phi}{A_{r}} \\
& v=q_{f r} \cdot \frac{w \cdot \phi}{K}=q_{f r} \cdot t_{e}
\end{aligned}
$$

em que:

$l, w, h=$ comprimento, largura e profundidade da trincheira $(L)$;

$\phi=$ porosidade da brita no interior da trincheira (adimensional);

$t_{e}=$ tempo de esvaziamento (T).

Ferguson (1995) estimou o volume de armazenamento a partir do hidrograma de entrada calculado pelo método do Soil Conservation Service, para estruturas de infiltração 
na macrodrenagem, instaladas ao longo (on-line) e às margens (off-line) do canal. Os hidrogramas de entrada, em ambos os casos, são mostrados na Figura 3.11, e o volume de armazenamento é obtido geometricamente.
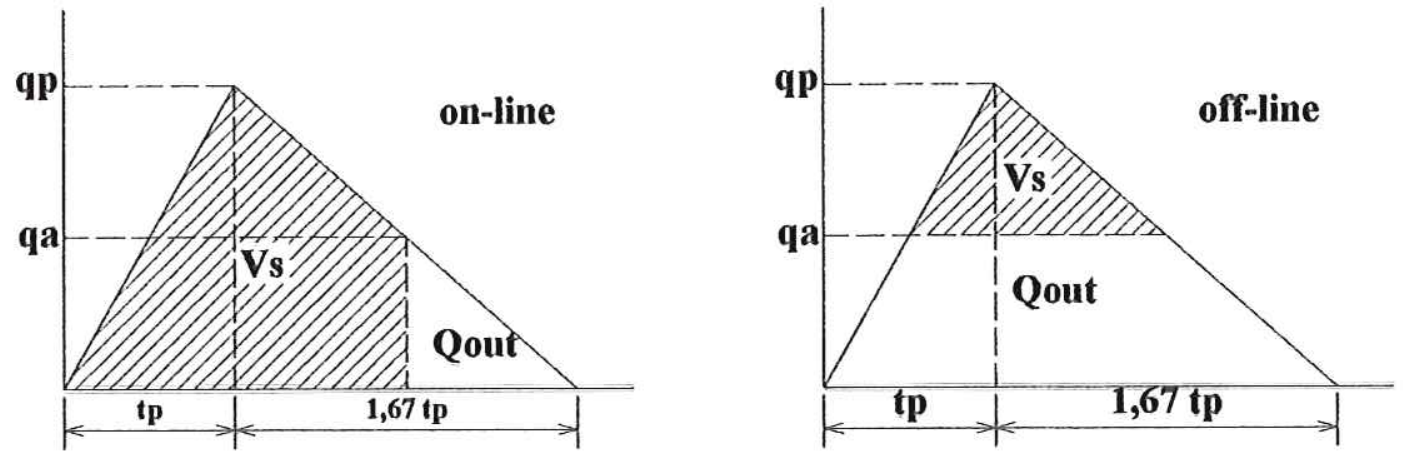

Figura 3.11 - hidrogramas de entrada dos sistemas de infiltração on-line e off-line. Fonte: Ferguson, 1995.

Em que:

$V_{s}=$ volume de armazenamento

$Q_{p}=$ vazão de pico do hidrograma unitário

$t_{p}=$ tempo para atingir o pico do hidrograma

$q_{a}=$ vazão de descarga especifica

$Q_{\text {out }}=$ vazão vertida

Os métodos de dimensionamento de estruturas de infiltração baseiam-se no balanço hídrico no interior do dispositivo, ou seja, o volume de armazenamento deve ser igual ao volume de entrada, menos o de saída. A diferença entre os métodos consiste em como obter tais volumes, seja pelo hidrograma unitário, seja pelo método racional, ou, no caso dos volumes de saída, qual o modelo de infiltração adotado. O método proposto neste trabalho, que será apresentado mais adiante, trabalha com a curva idf para a estimativa do volume de entrada, e com dois diferentes modelos de infiltração, Philip e Richards', para o volume de saída.

-A elaboração de manuais de projeto de estruturas de infiltração é o primeiro para viabilizar sua utilização em grande escala. No entanto, ainda há muitos aspectos a serem estudados, como, por exemplo, o comportamento hidráulico das estruturas de infiltração em meio não saturado, que foi o objetivo deste trabalho. Para tanto, é necessário um conhecimento básico sobre a dinâmica da água no solo, e sobre as propriedades que influenciam na infiltração.

\subsection{Dinâmica da água no solo}


Dois pontos são de fundamental importância para o conhecimento do movimento da água no solo: o conceitos de umidade e potencial (Libardi, 2000). No estudo da infiltração, aplica-se estes conceitos na análise da condutividade hidráulica do solo.

\subsubsection{Conduitividade hidiráulica}

A condutividade hidráulica é a mais importante propriedade que governa o movimento da água no solo (Soto, 1999). Ela é igual, numericamente, ao volume de água que atravessa verticalmente, em um segundo, uma amostra de solo de dimensões $1 \times 1 \times 1 \mathrm{~m}^{3}$, sob uma diferença de potencial total de $1 \mathrm{~J} / \mathrm{m}^{3}$. Trata-se, portanto, de um coeficiente que expressa a facilidade com que a água é transportada através do solo (Libardi, 2000).

A água, em estado líquido no solo, flui em decorrência dos gradientes de potencial existentes, sendo que o fluxo ocorre da região de maior potencial para a região de menor potencial (Soto, 1999). A condutividade hidráulica de um solo é função direta de sua geometria porosa e da umidade. O movimento da água é mais lento no solo não saturado do que no solo saturado, devido às descontinuidades dos poros com água e ar (Soto, 1999). Desta forma, quando a umidade do solo é igual à de saturação, sua condutividade hidráulica é máxima. (Libardi, 2000). Daí a importância de utilizar métodos de cálculo em solo não saturado para estimar os volumes de armazenamento de estruturas de infiltração.

Deste modo, para os fins propostos neste trabalho, interessa o conhecimento da condutividade hidráulica não saturada, ou seja, da curva de condutividade em função da umidade $k=f(\theta)$. A Equação 3.11, proposta por Darcy (1856, apud Libardi, 2000) quantifica o movimento de água no solo saturado, e foi adaptada por Buckingham (1907, apud Libardi, 2000) para solos não saturados (eq. 3.12).

$$
\begin{aligned}
& \vec{q}=-K \nabla \phi t \\
& \vec{q}=-k(\theta) \nabla \phi t
\end{aligned}
$$

Em que:

$q=$ densidade de fluxo $\left(L T^{l}\right)$; relação entre vazão e área onde ocorre efetivamente o fluxo, que é a seção porosa do solo. Apesar de possuir dimensão de velocidade, não é mumericamente igual a esta, pois não considera a área total, somente a área efetiva de fluxo;

$k(\theta)=$ condutividade hidráulica não saturada, em função da umidade (LT $\left.{ }^{l}\right)$;

$K=$ condutividade hidráulica saturada $\left(L T^{l}\right) e$

$\phi t=$ potencial total da água no solo $(L)$. 
Mais adiante, serão descritos os métodos de laboratório e campo para a determinação da condutividade hidráulica saturada e não saturada.

\subsubsection{Potencial total da água no solo}

O estudo dos potenciais da água no solo é feito em termos de diferença de potencial em relação a um determinado estado de referência padrão, pré-fixado. $\mathrm{O}$ conceito de estado padrão é adotado porque, em dinâmica da água no solo, o que interessa é sempre a diferença de potencial, e não o seu valor absoluto. Portanto, torna-se útil adotar um estado padrão que possa ser utilizado em todas as medidas de potencial da água no solo, em qualquer lugar que sejam feitas, sob quaisquer condições de temperatura e pressão. Para o estudo do movimento da água no solo, considera-se como estado padrão a água, à mesma temperatura da água no solo, sob pressão atmosférica, num referencial de posição conhecido.

Sendo assim, define-se potencial da água no solo a diferença entre o potencial químico da água na fase sólidos-água-ar e o potencial químico da água na fase estado padrão (Libardi, 2000). O potencial total da água no solo é formado pelas componentes de gravidade, pressão, temperatura, pneumática e mátrica.

Os potenciais da água no solo têm como unidade energia por unidade de massa de água $(\mathrm{J} / \mathrm{kg})$. Entretanto, é útil expressá-los em termos de unidade de energia por unidade de volume de água $\left(\mathrm{J} / \mathrm{m}^{3}\right)$. Dimensionalmente, o resultado desta unidade é o de pressão, $\mathrm{N} / \mathrm{m}^{2}$ ou Pa (Libardi, 2000).

Utilizamos aqui o termo água para efeito de simplificação. Na verdade, em Física dos Solos, a denominação correta é feita em termos de solução, pois a água apenas em circunstâncias ideais se apresenta na forma pura no solo. Estudos mais aprofundados devem ser tratados, portanto, em termos de potenciais da solução no solo, e potenciais da componente água na solução no solo.

O potencial total da solução no solo, $\phi t$, em condições não saturadas, é composto pelos potenciais de pressão $(\phi p)$, pressão de ar, ou pneumático $(\phi n)$, mátrico $(\phi m)$, gravitacional $(\phi g)$, de temperatura $(\phi T)$ e osmótico $(\phi o): \phi \mathrm{t}=\phi \mathrm{p}+\phi \mathrm{n}+\phi \mathrm{m}+\phi \mathrm{g}+\phi \mathrm{T}+\phi \mathrm{o}$.

Conforme será visto adiante, para os problemas práticos de engenharia, em que se estuda a infiltração de água em solos não saturados, as principais componentes do potencial total são os potenciais mátrico e gravitacional. Isso porque os potenciais de temperatura e osmótico possuem ordem de grandeza muito inferior aos demais, e porque os 
potenciais de pressão e pneumático são nulos na zona não saturada de rígidos (não expansivos).

\subsubsection{Potencial de pressão}

A componente de pressão do potencial total da água no solo, ou simplesmente potencial de pressão $(\phi p)$, corresponde à variação parcial do potencial químico da água devida apenas à diferença entre a pressão externa que atua na fase sólidos-água-ar no solo, num estado considerado, e a pressão externa que atua na fase estado padrão.

$$
\phi p=\int_{P_{0}}^{P} \frac{\partial V}{\partial m_{a}} d P=\int_{P_{0}}^{P} v_{a} d P
$$

em que:

$\phi p=$ potencial de pressão, em $\mathrm{J} / \mathrm{m}^{3}$;

$P=$ pressão externa atuante na fase sólidos-água-ar no solo, no estado considerado;

$P_{0}=$ pressão atuante na fase estado padrão;

$V=$ volume do sistema;

$m_{a}=$ massa de água;

$v_{\alpha}=$ volume específico da água $=\partial \mathrm{V} / \partial \mathrm{m}_{a}$

No caso de solos saturados tem-se que:

$\phi p=P_{1}+P_{a t m}-P_{0}$

em que

$P_{l}=$ pressão de líquido $e$

$P_{\text {atm }}=$ pressão atmosférica .

Em caso de solos não saturados, se o solo for rígido (não expansivo), tem-se:

$$
\phi p=0
$$

No caso de solo não saturado expansivo, vale a Equação 3.13, considerando que:

Para $m_{a} \rightarrow 0$ (solo seco) $\Rightarrow v_{\alpha} \rightarrow 0$

Para $m_{a} \rightarrow m_{a \text { máx }}\left(\right.$ saturação) $\Rightarrow v_{\alpha} \rightarrow 1 / \rho_{a}$

Os experimentos conduzidos com trincheiras de infiltração neste trabalho foram realizados em dois solos não expansivos, na condição não saturada, em que $\phi p=0$.

\subsubsection{Potencial pneumático}


Quando a pressão do ar no solo, no ponto de medida, for diferente da pressão no estado padrão, origina-se a componente denominada potencial pneumático, que, por isso, representa o efeito das variações da pressão do ar no solo sobre o potencial da água no solo (Libardi, 2000, in Dinâmica da Água no Solo). O potencial pneumático é expresso por:

$$
\phi n=\int_{P_{a 0}}^{P_{0}}\left(\frac{1}{\rho_{a}}-v_{a}\right) d P_{a r}
$$

em que:

$\phi n=$ potencial pneumático, $\mathrm{em} \mathrm{J} / \mathrm{m}^{3}$;

$P_{a}=$ pressão do ar na fase sólidos-água-ar no estado considerado;

$P_{a r 0}=$ pressão do ar na fase estado padrão;

Para solos saturados, em que $v_{\alpha}=1 / \rho_{a}$, tem-se $\phi n=0$.

Para solos não saturados, não expansivos, tem-se $v_{\alpha}=0$, e, portanto:

$$
\phi n=\frac{1}{\rho_{a}}\left(P_{a r}-P_{0}\right)
$$

Para solos não saturados expansivos, aplica-se a Equação 3.16, sem simplificações.

Em condições experimentais de campo, pode-se considerar $\phi n=0$, porque a pressão de ar que atua na água no solo é a pressão atmosférica local, considerada como pressão de referência (Libardi, 2000)

\subsubsection{Potencial de temperatura}

O potencial de temperatura $(\phi T)$ corresponde à variação parcial do potencial químico da água devida apenas a uma diferença entre a temperatura da fase sólidos-água-ar no solo, no estado considerado, e a temperatura da fase estado padrão. Matematicamente, o potencial de temperatura é definido por:

$$
\phi T=\int_{T_{0}}^{T} \frac{\partial(-S)}{\partial m_{a}} d T
$$

em que:

$\phi T=$ potencial de temperatura, em $\mathrm{J} / \mathrm{m}^{3}$;

$T$ = temperatura da fase sólidos-água-ar no solo, no estado considerado;

$T_{0}=$ temperatura da fase estado padrão;

$S=$ entropia do sistema;

$m_{a}=$ massa de água 
Conforme salienta Libardi (2000), quando se considera o potencial de temperatura no potencial da água no solo, muitas equações nas quais o potencial total da água é utilizado não fornecem resultados quantitativos corretos. Deste modo, o conceito de potencial é limitado a sistemas isotérmicos, ou aproximadamente isotérmicos, em que a influência da temperatura possa ser desprezada. Em caso de sistemas verdadeiramente não isotérmicos, lança-se mão da termodinâmica dos processos irreversíveis.

Na prática, e para os fins a que se propôs este trabalho, pode-se considerar que, nas camadas sub superficiais do solo, a temperatura é praticamente constante ao longo do dia, e que o sistema estudado é isotérmico, em que $\phi T=0$.

\subsubsection{Potencial gravitacional}

Define-se potencial gravitacional $\phi g$ como a diferença do produto da aceleração da gravidade $g$ pela distância vertical $Z$, em relação a um dado referencial, entre as fases sólidos-água-ar no estado considerado e a fase estado padrão:

$$
\phi g=g\left(Z-Z_{0}\right)
$$

Como o plano horizontal de referência, em relação ao qual são medidas verticalmente as distâncias $Z$ e $Z_{o}$ é arbitrário, convém fazê-lo coincidir com a fase estado padrão, de modo que $Z_{o}=0$, e a Equação 3.19 fica reduzida a:

$$
\phi g=g Z
$$

\subsubsection{Potencial osmótico}

O potencial osmótico deriva da diferença de composição entre a solução no solo, contendo água, sais minerais e substâncias orgânicas, e a água pura (Soto, 2004). Ele ocorre devido à solução nos poros possuir sais em dissolução, e exercer uma sucção osmótica para levar a solução no solo do estado original ao estado padrão (água pura).

$$
\phi o=-\frac{g}{\gamma_{w}} \cdot\left(-P_{o s m}\right)
$$

em que:

$\gamma_{w}=$ peso especifico da água, $M L^{-2} T^{2}$

$P_{\text {osm }}=$ pressão osmótica, $M L^{-1} T^{2}$

Para efeito de simplificação, considerou-se, neste trabalho, que a solução utilizada nos experimentos de infiltração em campo constitui-se de água pura, o que anula os efeitos do potencial osmótico. 


\subsubsection{Potencial mátrico}

Nos ensaios conduzidos em campo neste trabalho, como será visto adiante, destaca-se a componente mátrica do potencial total da água no solo. O potencial mátrico é a componente que representa os efeitos da matriz do solo sobre o potencial total da água no solo, incluindo forças associadas com a adsorção e a capilaridade, responsáveis pela retenção da água no solo. É definido como a variação parcial do potencial da água no solo devida apenas a uma diferença entre a umidade da fase sólidos-água-ar e da fase estado padrão (Libardi, 2000).

O potencial mátrico pode ser entendido como a "pressão de sucção" necessária para remover a água retida na matriz do solo. Quanto mais seco estiver o solo, maior será a sucção necessária para desprender água de sua matriz, o que conduz intuitivamente à noção de que o potencial mátrico é função da umidade, e é sempre negativo. Matematicamente:

$$
-\phi m(\theta)=\int_{\theta}^{\theta_{0}} \frac{\partial \mu_{a}}{\partial \theta} d \theta
$$

em que:

$\phi m=$ potencial mátrico do solo;

$\theta=$ umidade volumétrica;

$\theta_{0}=$ umidade volumétrica da fase estado padrão;

$\mu_{a}=$ potencial químico da água no solo.

\subsubsection{Curva de retenção}

O conhecimento da curva de potencial mátrico em função da umidade, $\phi_{m}=f(\theta)$, é de fundamental importância para o estudo da infiltração da água no solo. Esta relação é conhecida como curva de retenção do solo.

Algumas relações são comumente utilizadas para calibrar a curva de retenção de um solo. Os principais modelos são:

\section{- Brooks e Corey (1964)}

$$
\theta=\left(\theta_{s}-\theta_{r}\right) \cdot\left(\frac{\phi m_{a}}{\phi m}\right)^{\lambda}+\theta_{r}
$$

em que:

$\theta=$ umidade volumétrica $\left(\mathrm{cm}^{3} / \mathrm{cm}^{3}\right)$

$\theta_{s}=$ umidade volumétrica de saturação $\left(\mathrm{cm}^{3} / \mathrm{cm}^{3}\right)$ 
$\theta_{r}=$ umidade volumétrica residual $\left(\mathrm{cm}^{3} / \mathrm{cm}^{3}\right)$

$\phi_{m}=$ potencial mátrico $\left(\mathrm{cm}_{\mathrm{H} 2 \mathrm{O}}\right)$

$\phi_{m a}=$ potencial mátrico que corresponde à entrada de ar $\left(\mathrm{cm}_{\mathrm{H} 2 \mathrm{O}}\right)$

$\lambda=$ parâmetro de ajuste do modelo

O modelo de Brooks e Corey possui a desvantagem da descontinuidade da função para $\phi_{m}=0$.

- Van Genuchten (1980)

$$
\theta=\theta_{r}+\frac{\left(\theta_{s}-\theta_{r}\right)}{\left[1+\left(\alpha_{v} \cdot \phi_{m}\right)^{n}\right]^{n}}
$$

em que:

$\alpha_{v}=$ parâmetro de ajuste da curva $\left(\mathrm{cm}^{-1}\right)$

$n=$ coeficiente de ajuste da curva

$m=$ coeficiente de ajuste da curva $(m=1-1 / n)$

O modelo de Van Genuchten é vantajoso para a modelagem numérica, por não possuir descontinuidade.

- Fredlund et al (1994, apud Soto, 2004)

$$
\theta=\theta_{s} \cdot\left[1-\frac{\ln \left(1+\frac{\phi m}{\phi m_{r}}\right)}{\ln \left(1+\frac{10^{6}}{\phi m_{r}}\right)}\right] \cdot\left[\frac{1}{\ln \left(e+\left(\frac{\phi m}{\phi m_{a}}\right)^{n}\right)}\right]^{m}
$$

em que:

$\phi_{m r}=$ potencial mátrico que corresponde à umidade volumétrica residual, em $\mathrm{cm}_{\mathrm{Hz}}$;

$e=2,71828$

$10^{6}=$ valor limite de sucção para qualquer tipo de solo, em $\mathrm{kPa}$;

$n, m=$ coeficientes de ajuste da curva;

Mais adiante, no capítulo sobre metodologia, será visto o método utilizado para a obtenção das curvas de retenção dos solos 1 e 2 e o modelo ajustado.

\section{Fenômeno de histerese}

Para um mesmo solo, a curva de retenção pode descrever uma trajetória diferente em função do acréscimo ou decréscimo de qualquer de suas variáveis (processos de drenagem e umedecimento). Assim, verifica-se que, num determinado solo, as trajetórias de secagem 
e umedecimento podem não coincidir para um mesmo valor de sucção, manifestando-se o fenômeno denominado histerese. (Soto, 2004).

Este comportamento da curva de retenção, ilustrado na Figura 3.12, afeta diretamente as condições de fluxo no solo não saturado, e pode ser atribuído a diferentes causas, segundo Soto (2004):

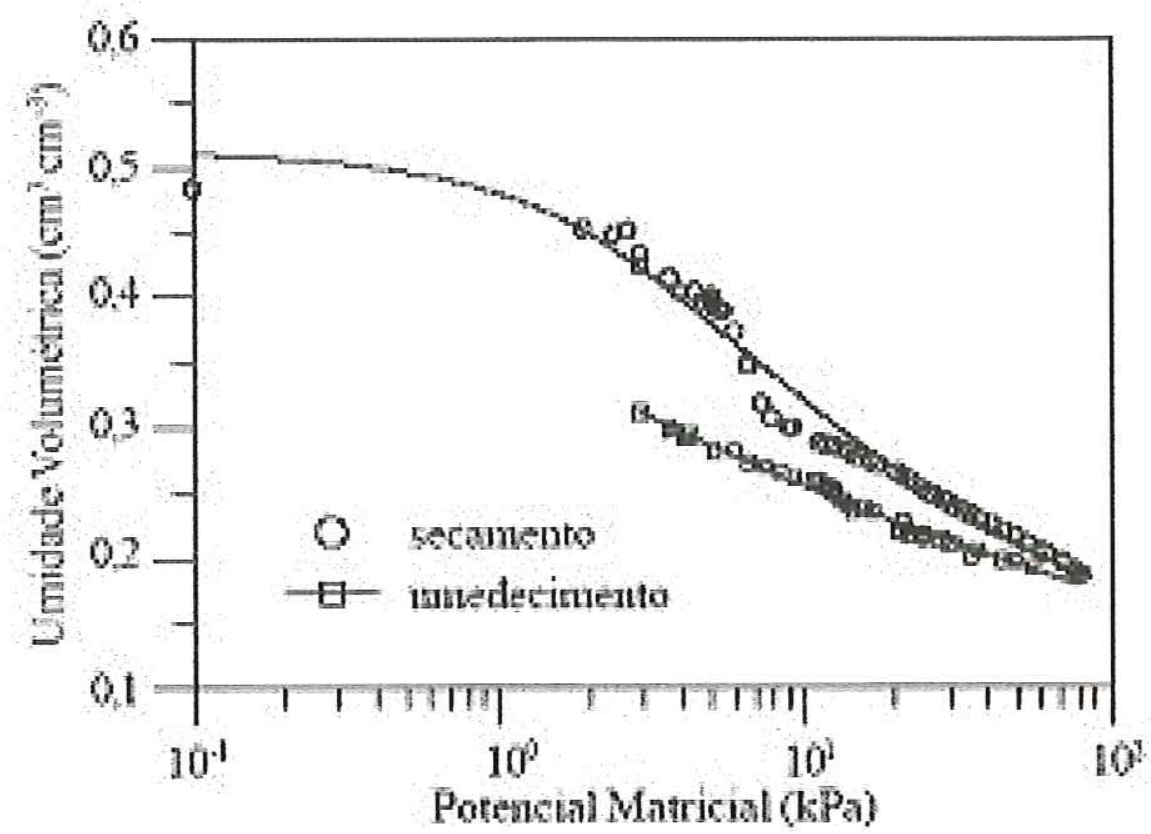

Figura 3.12 - Exemplo da influência dos processos de secagem e umdedecimento na forma da curva de retenção. Fonte: Otto, S.R.L., Alcaide, M., 2001.

- O efeito de ângulo de contato do menisco de água, mais intenso no umedecimento do que na drenagem;

- Irregularidades geométricas dos poros interconectados que atingem equilíbrio em posições diferentes para os dois procedimentos, com diferentes volumes de água;

- Bolhas de ar capturadas nos vazios do solo no processo de umedecimento;

- Alterações da estrutura do solo produzidas pela expansão ou contração nos solos argilosos, nos processos de umedecimento e drenagem.

\subsection{Modelos de infilttração}

Define-se infíltração como a entrada de água no solo através da interface soloatmosfera (Libardi, 2000). O termo taxa de infiltração refere-se à quantidade de água que atravessa a unidade de área da superfície do solo por unidade de tempo. A infíltração acumulada (I) é a quantidade total de água infiltrada no solo desde o início da infiltração até o instante $t$, expressa em termos de altura d'água, ou volume por unidade de área. 
É fato experimental que, durante o processo de infiltração, estando o solo inicialmente seco, a taxa de infiltração tende a decrescer com o tempo, atingindo um valor final constante. Um gráfico relacionando a taxa de infiltração, a partir de uma superficie inundada, com o tempo, é chamado lei de infiltração, e o valor final constante é conhecido como capacidade de infiltração.

Existem diversas equações propostas para expressar a lei de infiltração da água em solos. Segundo Libardi (2000), são equações desenvolvidas empiricamente ou a partir de considerações físicas, e aplicam-se somente a solos homogêneos e que permanecem homogêneos durante o processo.

\subsubsection{Equação de Green \& Ampt (1911, apud Libardi, 2000) ${ }^{5}$}

Para o desenvolvimento de sua equação de fluxo, estes autores assumiram que, procedendo ao processo de infiltração, mantendo-se uma carga hidráulica H0 constante na superficie do solo, existe uma frente de molhamento bem nítida e precisamente definida, atrás da qual o solo se encontra uniformemente saturado, com condutividade hidráulica K0, e que o potencial mátrico nesta frente permanece sempre constante, independentemente do tempo e posição, e igual ao valor do potencial mátrico do solo antes da infiltração.

$$
i=-K_{0} \frac{\left(H_{0}+L+H_{f}\right)}{L}
$$

em que:

$\mathrm{i}=$ taxa de infiltração;

$\mathrm{t}=$ tempo, $\mathrm{s}$;

$\mathrm{L}=$ comprimento da coluna saturada, $\mathrm{m}$;

$\mathrm{K}_{0}=$ condutividade hidráulica saturada, $\mathrm{m} / \mathrm{s}$;

$\mathrm{H}_{0}=$ potencial de pressão constante na superfície do solo, $\mathrm{mH} 2 \mathrm{O}$

$-\mathrm{Hf}=$ potencial mátrico constante na frente de molhamento, $\mathrm{mH} 2 \mathrm{O}$

\subsubsection{Equação de Kostiakov (1932, apud Libardi, 2000) ${ }^{6}$}

Trata-se de uma equação inteiramente empírica, da forma:

$$
i=i_{i} \cdot t^{-a}
$$

\footnotetext{
${ }^{5}$ Green, W.H. \& Ampt, G.A. (1911). Studies in soil phisics. I. The flow of air and water through soils. Journal of Agricultural Science 4, 1-24.

${ }^{6}$ Kostiakov, A.N. (1932). On the dynamics of the coefficient of water percolation in soils and on the necessity for studying it from a dynamic point of view for purposes of amelioretion. Trans. $6^{\text {th }}$ Comm. Intern. Soc. Soil Sci., Moscou, Part A, 17-21.
} 
em que:

$t=$ tempo, $s$

$i=$ taxa de infiltração no instante $t$, em $\mathrm{m}^{3} / \mathrm{s} \mathrm{m}^{2}$

$i_{i}=$ taxa de infiltração em $t=0, \mathrm{em} \mathrm{m}^{3} / \mathrm{s} \cdot \mathrm{m}^{2}$

$a=$ constante de decaimento da taxa de infiltração, tal que $0<a<1$.

A infiltração acumulada $I$ até o instante $t$ é dada por;

$$
I=i_{i} \cdot \frac{t^{(1-a)}}{1-a}
$$

Esta equação é válida para instantes $t$ inferiores ao tempo $T$ em que se atinge a capacidade de infiltração igual à condutividade hidráulica saturada $\mathrm{K}_{0}$ :

$$
K_{0}=i_{i} T^{-a}
$$

De modo que se atenda a condição de que, para $t \rightarrow \infty, i \rightarrow K_{0}$.

\subsubsection{Equação de Horton (1940, apud Libardi, 2000) ${ }^{7}$}

Na natureza, existem muitos processos de decaimento que obedecem à lei de que a taxa de variação de uma determinada grandeza que se aproxima de um valor final constante é proporcional à diferença entre seu valor num determinado tempo e o valor final constante. No caso em questão, a grandeza é a taxa de infiltração $i$, cujo valor final constante é $i_{f}$. A equação de Horton baseia-se nesta lei, e é expressa por:

$i=i_{f}+\left(i_{i}-i_{f}\right) \cdot e^{-C \cdot t}$

em que:

$i=$ taxa de infiltração no instante $t, \mathrm{em} \mathrm{m}^{3} / \mathrm{s} \cdot \mathrm{m}^{2}$;

$i_{f}=$ taxa de infiltração constante em $t \rightarrow \infty, \mathrm{em} \mathrm{m}^{3} / \mathrm{s}^{2} \mathrm{~m}^{2}$;

$i_{i}=$ taxa de infiltração em $t=0, \mathrm{em} \mathrm{m} / \mathrm{s} \cdot \mathrm{m}^{2}$;

$C=$ constante de decaimento da taxa de infiltração.

$t=$ tempo, $s$

\subsubsection{Equação de Philip (1957, apud Libardi, 2000) ${ }^{8}$}

\footnotetext{
${ }^{7}$ Horton, R.E. (1940). An approach toward a physical interpretation of infiltration-capacity. Soil Sci. Soc. Am. Proc. 5: 399-417.

${ }^{8}$ Philip, J.R. (1957). The theory of infiltration 4. Sorptivity and algebraic infiltration equations. Soil Sci. 84, 257-264.
} 
Trata-se de uma equação desenvolvida a partir da equação do perfil de umidade. Para a obtenção da lei de infiltração, Philip considera duas possibilidades: infíltração vertical e infiltração horizontal.

O primeiro caso é expresso pela equação:

$I=C \sqrt{t}+F t$

A infiltração em uma coluna de solo horizontal é dada por:

$i=\frac{C}{2 \sqrt{t}}$

e a infiltração acumulada, no caso horizontal, é:

$I=C \sqrt{t}$

em que:

$t=$ tempo

$I$ = infiltração acumulada até o instante $t$, em $\mathrm{m}^{3} / \mathrm{m}^{2}$;

$i=$ taxa de infiltração no instante $t, \mathrm{em} \mathrm{m}^{3} / \mathrm{s} \mathrm{m}^{2}$;

$F=$ valor constante para o qual tende a taxa de infiltração para tempos longos de infiltração, relacionada com a contribuição da gravidade para o movimento d'água.

$C=$ sortividade, grandeza relacionada com a capacidade do solo homogêneo absorver água em relação à sua umidade inicial.

A vantagem da equação proposta por Philip (1957, apud Libardi, 2000) para explicar a lei de infíltração, segundo Libardi (2000), é o fato de ela ser baseada na teoria e de suas constantes possuírem significado físico.

\subsubsection{Equação de Richards' (1931, apud Tabuada et al, 1995a) ${ }^{9}$}

Os modelos tradicionais vistos até aqui quantificam a infiltração de forma unidimensional. Entretanto, no caso das trincheiras de infiltração, o movimento da água no entorno da estrutura ocorre nas duas direções de sua seção transversal, e sofre uma variação, ainda que pequena, ao longo do comprimento da trincheira. Portanto, a utilização de um modelo unidimensional forneceria uma aproximação pouco condizente com a realidade. Desta forma, buscou-se um modelo que descreve-se o movimento da água no solo não saturado de forma bidimensional.

\footnotetext{
${ }^{9}$ Richards, L.A. (1931). Capillary conduction of liquids through porous medium. Physics, 1, 318-333.
} 
O modelo de Richards' baseia-se na substituição da Equação de Darcy-Buckingham na Equação da Continuidade, originando uma equação diferencial que descreve o movimento da água no solo como função da condutividade hidráulica não saturada $K(\theta)$.

- Equação de Darcy-Buckingham, para a quantificação do movimento da água em meio não saturado:

$$
\vec{q}=-k(\theta) \nabla \phi t
$$

em que:

$k(\theta)$ é a condutividade hidráulica em função da umidade, $e$

$\phi t$ é o potencial total da água no solo, ou seja, é a soma dos potenciais de pressão, pneumático (ar), mátrico, gravitacional, de temperatura e osmótico.

- Equação da continuidade:

$\frac{\partial \theta}{\partial t}=-\vec{\nabla} \vec{q}$

em que:

té tempo;

$\theta$ é a umidade volumétrica, $e$

$q$ é a densidade de fluxo (relação entre a vazão que passa pelo solo e a área efetiva de escoamento, com dimensão $L T^{1}$ );

Substituindo 3.34 em 3.35 tem-se:

$$
\frac{\partial \theta}{\partial t}=\vec{\nabla}(k(\theta) \vec{\nabla} \phi t)
$$

A equação 3.36 é conhecida como Equação de Richards', e pode ser escrita em termos de condutividade hidráulica não saturada ou em termos de potencial mátrico (curva de retenção).

O uso de equações empíricas ou semi-empíricas como modelos de infiltração, apenas permite computar os volumes infiltrados, enquanto que Richards' leva em consideração as condições iniciais de umidade do solo, e, não apenas quantifica os volumes infiltrados, mas também descreve o movimento da água no solo.

Em 1995, Tabuada et al. propuseram um método que quantifica bidimensionalmente o campo de umidade em torno de sulcos curtos de irrigação, estruturas utilizadas na agricultura, e que são semelhantes em geometria e comportamento hidráulico às trincheiras de infiltração. Sendo assim, o método pôde ser aplicado às estruturas de drenagem, com as mesmas considerações e condições de contorno relativas às estruturas de irrigação. 
O modelo de Tabuada et al. (1995a) tem como base a equação de Richards para o movimento da água em meios porosos não saturados, que é função do potencial total da água no solo e da condutividade hidráulica não saturada. A equação é desenvolvida em sua forma bidimensional, e as seguintes hipóteses são adotadas:

- Solo não expansivo ( $\phi \mathrm{p}=0$ na zona não saturada);

- Meio homogêneo e isotrópico (vale o ajuste unimodal de van Genuchten);

- Efeitos de temperatura, osmose e histerese desprezíveis $(\phi \mathrm{T}=0 ; \phi \mathrm{o}=0)$.

Os dados de entrada do modelo são:

- A curva de retenção do solo, $\phi m=f(\theta)$;

- A condutividade hidráulica do solo em função do grau de saturação $\mathrm{k}(\theta)$;

- As condições de contorno, que relacionam o potencial mátrico $\phi \mathrm{m}$ com as variáveis espaço e tempo.

As condições de contorno são específicas para cada região do domínio, no entorno da estrutura de infiltração, e para cada uma das três fases da infiltração:

- Abastecimento: a água é aduzida à trincheira, e a lâmina d'água é crescente;

- Recessão: ocorre após o término do abastecimento e a lâmina d'água é decrescente;

- Redistribuição: movimento da água no solo após o término da recessão, ou seja, quando não houver mais lâmina d'água na trincheira.

O volume total infiltrado, num dado intervalo de tempo, é calculado através do somatório dos volumes infiltrados em cada trecho do domínio e em cada fase da infiltração, anterior ao instante considerado. Os volumes parciais, a cada intervalo, são determinados com base nas condições iniciais do intervalo estudado. Desta forma, obtémse o principal parâmetro de projeto de uma trincheira de infiltração, que é a sua capacidade de infiltração.

Posteriormente, Tabuada et al. (1995b) trataram de sulcos longos, abastecidos com água em seu extremo montante, com ocorrência de escoamento superficial longitudinal e, portanto, com o desenvolvimento de uma frente de avanço ao mesmo tempo em que se processa a infiltração no perímetro molhado, o que ocorre de forma transiente. Para tanto, foi utilizada a equação de Richards em conjunto com as equações de Saint-Vennant. No caso das trincheiras de infiltração, a frente de avanço é desprezível, uma vez que trata-se de uma estrutura suficientemente curta para que a variação longitudinal do escoamento não sofra alterações consideráveis. Neste trabalho, Tabuada et al. (1995b) consideram sulcos curtos aqueles com menos de 15 metros de comprimento. 
Mais adiante, no item sobre modelagem numérica, será visto detalhadamente como a equação de Richards' foi desenvolvida em forma bidimensional e discretizada para solução computacional, a fim de quantificar o movimento da água na zona não saturada, no entorno de trincheiras de infiltração.

Esta síntese inicial procurou expor o problema das enchentes sob a ótica da deficiência de planejamento da ocupação urbana, que constinui, no Brasil e em vários lugares do mundo, a principal causa das cheias em bacias urbanas. Procurou-se apresentar as possíveis formas de reversão desse processo, visando restabelecer o ciclo hidrológico natural da bacia. A metodologia apresentada a seguir foi formulada no intuito de monitorar o desempenho de trincheiras de infiltração e modelar o fenômeno bidimensional da infiltração em torno de trincheiras, com vistas a propor uma metodologia de dimensionamento e projeto. A seguir, faz-se uma análise simplificada da efíciência de um sistema de trincheiras de infiltração instalado em um loteamento. 


\section{METODOLOGIA}

A revisão bibliográfica mostrou que a redução das cheias urbanas envolve medidas estruturais e não estruturais para o controle do deflúvio superficial direto, e que elas podem funcionar através da infilttração ou detenção das águas de chuva. Neste trabalho estudou-se as trincheiras de infiltração como elementos de controle do escoamento superficial na origem, ou seja, nos lotes urbanos onde é gerado.

A seqüência de atividades adotada foi a seguinte:

- Trabalho experimental:

- Escolha das áreas para a implantação de trincheiras experimentais;

- Ensaios de campo e laboratório para a caracterização dos solos escolhidos;

- Ensaios com trincheiras experimentais.

- Averiguação da eficiência das trincheira para o período de retorno e chuva de projeto considerados;

- Simulação numérica:

- Escolha do modelo;

- Adaptação para a situação das trincheiras.

- Simulação para os dois solos estudados.

- Comparação entre os resultados experimentais e numéricos;

- Apresentação de uma metodologia para o dimensionamento de trincheiras de infiltração;

- Avaliação da redução do hidrograma de cheia de uma micro bacia urbana, devida à utilização de trincheiras de infiltração.

\subsection{Trabalho experimental}

\subsubsection{Escolha e classificação dos solos}

Os trabalhos experimentais foram realizados em duas áreas, com características distintas de infiltração: Solo 1, argiloso, localizado no interior da Estação Climatológica do 
CRHEA (Centro de Recursos Hídricos e Ecologia Aplicada) da Escola de Engenharia de São Carlos, e Solo 2, arenoso, localizado no interior do campus da USP em São Carlos, nas imediações do Departamento de Hidráulica e Saneamento.

Em cada solo foi instalada uma área experimental coberta, para minimizar os efeitos das intempéries na condução e nos resultados dos ensaios, e fechada, para restringir o acesso ao local.

Realizou-se a análise granulométrica conjunta em amostras dos dois solos, conforme Norma NBR-6502. O procedimento de ensaio consistiu em submeter amostras representativas das áreas de estudo, a um processo peneiramento, em uma seqüência de peneiras de aberturas conhecidas e decrescentes, normalizadas pela NBR-5734/80. O tempo de peneiramento e a freqüência de vibração do agitador mecânico de peneiras são normalizados pela NBR-6502.

Anotou-se a massa de amostra retida em cada peneira, obtendo-se a porcentagem da amostra que passa pela peneira. Em seguida, plotou-se estes dados de porcentagem que passa versus diâmetro dos grãos (ou abertura da peneira) em gráficos de granulometria normalizados pela NBR 5734/80, obtendo-se a composição granulométrica das amostras.

As curvas de granulometria dos solos 1 e 2 estão apresentadas na seção resultados, figuras 5.1 e 5.2, bem como a tabela 5.1, com o resumo da classificação granulométrica de ambos os solos.

\subsubsection{Caracterização dos solos}

Os solos 1 e 2 foram caracterizados por ensaios de laboratório e campo. Foram determinadas:

- Curva de retenção (laboratório);

- Condutividade hidráulica saturada (laboratório);

- Condutividade hidráulica não saturada (campo);

- Taxa de infiltração (campo).

Os ensaios de laboratório foram realizados no laboratório de solos do Departamento de Geotecnia da Escola de Engenharia de São Carlos.

\subsubsection{Determinação da curva de retenção}

A finalidade do ensaio de determinação da curva de retenção, ou curva característica dos solos, foi relacionar a umidade com o potencial mátrico do solo. 
As curvas de retenção dos solos 1 e 2 foram obtidas pelo processo de drenagem. As amostras foram retiradas de blocos indeformados, de dimensões $25 \times 25 \times 25 \mathrm{~cm}^{3}$, coletados à profundidade de $120 \mathrm{~cm}$, nas duas áreas experimentais. Esta profundidade foi escolhida no intuito de obter uma amostra livre de raízes e possíveis impurezas e materiais de aterro presentes no local. Este procedimento visa a homogeneidade e representatividade da amostra, de modo a reduzir as incertezas associadas a coleta.

Após a coleta, os blocos foram envolvidos em parafina, para preservar as condições de umidade da amostra. As Figuras 4.1 e 4.2 ilustram um dos blocos coletados. $\mathrm{O}$ procedimento descrito a seguir foi realizado para os dois blocos de amostras indeformadas dos solos 1 e 2:

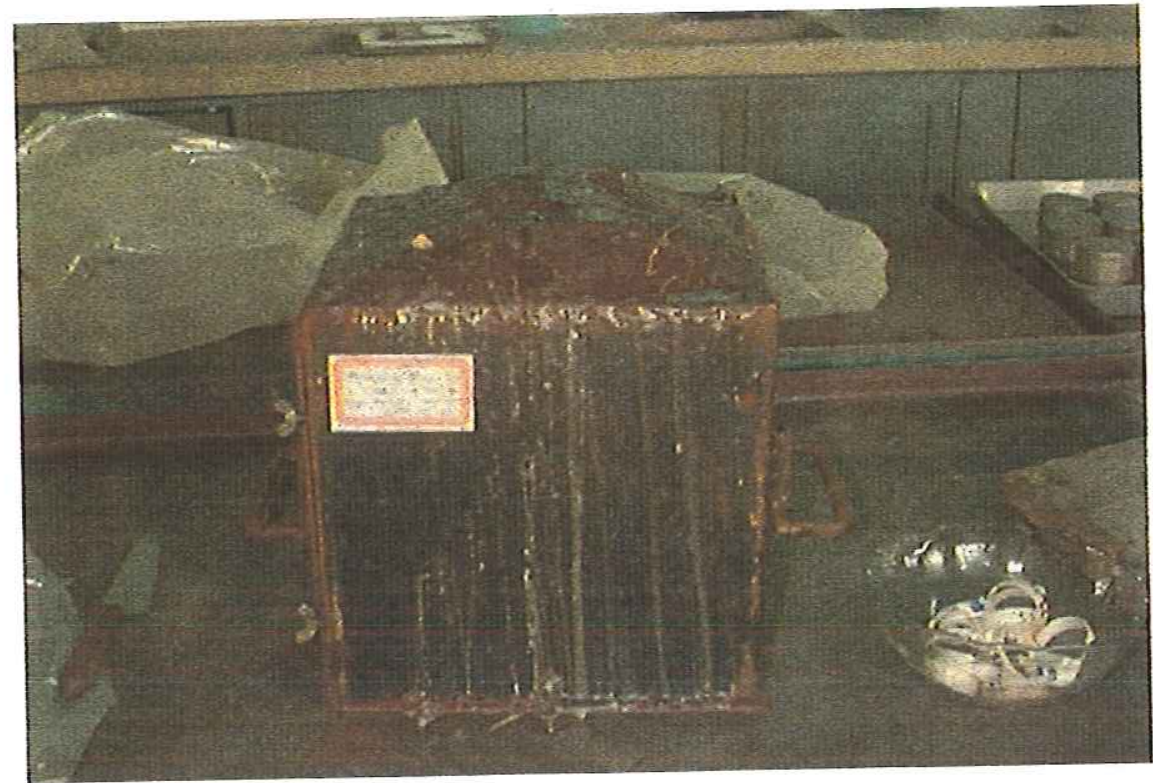

Figura 4.1 - Bloco de solo indeformado, envolto em parafina e preso por chapas de metal.

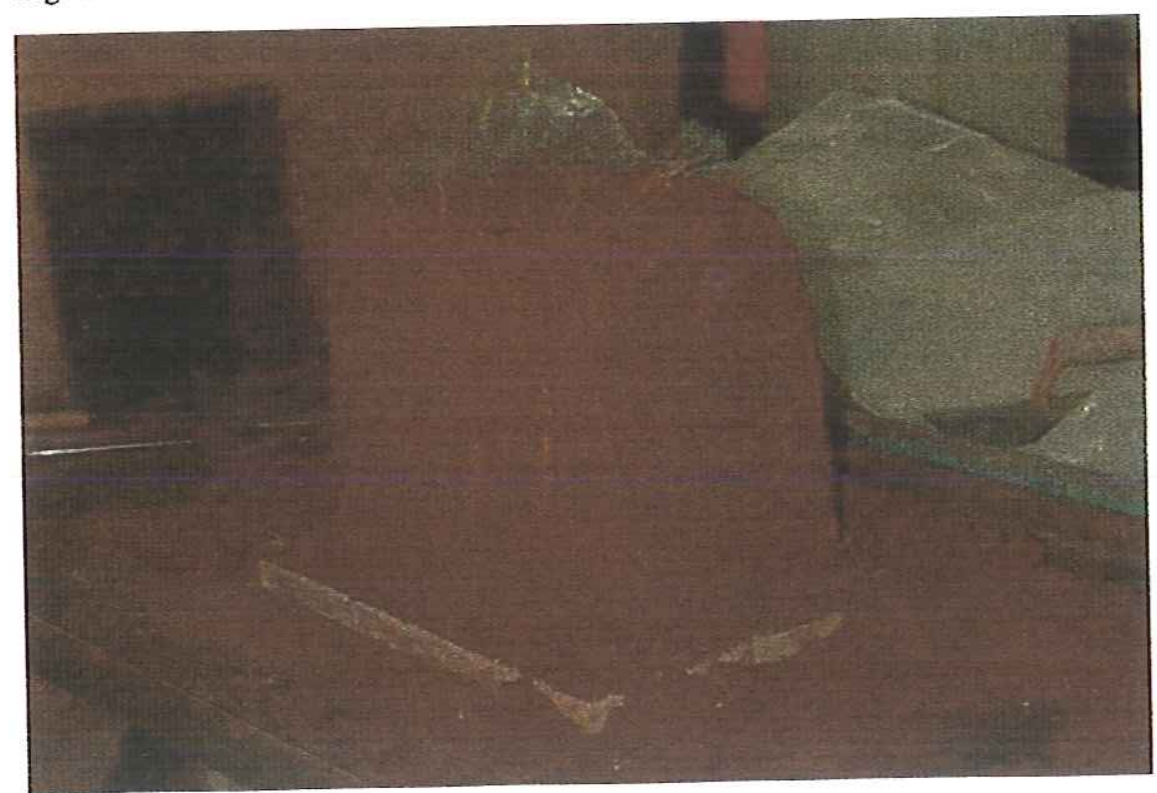

Figura 4.2 - Bloco sem parafina. 
Foram retiradas quinze amostras cilíndricas do bloco, e transferidas para anéis de PVC de $5 \mathrm{~cm}$ de diâmetro e $1 \mathrm{~cm}$ de altura tomando-se o cuidado de, durante a transferência, não alterar a estrutura das amostras. A Figura 4.3 ilustra o procedimento de transferência das amostras cilíndricas para os anéis de PVC.

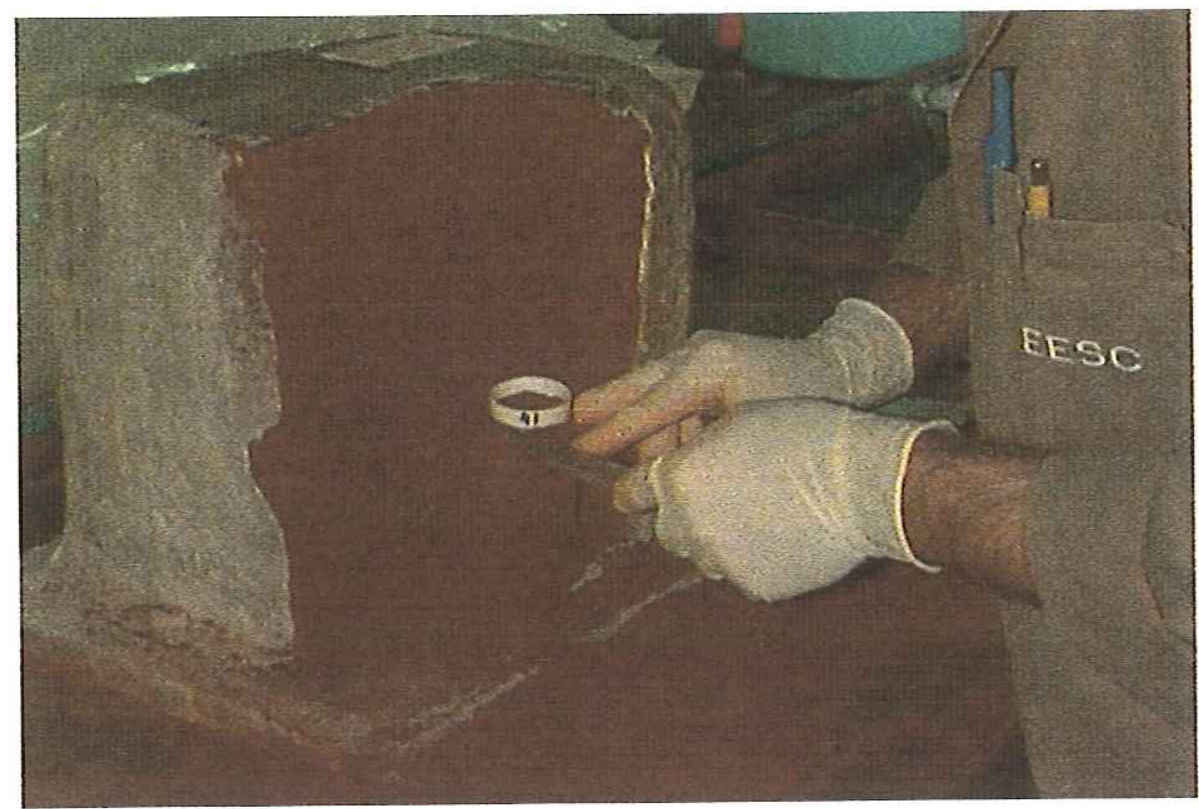

Figura 4.3 - Retirada da amostra cilíndrica.

As amostras foram colocadas sobre uma placa porosa umedecida, e submetidas a um processo de saturação por 24 horas, da forma ilustrada na Figura 4.4.

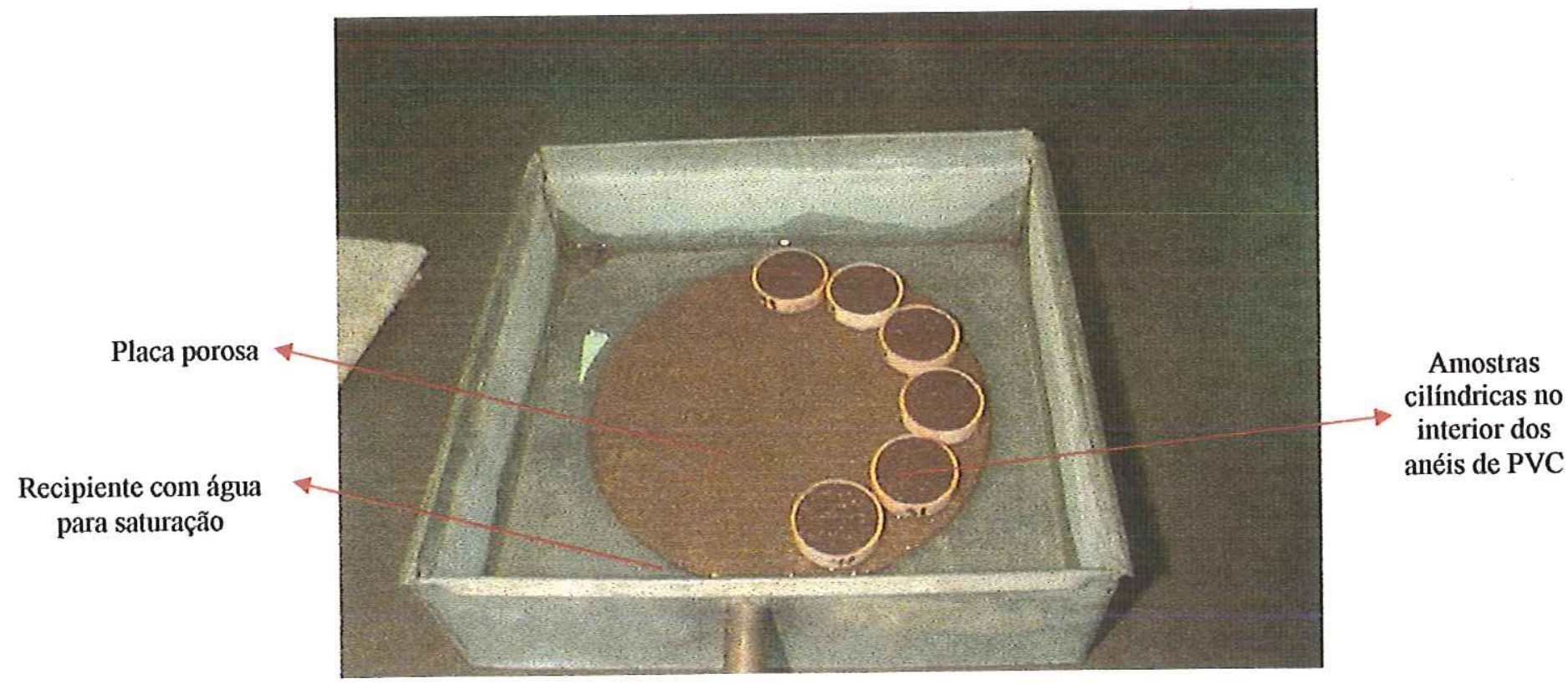

Figura 4.4 - Processo de saturação das amostras de solo. 
Após a saturação, a placa porosa, juntamente com as amostras, foi colocada no interior de uma câmara de pressão, semelhante a uma panela de pressão, também conhecida como câmara de pressão de Richards, ilustrada na Figura 4.5.

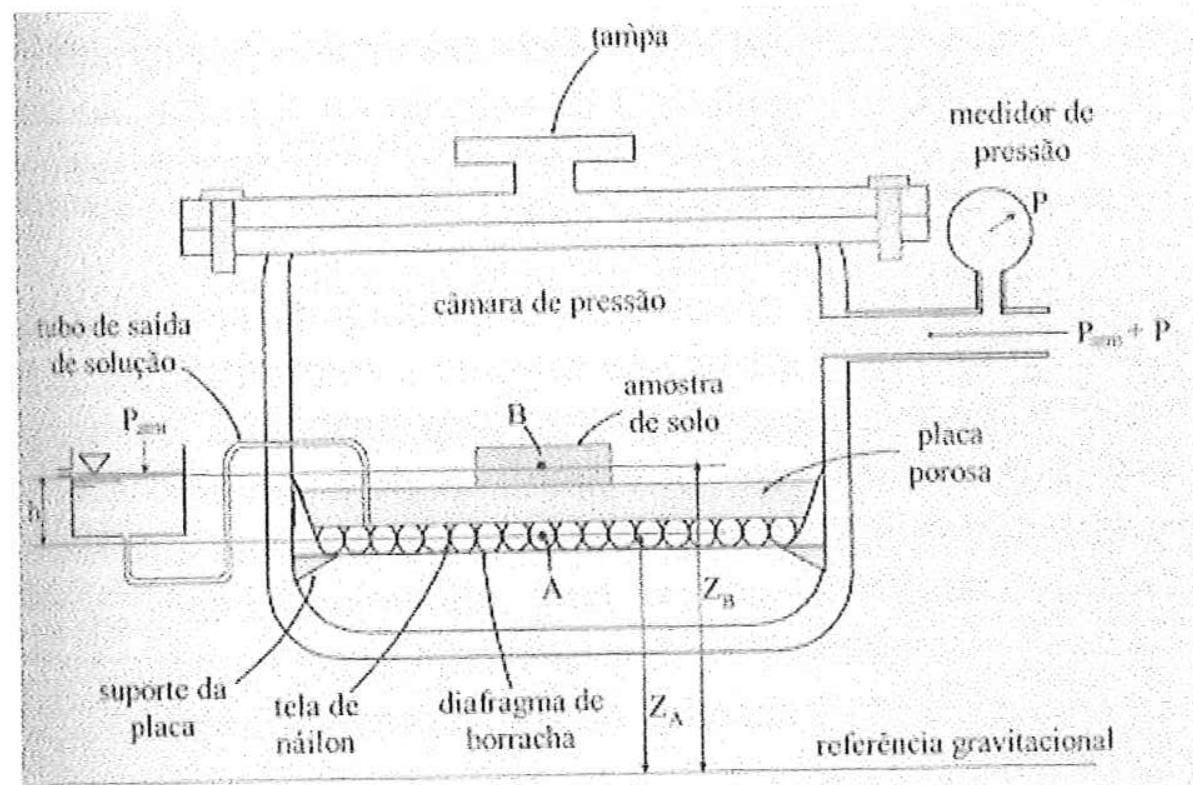

Figura 4.5 - Esquema da câmara de pressão de Richards (Fonte: Libardi, 2000, Dinâmica da Água no Solo)

A placa cerâmica tem sua face inferior coberta por um diafragma de borracha, selado na borda. Tomou-se o cuidado de que as amostras estivessem em perfeito contato com a placa. Aplicou-se, na parte superior da câmara, uma pressão P conhecida, de modo que a água contida na amostra se movesse para a parte inferior da câmara, através da placa porosa, e para a parte exterior do sistema, através do tubo de saída. A placa saturada permite a percolação somente da água contida na amostra, de maneira que o ar injetado permanece sob pressão na parte superior da câmara, não atravessando a placa. A tensão superficial na interface líquido-gás em cada poro da placa de cerâmica suporta a pressão, não permitindo a passagem do ar através da placa, daí a necessidade da placa estar perfeitamente saturada, sem nenhuma bolha de ar em seus poros. A pressão máxima que uma placa saturada pode suportar, sem que o ar a atravesse, é inversamente proporcional ao diâmetro do poro.

Após um determinado tempo de aplicação da pressão $\mathrm{P}$, o gotejamento através do tubo de saída cessou, indicando que o sistema atingiu a condição de equilíbrio, em que o potencial mátrico da amostra, naquela condição de umidade, é igual à pressão $\mathrm{P}$ aplicada. 
Nesta etapa, retirou-se a amostra e determinou-se sua umidade. Em seguida, repetiu-se o processo, aplicando-se uma pressão $\mathbf{P}$ maior que a pressão de equilíbrio anterior. Fez-se isso até que não houvesse mais alteração na umidade da amostra, por mais que fosse aumentada a pressão P. O valor de umidade da amostra de solo, nesta ocasião, é chamado de umidade residual $\theta_{\mathrm{r}}$, e a umidade da amostra no início do experimento é chamada umidade de saturação $\theta_{\mathrm{S}}$.

Um ensaio completo para a determinação da curva de retenção de uma amostra de solo dura, em média, 40 dias. As Figuras 4.6 e 4.7 ilustram a câmara de pressão utilizada.

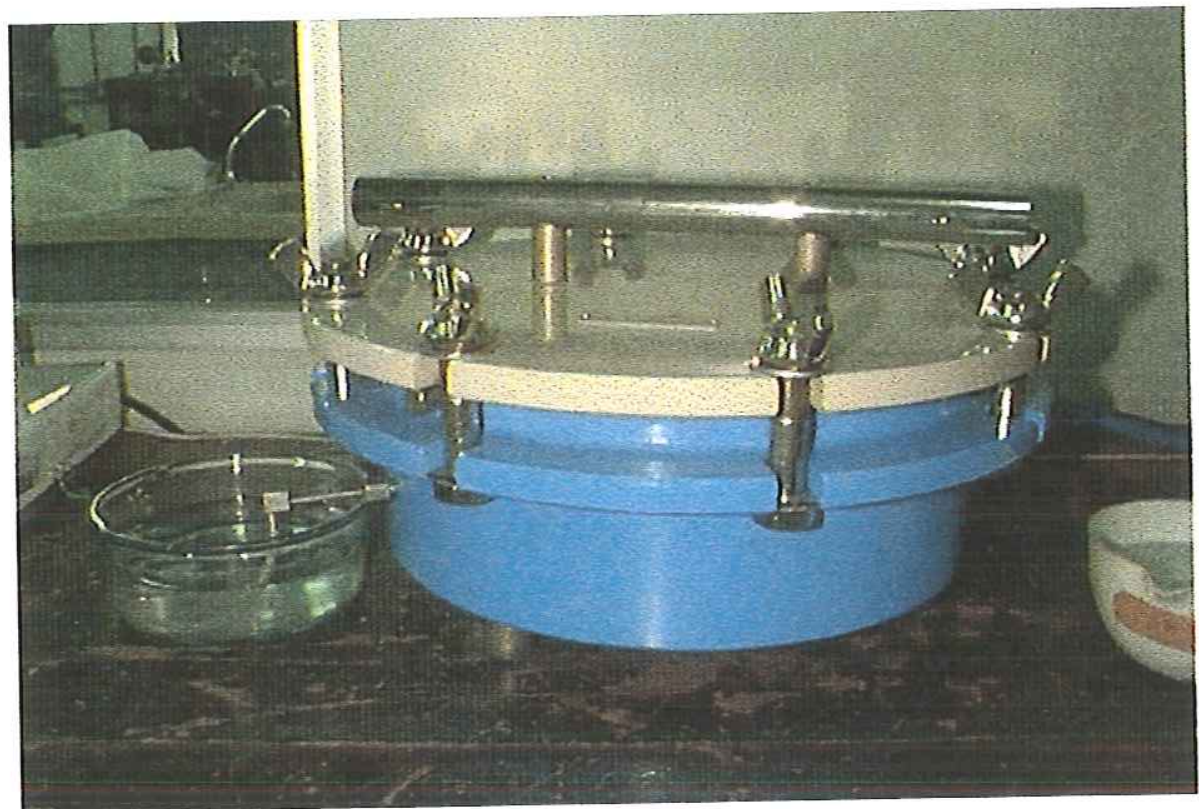

Figura 4.6 - Câmara de pressão de Richards'

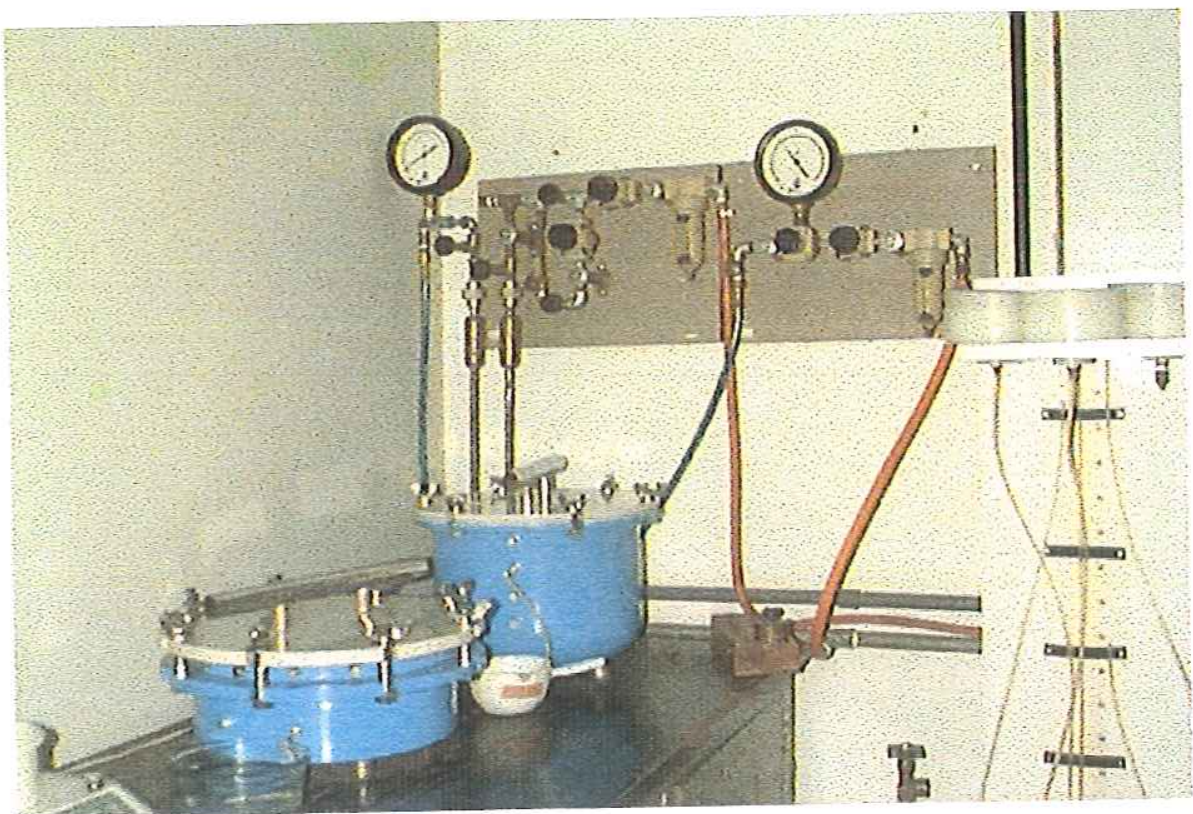

Figura 4.7 - Câmaras de pressão conectadas a um sistema de injeção e medição de pressão 
Para traçar a curva de retenção fez-se a calibração dos pontos obtidos pela Equação 3.24, apresentada no Capítulo 3, proposta por Van Genuchten (1980).

$$
\theta=\theta_{r}+\frac{\left(\theta_{s}-\theta_{r}\right)}{\left[1+\left(\alpha_{v} \cdot \phi_{m}\right)^{n}\right]^{m}}
$$

Para determinar $\theta_{s}, \theta_{s}, \alpha_{v}, m$ e $n$, foram utilizadas duas ferramentas: o programa Curvaret, desenvolvido pelos departamentos de Física e Meteorologia e de Agricultura da Escola Superior de Agricultura Luiz de Queiroz - ESALQ, da Universidade de São Paulo, específico para o ajuste dos dados obtidos em laboratório à equação de Van Genuchten, e o software Systat ${ }^{\circledR}$, que ajusta pontos experimentais a qualquer modelo desejado. As figuras 4.8 a 4.13 mostram as áreas de trabalho do Curvaret e do Systat.

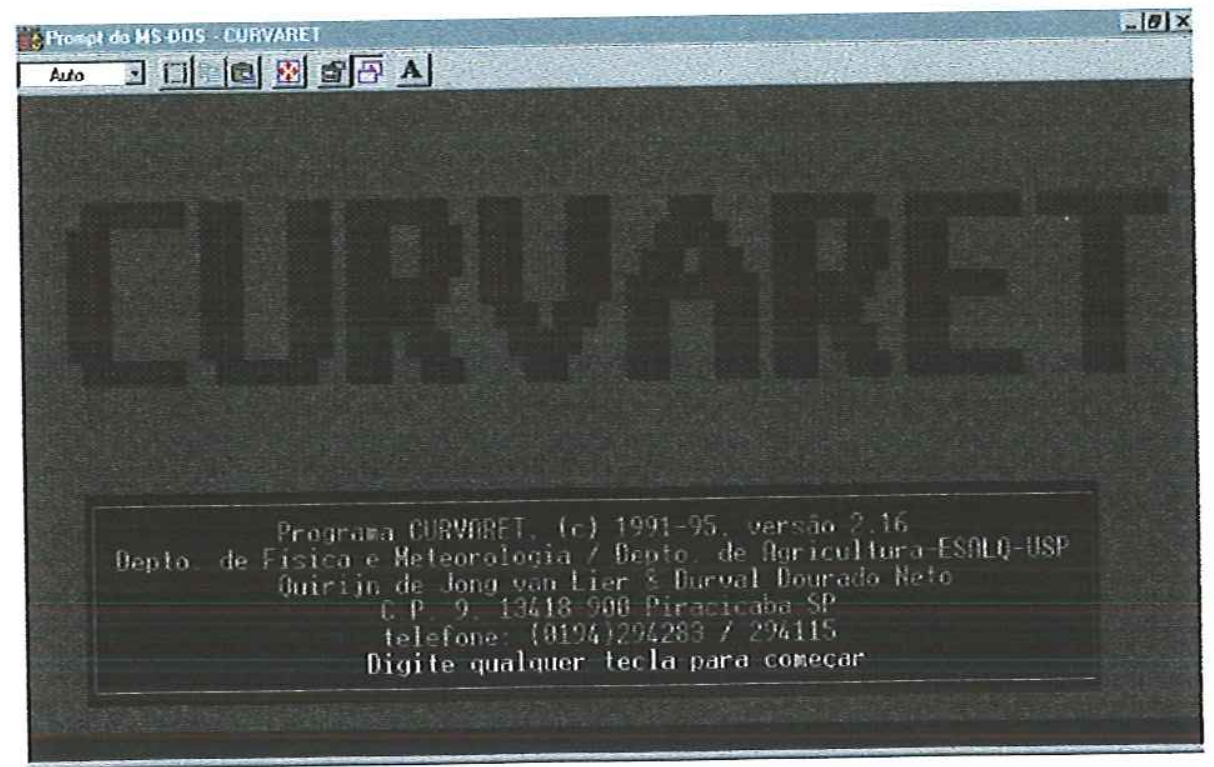

Fig. 4.8 - Tela de inicialização do CurvaRet

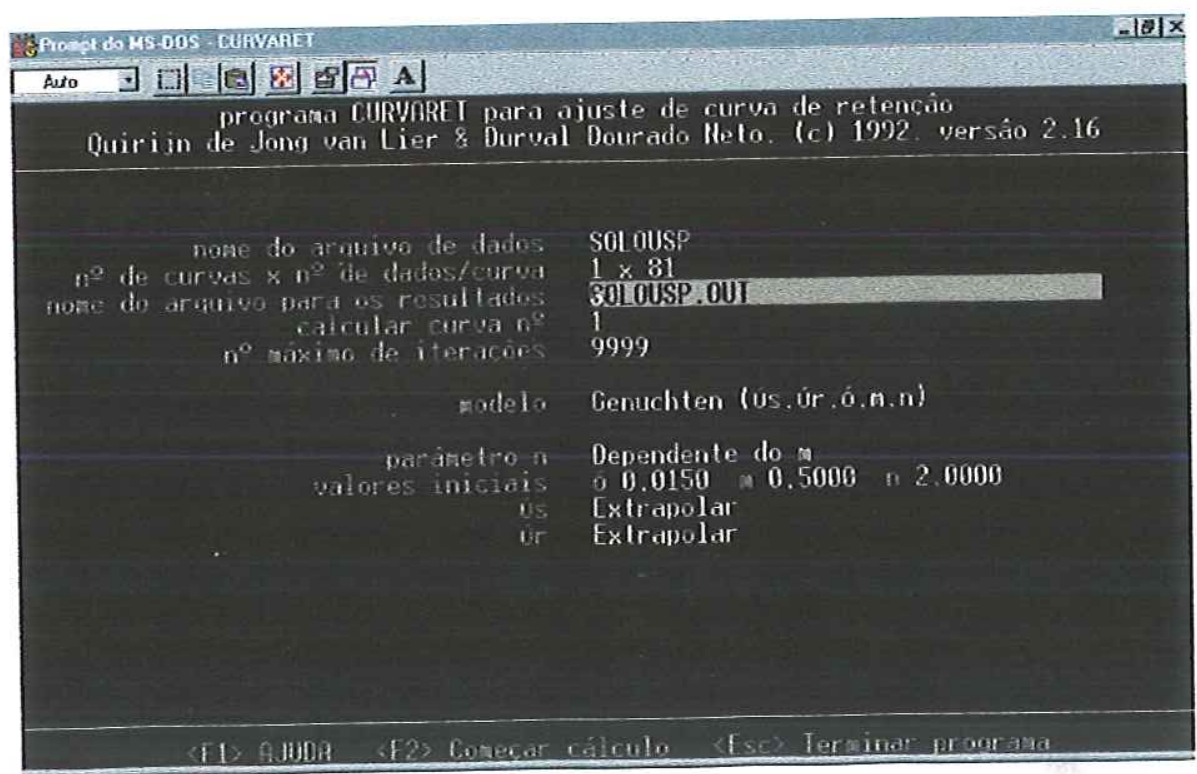

Figura 4.9 - Tela de entrada de dados do CurvaRet 


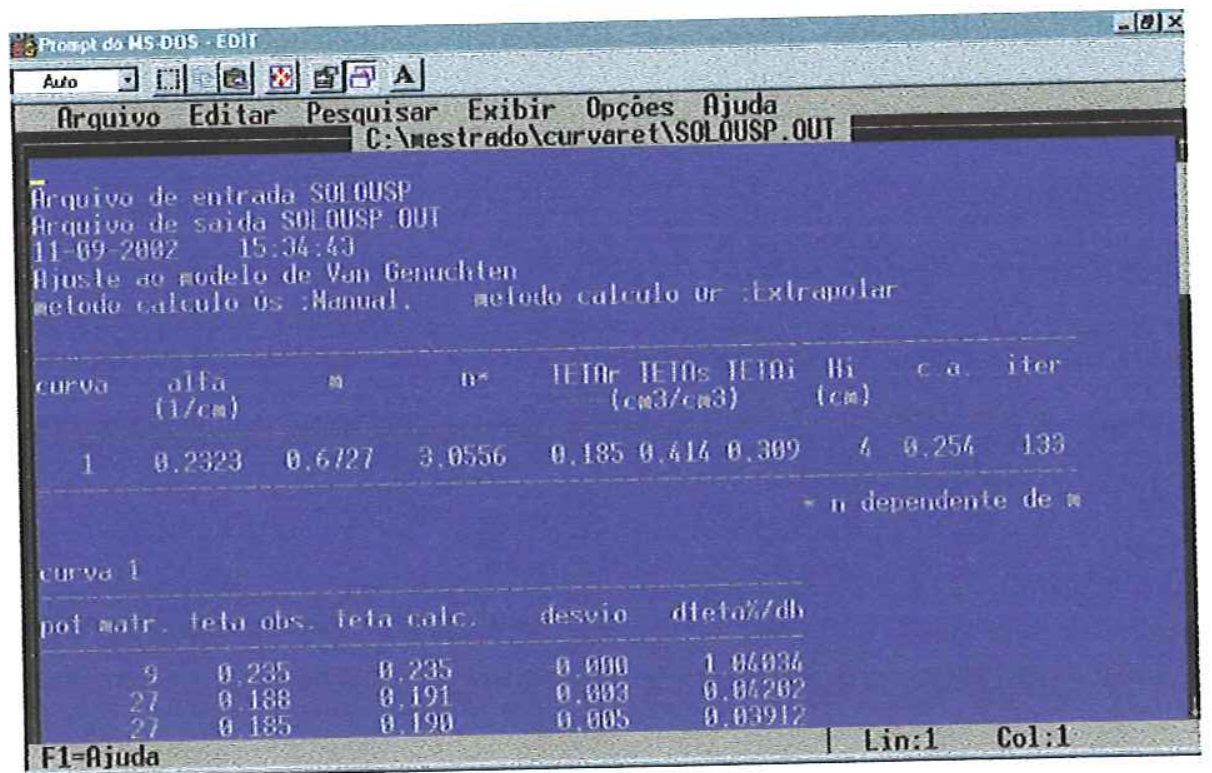

Figura 4.10 - Tela de saída de dados do CurvaRet

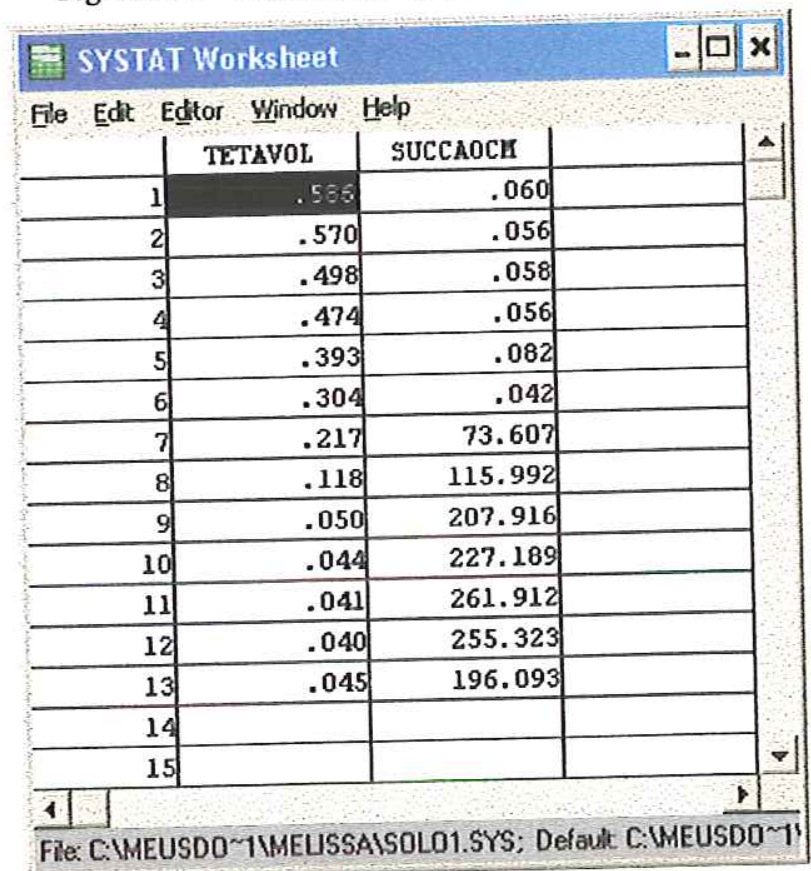

Figura 4.11 - Ambiente de trabalho do Systat ${ }^{\odot}$ 


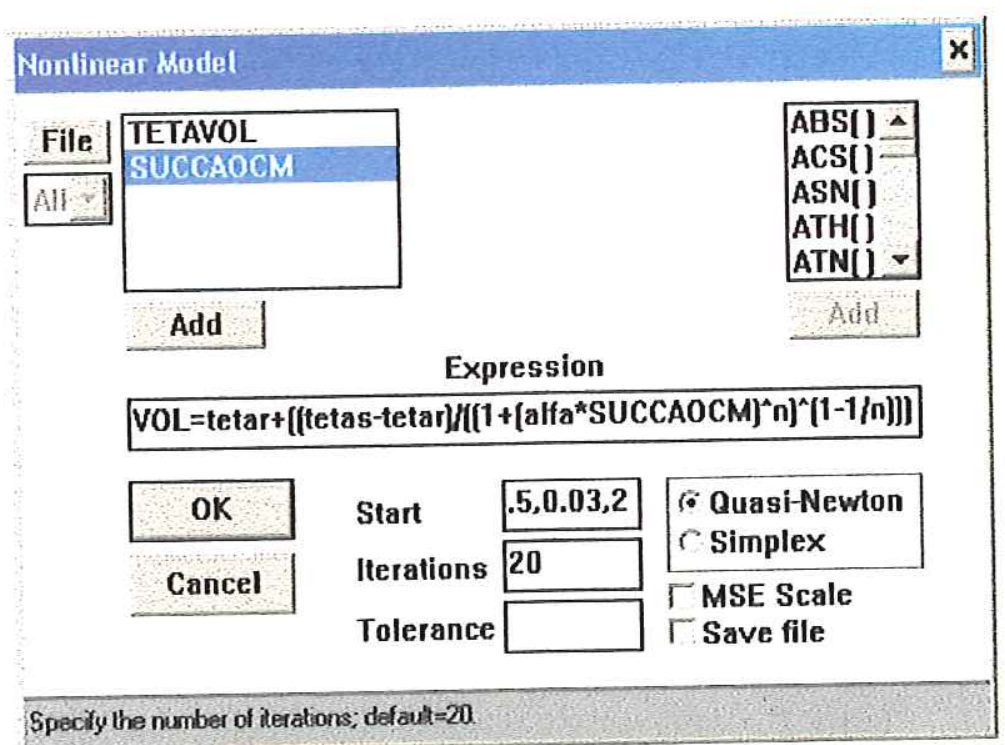

Figura 4.12 - Tela de inserção do modelo no Systat ${ }^{\ominus}$

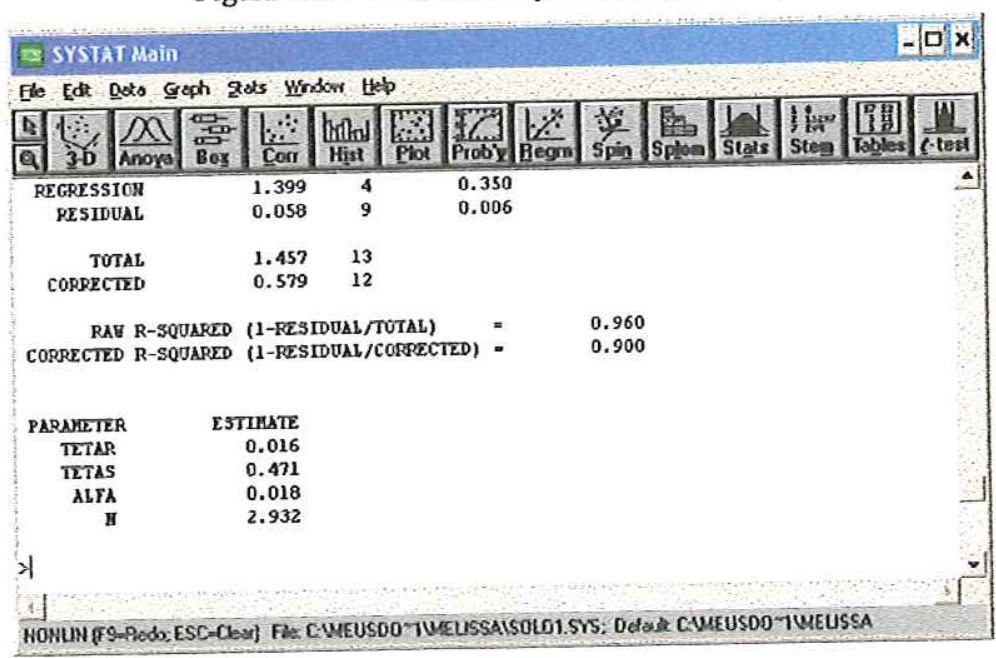

Figura 4.13 - Tela de saída de dados do Systat ${ }^{\ominus}$

Os resultados dos ajustes obtidos para os dois solos, por meio dos dois softwares, é apresentado na seção 5, Figuras 5.3 e 5.4 e Tabela 5.2.

\subsubsection{Determinação da Condutividade Hidráulica Saturada}

Para determinar a condutividade hidráulica ou permeabilidade saturada dos solos 1 e 2 foi realizado o ensaio de permeabilidade a carga constante normalizado pela NBR-13292.

O ensaio de permeabilidade a carga constante fundamenta-se na lei de Darcy, descrita pela Equação 4.1.:

$v=k \frac{\Delta h}{L}$

Onde:

$v=$ velocidade de descarga;

$k=$ coeficiente de condutividade hidráulica; 
$L=$ comprimento da amostra de solo;

$\Delta h=$ diferença de carga total.

Para a realização do ensaio, extraiu-se uma amostra cilíndrica de solo indeformado, de aproximadamente $12 \mathrm{~cm}$ de altura e $5 \mathrm{~cm}$ de diâmetro, do mesmo bloco utilizado para o ensaio de curva de retenção. Esta amostra foi introduzida em um permeâmetro de carga constante, ilustrado na Figura 4.14.

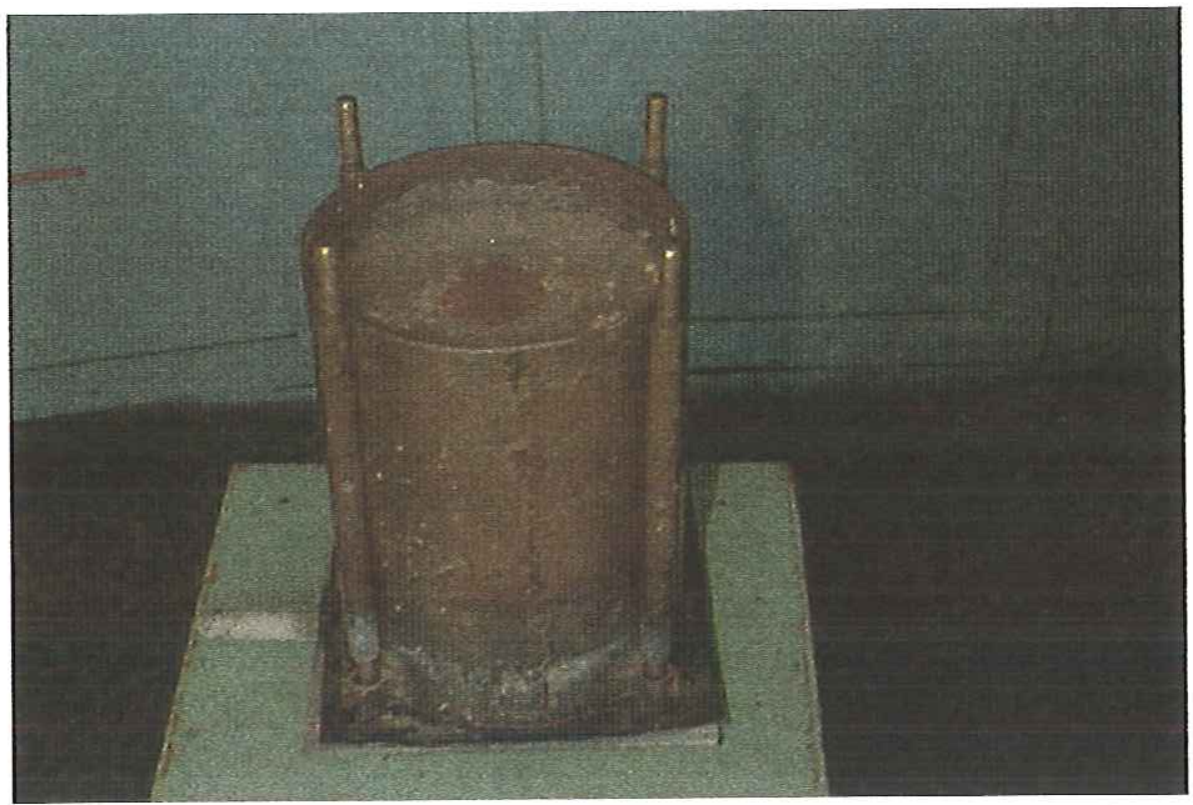

Figura 4.14 - Permeâmetro de carga constante.

O ensaio consistiu, basicamente, em manter constante a carga total aplicada na amostra, e medir a vazão correspondente, a partir do volume de água percolado e do tempo de ensaio.

Isolando o coeficiente $k$ na equação 4.1 , obtém-se:

$$
k=\frac{v \cdot L}{\Delta h}
$$

$\operatorname{mas} \nu=Q / A$ e $Q=V / t$, portanto:

$$
k=\frac{V \cdot L}{A \cdot t \cdot \Delta h}
$$

Durante a realização do ensaio, obteve-se os fatores da direita da Equação 4.3, tornando possível o cálculo do coeficiente $k$. $\mathrm{O}$ ensaio foi realizado para os solos 1 e 2 , com três valores distintos de $\Delta h$, e o coeficiente de condutividade hidráulica saturada foi obtido a partir das médias destes três valores. 
No capítulo 5, Tabelas 5.3 e 5.4, são apresentadas as planilhas de acompanhamento e resultados dos ensaios de condutividade hidráulica saturada para os solos 1 e 2 .

\subsubsection{Equipamentos de campo}

Para a realização destes ensaios, bem como os experimentos com as trincheiras de infiltração, foi necessário dispor de equipamentos que permitissem a medida da umidade e do potencial mátrico do solo em condições de campo. Para a medida da umidade, optou-se por utilizar um equipamento conhecido como sonda de nêutrons. Para a medida do potencial mátrico, utilizou-se tensiômetros.

\section{Sonda de nêutrons}

Trata-se de um equipamento, utilizado para a determinação da umidade do solo em condições de campo, que consiste de uma fonte radioativa, um detetor, um circuito eletrônico para amplificação de sinais conectado a um mostrador digital e um tubo de acesso instalado no solo.

Para a medição da umidade, o equipamento é posicionado sobre o tubo instalado verticalmente no solo, no interior do qual insere-se a sonda até a profundidade desejada, por meio de um cabo que faz a interligação entre a fonte radioativa e os componentes eletrônicos.

O princípio de funcionamento do equipamento é baseado na propriedade de moderação de nêutrons rápidos pela água presente no solo. A fonte radioativa, constituída por uma cápsula de Amerício-241:Berílio, emite um campo de radiação de nêutrons rápidos, os quais, ao colidir com núcleos de átomos de hidrogênio, tornam-se lentos, ou termalizados. Por não possuir carga elétrica, os nêutrons termalizados não podem ser detectados diretamente; mas podem ser absorvidos pelo núcleo dos átomos de um gás (Boro Trifluorídrico ou Hélio-3), o qual torna-se um emissor de fótons, que por sua vez podem ser facilmente detectados por um dispositivo eletrônico adequado. Os pulsos elétricos gerados são conduzidos à superfície, ampliados e apresentados no mostrador em forma de contagem. A umidade do solo é obtida com o emprego de uma curva de calibração que expressa a relação entre contagens e umidade volumétrica, sendo definida para cada tipo de solo.

O método dos nêutrons para a determinação da umidade do solo está alicerçado em duas importantes considerações: (i) o hidrogênio é praticamente o único elemento que 
modera os nêutrons rápidos, tornando-os lentos, e (ii) o hidrogênio no solo está quase que inteiramente na forma de água. Por isso, a densidade da nuvem de nêutrons termalizados reflete a umidade do solo (Beltrame \& Taylor 1980).

A Figura 4.15 traz o esquema de funcionamento da sonda de nêutrons. A única diferença entre o esquema ilustrado e a sonda utilizada neste trabalho é que, no desenho, a cápsula com a fonte radioativa está separada do restante do equipamento. Na sonda utilizada na pesquisa, o equipamento é encaixado sobre o tubo de acesso, e a fonte desce pelo interior do tubo sem que haja contato manual direto entre o operador e a cápsula. A Figura 4.16 ilustra a operação da sonda.

Os tubos de acesso utilizados neste trabalho foram de alumínio, material recomendado pelo fabricante, por permitir pouca atenuação da radiação, com diâmetro $D=2,5^{\prime \prime}$.

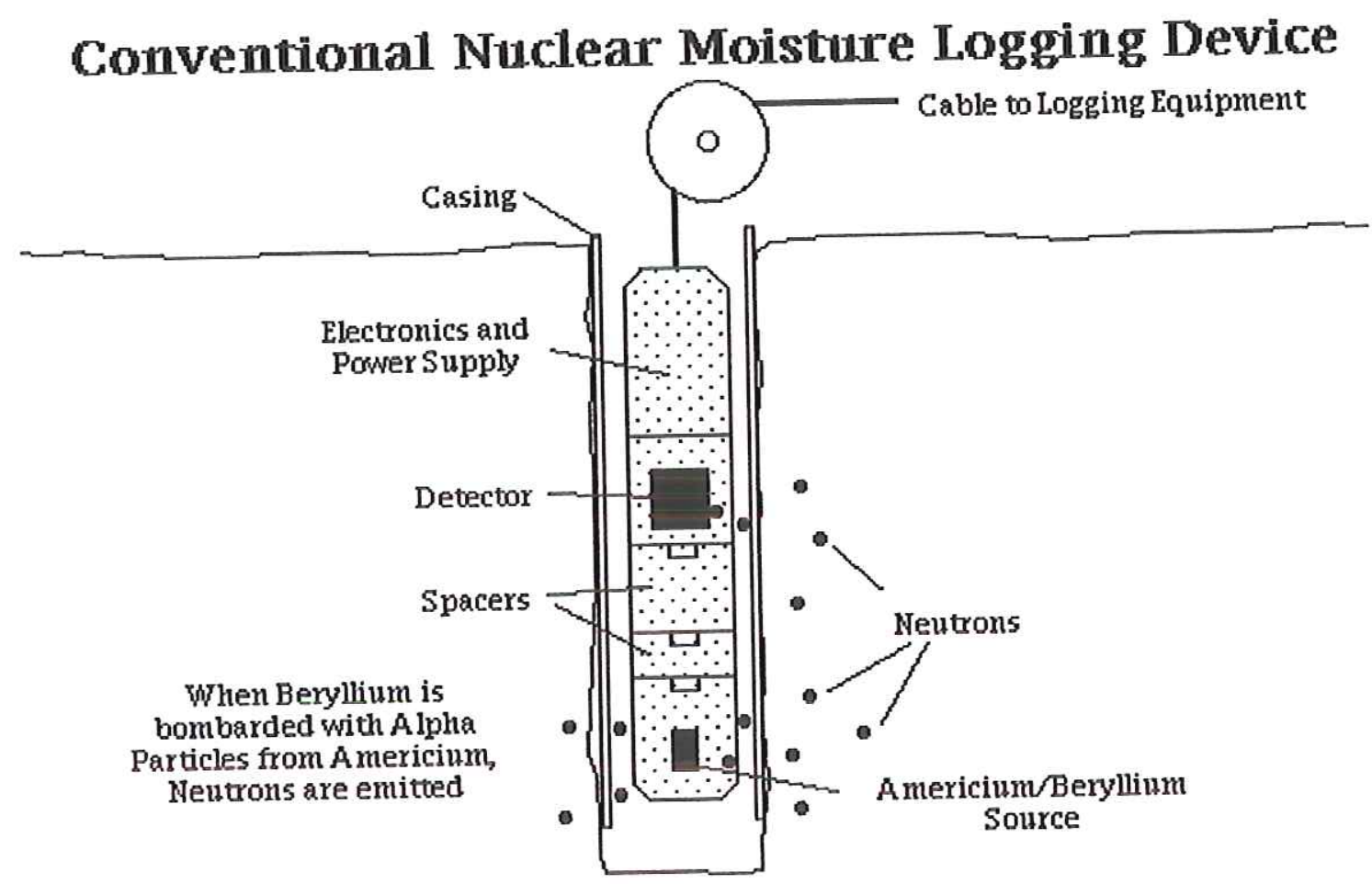

Figura 4.15 - Esquema de funcionamento da sonda de nêutrons. 


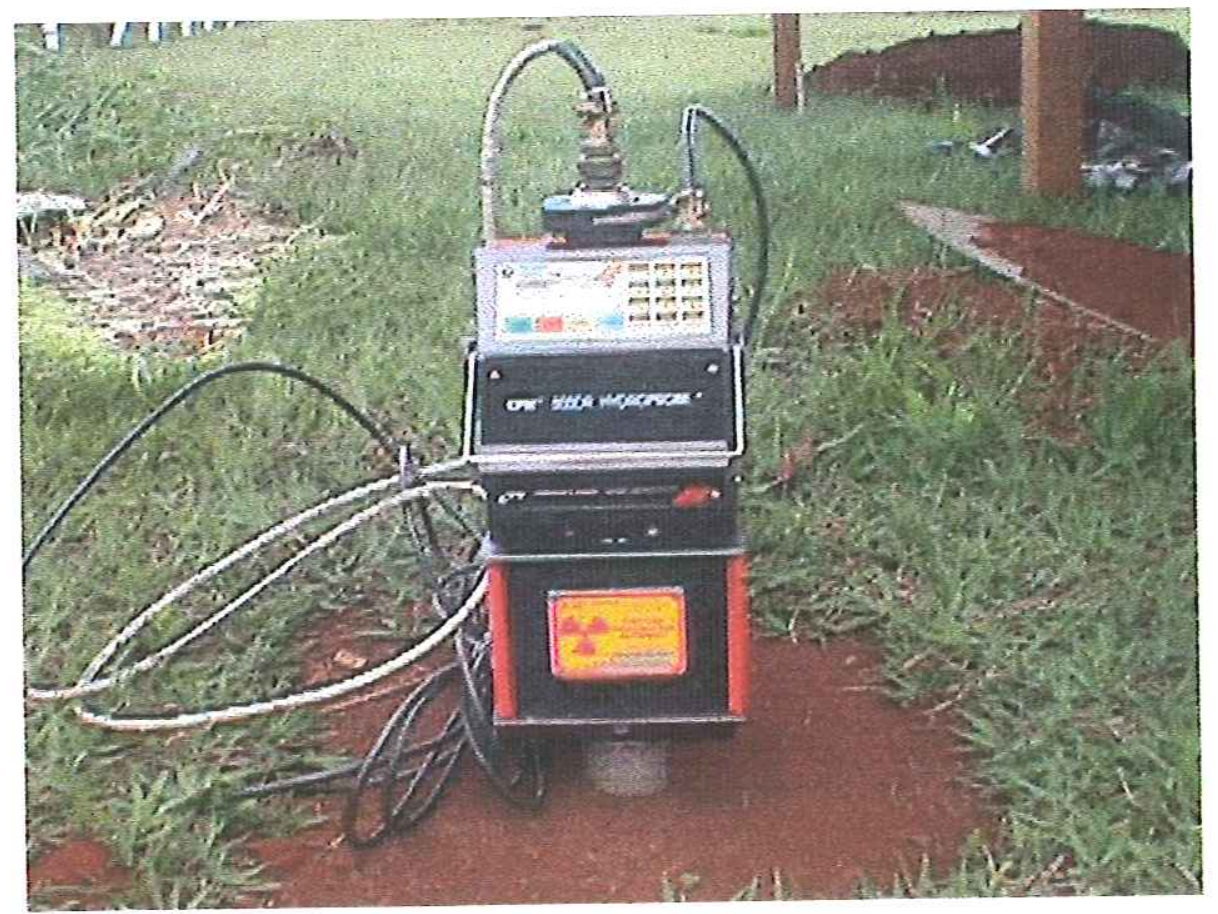

Figura 4.16 - Sonda de nêutrons utilizada neste trabalho.

\section{Calibração da sonda de nêutrons}

A calibração da sonda de nêutrons, nos solos 1 e 2, foi feita da seguinte forma:

- Foram instalados tubos de acesso para a sonda de nêutrons, nas áreas experimentais, em posições representativas da área de estudo;

- Irrigou-se a área ao redor de cada tubo, num raio de aproximadamente 1 metro;

- Procedeu-se à contagem padrão da sonda, conforme especificado adiante;

- Foram efetuadas leituras de contagem até a profundidade $z=1,80 \mathrm{~m}$, em intervalos de $5 \mathrm{~cm}$. Em cada ponto, realizou-se 5 leituras, registrando-se a média;

- Simultaneamente ao item anterior, foram coletadas, com o auxílio de um trado, amostras de solo a $10 \mathrm{~cm}$ do tubo. Os nêutrons emitidos pela sonda atingem um raio de $15 \mathrm{~cm}$. Utilizou-se um trado de 11/2" para a amostragem, realizada a cada $10 \mathrm{~cm}$ de profundidade;

- As amostras coletadas foram imediatamente embaladas em sacos plásticos, etiquetadas e fechadas hermeticamente, para evitar a perda de umidade por evaporação;

- Em laboratório, determinou-se o teor de umidade, em massa, de todas as amostras, via método gravimétrico descrito a seguir:

a) Mediu-se a massa de três cápsulas de alumínio para cada amostra a ser analisada, encontrando-se os valores de $m_{c}$ (massa da cápsula) de cada uma; 
b) Foram numeradas as cápsulas e anotadas as respectivas massas;

c) Colocou-se uma porção das amostras no interior das cápsulas, e mediu-se novamente a massa $\left(m+m_{c}\right)$, massa de solo e água = massa da cápsula;

d) As cápsulas destampadas foram levadas à estufa, por 24 horas, à temperatura de $100^{\circ} \mathrm{C}$;

e) Foram retiradas as cápsulas da estufa, tampando-as imediatamente, para evitar a absorção de umidade do meio;

f) Foram pesadas todas as cápsulas, obtendo-se $\left(m_{s}+m_{c}\right)$, massa de solo + massa da cápsula;

g) A diferença entre as massas obtidas em $c$ e $f$ é a massa de água $m_{w}$;

h) Dividiu-se $m_{w}$ por $m_{s}$ para obter o teor de umidade gravimétrico $U \%$;

i) A umidade volumétrica $\theta \%$ foi obtida, à partir da umidade gravimétrica $U \%$, de acordo com a equação 4.4, proposta por Libardi (2000):

$\theta=\rho_{r} \cdot U$

Onde:

$\theta=$ umidade gravimétrica;

$\rho_{r}=$ densidade aparente, ou densidade relativa do solo, definida pela razão entre a densidade do solo e a densidade da água. Considera-se a densidade da água $\rho_{\mathrm{a}}=1 \mathrm{~g} / \mathrm{cm}^{3}$.

$\mathrm{U}=$ umidade gravimétrica.

- Foram plotados os valores de umidade volumétrica no eixo das ordenadas contra os valores de contagem normalizados pela contagem padrão $C / C p$ no eixo das abcissas;

- Ao confrontar os valores de $\theta \%$ com os valores de $C / C p$, tomou-se o seguinte cuidado: as amostras foram coletadas a cada $10 \mathrm{~cm}$; portanto, a umidade medida em laboratório é a média destes $10 \mathrm{~cm}$ de coluna de solo no trado. Sendo assim, comparou-se cada valor de umidade obtido em laboratório com a média de 3 contagens da sonda, realizadas a 0,5 e $10 \mathrm{~cm}$ ao longo do comprimento da amostra de solo, no trado.

- Repetiu-se todo o procedimento dias após a primeira coleta, para obter amostras de solo seco, e traçar a curva de calibração ao longo de vários valores de umidade do solo. Ao todo, foram analisados os valores de umidade em 72 pontos, sendo $36 \mathrm{em}$ cada área experimental estudada. 


\section{Contagem padrão da sonda de nêutrons}

A forma de operação da sonda, baseada na contagem de nêutrons termalizados por átomos de hidrogênio, proporciona precisão satisfatória na determinação do teor de umidade do solo. No entanto, podem haver pequenas variações diárias na contagem de uma mesma amostra, nas mesmas condições de umidade. Isso ocorre em decorrência da natureza estocástica das interções radioativas entre os nêutrons emitidos pela fonte e os átomos de hidrogêonio presentes na amostra.

Este efeito pode ser minimizado através da normalização das contagens por meio da relação com uma contagem padrão, realizada diariamente. $\mathrm{O}$ equipamento possui a função contagem padrão, que, quando ativada, faz com que a sonda efetue 32 contagens sucessivas, e calcule sua média, fornecendo a contagem padrão.

O local de realização da contagem padrão $(C p)$ sugerido pelo fabricante é a caixa da sonda, estando esta recolhida no interior de sua blindagem. Internamente, esta blindagem é revestida de forma homogênea por uma cera que propicia a medição de contagens constantes ao longo da vida útil do equipamento. Desta forma, as leituras de contagem $(C)$ realizadas no decorrer dos experimentos foram normalizadas pela Contagem Padrão $(C p)$, e esta relação foi utilizada para o cálculo do teor de umidade, de acordo com a calibração de cada solo em estudo. O cálculo do teor de umidade foi feito com base na equação 4.5:

$$
\theta=a \cdot \frac{C}{C_{p}}+b
$$

As Figuras 5.7a e 5.7b apresentam o resultado da calibração da sonda de neutrons para os solos 1 e 2 .

\section{Proteção radiológica no uso da sonda de nêutrons}

Para que fosse possível adquirir e operar a sonda de nêutrons, foi necessário o atendimento às exigências de proteção radiológica da CNEN - Comissão Nacional de Energia Nuclear, por tratar-se de uma fonte emissora de radiação ionizante. Os procedimentos de adequação das atividades às normas da CNEN consistiram em:

i. Aquisição de licença de pessoa física para o uso, preparo e manuseio de fontes radioativas;

ii. Credenciamento do Laboratório de Hidráulica Ambiental, junto à CNEN, como instalação radioativa, e 
iii. Licenciamento para importação de material radioativo.

Para o atendimento ao item i, os responsáveis pela operação da fonte (mestranda e orientador da pesquisa) participaram de um curso de radioproteção com 40 horas de duração, destinado a profissionais de nível superior. A aprovação neste curso, e a comprovação de vínculo científico com a universidade, permitiram a aquisição de um registro pessoal, junto à $\mathrm{CNEN}$, específico para a operação da sonda de neutrons.

Com relação ao item ii, foi elaborado um relatório de análise de segurança, conforme determinações da $\mathrm{CNEN}$, com todas as especificações da fonte radioativa, do laboratório ao qual a mesma pertence e dos procedimentos de radioproteção adotados quando do manuseio da fonte. Este relatório foi submetido à análise da equipe técnica da CNEN e, uma vez aprovado, permitiu o credenciamento do referido laboratório como instalação radioativa. O relatório de análise de segurança do Laboratório de Hidráulica Ambiental compõe o ANEXO I deste trabalho. As cópias dos registros pessoais e do laboratório compõem o ANEXO 2.

Tendo sido licenciado o laboratório e adquiridas as licenças pessoais para operação da fonte radioativa, solicitou-se a licença para importação, em atendimento ao item iii. Desta forma, foi possível adquirir a sonda de nêutrons necessária ao desenvolvimento dos trabalhos de pesquisa.

Em atendimento às exigências da CNEN, as áreas de trabalho experimental possuem acesso restrito, e as operações são monitoradas por dosímetros de leitura direta, conforme ilustra a figura 4.17. O local onde a sonda é guardada quando não está em atividade, é sinalizado e possui acesso restrito. 


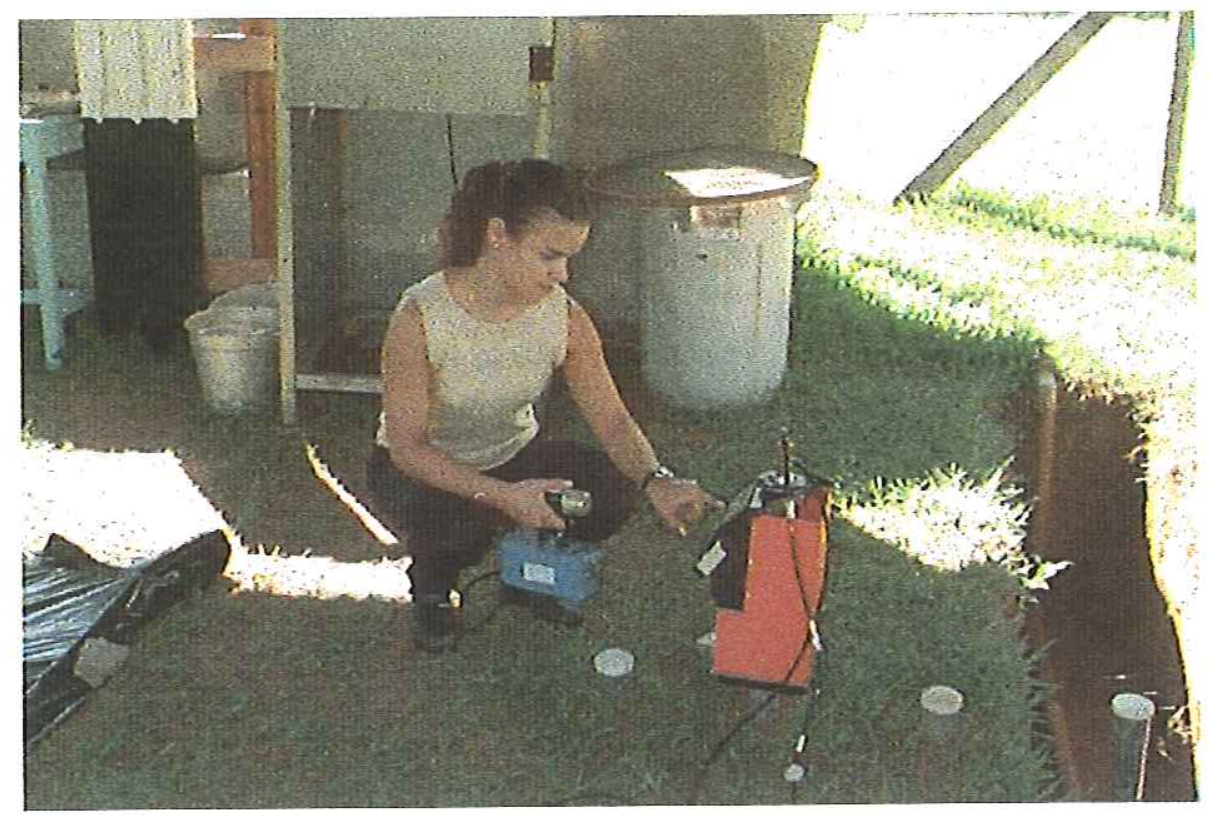

Figura 4.17 - Monitoramento das doses de radiação com detetor Geiger-Muller.

\section{Tensiômetros}

A medida do potencial mátrico em condições de campo é útil para determinar, de maneira indireta, o teor de umidade de um solo, quando se conhece sua curva de retenção. Esta medida é possível com o uso de um instrumento conhecido como tensiômetro. Ele consiste, basicamente, de uma cápsula porosa fixada à extremidade de um tubo preenchido com água. No extremo oposto, o tubo é conectado a uma cuba contendo mercúrio.

$\mathrm{O}$ tubo é enterrado no solo, à profundidade em que se deseja fazer a medição do potencial mátrico. Deve-se observar que a cápsula porosa esteja em perfeito contato com o solo. Isto pode ser facilitado se for feito o umedecimento prévio do solo, de maneira que este esteja saturado no momento da instalação do tensiômetro. $\mathrm{O}$ contato entre a cápsula e o solo é fundamental para que, através dos poros da cápsula, a água do tensiômetro entre em contato hidráulico e se equilibre com a água no solo.

O princípio de funcionamento é semelhante ao da câmara de pressão de Ridhards', onde a cápsula porosa substitui a placa cerâmica. No entanto, não se aplica uma pressão no tensiômetro com o intuito de alterar a umidade do solo; ao contrário, dependendo do teor de umidade do solo, a água no tensiômetro fluirá através da cápsula até entrar em condição de equilíbrio com a água no solo, e este movimento de água gera uma sucção na coluna de mercúrio. Colocando-se uma régua ligada à coluna, mede-se o deslocamento de mercúrio, e, por meio da equação 4.6, calcula-se o potencial mátrico.

A carga hidráulica total é dada por: 
$h=\left(\frac{\rho_{\mathrm{Hg}}-\rho_{\mathrm{H}_{2} \mathrm{O}}}{\rho_{\mathrm{H}_{2} \mathrm{O}}}\right) \cdot H-h_{c}-z$

em que:

$\rho_{H g}=13600 \mathrm{~kg} / \mathrm{m}^{3}$

$\rho_{\mathrm{H} 2 \mathrm{O}}=1000 \mathrm{~kg} / \mathrm{m}^{3}$;

$H=$ deslocamento da coluna de mercúrio;

$h_{c}=$ distância entre o nível de mercúrio, na cuba, e a superficie do solo, e

$z=$ distância entre a superfície do solo e o centro da cápsula porosa.

Para solos expansivos, não se pode desprezar a parcela de $h$ devida à variação do potencial pneumático no solo, o que conduz à Equação 4.7:

$\phi_{p}+\phi_{m}=-12,6 H+h c+z$

Em que $\phi_{p}$ é o potencial pneumático da água no solo e

$\phi_{m}$ é o potencial mátrico.

Já considerando a natureza negativa destes potenciais.

Para solos não expansivos, que é o caso dos solos 1 e 2 estudados neste trabalho, o potencial pneumático é nulo, e a Equação 4.7. se reduz a:

$$
\phi_{m}=-12,6 H+h c+z
$$

A Equação 4.8. foi utilizada para converter as leituras fornecidas pelos manômetros de mercúrio em medidas de potencial mátrico.

\subsubsection{Determinação da condutividade hidráulica não saturada}

Para estabeleder uma relação numérica entre a umidade do solo e a sua condutividade hidráulica, Libardi et al. (1980) propõem um ensaio de campo, que foi realizado para os Solos 1 e 2 . O procedimento de realização do ensaio, nos solos 1 e 2 , foi o seguinte:

- Delimitou-se, com chapas de aço enterradas à profundidade de 0,50 m, uma área de 2,50×2,50 $\mathrm{m}^{2}$ no interior da área experimental; A função destas chapas, de espessura $2 \mathrm{~mm}$, é isolar a área a ser irrigada e direcionar o fluxo de água no sentido vertical.

- No interior da área delimitada, foram instalados tensiômetros, às profundidades de $10,20,30,40,50,75,100$ e $125 \mathrm{~cm}$, e 4 tubos de acesso para a sonda de nêutrons, enterrados à profundidade de $170 \mathrm{~cm}$. 
- Iniciou-se o processo de irrigação da área delimitada, à uma vazão conhecida. Durante as horas seguintes ao início da irrigação, foram efetuadas diversas leituras de potencial mátrico e umidade, à profundidades $20,50,75$ e $125 \mathrm{~cm}$;

- Após algumas horas, constatou-se o regime permanente em todas as profundidades observadas, ou seja, as leituras de umidade e potencial não variavam mais no tempo. Neste momento, cessou-se a irrigação, e este foi considerado o instante $t=0$ de redistribuição;

- Cobriu-se a área com uma lona plástica, para minimizar a perda de água do solo por evaporação. A figura 4.18 ilustra a área experimental de ensaios de condutividade hidráulica em condições de campo.

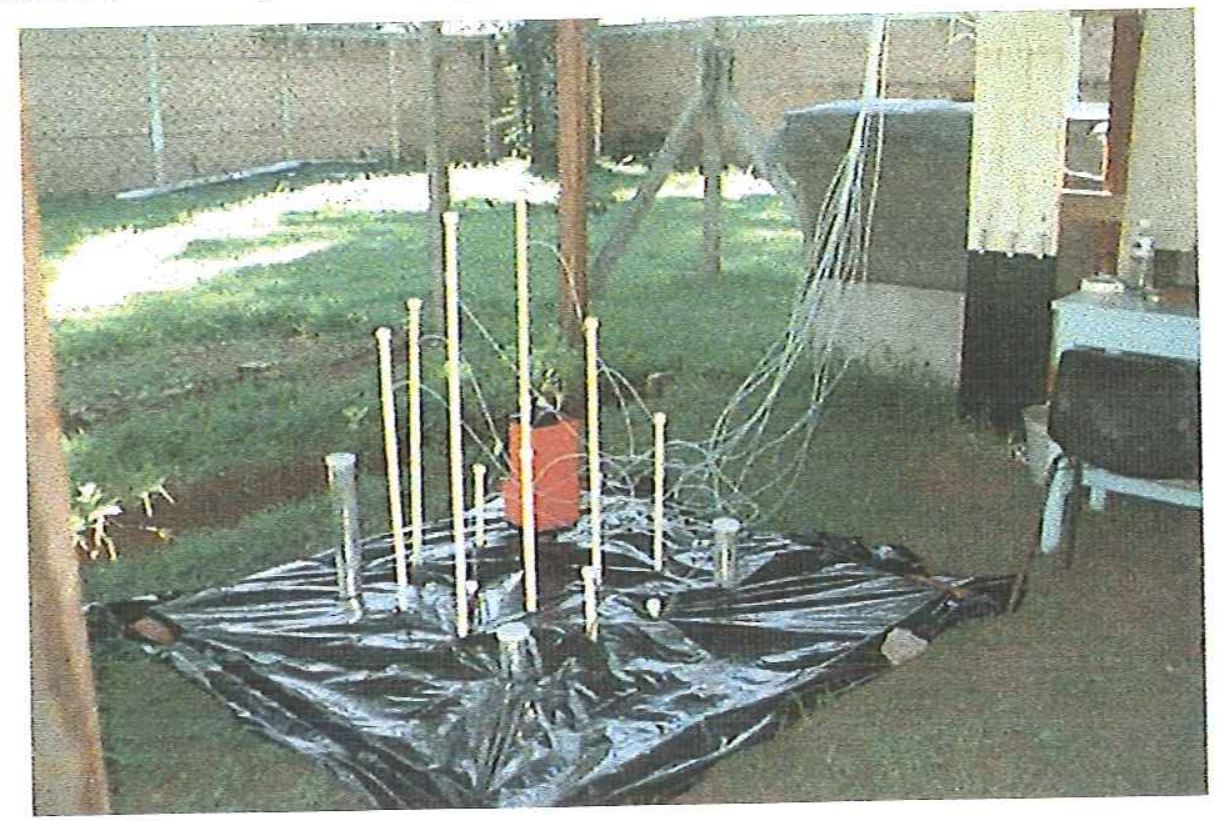

Figura 4.18 - Ensaio de condutividade hidráulica em campo

- Iniciou-se a medição diária da umidade do solo às profundidades de 10 a $150 \mathrm{~cm}$, e do potencial às profundidades em que foram instalados os tensiômetros. Para as medidas de umidade, considerou-se a média das contagens obtidas nos 4 tubos de acesso da sonda;

- O acompanhamento diário foi encerrado quando foram encontrados valores de umidade do solo iguais aos anteriores à irrigação, o que aconteceu após 15 dias do início do experimento. Os perfis de umidade registrados para os Solos 1 e 2 são apresentados na seção 5, figuras 5.7 e 5.8 .

- Os passos seguintes consistiram na análise dos dados e determinação dos perfis de umidade e curvas de condutividade hidráulica. A seqüência de cálculos para a determinação da condutividade hidráulica não saturada foi a seguinte: 
- Fez-se o gráfico $\theta_{0^{-}} \theta$ vesrus $\ln t$ de cada profundidade $z$ para $t>1$ dia. O coeficiente angular desta curva é, de acordo com a Equação 4.9, igual a $1 / \gamma$.

$\theta_{0}-\theta=\frac{1}{\gamma} \ln t+\frac{1}{\gamma} \ln \left(\frac{\gamma \cdot K_{0}}{a z}\right)$

Em que:

$\theta_{0}$ é a umidade volumétrica inicial, em $t=0\left(\mathrm{~cm}^{3} / \mathrm{cm}^{3}\right)$;

$\theta$ é a umidade volumétrica no instante $t\left(\mathrm{~cm}^{3} / \mathrm{cm}^{3}\right)$;

$K_{0}$ é a condutividade hidráulica no istante $t=0$;

$z$ é a profundidade;

yé parâmetro da Equação 4.10, que define a função matemática para $K(\theta)$;

$K(\theta)=K_{0} \cdot e^{-\gamma\left(\theta_{0}-\theta\right)}$

Em que:

$a=\gamma / \bar{\gamma}$, sendo $\bar{\gamma}_{o}$ valor médio de $\gamma$ desde a superficie até a profundidade $z$.

- Plotou-se o gráfico $\bar{\theta}_{0}-\bar{\theta}$ versus $\ln t$ e calculou-se $K_{0}$ a partir dos coeficientes angular e linear da Equação 4.11.

$$
\bar{\theta}_{0}-\bar{\theta}=\frac{1}{\gamma} \ln t+\frac{1}{\gamma} \ln \left(\frac{\bar{\gamma} \cdot K_{0}}{z}\right)
$$

- Com os valores de $\theta_{0}$, $\gamma$ e $K_{0}$, ajustou-se a Equação 4.10. para cada profundidade $z$ :

Ao longo dos 14 dias de ensaio, foram realizadas determinações dos perfis de umidade entre 0 e 1,50 de profundidade. Esses perfis, obtidos para os solos 1 e 2, são apresentados nas Figuras 5.8 e 5.9.

As Figuras 5.10 e 5.11 apresentam os gráficos de $\theta_{0^{-}} \theta$ vesrus $\ln t$ para cada solo, dos quais foram extraídos os parâmetros $\gamma$ da equação 4.11, para cada profundidade $\mathrm{z}$, até $1,50 \mathrm{~m}$, que são apresentados na Tabela 5.5. Os gráficos de $\bar{\theta}_{0}-\bar{\theta}$ versus $\ln t$, de onde se extraiu os valores de $K_{0}$ para cada profundidade, são ilustrados nas Figuras 5.12 e 5.13. Os valores de $\mathrm{K}_{0}$ são também apresentados na Tabela 5.5 .

\section{4,1.5. Ensaios com trincheiras experimentais}

Os ensaios de infiltração nas trincheiras experimentais foram conduzidos de maneira a estudar seu comportamento hidráulico em resposta à adução de determinados volumes de água. Foram construídas trincheiras experimentais nos Solos 1 e 2, com o intuito de 
estudar as três fases do processo de infiltração: adução, recessão e redistribuição. Para a obtenção de dados, utilizou-se os seguintes equipamentos:

- Nas fases de adução e recessão: transdutores de pressão para o acompanhamento do nível d'água na trincheira;

- Na fase de redistribuição: sonda de nêutrons para o acompanhamento do perfil de umidade no entorno da trincheira.

Os volumes aduzidos às trincheiras foram determinados com base na curva de chuva para a cidade de São Carlos (Equação 3.2), para um período de retorno de 2 anos e tempo de precipitação de 25 minutos, em um lote de $250 \mathrm{~m}^{2}$, com área impermeável de $150 \mathrm{~m}^{2}$ (60\% de ocupação). A intensidade de precipitação, nessas condições, é de $55,5 \mathrm{~mm} / \mathrm{h}$, que, em 25 minutos, gera uma lâmina de precipitação de $23,14 \mathrm{~mm}$, equivalente a um volume de $3,47 \mathrm{~m}^{3}$ sobre a área de $150 \mathrm{~m}^{2}$. Este volume foi utilizado para realizar os experimentos de campo com trincheiras nos dois solos.

\section{Sistema de leitura de nível d'água por meio de transdutores de pressão}

Os transdutores de pressão são instrumentos sensíveis à variação de coluna d'água. São compostos por um sistema elétrico de detecção feito por uma membrana, que deve ser submetida, em uma das faces, à pressão atmosférica, e, em outra, à coluna d'água que se deseja medir. A membrana de detecção sofre deformação proporcional ao gradiente de pressão a que é submetida, e esta deformação gera a emissão de pulsos elétricos de fraca intensidade. Estes pulsos são amplificados e transmitidos a uma placa de aquisição de dados instalada em um micro computador, equipado com um software registrador gráfico das variações de pulso. Por meio da calibração prévia dos valores registrados com valores observados de coluna d'água, estabeleceu-se uma correlação entre as duas variáveis, que foi válida para as leituras futuras. As Figuras 4.19 a 4.21 ilustram o esquema de funcionamento do sistema de transdutores, o transdutor com o amplificador de sinais, e a tela do registrador gráfico.

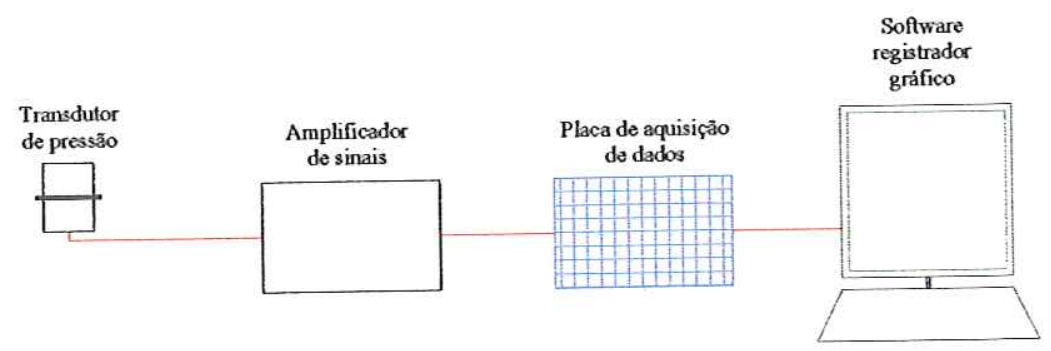




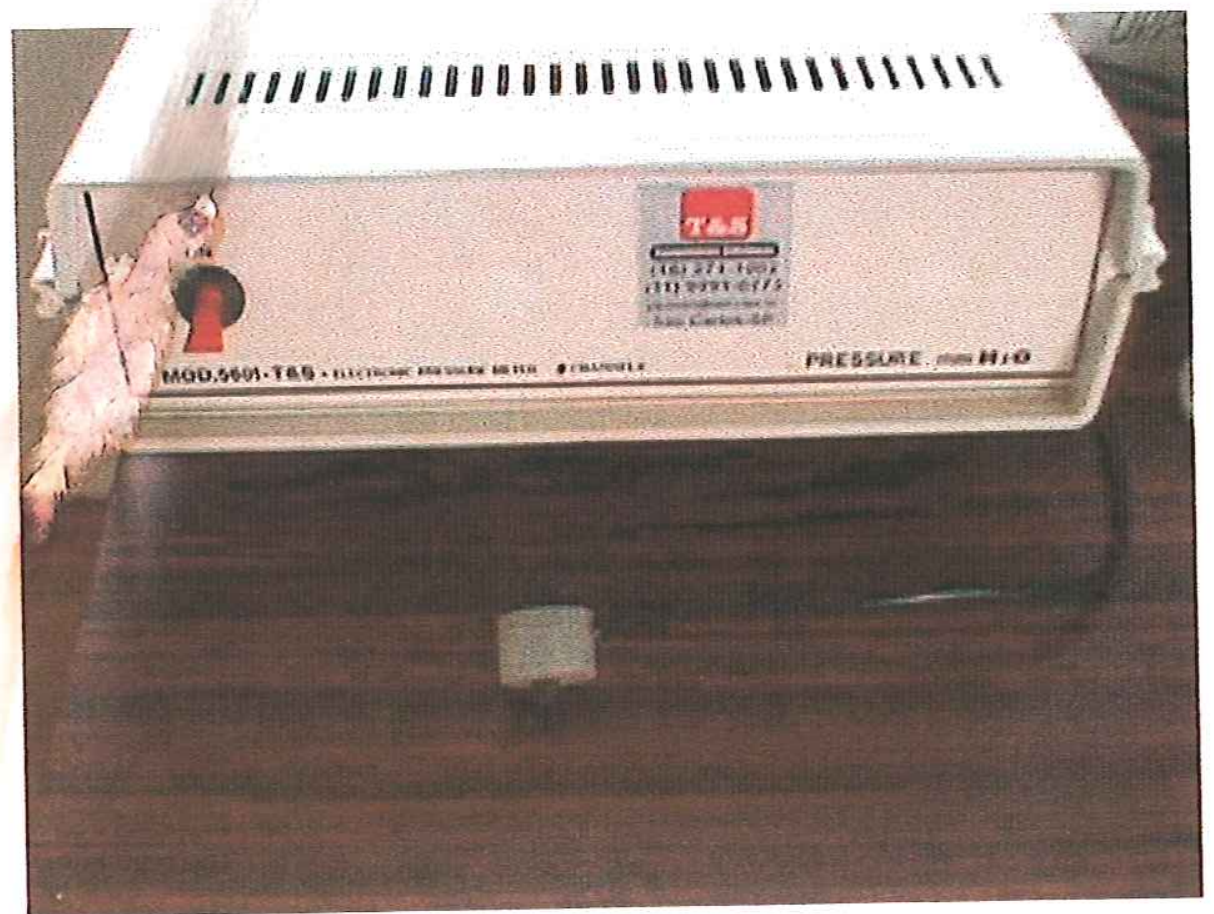

Figura 4.20 - Transdutor de pressão e amplificador de sinais.

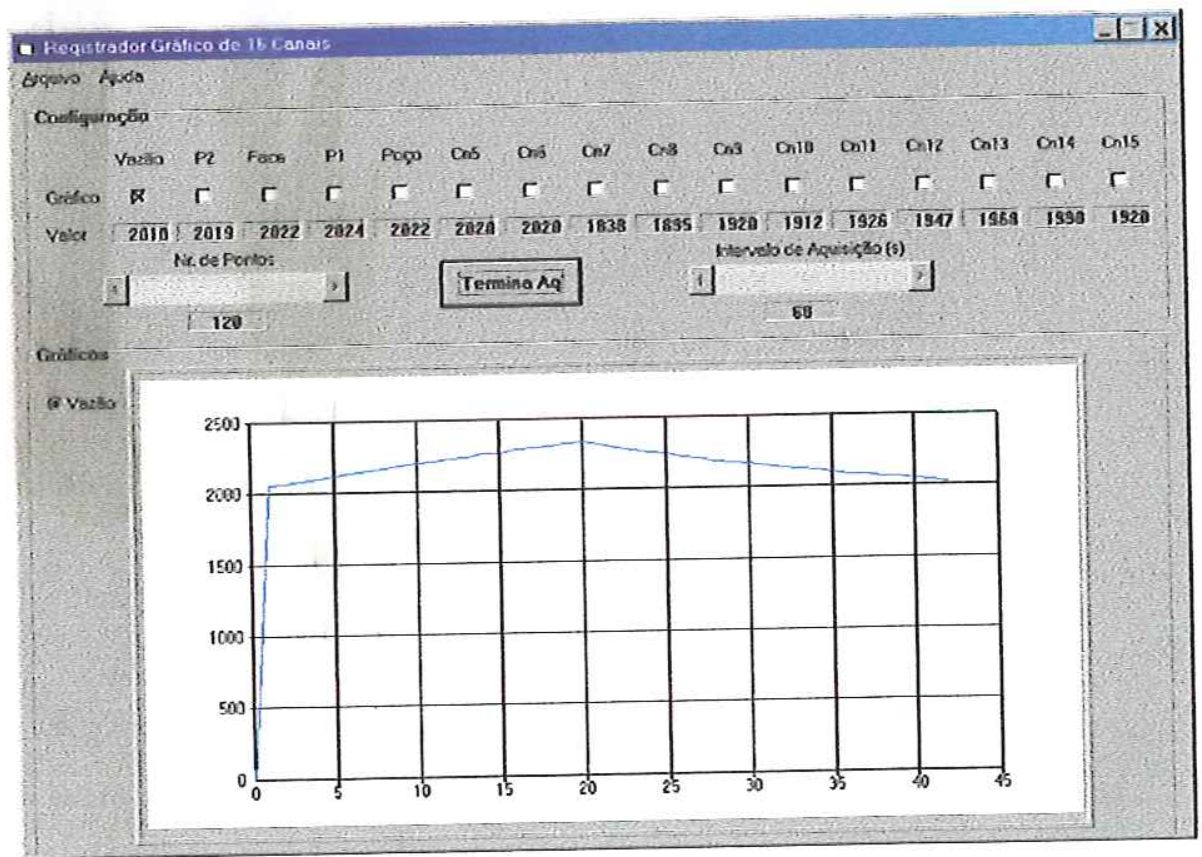

Figura 4.21 - Tela do software da placa de aquisição de dados do sistema de transdutores

\section{Instalações Experimentais}

Em cada área experimental foram instaladas duas trincheiras de infiltração: uma piloto, na qual foram conduzidos os ensaios iniciais de estudo do solo e calibração dos instrumentos, e uma experimental, em que foram realizados os ensaios de infiltração, ambas com as seguintes dimensões: largura $\mathrm{B}=0,50 \mathrm{~m}$; comprimento $\mathrm{L}=4,00 \mathrm{~m}$ e profundidade $\mathrm{H}=0,70 \mathrm{~m}$. 
O trabalho experimental teve o objetivo de estudar o comportamento hidráulico das trincheiras instaladas nos dois solos, de modo que os ensaios foram conduzidos exclusivamente para este fim. As trincheiras experimentais foram alimentadas a partir de reservatórios com volumes controlados. Não foram realizados estudos sobre os efeitos da colmatação na eficiência das estruturas, pelo que utilizou-se, para a alimentação das trincheiras, água tratada, proveniente da rede de abastecimento urbano, e, portanto, livre de sólidos em suspensão, não sendo necessário o revestimento por manta geotêxtil. Além disso, trabalhou-se com todo o volume útil das trincheiras, que não foram preenchidas com brita, procedimento recomendável em trincheiras instaladas em lotes urbanos, para a contenção dos taludes, melhor fixação do geotêxtil e prevenção de acidentes.

Partiu-se da premissa de que o não preenchimento da trincheira com brita não provoca alterações significativas no seu comportamento hidráulico, sendo que, a única diferença, é que o volume útil da trincheira oca é de $100 \%$, enquanto que, na trincheira preenchida com brita, o volume útil é igual à porosidade da brita utilizada, e este fator deve ser levado em consideração para o dimensionamento.

A alimentação de água para as trincheiras foi feita a partir de um sistema de dois reservatórios de $1,00 \mathrm{~m}^{3}$ cada, interligados pelo fundo e conectados às trincheiras por meio

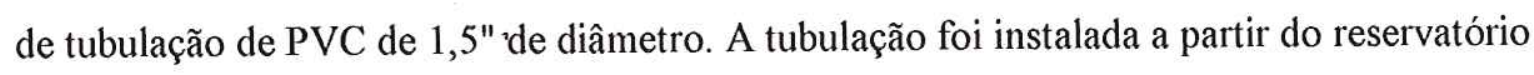
até a extremidade longitudinal superior da trincheira, sendo, neste ponto, provida de registro de abertura rápida. A partir do registro, a tubulação foi prolongada verticalmente até o fundo da trincheira, e, deste ponto, horizontalmente até a extremidade oposta da trincheira, percorrendo todo o eixo longitudinal, junto ao solo. Neste trecho horizontal da tubulação, o tubo de PVC foi perfurado em seções eqüidistantes de $4 \mathrm{~cm}$, cada uma com 4 furos distribuídos na circunferência do tubo, no intuito de promover uma alimentação uniforme de água por todo o comprimento da trincheira, e, deste modo, obter igual lâmina d'água ao longo da seção longitudinal.

Adotou-se a seção transversal do centro da trincheira como seção de controle, de modo que todas as três fases do processo foram estudadas a partir de observações de nível d'água e frente de umidade realizadas nesta seção. Foram instalados tubos de acesso para a sonda de nêutrons, em alinhamento, a partir do centro da seção transversal, até a distância de $0,90 \mathrm{~m}$ do centro. Os tubos foram enterrados à profundidade de $1,70 \mathrm{~m}$. A Figura 4.22 ilustra a disposição da instalação experimental. 


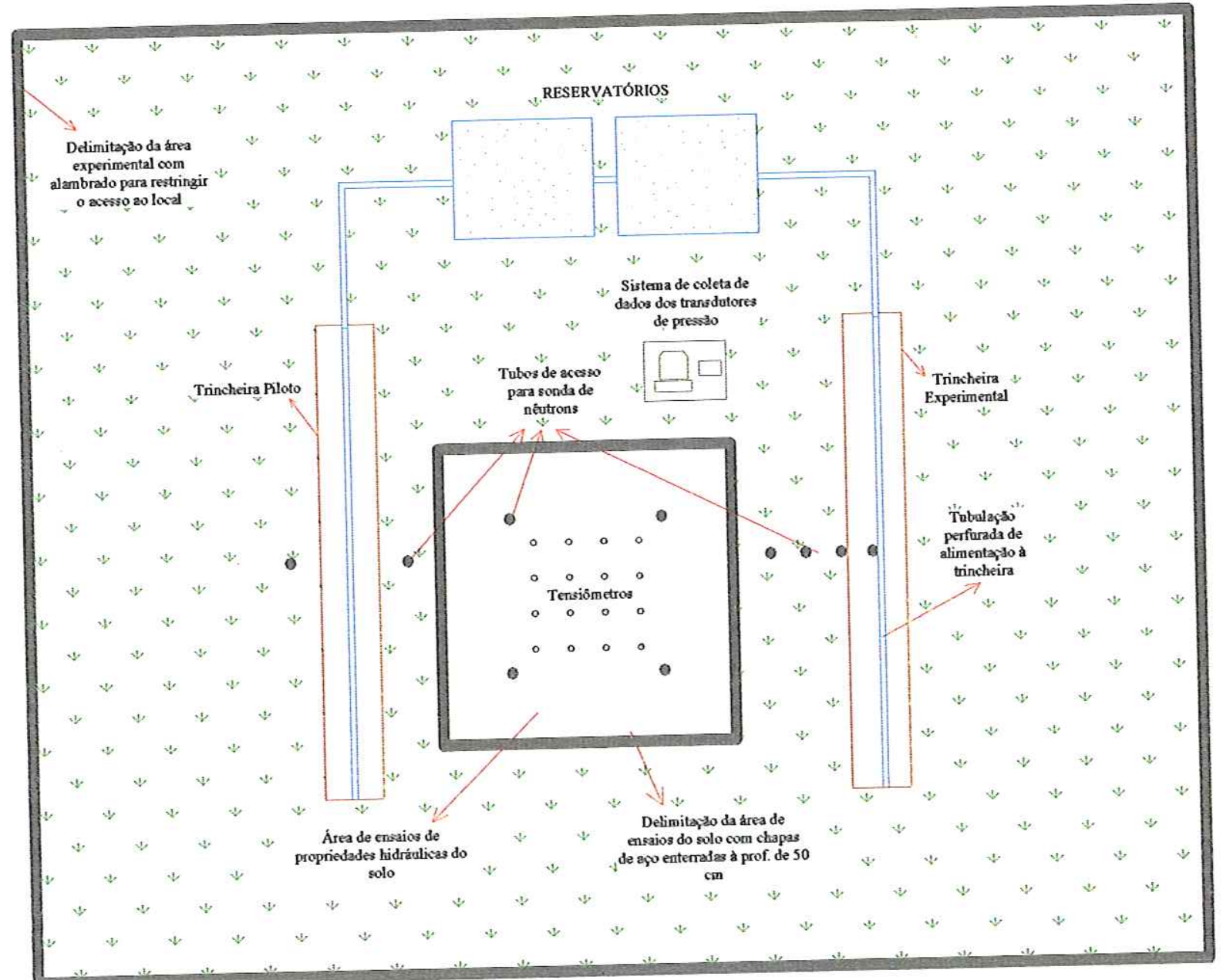

Figura 4.22 - Esquema da instalação experimental.

Os tubos de acesso foram instalados em apenas um dos lados da seção transversal da trincheira. Isso porque, em experimentos piloto, constatou-se que a variação dos valores de umidade em posições eqüidistantes ao eixo longitudinal da trincheira, em um mesmo instante, é menos significativa do que o erro decorrente do tempo gasto para efetuar leituras nos dois lados da trincheira. Por este motivo, optou-se por adotar a condição de simetria, e realizar medições de umidade em apenas um dos lados da seção transversal. Desta forma, minimizou-se o tempo decorrido entre a medida da umidade no primeiro e no último ponto, de modo que as leituras puderam ser consideradas como representativas de um mesmo instante. A Figura 4.23 ilustra a trincheira experimental instalada no Solo 2. 


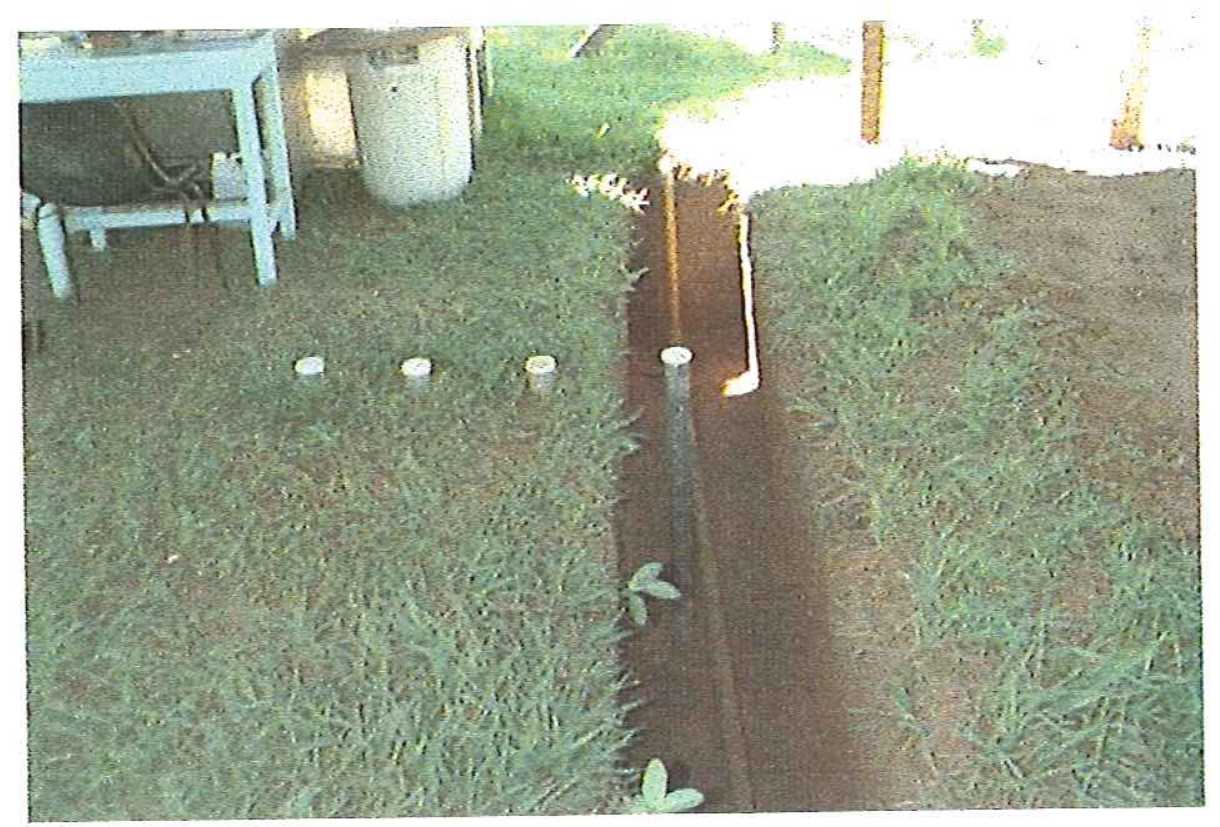

Figura 4.23 - Trincheira experimental - Solo 2

\section{Condução dos ensaios e processamento dos dados}

Com o objetivo de avaliar quantitativamente o comportamento de infiltração das trincheiras, os experimentos foram monitorados nas três fases do processo de infiltração:

Fase 1 - Adução: alimentação da trincheira com água, caracterizada por lâmina d'água (z) crescente $(0<\mathrm{z} \leq \mathrm{H}$, em que $\mathrm{H}=$ profundidade da trincheira).

Fase 2 - Recessão: ocorre desde o instante em que é cessada a alimentação até o instante em que a lâmina d'água no interior da trincheira se iguala a zero $(0, \mathrm{H} \geq \mathrm{z}>0)$.

Fase 3 - Redistribuição: drenagem interna da água no entorno da seção transversal da trincheira, iniciada no instante em que acaba a recessão $(\mathrm{z}=0)$.

As fases 1 e 2 foram monitoradas por meio de leituras de nível d'água no interior da trincheira, realizadas com transdutores de pressão acoplados a um sistema de coleta automática de dados. Uma vez conhecidas a geometria da trincheira e a vazão de alimentação, pôde-se determinar os volumes infiltrados a cada instante.

A fase 3 foi monitorada por meio de leituras de umidade volumétrica do solo realizadas com sonda de nêutrons na seção de controle.

A água foi aduzida às trincheiras a partir do sistema de reservatórios acoplados. Registrou-se, com o auxílio dos transdutores de pressão, a variação de volume na trincheira, durante as fases de adução e recessão. Para a condução do ensaio, foram utilizados dois transdutores. O primeiro, denominado T2, foi colocado no fundo da seção 
de controle da trincheira, e o segundo, denominado T4, foi instalado no reservatório de alimentação. Uma vez conhecidas as geometrias do reservatório e da trincheira, foi possível acompanhar a variação de volume em ambos. As leituras foram registradas em intervalos de 60 segundos.

De posse dos valores de volume obtidos continuamente no reservatório e na trincheira, bem como das vazões de entrada e saída de água do reservatório, calculou-se a vazão de infiltração de água na trincheira, $\mathrm{em} \mathrm{m} / \mathrm{s} \cdot \mathrm{m}^{2}$.

Em seguida, os valores observados foram confrontados com os fornecidos pela equação de Philip (1957, apud Libardi, 2000) para infiltração horizontal. Fez-se isso com o intuito de obter um meio simplificado de quantificar o volume infiltrado, a fim de propor uma metodologia simples de dimensionamento.

O modelo de Philip, apresentado no Capítulo 3 e descrito pelas Equações 3.32 e 3.33, foi escolhido por descrever o processo de infiltração horizontal, que é melhor ajustável ao caso das trincheiras de infiltração, em que supõe-se a condição de colmatação do fundo, na qual a infiltração lateral torna-se predominante.

$$
i=\frac{C}{2 \sqrt{t}}
$$

A infiltração acumulada até um determinado instante t é calculada pela Equação 3.32:

$$
I=C \sqrt{t}
$$

As planilhas com os volumes infiltrados observados e calculados pelo modelo de Philip são apresentadas nas Tabelas 5.6 e 5.7, para os solos 1 e 2, respectivamente. Para efeito de simplificação, as tabelas são apresentadas com intervalos de discretização de 5 minutos, embora as observações e o ajuste tenham sido feitos com discretização de 1 minuto. A partir da calibração dos dados experimentais pela equação de Philip, obteve-se a curva de decaimento da taxa de infíltração para os Solos 1 e 2, ilustradas nas figuras 5.14 e 5.15, e cujos parâmetros de ajuste encontram-se resumidos na Tabela 5.8. As Figuras 5.16 e 5.17 apresentam os gráficos dos volumes de entrada, armazenamento e infilttração, em função do tempo, para os Solos 1 e 2.

Terminadas a fases de alimentação e recessão, procedeu-se ao acompanhamento da frente de umidade no solo, em torno da seção transversal da trincheira. As medidas de umidade, com sonda de nêutrons, foram efetuadas desde o instante $t=0$, coincidente com o final da fase de recessão, até se obter valores de umidade iguais ou inferiores aos do início do ensaio, antes da adução. Neste momento, deu-se por terminado o experimento. 
Uma vez determinados os valores de umidade nos diversos pontos distribuídos ao longo da seção transversal da trincheira, em cada instante da redistribuição, traçou-se linhas de iso-umidade, para uma melhor visualização do desenvolvimento do campo de umidade. Esta etapa foi realizada com o auxílio do software Idrisi. Este software, desenvolvido pela ClarkLabs e comercializado no Brasil pela SulSoft, reúne ferramentas nas áreas de processamento de imagens de sensoriamento remoto, SIG, geoestatística, apoio à decisão e análise de imagens geográficas. Fez-se uma adaptação das funções do Idrisi para o traçado do campo de umidade ao redor das trincheiras, a partir de valores pontuais de umidade, com o auxílio do recurso de interpolação do software.

As Tabelas 5.9 e 5.10 apresentam as leituras de umidade ao redor da seção transversal da trincheira, e as Figuras 5.18, 5.19 e 5.20 ilustram o desenvolvimento da frente de umidade.

\subsection{Modelagem Numérica}

Para quantificar a redistribuição da água no solo ao redor da trincheira, adaptou-se o modelo numérico proposto por Tabuada et al. (1995a) para sulcos curtos de irrigação. A escolha do modelo baseou-se nos seguintes critérios:

i. As trincheiras enquadram-se na mesma classificação dos sulcos curtos com relação à forma de abordagem do problema, pois são suficientemente curtas para que se possa considerar instantânea a fase de avanço da frente de molhamento ao longo da seção longitudinal. Sendo assim, a lâmina d'água é sempre a mesma ao longo do comprimento da trincheira. Isso permite uma abordagem bidimensional do problema, uma vez que as variações no campo de umidade ocorrem, principalmente, na duas dimensões da seção transversal da trincheira. Para efeito de classificação, Tabuada et al. (1995a) consideram sulcos curtos aqueles com menos de 30 metros de comprimento.

ii. As mesmas considerações admitidas no modelo de Tabuada et al. (1995a) para sulcos de irrigação são assumidas para as trincheiras de infiltração: água e solo incompressíveis; meio homogêneo e isotrópico; os efeitos de histerese, temperatura e osmose são desprezíveis.

iii. Por fim, as semelhanças entre as duas estruturas (sulcos e trincheiras) permitiram que a adaptação do modelo para o caso das trincheiras fosse de caráter geométrico, uma vez que estas possuem seção retangular, ao passo que os sulcos têm seção trapezoidal. 
Feitas as considerações necessárias, o desenvolvimento do modelo baseou-se na Equação 3.35, apresentada no Capítulo 3, proposta por Richards' (1931, apud Tabuada et al., 1995a) para a quantificação da infiltração da água no solo.

$$
\frac{\partial \theta}{\partial t}=\vec{\nabla}(k(\theta) \vec{\nabla} \phi t)
$$

Desenvolvendo a equação de Richards' na forma bidimensional, tem-se:

$$
\frac{\partial \theta}{\partial t}=\partial\left(\frac{k(\theta)}{\partial x} \cdot \frac{\partial \phi t}{\partial x}\right)+\partial\left(\frac{k(\theta)}{\partial z} \cdot \frac{\partial \phi t}{\partial z}\right)
$$

Onde $x$ é a direção horizontal e $z$ a vertical da seção transversal da trincheira.

Como se trata de solo não saturado, os potenciais de pressão e pneumático são inexistentes. Considerando as hipóteses assumidas inicialmente, os potenciais osmótico e de temperatura também são nulos. Assim, a definição do potencial total da água no solo fica reduzida à equação 4.13:

$$
\phi t=\phi m+\phi g
$$

Em que,

$\phi_{m}$ é o potencial mátrico, $e$

фg é o potencial gravitacional, dado pela coordenada $z$ da posição no solo.

Assim,

$$
\phi t=\phi m+z
$$

Substituindo 4.14 em 4.12, e fazendo as simplificações pertinentes, chega-se à Equação 4.15, que é a equação de Richards' na forma bidimensional, considerando as hipóteses adotadas.

$$
\frac{\partial \theta}{\partial t}=\frac{\partial k(\theta)}{\partial x} \cdot \frac{\partial \phi m}{\partial x}+\frac{\partial k(\theta)}{\partial z} \cdot\left(\frac{\partial \phi m}{\partial z}-1\right)
$$

Para o desenvolvimento do modelo matemático, Tabuada et al. (1995a) utilizaram a Equação 4.16, que é a equação de Richards' bidimensional, escrita em termos de potencial mátrico:

$$
c(\phi m) \frac{\partial \phi m}{\partial t}=\frac{\partial k(\phi m)}{\partial x} \cdot \frac{\partial \phi m}{\partial x}+\frac{\partial k(\phi m)}{\partial z} \cdot\left(\frac{\partial \phi m}{\partial z}-1\right)
$$

em que:

$$
c(\phi m) \frac{\partial \phi m}{\partial t}=\frac{\partial \theta}{\partial t} \Rightarrow c(\phi m)=\frac{\partial \theta}{\partial \phi m}
$$


A vantagem de se trabalhar com a equação em termos de potencial mátrico é que este, ao contrário da umidade, é contínuo no perfil.

A Equação 4.16 foi discretizada, para solução computacional, pelo método das diferenças finitas, resultando em:

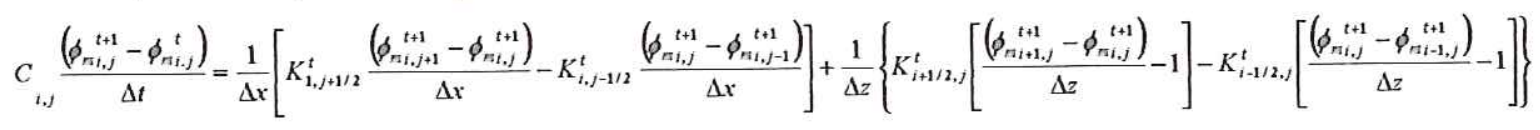

Em que:

t é o indice de tempo;

i é o indice de espaço na direção vertical e

jé o indice de espaço na direção horizontal.

A Equação 4.17 foi agrupada em termos, e rescrita como:

$$
A_{i, j} \phi_{m i, j-1}^{t+1}+B_{i, j} \phi_{m i-1, j}^{t+1}+D_{i, j} \phi_{m i, j}^{t+1}+E_{i, j} \phi_{m i+1, j}^{t+1}+F_{i, j} \phi_{m i, j+1}^{t+1}=G_{i, j}
$$

Em que:

$$
\begin{aligned}
& A_{i, j}=\frac{K_{i, j-1 / 2}^{t}}{(\Delta x)^{2}} \\
& B_{i, j}=\frac{K_{i-1 / 2, j}^{t}}{(\Delta z)^{2}} \\
& D_{i, j}=-\frac{C_{i, j}^{t}}{\Delta t}-A_{i, j}-B_{i, j}-E_{i, j}-F_{i, j} \\
& E_{i, j}=\frac{K_{i+1 / 2, j}^{t}}{(\Delta z)^{2}} \\
& F_{i, j}=\frac{K_{i, j+1 / 2}^{t}}{(\Delta x)^{2}} \\
& G_{i, j}=-\Delta z \cdot B_{i, j}+\Delta z \cdot E_{i, j}-\frac{C_{i, j}}{\Delta t} \cdot h_{i, j}
\end{aligned}
$$

Adotou-se, para a solução do problema, a condição de simetria, na qual a infilttração não varia em relação a pontos eqüidistantes ao eixo longitudinal do sulco de irrigação, ou da trincheira de infiltração. Sendo assim, considera-se a área de domínio definida pelos pontos OACDEFO da Figura 4.24, que ilustra um sulco de irrigação, de seção transversal trapezoidal. A adaptação para o caso das trincheiras é mostrada na Figura 4.25.: 


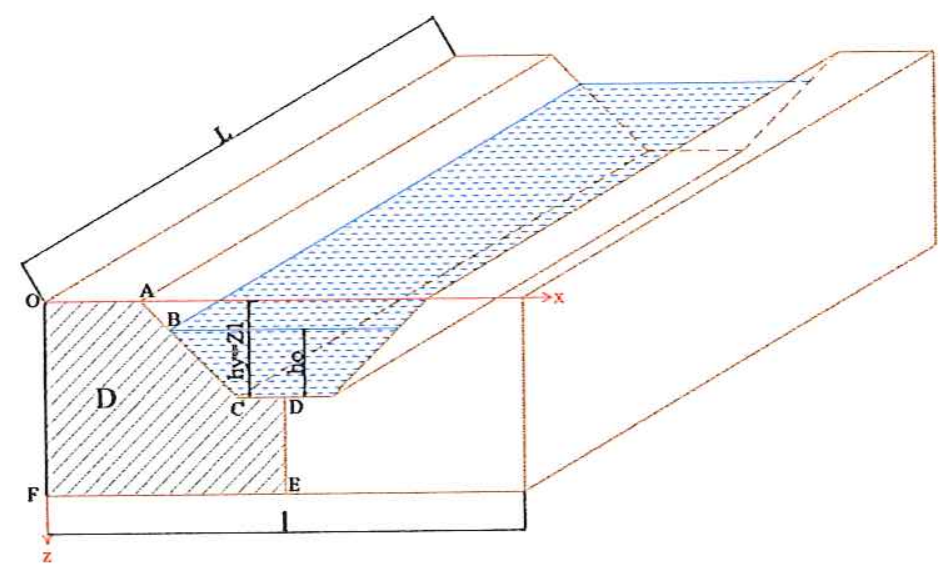

Figura 4.24 - Esquema do sulco de irrigação.

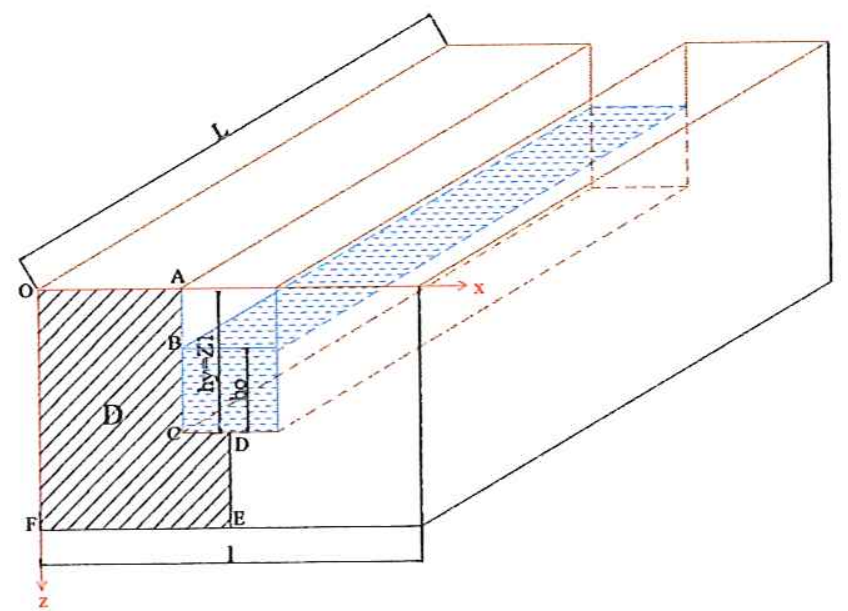

Figura 4.25 - Esquema da trincheira de infiltração

Em ambos os esquemas, $h_{0}$ é a altura da lâmina d'água, $h_{y}=Z_{1}$ é a profundidade da estrutura de infilltração, $L$ é o comprimento e lé a largura.

A discretização no domínio foi feita pelo método das diferenças finitas. $\mathrm{O}$ domínio foi dividido em elementos retangulares, de dimensões $\Delta x$ e $\Delta z$, criando uma matriz de $m$ linhas e $n$ colunas, como ilustram as figuras 4.26 e 4.27 .

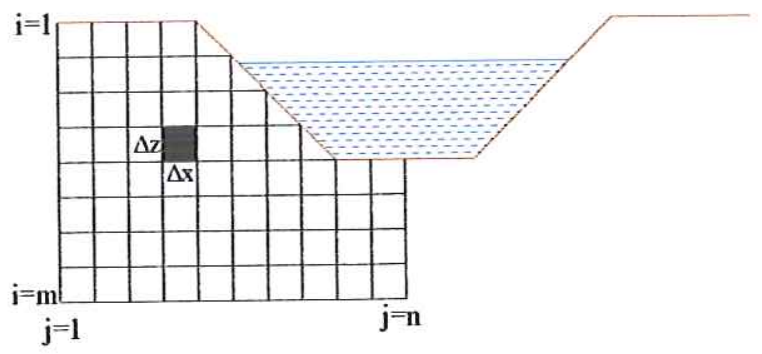

Figura 4.26 - Discretizção do domínio para a solução do sulco de irrigação. 


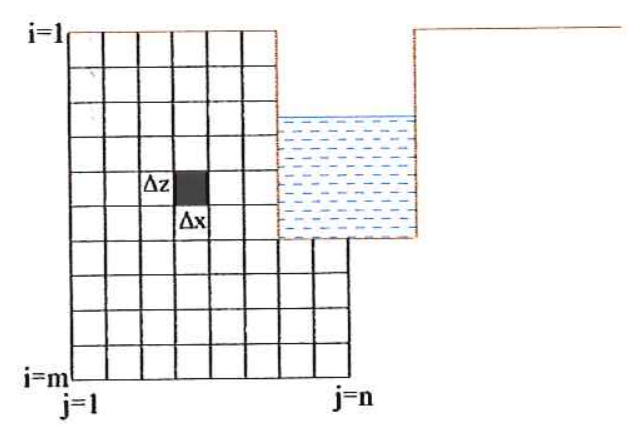

Figura 4.27 - Discretização do domínio para a solução da trincheira de infiltração.

A cada nó $(i, j)$, o valor de $\phi_{m}$ é calculado para o instante $t+1$, partindo-se do valor de $\phi_{m}$ no instante $t$. No primeiro intervalo $\Delta t, \phi_{m}$ representa a condição inicial do solo. Uma vez conhecidos os valores de $\phi_{m}$ em cada nó $(i, j)$, a umidade correspondente é computada utilizando-se a relação $\phi_{m}(\theta)$, que é a curva de retenção do solo.

Para um dado intervalo $t$, a partir do início da irrigação, o volume infiltrado na $L x l$ é dado pela Equação 4.25:

$$
V(t)=2\left\lfloor L \iint_{D}\left(\theta_{x, z, t}-\theta_{i n}\right) d x d z\right\rfloor
$$

Em que $\theta_{\text {in }}$ é a umidade volumétrica inicial.

Da mesma forma, $\phi_{m}$ in representa o potencial mátrico inicial, que é o dado de entrada para a solução do problema.

As condições de contorno são diferentes nas três fases do processo: abastecimento, recessão e redistribuição, e são mostradas na Tabela 4.1. A adaptação das condições de contorno ao problema das trincheiras de infiltração é feita com base no ângulo de inclinação do talude do sulco de irrigação, que, no caso das trincheiras, é $90^{\circ}$. 
Tabela 4.1 - Condições de contorno

\begin{tabular}{|c|c|c|c|}
\hline $\begin{array}{l}\text { Superfície de contorno } \\
\text { (conforme Fig. } 4.23 \text { ) }\end{array}$ & $\begin{array}{c}\text { Avanço-Abastecimento } \\
0<\mathrm{t}<\mathrm{t}_{\mathrm{ab}}\end{array}$ & $\begin{array}{l}\text { Recessão } \\
\mathrm{t}_{\mathrm{ab}}<\mathrm{t}<\mathrm{t}_{\mathrm{rec}}\end{array}$ & $\begin{array}{l}\text { Redistribuição } \\
\mathrm{t}_{\mathrm{rec}}<\mathrm{t}<\mathrm{t}_{\text {red }}\end{array}$ \\
\hline CD & $\phi_{m}\left(x, Z_{1}, t\right)=h_{0}(t)$ & $\phi_{m}\left(x, Z_{1}, t\right)=h_{r e c}(t)$ & $K\left(\phi_{m}\right)\left(\frac{\partial \phi_{m}}{\partial z}-1\right)=0$ \\
\hline $\mathrm{BC}$ & $\phi_{m}(x, z, t)=h_{a b}(x, z, t)$ & $\phi_{m}(x, z, t)=h_{r e c}(x, z, t)$ & $\vec{q} \mid \vec{N}=0$ \\
\hline $\mathrm{AB}$ & $\vec{q} \mid \vec{N}=0$ & $\vec{q} \mid \vec{N}=0$ & $\vec{q} \mid \vec{N}=0$ \\
\hline $\mathrm{AO}$ & $K\left(\phi_{m}\right)\left(\frac{\partial \phi_{m}}{\partial z}-1\right)=0$ & $K\left(\phi_{m}\right)\left(\frac{\partial \phi_{m}}{\partial z}-1\right)=0$ & $K\left(\phi_{m}\right)\left(\frac{\partial \phi_{m}}{\partial z}-1\right)=0$ \\
\hline OF & $\frac{\partial \phi_{m}}{\partial x}=0$ & $\frac{\partial \phi_{m}}{\partial x}=0$ & $\frac{\partial \phi_{m}}{\partial x}=0$ \\
\hline $\mathrm{DE}$ & $\frac{\partial \phi_{m}}{\partial x}=0$ & $\frac{\partial \phi_{m}}{\partial x}=0$ & $\frac{\partial \phi_{m}}{\partial x}=0$ \\
\hline $\mathrm{FE}$ & $\phi \mathrm{m}=\phi \mathrm{m}_{\text {inicial }}$ & $\phi \mathrm{m}=\phi \mathrm{m}_{\text {inicial }}$ & $\phi \mathrm{m}=\phi \mathrm{m}_{\text {inicial }}$ \\
\hline
\end{tabular}

* N é a direção normal à superfície considerada.

O fluxo na direção $N$ é representado por $\vec{q} \mid \vec{N}$. Esta condição de contorno, que aparece para o trecho $A B$ do domínio $D$, refere-se à inexistência de fluxo na direção perpendicular ao talude do sulco de irrigação. Na adaptação para a trincheira de infiltração, a direção $N$ coincide com a direção $x$, uma vez que a inclinação do talude é $90^{\circ}$. A densidade de fluxo $q$ é dada pela Equação 4.26:

$$
\vec{q}=-K(\theta) \frac{\partial \phi_{m}}{\partial x} \dot{i}-K(\theta)\left(\frac{\partial \phi_{m}}{\partial z}-1\right) \vec{k}
$$

O problema a ser resolvido consiste em obter, a cada instante, os valores de potencial mátrico que satisfaçam à Equação 4.17, quando são conhecidas as relações $K=K\left(\phi_{m}\right)$ e $c\left(\phi_{m}\right)$, as condições iniciais de umidade do solo e as condições de contorno. As relações $K\left(\phi_{m}\right)$ e $c\left(\phi_{m}\right)$ foram obtidas experimentalmente, sob a forma de curvas $\phi_{m}(\theta)$, para os dois solos, conforme procedimento descritos anteriormente (ensaio de curva de retenção).

As seguintes considerações foram adotadas por Tabuada et al. (1995a) para a solução computacional do problema:

i. As relações $K\left(\phi_{m}\right) e c\left(\phi_{m}\right)$ permanecem constantes durante cada iteração de cálculo, e iguais aos valores computados no final da interção anterior; 
ii. $\mathrm{O}$ valor do parâmetro $K\left(\phi_{m}\right)$ entre dois nós sucessivos é igual à média aritmética dos valores nestes dois nós, conforme mostram as Equações 4.27 e 4.28:

$$
\begin{aligned}
& K_{i \pm 1 / 2, j}^{t}=\frac{1}{2}\left(K_{i, j}^{t}+K_{i \pm 1, j}^{t}\right) \\
& K_{i, j \pm 1 / 2}^{t}=\frac{1}{2}\left(K_{i, j}^{t}+K_{i, j \pm 1}^{t}\right)
\end{aligned}
$$

Para a solução do sistema de equações, utilizou-se o método iterativo de Gauss-Seidel (Wang e Anderson, 1982). A convergência foi considerada satisfatória quando a diferença entre os valores de potencial calculados em duas interações sucessivas (residual de GaussSeidel) satisfez à equação 4.29:

$$
\phi_{m i, j}^{t+1, i+1}-\phi_{m i, j}{ }^{t+1, i t} \prec 0,005 \mathrm{cmH}_{2} \mathrm{O}
$$

Tabuada et al. (1995a) desenvolveram um programa computacional chamado BIDISUL (sulcos bidimensionais) para a solução do modelo matemático.

O modelo assume que a taxa de adução de água ao sulco seja constante, e que, no final de cada intervalo $\Delta t$ o volume de água aduzido seja conhecido. Isto permite calcular a profundidade da lâmina d'água $h_{0}$, uma vez que a geometria da estrutura de infiltração é conhecida. Desta forma, é possível calcular o volume de água infiltrado durante o mesmo período $\Delta t$ utilizando a Equação 4.25. Tal volume é subtraído do volume total aplicado até o final do intervalo $(t+\Delta t)$, permitindo o cálculo de uma nova condição de contorno, de acordo com a Tabela 4.1. Este processo é repetido até que a profundidade máxima da lâmina d'água seja atingida, e, com isso, seja cessada a adução, e inicie-se o processo de recessão. Adota-se, então, um processo de cálculo similar ao anterior, para a determinação dos valores decrescentes de $h_{0}$, até que a profundidade da lâmina seja zero. Neste instante, termina a fase de recessão e inicia-se a redistribuição, que é simulada pelos mesmos processos de cálculo, porém com condições de contorno constantes, conforme Tabela 4.1.

Além da simulação das fases de abastecimento, recessão e redistribuição, o modelo calcula as perdas de percolação durante um dado intervalo de tempo, em relação a uma dada profundidade. A evolução da distribuição da umidade do solo é também simulada e pode ser graficamente representada em forma bidimensional, em qualquer instante $t$ da simulação. O fluxograma do modelo é apresentado na Figura 4.28. A listagem completa do modelo BidiSul é apresentada no ANEXO 3. O Capítulo 6 traz explicações mais detalhadas sobre o programa computacional, bem como um manual de instruções. 


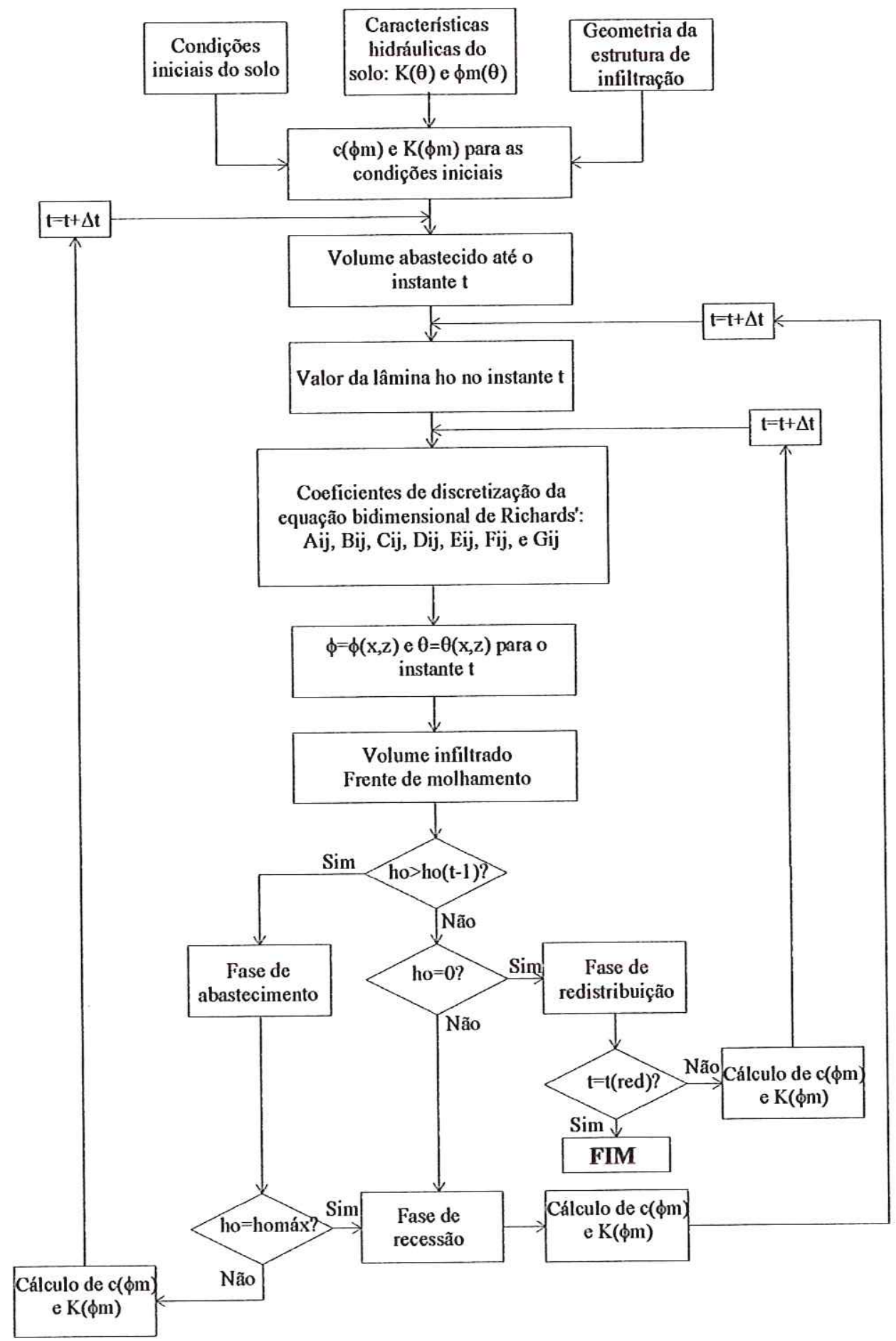

Figura 4.28 - Fluxograma do modelo BidiSul 


\subsubsection{Simulação numérica - procedimento}

Para cada solo, foram conduzidas duas simulações:

\section{Simulação A}

O programa computacional foi rodado considerando, como condições iniciais de umidade, o mesmo perfil inicial de umidade observado em campo. O modelo foi alimentado com a mesma vazão utilizada nos experimentos de campo, e durante o mesmo tempo de aplicação.

Esta simulação foi feita com o intuito de comparar os resultados fornecidos pelo modelo com os observados experimentalmente, tanto os valores de lâmina d'água e volume infiltrado, quanto os perfis de umidade nos diferentes instantes da fase de redistribuição.

A simulação foi conduzida de modo a ser encerrada em duas possíveis circunstâncias: a lâmina d'água atingir a capacidade máxima da trincheira ou o tempo total de abastecimento (igual ao do experimento de campo) ser atingido.

\section{$\underline{\text { Simulação B }}$}

O programa foi rodado com os mesmos parâmetros da simulação anterior, alterando, no entanto, os valores de umidade inicial para a umidade de saturação. Todo o perfil de umidade foi inicializado com valores saturados.

O objetivo desta simulação, partindo de um perfil totalmente saturado, foi avaliar o comportamento da trincheira na situação de operação mais desfavorável possível.

A vazão e tempo de alimentação foram as mesmas dos ensaios de campo. Os critérios de encerramento da simulação B foram os mesmos da simulação A.

Em ambas as simulações, observou-se o desenvolvimento da lâmina d'água no interior da trincheira nas fases de alimentação e recessão, bem como os perfis de umidade do solo ao longo da fase de redistribuição.

Os resultados das simulações A são apresentados na seção 5.3.1, em que a Tabela 5.11 apresenta a evolução do nível d'água e do volume infiltrado nas fases de alimentação e recessão; as Figuras 5.25 e 5.26 apresentam a variação do nível d'água na trincheira, para os dois solos, e as Figuras 5.27 e 5.28 apresentam os perfis de umidade nas três fases para os solos 1 e 2. Os resultados da Simulação B são apresentados na seção 5.3.2, em que a Tabela 5.12 apresenta a evolução do nível d'água e do volume infiltrado durante as fases de alimentação e recessão; as Figuras 5.31 e 5.32 apresentam a evolução do nível d'água, em comparação com a Simulação A, e as Figuras 5.33 e 5.34 ilustram o desenvolvimento do perfil de umidade fornecido pela simulação B para os Solos 1 e 2, respectivamente. 


\section{RESULTADOS E DISCUSSÕES}

\subsection{Caracterização dos solos}

\subsubsection{Análise granulométrica conjunta}

A análise granulométrica, realizada para os solos 1 e 2, conforme procedimento descrito no item 4.1.1 e normalizado pela NBR-6502, mostrou que o Solo 1 contém $45 \%$ de argila e silte, e o Solo 2, aproximadamente $70 \%$ de areia em sua composição. De acordo com essa distribuição granulométrica, o Solo 1 é classificado como areia fina a média siltosa vermelha, e o Solo 2, areia média a fina argilosa marrom.

Os solos 1 e 2 mostraram possuir textura suficientemente distinta para possibilitar o estudo comparativo do comportamento hidráulico das trincheiras em diferentes condições de infiltração. As figuras 5.1 e 5.2 apresentam as curvas granulométricas dos dois solos, e a tabela 5.1 traz a composição granulométrica, bem como os índices físicos dos dois solos.

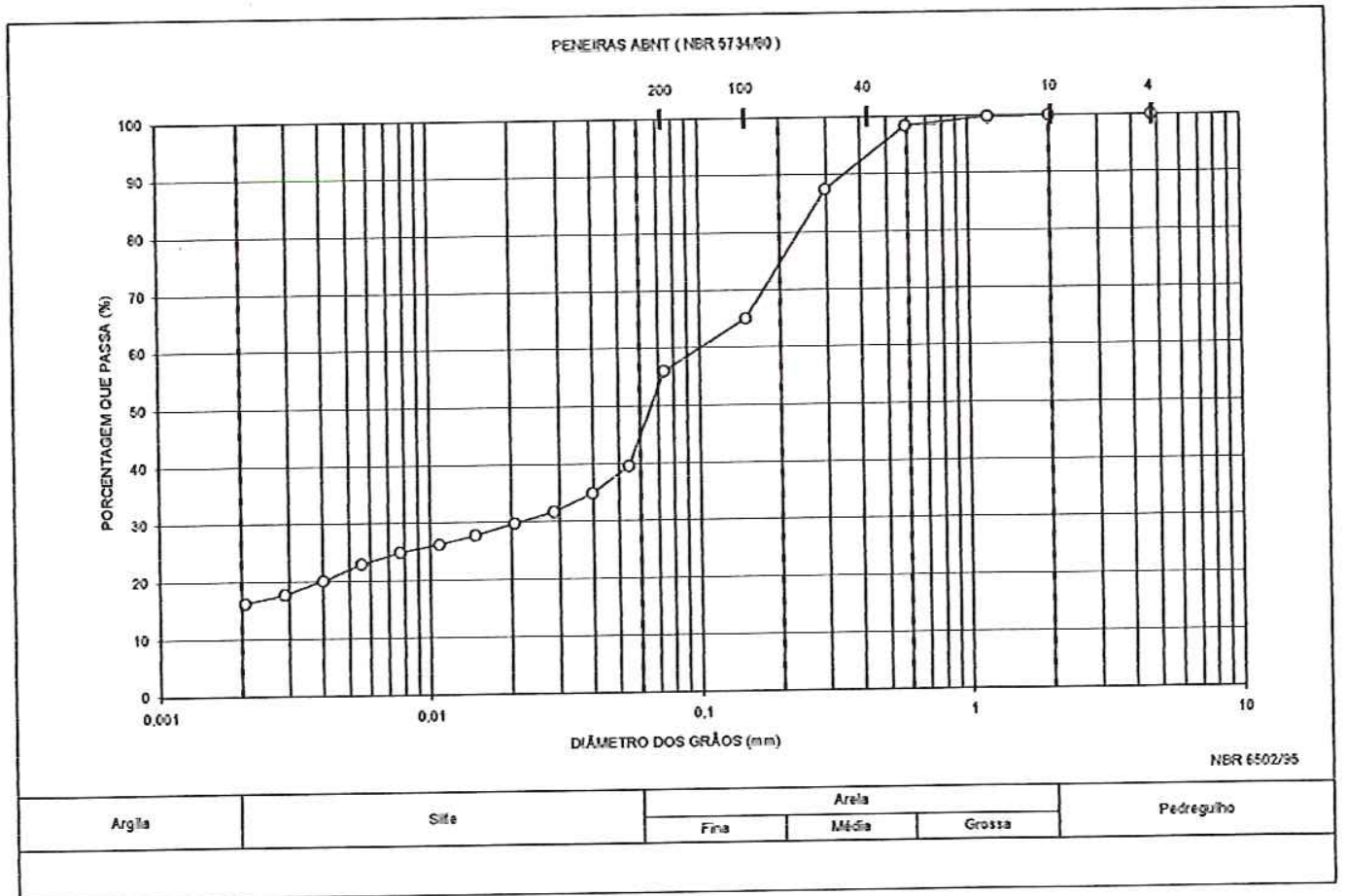

Figura 5.1. - Curva granulométrica do Solo 1. 


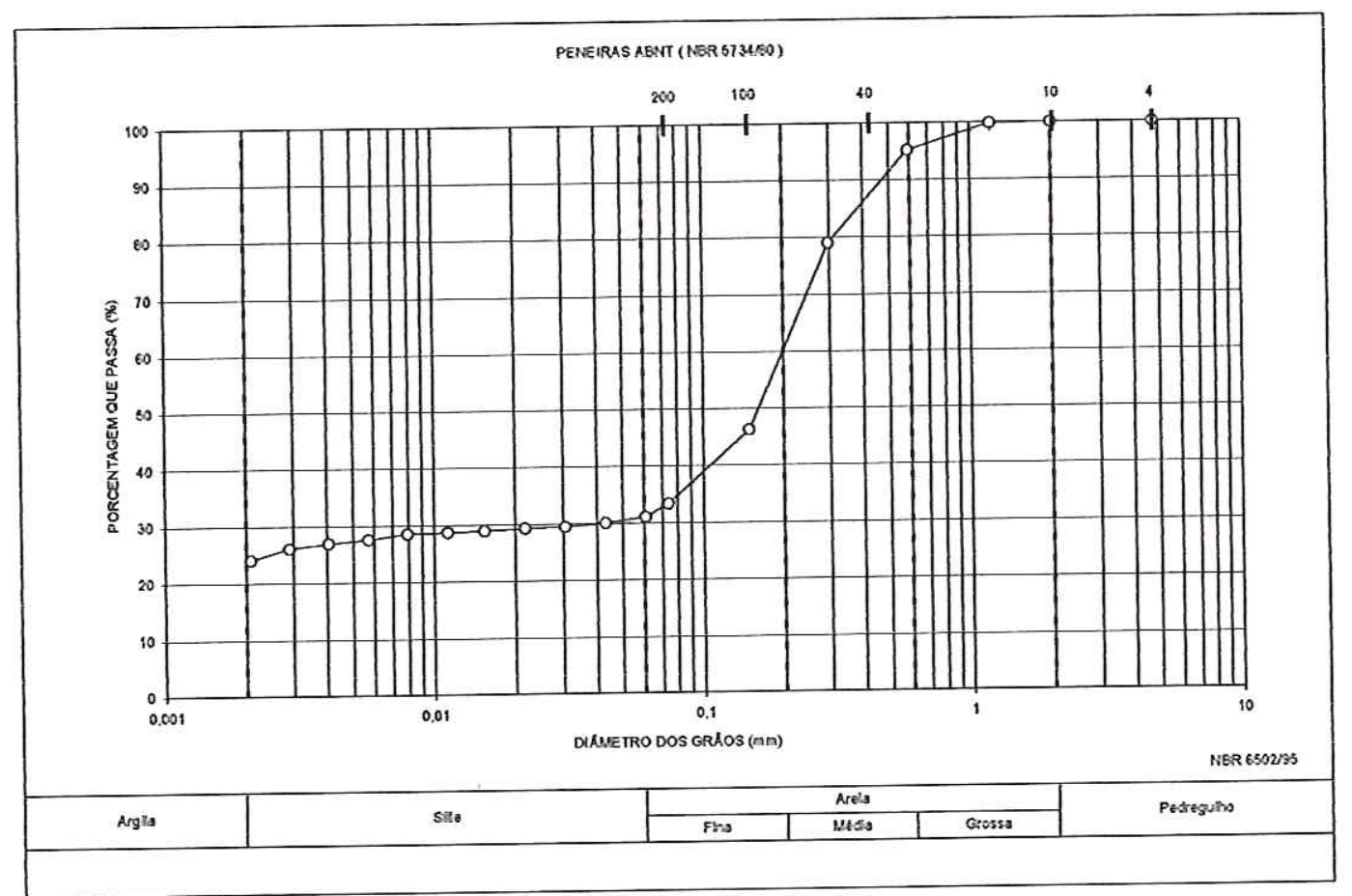

Figura 5.2. - Curva granulométrica do Solo 2.

Tabela 5.1 - Composição granulométrica e índices físicos dos solos 1 e 2

\begin{tabular}{|c|c|c|c|c|}
\hline Composição granulométrica & \multicolumn{2}{|c|}{ Solo 1} & \multicolumn{2}{|c|}{ Solo 2} \\
\hline Argila & 16,2 & \multirow{2}{*}{45,0} & 25,0 & \multirow{2}{*}{30,0} \\
\hline Silte & 28,8 & & 5,0 & \\
\hline Areia fina & 30,0 & \multirow{3}{*}{55,0} & 30,0 & \multirow{3}{*}{69,9} \\
\hline Areia média & 23,4 & & 35,0 & \\
\hline Areia grossa & 1,6 & & 4,9 & \\
\hline Pedregulho & 0,0 & 0,0 & 0,1 & 0,1 \\
\hline Massa específica do solo $(\rho)\left(\mathrm{g} / \mathrm{cm}^{3}\right)$ & \multicolumn{2}{|c|}{1,617} & \multicolumn{2}{|c|}{1,833} \\
\hline Massa específica dos sólidos $\left(\rho_{\mathrm{s}}\right)\left(\mathrm{g} / \mathrm{cm}^{3}\right)$ & \multicolumn{2}{|c|}{2,886} & \multicolumn{2}{|c|}{2,696} \\
\hline Massa específica aparente seca $\left(\rho_{\mathrm{d}}\right)\left(\mathrm{g} / \mathrm{cm}^{3}\right)$ & \multicolumn{2}{|c|}{1,360} & \multicolumn{2}{|c|}{1,690} \\
\hline Condutividade hidráulica saturada $(\mathrm{m} / \mathrm{s})$ & \multicolumn{2}{|c|}{$5,69 \mathrm{E}-05$} & \multicolumn{2}{|c|}{$6,73 \mathrm{E}-05$} \\
\hline
\end{tabular}

\subsubsection{Curva de retenção}

Os ensaios para a determinação da curva de retenção foram conduzidos conforme descrito no item 4.1.2, e os resultados dos ajustes dos pontos experimentais ao modelo de Van Genuchten são apresentados na Tabela 5.2. As figuras 5.3 e 5.4 apresentam as curvas ajustadas e os pontos experimentais observados para os Solos 1 e 2, respectivamente. 
Tabela 5.2 - Resultados do ajuste da curva de retenção modelo de Van Genuchten

\begin{tabular}{|c|c|c|c|c|}
\cline { 2 - 5 } \multicolumn{1}{c|}{} & \multicolumn{2}{c|}{ Ajuste Solo 1 } & \multicolumn{2}{c|}{ Ajuste Solo 2 } \\
\cline { 2 - 5 } \multicolumn{1}{c|}{} & Curvaret & Systat & Curvaret & Systat \\
\hline Teta $-\mathbf{r}\left(\mathbf{c m}^{3} / \mathbf{c m}^{3}\right)$ & 0,108 & 0,108 & $-0,081 *$ & $-0,08$ \\
\hline Teta - s $\left(\mathbf{c m}^{3} / \mathbf{c m}^{3}\right)$ & 0,529 & 0,526 & 0,375 & 0,3718 \\
\hline Alfa & 6,7227 & 6,7119 & 6,355 & 6,322 \\
\hline m & 0,2144 & 0,2143 & 0,1344 & 0,1340 \\
\hline $\mathbf{n}$ & 1,2729 & 1,2728 & 1,1552 & 1,1552 \\
\hline
\end{tabular}

* O valor negativo da umidade residual $\theta$ r é fisicamente impossível, uma vez que trata-se de uma propriedade hidráulica do solo que significa o mínimo volume de água por volume de solo que o mesmo pode assumir. No entanto, no ajuste da curva de retenção, a regressão dos valores observados à equação de Van Genuchten gera este valor negativo. A fixação de um $\theta$ r, igual, por exemplo, ao valor mínimo de umidade observado, de modo a "forçar" um $\theta$ r positivo, gera inconsistência nos demais parâmetros, que não encontram convergência no processo de regressão. O ensaio de laboratório foi repetido três vezes, com amostras diferentes, coletadas em ocasiões diferentes, e os resultados se confirmaram. Uma análise das possíveis causas que podem gerar este tipo de resultado será feita adiante, na discussão dos resultados.

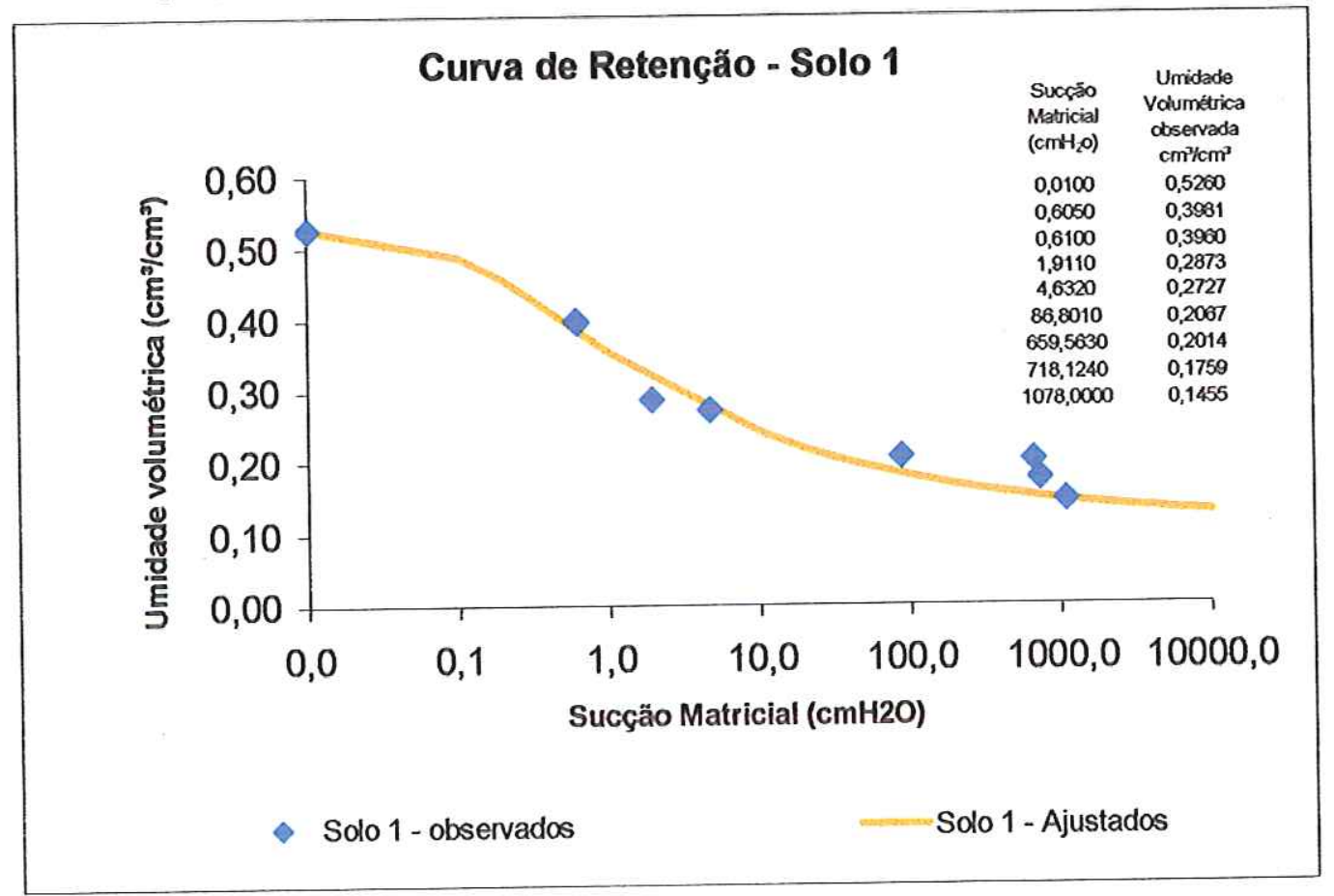

Figura 5.3 - Curva de retenção do Solo 1 


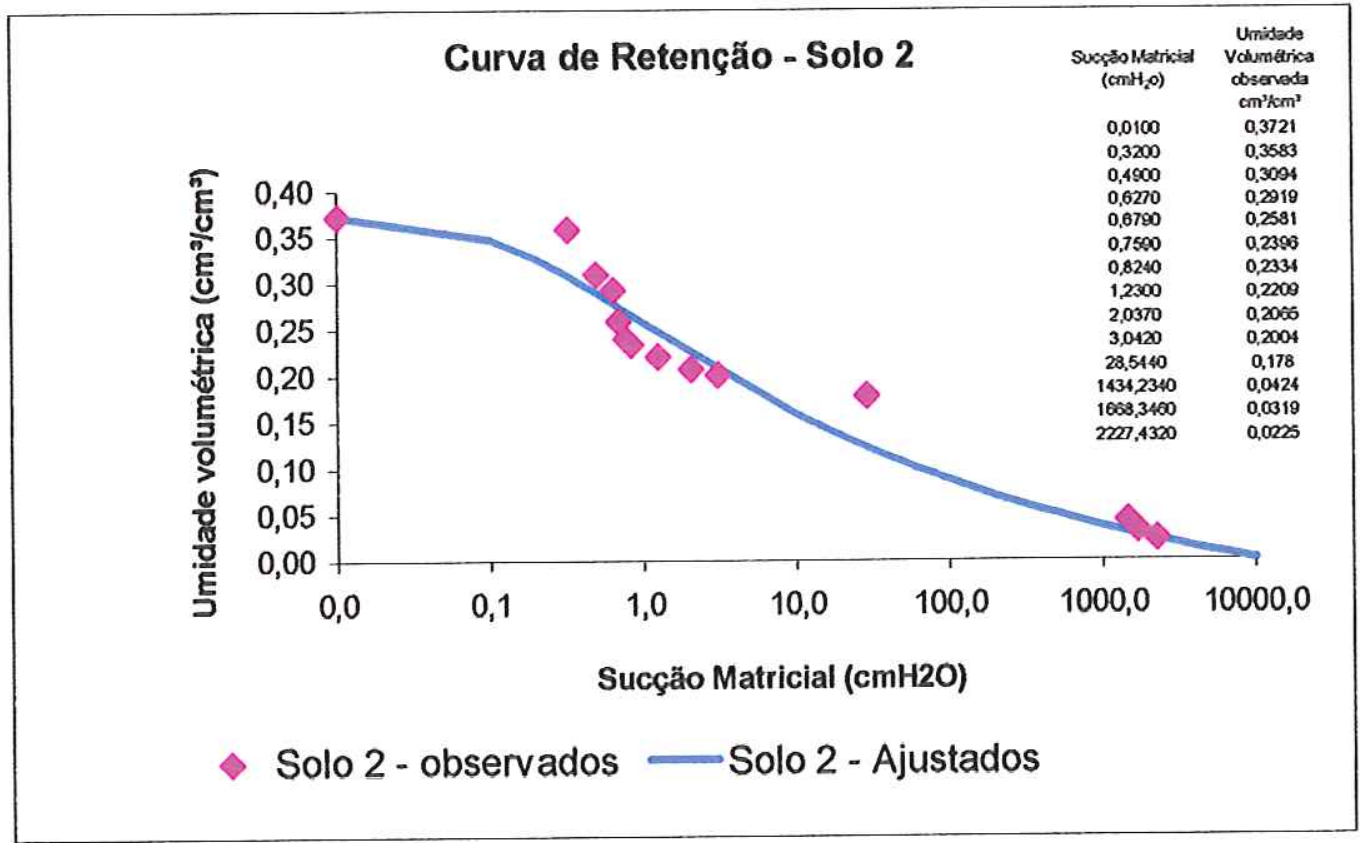

Figura 5.4 - Curva de retenção do Solo 2

A distribuição dos pares de pontos potencial mátrico versus umidade volumétrica do Solo 2 apresentou-se heterogênea, mostrando dois módulos de pares bem definidos. Os modelos de curva de retenção que se têm disponíveis na literatura, e que foram apresentados no Capítulo 3, especialmente o modelo de van Genuchten, utilizado neste trabalho, são satisfatoriamente representativos de parte do comportamento da curva de retenção dos dois solos estudados. As Figuras 5.5 e 5.6 apresentam as curvas de retenção dos Solos 1 e 2 ajustadas em duas fases.

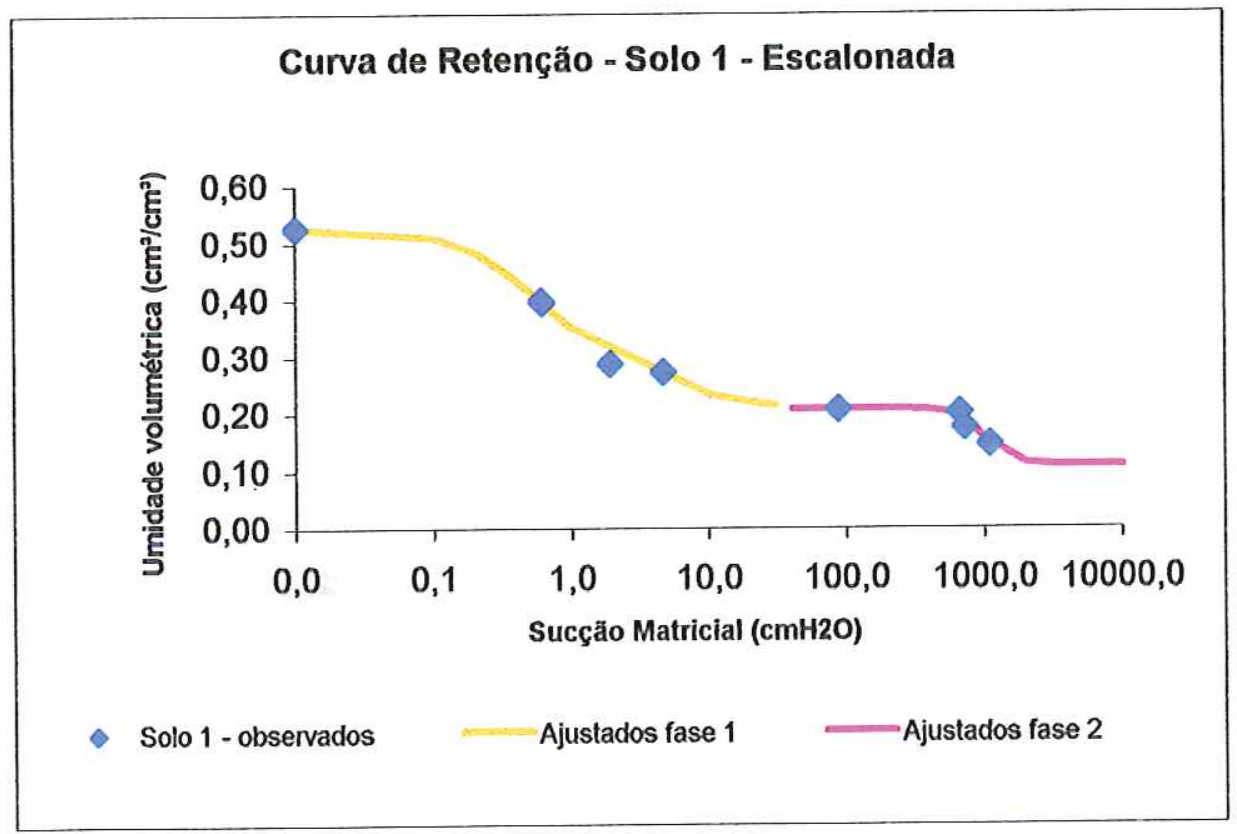

Figura 5.5 - Curva de retenção do Solo 1 ajustada em duas fases 


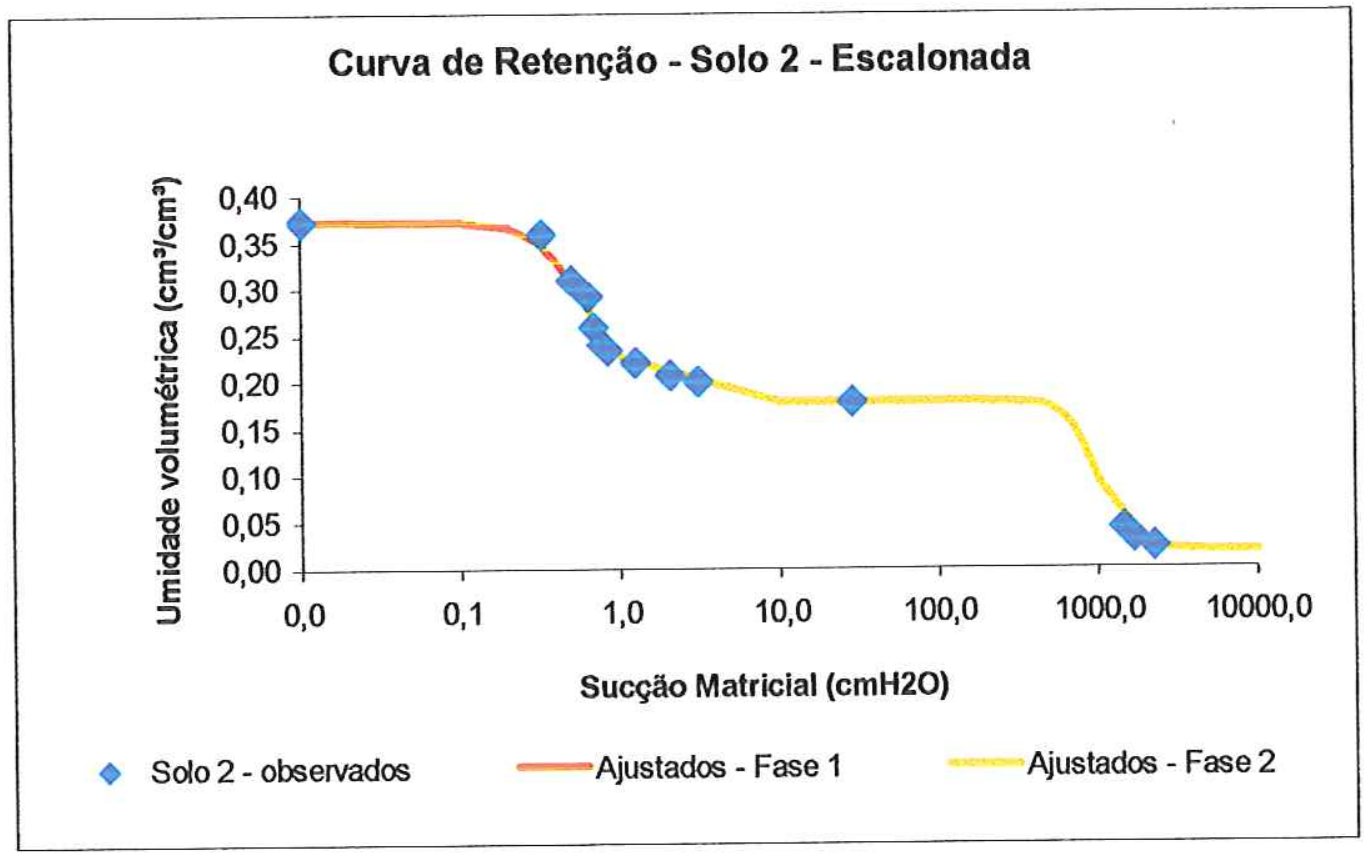

Figura 5.6 - Curva de retenção do Solo 2 ajustada em duas fases

Segundo Soto (2004), a forma escalonada da curva pode-se dever a que, em uma determinada faixa de sucção, os valores de umidade estejam associados a poros de dimensões relativamente uniformes. Já em outra faixa de sucção, esses valores estariam associados a um conjunto de poros de menores dimensões (distribuição bimodal dos poros).

Novos ensaios de curva de retenção foram realizados como medida de certificação, e os resultados se confirmaram. Sabe-se da experiência prática em Geotecnia, que os solos do interior do estado de São Paulo tendem a apresentar esse comportamento multi-modal de distribuição de poros. A confirmação dos resultados indica que o modelo tradicional de Van Genuchten deve ser aplicado por partes da curva de retenção quando há comportamento multi-modal.

\subsubsection{Condutividade hidráulica saturada}

O ensaio de condutividade hidráulica saturada foi conduzido conforme especificado no item 4.1.2, segundo a NBR-13292, baseada na formulação de Darcy para solos saturados, com o uso de um permeâmetro de carga constante e amostras indeformadas dos Solos $1 \mathrm{e}$ 2. As planilhas de cálculo da condução dos ensaios são apresentadas nas Tabelas 5.3 e 5.4. 
Tabela 5.3 - Ensaio de condutividade hidráulica saturada para o Solo 1

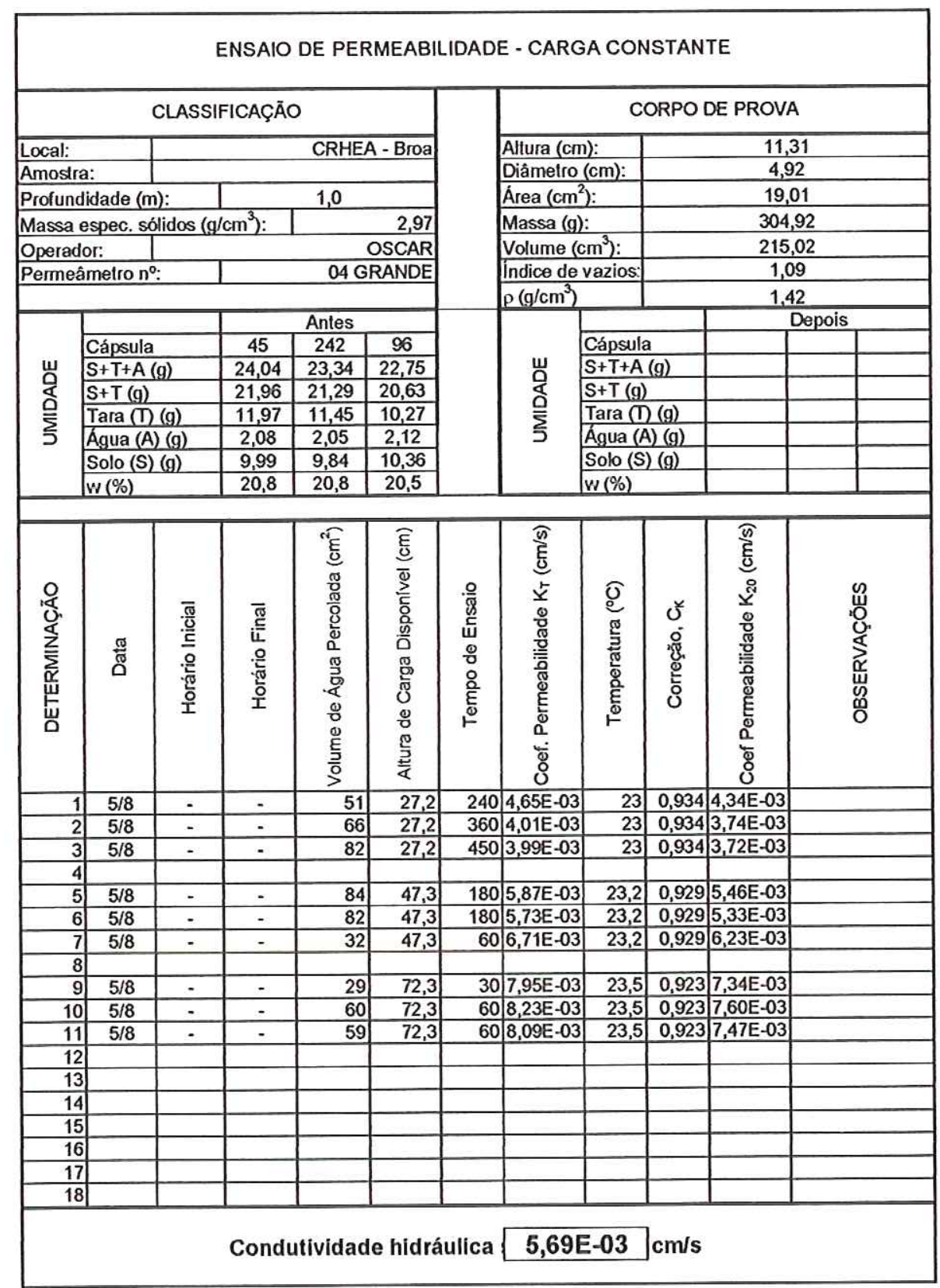


Tabela 5.4 - Ensaio de condutividade hidráulica saturada para o Solo 2

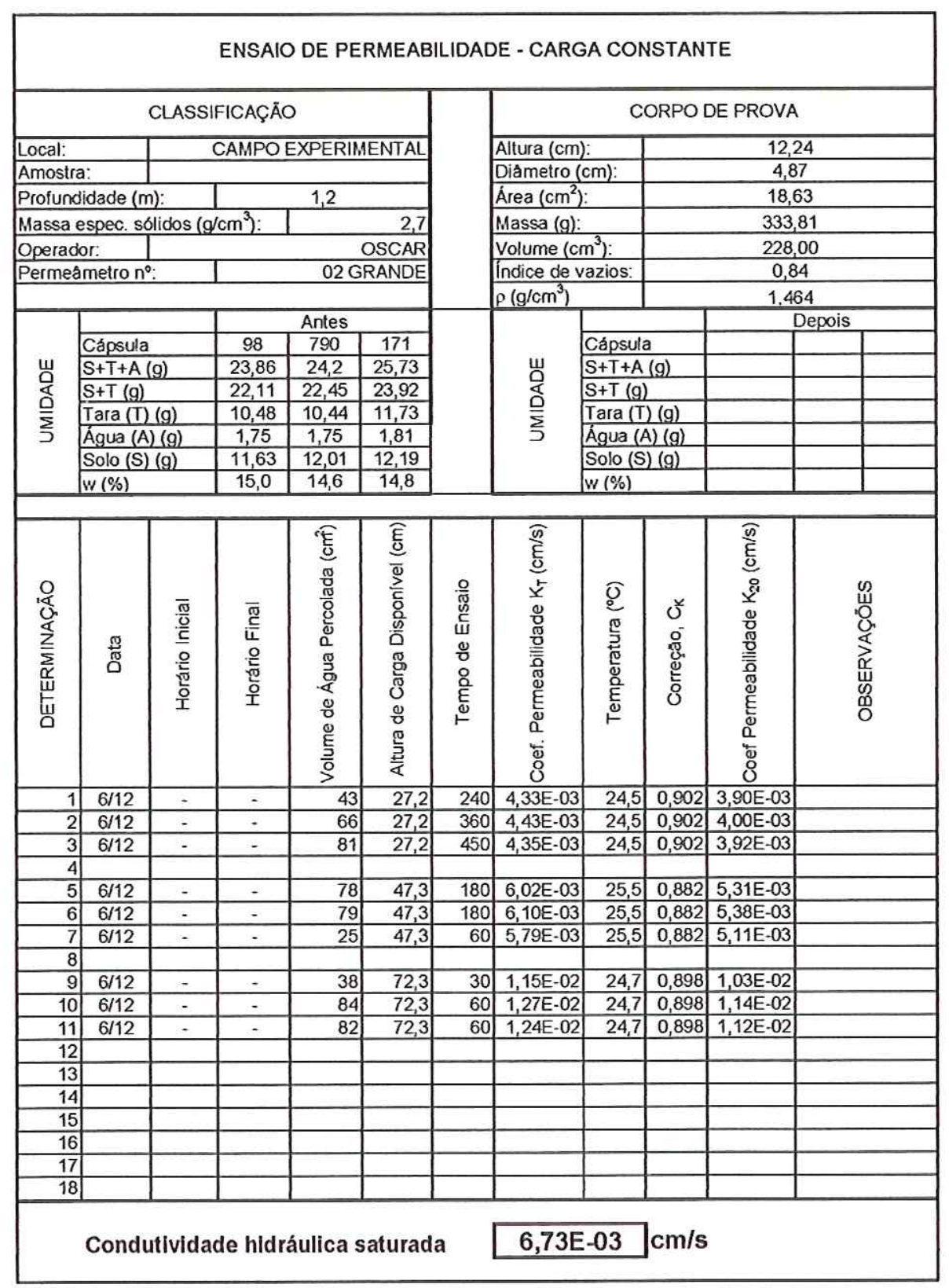

O Solo 1 apresentou condutividade hidráulica saturada igual a $0,00569 \mathrm{~cm} / \mathrm{s}$, ou $20,484 \mathrm{~cm} / \mathrm{h}$, e, para o Solo 2, observou-se $0,00673 \mathrm{~cm} / \mathrm{s}$, ou $24,228 \mathrm{~cm} / \mathrm{h}$. Como era esperado, devido ao seu maior teor de argila e silte, o Solo 1 apresentou menor condutividade hidráulica saturada.

\subsubsection{Calibração da sonda de nêutrons}

A calibração da sonda de nêutrons foi realizada conforme descrito no item 4.1.3, para os Solos 1 e 2. Os resultados são apresentados nas Figuras 5.7a e 5.7b. 


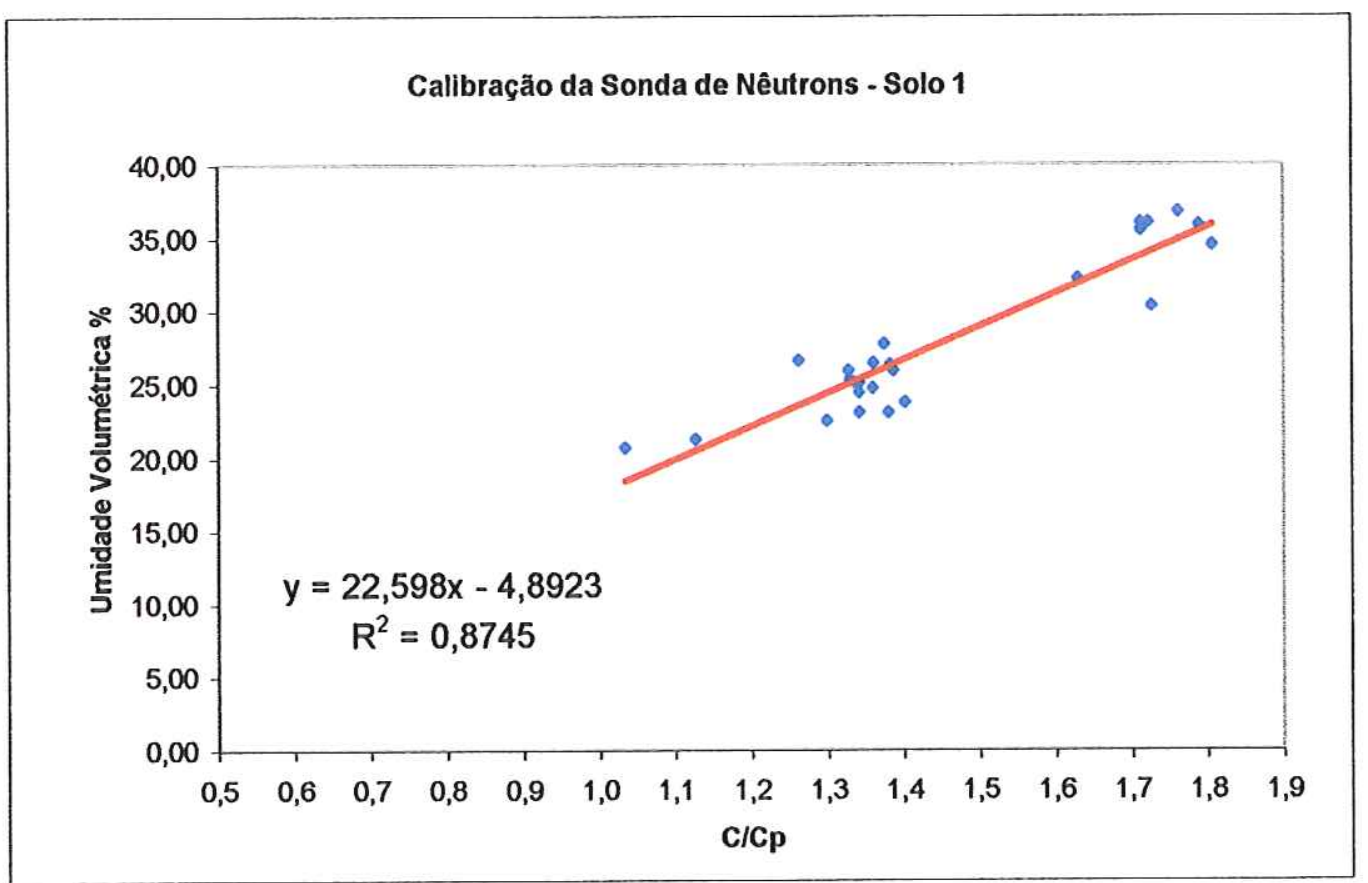

(a)

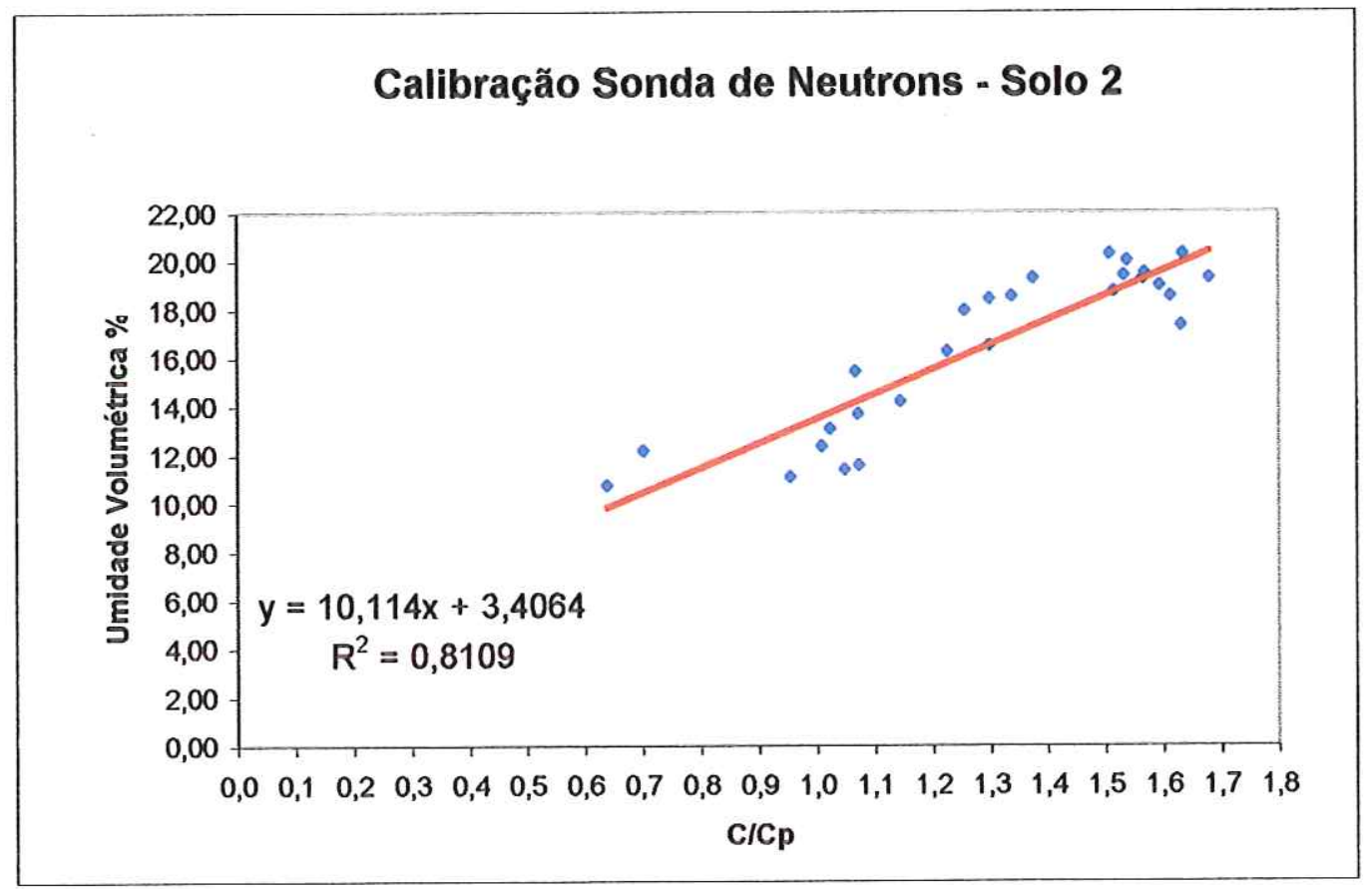

(b)

Figura 5.7 - Calibração da sonda de nêutrons para os Solos 1 e 2

$\mathrm{O}$ ajuste das contagens lidas no equipamento à reta de calibração proposta pelo fabricante da sonda (Equação 4.5) forneceu $\mathrm{R}^{2}$ de $87 \%$ para o Solo 1 e $81 \%$ para o Solo 2. Este ajuste, embora seja satisfatório, por estar dentro da margem de considerada adequada para o equipamento, é reflexo de duas fontes de incertezas: 
a) a natureza estocástica das iterações radioativas que geram as contagens fornecidas pela sonda. Apesar de normalizadas pela contagem padrão, conforme descrito no item 4.1.3, este procedimento minimiza os efeitos estocásticos, mas não os elimina por completo, e

b) a heterogeneidade dos solos, principalmente o Solo 2 , já observada nas curvas de retenção.

\subsubsection{Condutividade hidráulica não saturada}

A curva de condutividade hidráulica não saturada foi determinada para os Solos 1 e 2 conforme procedimento descrito no item 4.1.4, proposto por Libardi et al. (1980). As Figuras 5.8 e 5.9 apresentam os resultados da primeira etapa do método, que consiste na determinação dos perfis diários de umidade. Estes perfis ilustram a capacidade de drenagem dos solos 1 e 2 . No instante $t=0$, logo após o término da irrigação da área de estudos, a umidade média no Solo 1 aumentou da faixa dos $32 \%$ para os $45 \%$, e, no Solo 2 , de $21 \%$ para $28 \%$. Isso demonstra a maior capacidade de retenção da água do Solo $1 \mathrm{em}$ relação ao Solo 2.

Na primeira hora após o término da irrigação, os valores de umidade do perfil do Solo 1 sofreram redução média de $5 \%$ até a profundidade de $70 \mathrm{~cm}$, e $1 \%$ a profundidades superiores a esta. Os valores de umidade do Solo 2 , sofreram redução de $3 \%$ na porção mais rasa de solo e em torno de $1 \%$ a profundidades superiores a $60 \mathrm{~cm}$.

Para $\mathrm{t}>1$ dia, a redução média nos valores de umidade foi em torno de $8 \%$ para o Solo 1 e $5 \%$ para o Solo 2. Em seguida, por meio de medições diárias de umidade, observou-se que os valores anteriores à irrigação foram atingidos cerca de 10 dias após a irrigação para o Solo 2, e ainda não tinham sido observados após 14 dias de medições no Solo 1.

Na segunda etapa, cujos resultados são mostrados nas Figuras 5.10 e 5.11, foram obtidas as curvas, em escala logarítmica, de umidade inicial menos umidade no instante t, para cada profundidade z. Do coeficiente angular destas curvas, obteve-se o parâmetro $\gamma$ da equação 4.10. Ajuste semelhante, considerando os valores médios de umidade é apresentado nas Figuras 5.12 e 5.13, das quais se obteve, a partir dos coeficientes angulares das retas ajustadas para cada profundidade, o parâmetro Ko da Equação 4.10.

Conforme proposto pelo método, a Equação 4.10 é ajustada para cada profundidade do solo, em intervalos de $10 \mathrm{~cm}$. A Tabela 5.5 apresenta os parâmetros de ajuste para as profundidades 10 a $150 \mathrm{~cm}$, para os Solos 1 e 2. 


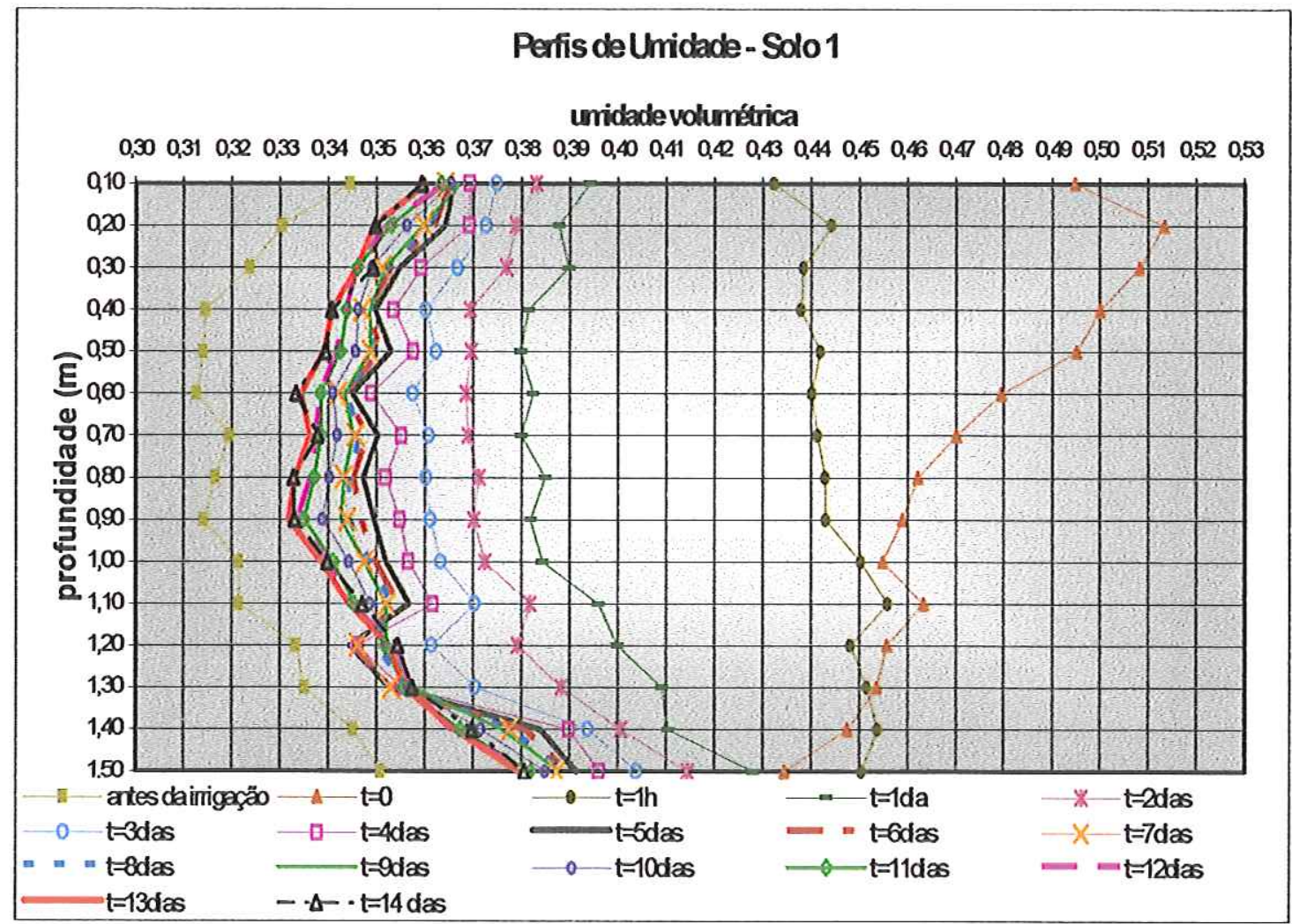

Figura 5.8 - Perfis de umidade volumétrica do Solo 1, ao longo de 15 dias de irrigação, até $\mathrm{z}=1,50$

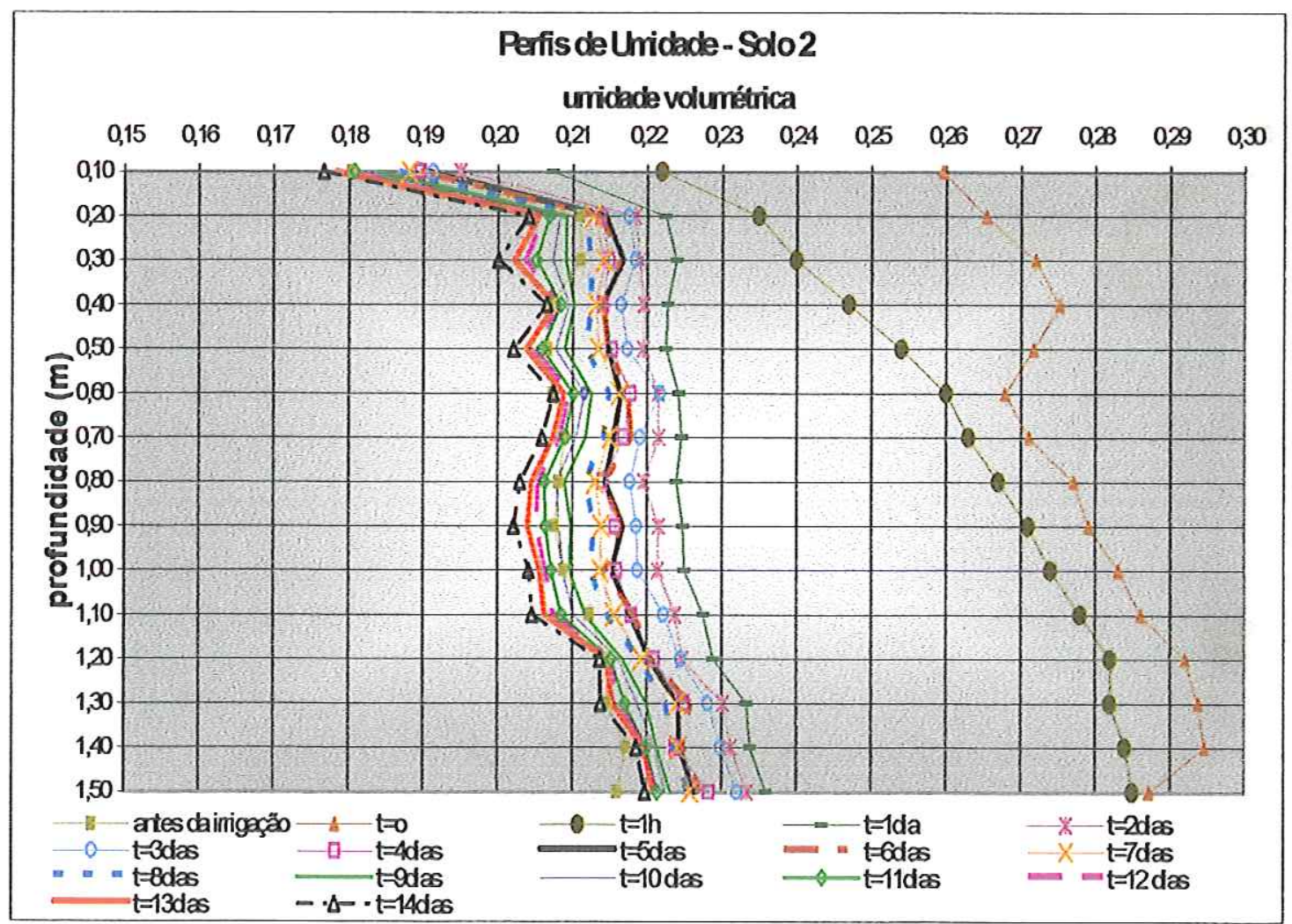

Figura 5.9 - Perfis de umidade volumétrica do Solo 2, ao longo de 15 dias de irrigação, até z=1,50 


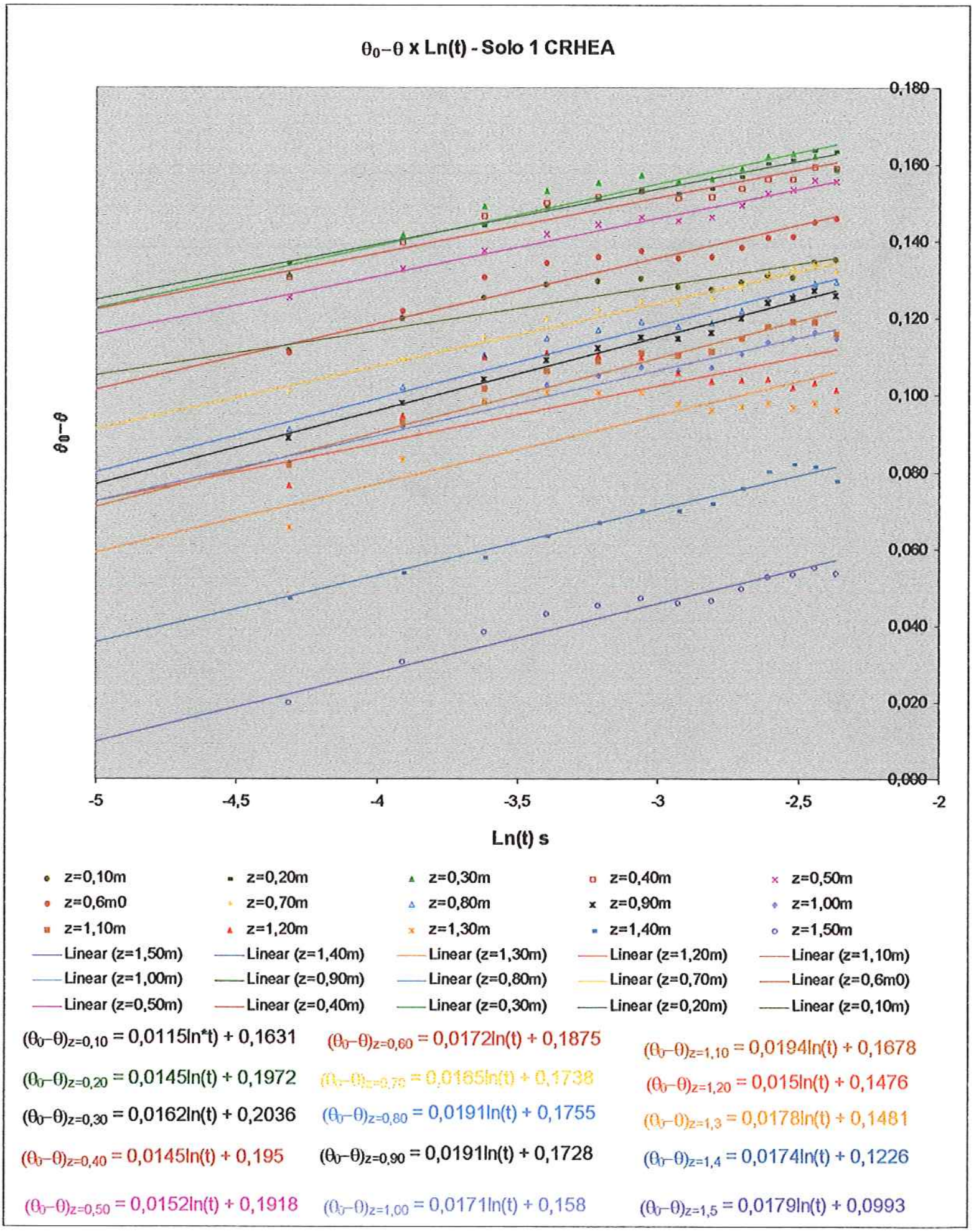

Figura $5.10-\theta_{0^{-}} \theta$ vesrus $\ln \mathrm{t}$ para o Solo 1 


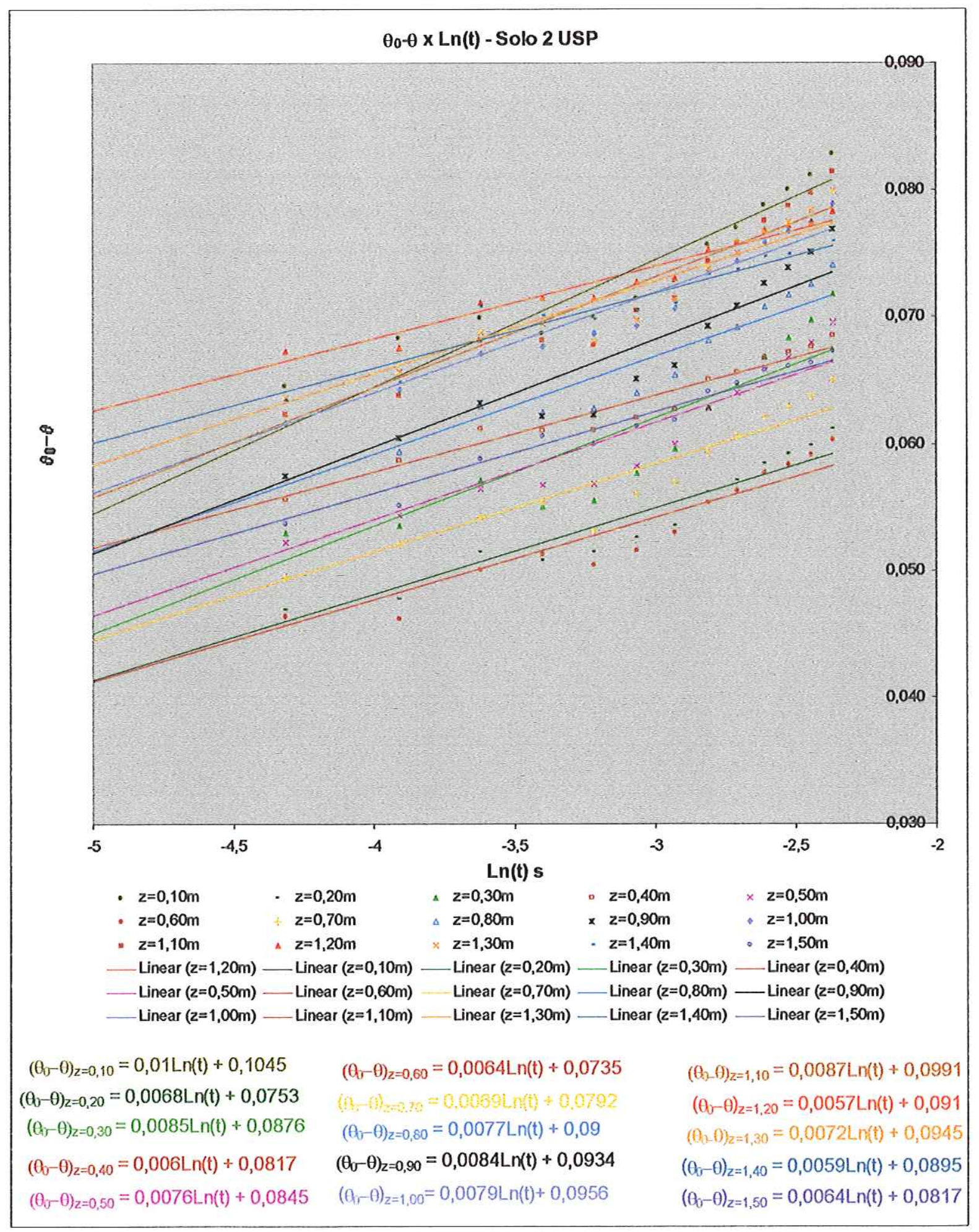

Figura $5.11-\theta_{v}-\theta$ vesrus $\ln t$ para o Solo 2 


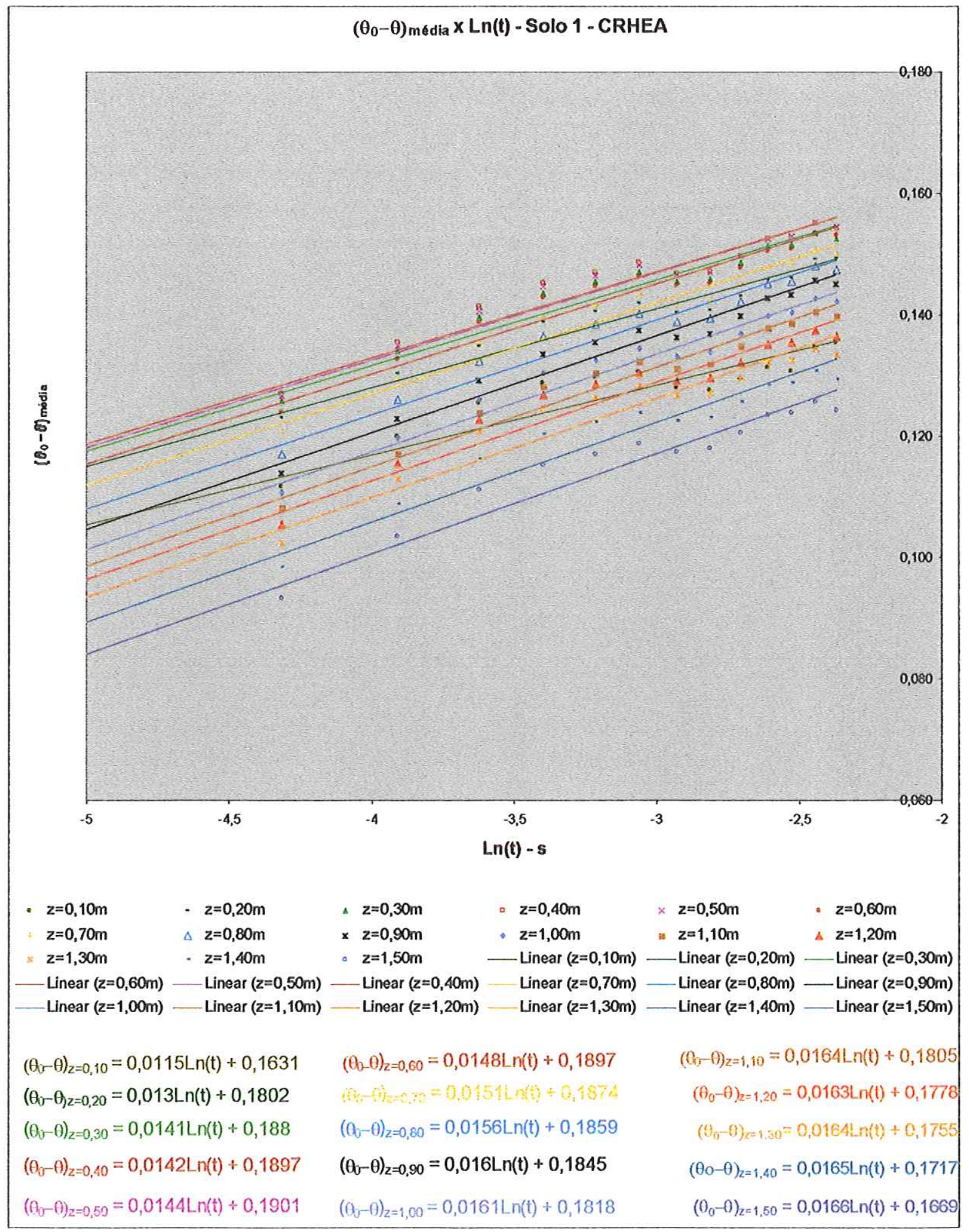

Figura $5.12-\bar{\theta}_{0}-\bar{\theta}_{\text {vesrus } \ln t \text { para o Solo } 1}$ 


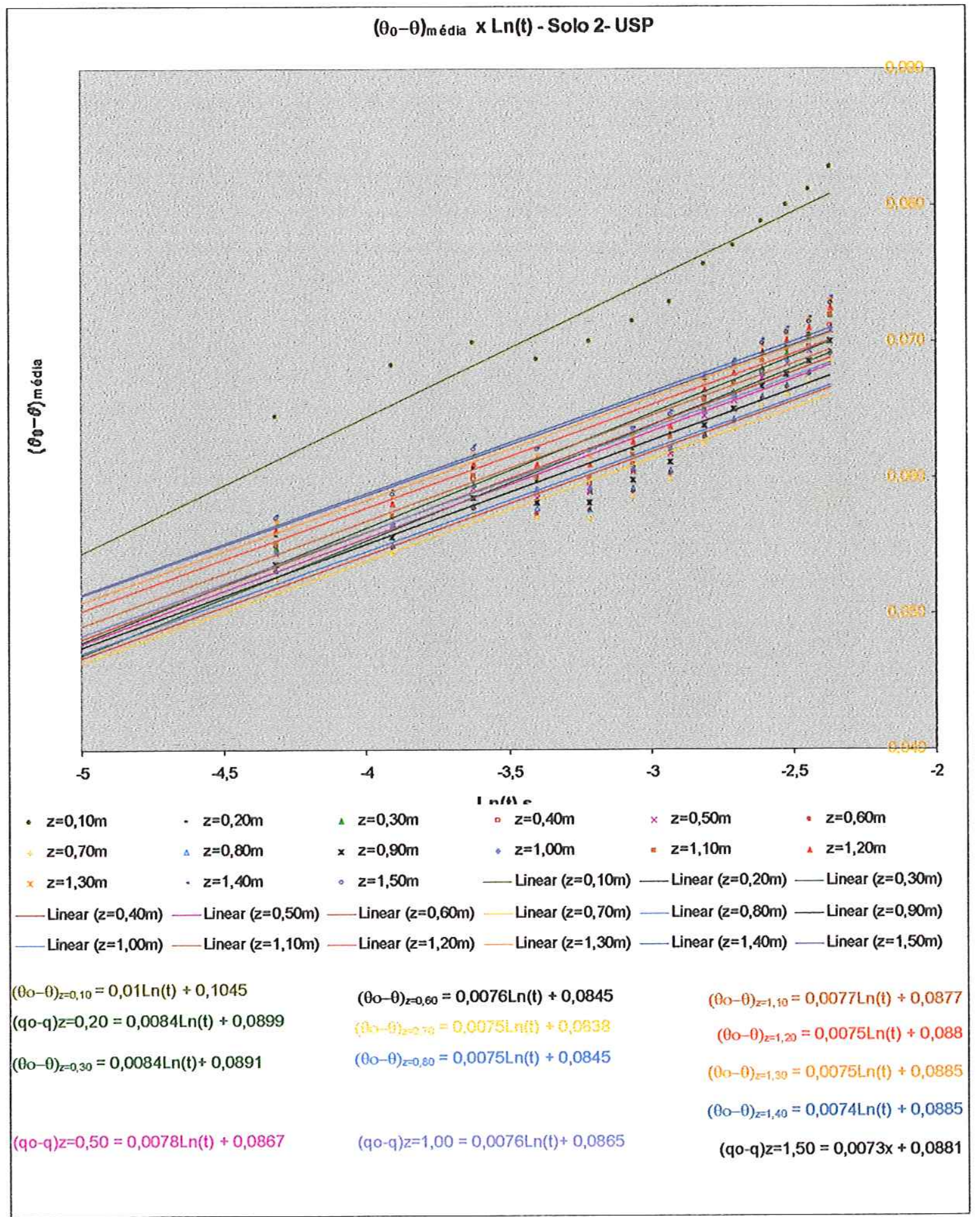

Figura 5.13- $\bar{\theta}_{0}-\bar{\theta}_{\text {vesrus } \ln t \text { para o Solo } 2}$ 
Tabela 5.5 - Parâmetros da equação de condutividade hidráulica não saturada

\begin{tabular}{|c|c|c|c|c|c|c|}
\hline \multirow[b]{2}{*}{$\begin{array}{c}\text { Prof. } z \\
\text { (m) }\end{array}$} & \multicolumn{3}{|c|}{ Solo 1} & \multicolumn{3}{|c|}{ Solo 2} \\
\hline & $\theta_{0\left(\mathrm{~cm}^{*} \mathrm{~cm}^{2}\right)}$ & $\gamma$ & Ko & $\theta_{0\left(\mathrm{~cm}^{2} / \mathrm{cm}^{2}\right)}$ & $\gamma$ & Ko \\
\hline 0,10 & 0,4947 & 86,9565 & 1660,07 & 0,2595 & 100,0000 & 34,54 \\
\hline 0,20 & 0,5132 & 68,9655 & 2722,47 & 0,2653 & 147,0588 & 74,70 \\
\hline 0,30 & 0,5081 & 61,7284 & 2611,76 & 0,2719 & 117,6471 & 101,86 \\
\hline 0,40 & 0,4999 & 68,9655 & 3598,78 & 0,2751 & 166,6667 & 226,42 \\
\hline 0,50 & 0,4950 & 65,7895 & 3896,03 & 0,2716 & 131,5789 & 262,07 \\
\hline 0,60 & 0,4794 & 58,1395 & 3273,50 & 0,2678 & 156,2500 & 307,35 \\
\hline 0,70 & 0,4701 & 60,6061 & 2593,75 & 0,2710 & 144,9275 & 373,83 \\
\hline 0,80 & 0,4621 & 52,3560 & 1868,78 & 0,2770 & 129,8701 & 469,03 \\
\hline 0,90 & 0,4589 & 52,3560 & 1466,63 & 0,2790 & 119,0476 & 525,86 \\
\hline 1,00 & 0,4548 & 58,4795 & 1290,76 & 0,2830 & 126,5823 & 666,45 \\
\hline 1,10 & 0,4633 & 51,5464 & 1086,74 & 0,2860 & 114,9425 & 748,74 \\
\hline 1,20 & 0,4557 & 57,1429 & 1068,17 & 0,2920 & 175,4386 & 1121,93 \\
\hline 1,30 & 0,4536 & 56,1798 & 946,82 & 0,2937 & 138,8889 & 995,10 \\
\hline 1,40 & 0,4475 & 57,4713 & 763,67 & 0,2946 & 169,4915 & 1619,15 \\
\hline
\end{tabular}

A determinação da condutividade hidráulica não saturada, neste trabalho, foi feita objetivando o ajuste do modelo na simulação numérica. Na primeira fase, exploratória, ajustou-se o modelo tipo Gardner descrito pela equação 4.10, cuja calibração é mostrada na Tabela 5.5.

Observa-se, da Tabela 5.5, que a condutividade hidráulica não saturada do Solo 1 evolui de forma a apresentar maiores teores de umidade inicial, o que se traduz em valores altos de Ko e consequentemente valores de Gamma menores que 100. Para o Solo 2, os teores iniciais de umidade são, aproximadamente, a metade que no solo 1, o que é representado em baixos valores de Ko e valores de Gamma maiores de 100, evidenciando a tendência geral dos parâmetros da curva. Esta análise exploratória somente permite avaliar a dependência destes parâmetros, possivelmente revelando a natureza heterogênea do solo, e justificando uma análise exploratória posterior com modelo de van Genuchten.

Para a simulação numérica optou-se por trabalhar com o modelo de van Genuchten, obtido a partir da formulação de Mualen, para a condutividade hidráulica não saturada, em concordância com o modelo adotado para a curva de retenção. O modelo é representado pela Equação 5.1, com os mesmos parâmetros ajustados para a curva de retenção, apresentados na Tabela 5.2:

$$
K(\theta)=K_{0} \omega^{l}\left[1-\left(1-\omega^{\frac{1}{m}}\right)^{m}\right]^{2}
$$

em que: 
$\omega=\frac{\theta-\theta_{r}}{\theta_{s}-\theta_{r}}$

$l=0,5$ para solos de textura média a arenosa.

\subsection{Ensaios com trincheiras de infiltração}

Os ensaios com trincheiras de infilttração foram conduzidos conforme descrito no item 4.1.5. O acompanhamento dos ensaios foi realizado de maneiras distintas para as Fases $1 \mathrm{e}$ 2, e para a Fase 3. Nas duas primeiras fases, alimentação e recessão, observou-se o nível d'água na trincheira e o volume infiltrado em cada instante. Na Fase 3, de redistribuição, acompanhou-se o campo de umidade ao redor da trincheira, com sonda de nêutrons.

As Tabelas 5.6 e 5.7 apresentam os valores de lâmina d'água e volume infiltrado nas fases de alimentação e recessão, para os Solos 1 e 2, por meio dos quais foi ajustado o modelo de infiltração horizontal de Philip, conforme descrito na metodologia, e que é apresentado na Tabela 5.8 e nas Figuras 5.14 e 5.15. A escolha do modelo horizontal foi feita baseando-se na premissa de que o fundo da trincheira é colmatado após pouco tempo de operação da mesma, impedindo ou reduzindo em grande parte a parcela de infiltração vertical, pelo fundo, predominando, portanto, a infiltração horizontal, pelas paredes da trincheira.

As Figuras 5.16 e 5.17 ilustram o desenvolvimento dos volumes de abastecimento, armazenamento e infiltração, durante as fases de alimentação e recessão, para os Solos 1 e 2 , respectivamente.

O acompanhamento do perfil de umidade durante a fase de redistribuição é apresentado nas Tabelas 5.9 e 5.10. Para efeito de visualização, os dados apresentados nas tabelas foram interpolados com o auxíliio da ferramenta Idrisi e são apresentados nas Figuras 5.18 e 5.19 . 
Tabela 5.6 - Variação do volume na trincheira durante a alimentação e recessão - Solo 1

\begin{tabular}{|c|c|c|c|c|c|c|c|}
\hline$t$ (min) & $\begin{array}{c}\mathrm{Na}_{\text {trinch }} \\
\text { (cm) }\end{array}$ & $\begin{array}{c}\text { Vol. } \\
\text { Aduzido } \\
\mathrm{m}^{\mathbf{3}}\end{array}$ & $\begin{array}{c}\text { Vol na } \\
\text { Trincheira } \\
\left(\mathrm{m}^{3}\right)\end{array}$ & $\begin{array}{c}\text { Vol. } \\
\text { Infiltrado } \\
\mathrm{m}^{3}\end{array}$ & $\begin{array}{c}Q_{\operatorname{lnf}} \\
\left(\mathrm{m}^{3} / \mathrm{s}\right)\end{array}$ & $\begin{array}{l}\text { I }\left(\mathrm{m}^{3} / \mathrm{s} / \mathrm{m}^{2}\right) \\
\text { Observado }\end{array}$ & $\begin{array}{l}\text { I }\left(\mathrm{m}^{3} / \mathrm{s} / \mathrm{m}^{2}\right) \\
\text { Calculado }\end{array}$ \\
\hline 0 & 0,11 & - & 0,00215 & - & - & - & - \\
\hline 1 & 1,71 & 0,08808 & 0,03429 & 0,05378 & 0,00093 & 0,00043 & 0,00024 \\
\hline 2 & 3,72 & 0,12911 & 0,07447 & 0,05464 & 0,00001 & 0,00001 & 0,00021 \\
\hline 3 & 4,87 & 0,17015 & 0,09743 & 0,07272 & 0,00030 & 0,00012 & 0,00019 \\
\hline 4 & 6,02 & 0,20727 & 0,12039 & 0,08688 & 0,00024 & 0,00009 & 0,00018 \\
\hline 5 & 7,11 & 0,24439 & 0,14220 & 0,10219 & 0,00026 & 0,00010 & 0,00016 \\
\hline 6 & 8,20 & 0,27563 & 0,16402 & 0,11161 & 0,00016 & 0,00006 & 0,00015 \\
\hline 7 & 9,35 & 0,30491 & 0,18698 & 0,11793 & 0,00011 & 0,00004 & 0,00014 \\
\hline 8 & 10,50 & 0,36555 & 0,20994 & 0,15561 & 0,00063 & 0,00021 & 0,00013 \\
\hline 9 & 12,28 & 0,42814 & 0,24552 & 0,18262 & 0,00045 & 0,00014 & 0,00012 \\
\hline 10 & 14,00 & 0,48682 & 0,27996 & 0,20686 & 0,00040 & 0,00012 & 0,00011 \\
\hline 15 & 21,80 & 0,71945 & 0,43609 & 0,28336 & 0,00015 & 0,00004 & 0,00009 \\
\hline 20 & 28,41 & 0,97168 & 0,56811 & 0,40357 & 0,00044 & 0,00010 & 0,00008 \\
\hline 25 & 35,24 & 1,22545 & 0,70472 & 0,52072 & 0,00041 & 0,00008 & 0,00007 \\
\hline 30 & 41,78 & 1,48513 & 0,83560 & 0,64954 & 0,00041 & 0,00007 & 0,00007 \\
\hline 35 & 47,41 & 1,72819 & 0,94810 & 0,78009 & 0,00047 & 0,00008 & 0,00006 \\
\hline 40 & 52,11 & 1,96693 & 1,04224 & 0,92469 & 0,00046 & 0,00007 & 0,00006 \\
\hline 45 & 56,24 & 2,19670 & 1,12489 & 1,07181 & 0,00051 & 0,00007 & 0,00006 \\
\hline 50 & 59,69 & 2,41794 & 1,19377 & 1,22417 & 0,00054 & 0,00007 & 0,00006 \\
\hline 55 & 62,62 & 2,63717 & 1,25232 & 1,38485 & 0,00049 & 0,00006 & 0,00006 \\
\hline 60 & 65,08 & 2,84990 & 1,30168 & 1,54822 & 0,00054 & 0,00007 & 0,00006 \\
\hline 65 & 67,15 & 3,05197 & 1,34301 & 1,70896 & 0,00057 & 0,00007 & 0,00006 \\
\hline 70 & 68,82 & 3,25260 & 1,37630 & 1,87630 & 0,00057 & 0,00007 & 0,00006 \\
\hline 75 & 68,59 & 3,45440 & 1,37171 & 2,08269 & 0,00048 & 0,00006 & 0,00006 \\
\hline 80 & 61,30 & & 1,22592 & 2,22849 & 0,00048 & 0,00006 & 0,00006 \\
\hline 85 & 54,92 & & 1,09849 & 2,35592 & 0,00042 & 0,00006 & 0,00006 \\
\hline 90 & 48,73 & & 0,97450 & 2,47990 & 0,00038 & 0,00006 & 0,00006 \\
\hline 95 & 43,39 & & 0,86774 & 2,58666 & 0,00036 & 0,00006 & 0,00006 \\
\hline 100 & 38,28 & & 0,76557 & 2,68884 & 0,00034 & 0,00006 & 0,00006 \\
\hline 105 & 33,63 & & 0,67258 & 2,78182 & 0,00031 & 0,00006 & 0,00006 \\
\hline 110 & 29,21 & & 0,58418 & 2,87022 & 0,00029 & 0,00006 & 0,00006 \\
\hline 115 & 25,31 & & 0,50612 & 2,94828 & 0,00027 & 0,00006 & 0,00006 \\
\hline 120 & 21,69 & & 0,43380 & 3,02061 & 0,00025 & 0,00006 & 0,00006 \\
\hline 125 & 18,42 & & 0,36836 & 3,08604 & 0,00021 & 0,00006 & 0,00006 \\
\hline 130 & 15,38 & & 0,30752 & 3,14689 & 0,00021 & 0,00006 & 0,00006 \\
\hline 135 & 12,51 & & 0,25012 & 3,20429 & 0,00019 & 0,00006 & 0,00006 \\
\hline 140 & 9,81 & & 0,19616 & 3,25824 & 0,00017 & 0,00006 & 0,00006 \\
\hline 145 & 7,28 & & 0,14565 & 3,30876 & 0,00017 & 0,00006 & 0,00006 \\
\hline 150 & 4,99 & & 0,09973 & 3,35468 & 0,00015 & 0,00006 & 0,00006 \\
\hline 155 & 2,98 & & 0,05955 & 3,39486 & 0,00013 & 0,00006 & 0,00006 \\
\hline 160 & 1,20 & & 0,02396 & 3,43044 & 0,00011 & 0,00005 & 0,00006 \\
\hline 161 & 0,80 & & 0,01592 & 3,43848 & 0,00013 & 0,00006 & 0,00006 \\
\hline 162 & 0,45 & & 0,00904 & 3,44537 & 0,00011 & 0,00006 & 0,00006 \\
\hline 163 & 0,16 & & 0,00330 & 3,45111 & 0,00010 & 0,00005 & 0,00006 \\
\hline
\end{tabular}


Tabela 5.7 - Variação do volume na trincheira durante a alimentação e recessão - Solo 2

\begin{tabular}{|c|c|c|c|c|c|c|c|}
\hline $\mathbf{t}$ (min) & $\begin{array}{c}\mathrm{Na}_{\text {trinch }} \\
\text { (cm) }\end{array}$ & $\begin{array}{c}\text { Vol. } \\
\text { Aduzido } \\
\mathbf{m}^{\mathbf{3}}\end{array}$ & $\begin{array}{c}\text { Vol. Na } \\
\text { Trincheira } \\
\left(\mathrm{m}^{3}\right)\end{array}$ & $\begin{array}{c}\text { Vol. } \\
\text { Infiltrado } \\
\mathrm{m}^{\mathbf{3}}\end{array}$ & $Q_{I}\left(m^{3} / \mathrm{s}\right)$ & $\begin{array}{l}\text { I }\left(\mathrm{m}^{3} / \mathrm{s} / \mathrm{m}^{2}\right) \\
\text { Observado }\end{array}$ & $\begin{array}{l}\text { I }\left(\mathrm{m}^{3} / \mathrm{s} / \mathrm{m}^{2}\right) \\
\text { Calculado }\end{array}$ \\
\hline 0 & 0,00 & - & 0,00000 & - & - & - & - \\
\hline 1 & 1,15 & 0,06597 & 0,02300 & 0,04297 & 0,00072 & 0,00034 & 0,00048 \\
\hline 2 & 2,30 & 0,15607 & 0,04600 & 0,11007 & 0,00112 & 0,00051 & 0,00037 \\
\hline 3 & 4,05 & 0,23874 & 0,08100 & 0,15774 & 0,00079 & 0,00034 & 0,00030 \\
\hline 4 & 5,80 & 0,31956 & 0,11600 & 0,20356 & 0,00076 & 0,00030 & 0,00024 \\
\hline 5 & 7,20 & 0,37810 & 0,14400 & 0,23410 & 0,00051 & 0,00019 & 0,00019 \\
\hline 6 & 8,60 & 0,41436 & 0,17200 & 0,24236 & 0,00014 & 0,00005 & 0,00016 \\
\hline 7 & 10,44 & 0,45433 & 0,20877 & 0,24556 & 0,00005 & 0,00002 & 0,00014 \\
\hline 8 & 12,28 & 0,50544 & 0,24555 & 0,25990 & 0,00024 & 0,00008 & 0,00012 \\
\hline 9 & 14,08 & 0,55656 & 0,28165 & 0,27491 & 0,00025 & 0,00008 & 0,00011 \\
\hline 10 & 15,94 & 0,60767 & 0,31885 & 0,28882 & 0,00023 & 0,00007 & 0,00010 \\
\hline 15 & 24,37 & 0,85767 & 0,48732 & 0,37034 & 0,00034 & 0,00008 & 0,00007 \\
\hline 20 & 32,02 & 1,11509 & 0,64048 & 0,47461 & 0,00047 & 0,00010 & 0,00007 \\
\hline 25 & 38,64 & 1,37437 & 0,77286 & 0,60151 & 0,00045 & 0,00008 & 0,00007 \\
\hline 30 & 44,44 & 1,63364 & 0,88882 & 0,74482 & 0,00044 & 0,00007 & 0,00007 \\
\hline 35 & 49,64 & 1,89478 & 0,99275 & 0,90203 & 0,00063 & 0,00010 & 0,00007 \\
\hline 40 & 54,10 & 2,14663 & 1,08200 & 1,06463 & 0,00058 & 0,00008 & 0,00007 \\
\hline 45 & 58,25 & 2,38734 & 1,16500 & 1,22234 & 0,00057 & 0,00008 & 0,00007 \\
\hline 50 & 61,40 & 2,64477 & 1,22800 & 1,41677 & 0,00068 & 0,00009 & 0,00007 \\
\hline 55 & 64,40 & 2,90219 & 1,28800 & 1,61419 & 0,00075 & 0,00010 & 0,00007 \\
\hline 60 & 66,70 & 3,12991 & 1,33400 & 1,79591 & 0,00067 & 0,00008 & 0,00007 \\
\hline 65 & 68,80 & 3,36691 & 1,37600 & 1,99091 & 0,00069 & 0,00008 & 0,00007 \\
\hline 70 & 68,60 & 3,60240 & 1,37200 & 2,23040 & 0,00047 & 0,00006 & 0,00007 \\
\hline 75 & 59,15 & & 1,18300 & 2,41940 & 0,00058 & 0,00008 & 0,00007 \\
\hline 80 & 51,40 & & 1,02800 & 2,57440 & 0,00048 & 0,00007 & 0,00007 \\
\hline 85 & 44,75 & & 0,89500 & 2,70740 & 0,00038 & 0,00006 & 0,00007 \\
\hline 90 & 39,00 & & 0,78000 & 2,82240 & 0,00037 & 0,00007 & 0,00007 \\
\hline 95 & 34,00 & & 0,68000 & 2,92240 & 0,00033 & 0,00007 & 0,00007 \\
\hline 100 & 29,60 & & 0,59200 & 3,01040 & 0,00027 & 0,00006 & 0,00007 \\
\hline 105 & 26,20 & & 0,52400 & 3,07840 & 0,00020 & 0,00005 & 0,00007 \\
\hline 110 & 23,00 & & 0,46000 & 3,14240 & 0,00022 & 0,00005 & 0,00007 \\
\hline 115 & 19,80 & & 0,39600 & 3,20640 & 0,00020 & 0,00005 & 0,00007 \\
\hline 120 & 16,90 & & 0,33800 & 3,26440 & 0,00018 & 0,00005 & 0,00007 \\
\hline 125 & 14,40 & & 0,28800 & 3,31440 & 0,00017 & 0,00005 & 0,00007 \\
\hline 130 & 11,90 & & 0,23800 & 3,36440 & 0,00017 & 0,00005 & 0,00007 \\
\hline 135 & 9,65 & & 0,19300 & 3,40940 & 0,00015 & 0,00005 & 0,00007 \\
\hline 140 & 7,60 & & 0,15200 & 3,45040 & 0,00013 & 0,00005 & 0,00007 \\
\hline 145 & 5,75 & & 0,11500 & 3,48740 & 0,00012 & 0,00005 & 0,00007 \\
\hline 150 & 3,80 & & 0,07600 & 3,52640 & 0,00013 & 0,00006 & 0,00007 \\
\hline 155 & 1,90 & & 0,03800 & 3,56440 & 0,00013 & 0,00006 & 0,00007 \\
\hline 160 & 0,00 & & 0,00000 & 3,60240 & 0,00012 & 0,00006 & 0,00007 \\
\hline
\end{tabular}

Tabela 5.8 - Ajuste do modelo de infiltração horizontal de Philip para os Solos 1 e 2

\begin{tabular}{|c|c|}
\hline & $\mathrm{C}\left(\mathrm{m}^{3} / \mathrm{s} / \mathrm{m}^{2}\right)$ \\
\hline Solo 1 & 0,00571 \\
\hline Solo 2 & 0,00698 \\
\hline
\end{tabular}




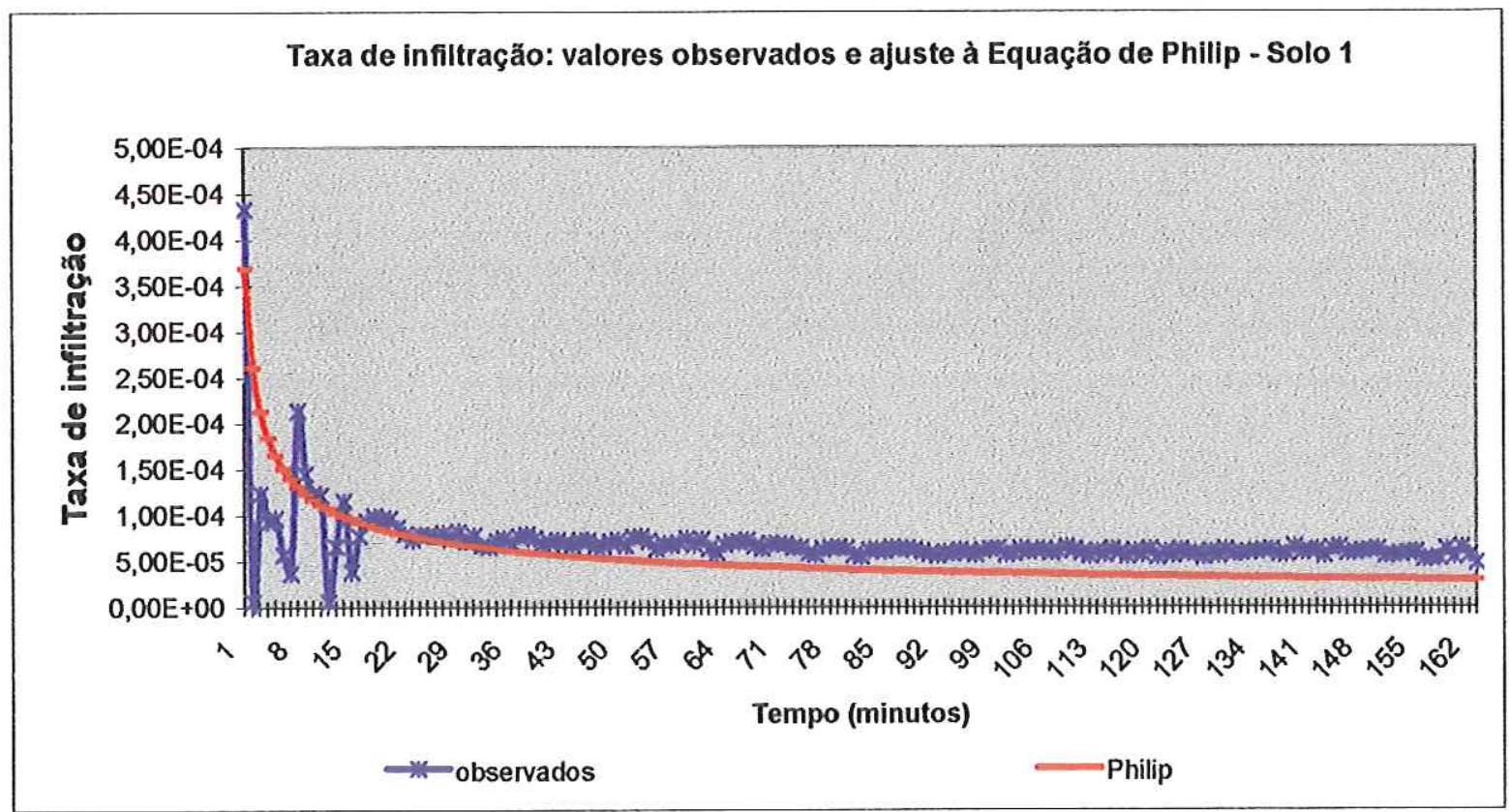

Figura 5.14 - Ajuste dos dados de infiltração ao modelo de infiltração horizontal de Philip - Solo 1

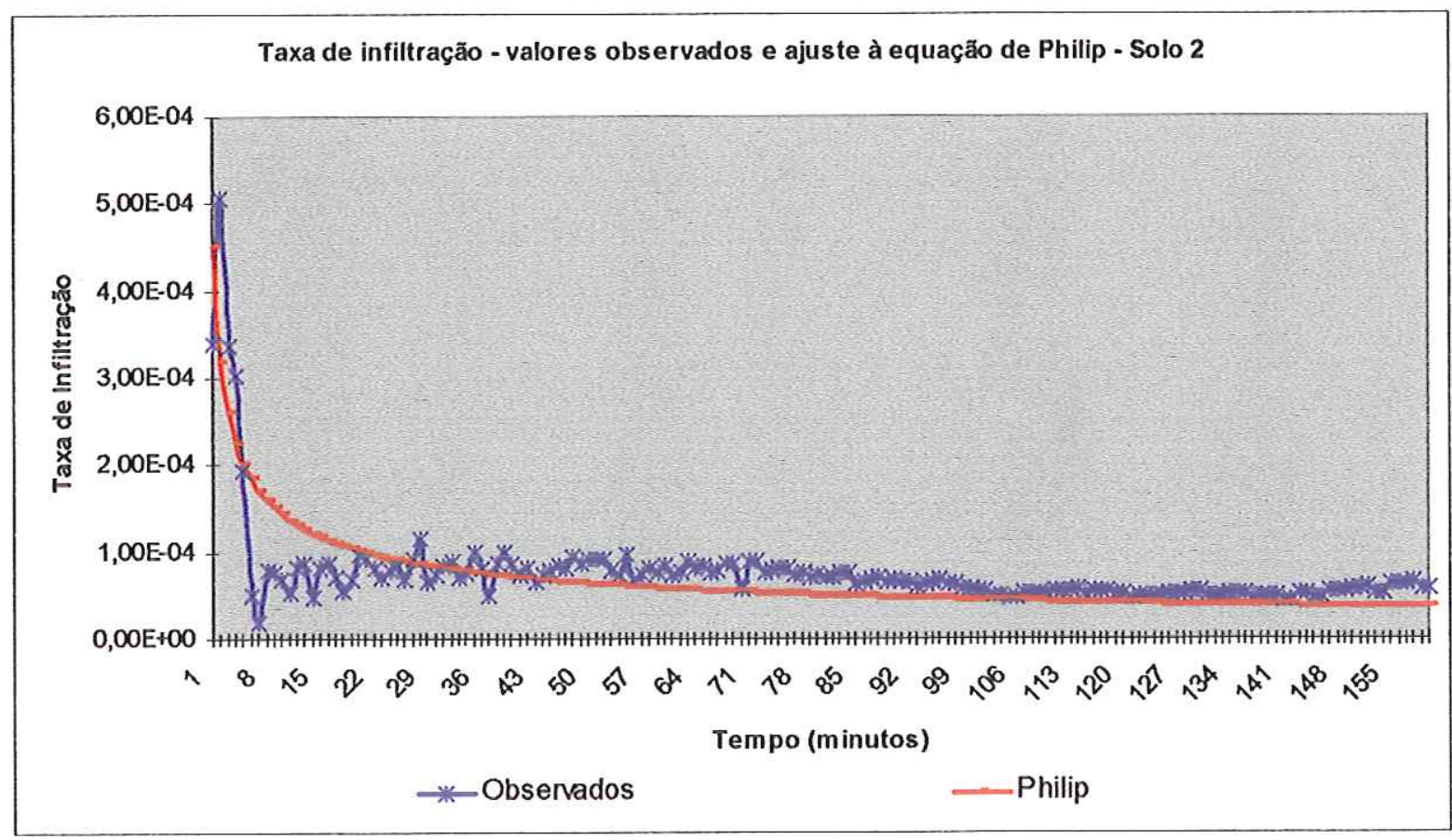

Figura 5.15 - Ajuste dos dados de infiltração ao modelo de infiltração horizontal de Philip - Solo 2

Embora seja um processo eminentemente tridimensional, a infiltração na trincheira, especialmente após os primeiros vinte a trinta minutos de irrigação apresentou volumes infiltrados próximos aos fornecidos pelo modelo de Philip. A variação observada nos primeiros dez minutos, tanto para o Solo 1 quanto para o Solo 2, é devida, provavelmente, ao fato de que, nos primeiros instantes, até que se forme uma lâmina d'água homogênea em toda a trincheira, a simplificação bidimensional de se trabalhar com as leituras de nível 
na seção central da trincheira exerce grande influência na determinação do volume total infiltrado em toda a trincheira.

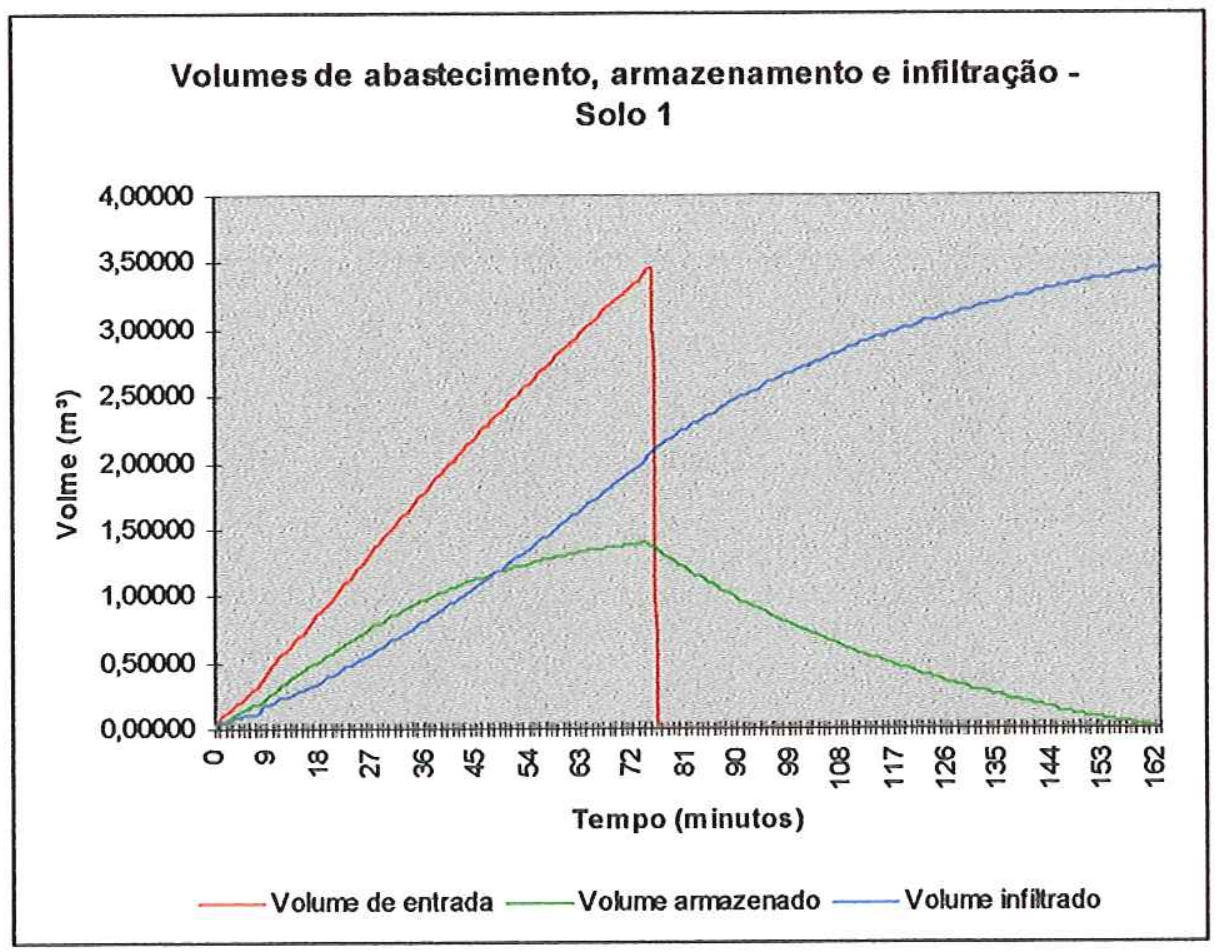

Figura 5.16 - Volumes de entrada, armazenamento e infiltração - Solo 1

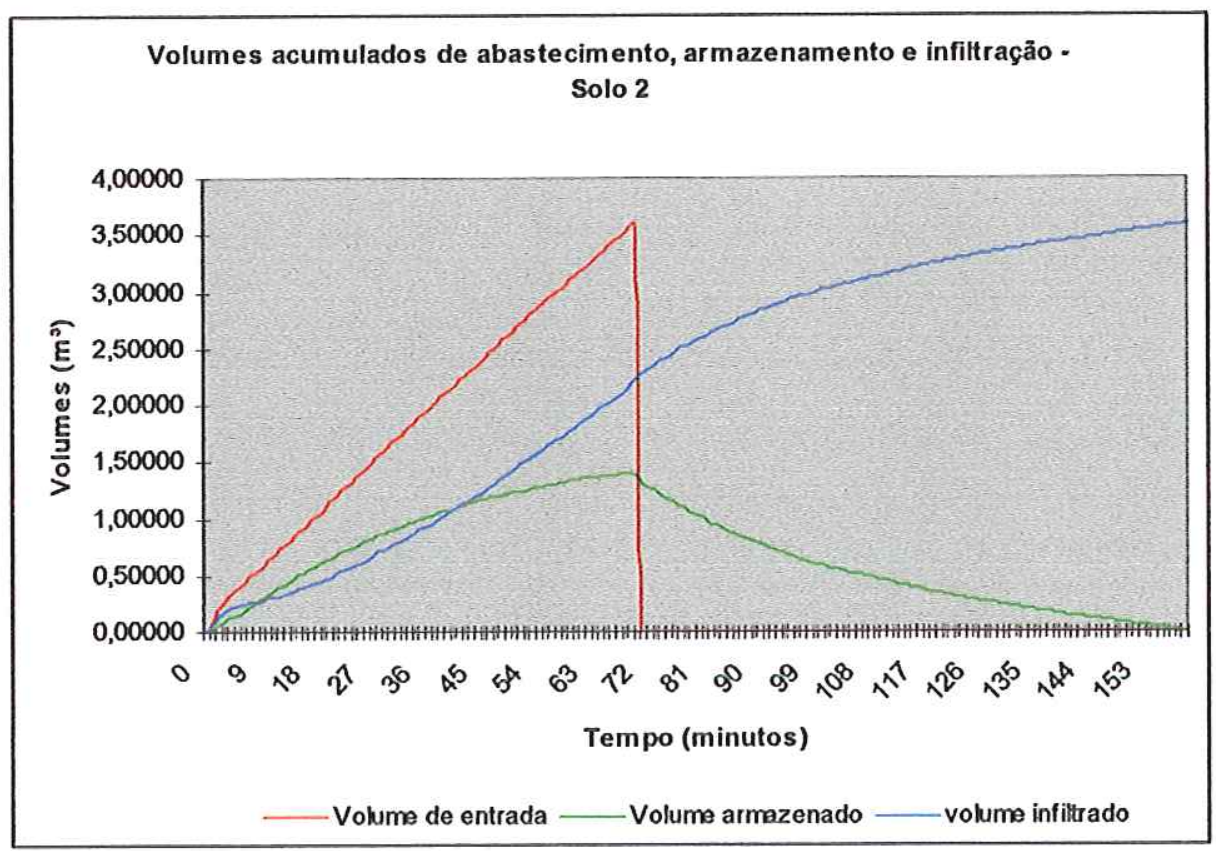

Figura 5.17 - Volumes de entrada, armazenamento e infiltração - Solo 2

As Figuras 5.16 e 5.17 ilustram que o comportamento de recessão do escoamento foi semelhante nos dois solos, atingindo lâmina d'água igual a zero após aproximadamente 160 minutos, para volumes de alimentação de $3,5 \mathrm{~m}^{3}$ em 75 minutos de adução. 
Tabela 5.9 - Acompanhamento da redistribuição - Solo 1 - Valores de umidade

Acompanhamento da Redistribuição - Solo 1

\begin{tabular}{|c|c|c|c|c|c|c|c|c|}
\hline \multicolumn{9}{|c|}{ 1." Mediçăo: } \\
\hline \multirow[t]{2}{*}{ Data: } & $07 / \angle 802$ & Hora: & & $8 \mathrm{da}$ irm & & Contager & drāo: & 5746 \\
\hline & \multicolumn{2}{|c|}{ Tubo A } & \multicolumn{2}{|c|}{ Tubo B } & \multicolumn{2}{|c|}{ Tubo C } & \multicolumn{2}{|c|}{ Tubo D } \\
\hline Prof. & C & e\% & C & $\theta \%$ & C & $\Theta \%$ & C & $\Theta \%$ \\
\hline 5 & & & 2171 & 3,75 & 3092 & 7,36 & 3463 & 8,82 \\
\hline 25 & & & 6891 & 22,25 & 7773 & 25,71 & 7742 & 25,58 \\
\hline 50 & & & 7737 & 25,56 & 7350 & 24,05 & 7148 & 23,26 \\
\hline 75 & $36 \mathrm{SH}$ & 9,68 & 8148 & 27,17 & 7871 & 26,09 & 6430 & 20,44 \\
\hline 100 & 9105 & 30,92 & 8619 & 29,02 & 8236 & 27,52 & 7315 & 23,91 \\
\hline 125 & 9576 & 32,77 & 8986 & 30,46 & 8465 & 28,42 & 7944 & 26,38 \\
\hline 150 & 9827 & 33,75 & 9318 & 31,76 & 8846 & 30,11 & 8404 & 28,18 \\
\hline 175 & 10160 & 35,06 & 8537 & 28,70 & 9109 & 30,94 & 8639 & 29,10 \\
\hline
\end{tabular}

\begin{tabular}{|c|c|c|c|c|c|c|c|c|}
\hline \multicolumn{9}{|c|}{ 2." Medição: } \\
\hline Data: & $07 / 0802$ & Hora: & & $\mathrm{t}=0 \mathrm{~h}$ & & ontagen & drão: & 5746 \\
\hline & \multicolumn{2}{|c|}{ Tubo A } & \multicolumn{2}{|c|}{ Tubo B } & \multicolumn{2}{|c|}{ Tubo C } & \multicolumn{2}{|c|}{ Tubo D } \\
\hline Prof. & C & $\theta \%$ & C & $\theta \%$ & C & $\theta \%$ & C & $\Theta \%$ \\
\hline 5 & & & 2742 & 5,99 & 2495 & 5,02 & 3367 & 8,44 \\
\hline 25 & & & 9006 & 30,54 & 8295 & 27,75 & 7517 & 24,70 \\
\hline 50 & & & 9673 & 33,15 & 9655 & 33,08 & 7583 & 24,96 \\
\hline 75 & 8388 & 28,11 & 11302 & 39,53 & 10482 & 36,32 & 8525 & 28,65 \\
\hline 100 & 11898 & 41,87 & 11629 & 40,81 & 10743 & 37,34 & 10030 & 34,55 \\
\hline 125 & 11918 & 41,95 & 12059 & 42,50 & 11021 & 38,43 & 10542 & 36,56 \\
\hline 150 & 11992 & 42,24 & 12119 & 42,74 & 11360 & 39,76 & 10816 & 37,63 \\
\hline 175 & 12310 & 43,48 & 12130 & 42,78 & 11573 & 40,60 & 10038 & 38,11 \\
\hline
\end{tabular}

\begin{tabular}{|c|c|c|c|c|c|c|c|c|}
\hline \multicolumn{9}{|c|}{ 3. ${ }^{2}$ Mediçãa: } \\
\hline Data: & $07 / 08: 02$ & Hora: & & $t=1 h$ & & outager & drato: & 5746 \\
\hline & \multicolumn{2}{|c|}{ Tubo A } & \multicolumn{2}{|c|}{ Tubo B } & \multicolumn{2}{|c|}{ Tubo C } & \multicolumn{2}{|c|}{ Tubo D } \\
\hline Prof. & C & Q\% & C & $\theta \%$ & c & $\Theta \%$ & C & $e \%$ \\
\hline 5 & & & 2643 & 5,60 & 3208 & 7,82 & 3201 & 7,79 \\
\hline 25 & & & 8636 & 29,09 & 8387 & 28,11 & 7621 & 25,11 \\
\hline 50 & & & 9059 & 30,86 & 9571 & 32,75 & 7656 & 25,36 \\
\hline 75 & 4905 & 14,47 & 10505 & 36,41 & 9844 & 33,82 & 8494 & 28,53 \\
\hline 100 & 10448 & 36,19 & 10931 & 38,08 & 10333 & 35,74 & 9923 & 34,13 \\
\hline 125 & 11163 & 38,99 & 11285 & 39,47 & 10691 & 37,14 & 10248 & 35,40 \\
\hline 150 & 11229 & 39,25 & 11541 & 40,47 & 10944 & 38,13 & 10769 & 37,4 \\
\hline 175 & 11525 & 40,41 & 11637 & 40,85 & 11200 & 39,13 & 10859 & 37,92 \\
\hline
\end{tabular}

\begin{tabular}{|c|c|c|c|c|c|c|c|c|}
\hline \multicolumn{9}{|c|}{ 4." Medição: } \\
\hline Data: & $07 / 0802$ & Hora: & & $t=2 h$ & & ontagen & đrầ: & 5746 \\
\hline & \multicolumn{2}{|c|}{ Tubo A } & \multicolumn{2}{|c|}{ Tubo B } & \multicolumn{2}{|c|}{ Tubo C } & \multicolumn{2}{|c|}{ Tubo D } \\
\hline Prof. & C & $\Theta \%$ & C & $\Theta \%$ & c & $\theta \%$ & C & $\Theta \%$ \\
\hline 5 & & & 2433 & 4,78 & 3123 & 7,48 & 3296 & 8,16 \\
\hline 25 & & & 8943 & 30,29 & 8616 & 29,01 & 7727 & 25,52 \\
\hline$s_{0}$ & & & 8705 & 29,36 & 9356 & 31,91 & 7764 & 25,67 \\
\hline 75 & 4736 & 13,80 & 9948 & 34,23 & 9528 & 32,58 & 8637 & 29,09 \\
\hline 100 & 10364 & 35,86 & 10357 & 35,83 & 9961 & 34,28 & 9733 & 33,39 \\
\hline 125 & 11005 & 38,37 & 10765 & 37,43 & 10258 & 35,44 & 9986 & 34,38 \\
\hline 150 & 10933 & 38,09 & 11138 & 38,89 & 10735 & 37,31 & 10550 & 36,59 \\
\hline 175 & 11265 & 39,39 & 11225 & 39,23 & 11032 & 38,48 & 10652 & 36,99 \\
\hline
\end{tabular}

\begin{tabular}{|c|c|c|c|c|c|c|c|c|}
\hline \multicolumn{9}{|c|}{$5^{2}$ Medição: } \\
\hline Data: & $07 / C B: 02$ & Hora: & & $t=3: 3 c$ & & ontage & drāo: & 5746 \\
\hline & \multicolumn{2}{|c|}{ Tubo A } & \multicolumn{2}{|c|}{ Tubo B } & \multicolumn{2}{|c|}{ Tubo C } & \multicolumn{2}{|c|}{ Tubo D } \\
\hline Prof. & C & $\theta \%$ & C & $0 \%$ & C & $\Theta \%$ & C & $\Theta \%$ \\
\hline 5 & & & 2361 & 4,50 & 3188 & 7,74 & 3040 & 7,16 \\
\hline 25 & & & 8624 & 29,04 & 8723 & 29,43 & 7681 & 25,34 \\
\hline 50 & & & 8546 & 28,73 & 9048 & 30,70 & 7682 & 25,35 \\
\hline 75 & 4673 & 13,56 & 9447 & 32,26 & 9364 & 31,94 & 8431 & 28,28 \\
\hline 100 & 9976 & 34,34 & 10007 & 34,46 & 9525 & 32,57 & 9431 & 32,20 \\
\hline 125 & 10490 & 36,35 & 10266 & 35,47 & 9885 & 33,98 & 9673 & 33,15 \\
\hline 150 & 10613 & 36,83 & 10692 & 37,14 & 10393 & 35,97 & 10322 & 35,69 \\
\hline 175 & 11172 & 39,02 & 10980 & 38,27 & 10835 & 37,70 & 10443 & 36,17 \\
\hline
\end{tabular}

\begin{tabular}{|c|c|c|c|c|c|c|c|c|}
\hline \multicolumn{9}{|c|}{ 6. Medição: } \\
\hline \multirow[t]{2}{*}{ Data: } & 07,0802 & Hora: & \multicolumn{3}{|c|}{$t=5 h$} & \multicolumn{2}{|c|}{ Contagem Padrão: } & 5746 \\
\hline & \multicolumn{2}{|c|}{ Tubo A } & \multicolumn{2}{|c|}{ Tubo B } & \multicolumn{2}{|c|}{ Tubo C } & \multicolumn{2}{|c|}{ Tubo D } \\
\hline Prof. & C & $\theta \%$ & C & $\Theta \%$ & C & $\theta \%$ & C & $\Theta \%$ \\
\hline 5 & & & 2258 & 4,09 & 3196 & 7,77 & 2984 & 6,94 \\
\hline 25 & & & 8598 & 28,94 & 8767 & 29,60 & 7751 & 25,62 \\
\hline 50 & & & 8404 & 28,18 & 9040 & 30,67 & 7795 & 25,79 \\
\hline 75 & 4670 & 13,55 & 9403 & 32,09 & 9043 & 30,68 & 8350 & 27,97 \\
\hline 100 & 9850 & 33,84 & 9727 & 33,36 & 9377 & 31,99 & 9300 & 31,69 \\
\hline 125 & 10068 & 34,70 & 9956 & 34,26 & 9554 & 32,68 & 9633 & 32,99 \\
\hline 150 & 10546 & 36,57 & 10500 & 36,39 & 10193 & 35,19 & 10151 & 35,02 \\
\hline 175 & 11072 & 38,63 & 10711 & 37,22 & 10418 & 36,07 & 10500 & 36,78 \\
\hline
\end{tabular}

\begin{tabular}{|c|c|c|c|c|c|c|c|c|}
\hline \multicolumn{9}{|c|}{ 7. Mediçăo: } \\
\hline Data: & 080802 & Hora: & & $t=24 h$ & & ontage & drāo: & 5821 \\
\hline & \multicolumn{2}{|c|}{ Tubo A } & \multicolumn{2}{|c|}{ Tubo B } & \multicolumn{2}{|c|}{ TuboC C } & \multicolumn{2}{|c|}{ Tubo D } \\
\hline Prof. & C & $\theta \%$ & C & $\Theta \%$ & C & $0 \%$ & C & $\Theta \%$ \\
\hline 5 & & & 2220 & 3,83 & 2782 & 6,01 & 2799 & 6,07 \\
\hline 25 & & & 8261 & 27,20 & 8958 & 29,90 & 7927 & 25,91 \\
\hline 50 & & & 7851 & 25,61 & 8646 & 28,69 & 7640 & 24,80 \\
\hline 75 & 4357 & 12,14 & 8877 & 29,58 & 8675 & 28,80 & 8097 & 26,57 \\
\hline 100 & 8911 & 29,71 & 9014 & 30,11 & 8810 & 29,32 & 8994 & 30,04 \\
\hline 125 & 9308 & 31,25 & 9219 & 30,91 & 9078 & 30,36 & 9183 & 30,77 \\
\hline 150 & 9694 & 32,74 & 9564 & 32,24 & 9221 & 30,91 & 9217 & 30,90 \\
\hline 175 & 10402 & 35,48 & 9839 & 33,30 & 9876 & 33,45 & 9864 & 33,40 \\
\hline
\end{tabular}

\begin{tabular}{|c|c|c|c|c|c|c|c|c|}
\hline \multicolumn{9}{|c|}{ 8.'Medição: } \\
\hline Data: & 09,0802 & Hora: & & $t=45$ & & ontagen & dr & 5831 \\
\hline & \multicolumn{2}{|c|}{ Tubo A } & \multicolumn{2}{|c|}{ Tabo B } & \multicolumn{2}{|c|}{ Tubo C } & \multicolumn{2}{|c|}{ Tubo D } \\
\hline Prof. & C & $\theta \%$ & C & $\theta \%$ & C & $\theta \%$ & c & $\theta \%$ \\
\hline 5 & & & 2190 & 3,70 & 2770 & 5,94 & 2732 & 5,80 \\
\hline 25 & & & 8132 & 26,65 & 8909 & 29,65 & 7872 & 25,64 \\
\hline 50 & & & 7762 & 25,22 & 8489 & 28,03 & 7508 & 24,24 \\
\hline 75 & 4207 & 11,49 & 8346 & 27,47 & 8347 & 27,48 & 7961 & 25,99 \\
\hline 100 & 8821 & 29,31 & 8734 & 28,97 & 8219 & 26,98 & 8663 & 28,70 \\
\hline 125 & 9299 & 31,15 & 8783 & 29,16 & 8546 & 28,25 & 8701 & 28,84 \\
\hline 150 & 9387 & 31,49 & 8959 & 29,84 & 8977 & 29,91 & 9133 & 30,51 \\
\hline 175 & 9938 & 33,62 & 9553 & 32,13 & 9440 & 31,70 & 9605 & 32,34 \\
\hline
\end{tabular}

\begin{tabular}{|c|c|c|c|c|c|c|c|c|}
\hline \multicolumn{9}{|c|}{ 9." Medição: } \\
\hline Data: & 120802 & Hora: & & $t=126 \mathrm{~h}$ & & ontager & adrão: & 5872 \\
\hline & \multicolumn{2}{|c|}{ Tubo A } & \multicolumn{2}{|c|}{ Tubo B } & \multicolumn{2}{|c|}{ Tubo C } & \multicolumn{2}{|c|}{ Tubo D } \\
\hline Prof. & C & $\theta \%$ & C & $\theta \%$ & $\bar{c}$ & $e \%$ & C & $\Theta \%$ \\
\hline 5 & & & 2112 & 3,34 & 2596 & 5,20 & 2630 & 5,33 \\
\hline 25 & & & 7858 & 25,38 & 8755 & 28,82 & 7760 & 25,00 \\
\hline 50 & & & 7388 & 23,58 & 8307 & 27,10 & 7239 & 23,00 \\
\hline 75 & 4144 & 11,14 & 8048 & 26,11 & 8013 & 25,97 & 7659 & 24,61 \\
\hline 100 & 8422 & 27,54 & 8400 & 27,46 & 8178 & 26,60 & 8238 & 26,83 \\
\hline 125 & 8509 & 29,02 & 8457 & 27,67 & 8459 & 27,68 & 8479 & 27,76 \\
\hline 150 & 9062 & 29,99 & 8765 & 28,86 & 8649 & 28,41 & 8814 & 29,04 \\
\hline 175 & 9234 & 30,65 & 9302 & 30,91 & 9073 & 30,04 & 9034 & 29,89 \\
\hline
\end{tabular}

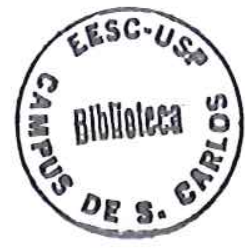


Tabela 5.10 - Acompanhamento da redistribuição - Solo 2 - Valores de umidade

\begin{tabular}{|c|c|c|c|c|c|c|c|c|}
\hline \multicolumn{9}{|c|}{ 1. ${ }^{2}$ Medl çăo: } \\
\hline \multirow[t]{2}{*}{ Data: } & \multirow{2}{*}{\multicolumn{2}{|c|}{\begin{tabular}{c|c}
$24 / 07 / 02$ & Hora: \\
Tubo E
\end{tabular}}} & \multicolumn{3}{|c|}{ (antes da aduszo) } & \multicolumn{2}{|c|}{ Contagem Padrão: } & \multirow{2}{*}{5914} \\
\hline & & & & & & & & \\
\hline Prof. & c & $\theta \%$ & $\mathrm{c}$ & $\theta \%$ & c & $\theta \%$ & c & $\theta \%$ \\
\hline 5 & & & 2713 & 8,05 & 2955 & 8,46 & 3312 & 9,07 \\
\hline 25 & & & 7272 & 15,84 & 7679 & 16,54 & 7576 & 16,36 \\
\hline 50 & & & 7216 & 15,75 & 8135 & 17,32 & 7962 & 17,012 \\
\hline 75 & 400 & 10,93 & 8233 & 17,9 & 8392 & 17,76 & 8107 & 17,27 \\
\hline 100 & 8308 & 17,61 & 8656 & 18,21 & 8440 & 17,84 & 8259 & 17,53 \\
\hline 125 & $\$ 832$ & 18,51 & 9165 & 19,18 & 8672 & 18,24 & 8630 & 18,17 \\
\hline 150 & 9325 & 19,35 & 9207 & 19,15 & 9246 & 19,22 & 8842 & 18,53 \\
\hline 175 & 10068 & 20,62 & 9513 & 19,68 & 9310 & 19,33 & 9265 & 19,25 \\
\hline
\end{tabular}

\begin{tabular}{|c|c|c|c|c|c|c|c|c|}
\hline \multicolumn{9}{|c|}{ 2.' Medlçâa: } \\
\hline Data: & $24 / 07 / 02$ & Inora: & & $t=0$ & & ontager & drăo: & 5914 \\
\hline & \multicolumn{2}{|c|}{ TuboE E } & \multicolumn{2}{|c|}{ Tubo F } & \multicolumn{2}{|c|}{ Tubo G } & \multicolumn{2}{|c|}{ Tubo H } \\
\hline Prof. & C & $\theta \%$ & C & $\theta \%$ & C & $\theta \%$ & C & $\theta \%$ \\
\hline 5 & & & 2700 & 8,02 & 3092 & 8,69 & 3295 & 9,04 \\
\hline 25 & & & 8923 & 18,67 & 8083 & 17,23 & 7581 & 16,37 \\
\hline 50 & & & 10044 & 20,58 & 9408 & 19,50 & 8849 & 18,54 \\
\hline 75 & 10910 & 22,06 & 11276 & 22,69 & 10182 & 20,82 & 9114 & 18,99 \\
\hline 100 & 12137 & 24,16 & 11703 & 23,42 & 10723 & 21,74 & 9519 & 19,69 \\
\hline 125 & 12170 & 24,22 & 11983 & 23,90 & 10813 & 21,90 & 9815 & 20,19 \\
\hline 150 & 12239 & 24,34 & 12065 & 24,04 & 11027 & 22,26 & 10030 & 20,56 \\
\hline 175 & 12380 & 24,58 & 12170 & 24,22 & 12547 & 24,86 & 10297 & 21,02 \\
\hline
\end{tabular}

\begin{tabular}{|c|c|c|c|c|c|c|c|c|}
\hline \multicolumn{9}{|c|}{ 3.' Medlçăo: } \\
\hline \multirow{2}{*}{ Data: } & $24 / 07 / 02$ & Hora: & \multirow{2}{*}{\multicolumn{2}{|c|}{$\frac{\mathrm{t}=1 \mathrm{~h}}{\text { Tubo } \mathrm{F}}$}} & \multicolumn{3}{|c|}{ |Contagem Padrão: } & 5914 \\
\hline & \multicolumn{2}{|c|}{ Tubo E } & & & \multicolumn{2}{|c|}{ Tubo G } & \multicolumn{2}{|c|}{ Tubo H } \\
\hline Prof. & $\mathrm{C}$ & $\mathbf{\theta} \%$ & $\mathbf{C}$ & $\theta \%$ & $\mathrm{C}$ & $\theta \%$ & $\mathrm{C}$ & $\theta \%$ \\
\hline 5 & & & 2756 & 8,12 & 3004 & 8,54 & 3230 & 8,93 \\
\hline 25 & & & 8166 & 17,88 & 8033 & 17,23 & 7525 & 16,28 \\
\hline 50) & & & $\$ 375$ & 18,58 & 9004 & 18,80 & 8730 & 18,34 \\
\hline 75 & 5869 & 13,44 & 10053 & 20,60 & 9604 & 19,83 & 8941 & 18,70 \\
\hline 100 & 10565 & 21,47 & 10473 & 21,32 & 9929 & 20,39 & 9261 & 19,24 \\
\hline 125 & 10500 & 22,05 & 10915 & 22,07 & 10187 & 20,83 & 9749 & 20,08 \\
\hline 150 & 11095 & 22,38 & 11172 & 22,51 & 10607 & 21,55 & 9920 & 20,37 \\
\hline 175 & 11817 & 23,62 & 11637 & 23,31 & 11812 & 23,61 & 10240 & 20,92 \\
\hline
\end{tabular}

\begin{tabular}{|c|c|c|c|c|c|c|c|c|}
\hline \multicolumn{9}{|c|}{ 4." Mfedlçâa: } \\
\hline Data: & $24: 07 / 02$ & Hora: & & $t=2 h$ & & natagen & Irà̃o: & 5914 \\
\hline & \multicolumn{2}{|c|}{ Tubo E } & \multicolumn{2}{|c|}{ TuboF } & \multicolumn{2}{|c|}{ Tubo G } & \multicolumn{2}{|c|}{ Tubo H } \\
\hline Prof. & c & $\theta \%$ & C & $\theta \%$ & C & $\theta \%$ & C & $\theta \%$ \\
\hline 5 & & & 2774 & 8,15 & 3010 & 8,55 & 3211 & 8,90 \\
\hline 25 & & & 8362 & 17,71 & 7993 & 17,08 & 7517 & 16,26 \\
\hline 50 & & & 8642 & 18, & 8896 & 18 & 8628 & 18,16 \\
\hline 75 & 5636 & 13,04 & 9531 & 19,7 & 9569 & 19,77 & Sss4 & 18,60 \\
\hline 100 & 10003 & 20,51 & 10234 & 20,91 & 9759 & $\{0,10$ & 9210 & 19,16 \\
\hline 125 & 10441 & 21,26 & 10357 & 21,12 & 9990 & 20,49 & 9624 & 19,87 \\
\hline 150 & 10507 & 21,89 & 10848 & 21,96 & 10213 & 20,87 & 9832 & 20,31 \\
\hline 175 & 11650 & 23,33 & 11610 & 23,26 & 11277 & 22,69 & 10015 & 20,53 \\
\hline
\end{tabular}

\begin{tabular}{|c|c|c|c|c|c|c|c|c|}
\hline \multicolumn{9}{|c|}{ 5.'Medlçăo: } \\
\hline Data: & $24 / 07 / 02$ & Hora: & & $t=3: 30$ & & ontager & drão: & 5914 \\
\hline & \multicolumn{2}{|c|}{ TuboE } & \multicolumn{2}{|c|}{ Tubo F } & \multicolumn{2}{|c|}{ Tubo G } & \multicolumn{2}{|c|}{ Tubo II } \\
\hline Prof. & C & $\theta \%$ & C & $\theta \%$ & C & $\theta \%$ & c & $\theta \%$ \\
\hline 5 & & & 2728 & 8,07 & 3036 & 8,60 & 3191 & 8,86 \\
\hline 25 & & & 8100 & 17,26 & 8013 & 17,11 & 7429 & 16,11 \\
\hline so & & & 8122 & 17,81 & 8705 & 18,29 & 8417 & 17,80 \\
\hline 75 & 5576 & 12,94 & 9416 & 19,51 & 9407 & 19,49 & 8790 & 18,44 \\
\hline 100 & 9350 & 20,25 & 10030 & 20,56 & 9592 & 19,81 & 9091 & 18,95 \\
\hline 125 & 10124 & 20,72 & 10120 & 20,71 & 9836 & 20,23 & 9476 & 19,61 \\
\hline 150 & 10514 & 21,39 & 10413 & 21,21 & 10083 & 20,65 & 9813 & 20,19 \\
\hline 175 & 11222 & 22,60 & 11042 & 22,29 & 10783 & 21,85 & 9917 & 20,37 \\
\hline
\end{tabular}

\begin{tabular}{|c|c|c|c|c|c|c|c|c|}
\hline \multicolumn{9}{|c|}{ 6." Medlç̧̃o: } \\
\hline Data: & $24,07 / 02$ & Hora: & & $t=5 h$ & & ontagen & dra & 5914 \\
\hline & \multicolumn{2}{|c|}{ Tubo E } & \multicolumn{2}{|c|}{ Tubo $\mathbf{F}$} & \multicolumn{2}{|c|}{ Tubo G } & \multicolumn{2}{|c|}{ Tubo H } \\
\hline Prof. & C & $\theta \%$ & c & $\theta \%$ & c & $\theta \%$ & C & $\mathbf{\theta} \%$ \\
\hline 5 & & & 2746 & 8,10 & 3051 & 8,62 & 3218 & 8,91 \\
\hline 25 & & & 8060 & 17,19 & sot1 & 17,16 & 73386 & 16,04 \\
\hline$s_{0}$ & & & 8306 & 17,61 & 8591 & 18,10 & 8368 & 17,72 \\
\hline 75 & 5377 & 12,60 & 9376 & 19,44 & 9326 & 19,36 & 8760 & 18,39 \\
\hline 100 & 9703 & 20,00 & 9926 & 20,38 & 9503 & 19,67 & 9121 & 19,00 \\
\hline 125 & 10073 & 20,63 & 10088 & 20,66 & 9753 & 20,09 & 9402 & 19,49 \\
\hline 150 & 10417 & 21,22 & 10370 & 21,14 & 10018 & 20,54 & 9778 & 20,13 \\
\hline 175 & 11163 & 22,50 & 11037 & 22,28 & 10725 & 21,75 & 9832 & 20,22 \\
\hline
\end{tabular}

\begin{tabular}{|c|c|c|c|c|c|c|c|c|}
\hline \multicolumn{9}{|c|}{ 7.' Mediçă } \\
\hline Data: & $2507 / 02$ & Hora: & & $t=24 \mathrm{~h}$ & & oalage & drâ: & 5867 \\
\hline & \multicolumn{2}{|c|}{ TuboE } & \multicolumn{2}{|c|}{ Tubo F } & \multicolumn{2}{|c|}{ Tubo G } & \multicolumn{2}{|c|}{ Tubo H } \\
\hline Prof. & c & $\theta \%$ & C & $\theta \%$ & c & $\theta \%$ & C & $\theta \%$ \\
\hline 5 & & & 2633 & 7,95 & 3047 & 8,65 & 3176 & 8,8 \\
\hline 25 & & & 7845 & 16,93 & 8010 & 17,21 & 7327 & 16,04 \\
\hline 50 & & & 8009 & 17,21 & 8467 & 18,00 & 8220 & 17,58 \\
\hline 75 & 5052 & 12,12 & 8903 & 18,75 & 8814 & 18,65 & 8493 & 18,05 \\
\hline 100 & 9134 & 19,15 & 9309 & 19,45 & 9012 & 18,94 & 8525 & 18,10 \\
\hline 125 & 9426 & 19,66 & 9720 & 20,16 & 9341 & 19,51 & 9018 & 18,95 \\
\hline 150 & 9982 & 20,61 & 9794 & 20,29 & 9797 & 20,30 & 9271 & 19,39 \\
\hline 175 & 10700 & 21,85 & 10424 & 21,38 & 9916 & 20,50 & 9643 & 20,03 \\
\hline
\end{tabular}

\begin{tabular}{|c|c|c|c|c|c|c|c|c|}
\hline \multicolumn{9}{|c|}{ 8.' Medlçà̃o: } \\
\hline \multirow{2}{*}{ Data: } & $26,07 / 02$ & Hora: & & $t=18 \mathrm{~h}$ & & ontager & drāo: & 5854 \\
\hline & \multicolumn{2}{|c|}{ Tubo E } & \multicolumn{2}{|c|}{ Tubo F } & \multicolumn{2}{|c|}{ Tubo G } & \multicolumn{2}{|c|}{ Tubo H } \\
\hline Prof. & $\mathrm{c}$ & $\theta \%$ & C & $\theta \%$ & c & $\theta \%$ & c & $\theta \%$ \\
\hline 5 & & & 2615 & 7,92 & 3028 & 8.64 & 3169 & 8,88 \\
\hline 25 & & & 7675 & 16,67 & 8013 & 17,25 & 7320 & 16,05 \\
\hline 50 & & & 7745 & 16,79 & 8340 & 17,82 & 8068 & 17,35 \\
\hline 75 & 4857 & 11,80 & 8436 & 17,98 & 8681 & 18,40 & 8251 & 17,66 \\
\hline 100 & 8742 & 18,51 & 9155 & 19,22 & 8653 & 18,36 & 8493 & 18,08 \\
\hline 125 & 9118 & 19,16 & 9300 & 19,47 & 9010 & 18,97 & 8507 & 18,80 \\
\hline 150 & 9659 & 20,09 & 9506 & 19,83 & 9243 & 19,38 & 9270 & 19,42 \\
\hline 175 & 10375 & 21,33 & 9934 & 20,57 & 9742 & 20,24 & 9250 & 19,39 \\
\hline
\end{tabular}

\begin{tabular}{|c|c|c|c|c|c|c|c|c|}
\hline \multicolumn{9}{|c|}{ 9.' Mediçāo: } \\
\hline \multirow{2}{*}{ Data: } & $29 / 07 / 02$ & Hora: & \multicolumn{3}{|c|}{$t=120 \mathrm{~h}$ (5 dias) } & \multicolumn{2}{|c|}{ Contagem Padrão: } & 5877 \\
\hline & \multicolumn{2}{|c|}{ Tubo E } & \multicolumn{2}{|c|}{ Tubo F } & \multicolumn{2}{|c|}{ Tubo G } & \multicolumn{2}{|c|}{ Tubo H } \\
\hline Prof. & C & $\theta \%$ & C & $\theta \%$ & C & $\theta \%$ & c & $\theta \%$ \\
\hline 5 & & & 2559 & 7,81 & 2968 & 8,51 & 2929 & 8,45 \\
\hline 25 & & & 7228 & 15,85 & 7981 & 17,14 & 7374 & 16,10 \\
\hline 50 & & & 7308 & 15,98 & 8085 & 17,32 & 7827 & 16,88 \\
\hline 75 & 4312 & 10,83 & 8336 & 17,75 & 8230 & 17,57 & 8055 & 17,27 \\
\hline 100 & 3472 & 17,99 & $\$ 822$ & 18,59 & 8439 & 17,93 & 8297 & 17,69 \\
\hline 125 & 8852 & 18,64 & 9227 & 19,29 & 8747 & 18,46 & 8535 & 18,09 \\
\hline 150 & 9385 & 19,56 & 9352 & 19,50 & 8343 & 18,62 & $\$ \$ 85$ & 18,70 \\
\hline 175 & 10067 & 20,73 & 9697 & 20,09 & 9549 & 19,84 & 9249 & 19,32 \\
\hline
\end{tabular}

\begin{tabular}{c|cccccccc}
$\begin{array}{c}\text { larg./prof. } \\
\text { (cm) }\end{array}$ & $\mathbf{0}$ & $\mathbf{3 0}$ & $\mathbf{6 0}$ & $\mathbf{9 0}$ & $\mathbf{6 0}$ & $\mathbf{3 0}$ & $\mathbf{0}$ \\
\cline { 2 - 6 } & $\mathbf{5}$ & $\mathbf{3}, 82$ & 7,36 & 3,75 & & 3,75 & 7,36 & 8,82 \\
$\mathbf{2 5}$ & 25,58 & 25,71 & 22,25 & & 22,25 & 25,71 & 25,58 \\
$\mathbf{5 0}$ & 23,26 & 24,05 & 25,56 & & 25,56 & 24,05 & 23,26 \\
$\mathbf{7 5}$ & 20,44 & 26,09 & 27,17 & 9,68 & 27,17 & 26,09 & 20,44 \\
$\mathbf{1 0 0}$ & 23,91 & 27,52 & 29,02 & 30,92 & 29,02 & 27,52 & 23,91 \\
$\mathbf{1 2 5}$ & 26,38 & 28,42 & 30,46 & 32,77 & 30,46 & 28,42 & 26,38 \\
$\mathbf{1 5 0}$ & 28,18 & 30,11 & 31,76 & 33,75 & 31,76 & 30,11 & 28,18 \\
$\mathbf{1 7 5}$ & 29,10 & 30,94 & 28,70 & 35,06 & 28,70 & 30,94 & 29,10 \\
\hline
\end{tabular}

Figura 5.18a - Perfil de umidade observado antes da alimentação - Solo1 


\begin{tabular}{|c|c|c|c|c|c|c|c|}
\hline arg./prof. & 0 & 30 & 60 & 90 & 60 & 30 & o \\
\hline 5 & 8,44 & 5,02 & 5,99 & & 5,99 & 5,02 & 8,44 \\
\hline 25 & 24,70 & 27,75 & 30,54 & & 30,54 & 27,75 & 24,70 \\
\hline 50 & 24,96 & 33,08 & 33,15 & & 33,15 & 33,08 & 24,96 \\
\hline 75 & 28,65 & 36,32 & 39,53 & 28,11 & 39,53 & 36,32 & 28,65 \\
\hline 100 & 34,55 & 37,34 & 40,81 & 41,87 & 40,81 & 37,34 & 34,55 \\
\hline 125 & 36,56 & 38,43 & 42,50 & 41,95 & 42,50 & 38,43 & 36,56 \\
\hline 150 & 37,63 & 39,76 & 42,74 & 42,24 & 42,74 & 39,76 & $37, \infty 3$ \\
\hline 175 & 38,11 & 40,60 & 42,78 & 43,48 & 42,78 & 40,60 & 38,11 \\
\hline
\end{tabular}

Figura 5.18b - Perfil de umidade observado no instante $t=0$ da redistribuição - Solo1

\begin{tabular}{|c|c|c|c|c|c|c|c|}
\hline $\begin{array}{l}\text { larg./prof. } \\
\text { (cm) }\end{array}$ & 0 & 30 & 60 & 90 & 60 & 30 & 0 \\
\hline 5 & 7,79 & 7,82 & 5,60 & & 5,60 & 7,82 & 7,79 \\
\hline 25 & 25,11 & 28,11 & 29,09 & & 29,09 & 28,11 & 25,11 \\
\hline 50 & 25,36 & 32,75 & 30,86 & & 30,86 & 32,75 & 25,36 \\
\hline 75 & 28,53 & 33,82 & 36,41 & 14,47 & 36,41 & 33,82 & 28,53 \\
\hline 100 & 34,13 & 35,74 & 38,08 & 36,19 & 38,08 & 35,74 & 34,13 \\
\hline 125 & 35,40 & 37,14 & 39,47 & 38,99 & 39,47 & 37,14 & 35,40 \\
\hline 150 & 37,44 & 38,13 & 40,47 & 39,25 & 40,47 & 38,13 & 37,44 \\
\hline 175 & 37,92 & 39,13 & 40,85 & 40,41 & 40,85 & 39,13 & 37,92 \\
\hline
\end{tabular}

Figura 5.18c - Perfil de umidade observado no instante $t=1$ h da redistribuição - Solol

\begin{tabular}{|c|c|c|c|c|c|c|c|}
\hline $\begin{array}{l}\text { larg./prof. } \\
\text { (cm) }\end{array}$ & 0 & 30 & 60 & 90 & 60 & 30 & 0 \\
\hline 5 & 8,16 & 7,48 & 4,78 & & 4,78 & 7,48 & 8,16 \\
\hline 25 & 25,52 & 29,01 & 30,29 & & 30,29 & 29,01 & 25,52 \\
\hline 50 & 25,67 & 31,91 & 29,36 & & 29,36 & 31,91 & 25,67 \\
\hline 75 & 29,09 & 32,58 & 34,23 & 13,80 & 34,23 & 32,58 & 29,00 \\
\hline 100 & 33,39 & 34,28 & 35,83 & 35,86 & 35,83 & 34,28 & 33,39 \\
\hline 125 & 34,38 & 35,44 & 37,43 & 38,37 & 37,43 & 35,44 & 34,38 \\
\hline 150 & 36,59 & 37,31 & 38,89 & 38,09 & 38,89 & 37,31 & 36,59 \\
\hline 175 & 36,99 & 38,48 & 39,23 & 39,39 & 39,23 & 38,48 & 36,99 \\
\hline
\end{tabular}

Figura 5.18d - Perfil de umidade observado no instante $t=2 \mathrm{~h}$ da redistribuição - Solo1

\begin{tabular}{|c|c|c|c|c|c|c|c|}
\hline $\begin{array}{l}\text { larg./prof. } \\
\text { (cm) }\end{array}$ & 0 & 30 & 60 & 90 & 60 & 30 & 0 \\
\hline 5 & 7,16 & 7,74 & 4,50 & & 4,50 & 7,74 & 7,16 \\
\hline 25 & 25,34 & 29,43 & 29,04 & & 29,04 & 29,43 & 25,34 \\
\hline 50 & 25,35 & 30,70 & 28,73 & & 28,73 & 30,70 & 25,35 \\
\hline 75 & 28,28 & 31,94 & 32,26 & 13,56 & 32,26 & 31,94 & 28,28 \\
\hline 100 & 32,20 & 32,57 & 34,46 & 34,34 & 34,46 & 32,57 & 32,20 \\
\hline 125 & 33,15 & 33,98 & 35,47 & 36,35 & 35,47 & 33,98 & 33,15 \\
\hline 150 & 35,69 & 35,97 & 37,14 & 36,83 & 37,14 & 35,97 & 35,69 \\
\hline 175 & 36,17 & 37,70 & 38,27 & 39,02 & 38,27 & 37,70 & 36,17 \\
\hline
\end{tabular}

Figura 5.18e - Perfil de umidade observado no instante $t=3: 30$ h da redistribuição - Solo1

\begin{tabular}{|c|c|c|c|c|c|c|c|}
\hline $\begin{array}{l}\text { larg./prof. } \\
\text { (cm) }\end{array}$ & 0 & 30 & 60 & 90 & 60 & 30 & 0 \\
\hline 5 & 6,94 & 7,77 & 4,09 & & 4,09 & 7,77 & 6,94 \\
\hline 25 & 25,62 & 29,60 & 28,94 & & 28,94 & 29,60 & 25,62 \\
\hline 50 & 25,79 & 30,67 & 28,18 & & 28,18 & 30,67 & 25,79 \\
\hline 75 & 27,97 & 30,68 & 32,09 & 13,55 & 32,09 & 30,68 & 27,97 \\
\hline 100 & 31,69 & 31,99 & 33,36 & 33,84 & 33,36 & 31,99 & 31,69 \\
\hline 125 & 32,99 & 32,68 & 34,26 & 34,70 & 34,26 & 32,68 & 32,99 \\
\hline 150 & 35,02 & 35,19 & 36,39 & 36,57 & 36,39 & 35,19 & 35,02 \\
\hline 175 & 36,78 & 36,07 & 37,22 & 38,63 & 37,22 & 36,07 & 36,78 \\
\hline
\end{tabular}

Figura 5.18f - Perfil de umidade observado no instante $t=5 \mathrm{~h}$ da redistribuição - Solo1 


\begin{tabular}{c|cccccccc|}
$\begin{array}{c}\text { larg./prof. } \\
\text { (cm) }\end{array}$ & $\mathbf{0}$ & $\mathbf{3 0}$ & $\mathbf{6 0}$ & $\mathbf{9 0}$ & $\mathbf{6 0}$ & $\mathbf{3 0}$ & $\mathbf{0}$ \\
$\mathbf{5}$ & 6,07 & 6,01 & 3,83 & & 3,83 & 6,01 & 6,07 \\
$\mathbf{2 5}$ & 25,91 & 29,90 & 27,20 & & 27,20 & 29,90 & 25,91 \\
$\mathbf{5 0}$ & 24,80 & 28,69 & 25,61 & & 25,61 & 28,69 & 24,80 \\
$\mathbf{7 5}$ & 26,57 & 28,80 & 29,58 & 12,14 & 29,58 & 28,80 & 26,57 \\
100 & 30,04 & 29,32 & 30,11 & 29,71 & 30,11 & 29,32 & 30,04 \\
$\mathbf{1 2 5}$ & 30,77 & 30,36 & 30,91 & 31,25 & 30,91 & 30,36 & 30,77 \\
$\mathbf{1 5 0}$ & 30,90 & 30,91 & 32,24 & 32,74 & 32,24 & 30,91 & 30,90 \\
$\mathbf{1 7 5}$ & 33,40 & 33,45 & 33,30 & 35,48 & 33,30 & 33,45 & 33,40 \\
\hline
\end{tabular}

Figura $5.18 \mathrm{~g}$ - Perfil de umidade observado no instante $t=24 \mathrm{~h}$ da redistribuição - Solo1

\begin{tabular}{|c|c|c|c|c|c|c|c|}
\hline rg./prof. & 0 & 30 & 60 & 90 & 60 & 30 & 0 \\
\hline 5 & 5,80 & 5,94 & 3,70 & & 3,70 & 5,94 & 5,80 \\
\hline 25 & 25,64 & 29,65 & 26,65 & & 26,65 & 29,65 & 25,64 \\
\hline 50 & 24,24 & 28,03 & 25,22 & & 25,22 & 28,03 & 24,24 \\
\hline 75 & 25,99 & 27,48 & 27,47 & 11,49 & 27,47 & 27,48 & 25,99 \\
\hline 100 & 28,70 & 26,98 & 28,97 & 29,31 & 28,97 & 26,98 & 28,70 \\
\hline 125 & 28,84 & 28,25 & 29,16 & 31,15 & 29,16 & 28,25 & 28,84 \\
\hline 150 & 30,51 & 29,91 & 29,84 & 31,49 & 29,84 & 29,91 & 30,51 \\
\hline 175 & 32,34 & 31,70 & 32,13 & 33,62 & 32,13 & 31,70 & 32,34 \\
\hline
\end{tabular}

Figura 5.18h - Perfil de umidade observado no instante $t=48 \mathrm{~h}$ da redistribuição - Solo1

\begin{tabular}{c|cccccccc|}
$\begin{array}{c}\text { larg./prof. } \\
\text { (cm) }\end{array}$ & $\mathbf{0}$ & $\mathbf{3 0}$ & $\mathbf{6 0}$ & $\mathbf{9 0}$ & $\mathbf{6 0}$ & $\mathbf{3 0}$ & $\mathbf{0}$ \\
\cline { 2 - 4 } $\mathbf{5}$ & 5,33 & 5,20 & 3,34 & & 3,34 & 5,20 & 5,33 \\
$\mathbf{2 5}$ & 25,00 & 28,82 & 25,38 & & 25,38 & 28,82 & 25,00 \\
$\mathbf{5 0}$ & 23,00 & 27,10 & 23,58 & & 23,58 & 27,10 & 23,00 \\
$\mathbf{7 5}$ & 24,61 & 25,97 & 26,11 & 11,14 & 26,11 & 25,97 & 24,61 \\
$\mathbf{1 0 0}$ & 26,83 & 26,60 & 27,46 & 27,54 & 27,46 & 26,60 & 26,83 \\
$\mathbf{1 2 5}$ & 27,76 & 27,68 & 27,67 & 29,02 & 27,67 & 27,68 & 27,76 \\
$\mathbf{1 5 0}$ & 29,04 & 28,41 & 28,86 & 29,99 & 28,86 & 28,41 & 29,04 \\
$\mathbf{1 7 5}$ & 29,89 & 30,04 & 30,91 & 30,65 & 30,91 & 30,04 & 29,89 \\
\hline
\end{tabular}

Figura 5.18i - Perfil de umidade observado no instante $t=120 \mathrm{~h}$ da redistribuição - Solo1

\begin{tabular}{|c|c|c|c|c|c|c|c|}
\hline $\begin{array}{l}\text { larg./prof. } \\
\text { (cm) }\end{array}$ & 0 & 30 & 60 & 90 & 60 & 30 & 0 \\
\hline 5 & 9,07 & 8,46 & 8,05 & & 8,05 & 8,46 & 9,07 \\
\hline 25 & 16,36 & 16,54 & 15,84 & & 15,84 & 16,54 & 16,36 \\
\hline 50 & 17,02 & 17,32 & 15,75 & & 15,75 & 17,32 & 17,02 \\
\hline 75 & 17,27 & 17,76 & 17,49 & 10,93 & 17,49 & 17,76 & 17,27 \\
\hline 100 & 17,53 & 17,84 & 18,21 & 17,61 & 18,21 & 17,84 & 17,53 \\
\hline 125 & 18,17 & 18,24 & 19,08 & 18,51 & 19,08 & 18,24 & 18,17 \\
\hline 150. & 18,53 & 19,22 & 19,15 & 19,35 & 19,15 & 19,22 & 18,53 \\
\hline 175 & 19,25 & 19,33 & 19,68 & 20,62 & 19,68 & 19,33 & 19,25 \\
\hline
\end{tabular}

Figura 5.19a - Perfil de umidade observado antes da alimentação - Solo2

\begin{tabular}{|c|c|c|c|c|c|c|c|}
\hline $\begin{array}{l}\text { larg./prof. } \\
\text { (cm) }\end{array}$ & 0 & 30 & 60 & 90 & 60 & 30 & 0 \\
\hline 5 & 9,04 & 8,69 & 8,02 & & 8,02 & 8,69 & 9,04 \\
\hline 25 & 16,37 & 17,23 & 18,67 & & 18,67 & 17,23 & 16,37 \\
\hline 50 & 18,54 & 19,50 & 20,58 & & 20,58 & 19,50 & 18,54 \\
\hline 75 & 18,99 & 20,82 & 22,69 & 22,06 & 22,69 & 20,82 & 18,99 \\
\hline 100 & 19,69 & 21,74 & 23,42 & 24,16 & 23,42 & 21,74 & 19,69 \\
\hline 125 & 20,19 & 21,90 & 23,90 & 24,22 & 23,90 & 21,90 & 20,19 \\
\hline 150 & 20,56 & 22,26 & 24,04 & 24,34 & 24,04 & 22,26 & 20,56 \\
\hline 175 & 21,02 & 24,86 & 24,22 & 24,58 & 24,22 & 24,86 & 21,02 \\
\hline
\end{tabular}

Figura 5.19b - Perfil de umidade observado no instante $t=0$ da redistribuição - Solo2 


\begin{tabular}{|c|c|c|c|c|c|c|c|}
\hline $\begin{array}{l}\text { larg./prof. } \\
\text { (cm) }\end{array}$ & 0 & 30 & 60 & 90 & 60 & 30 & 0 \\
\hline 5 & 8,93 & 8,54 & 8,12 & & 8,12 & 8,54 & 8,93 \\
\hline 25 & 16,28 & 17,23 & 17,88 & & 17,88 & 17,23 & 16,28 \\
\hline 50 & 18,34 & 18,80 & 18,58 & & 18,58 & 18,80 & 18,34 \\
\hline 75 & 18,70 & 19,83 & 20,60 & 13,44 & 20,60 & 19,83 & 18,70 \\
\hline 100 & 19,24 & 20,39 & 21,32 & 21,47 & 21,32 & 20,39 & 19,24 \\
\hline 125 & 20,08 & 20,83 & 22,07 & 22,05 & 22,07 & 20,83 & 20,08 \\
\hline 150 & 20,37 & 21,55 & 22,51 & 22,38 & 22,51 & 21,55 & 20,37 \\
\hline 175 & 20,92 & 23,61 & 23,31 & 23,62 & 23,31 & 23,61 & 20,92 \\
\hline
\end{tabular}

Figura 5.19c - Perfil de umidade observado no instante $t=1$ h da redistribuição - Solo2

\begin{tabular}{|c|c|c|c|c|c|c|c|}
\hline $\begin{array}{l}\text { larg./prof. } \\
\text { (cm) }\end{array}$ & 0 & 30 & 60 & 90 & 60 & 30 & 0 \\
\hline 5 & 8,90 & 8,55 & 8,15 & & 8,15 & 8,55 & 8,90 \\
\hline 25 & 16,26 & 17,08 & 17,71 & & 17,71 & 17,08 & 16,26 \\
\hline $\mathbf{5 0}$ & 18,16 & 18,62 & 18,19 & & 18,19 & 18,62 & 18,16 \\
\hline 75 & 18,60 & 19,77 & 19,79 & 13,04 & 19,79 & 19,77 & 18,60 \\
\hline 100 & 19,16 & 20,10 & 20,91 & 20,51 & 20,91 & 20,10 & 19,16 \\
\hline 125 & 19,87 & 20,49 & 21,12 & 21,26 & 21,12 & 20,49 & 19,87 \\
\hline 150 & 20,31 & 20,87 & 21,96 & 21,89 & 21,96 & 20,87 & 20,31 \\
\hline 175 & 20,53 & 22,69 & 23,26 & 23,33 & 23,26 & 22,69 & 20,53 \\
\hline
\end{tabular}

Figura 5.19d - Perfil de umidade observado no instante $t=2 h$ da redistribuição - Solo2

\begin{tabular}{|c|c|c|c|c|c|c|c|}
\hline larg./prof. & 0 & 30 & 60 & 90 & 60 & 30 & 0 \\
\hline 5 & 8,86 & 8,60 & 8,07 & & 8,07 & 8,60 & 8,86 \\
\hline 25 & 16,11 & 17,11 & 17,26 & & 17,26 & 17,11 & 16,11 \\
\hline 50 & 17,80 & 18,29 & 17,81 & & 17,81 & 18,29 & 17,80 \\
\hline 75 & 18,44 & 19,49 & 19,51 & 12,94 & 19,51 & 19,49 & 18,44 \\
\hline 100 & 18,95 & 19,81 & 20,56 & 20,25 & 20,56 & 19,81 & 18,95 \\
\hline 125 & 19,61 & 20,23 & 20,71 & 20,72 & 20,71 & 20,23 & 19,61 \\
\hline 150 & 20,19 & 20,65 & 21,21 & 21,39 & 21,21 & 20,65 & 20,19 \\
\hline 175 & 20,37 & 21,85 & 22,29 & 22,60 & 22,29 & 21,85 & 20,37 \\
\hline
\end{tabular}

Figura 5.19e - Perfil de umidade observado no instante $t=3: 30 \mathrm{~h}$ da redistribuição - Solo2

\begin{tabular}{ccccccccc}
$\begin{array}{c}\text { larg./prof. } \\
\text { (cm) }\end{array}$ & $\mathbf{0}$ & $\mathbf{3 0}$ & $\mathbf{6 0}$ & $\mathbf{9 0}$ & $\mathbf{6 0}$ & $\mathbf{3 0}$ & $\mathbf{0}$ \\
\cline { 2 - 6 } & $\mathbf{5}$ & 8,91 & 8,62 & 8,10 & & 8,10 & 8,62 & 8,91 \\
$\mathbf{2 5}$ & 16,04 & 17,16 & 17,19 & & 17,19 & 17,16 & 16,04 \\
$\mathbf{5 0}$ & 17,72 & 18,10 & 17,61 & & 17,61 & 18,10 & 17,72 \\
$\mathbf{7 5}$ & 18,39 & 19,36 & 19,44 & 12,60 & 19,44 & 19,36 & 18,39 \\
$\mathbf{1 0 0}$ & 19,00 & 19,67 & 20,38 & 20,00 & 20,38 & 19,67 & 19,00 \\
$\mathbf{1 2 5}$ & 19,49 & 20,09 & 20,66 & 20,63 & 20,66 & 20,09 & 19,49 \\
$\mathbf{1 5 0}$ & 20,13 & 20,54 & 21,14 & 21,22 & 21,14 & 20,54 & 20,13 \\
$\mathbf{1 7 5}$ & 20,22 & 21,75 & 22,28 & 22,50 & 22,28 & 21,75 & 20,22 \\
\hline
\end{tabular}

Figura 5.19f - Perfil de umidade observado no instante $t=5 \mathrm{~h}$ da redistribuição $-\mathrm{Solo2}$

\begin{tabular}{c|cccccccc|}
$\begin{array}{c}\text { larg./prof. } \\
\text { (cm) }\end{array}$ & $\mathbf{0}$ & $\mathbf{3 0}$ & $\mathbf{6 0}$ & $\mathbf{9 0}$ & $\mathbf{6 0}$ & $\mathbf{3 0}$ & $\mathbf{0}$ \\
\cline { 2 - 4 } $\mathbf{5}$ & $\mathbf{8}, 88$ & 8,66 & 7,95 & & 7,95 & 8,66 & 8,88 \\
$\mathbf{2 5}$ & 16,04 & 17,21 & 16,93 & & 16,93 & 17,21 & 16,04 \\
$\mathbf{5 0}$ & 17,58 & 18,00 & 17,21 & & 17,21 & 18,00 & 17,58 \\
$\mathbf{7 5}$ & 18,05 & 18,65 & 18,75 & 12,12 & 18,75 & 18,65 & 18,05 \\
$\mathbf{1 0 0}$ & 18,10 & 18,94 & 19,45 & 19,15 & 19,45 & 18,94 & 18,10 \\
$\mathbf{1 2 5}$ & 18,95 & 19,51 & 20,16 & 19,66 & 20,16 & 19,51 & 18,95 \\
$\mathbf{1 5 0}$ & 19,39 & 20,30 & 20,29 & 20,61 & 20,29 & 20,30 & 19,39 \\
$\mathbf{1 7 5}$ & 20,03 & 20,50 & 21,38 & 21,85 & 21,38 & 20,50 & 20,03 \\
\hline
\end{tabular}

Figura 5.19g - Perfil de umidade observado no instante $t=24$ h da redistribuição - Solo2 


\begin{tabular}{|c|c|c|c|c|c|c|c|}
\hline \multirow[b]{2}{*}{$\begin{array}{c}\text { larg/prof. } \\
\text { (cm) }\end{array}$} & \multicolumn{7}{|l|}{$\mathrm{t}=48 \mathrm{~h}$} \\
\hline & 0 & 30 & 60 & 90 & 60 & 30 & 0 \\
\hline 5 & 8,88 & 8,64 & 7,92 & & 7,92 & 8,64 & 8,88 \\
\hline 25 & 16,05 & 17,25 & 16,67 & & 16,67 & 17,25 & 16,05 \\
\hline 50 & 17,35 & 17,82 & 16,79 & & 16,79 & 17,82 & 17,35 \\
\hline 75 & 17,66 & 18,40 & 17,98 & 11,80 & 17,98 & 18,40 & 17,66 \\
\hline 100 & 18,08 & 18,36 & 19,22 & 18,51 & 19,22 & 18,36 & 18,08 \\
\hline 125 & 18,80 & 18,97 & 19,47 & 19,16 & 19,47 & 18,97 & 18,80 \\
\hline 150 & 19,42 & 19,38 & 19,83 & 20,09 & 19,83 & 19,38 & 19,42 \\
\hline 175 & 19,39 & 20,24 & 20,57 & 21,33 & 20,57 & 20,24 & 19,39 \\
\hline
\end{tabular}

Figura $5.19 \mathrm{~h}$ - Perfil de umidade observado no instante $t=48 \mathrm{~h}$ da redistribuição - Solo2

\begin{tabular}{|c|c|c|c|c|c|c|c|}
\hline $\begin{array}{l}\text { larg./prof. } \\
\text { (cm) }\end{array}$ & 0 & 30 & 60 & 90 & 60 & 30 & 0 \\
\hline 5 & 8,45 & 8,51 & 7,81 & & 7,81 & 8,51 & 8,45 \\
\hline 25 & 16,10 & 17,14 & 15,85 & & 15,85 & 17,14 & 16,10 \\
\hline 50 & 16,88 & 17,32 & 15,98 & & 15,98 & 17,32 & 16,88 \\
\hline 75 & 17,27 & 17,57 & 17,75 & 10,83 & 17,75 & 17,57 & 17,27 \\
\hline 100 & 17,69 & 17,93 & 18,59 & 17,99 & 18,59 & 17,93 & 17,69 \\
\hline 125 & 18,09 & 18,46 & 19,29 & 18,64 & 19,29 & 18,46 & 18,09 \\
\hline 150 & 18,70 & 18,62 & 19,50 & 19,56 & 19,50 & 18,62 & 18,70 \\
\hline 175 & 19,32 & 19,84 & 20,09 & 20,73 & 20,09 & 19,84 & 19,32 \\
\hline
\end{tabular}

Figura 5.19i - Perfil de umidade observado no instante $t=120 \mathrm{~h}$ da redistribuição - Solo2

Para efeito de visualização, os valores de umidade apresentados nas Figuras 5.18 e 5.19 foram interpolados, com o auxílio do software Idrisi, e são apresentados nas Figuras 5.20a-i.

Solo 1

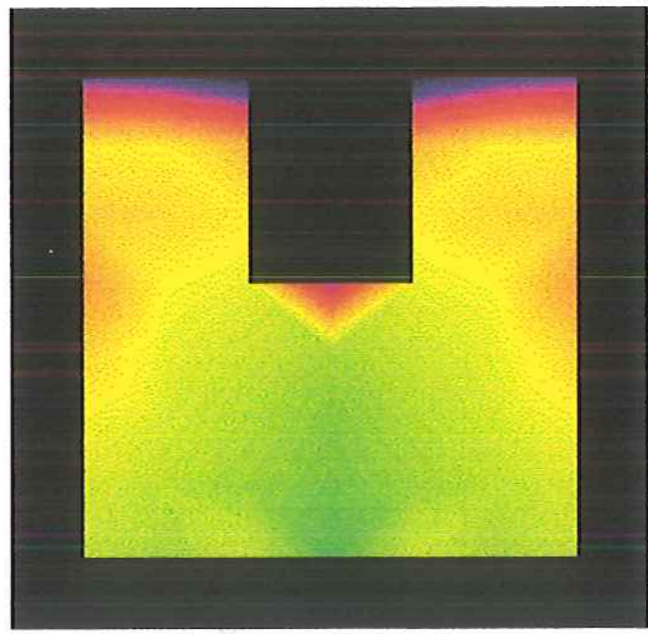

Solo 2

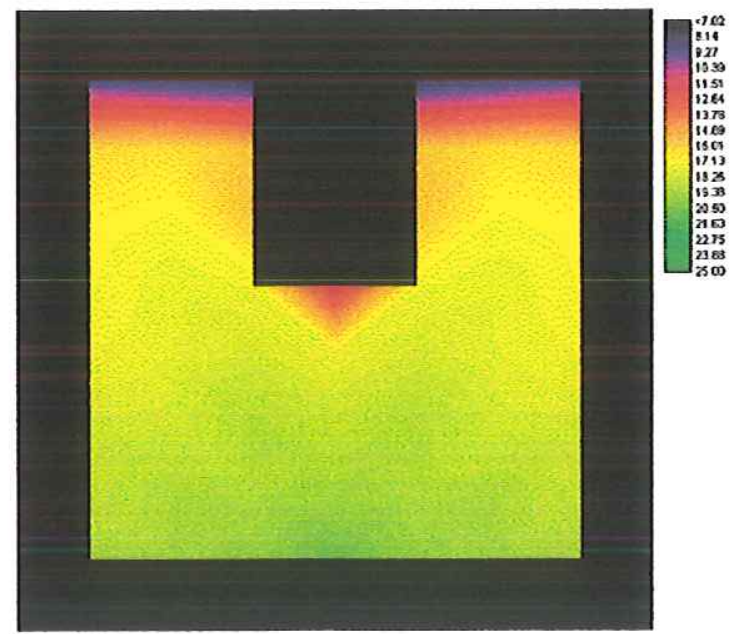

Figura 5.20a - Campo de umidade antes da irrigação 

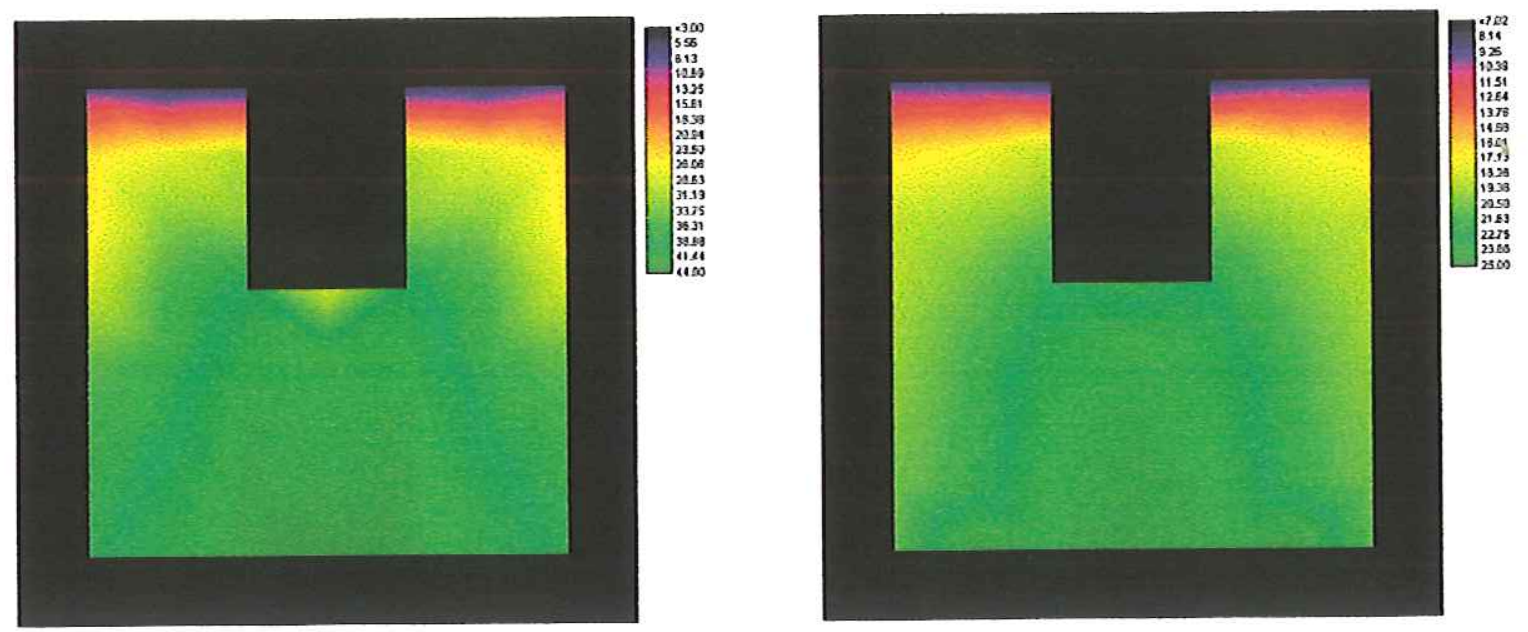

Figura 5.20b - Campo de umidade em $\mathrm{t}=0$ (início da redistribuição)
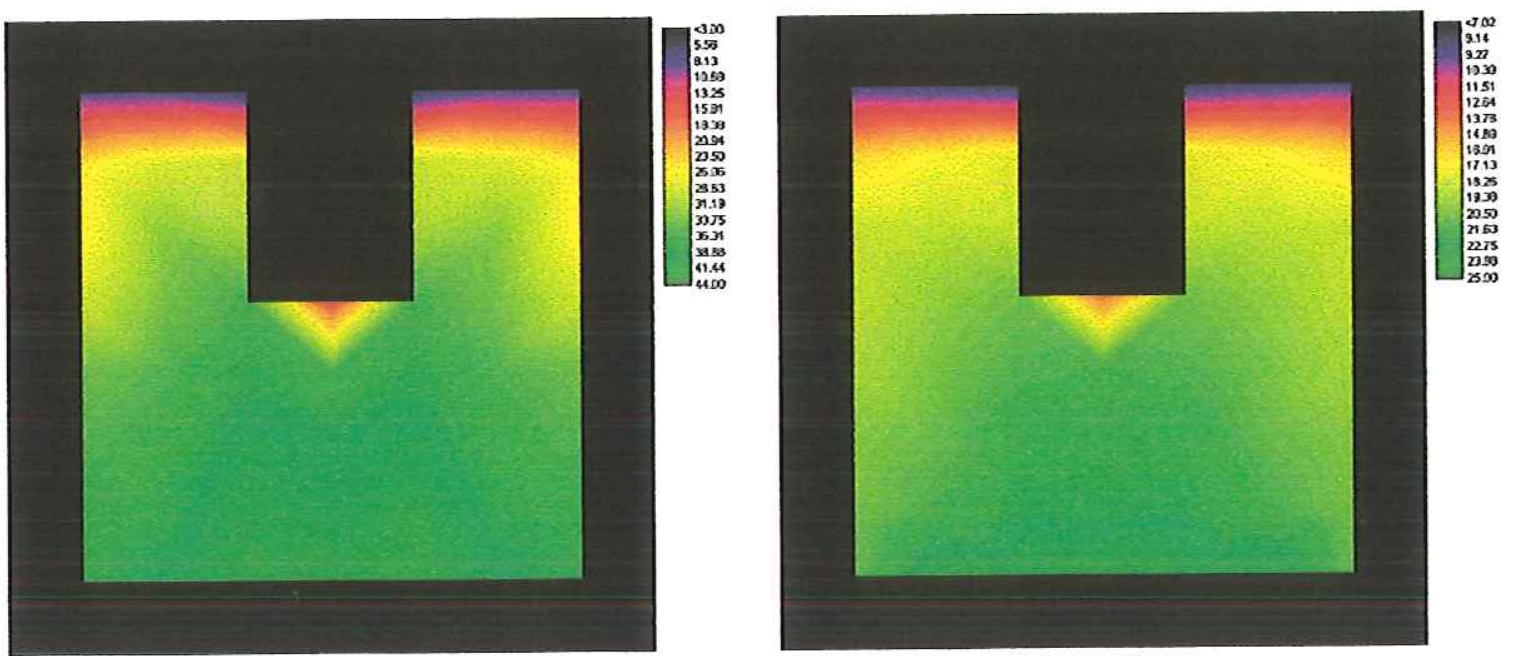

Figura 5.20c - Campo de umidade em $t=1 \mathrm{~h}$
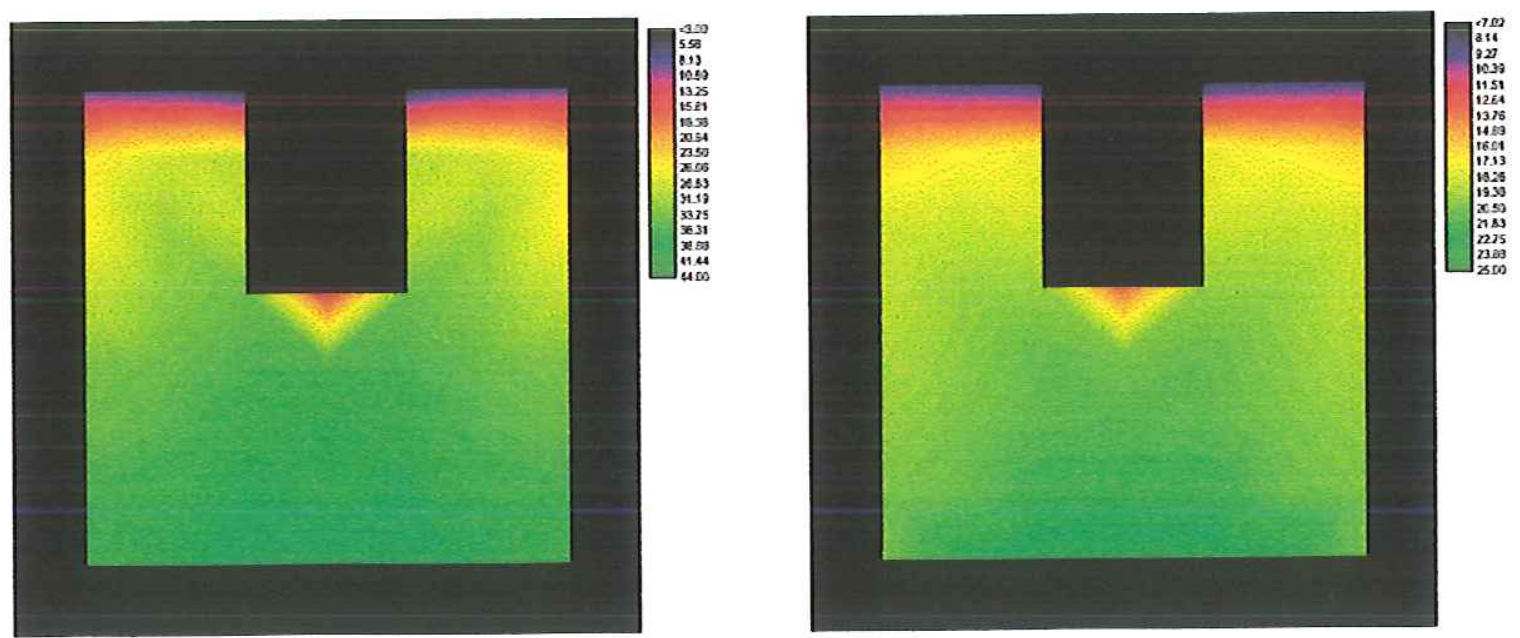

Figura 5.20d - Campo de umidade em $t=2 h$ 

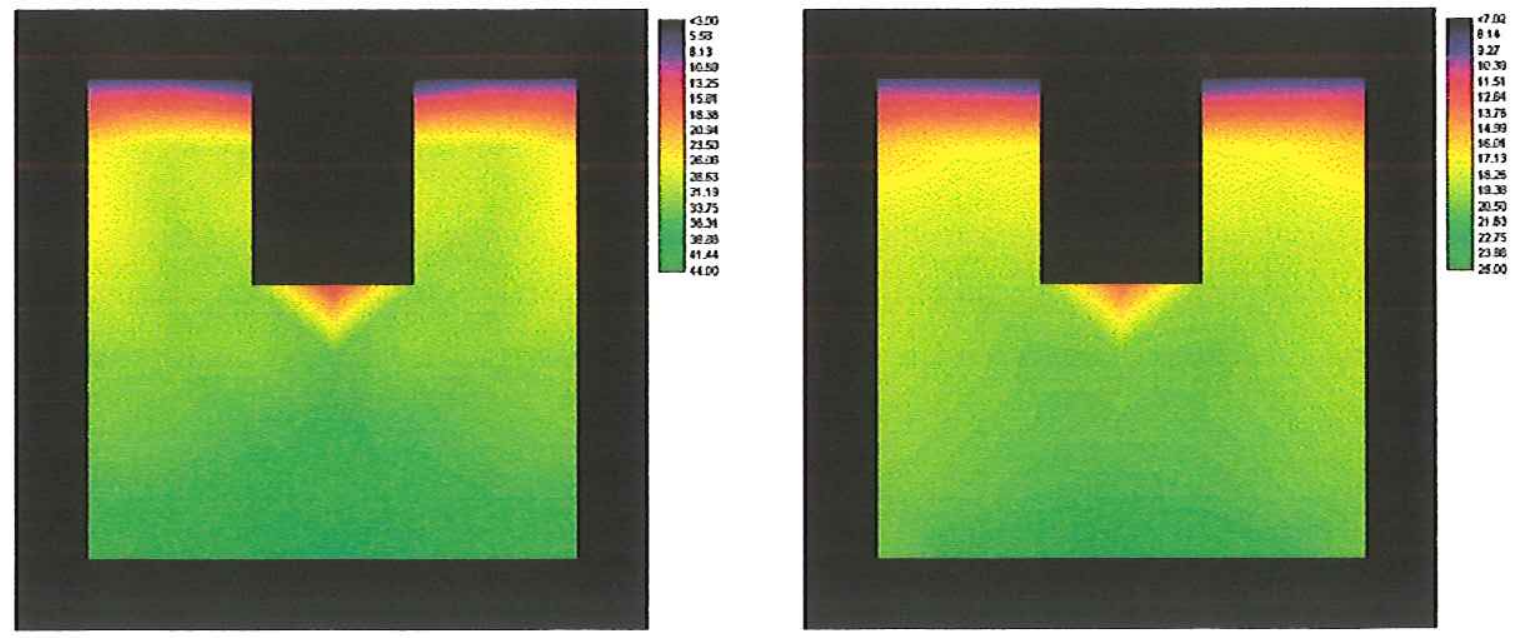

Figura 5.20e - Campo de umidade em $t=3: 30 h$
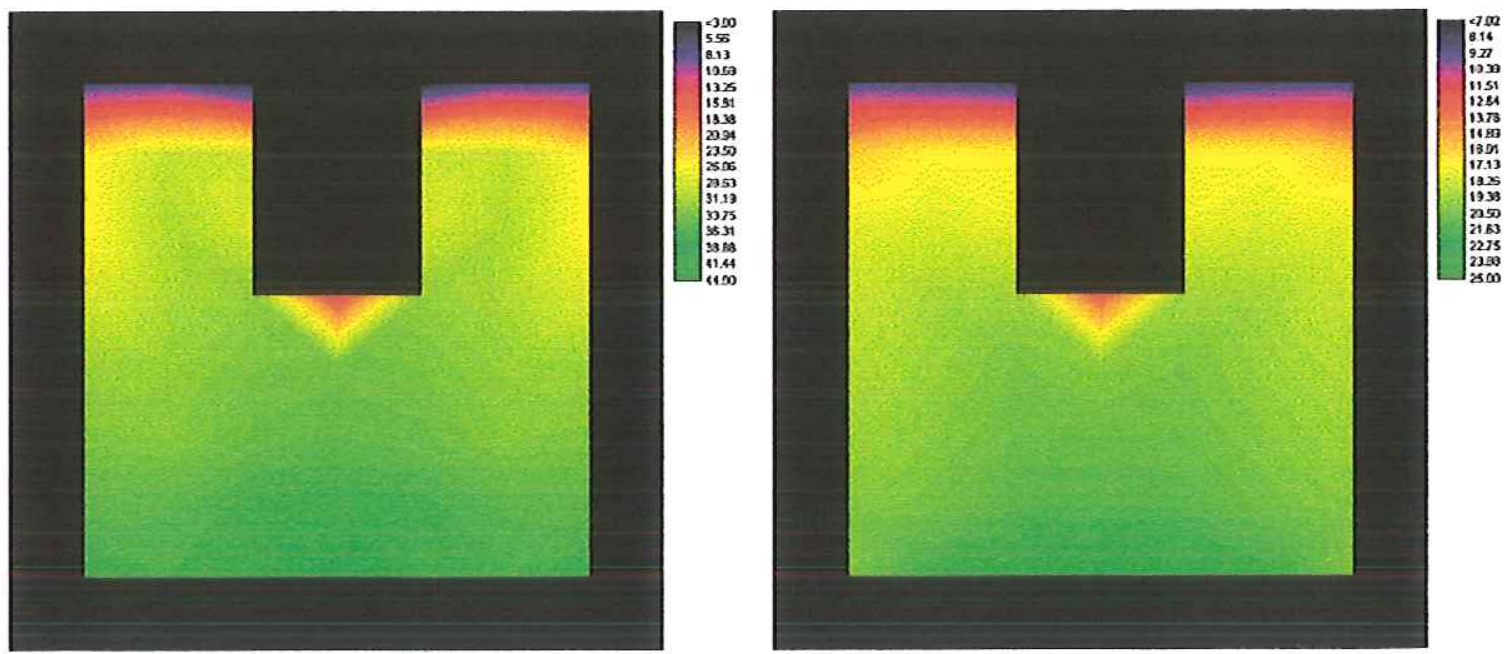

Figura 5.20f - Campo de umidade em $t=5 \mathrm{~h}$
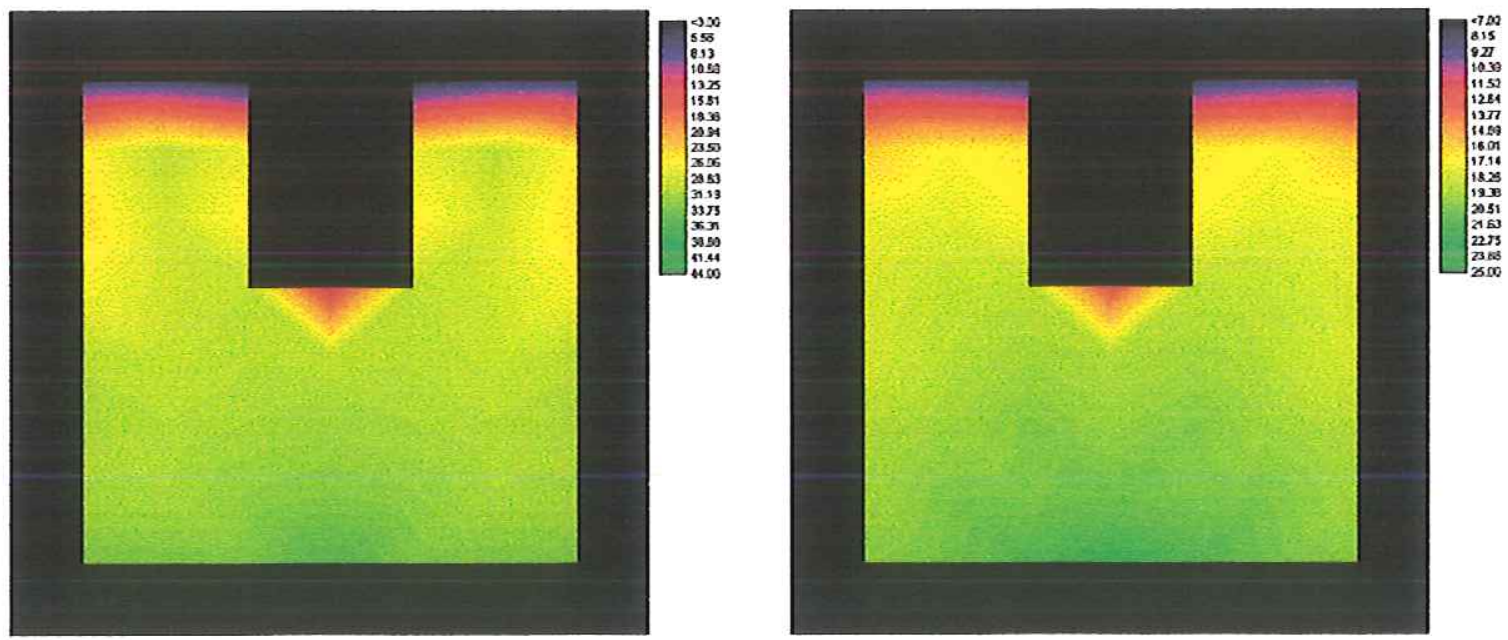

Figura 5.20g - Campo de umidade em $t=24 \mathrm{~h}$ 

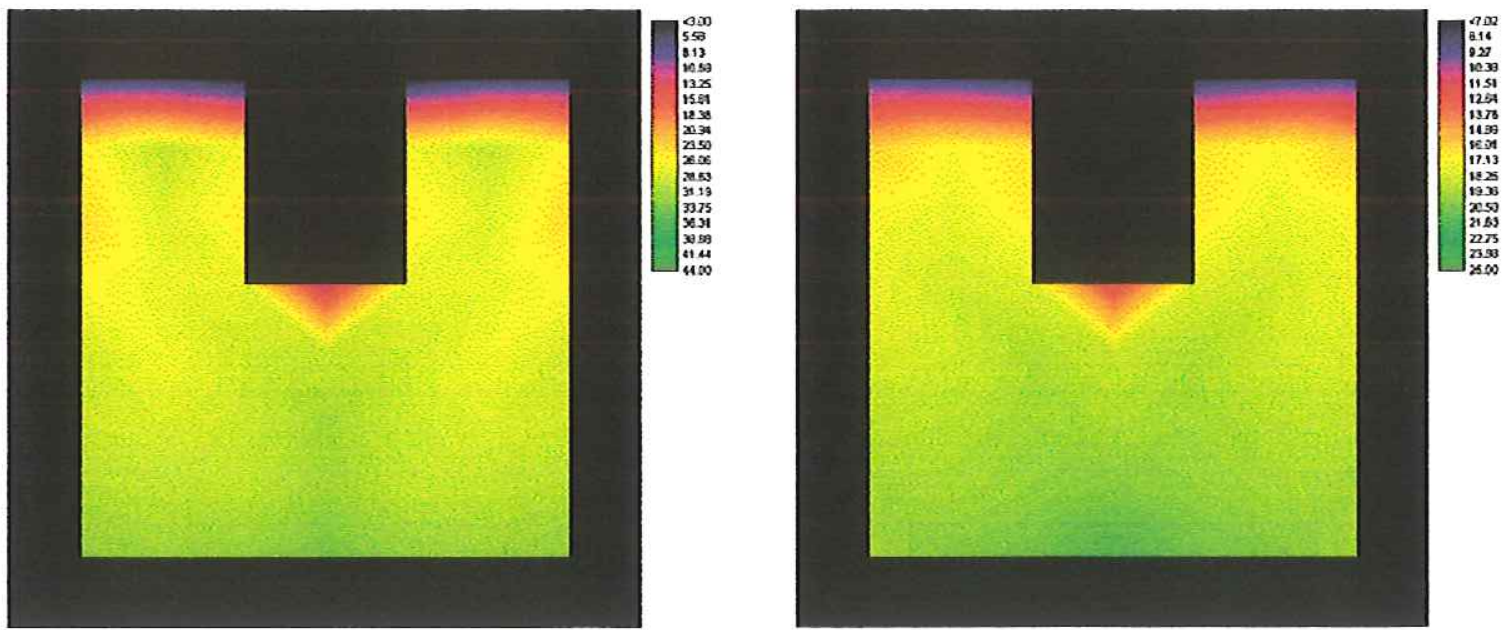

Figura 5.20h - Campo de umidade em $t=48 \mathrm{~h}$
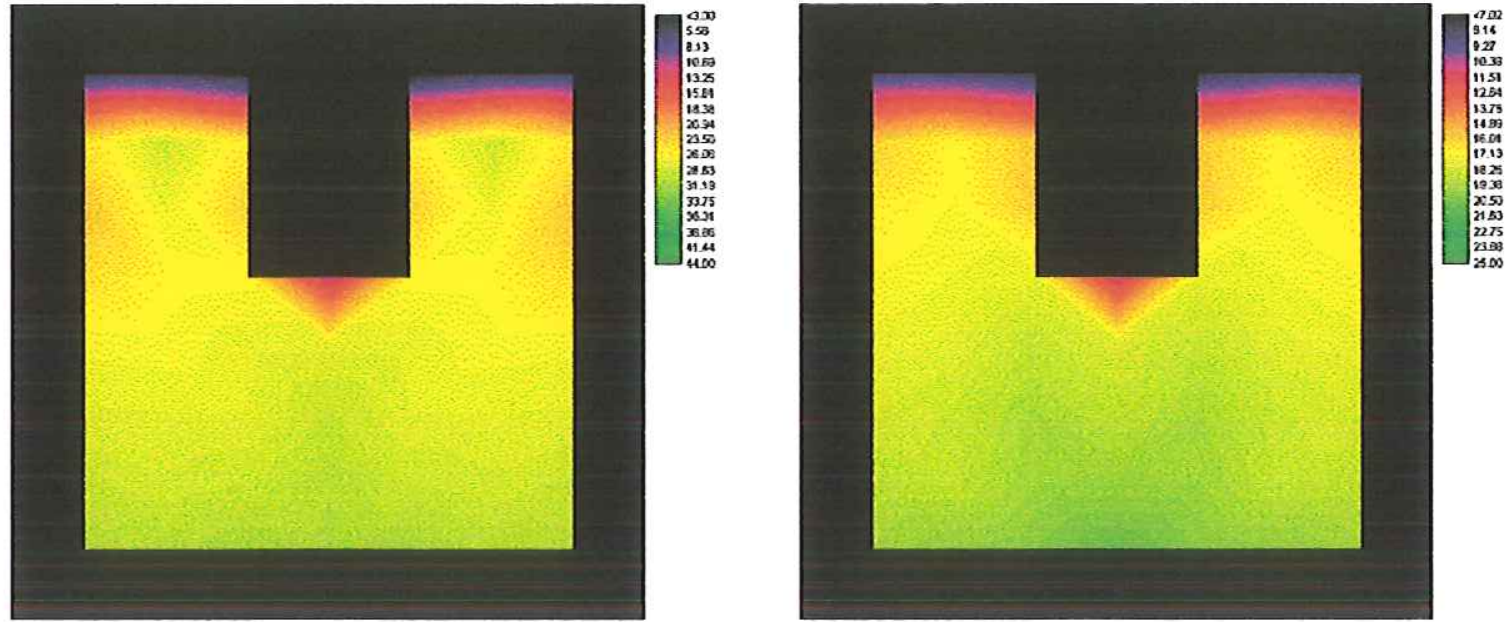

Figura 5.20i - Campo de umidade em $t=120 \mathrm{~h}$

Os campos de iso-umidade são apresentados nas Figuras 5.20a-i, em que são visualizadas as mudanças temporais na distribuição da umidade em torno da trincheira durante e após a aplicação de água.

Observa-se que, no início, o solo se encontrava relativamente seco nas superfícies expostas da trincheira (tanto o terreno quanto as laterais internas da trincheira). Logo após a infiltração, ou seja, no início da redistribuição, a porção mais umedecida do solo concentrava-se mais abaixo do fundo da trincheira do que nos lados.

Em aproximadamente 2 horas, a maior parte da água infiltrada já tinha se afastado do "campo de visão" da sonda de nêutrons (profundidade 1,70 m). Observa-se ainda, pela comparação do andamento da redistribuição da água infiltrada nos dois solos, que a matriz no fundo da trincheira, no caso do Solo 2 (areia média), conforme era de se esperar, drena 
mais rapidamente do que no caso do Solo 1 (areia fina). Tal fato fica mais evidente nas Figuras $5.20 \mathrm{c}$ e d.

\subsection{Simulação numérica}

Foram realizadas as simulações A e B, descritas no item 4.2.1, para os solos 1 e 2. Os resultados das simulações são apresentados em duas partes: a primeira, referente às fases de alimentação e recessão, em que se obteve dados de nível d'água na trincheira e volume infiltrado, apresentados nas Tabelas 5.11 (simulação A) e 5.12 (simulação B), e nas Figuras 5.25 e 5.26 (simulação A) e 5.31 e 5.32 (simulação B), e a segunda, referente à fase de redistribuição, em que se obteve os perfis de umidade ao redor das trincheiras, apresentados nas Figuras 5.27 e 5.28 (Simulação A) e 5.33 e 5.37 (Simulação B).

\subsubsection{Simulação A}

As simulações para os Solos 1 e 2 foram realizadas utilizando as mesmas vazões dos experimentos de campo, ou seja, $\mathrm{Q}=770 \mathrm{~cm}^{3} / \mathrm{s}$ para o Solo $1 \mathrm{e} \mathrm{Q}=860 \mathrm{~cm}^{3} / \mathrm{s}$ para o Solo 2 , sendo que, em ambos, o tempo de alimentação é $\mathrm{t}=72 \mathrm{~min}$. A simulação foi conduzida de modo a cessar quando fosse atingido o máximo nível d'água na trincheira ou o tempo total de alimentação $\mathrm{t}=72 \mathrm{~min}$. Considerou-se o nível $\mathrm{h}=69 \mathrm{~cm}$ como a máxima lâmina d'água posível na trincheira, cujo valor, ao ser atingido ou superado, cessaria a simulação.

As Figuras 5.21 a 5.24 apresentam os arquivos de entrada da Simulação A para os Solos 1 e 2. Detalhes sobre o formato e conteúdo dos arquivos de entrada são especificados no Capítulo 6 - Estrutura e manual de instruções do modelo computacional. 


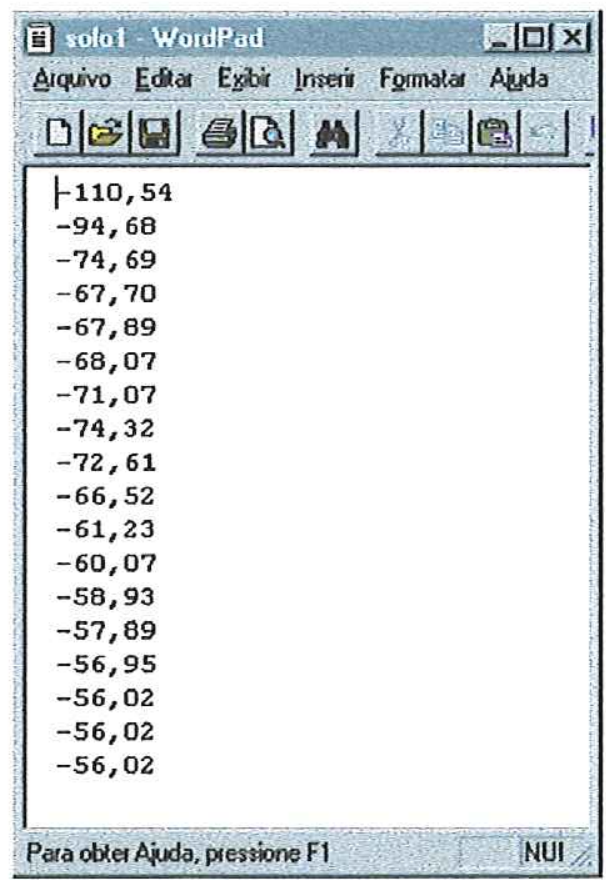

Figura 5.21 - Arquivo de entrada da Simulação A para o Solo 1: vetor com os valores iniciais de h ( cm $\left._{\mathrm{HzO}}\right)$

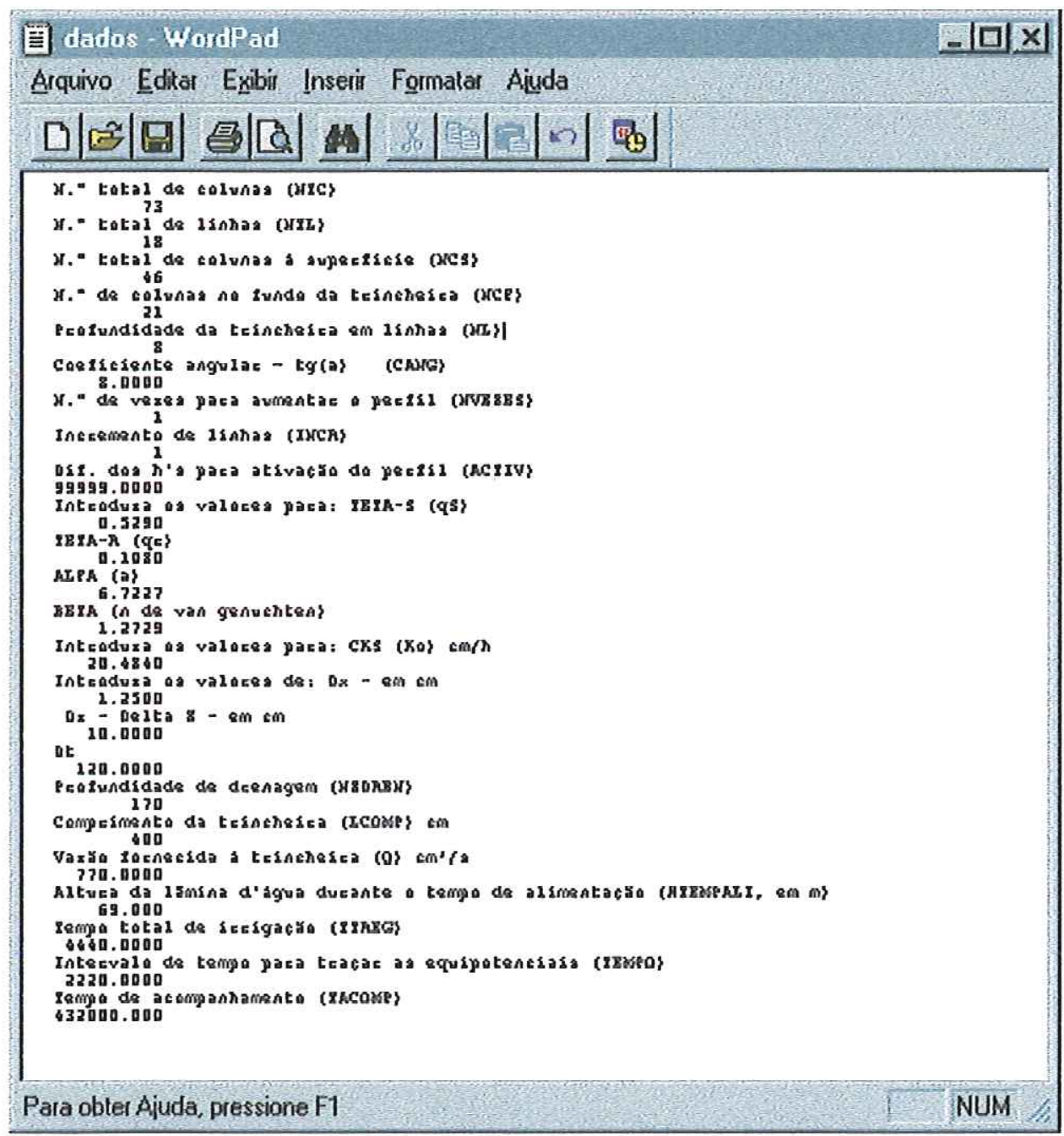

Figura 5.22 - Arquivo de entrada da Simulação A para o Solo 1: variáveis e parâmetros do modelo 


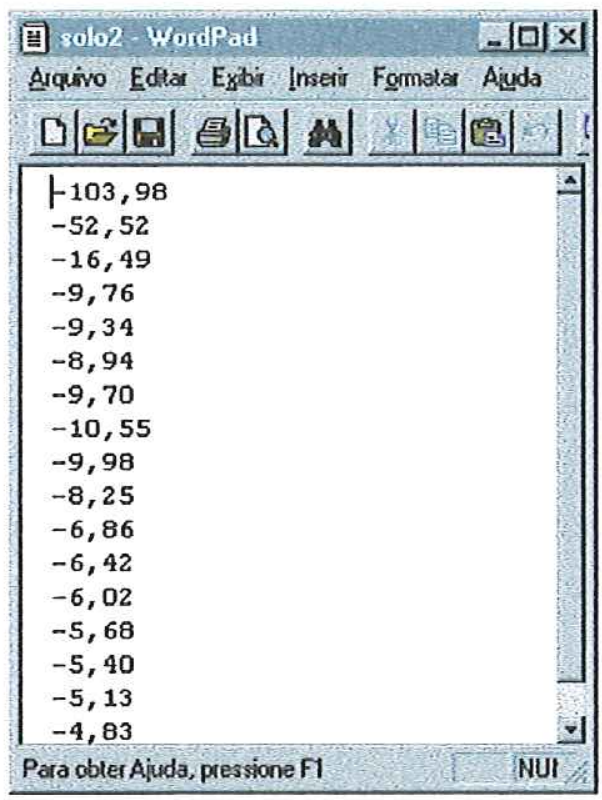

Figura 5.23 - Arquivo de entrada da Simulação A para o Solo 2: vetor com os valores iniciais de h ( (cm $_{\mathrm{H} 2 \mathrm{O})}$

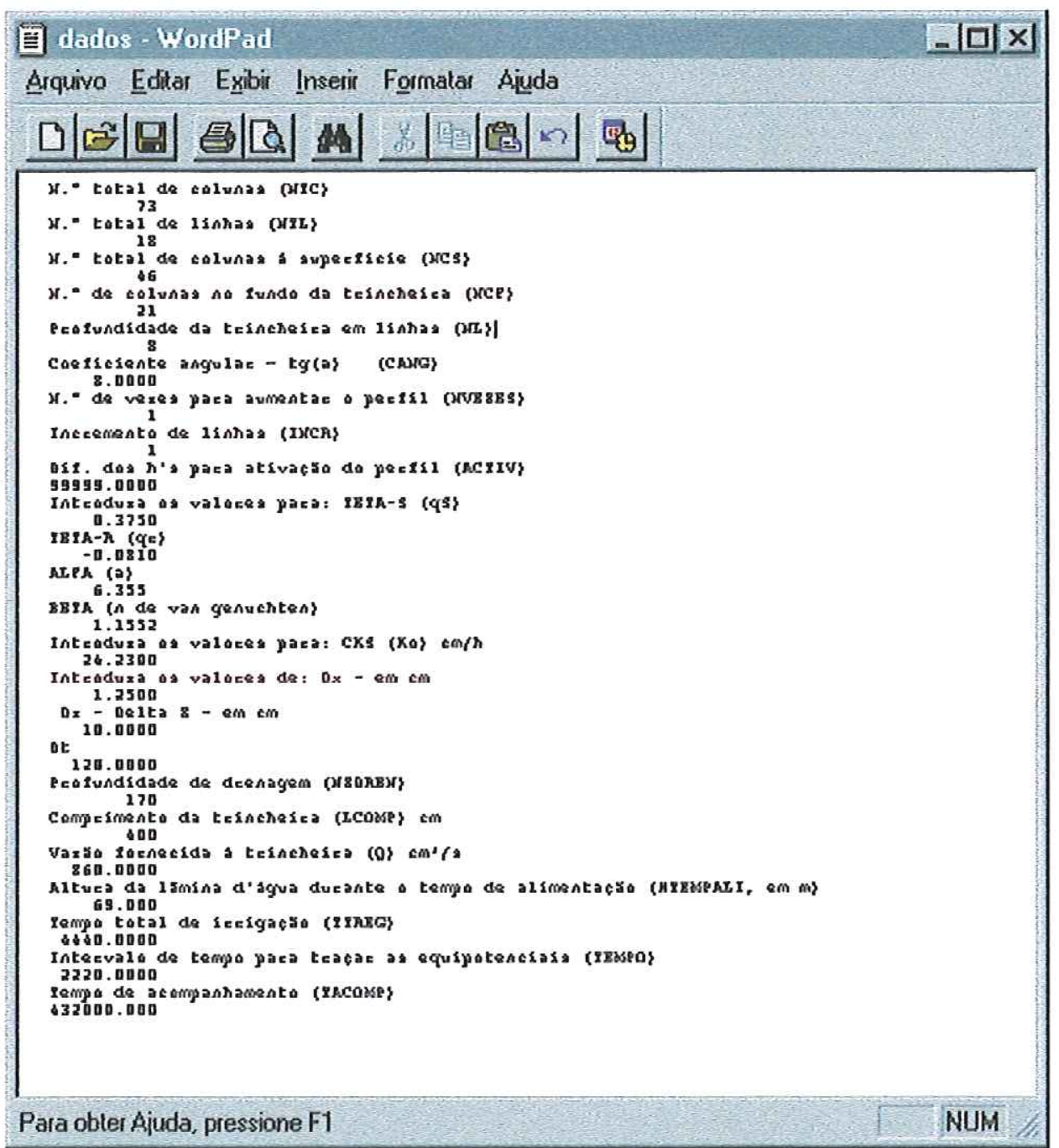

Figura 5.24 - Arquivo de entrada da Simulação A para o Solo 2: variáveis e parâmetros do modelo 
Tabela 5.11 - Fases de alimentação e recessão: Simulação A - valores de lâmina d'água e volume infiltrado, simulados e observados, Solos 1 e 2

\begin{tabular}{|c|c|c|c|c|c|c|c|c|}
\hline \multirow[b]{2}{*}{$t$ (min) } & \multicolumn{2}{|c|}{$\begin{array}{c}\text { Solo } 1 \\
\text { Simulação A }\end{array}$} & \multicolumn{2}{|c|}{$\begin{array}{c}\text { Solo } 1 \\
\text { Observado }\end{array}$} & \multicolumn{2}{|c|}{$\begin{array}{c}\text { Solo } 2 \\
\text { Simulação A }\end{array}$} & \multicolumn{2}{|c|}{$\begin{array}{c}\text { Solo } 2 \\
\text { Observado }\end{array}$} \\
\hline & $\begin{array}{l}\text { lag } \\
(\mathrm{cm})\end{array}$ & $\begin{array}{l}\text { Vinf. } \\
\left(\mathrm{m}^{3}\right)\end{array}$ & $\begin{array}{c}\text { lag } \\
(\mathrm{cm})\end{array}$ & $\begin{array}{l}\text { Vinf. } \\
\left(\mathrm{m}^{3}\right)\end{array}$ & $\begin{array}{c}\operatorname{lag} \\
(\mathrm{cm})\end{array}$ & $\begin{array}{l}\text { V inf. } \\
\left(\mathrm{m}^{3}\right)\end{array}$ & $\operatorname{lag}(\mathrm{cm})$ & $\begin{array}{l}\text { Vinf. } \\
\left(\mathrm{m}^{3}\right)\end{array}$ \\
\hline 0 & 2,81 & $0, \infty$ & 0,11 & 0,00 & 5,10 & 0,00 & 0,00 & 0,00 \\
\hline 2 & 3,74 & 0,04 & 3,72 & 0,05 & 3,99 & 0,02 & 2,30 & 0,11 \\
\hline 4 & 4,49 & 0,11 & 6,02 & 0,09 & 6,79 & 0,07 & 5,80 & 0,20 \\
\hline 6 & 4,57 & 0,19 & 8,20 & 0,11 & 9,49 & 0,12 & 8,60 & 0,24 \\
\hline 8 & 5,08 & 0,27 & 10,50 & 0,16 & 12,15 & 0,16 & 12,28 & 0,26 \\
\hline 10 & 5,49 & 0,35 & 14,00 & 0,21 & 14,62 & 0,21 & 15,94 & 0,29 \\
\hline 12 & 5,75 & 0,44 & 17,67 & 0,23 & 16,95 & 0,27 & 19,39 & 0,32 \\
\hline 14 & 5,76 & 0,53 & 20,31 & 0,27 & 19,22 & 0,32 & 22,73 & 0,35 \\
\hline 16 & 5,77 & 0,62 & 23,30 & 0,30 & 21,37 & 0,38 & 25,90 & 0,39 \\
\hline 18 & 5,85 & 0,72 & 25,82 & 0,35 & 23,09 & 0,44 & 29,02 & 0,43 \\
\hline 20 & 5,86 & 0,82 & 28,41 & 0,40 & 24,86 & 0,50 & 32,02 & 0,47 \\
\hline 22 & 6,29 & 0,89 & 31,10 & 0,45 & 27,49 & 0,55 & 34,81 & 0,53 \\
\hline 24 & 9,00 & 0,92 & 33,80 & 0,50 & 30,82 & 0,57 & 37,44 & 0,57 \\
\hline 26 & 11,65 & 0,96 & 36,73 & 0,55 & 33,73 & 0,61 & 39,96 & 0,62 \\
\hline 28 & 14,19 & 1,00 & 39,43 & 0,60 & 36,88 & 0,64 & 42,09 & 0,70 \\
\hline 30 & 16,65 & 1,04 & 41,78 & 0,65 & 39,93 & 0,67 & 44,44 & 0,74 \\
\hline 32 & 19,06 & 1,08 & 44,08 & 0,70 & 42,81 & 0,70 & 46,46 & 0,81 \\
\hline 34 & 21,42 & 1,12 & 46,31 & 0,75 & 45,62 & 0,74 & 48,71 & 0,86 \\
\hline 36 & 23,35 & 1,17 & 48,50 & 0,81 & 48,30 & 0,78 & 50,68 & 0,93 \\
\hline 38 & 25,45 & 1,21 & 50,28 & 0,87 & 51,00 & 0,81 & 52,76 & 0,99 \\
\hline 40 & 27,52 & 1,26 & 52,11 & 0,92 & 53,26 & 0,86 & 54,10 & 1,06 \\
\hline 42 & 29,58 & 1,31 & 53,78 & 0,98 & 56,74 & 0,90 & 55,80 & 1,13 \\
\hline 44 & 31,59 & 1,35 & 55,50 & 1,04 & 58,30 & 0,93 & 57,60 & 1,19 \\
\hline 46 & 33,04 & 1,41 & 56,99 & 1,10 & 60,84 & 0,97 & 58,90 & 1,26 \\
\hline 48 & 34,61 & 1,47 & 58,48 & 1,16 & 63,03 & 1,02 & 60,20 & 1,34 \\
\hline 50 & 36,25 & 1,52 & 59,69 & 1,22 & 65,58 & 1,05 & 61,40 & 1,42 \\
\hline 52 & 37,59 & 1,58 & 61,01 & 1,29 & 68,11 & 1,09 & 62,20 & 1,50 \\
\hline 54 & 39,43 & 1,63 & 61,98 & 1,36 & 70,62 & 1,12 & 63,90 & 1,57 \\
\hline 56 & 40,09 & $1, \circledast 9$ & 63,19 & 1,42 & 69,30 & 1,20 & 64,90 & 1,65 \\
\hline 58 & 41,49 & 1,76 & 64,22 & 1,48 & 67,97 & 1,23 & 65,80 & 1,72 \\
\hline 60 & 41,57 & 1,85 & 65,08 & 1,56 & 67,14 & 1,25 & 66,70 & 1,80 \\
\hline 62 & 41,72 & 1,94 & 65,89 & 1,61 & 65,74 & 1,29 & $67, \infty$ & 1,87 \\
\hline 64 & 41,92 & 2,03 & 66,81 & 1,67 & 64,37 & 1,33 & 68,40 & 1,95 \\
\hline 66 & 42,13 & 2,12 & 67,50 & 1,74 & 63,02 & 1,36 & 69,20 & 2,03 \\
\hline 68 & 44,17 & 2,16 & 68,13 & 1,81 & 61,68 & 1,40 & 69,70 & 2,11 \\
\hline 70 & 45,48 & 2,22 & 68,82 & 1,88 & 60,36 & 1,43 & 68,60 & 2,18 \\
\hline 72 & 46,75 & 2,28 & 69,39 & 1,94 & 59,04 & 1,47 & 64,40 & 2,26 \\
\hline 74 & 44,51 & 2,40 & 70,02 & 2,01 & 57,74 & 1,50 & 60,90 & 2,33 \\
\hline 76 & 42,34 & 2,45 & 67,21 & 2,11 & 57,35 & 1,51 & 57,40 & 2,40 \\
\hline 78 & 40,21 & 2,50 & 64,22 & 2,17 & 56,10 & 1,54 & 54,30 & 2,47 \\
\hline 80 & 38,07 & 2,55 & 61,30 & 2,23 & 55,19 & 1,57 & 51,40 & 2,52 \\
\hline 82 & 35,94 & 2,60 & 58,83 & 2,28 & 53,73 & 1,60 & 48,70 & 2,58 \\
\hline 84 & 35,51 & 2,61 & 56,19 & 2,33 & 52,84 & 1,63 & 45,90 & $2, \widetilde{3}$ \\
\hline 86 & 33,79 & 2,65 & 53,60 & 2,38 & 51,37 & 1,66 & 43,60 & 2,68 \\
\hline 88 & 32,30 & 2,69 & 51,08 & 2,43 & 50,69 & 1,68 & 41,20 & 2,73 \\
\hline 90 & 30,09 & 2,74 & 48,73 & 2,48 & 49,20 & 1,72 & 39,00 & 2,77 \\
\hline 92 & 28,75 & 2,77 & 46,60 & 2,52 & 48,00 & 1,75 & 36,90 & 2,81 \\
\hline 94 & 26,49 & 2,82 & 44,48 & 2,56 & 47,40 & 1,76 & 35,00 & 2,85 \\
\hline 96 & 26,05 & 2,83 & 42,35 & 2,61 & 46,16 & 1,79 & 33,00 & 2,89 \\
\hline 98 & 25,60 & 2,84 & 40,34 & 2,65 & 45,52 & 1,81 & 31,20 & 2,93 \\
\hline 100 & 25,16 & 2,85 & 38,28 & 2,69 & 44,31 & 1,84 & 29,60 & 2,96 \\
\hline 102 & 24,07 & 2,87 & 36,44 & 2,73 & 43,69 & 1,85 & 28,10 & 2,99 \\
\hline 104 & 22,60 & 2,91 & 34,55 & 2,76 & 42,47 & 1,88 & 26,80 & 3,02 \\
\hline 106 & 21,56 & 2,93 & 32,71 & 2,80 & 42,06 & 1,89 & 25,60 & 3,04 \\
\hline 108 & 21,11 & 2,94 & 30,99 & 2,83 & 41,10 & 1,92 & 24,30 & 3,07 \\
\hline 110 & 20,66 & 2,95 & 29,21 & 2,87 & 40,68 & 1,93 & 23,00 & 3,09 \\
\hline 112 & 20,21 & 2,96 & 27,66 & 2,90 & 40,26 & 1,94 & 21,70 & 3,12 \\
\hline 114 & 19,75 & 2,97 & 26,11 & 2,93 & 39,85 & 1,95 & 20,40 & 3,14 \\
\hline
\end{tabular}


Tabela 5.11 - Continuação. Fases de alimentação e recessão: Simulação A - valores de lâmina d'água e volume infiltrado, simulados e observados, Solos 1 e 2

\begin{tabular}{|c|c|c|c|c|c|c|c|c|}
\hline & \multicolumn{2}{|c|}{$\begin{array}{c}\text { Solo } 1 \\
\text { Simulaçāo A }\end{array}$} & \multicolumn{2}{|c|}{ Solo 1 Observado } & \multicolumn{2}{|c|}{$\begin{array}{c}\text { Solo } 2 \\
\text { Simulaçāo A }\end{array}$} & \multicolumn{2}{|c|}{$\begin{array}{c}\text { Solo } 2 \\
\text { Observado }\end{array}$} \\
\hline$t(\min )$ & $\begin{array}{l}\text { lag } \\
\text { (cm) }\end{array}$ & $\begin{array}{l}\text { Vinf. } \\
\left(m^{3}\right)\end{array}$ & $\operatorname{lag}(\mathrm{cm})$ & $\begin{array}{l}V \text { inf. } \\
\left(m^{3}\right)\end{array}$ & $\begin{array}{l}\text { lag } \\
\text { (cm) }\end{array}$ & $\begin{array}{l}\text { Vinf. } \\
\left(m^{3}\right)\end{array}$ & $\operatorname{lag}(\mathrm{cm})$ & $\begin{array}{l}\text { Vinf. } \\
\left(m^{3}\right)\end{array}$ \\
\hline 116 & 19,30 & 2,98 & 24,56 & 2,96 & 39,43 & 1,96 & 19,20 & 3,17 \\
\hline 118 & 18,84 & 2,99 & 23,12 & 2,99 & 39,01 & 1,97 & 18,00 & 3,19 \\
\hline 120 & 18,38 & 3,00 & 21,69 & 3,02 & 38,59 & 1,98 & 16,90 & 3,21 \\
\hline 122 & 17,92 & 3,01 & 20,37 & 3,05 & 38,17 & 1,99 & 15,90 & 3,23 \\
\hline 124 & 17,46 & 3,02 & 19,05 & 3,07 & 37,75 & 2,00 & 14,90 & 3,25 \\
\hline 126 & 17,00 & 3,03 & 17,79 & 3,10 & 37,33 & 2,01 & 13,90 & 3,27 \\
\hline 128 & 16,54 & 3,04 & 16,58 & 3,12 & 36,91 & 2,02 & 12,90 & 3,29 \\
\hline 130 & 16,08 & 3,05 & 15,38 & 3,15 & 36,49 & 2,03 & 11,90 & 3,31 \\
\hline 132 & 15,62 & 3,06 & 14,23 & 3,17 & 36,07 & 2,04 & 11,00 & 3,33 \\
\hline 134 & 15,15 & 3,07 & 13,08 & 3,19 & 35,64 & 2,06 & 10,10 & 3,35 \\
\hline 136 & 14,9 & 3,08 & 11,93 & 3,22 & 35,22 & 2,06 & 9,20 & 3,37 \\
\hline 138 & 14,22 & 3,09 & 10,90 & 3,24 & 34,79 & 2,07 & 8,40 & 3,38 \\
\hline 140 & 13,75 & 3,10 & 9,81 & 3,26 & 34,37 & 2,08 & 7,60 & 3,40 \\
\hline 142 & 13,28 & 3,11 & 8,77 & 3,28 & 33,94 & 2,09 & 6,90 & 3,41 \\
\hline 144 & 12,82 & 3,12 & 7,80 & 3,30 & 33,51 & 2,10 & 6,10 & 3,43 \\
\hline 146 & 12,35 & 3,13 & 6,82 & 3,32 & 33,08 & 2,11 & 5,40 & 3,44 \\
\hline 148 & 11,87 & 3,14 & 5,90 & 3,34 & 32,65 & 2,12 & 4,60 & 3,46 \\
\hline 150 & 11,40 & 3,15 & 4,99 & 3,35 & 32,22 & 2,13 & 3,80 & 3,48 \\
\hline 152 & 10,93 & 3,16 & 4,18 & 3,37 & 31,79 & 2,14 & 3,00 & 3,49 \\
\hline 154 & 10,45 & 3,17 & 3,38 & 3,39 & 31,36 & 2,15 & 2,30 & 3,51 \\
\hline 156 & 9,98 & 3,18 & 2,63 & 3,40 & 30,93 & 2,16 & 1,50 & 3,52 \\
\hline 158 & 9,50 & 3,19 & 1,94 & 3,42 & 30,49 & 2,17 & 0,70 & 3,54 \\
\hline 160 & 9,02 & 3,20 & 1,20 & 3,43 & 30,06 & 2,18 & 0,00 & 3,55 \\
\hline 162 & 8,54 & 3,21 & 0,45 & 3,45 & 29,62 & 2,19 & & \\
\hline 164 & 8,06 & 3,22 & & & 29,19 & 2,20 & & \\
\hline 166 & 7,58 & 3,23 & & & 28,75 & 2,21 & & \\
\hline 168 & 7,10 & 3,24 & & & 28,31 & 2,22 & & \\
\hline 170 & 6,62 & 3,25 & & & 27,87 & 2,23 & & \\
\hline 172 & 6,13 & 3,26 & & & 27,44 & 2,24 & & \\
\hline 174 & 5,65 & 3,27 & & & 27,00 & 2,25 & & \\
\hline 176 & 5,16 & 3,28 & & & 26,55 & 2,26 & & \\
\hline 178 & 4,67 & 3,29 & & & 26,11 & 2,27 & & \\
\hline 180 & 4,18 & 3,30 & & & 25,67 & 2,28 & & \\
\hline 182 & 3,69 & 3,31 & & & 25,23 & 2,29 & & \\
\hline 184 & 3,20 & 3,32 & & & 24,78 & 2,30 & & \\
\hline 186 & 2,71 & 3,33 & & & 24,34 & 2,31 & & \\
\hline 188 & 2,21 & 3,34 & & & 23,89 & 2,32 & & \\
\hline 190 & 1,72 & 3,35 & & & 23,44 & 2,33 & & \\
\hline 192 & 1,22 & 3,36 & & & 23,00 & 2,34 & & \\
\hline 194 & 0,00 & 3,36 & & & 22,55 & 2,35 & & \\
\hline 196 & 0,00 & 3,36 & & & 22,10 & 2,36 & & \\
\hline 198 & 0,00 & 3,36 & & & 21,65 & 2,37 & & \\
\hline 200 & 0,00 & 3,36 & & & 21,19 & 2,38 & & \\
\hline 202 & 0,00 & 3,36 & & & 20,74 & 2,39 & & \\
\hline 204 & 0,00 & 3,36 & & & 20,29 & 2,40 & & \\
\hline 206 & 0,00 & 3,36 & & & 19,83 & 2,41 & & \\
\hline 208 & 0,00 & 3,36 & & & 19,38 & 2,42 & & \\
\hline 210 & 0,00 & 3,36 & & & 18,92 & 2,43 & & \\
\hline 212 & 0,00 & 3,36 & & & 18,47 & 2,44 & & \\
\hline 214 & 0,00 & 3,36 & & & 18,01 & 2,45 & & \\
\hline 216 & 0,00 & 3,36 & & & 17,55 & 2,46 & & \\
\hline 218 & 0,00 & 3,36 & & & 17,09 & 2,47 & & \\
\hline 220 & 0,00 & 3,36 & & & 16,63 & 2,48 & & \\
\hline 222 & 0,00 & 3,36 & & & 16,16 & 2,49 & & \\
\hline 224 & 0,00 & 3,36 & & & 15,70 & 2,50 & & \\
\hline 226 & 0,00 & 3,36 & & & 15,24 & 2,51 & & \\
\hline 228 & 0,00 & 3,36 & & & 14,77 & 2,52 & & \\
\hline
\end{tabular}


Tabela 5.11 - Continuação. Fases de alimentação e recessão: Simulação A - valores de lâmina d'água e volume infiltrado, simulados e observados, Solos 1 e 2

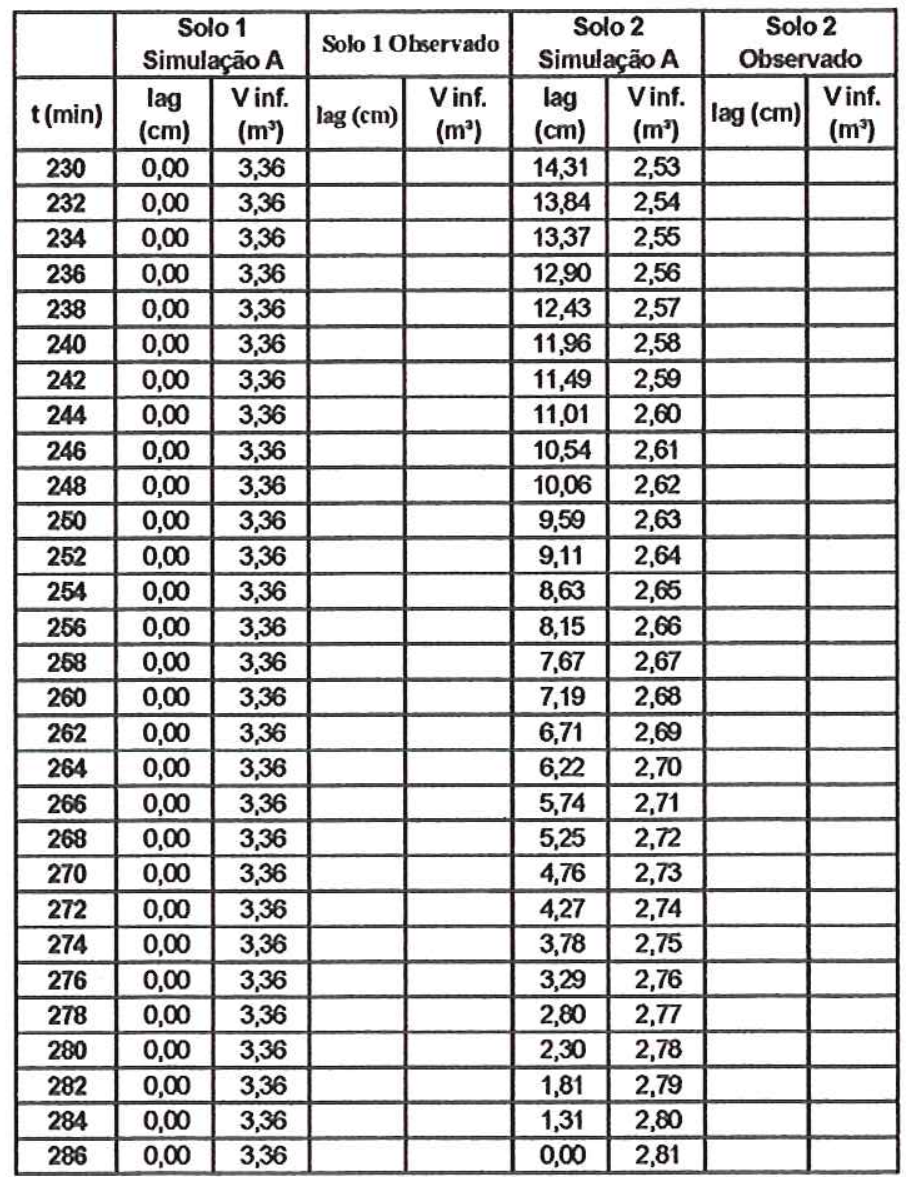

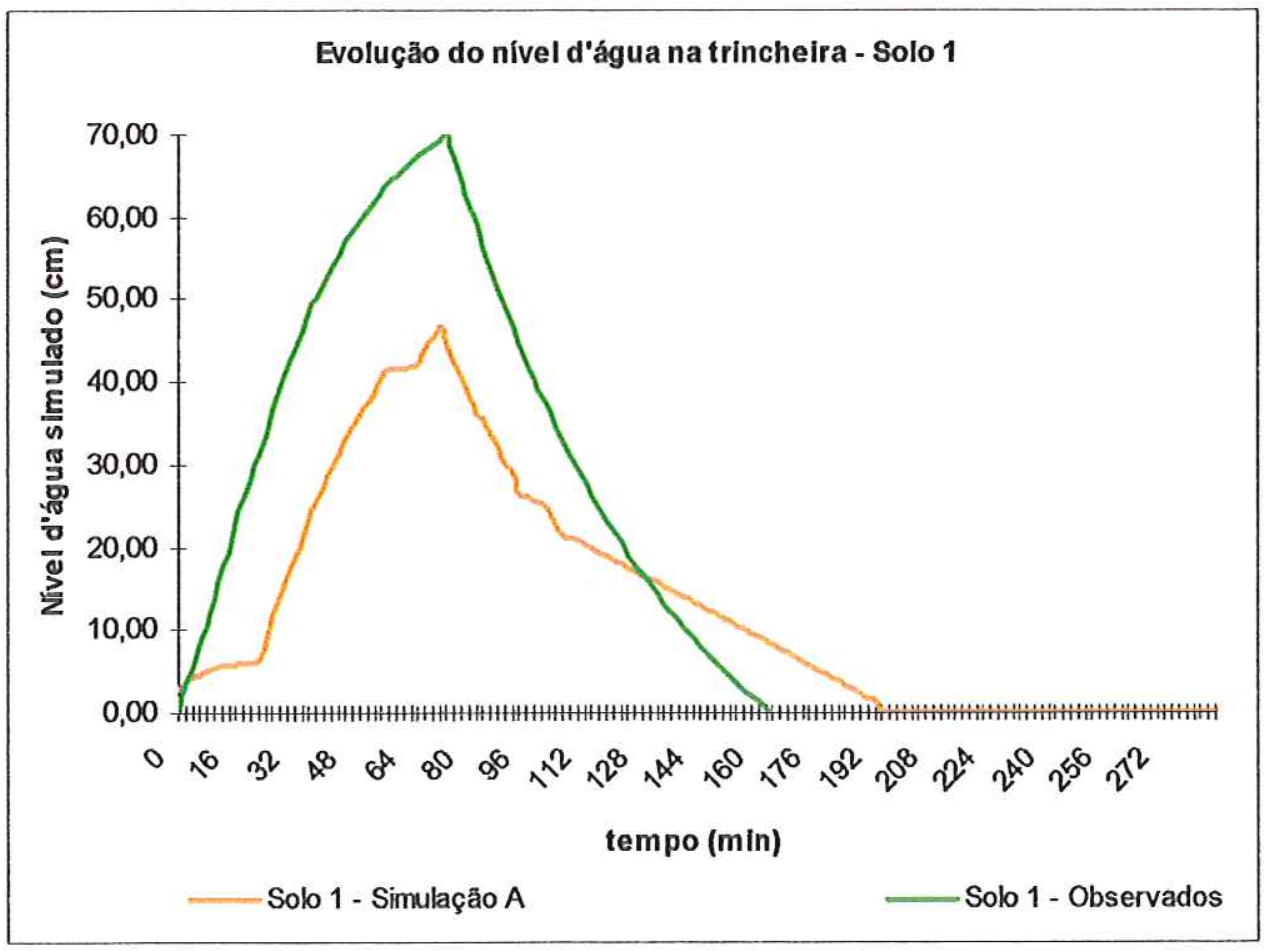

Figura 5.25 - Evolução do nível dágua na trincheira Solo 1 - Simulação A e valores observados 


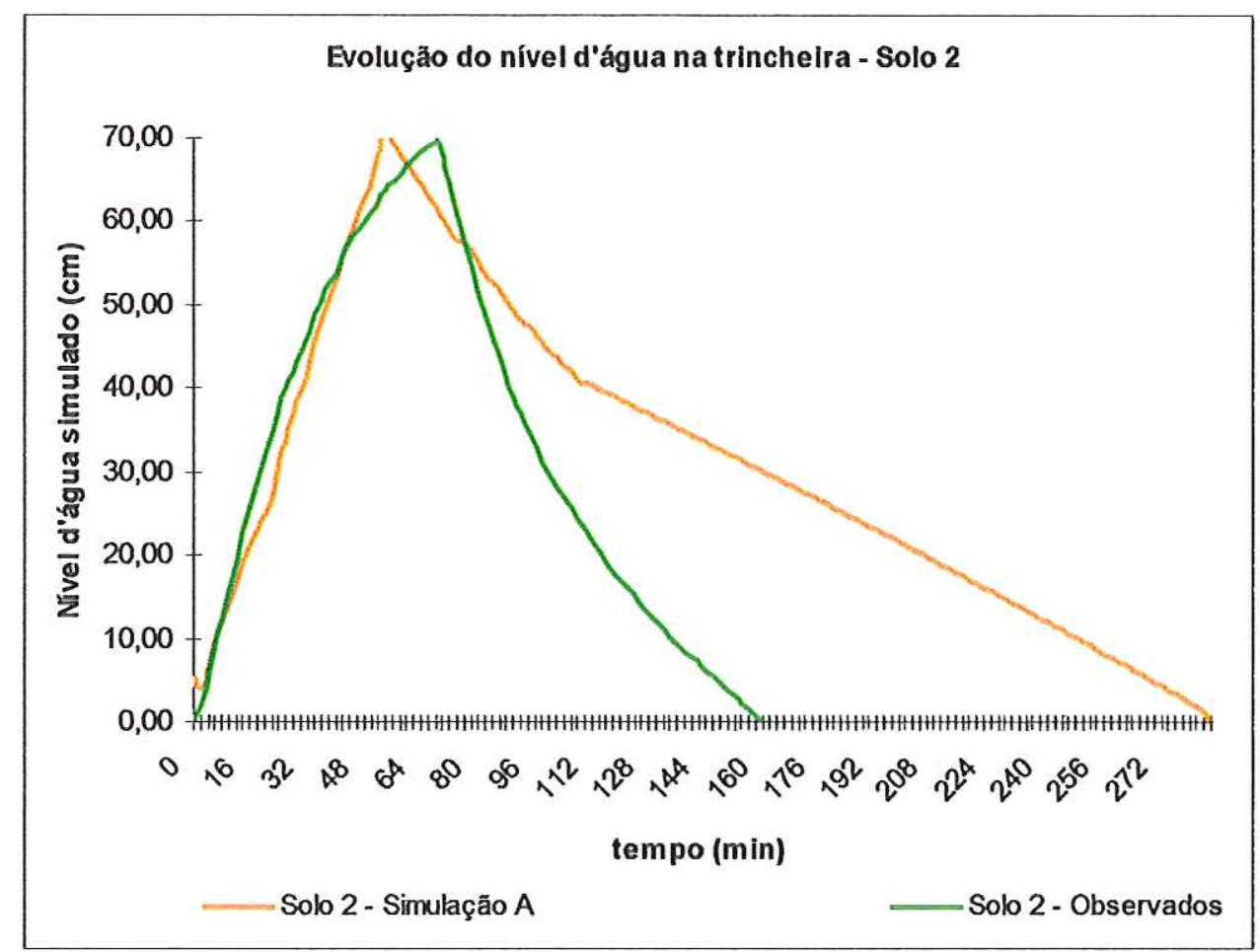

Figura 5.26 - Evolução do nível dágua na trincheira Solo 2 - Simulação A e valores observados

Conforme pode ser observado na Tabela 5.11, na Simulação A para o Solo 1, verificou-se que, ao final da alimentação ( $\mathrm{t}=72 \mathrm{~min})$, ainda não havia sido atingido o nível d'água máximo na trincheira. Esse resultado revela uma estimativa superestimada da taxa de infiltração do solo, uma vez que, nos valores observados para o Solo 1, para a mesma vazão e tempo de alimentação, o nível máximo foi atingido. A simulação A para o Solo 2 apresentou comportamento distinto: o nível máximo na trincheira, de $70,62 \mathrm{~cm}$, foi atingido aos 54 minutos da alimentação, ou seja, 14 minutos antes do observado nos experimentos de campo, revelando uma estimativa da taxa de infiltração, durante a fase de alimentação, inferior à observada em campo.

Se, durante a fase de alimentação, a capacidade de infiltração da trincheira se revelou superestimada para o Solo 1 e subestimada para o Solo 2, na fase de recessão a simulação apresentou valores de infiltração muito abaixo dos observados para ambos os solos, subestimando a capacidade da trincheira, fato que é mais facilmente visualizado nas Figuras 5.25 e 5.26. Os valores de lâmina d'água observados em campo revelaram que, na trincheira instalada no Solo 1, a fase de recessão acabou aos 164 minutos contados a partir do início da alimentação, e, no Solo 2, aos 160 minutos. Os valores simulados foram de 194 minutos para o Solo 1 e 286 minutos para o Solo 2. 
Nas Figuras 5.27 e 5.28 observa-se o desenvolvimento dos perfis de umidade dos Solos 1 e 2, respectivamente, durante a fase de redistribuição.

\begin{tabular}{|c|c|c|c|c|c|c|c|c|c|c|c|c|c|c|c|c|c|c|c|}
\hline $\begin{array}{l}\text { rotharg } \\
\text { (cm) }\end{array}$ & 1 & 10 & 20 & 30 & 40 & 50 & 60 & 70 & 80 & 90 & 100 & 110 & 120 & 130 & 140 & 150 & 160 & 170 & 180 \\
\hline 10 & 209 & 209 & 209 & 209 & 209 & 209 & 1209 & & & & & & 0,1209 & 0,1209 & 0,1209 & 0,1200 & 0,1209 & 0,1209 & 0,12 \\
\hline 20 & 529 & 529 & 529 & 1529 & 529 & 29 & 0.1529 & & & & & & & 0.1529 & 0.1529 & 1529 & 0,1529 & 0,1529 & \\
\hline 30 & 7 & 2167 & 0,2167 & 0,2167 & 0,2167 & 0,2167 & 0,2167 & & & & & & 0,2167 & 0.2167 & 0,2167 & 0,2167 & 0,2167 & 0,2167 & 0.2167 \\
\hline 40 & $i$ & 2481 & 248 & 0.2481 & 0,2481 & 0.2481 & 0.2481 & & & & & & 0,2481 & 0,2481 & 0,2481 & 0.2481 & 0,2481 & 0,2481 & 0,2481 \\
\hline 50 & 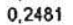 & 2481 & 0.2481 & 0,2481 & 0,2481 & 0,2481 & 0,24 & & & & & & 0,2481 & 0.2481 & 0,2481 & 0.2481 & 0,2481 & 0,2481 & 0.2481 \\
\hline 60 & 12 & 2432 & 2432 & 0,2432 & 0.2432 & ค0 & 0.24 & & & & & & & 0,2432 & & & & 0.2432 & 0,2432 \\
\hline 70 & 4 & 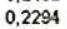 & 0. & 0,229 & 0 & 0, & 0,22 & & & & & & 4 & 0,2 & 94 & 0,2294 & 0,2294 & 0,2294 & 0.2294 \\
\hline 80 & 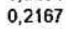 & 216 & 21 & 0,21 & 0,21 & 0,21 & 0.2167 & & & & & 0,2167 & 0,2167 & 0,2167 & 0,2167 & 0,2167 & 0,2167 & 0.2167 & 0,2167 \\
\hline 年 & & 225 & 0.22 & 0 & 0 & 0, & & & 1 & 1 & & & & & & & & & 0,2251 \\
\hline 10 & 2530 & 0.2530 & 0,2530 & 0,2530 & 0,2530 & 0,2530 & 0,2530 & 2530 & 0,2530 & 0.2530 & 0,2530 & 0,2530 & 0.25 & 0,25 & 0.2530 & 0.2 & 30 & & 0,2530 \\
\hline & & 0.2797 & 0.2797 & 0,27 & 0,27 & 0 & 0,2 & & & & & & 0,2 & 0,27 & 0.2797 & 0,2 & 97 & 0.2 & 0,2797 \\
\hline 12 & & 0 & 0. & 0.2 & 0,2 & & & & & & & & & & & & & & 0,2855 \\
\hline 13 & 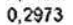 & 0,2973 & 0,29 & 0,29 & 0.29 & 0,2 & 0. & 3 & 3 & 0, & 0,2 & 0.2 & 0.2973 & 0,2973 & 0.2973 & 0.2973 & 0,2973 & 0.2973 & 0.2973 \\
\hline & & & & & & & & & & & & & & & & & & & \\
\hline 150 & & 0.30 & 0,3 & 0.3 & & & & & & & & & & 0,3 & & & & & 0,3096 \\
\hline & & & & & 0,30 & & & & & & & & & 0,3096 & & 0,3096 & 0,3096 & & 0 \\
\hline 70 & & 0,3096 & 0,30 & 0,30 & 0,30 & 0,3 & 0 , & & 3096 & & & & & 0,3 & 0,3006 & 0,3096 & 6 & 0,3 & \\
\hline 180 & 096 & 3096 & 0,3096 & 0,3096 & 0,3096 & 0,3096 & 0,3096 & 3096 & 3096 & 3096 & 0,3096 & 0.3096 & 0,3096 & 0,3096 & 0,3096 & 0,3096 & 0.3096 & 0.3096 & 0,3096 \\
\hline
\end{tabular}

Figura 5.27a - Solo 1 - Perfil de umidade simulado - Antes da irrigação

\begin{tabular}{|c|c|c|c|c|c|c|c|c|c|c|c|c|c|c|c|c|c|c|c|}
\hline otharg & 1 & 10 & 20 & 30 & 40 & 50 & 60 & 70 & 80 & 90 & 100 & 110 & 120 & 130 & 140 & 150 & 160 & 170 & 180 \\
\hline 10 & 0,1211 & 1211 & 1211 & 1211 & 0,1211 & 0,1211 & 0,1211 & & & & & & 0,1211 & 0.1211 & 0,1211 & 0,1211 & 0,1211 & 0,1211 & 0,1211 \\
\hline 20 & 0,1537 & 0,1537 & 0,1537 & 0.1537 & 0,1537 & 0.1537 & 0,1537 & & & & & & 0.1537 & 0,1537 & 0,1537 & 0.1537 & 0,1537 & 0,1537 & 0.1537 \\
\hline 30 & 0,2150 & 0,2150 & 0.2150 & 0,2150 & 0,2150 & 0.2150 & 0,2151 & & & & & & 0,2151 & 0,2150 & 0,2150 & 0,2150 & 0,2150 & 0,2150 & 0,2150 \\
\hline 40 & 0,2459 & 0,2459 & 0,2459 & 0,2459 & 0,2459 & 0.2459 & 0,2453 & & & & & & 0,2453 & 0,2459 & 0,2459 & 0,2459 & 0,2459 & 0,2459 & 0,2459 \\
\hline 50 & 0,2478 & 0,2478 & 0,2478 & 0,2478 & 0,2478 & 0,2478 & 0,2472 & & & & & & 0,2472 & 0,2478 & 0,2478 & 0,2478 & 0,2478 & 0,2478 & 0,2478 \\
\hline 60 & 0,2432 & 0,2432 & 0,2432 & 0.2432 & 0,2432 & 0,2432 & 0,2430 & & & & & & 0,2430 & 0,2432 & 0.2432 & 0,2432 & 0,2432 & 0.2432 & 0,2432 \\
\hline 70 & 0,2301 & 0,2301 & 0.2301 & 0.2301 & 0,2301 & 0,2301 & 0,2325 & & & & & & 0.2325 & 0.2301 & 0,2301 & 0,2301 & 0,2301 & 0,2301 & 0,2301 \\
\hline 80 & 0,2177 & 0,2177 & 0,2177 & 0,2177 & 0,2177 & 0,2177 & 0,2595 & & & 0 & 0 & 00 & 0,2595 & 0,2177 & 0,2177 & 0,2177 & 0,2177 & 0,2177 & 0,2177 \\
\hline 9 & 2255 & 0,2255 & 2255 & 0,2255 & 0.225 & 0,22 & 0,2301 & 4562 & 4586 & 4586 & 0,4586 & 0,4562 & 0,2301 & 0,2255 & 0,2255 & 0,2255 & 0,2255 & 0,2255 & 0,2255 \\
\hline 100 & 0,2521 & 0,2521 & 0,2521 & 0,2521 & 0,2521 & 0,2521 & 0.2524 & 0,2568 & 0,2571 & 0,2571 & 0,2571 & 0,2568 & 0,2524 & 0,2521 & 0,2521 & 0,2521 & 0,2521 & 0,2521 & 0,2521 \\
\hline 110 & 2775 & 2775 & 2775 & 0,2775 & 0,2775 & 0,2775 & 02775 & ד? & 0,2776 & 0,2776 & 0,2776 & 0,2776 & 0,2775 & 0,2775 & 0,2775 & 0,2775 & 0,2775 & 0,2775 & 0,2775 \\
\hline 120 & 0 & 0,2 & 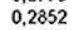 & 0,2 & 0,2 & & & & & & & & & & & & 0,2852 & & 0,2852 \\
\hline 130 & 0,2962 & 0,2962 & 0,2962 & 0,2962 & 0.2962 & 0,2962 & 0,2962 & 0.2962 & 0,2962 & 0.2962 & 0,2962 & 0.2962 & 0,2962 & 0,2962 & 0,2962 & 0,2962 & 0,2962 & 0,2962 & 0,2962 \\
\hline 14 & 8 & 3023 & 8 & 0. & & 0,3 & & 8 & 03 & 03028 & & & & & & 0,3028 & 0,3028 & 0,3028 & 0,3028 \\
\hline 150 & 0,3083 & 0,3038 & 3038 & 0,3088 & 0,3038 & 0,3038 & 0,3038 & 8 & 0,3038 & 0,3088 & 0,3088 & 0,3038 & 0,3038 & 0,3038 & 0,3038 & 0,3038 & 0,3038 & 0,3083 & 0,3038 \\
\hline 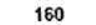 & 0,3097 & 0,3097 & 3097 & 0,3097 & 0,3097 & 0,3097 & 0 & 0,3097 & 0,3097 & 0,3097 & 0,3097 & 0,3097 & 0,3097 & 0,3097 & 0,3097 & 0,3097 & 0,3097 & 0,3097 & 0,3097 \\
\hline 170 & 0,3121 & 0,3121 & 0.3121 & 0,3121 & 0,312 & 0,31 & 0 & 0,3121 & 0,3121 & 0,3121 & 0,3 & & & & 0.3121 & 0,3121 & 0,3121 & 0,3121 & 0,3121 \\
\hline 180 & 0,3472 & 0,3473 & 0.3473 & 0,3473 & 0,3473 & 0,3473 & 0,3473 & 0,3473 & 0,3473 & 0,3473 & 0,3473 & 0,3473 & 0,3473 & 0,3473 & 0,3473 & 0.3473 & 0,3473 & 0,3473 & 0,3472 \\
\hline
\end{tabular}

Figura 5.27b - Solo 1 - Perfil de umidade simulado - Instante $t=2$ min da fase de alimentação

\begin{tabular}{|c|c|c|c|c|c|c|c|c|c|c|c|c|c|c|c|c|c|c|c|}
\hline $\begin{array}{l}\text { rothar } \\
\text { (cm }\end{array}$ & 1 & 10 & 20 & 30 & 40 & 50 & 60 & 70 & 80 & 90 & 100 & 110 & 120 & 130 & 140 & 150 & 160 & 170 & 180 \\
\hline 10 & 0,1260 & 0,1260 & 0,1260 & 0,1261 & 0,1261 & 0,1263 & & & & & & & & 0,1263 & 0,1261 & 0,1261 & 0,1260 & 0,1260 & 0,1260 \\
\hline 20 & 0.1587 & 0,1587 & 0,1588 & 0,1592 & 0,1605 & 0.1644 & & & & & & & & 0,1644 & 0,1605 & 0,1592 & 0,1588 & 0,1587 & 0,1587 \\
\hline 30 & 0.1965 & 0,1909 & 0.1991 & 0,2077 & 0.2302 & 0.2674 & 0.3123 & & & & & & 0,3123 & 0,2674 & 0,2302 & 0,2077 & 0,1991 & 0,1969 & 0,1965 \\
\hline 40 & 2230 & 0,2268 & 2496 & 0.3116 & 0,3888 & 0,4652 & 0,5373 & & & & & & 0,5373 & 0,4652 & 0,3888 & 0,3116 & 0,2496 & 0,2268 & 0,2230 \\
\hline 50 & 2384 & 0,2560 & 3855 & 0,5140 & 0.5670 & 0.5700 & 0,5700 & & & & & & 0.5700 & 0.5700 & 0,5670 & 0,5140 & 0,3855 & 0,2560 & 0,2384 \\
\hline 60 & 0,2594 & 0,3487 & 0,5012 & 0,5626 & 0,5700 & 0,5700 & 0,57 & & & & & & 0,5700 & 0,5700 & 0,5700 & 0,5626 & 0,5012 & 0,3487 & 0,2594 \\
\hline 70 & 3174 & 441 & .5409 & 5689 & 0,57 & 0,57 & 0,5700 & & & & & & 20 & 0.5700 & 0,5700 & 0.5669 & 0.5409 & 0,4413 & 0,3174 \\
\hline 80 & 961 & 487 & 5536 & 0,5696 & 0,57 & 0 & 0,5700 & 0 & 5700 & 0,5700 & .5700 & 0 & 0.5 & 0.5 & 0,5700 & 0,5 & 0,5536 & 0,4878 & 0,3961 \\
\hline 90 & 1476 & 5091 & 65 & 5695 & 0,57 & 0.57 & 0,5 & 5700 & 0 & 5700 & 5700 &, 5700 & 0,5700 & 0,5700 & 0,5700 & 0,5695 & 0,5574 & 0,5091 & 0,4476 \\
\hline 100 & & 51 & & & & & 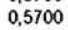 & 0 & 0 & & & & 0,5 & & & 0 & 0,5 & 0 & 0,4693 \\
\hline 110 & 1693 & 515 & 5553 & 0,5681 & 0.57 & 0,57 & 0,5700 & 0,5700 & 5700 & & 0,5 & & 0,5700 & 0,5700 & 0,5700 & & 0,5553 & 0,5152 & 0,4693 \\
\hline 120 & 1504 & 505 & 6514 & 5665 & 056 & 057 & 05700 & 05700 & 05700 & 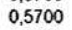 & 057 & 0 & 0,5700 & 0,5700 & 0,5698 & 0,5665 & 0,5514 & 0,5058 & 0,4504 \\
\hline 130 & $\$ 170$ & 450 & & & & & & & & & & & & & & & & & 0,4170 \\
\hline 140 & 1038 & 4786 & 54 & 0,5638 & 0,5 & 0.5 & 0,5700 & 0,5 & 0 & 0 & 0,5 & & 0,5700 & 0,5700 & 0,5691 & 0,5638 & 0,5438 & 86 & 0,4038 \\
\hline 15 & & 0 & & & & & & & & & & & & & & & & & \\
\hline 160 & 0,5351 & 5443 & 5600 & 5675 & 0.5697 & 0,57 & 0.5700 & & & & & & 0,5700 & 0,5700 & 0,5697 & 0,5675 & 0,5600 & 0,5443 & 0,5351 \\
\hline & & s & 570 & 0,5696 & 0.5700 & & & 0,5700 & & & & & 0,5700 & & 0,5700 & & 0,5679 & 0,5649 & \\
\hline 180 & 0,5697 & 0,5698 & .5700 & 0,5700 & 0.5700 & 0,5700 & 0.5700 & 0,5700 & 0.5700 & 0,5700 & 0,5700 & 0,5700 & 0,5700 & 0,5700 & 0,5700 & 0,5700 & 0,5700 & 0,5693 & 0,5697 \\
\hline
\end{tabular}

Figura 5.27c - Solo 1 - Perfil de umidade simulado - Instante $t=72 \mathrm{~min}$ da fase de alimentação (NA máximo)

\begin{tabular}{|c|c|c|c|c|c|c|c|c|c|c|c|c|c|c|c|c|c|c|c|}
\hline profliarg & 1 & 10 & 20 & 30 & 40 & 50 & 60 & 70 & 80 & 90 & 100 & 110 & 120 & 130 & 140 & 150 & 160 & 170 & 180 \\
\hline 10 & 1463 & 1463 & 1468 & 1487 & 1530 & 0,1604 & 1604 & & & & & & 0,1604 & 0,1604 & 0,1530 & 0,1487 & 0,1468 & 0,1463 & 0,14 \\
\hline 20 & 0,2033 & 2033 & 2036 & 0.2051 & 0.2100 & 0,2183 & 0,2183 & & & & & & 0,2183 & 0,2183 & 0,2100 & 0,2051 & 0,2036 & 0,2033 & 0,20 \\
\hline 30 & 2791 & 0,2792 & 0,2801 & 0,2839 & 0,2947 & 0,3049 & 0,3124 & & & & & & 0,3124 & 0,3049 & 0,2947 & 0,2839 & 0,2801 & 0,2792 & 0,27 \\
\hline 40 & 3582 & 0,3587 & 0,3635 & 0,3793 & 0.4048 & 0,4071 & 0,4075 & & & & & & 0,4075 & 0,4071 & 0,4048 & 0,3793 & 0,3635 & 0,3587 & 0,358 \\
\hline 50 & 4365 & 0,4427 & 0.4642 & 0,4741 & 0,4761 & 0,4762 & 0,4760 & & & & & & 0,4760 & 0,4762 & 0,4761 & 0,4741 & 0,4642 & 0.4427 & 0,4365 \\
\hline 60 & 5020 & 0,5076 & 0,5174 & 0,5239 & 0,5275 & 0,5296 & 0,5305 & & & & & & 0,5305 & 0,5296 & 0,5275 & 0,5239 & & 0,5076 & 0,5 \\
\hline 70 & 3310 & 0,5338 & 0,54 & 0,5462 & 0,5518 & 0,5568 & 0,5606 & & & & & & 0,5606 & 0,5568 & 0,5518 & 0,5462 & 0,5400 & 0,5338 & 0,5310 \\
\hline 80 & 5472 & 0,5485 & 0,5520 & 0,5565 & 0,5611 & 0,5657 & 0,5694 & 0,5700 & 0,5700 & 0,5700 & 00 & 00 & 0,5694 & 0.5657 & 0,5611 & 0,5565 & 0,5520 & 0,5485 & 0,5472 \\
\hline 90 & 8579 & 0,5586 & 0,56 & 0,56 & 0,5661 & 0.5684 & 0,56 & 0.5700 & 57 & 57 & 0 & Do & 0,5697 & 0.5684 & 0.5 & 0,5633 & 0,5606 & 0,5586 & 0.55 \\
\hline 100 & 5644 & 0.5647 & 0,565 & 0,5671 & 0,5684 & 0,5694 & 0,5699 & 0,5700 & 0,5700 & 0,5700 & 0,5700 & 0,5700 & 0,5699 & 0.5694 & 0,5684 & 0,5671 & 0,5657 & 0.5647 & 0,5 \\
\hline 110 & 5679 & 0,5650 & 0.5684 & 0,5690 & 0,5695 & 0,5693 & 0,5700 & 0,5700 & 0,5700 & 0,5700 & 0,5700 & 0,5700 & 0.5700 & 0.5693 & 0,5695 & 0,5690 & 0,5684 & 0.5680 & 0,56 \\
\hline 120 & & $0,5 €$ & 0. & 0,5 & 0,5 & 0,5 & & & & & & & & & & & & & 0,58 \\
\hline 130 & 5699 & 0,5659 & 0.5700 & 0,5700 & 0,5700 & 0.5700 & 0,5700 & 0,5700 & 0,5700 & 0,5700 & 0,5700 & 0,5700 & 0,5700 & 0,5700 & 0,5700 & 0,5700 & 0,5700 & 0,5699 & 0,56 \\
\hline 140 & 0 & 0.5700 & 0,5 & 0,5 & 0,5 & 0,5 & 0,5 & & & & & & & & & & & & \\
\hline 150 & 5700 & 0,5700 & 0,5700 & 0,5700 & 0.5700 & 0,5700 & 0,5700 & 0,5700 & 0,5700 & 0,5700 & 0,5700 & 0.5700 & 0,5700 & 0.5700 & 0,5700 & 0,5700 & 0,5700 & 0,5700 & 0,57 \\
\hline 160 & 5700 & 0,5700 & 0.570 & 0,5700 & 0,5700 & 0,5700 & 0,5700 & 0.5700 & 0,5700 & 0.5700 & 0.5700 & 0.5700 & 0,5700 & 0.5700 & 0,5700 & 0,5700 & 0,5700 & 0,5700 & 0,57 \\
\hline 170 & 5700 & 0,5700 & 0.57 & 0,57 & 0.5700 & 0.5700 & 0,5700 & 0,5700 & 0.5700 & 0,5700 & 0,5700 & & 0,5700 & 0,5700 & 0,5700 & 0,5700 & 0.5700 & 0,5700 & 0,5 \\
\hline 180 & 0.5700 & 0.5700 & 0,5700 & 0.5700 & 0,5700 & 0,5700 & 0.5700 & 0.5700 & 0.5700 & 0,5700 & 0,5700 & 0.5700 & 0,5700 & 0.5700 & 0.5700 & 0.5700 & 0,5700 & 0.5700 & 0.570 \\
\hline
\end{tabular}

Figura 5.27d - Solo 1 - Perfil de umidade simulado - Instante $t=194 \mathrm{~min}$ da fase de recessão $\equiv$ instante 


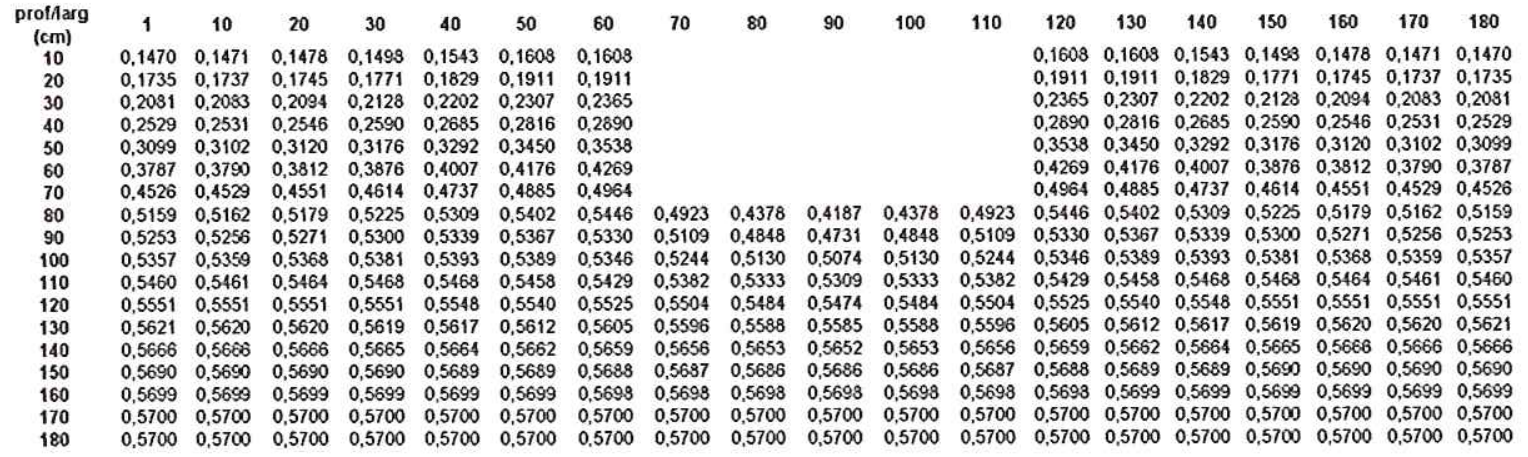

Figura 5.27e - Solo 1 - Perfil de umidade simulado - Instante $t=20$ min da fase de redistribuição

\begin{tabular}{|c|c|c|c|c|c|c|c|c|c|c|c|c|c|c|c|c|c|c|c|}
\hline $\begin{array}{l}\text { profflarg } \\
(\mathrm{cm})\end{array}$ & 1 & 10 & 20 & 30 & 40 & 50 & 60 & 70 & 80 & 90 & 100 & 110 & 120 & 130 & 140 & 150 & 160 & 170 & 180 \\
\hline 10 & 0.1471 & 0,1472 & 0,1480 & 0,1503 & 0,1547 & 0,1601 & 0.1601 & & & & & & 0.1601 & 0,1601 & 0,1547 & 0,1503 & 0,1480 & 0,1472 & 0,1471 \\
\hline 20 & 0.1731 & 0,1733 & 0,1743 & 0,1772 & 0,1830 & 0.1899 & 0.1899 & & & & & & 0,1899 & 0,1899 & 0.1830 & 0,1772 & 0.1743 & 0,1733 & .1731 \\
\hline 30 & 0,2069 & 0,2071 & 0,2035 & 0,2123 & 0,2197 & 0,2287 & 0,2321 & & & & & & 0,2321 & 0,2287 & 0,2197 & 0,2123 & 0,2085 & 0,2071 & 0,2069 \\
\hline 40 & 0,2508 & 0,2511 & 0.2529 & 0,2578 & 0,2674 & 0.2787 & 0,2832 & & & & & & 0,2832 & 0,2787 & 0,2674 & 0.2578 & 0,2529 & 0,2511 & 0,2503 \\
\hline 50 & 0,3069 & 0,3073 & 0,3095 & 0.3158 & 0,3276 & 0,3412 & 0,3467 & & & & & & 0,3467 & 0,3412 & 0,3276 & 0,3158 & 0,3095 & 0,3073 & 0,3069 \\
\hline 60 & 0,3749 & 0,3754 & 0.3781 & 0,3853 & 0,3987 & 0,4134 & 0,4194 & & & & & & 0.4194 & 0,4134 & 0.3987 & 0,3853 & 0,3781 & 0,3754 & 0,3749 \\
\hline 70 & 0,4487 & 0,4493 & 0,4520 & 0,4591 & 0,4717 & 0,4847 & 0,4900 & & & & & & 0,4900 & 0,4847 & 0,4717 & 0,4591 & 0,4520 & 0,4493 & 0,4487 \\
\hline 80 & 0,5129 & 0,5134 & 0,5155 & 0,5203 & 0.5295 & 0,5378 & 0,5408 & 0,4874 & 0,4292 & 4047 & 1292 & 874 & 0,5408 & 0,5378 & 0,5295 & 0,5203 & 0,5155 & 0,5134 & 0,5129 \\
\hline 90 & 0 & 0 & 0 & 524 & 0,5292 & & & 5037 & 4726 & 4570 & 4726 & 37 & 0,5 & 0 & 0.5 & 0,5246 & 0,5209 & 0,5189 & 0,5184 \\
\hline 100 & 0,5254 & 0,5257 & 0,5270 & 0,5290 & 0,5303 & 0,5306 & 0,5254 & 0,5125 & 0,4969 & 0,4889 & 0,4969 & 0,5125 & 0.5254 & 0,5306 & 0,5308 & 0,5290 & 0,5270 & 0,5257 & 0,5254 \\
\hline 110 & 5330 & 05300 & 05316 & 05353 & 0,5355 & 0,5342 & 0,5302 & 0.5231 & 0,5155 & 0,5116 & 0,5155 & 0,5231 & 0.5302 & 0.5342 & 0,5 & 0,5 & 0,5346 & 0,5340 & 0,5339 \\
\hline 120 & 0,5434 & 0,5434 & 0,5435 & 0,5436 & 0,5432 & 0,5418 & 0,5 & 0.5355 & 0.5318 & 0,5300 & 0,5318 & 0.5 & 0,5 & & & & 0,5435 & & 0,5434 \\
\hline 130 & 0,5528 & 0,5 & 0,5527 & 0,5525 & 0.5520 & 0,5511 & 0,5496 & 0,5477 & 0,5461 & 0,5453 & 0,5461 & 0,5477 & 0,5496 & 0,5511 & 0,5520 & 0,5525 & 0.5527 & 0,5528 & 0,5528 \\
\hline 140 & & 00 & $0 r$ & 505 & 0,5601 & 0,559 & 0,55 & 0,5581 & 0.5574 & 0 , & 0,5 & 31 & & & & & & 0,5608 & 0,5608 \\
\hline 150 & 0,5663 & 0,5663 & 0.5662 & 0,5661 & 0,5659 & 0,5657 & 0.5654 & 0,5651 & 0,5649 & 0,5648 & 0.5649 & 0,5651 & 0,5654 & 0,5657 & 0,5659 & 0,5661 & 0,5662 & 0,5663 & 0,5663 \\
\hline 16 & 0 & 0 & 91 & 0,5 & 0,5 & 0,5 & & 0,5688 & 0,5687 & 0,5687 & 0,5687 & 0,5688 & 0,5689 & 0,5689 & 0,5690 & 0,5691 & 0,5691 & 0,5691 & 0,5691 \\
\hline 170 & 0,5700 & 0,57 & 0,5700 & 0,5699 & 0,5699 & 0,5699 & 0,5699 & 0,56 & 0.5699 & 0,5699 & 0,5699 & 0,5699 & 0,5 & 0,5659 & 0,5699 & 0,5699 & 0.5700 & 0,5700 & 0,5700 \\
\hline & 0.5700 & 0,5700 & 0,5700 & 0,5700 & 0,5700 & 0,5700 & 0,5700 & 0.5700 & 0.5700 & 0,5700 & 0,5700 & 0.5700 & 0.5700 & 0,5700 & 0,5700 & 0,5700 & 0,5700 & 0,5700 & 0,5700 \\
\hline
\end{tabular}

Figura 5.27f - Solo 1 - Perfil de umidade simulado - Instante $t=1 \mathrm{~h}$ da fase de redistribuição

\begin{tabular}{|c|c|c|c|c|c|c|c|c|c|c|c|c|c|c|c|c|c|c|c|}
\hline fflarg & 1 & 10 & 20 & 30 & 40 & 50 & 60 & 70 & 80 & 90 & 100 & 110 & 120 & 130 & 140 & 150 & 160 & 170 & 180 \\
\hline 10 & 0,1472 & 0,1474 & 0,1484 & 0,1508 & 0,1550 & 0.1592 & 0,1592 & & & & & & 0,1592 & 0,1592 & 0,1550 & 0,1503 & 0,1484 & 0,1474 & 0,1472 \\
\hline 20 & 0.1732 & 0,1735 & 1748 & 0.1779 & 0,1833 & 0,1887 & 0,1887 & & & & & & 0,1887 & 0,1837 & 0,1833 & 0,1779 & 0,1748 & 0,1735 & 0,1732 \\
\hline 30 & 0,2070 & 0,2074 & 0,2091 & 0.2132 & 0,2201 & 0,2271 & 0,2294 & & & & & & 0,2294 & 0,2271 & 0,2201 & 0.2132 & 0,2091 & 0.2074 & 0,2070 \\
\hline 40 & 0,2510 & 0,2514 & 0,2536 & 0,2589 & 0,2678 & 0,2766 & 0,2797 & & & & & & 0,2797 & 0,2766 & 0,2678 & 0,2589 & 0,2536 & 0,2514 & 0,2510 \\
\hline 50 & 0,3070 & 0,3076 & 0.3 & 0.3171 & 0,3281 & 0,3387 & 0,3425 & & & & & & 0.3425 & 0,3387 & 0,3281 & 0,3171 & 0,3104 & 0,3076 & 0,3070 \\
\hline 60 & 0,3751 & 0,3759 & 3791 & 0,3868 & 0,3991 & 0,4106 & 0,4149 & & & & & & 0,4149 & 0,4106 & 0,3991 & 0,3868 & 0,3791 & & 0,3751 \\
\hline 70 & 0,4489 & 0,4497 & 0.4530 & 0,460 & 0,4720 & 0,4823 & 0.4 & & & & & & 0,4861 & 0.4823 & 0,4720 & 0.4605 & 0,4530 & 0,4497 & 0.4489 \\
\hline 80 & 0.5131 & 0,5137 & 0,5162 & 0,5217 & 0,5297 & 0.5363 & 0,5384 & 0,4837 & 6 & 977 & 6 & 37 & 0,5384 & 0,5363 & 0,5297 & 0,5217 & 0,5162 & 0,5137 & 0.5131 \\
\hline 90 & & & & & 0. & 0. & 0 , & 0,4999 & 68 & 4499 & 68 & 99 & 0,5251 & 0,5 & 0,5 & 0.5243 & 0. & 0 & 0,5179 \\
\hline 100 & 0,5234 & 0,5238 & 0,5252 & 0.5272 & 0,5288 & 0.5280 & 0,5220 & 0,5077 & 0,4903 & 0,4812 & 0.4903 & 0,5077 & 0,5220 & 0,5280 & 0,5283 & 0,5272 & 0,5252 & 0,5238 & 0,5234 \\
\hline 110 & 0,5302 & 0,5304 & 5311 & 0.5319 & 0,5319 & 0,5302 & 0,5254 & 0,5170 & 0,5079 & 0,5031 & 0,5079 & 0.5170 & 0,5254 & 0,5302 & 0,5319 & 0,5319 & 0.5311 & 0,5304 & 0,5302 \\
\hline 120 & 0,5385 & 0,5360 & & 0.5 & 0.5 & 0.5 & & 0 & 7 & 13 & & & 0,5 & 0,5365 & & 0,5388 & & & 0,5385 \\
\hline 130 & 0,5478 & 0,5478 & 0.5477 & 0,5475 & 0,5468 & 0,5455 & 0,5435 & 0,5409 & 0,5386 & 0,5375 & 0,5386 & 0,5409 & 0,5435 & 0,5455 & 0,5468 & 0,5475 & 0,5477 & 0,5478 & 0,5478 \\
\hline 140 & 0,5569 & 0 & 5567 & 0,5564 & 0,5559 & 0.5 & & & & 13 & 0,5518 & & 0,5541 & 0,5551 & 0,5559 & 0,5584 & 0.5567 & 0,5568 & 0,5569 \\
\hline 150 & 0,5640 & 640 & 0,5639 & 0,5637 & 0,5634 & 0,5631 & 0,5626 & 0,5621 & 0,5617 & 0,5615 & 0,5617 & 0,5621 & 0,5626 & 0,5 & 0, & 0,5 & 0 & 10 & 0,5640 \\
\hline 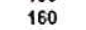 & 0,5682 & 0,5682 & 0,5682 & 0,5681 & 0,5680 & 0,5679 & 0,5678 & 0,5676 & 0.5675 & 0,5674 & 0,5675 & 0,5676 & 05678 & & 0,5 & 0,5681 & 0,5682 & 5682 & 0,5682 \\
\hline 170 & 0,5698 & 0,5693 & 0,5698 & 0,5698 & 0,5693 & 0,5693 & 0,56 & & & & & & & & & & 0,5698 & 0,5698 & 0,5698 \\
\hline & 0,5700 & 0.5700 & 0,5700 & 0.5700 & 0.5700 & 0,5700 & 0.5700 & 0,5700 & 0,5700 & 0,5700 & 0,5700 & 0,5700 & 0,5700 & 0,5700 & 0,5700 & 0,5700 & 0,5700 & 0,5700 & 0.5700 \\
\hline
\end{tabular}

Figura $5.27 \mathrm{~g}$ - Solo 1 - Perfil de umidade simulado - Instante $\mathrm{t}=2 \mathrm{~h}$ da fase de redistribuição

\begin{tabular}{|c|c|c|c|c|c|c|c|c|c|c|c|c|c|c|c|c|c|c|c|}
\hline & 1 & 10 & 20 & 30 & 40 & 50 & 60 & 70 & 80 & 90 & 100 & 110 & 120 & 130 & 140 & 150 & 160 & 170 & 180 \\
\hline 10 & 1473 & 476 & 487 & 512 & 550 & 1584 & 1584 & & & & & & 0,1584 & 0,1584 & 0,1550 & 0,1512 & 0,1487 & 0.1476 & 0,1473 \\
\hline 20 & 1734 & 1737 & 752 & 785 & 33 & 1877 & 77 & & & & & & 0,1877 & 0,1877 & 0,1833 & 0,1785 & 0.1752 & 0,1737 & 0,1734 \\
\hline 30 & 073 & 077 & 097 & 139 & 2202 & 2258 & 0,2275 & & & & & & 0,2275 & 0,2258 & 0.2202 & 0.2139 & 0,2097 & 0.2077 & 0,2073 \\
\hline 40 & 6 & & & & & & & & & & & & 2773 & 0,2750 & 0,2679 & & & & \\
\hline 50 & 074 & 3052 & 4 & 32 & 0,3281 & 7 & 0 & & & & & & 6 & 0,3367 & 0,3281 & & 0,3114 & 0,3032 & 3074 \\
\hline 60 & 756 & 3784 & & & & & & & & & & & & 0,4085 & 0,3991 & & 0,3802 & 0,3764 & 0,3756 \\
\hline 70 & & & & & & & & & & & & & & 0,4804 & 0.4720 & 0,4616 & 0,4540 & 0.4503 & 494 \\
\hline 80 & & 5142 & & & 0 & 1 & 0.5 & & 4215 & , ,3954 & 0,4215 & 0,4816 & 0,5367 & 0,5351 & 0,5296 & 0,5225 & 0.5170 & & \\
\hline & & & & & & & & & & & & & & & & & & & \\
\hline 100 & 2 & & & & & & & & & & & & & & & & & & \\
\hline 110 & & & & & 1 & 0 & & 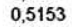 & 8 & 50 & 0,5058 & 0.5 & 0,5240 & 0.5291 & 0.5311 & 0,5311 & 0 & & \\
\hline & & & & & & & & & & & & & & & & & & & \\
\hline 130 & 5466 & 0,5466 & 0 & 0 & & & & & & & & & & & & & & & \\
\hline & & & & & & & & & & & & & & & & & & & 58 \\
\hline 150 & & & & & & & & & & & & & & & & & & & \\
\hline 160 & & 9 & 0 & & & & & & & & & & & & & & & 0,5679 & 0,5680 \\
\hline 710 & & & & & & & & & & & & & & & & & & & \\
\hline & 0,5100 & & $0,5 / 00$ & 0,5700 & 0,5700 & 0,5700 & 0,5700 & 0,5700 & 0,5700 & 0,5700 & 0,5700 & 0,5700 & 0.5700 & 0,5700 & 0,5700 & 0,5700 & 0,5700 & 0,5700 & 0,5700 \\
\hline
\end{tabular}

Figura 5.27h - Solo 1 - Perfil de umidade simulado - Instante $t=3 \mathrm{~h}$ da fase de redistribuição 


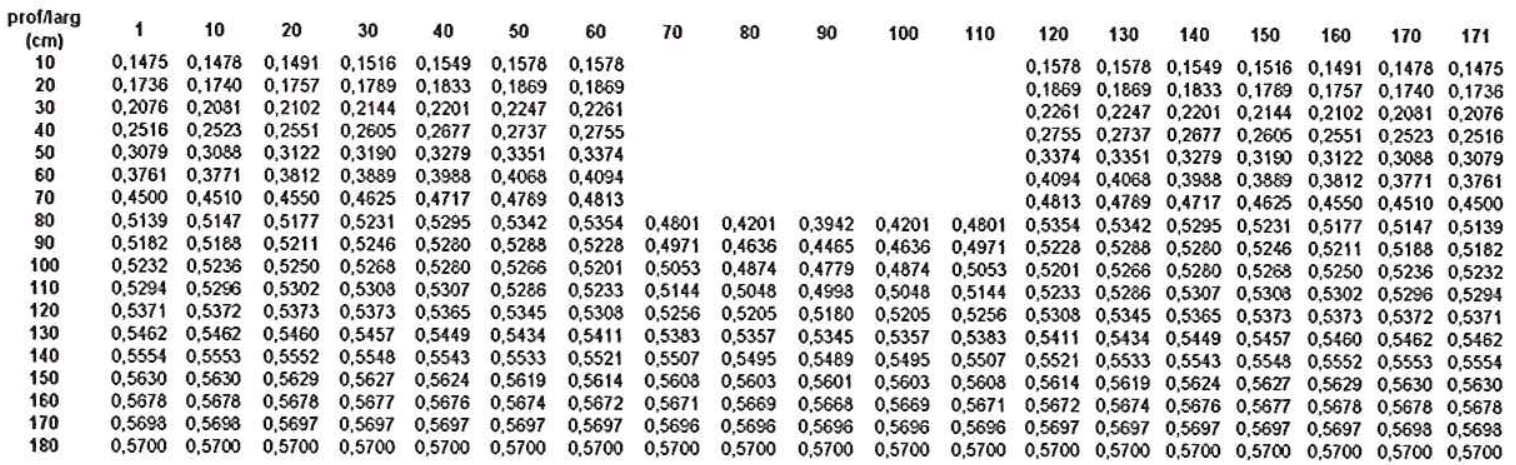

Figura 5.27i - Solo 1 - Perfil de umidade simulado - Instante $t=4 \mathrm{~h}$ da fase de redistribuição

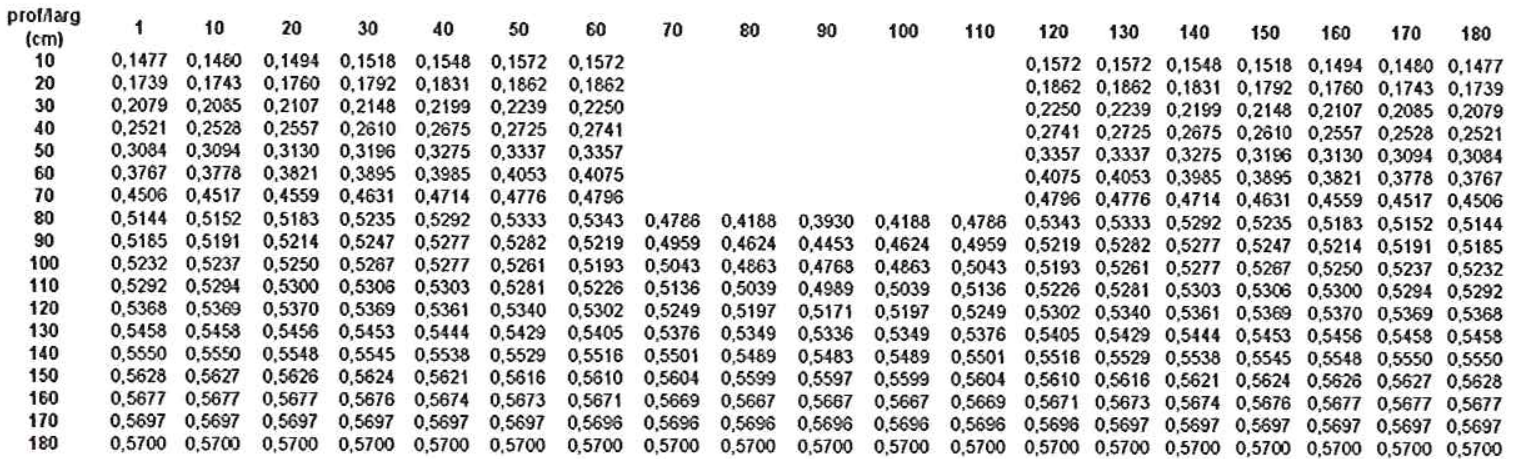

Figura 5.27j - Solo 1 - Perfil de umidade simulado - Instante $t=5 \mathrm{~h}$ da fase de redistribuição

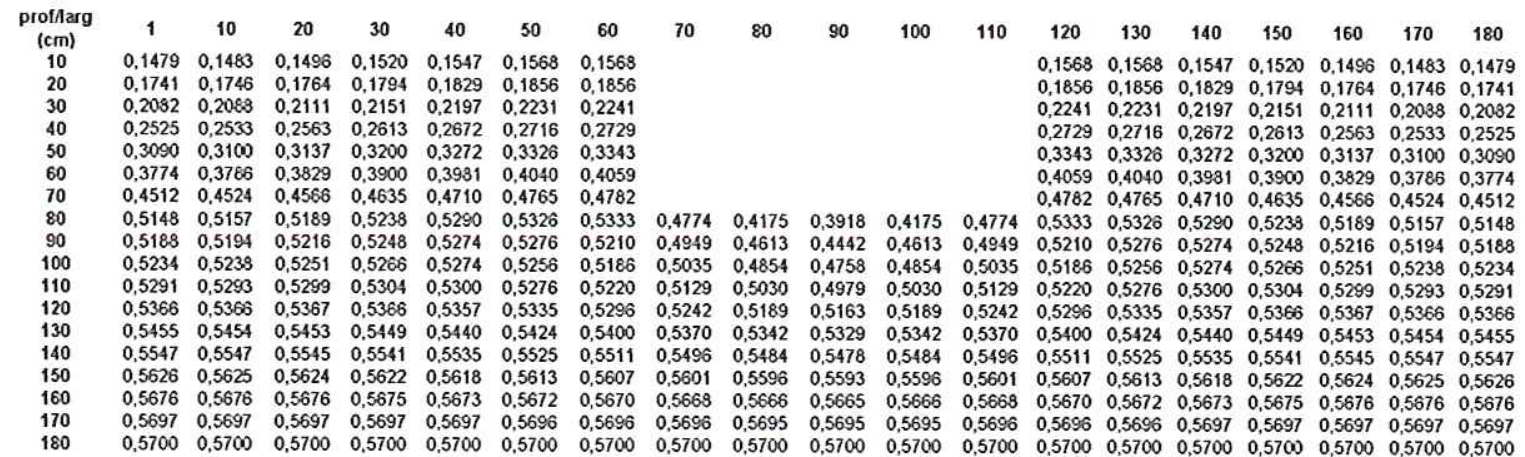

Figura 5.27k - Solo 1 - Perfil de umidade simulado - Instante $t=6 \mathrm{~h}$ da fase de redistribuição

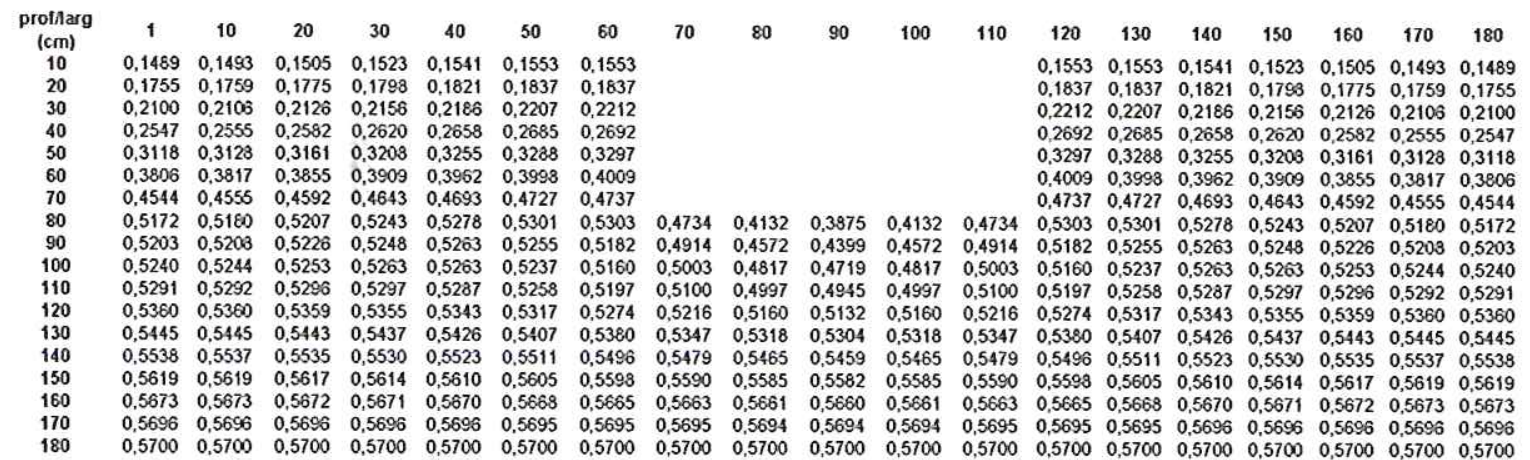

Figura 5.271 - Solo 1 - Perfil de umidade simulado - Instante $t=12 \mathrm{~h}$ da fase de redistribuição 


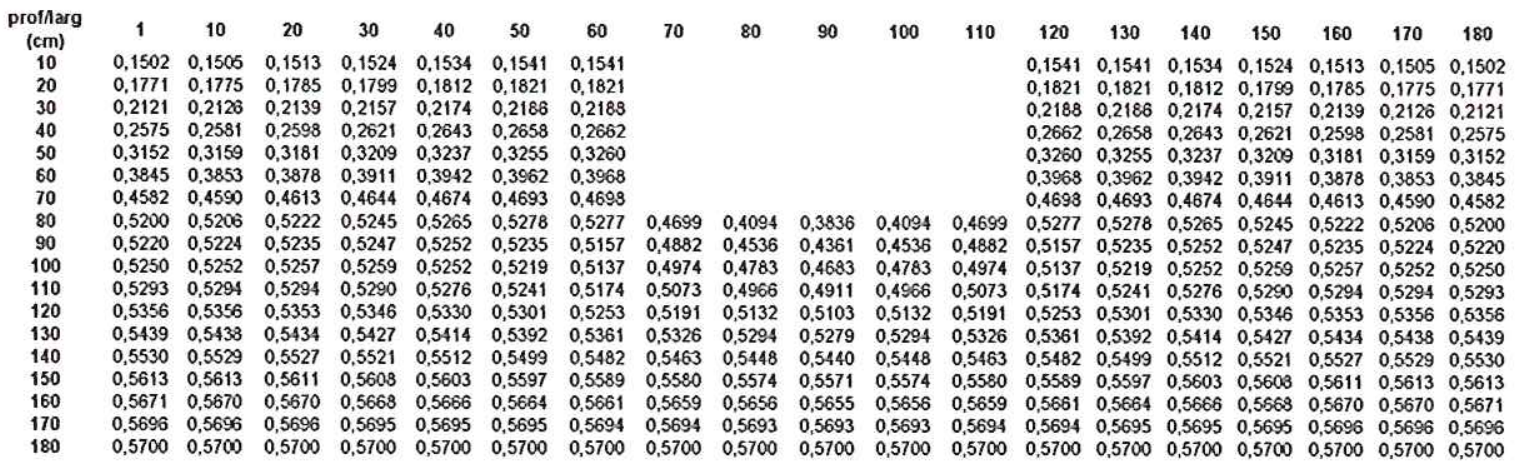

Figura 5.27m - Solo 1 - Perfil de umidade simulado - Instante $t=24 \mathrm{~h}$ da fase de redlistribuição

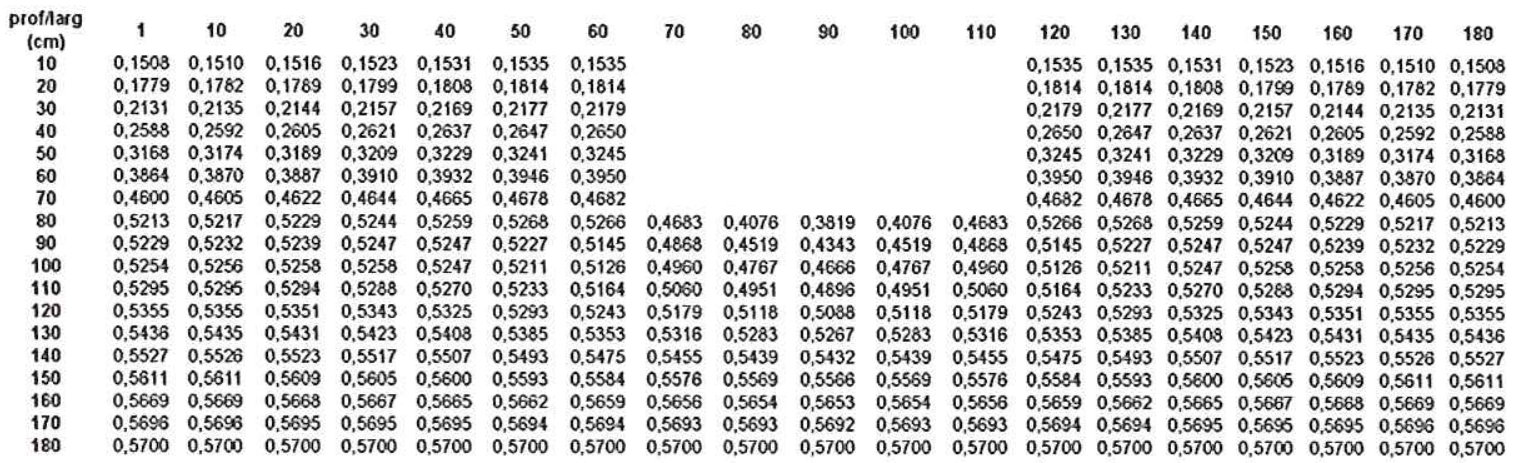

Figura 5.27n - Solo 1 - Perfil de umidade simulado - Instante $t=48 \mathrm{~h}$ da fase de redistribuição

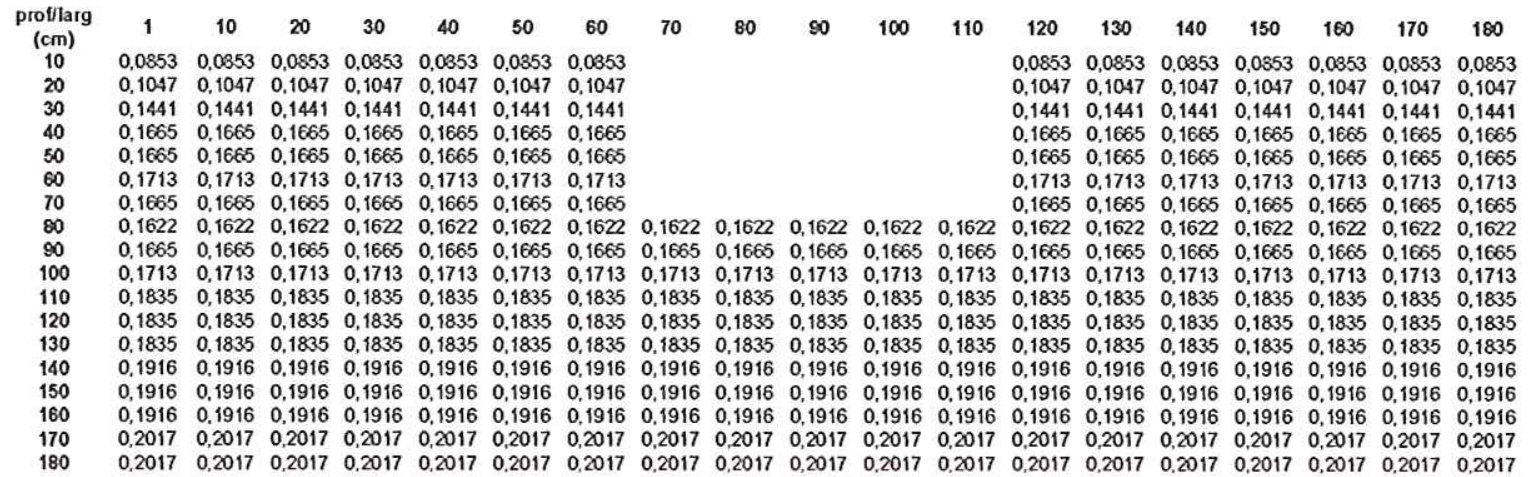

Figura 5.28a - Solo 2 - Perfil de umidade simulado - Antes da irrigação

\begin{tabular}{|c|c|c|c|c|c|c|c|c|c|c|c|c|c|c|c|c|c|c|c|}
\hline $\begin{array}{l}\text { rofflar } \\
\text { (cm) }\end{array}$ & 1 & 10 & 20 & 30 & 40 & 50 & 60 & 70 & 80 & 90 & 100 & 11 & 120 & 130 & 140 & 150 & 160 & 170 & 180 \\
\hline 10 & 0853 & 0,0353 & 0853 & 0,0853 & 0,0853 & 0,0853 & 0,0853 & & & & & & 0,0853 & 0.0853 & 0,0853 & 0,0853 & 0,0853 & 0,0853 & 853 \\
\hline 30 & 1441 & 0,1441 & 1441 & 0,1441 & 0,1441 & 0,1441 & 0,1441 & & & & & & 0.1441 & 0,1441 & 0.1441 & 0.1441 & 0,1441 & 0,1441 & 0,1441 \\
\hline 40 & 1665 & 0.1665 & 1665 & 0.1665 & 0,1665 & 0,1665 & 0,1665 & & & & & & 0,1665 & 0,1665 & 0,1665 & 0,1065 & 0,1665 & & 0,1665 \\
\hline$\infty$ & 1713 & 0,1713 & 0,1713 & 0,1713 & 0,1713 & 0,1713 & 0,171 & & & & & & 0,1713 & 0,1713 & 0,1713 & 0,1713 & 0,1713 & & 0,1713 \\
\hline 70 & 1665 & 0,1665 & 1665 & 0,1665 & 0,1665 & 0,1665 & 0,1665 & & & & & & 0,1665 & 0,1665 & 0,1665 & 0,1665 & 0,1 & & 0 , \\
\hline$\infty 0$ & 1622 & 0,1622 & 0.1622 & 0,1622 & 0,1622 & 0.1622 & 0,1622 & 20 & 3720 & 0,3720 & 0,3720 & 0,3720 & 0,1622 & 0,1622 & 0.1622 & 0,1622 & 0,1622 & 0,1622 & 0,1622 \\
\hline 90 & 1665 & 0,1665 & 0,1665 & 0,166 & 0,1665 & 0.1665 & 0.1 & 0 & 0,3720 & 0.3 & 0,3720 & 0.3 & & 0.1 & 0,1 & & & & \\
\hline 120 & 1835 & 0,1835 & 0,1835 & 0,1835 & 0,1835 & 0,1835 & 0,1835 & 0.1835 & 0,1835 & 0,1835 & 0,1835 & 0,1835 & 0.1 & 0,1835 & 0,1835 & 0, & 0 , & 0 & 0,1835 \\
\hline & 1935 & 03925 & 0 & & & & & & & & & & & & & & & & \\
\hline 140 & 0,1916 & 0,1916 & 0,1916 & 0,1916 & 0,1916 & 0,1916 & 0,1916 & 0,1916 & 0,1916 & 0,1916 & 0,1916 & 0,1916 & 0,1916 & 0,1916 & 0.1916 & 0,1916 & 0,1916 & 0,1916 & 0,1916 \\
\hline 150 & 1018 & 0,19 & 019 & & 0,1916 & & & & & 0,1916 & 0,1916 & & & & & & & & \\
\hline 160 & 1916 & 0,1916 & 0,1916 & 0,1916 & 0,1916 & 0,1916 & 0,1916 & 0,1916 & 0,1916 & 0,1916 & 0,1916 & 16 & & 0, & 0,1916 & 0,1 & 0, & & 916 \\
\hline 170 & 2017 & 0,20 & 0,20 & 0,2017 & 0,2017 & 0,2017 & 0,20 & & & 0,2017 & 0,2017 & & & & 0,2017 & 0,2017 & & & \\
\hline 180 & 0,2017 & 0,2017 & 0,2017 & 0,2017 & 0,2017 & 0,2017 & 0,2017 & 0.2017 & 0,2017 & 0,2017 & 0,2017 & 0.2017 & 0.2017 & 0.2017 & 0,2017 & 0,2017 & 0,2017 & 0.2017 & 0,2017 \\
\hline
\end{tabular}

Figura 5.28b - Solo 2 - Perfil de umidade simulado - Instante $t=2$ min da fase de alimentação 


prof/larg
(cm)
10
20
30
40
50
60
70
80
90
100
110
120
130
140
150
160
170
180

$\begin{array}{lllllll}1 & 10 & 20 & 30 & 40 & 50 & 60\end{array}$

70

$80 \quad 50 \quad 100$

110

$\begin{array}{lllllll}0,0253 & 0,0353 & 0,0553 & 0,0353 & 0,0353 & 0,3720 & 0,3720 \\ 0.1047 & 0,1047 & 0,1047 & 0,1047 & 0,1047 & 0,3720 & 0,3720\end{array}$

$\begin{array}{llllllllllllllll}0.1441 & 0.1441 & 0.1441 & 0.1441 & 0,3720 & 0,3720 & 0,3720\end{array}$

$\begin{array}{lllllllllll}0.1441 & 0.1441 & 0.1441 & 0.1441 & 0,3720 & 0.3720 & 0.3720\end{array}$

$\begin{array}{llllllll}0,1665 & 0,1665 & 0.1665 & 0,1665 & 0,3720 & 0,3720 & 0,3720\end{array}$

$\begin{array}{llllllllll}0,1655 & 0,1665 & 0,1665 & 0,1665 & 0,3720 & 0,3720 & 0,3720\end{array}$

$\begin{array}{llllllll}0,1713 & 0,1713 & 0,1713 & 0,1713 & 0,3720 & 0.3720 & 0,3720\end{array}$

$\begin{array}{lllllll}0.1765 & 0,1665 & 0,1665 & 0,3720 & 0,3720 & 0,3720\end{array}$

$\begin{array}{lllllllllllllllllll}0.1622 & 0,1622 & 0.1622 & 0,1622 & 0,3720 & 0,3720 & 0,3720 & 0,3720 & 0,3720 & 0,3720 & 0,3720 & 0,3720 & 0,3720 & 0,3720 & 0,3720 & 0,1622 & 0.1622 & 0,1622 & 0.1622\end{array}$

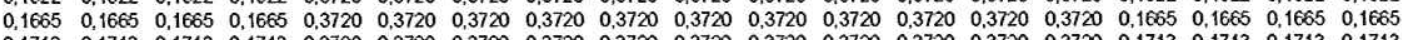

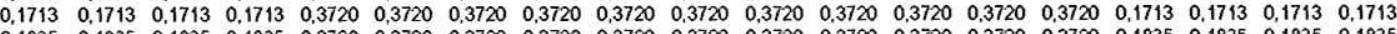

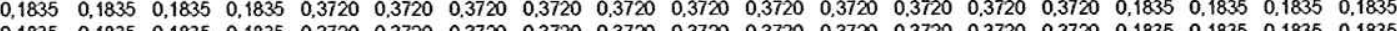

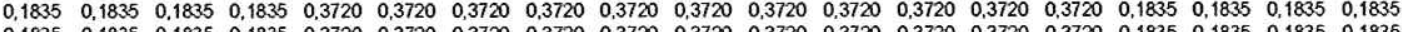

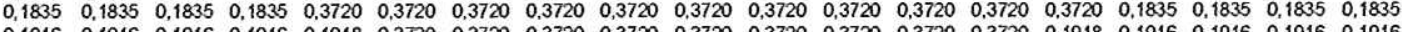
$\begin{array}{lllllllllllllllllllllllll}0,1916 & 0,196 & 0.1916 & 0,1916 & 0,1918 & 0,3720 & 0,3720 & 0,3720 & 0,3720 & 0,3720 & 0,3720 & 0,3720 & 0,3720 & 0,3720 & 0,1918 & 0,1916 & 0,1916 & 0,1916 & 0,1916\end{array}$ $\begin{array}{llllllllllllllllllllllll}0,1916 & 0,1916 & 0,1916 & 0,1916 & 0,1916 & 0,3720 & 0,3720 & 0,3720 & 0,3720 & 0,3720 & 0,3720 & 0,3720 & 0,3720 & 0,3720 & 0,1916 & 0,1916 & 0,1916 & 0,1916 & 0,1916\end{array}$ $\begin{array}{lllllllllllllllllllllll}0.1916 & 0,1916 & 0,1916 & 0,1916 & 0.1916 & 0,3720 & 0,3720 & 0,3720 & 0,3720 & 0,3720 & 0,3720 & 0,3720 & 0,3720 & 0,3720 & 0,1916 & 0,1916 & 0,1916 & 0,1916 & 0,1916\end{array}$

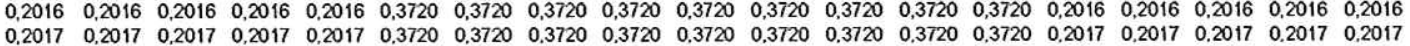

Figura 5.28c - Solo 2 - Perfil de umidade simulado - Instante $t=54 \mathrm{~min}$ da fase de alimentação (NA máximo)

\begin{tabular}{|c|c|c|c|c|c|c|c|c|c|c|c|c|c|c|c|c|c|c|c|}
\hline of/larg & 1 & 10 & 20 & 30 & 40 & 50 & 60 & 70 & 80 & 90 & 100 & 110 & 120 & 130 & 140 & 150 & 160 & 170 & 180 \\
\hline 10 & 0,0853 & 0353 & 0853 & 0,1456 & 1701 & 1656 & 0,1656 & & & & & & 0.1656 & 0,1656 & 0,1701 & 0,1455 & 0,0853 & 0,0853 & 0,0853 \\
\hline 20 & 0,1047 & 0,1047 & 0,1049 & 0,1773 & 1858 & 0,1858 & 0,1858 & & & & & & 0.1858 & 0,1858 & 0,1858 & 0,1773 & 0.1049 & 0,1047 & 0.1047 \\
\hline 30 & 0.1441 & 0.1481 & 0.1615 & 0.1650 & 0,1650 & 0,1650 & 0,1650 & & & & & & 0,1650 & 0,1650 & 0,1650 & 0,1650 & 0,1615 & 0,1481 & 0.1441 \\
\hline 40 & 0.1619 & 0,1650 & 0,1650 & 0,1650 & 0.1650 & 0,1650 & 0,1650 & & & & & & 0,1650 & 0.1650 & 0,1650 & 0,1650 & 0,1650 & 0,1650 & 0.1619 \\
\hline 50 & 1775 & 0,1775 & 0,1775 & 0,1775 & 0,1775 & 0,1775 & 0,1775 & & & & & & 0,1775 & 0,1775 & 0,1775 & 0,1775 & 0,1775 & & 0,1775 \\
\hline$\infty$ & 0,1998 & 0,2012 & 0,1636 & 0,1634 & 0,1634 & 0,1634 & 0,16 & & & & & & 34 & 0,1634 & 0,1634 & 0,1634 & 0,1636 & 0.2012 & 0,1998 \\
\hline 70 & 0,2358 & 0,2842 & 0,2166 & 0,2489 & 0.1951 & 0,1702 & 0,1687 & & & & & & & 0,1702 & & 0,2489 & 0,2166 & 0,2842 & 0,2358 \\
\hline 80 & 326 & 0,2651 & 0,2110 & 0,2470 & 0,1941 & 0,2266 & 0,3098 & 0,3720 & 0,3720 & 0,3720 & 720 & 3720 & 0,3 & 0,2 & 0.1941 & 0,2470 & 0,2110 & 0,2651 & 0,2326 \\
\hline 90 & 0,2203 & 0.2431 & 0.2145 & 0.2571 & 0.2523 & 0 & & 0,3720 & 0,3720 & 0,3720 & 0,3720 & 0.3720 & 0.3720 & 0.2893 & 0.2523 & 0,2571 & 0.2145 & 0.2431 & 0.2203 \\
\hline 100 & & 8 & 0.2 & & & & & & & & & & & & & & & & \\
\hline 110 & 96 & 0,2077 & 0,2626 & 0.2853 & 0,2996 & 0,3 & 0,2558 & 0,3720 & 0,3720 & 0,3720 & 0,3720 & 0.3720 & 0,2558 & 0,3045 & 0,2996 & 0,2858 & 0,2626 & 0,2077 & 0,1961 \\
\hline 120 & & 3 & 0,2767 & 0,2 & & & & 0,3720 & & 0,3720 & & & & & & & & & \\
\hline 130 & 1926 & 1 & 0,2345 & 0.2701 & 0,2 & 0,2 & 0,3 & 0,3720 & 0,3720 & 0,3720 & 0,3720 & 0,3720 & 0,3720 & 0,2411 & 49 & 0,2701 & 0,2345 & 0,1861 & 0,1926 \\
\hline 140 & 031 & 1911 & 0,2 & 0,2563 & & 0.2 & 0,3720 & 0,3720 & 0,3720 & 0,3720 & 0,3720 & 0,3720 & & & & & & & \\
\hline & 0,1811 & 1860 & 0,2356 & 0.2169 & 0.2 & 0,2765 & 0,3720 & 0,3720 & 0,3720 & 0.3720 & 0,3720 & 0.3720 & 0,3720 & 0,2 & 56 & 0,2 & 0,2356 & 0,1860 & 0,1811 \\
\hline 160 & & 890 & 0,2 & 0,2334 & 0.2 & 0,3 & & 0,3720 & 0,3720 & 0,3720 & 0,3720 & & & & & & & & \\
\hline 100 & 0,1966 & 1660 & 0.1678 & 0.1657 & 0,2631 & 0,3720 & 0,3720 & 0,3720 & 0,3720 & 0.3720 & 0,3720 & 0,3720 & 0,3720 & 0,3 & 31 & 57 & 0,1678 & 0,1660 & 0,1966 \\
\hline 180 & 0,3046 & 3310 & 0.3266 & 0.3184 & 0,3720 & 0,3720 & 0,3720 & 0.3720 & 0,3720 & 0.3720 & 0,3720 & 0.3720 & 0.3720 & 0.3720 & 0,3720 & 0,3184 & 0,3266 & 0,3310 & 0,3046 \\
\hline
\end{tabular}

Figura 5.28d - Solo 2 - Perfil de umidade simulado - Instante $t=286 \mathrm{~min}$ da fase de recessão $\equiv$ instante $\mathrm{t}=\mathbf{0}$ da fase de redistribução $(\mathrm{NA}=\mathbf{0})$

\begin{tabular}{|c|c|c|c|c|c|c|c|c|c|c|c|c|c|c|c|c|c|c|c|}
\hline ffla & 1 & 10 & 20 & 30 & 40 & 50 & 60 & 70 & 80 & 90 & 100 & 110 & 120 & 130 & 140 & 150 & 160 & 170 & 180 \\
\hline 10 & 1853 & 853 & 853 & 453 & 701 & 656 & 6 & & & & & & 1656 & 1656 & 1701 & 0,1453 & 0,0353 & 0,0853 & 08 \\
\hline 20 & 1047 & 047 & 049 & 773 & & 64 & & & & & & & & & & 0,1773 & & & \\
\hline 30 & 1439 & 1479 & 1610 & 1657 & 1661 & 0,1661 & 0.1650 & & & & & & 0,1660 & 0.1661 & 0.1661 & 0,1657 & 0,1610 & 0,1479 & 1439 \\
\hline 40 & 1619 & 1651 & 1653 & 1654 & 1654 & 0,1654 & 0,1654 & & & & & & 0,1654 & 0.1654 & 0,1654 & 0,1654 & 0,1653 & 0.1651 & 1619 \\
\hline 50 & 1778 & 1779 & 1779 & 1779 & 1779 & 0,1779 & 0,1779 & & & & & & 0.1779 & 0.1779 & 0.1779 & 0,1779 & 0,1779 & 0,1779 & 0,1778 \\
\hline 60 & 2010 & 2010 & 644 & 1641 & 1642 & 0,1642 & 0,1642 & & & & & & 0,1642 & & & & 0,1644 & & \\
\hline 70 & 439 & 7720 & 2178 & 2517 & 1960 & 0,1706 & 0,1675 & & & & & & 0,1675 & & & & & & \\
\hline$\infty$ & 2515 & 3720 & 2171 & 2893 & 1967 & 0,2272 & 0.1780 & 352 & 1275 & 1253 & 75 & 0 & & & & & & & \\
\hline 90 & 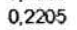 & 3720 & 2145 & 2575 & & 0,2888 & & 1482 & & 0.1377 & & & & & & & & & \\
\hline 100 & & & & & & & & & & & 1 & & & & & & & & \\
\hline 110 & & & & & & & & & & 0.1653 & 0,1638 & 0,1 & & & & & & & \\
\hline 120 & & & & & & & & 67 & & & 19 & & & & & & & & \\
\hline 130 & & & & & & & & & & & & & & & & & & & \\
\hline 140 & & & & & & & & & & & 0 & & & & & & & & \\
\hline $15 \mathrm{C}$ & & & & & & & & & & & 1 & & & & & & & & \\
\hline $16 c$ & & & & & & & & & & & & & & & & & & & \\
\hline 170 & & & & & & & & & & & & & & & & & & & \\
\hline 180 & 0,3049 & 0,3247 & & 0,3142 & 0.286 & 0,2460 & 0,325 & 0.3720 & 0.37 & 0,3720 & 0,3720 & 0.37 & & & & & & & \\
\hline \multicolumn{20}{|c|}{ zura 5.28e - Solo 2 - Perfil de umidade simulado - Instante $t=20$ min da fase de redistribuição } \\
\hline & 1 & & & & & & & & & 8 & & & & & & & & & 0 \\
\hline 10 & 1853 & & & & & & & & & & & & & & & & & & \\
\hline 2 & & & & & & & & & & & & & & & & & & & \\
\hline 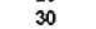 & & & & & & & & & & & & & & & & & & & 38 \\
\hline 4 & & & & & & & & & & & & & & & & & & & \\
\hline 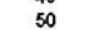 & & & & & & & & & & & & & & & & & & & 782 \\
\hline 6 & & & & & & & & & & & & & & & & & & & \\
\hline 7 & & & & & & & & & & & & & & & & & & & \\
\hline 8 & & & & & & & & & & & & & & & & & & & \\
\hline & & & & & & & & & & & 3 & & & & & & & & 0,2210 \\
\hline & & & & & & & & & & & & & & & & & & & \\
\hline 11 & & & & & & & & & & & 38 & & & & & & & & 962 \\
\hline & & & & & & & & & & & & & & & & & & & \\
\hline 130 & & & & & & & & & & & 0,1 & & & & & & & & \\
\hline & & & & & & & & & & & & & & & & & & & \\
\hline 15 & & & & & & & & & & & 0,1 & & & & & & & & \\
\hline to & & & & & & & & & & & & & & & & & & & \\
\hline & & & & & & & & & & & 0,1511 & & & & & & & 0,1647 & \\
\hline I & 0050 & 3196 & 3184 & 104 & 25 & 0,2460 & 0.2660 & 0.1889 & 835 & 0.1819 & 0,1835 & 0.1889 & 0,2660 & 0.2460 & 825 & 0.3104 & 0.3184 & 0.3196 & 0.306 \\
\hline
\end{tabular}

Figura 5.28f - Solo 2 - Perfil de umidade simulado - Instante $t=1$ h da fase de redistribuição 


\begin{tabular}{|c|c|c|c|c|c|c|c|c|c|c|c|c|c|c|c|c|c|c|c|}
\hline rofilarg & 1 & 10 & 20 & 30 & 40 & 50 & 60 & 70 & 80 & 90 & 100 & 110 & 120 & 130 & 140 & 150 & 160 & 170 & 180 \\
\hline 10 & 0,0853 & 0,0353 & 0.0353 & 0,1450 & 0,1700 & 0,1656 & 0,1656 & & & & & & 0,1656 & 0,1656 & 0,1700 & 0,1450 & 0.0353 & 0,0853 & 0.0853 \\
\hline 30 & 0,1436 & 0,1475 & 0,1699 & 0.1675 & 1691 & 0,1691 & 0,1651 & & & & & & 0,1651 & 0,1691 & 0,1691 & 0,1675 & 0,1599 & 0,1475 & 0.1436 \\
\hline 40 & 0,1621 & 0,1654 & 0,1661 & 0,1664 & 0,1665 & 0,1665 & 0,1663 & & & & & & 0.1663 & 0,1665 & 0,1665 & 0.1664 & 0,1661 & 0.1654 & 0.1621 \\
\hline 60 & 0,2036 & 0,2033 & 0,1664 & 0,1659 & 0,1661 & 0,1661 & 0,1661 & & & & & & 0,1661 & 0,1661 & 0,1661 & 0,1659 & 0,1664 & 0.2038 & 0.2036 \\
\hline 70 & 0,3720 & 0,3720 & 0,3720 & 0,2238 & 0,2072 & 0.1715 & 0,1683 & & & & & & 0,1683 & 0,1715 & 0,2072 & 0,2238 & 0,3720 & 0,3720 & 0,3720 \\
\hline 80 & 0,3720 & 0,3720 & 0,3720 & 0,3720 & 0,3720 & 0,2292 & 0,1924 & 0,1352 & 0,1275 & 0,1253 & 0,1275 & 0,1352 & 0,1924 & 0,2292 & 0,3720 & 0,3720 & 0,3720 & 0,3720 & 0,3720 \\
\hline 90 & 0,3720 & 0,3720 & 0,3720 & 0,3720 & 0,3720 & 0,2802 & 0,1624 & 0,1482 & 0.1403 & 0.1377 & 0,1403 & 0,1482 & 0,1624 & 0,2802 & 0,3720 & 0,3720 & 0,3720 & 0,3720 & 0,3720 \\
\hline 120 & 0,1859 & 370 & 0,2793 & 0,3720 & 0,2728 & & & 0,1908 & 01819 & 0.1793 & 0,1819 & & & & & & & & \\
\hline 130 & 0,1913 & 0,3720 & 0,2410 & 0,2770 & 0.2615 & 0,2412 & 0,1619 & 0,1879 & 0.1934 & 0,1939 & 0.1934 & 0.1879 & 0.1619 & 0.2412 & 0,2615 & 0,2770 & 0,2410 & 0,3720 & 0.1913 \\
\hline 140 & 2021 & 770 & 0,2608 & 0,2618 & 0.2401 & & 0,1621 & 0,2107 & 0,2141 & & 0,2141 & 0,2107 & & & & & & & \\
\hline 150 & 0,1812 & 0,1861 & 0,2437 & 0,2410 & 0,2415 & 0,2774 & 0,2331 & 0,1614 & 0,1623 & 0,1636 & 0,1623 & 0,1614 & 0,2331 & 0,2774 & 0,2415 & 0,2410 & 0,2437 & 0,1861 & 0,1812 \\
\hline 160 & 1827 & 0,1891 & 0,2252 & 0,2368 & 0.2587 & 0,2092 & 0,3720 & 0,1734 & 0,1680 & 0,1669 & 0,1680 & & & & & & 552 & & 827 \\
\hline 170 & 0,1912 & 0,1641 & 0,1656 & 0,1651 & 0,1895 & 0,1784 & 0,3720 & 0,1525 & 0,1511 & 0,1505 & 0,1511 & 0,1525 & 0,3720 & 0,1784 & 0,1895 & 0,1651 & 0.1656 & 0,1641 & 0,1912 \\
\hline 180 & 0,3049 & 0,3135 & 0,3127 & 0,3057 & 0.2788 & 0,2460 & 0.2660 & 0,1889 & 0,1835 & 0,1819 & 0.1835 & 0.1889 & 0,2660 & 0,2460 & 0,2783 & 0,3057 & 0.3127 & 0,3135 & 0,3049 \\
\hline
\end{tabular}

Figura 5.28g - Solo 2 - Perfil de umidade simulado - Instante $t=2 \mathrm{~h}$ da fase de redistribuição

\begin{tabular}{|c|c|c|c|c|c|c|c|c|c|c|c|c|c|c|c|c|c|c|c|}
\hline $\begin{array}{l}\text { profilarg } \\
\text { (cm) }\end{array}$ & 1 & 10 & 20 & 30 & 40 & 50 & 60 & 70 & 80 & 90 & 100 & 110 & 120 & 130 & 140 & 150 & 160 & 170 & 180 \\
\hline 10 & 0,0853 & 0353 & 0853 & 0,1448 & 0,1700 & 0,1656 & 0,1656 & & & & & & 0,1656 & 0,1656 & 0,1700 & 0,1448 & 0,0353 & 0,0853 & 0.0353 \\
\hline 30 & 0,1434 & 0.1472 & 0,1592 & 0.1686 & 0,1711 & 0,1710 & 1652 & & & & & & 0,1652 & 0.1710 & 0,1711 & 0,1686 & 0.1592 & 0,1472 & 0.1434 \\
\hline 40 & 0,1622 & 0,1656 & 0,1665 & 0,1671 & 0,1672 & 0,1672 & 0,1609 & & & & & & 0,1669 & 0,1672 & 0,1672 & 0,1671 & 0,1665 & 0,1656 & 0,1622 \\
\hline 60 & 0,2041 & 0,2019 & 0,1883 & 0,1671 & 0,1673 & 0,1673 & 0,167 & & & & & & 0,1673 & 0,1673 & 0,1673 & 0,1671 & 0,1883 & 0,2019 & 0.2041 \\
\hline 70 & 0,3720 & 0,3720 & 3720 & 0,2188 & 0,1896 & 0,1720 & 0,1688 & & & & & & 38 & 0,1720 & 0,1896 & 0,2188 & & 0,3720 & 0.3720 \\
\hline 80 & 7720 & 0,3720 & 0,3720 & 0,3720 & 0,3720 & 0,2311 & 0.2047 & 0,1352 & 0,1275 & 0,1253 & 0,1275 & 0,1352 & 0,2047 & 0,2311 & 0.3720 & 0,3720 & 0.3720 & 0,3720 & 0,3720 \\
\hline 90 & 0,3720 & 0,3720 & 3720 & 0,3720 & 0,3720 & 0,2756 & 0.1625 & 0,1482 & 0,1403 & 0,1377 & 0,1403 & 0.1482 & 0,1625 & 0.2756 & 0,3720 & 0,3720 & 0,3720 & 0.3720 & 0.3720 \\
\hline 120 & 0,3720 & 0,37 & 3720 & 0,3720 & 0,3720 & 0,2 & 0,16 & 0,1908 & 0,1819 & 0,1793 & & & & & & & & & 0,3720 \\
\hline 130 & 7700 & 0,37 & 3720 & 0,3720 & 0,3720 & 0,2 & 0,16 & 0,1879 & 0,1934 & 0,1939 & 0,1934 & 0.18 & 0,1 & 0,2427 & 0,3720 & 0,3 & 20 & 0,3720 & 0,3720 \\
\hline 140 & 0.210 & 0,3720 & 0,3720 & 0,3720 & 0,3720 & 0,2480 & 0,1621 & 0,2107 & 0,2140 & 0,2154 & 0,2140 & & 0. & 0,2480 & & & & 0,3720 & 104 \\
\hline 150 & & 0,372 & 0,2811 & 0,3720 & 0,2468 & 0.2758 & 0,1672 & 0,1615 & 0,1624 & 0,1637 & 0,1624 & 0,1615 & 0,1672 & 0,2758 & 0,2468 & 0,3720 & 11 & 0,3720 & 0,1812 \\
\hline 160 & & 0,3720 & 0,2229 & 0.2377 & 0,2564 & 0,2114 & 0,1538 & 0,1734 & 0,1680 & 0,1669 & 0,1680 & & & & 0,2564 & & 229 & 0,3720 & 827 \\
\hline 170 & ( & 0,372 & 0,1651 & 0,1650 & 0,1897 & 0,1786 & 0,1496 & & 0.1511 & 0,1505 & 0.1511 & & & 0,1786 & 0,1897 & 0,1650 & & 0,3720 & 0,1891 \\
\hline 180 & 0,3043 & 0,3166 & 0,3081 & 0,3019 & 0,2763 & 0,2457 & 0,1912 & 0,1889 & 0,1835 & 0,1819 & 0,1835 & 0,1889 & 0,1912 & 0,2457 & 0,2763 & 0,3019 & 0,3081 & 0,3166 & 0,3043 \\
\hline
\end{tabular}

Figura 5.28h - Solo 2 - Perfil de umidade simulado - Instante $t=3 \mathrm{~h}$ da fase de redistribuição

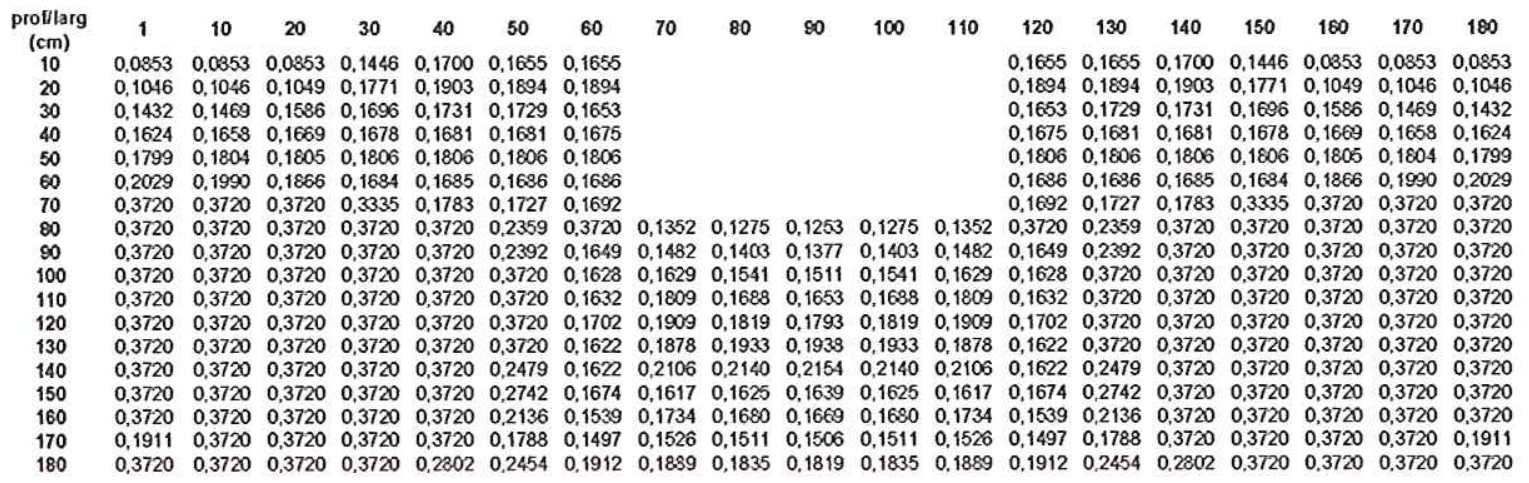

Figura 5.28i - Solo 2 - Perfil de umidade simulado - Instante $t=4$ h da fase de redistribuição

\begin{tabular}{|c|c|c|c|c|c|c|c|c|c|c|c|c|c|c|c|c|c|c|c|}
\hline$=m$ ) & 1 & 10 & 20 & 30 & 40 & 50 & 60 & 70 & 80 & 90 & 100 & 110 & 120 & 130 & 140 & 150 & 160 & 170 & 100 \\
\hline 10 & 0853 & 0853 & 0853 & 0.1444 & 0,1699 & 0.1655 & 0,1655 & & & & & & .1655 & 0.1655 & 0,1699 & 0.1444 & 0,0853 & 0.0853 & 0,0853 \\
\hline 30 & 1430 & 0,1467 & 1530 & 0,1707 & 0.1752 & 0.1750 & 0.1656 & & & & & & 1665 & 0.1750 & 0.1752 & 0,1707 & 0,1580 & 0,1467 & 0,1430 \\
\hline 40 & 0,1625 & 0.1659 & 0.1673 & 0,1686 & 0,1690 & 0,1600 & 0,1681 & & & & & & .1681 & 0,1600 & 0,1690 & 0,1686 & 0,1673 & 0,1659 & 0,1625 \\
\hline 60 & 2008 & 0.1909 & 0,1864 & 0,1768 & 0,1698 & 0,1699 & 0,169 & & & & & & 1699 & 0,169 & 0,1698 & 0,1768 & 0,1864 & 0,1969 & 0,2008 \\
\hline 70 & 3720 & 0,3720 & 0,3720 & 0,3720 & 0,1817 & 0,1633 & 0,1604 & & & & & & & & 0,1817 & 0,3720 & 0.3720 & 0,3720 & 0,3720 \\
\hline 80 & 20 & 0,3720 & 0,3720 & 0,3720 & 0,3720 & 0,3720 & 0,1732 & 0,1352 & 0,1275 & 0,1253 & 0,1275 & 0,1352 & 0,1732 & 0,3720 & 0,3720 & 0,3720 & 0,3720 & 0,3720 & 0,3720 \\
\hline 90 & 3720 & 0,3720 & 0,3720 & 0,3720 & 0,3720 & 0,3720 & 0.3720 & 0.1482 & 0.1403 & 0,1377 & 0,1403 & 0,1482 & 0,3720 & 0,3720 & 0,3720 & 0,3720 & 0,3720 & 0.3720 & 0,3720 \\
\hline 120 & 0,3720 & 0,3720 & 0,3720 & 0,3720 & 0,3720 & 0,3720 & 0,1714 & 0,1910 & 0,1819 & 0.1793 & 0,1819 & 0,1910 & & & 0.3720 & & & & 0,3720 \\
\hline 130 & 3720 & 3720 & 0,3720 & 0,3720 & 0,3720 & 0,3720 & 0,1624 & 0.1878 & 01933 & 0,1938 & 0.1933 & 0,1878 & 0,1 & 0,3720 & 0,3720 & 0,3720 & 0,3 & 0,3 & 0,3720 \\
\hline 140 & 0,3720 & 0,3720 & 0,3720 & 0,3720 & 0,3720 & 0,3720 & 0,1623 & 0,2106 & 0,2139 & 0,2153 & 0,2139 & 0,2106 & 0,1623 & 0,3720 & 0,3720 & 0,3720 & 20 & 0,3720 & 0,3720 \\
\hline 150 & 3720 & 0,3720 & 0,3720 & & 0,3720 & & & & & & 0.1627 & & 0,1677 & 0,3720 & 0,3720 & 0,3720 & 0,3720 & 0,3720 & 0,3720 \\
\hline 160 & 3720 & 0,3720 & 0,3720 & 0,3720 & 0,3720 & 0,3720 & 0,1540 & 0.1734 & 0,1680 & $0.16 \oplus$ & 0,1680 & 0,1 & 0,1540 & 0,3720 & 0,3720 & 0,3720 & 0,3720 & 0,3720 & 0,3720 \\
\hline $1 / 0$ & 3720 & 0,3720 & 0,3720 & & 0,3720 & & & & & & & & & & 0,3720 & 0,3720 & & 0.3720 & 0,3720 \\
\hline 180 & 0,3720 & 0,3720 & 0,3720 & 0,3720 & 0,3720 & 0.2451 & 0,1912 & 0,1889 & 0,1835 & 0,1819 & 0,1835 & 0,1889 & 0,1912 & 0.2451 & 0,3720 & 0,3720 & 0,3720 & 0,3720 & 0,3720 \\
\hline
\end{tabular}

Figura 5.28j - Solo 2 - Perfil de umidade simulado - Instante $t=5$ h da fase de redistribuição 
Na fase de redistribuição, se comparadas as Figuras 5.18 e 5.19 aos valores simulados apresentados nas Figuras 5.27 e 5.28, observa-se que, nas simulações, o Solo 1 rapidamente atinge a umidade de saturação em todo o perfil, o que não ocorre totalmente nos ensaios observados. Logo no instante $\mathrm{t}=0$ da redistribuição a parte inferior do domínio, na simulação A para os Solos 1 e 2, apresenta-se totalmente saturada.

A defasagem na capacidade de drenagem do solo nos ensaios simulados em relação aos ensaios de campo nos primeiros instantes após o término da fase de recessão, é também observada nas horas seguintes, em que a drenagem ocorre mais lentamente que nas condições observadas.

No entanto, embora em ambos os solos a drenagem na simulação tenha ocorrido mais lentamente que nos experimentos de campo, a simulação A para o Solo 2 revelou drenagem mais rápida que para o Solo 1 . O Solo 2 já apresentava-se com valores de umidade próximos aos do início do experimento no instante $\mathrm{t}=5 \mathrm{~h}$, conforme pode ser observado nas Figuras 5.28 e-j, enquanto que, no Solo 2, ainda eram observados valores próximos da saturação na região inferior do domínio, após 48 horas do início da alimentação.

Deste modo, há uma tendência de que a simulação subestime a capacidade de infiltração e drenagem do solo, em todas as fases do processo de infiltração. Este fato deve-se, provavelmente, às incertezas associadas à curva de retenção ajustada para os Solos 1 e 2, já discutidas na seção 5.1.2.

\subsubsection{Simulação $B$}

A simulação B para os Solos 1 e 2 foi realizada utilizando as mesmas vazões dos experimentos de campo e da simulação $A$, ou seja, $Q=770 \mathrm{~cm}^{3} / \mathrm{s}$ para o Solo 1 e $Q=860$ $\mathrm{cm}^{3} / \mathrm{s}$ para o Solo 2 , sendo que, em ambos, o tempo de alimentação é $\mathrm{t}=72 \mathrm{~min}$. Todo o perfil foi inicializado com umidade de saturação. Tal como na simulação $A$, a simulação $B$ foi conduzida de modo a cessar quando fosse atingido o máximo nível d'água na trincheira ou o tempo total de alimentação $\mathrm{t}=72 \mathrm{~min}$. Assim como na Simulação A, considerou-se o nível $\mathrm{h}=69 \mathrm{~cm}$ como a máxima lâmina d'água posível na trincheira, cujo valor, ao ser atingido ou superado, cessaria a simulação. Deste modo, os arquivos de entrada com os parâmetros e variáveis do modelo permaneceram inalterados em relação aos apresentados nas Figuras 5.22 e 5.24. Os arquivos de entrada com os valores iniciais de h são mostrados nas Figuras 5.29 e 5.30 . 


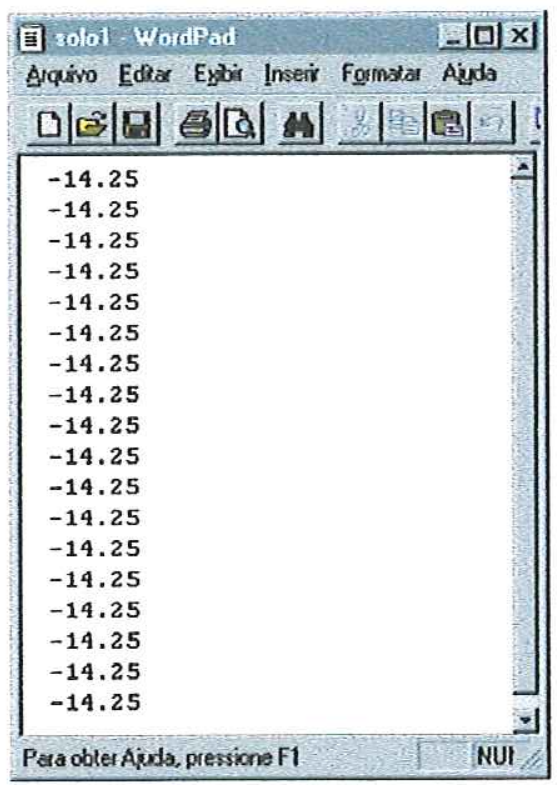

Figura 5.29 - Arquivo com os valores iniciais de h para a Simulação B - Solo 1

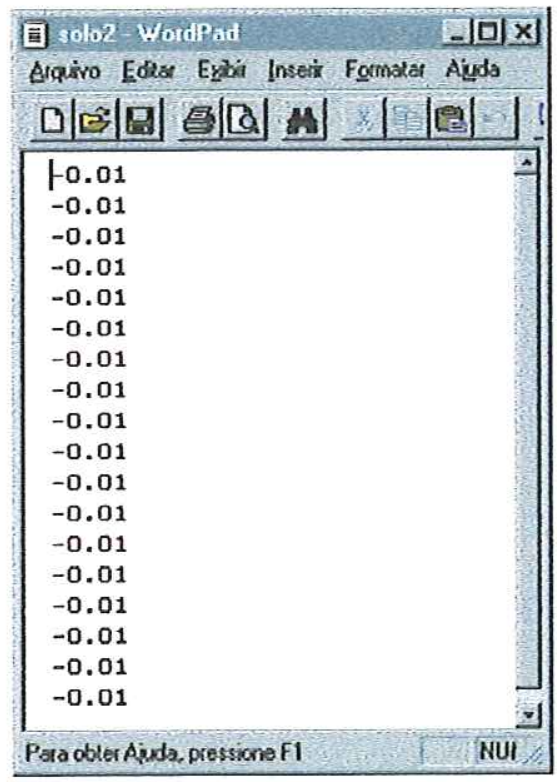

Figura 5.30 - Arquivo com os valores iniciais de h para a Simulação B - Solo 2

A Tabela 5.12 apresenta os valores de lâmina d'água e volumes infiltrados fornecidos pela Simulação B para os Solos 1 e 2. As Figuras 5.31 e 5.32 apresentam a evolução do nível d'água na trincheira, nas simulações A e B, para os Solos 1 e 2, respectivamente. 
Tabela 5.12 - Fases de alimentação e recessão: Simulação B - valores de lâmina d'água e volume infiltrado, Solos 1 e 2

\begin{tabular}{|c|c|c|c|c|}
\hline & \multicolumn{2}{|c|}{ Solo 1} & \multicolumn{2}{|c|}{ Solo 2} \\
\hline$t(\min )$ & $\operatorname{lag}(\mathrm{cm})$ & $V \inf \left(m^{3}\right)$ & $\operatorname{lag}(\mathrm{cm})$ & vol inf $\left(m^{3}\right)$ \\
\hline 0 & 4,57 & 0,00 & 5,10 & 0,00 \\
\hline 2 & 4,57 & 0,00 & 5,10 & 0,00 \\
\hline 4 & 9,04 & 0,00 & 10,07 & 0,00 \\
\hline 6 & 13,41 & 0,00 & 14,92 & 0,00 \\
\hline 8 & 17,70 & 0,00 & 19,67 & 0,00 \\
\hline 10 & 21,90 & 0,00 & 24,32 & 0,00 \\
\hline 12 & 26,03 & 0,00 & 28,88 & 0,00 \\
\hline 14 & 30,08 & 0,00 & 33,34 & 0,00 \\
\hline 16 & 34,06 & 0,00 & 37,72 & 0,00 \\
\hline 18 & 37,97 & 0,00 & 42,02 & 0,00 \\
\hline 20 & 41,83 & 0,00 & 46,25 & 0,00 \\
\hline 22 & 44,87 & 0,02 & 50,41 & 0,00 \\
\hline 24 & 47,74 & 0,04 & 54,50 & 0,00 \\
\hline 26 & 50,78 & 0,06 & 58,52 & 0,00 \\
\hline 28 & 53,68 & 0,08 & 62,48 & 0,00 \\
\hline 30 & 56,68 & 0,09 & 66,38 & 0,00 \\
\hline 32 & 59,91 & 0,10 & 70,23 & 0,00 \\
\hline 34 & 63,30 & 0,10 & 69,86 & 0,00 \\
\hline 36 & 66,74 & 0,11 & 69,49 & 0,00 \\
\hline 38 & 70,18 & 0,11 & 69,12 & 0,01 \\
\hline 40 & 69,80 & 0,12 & 68,75 & 0,02 \\
\hline 42 & 69,43 & 0,13 & 68,37 & 0,03 \\
\hline 44 & 69,06 & 0,14 & 68,00 & 0,04 \\
\hline 46 & 68,69 & 0,15 & 67,63 & 0,05 \\
\hline 48 & 68,32 & 0,16 & 67,25 & 0,06 \\
\hline 50 & 67,95 & 0,17 & 66,88 & 0,07 \\
\hline 52 & 67,57 & 0,18 & 66,50 & 0,08 \\
\hline 54 & 67,20 & 0,19 & 66,13 & 0,09 \\
\hline 56 & 66,82 & 0,20 & 65,75 & 0,10 \\
\hline 58 & 66,45 & 0,21 & 65,38 & 0,11 \\
\hline 60 & 66,07 & 0,22 & 65,00 & 0,12 \\
\hline 62 & 65,70 & 0,23 & 64,62 & 0,13 \\
\hline 64 & 65,32 & 0,24 & 64,24 & 0,14 \\
\hline 66 & 64,94 & 0,25 & 63,86 & 0,15 \\
\hline 68 & 64,57 & 0,26 & 63,48 & 0,16 \\
\hline 70 & 64,19 & 0,27 & 63,10 & 0,17 \\
\hline 72 & 63,81 & 0,28 & 62,72 & 0,18 \\
\hline 74 & 63,43 & 0,29 & 62,34 & 0,19 \\
\hline 76 & 63,05 & 0,30 & 61,96 & 0,20 \\
\hline 78 & 62,67 & 0,31 & 61,58 & 0,21 \\
\hline 80 & 62,29 & 0,32 & 61,20 & 0,22 \\
\hline 82 & 61,91 & 0,33 & 60,81 & 0,23 \\
\hline 84 & 61,52 & 0,34 & 60,43 & 0,24 \\
\hline 86 & 61,14 & 0,35 & 60,05 & 0,25 \\
\hline 88 & 60,76 & 0,36 & 59,66 & 0,26 \\
\hline 90 & 60,37 & 0,37 & 59,28 & 0,27 \\
\hline 92 & 59,99 & 0,38 & 58,89 & 0,28 \\
\hline 94 & 59,60 & 0,39 & 58,50 & 0,29 \\
\hline 96 & 59,22 & 0,40 & 58,12 & 0,30 \\
\hline 98 & 58,83 & 0,41 & 57,73 & 0,31 \\
\hline 100 & 58,45 & 0,42 & 57,34 & 0,32 \\
\hline 102 & 58,06 & 0,43 & 56,95 & 0,33 \\
\hline 104 & 57,67 & 0,44 & 56,56 & 0,34 \\
\hline 106 & 57,28 & 0,45 & 56,17 & 0,35 \\
\hline 108 & 56,89 & 0,46 & 55,78 & 0,36 \\
\hline 110 & 56,50 & 0,47 & 55,39 & 0,37 \\
\hline 112 & 56,11 & 0,48 & 55,00 & 0,38 \\
\hline 114 & 55,72 & 0,49 & 54,61 & 0,39 \\
\hline
\end{tabular}


Tabela 5.12 - Continuação: Fases de alimetação e recessão: Simulação B - valores de lâmina d'água e volume infiltrado, Solos 1 e 2

\begin{tabular}{|c|c|c|c|c|}
\hline \multirow[b]{2}{*}{$\mathrm{t}(\mathrm{min})$} & \multicolumn{2}{|c|}{ Solo 1} & \multicolumn{2}{|c|}{ Solo 2} \\
\hline & $\operatorname{lag}(\mathrm{cm})$ & $V \inf \left(m^{3}\right)$ & $\operatorname{lag}(\mathrm{cm})$ & vol inf $\left(\mathrm{m}^{3}\right)$ \\
\hline 116 & 55,33 & 0,50 & 54,21 & 0,40 \\
\hline 118 & 54,94 & 0,51 & 53,82 & 0,41 \\
\hline 120 & 54,55 & 0,52 & 53,42 & 0,42 \\
\hline 122 & 54,15 & 0,53 & 53,03 & 0,43 \\
\hline 124 & 53,76 & 0,54 & 52,63 & 0,44 \\
\hline 126 & 53,37 & 0,55 & 52,24 & 0,45 \\
\hline 128 & 52,97 & 0,56 & 51,84 & 0,46 \\
\hline 130 & 52,58 & 0,57 & 51,44 & 0,47 \\
\hline 132 & 52,18 & 0,58 & 51,05 & 0,48 \\
\hline 134 & 51,78 & 0,59 & 50,65 & 0,49 \\
\hline 136 & 51,39 & 0,60 & 50,25 & 0,50 \\
\hline 138 & 50,99 & 0,61 & 49,85 & 0,51 \\
\hline 140 & 50,59 & 0,62 & 49,45 & 0,52 \\
\hline 142 & 50,19 & 0,63 & 49,05 & 0,53 \\
\hline 144 & 49,79 & 0,64 & 48,64 & 0,54 \\
\hline 146 & 49,39 & 0,65 & 48,24 & 0,55 \\
\hline 148 & 48,99 & 0,66 & 47,84 & 0,56 \\
\hline 150 & 48,59 & 0,67 & 47,43 & 0,57 \\
\hline 152 & 48,18 & 0,68 & 47,03 & 0,58 \\
\hline 154 & 47,78 & 0,69 & 46,63 & 0,59 \\
\hline 156 & 47,38 & 0,70 & 46,22 & 0,60 \\
\hline 158 & 46,97 & 0,71 & 45,81 & 0,61 \\
\hline 160 & 46,57 & 0,72 & 45,41 & 0,62 \\
\hline 162 & 46,16 & 0,73 & 45,00 & 0,63 \\
\hline 164 & 45,75 & 0,74 & 44,59 & 0,64 \\
\hline 166 & 45,35 & 0,75 & 44,18 & 0,65 \\
\hline 168 & 44,94 & 0,76 & 43,77 & 0,66 \\
\hline 170 & 44,53 & 0,77 & 43,36 & 0,67 \\
\hline 172 & 44,12 & 0,78 & 42,95 & 0,68 \\
\hline 174 & 43,71 & 0,79 & 42,54 & 0,69 \\
\hline 176 & 43,30 & 0,80 & 42,12 & 0,70 \\
\hline 178 & 42,89 & 0,81 & 41,71 & 0,71 \\
\hline 180 & 42,48 & 0,82 & 41,30 & 0,72 \\
\hline 182 & 42,06 & 0,83 & 40,88 & 0,73 \\
\hline 184 & 41,65 & 0,84 & 40,47 & 0,74 \\
\hline 186 & 41,24 & 0,85 & 40,05 & 0,75 \\
\hline 188 & 40,82 & 0,86 & 39,63 & 0,76 \\
\hline 190 & 40,41 & 0,87 & 39,22 & 0,77 \\
\hline 192 & 39,99 & 0,88 & 38,80 & 0,78 \\
\hline 194 & 39,57 & 0,89 & 38,38 & 0,79 \\
\hline 196 & 39,15 & 0,90 & 37,96 & 0,80 \\
\hline 198 & 38,74 & 0,91 & 37,54 & 0,81 \\
\hline 200 & 38,32 & 0,92 & 37,12 & 0,82 \\
\hline 202 & 37,90 & 0,93 & 36,69 & 0,83 \\
\hline 204 & 37,48 & 0,94 & 36,27 & 0,84 \\
\hline 206 & 37,05 & 0,95 & 35,85 & 0,85 \\
\hline 208 & 36,63 & 0,96 & 35,42 & 0,86 \\
\hline 210 & 36,21 & 0,97 & 35,00 & 0,87 \\
\hline 212 & 35,79 & 0,98 & 34,57 & 0,88 \\
\hline 214 & 35,36 & 0,99 & 34,15 & 0,89 \\
\hline 216 & 34,94 & 1,00 & 33,72 & 0,90 \\
\hline 218 & 34,51 & 1,01 & 33,29 & 0,91 \\
\hline 220 & 34,08 & 1,02 & 32,86 & 0,92 \\
\hline 222 & 33,66 & 1,03 & 32,43 & 0,93 \\
\hline 224 & 33,23 & 1,04 & 32,00 & 0,94 \\
\hline 226 & 32,80 & 1,05 & 31,57 & 0,95 \\
\hline 228 & 32,37 & 1,06 & 31,14 & 0,96 \\
\hline
\end{tabular}


Tabela 5.12 - Continuação: Fases de alimetação e recessão: Simulação B - valores de lâmina d'água e volume infiltrado, Solos 1 e 2

\begin{tabular}{|c|c|c|c|c|}
\hline \multirow[b]{2}{*}{$t(\min )$} & \multicolumn{2}{|c|}{ Solo 1} & \multicolumn{2}{|c|}{ Solo 2} \\
\hline & $\operatorname{lag}(\mathrm{cm})$ & $V \inf \left(m^{\prime}\right)$ & $\operatorname{lag}(\mathrm{cm})$ & vol inf $\left(m^{5}\right)$ \\
\hline 230 & 31,94 & 1,07 & 30,70 & 0,97 \\
\hline 232 & 31,51 & 1,08 & 30,27 & 0,98 \\
\hline 234 & 31,07 & 1,09 & 29,83 & 0,99 \\
\hline 236 & 30,64 & 1,10 & 29,40 & 1,00 \\
\hline 238 & 30,21 & 1,11 & 28,96 & 1,01 \\
\hline 240 & 29,77 & 1,12 & 28,53 & 1,02 \\
\hline 242 & 29,34 & 1,13 & 28,09 & 1,03 \\
\hline 244 & 28,90 & 1,14 & 27,65 & 1,04 \\
\hline 246 & 28,46 & 1,15 & 27,21 & 1,05 \\
\hline 248 & 28,02 & 1,16 & 26,77 & 1,06 \\
\hline 250 & 27,58 & 1,17 & 26,33 & 1,07 \\
\hline 252 & 27,14 & 1,18 & 25,88 & 1,08 \\
\hline 254 & 26,70 & 1,19 & 25,44 & 1,09 \\
\hline 256 & 26,26 & 1,20 & 25,00 & 1,10 \\
\hline 258 & 25,82 & 1,21 & 24,55 & 1,11 \\
\hline 260 & 25,38 & 1,22 & 24,11 & 1,12 \\
\hline 262 & 24,93 & 1,23 & 23,66 & 1,13 \\
\hline 264 & 24,49 & 1,24 & 23,21 & 1,14 \\
\hline 266 & 24,04 & 1,25 & 22,76 & 1,15 \\
\hline 268 & 23,59 & 1,26 & 22,32 & 1,16 \\
\hline 270 & 23,15 & 1,27 & 21,86 & 1,17 \\
\hline 272 & 22,70 & 1,28 & 21,41 & 1,18 \\
\hline 274 & 22,25 & 1,29 & 20,96 & 1,19 \\
\hline 276 & 21,80 & 1,30 & 20,51 & 1,20 \\
\hline 278 & 21,35 & 1,31 & 20,05 & 1,21 \\
\hline 280 & 20,90 & 1,32 & 19,60 & 1,22 \\
\hline 282 & 20,44 & 1,33 & 19,14 & 1,23 \\
\hline 284 & 19,99 & 1,34 & 18,69 & 1,24 \\
\hline 286 & 19,53 & 1,35 & 18,23 & 1,25 \\
\hline 288 & 19,08 & 1,36 & 17,77 & 1,26 \\
\hline 290 & 18,62 & 1,37 & 17,31 & 1,27 \\
\hline 292 & 18,16 & 1,38 & 16,85 & 1,28 \\
\hline 294 & 17,70 & 1,39 & 16,39 & 1,29 \\
\hline 296 & 17,24 & 1,40 & 15,93 & 1,30 \\
\hline 298 & 16,78 & 1,41 & 15,46 & 1,31 \\
\hline 300 & 16,32 & 1,42 & 15,00 & 1,32 \\
\hline 302 & 15,86 & 1,43 & 14,53 & 1,33 \\
\hline 304 & 15,39 & 1,44 & 14,07 & 1,34 \\
\hline 306 & 14,93 & 1,45 & 13,60 & 1,35 \\
\hline 308 & 14,46 & 1,46 & 13,13 & 1,36 \\
\hline 310 & 14,00 & 1,47 & 12,66 & 1,37 \\
\hline 312 & 13,53 & 1,48 & 12,19 & 1,38 \\
\hline 314 & 13,06 & 1,49 & 11,72 & 1,39 \\
\hline 316 & 12,59 & 1,50 & 11,24 & 1,40 \\
\hline 318 & 12,12 & 1,51 & 10,77 & 1,41 \\
\hline 320 & 11,65 & 1,52 & 10,30 & 1,42 \\
\hline 322 & 11,17 & 1,53 & 9,82 & 1,43 \\
\hline 324 & 10,70 & 1,54 & 9,34 & 1,44 \\
\hline 326 & 10,23 & 1,55 & 8,86 & 1,45 \\
\hline 328 & 9,75 & 1,56 & 8,38 & 1,46 \\
\hline 330 & 9,27 & 1,57 & 7,90 & 1,47 \\
\hline 332 & 8,79 & 1,58 & 7,42 & 1,48 \\
\hline 334 & 8,31 & 1,59 & 6,94 & 1,49 \\
\hline 336 & 7,83 & 1,60 & 6,46 & 1,50 \\
\hline 338 & 7,35 & 1,61 & 5,97 & 1,51 \\
\hline 340 & 6,87 & 1,62 & 5,48 & 1,52 \\
\hline 342 & 6,38 & 1,63 & 5,00 & 1,53 \\
\hline 344 & 5,90 & 1,64 & 4,51 & 1,54 \\
\hline 346 & 5,41 & 1,65 & 4,02 & 1,55 \\
\hline 348 & 4,93 & 1,66 & 3,53 & 1,56 \\
\hline 350 & 4,44 & 1,67 & 3,04 & 1,57 \\
\hline 352 & 3,95 & 1,68 & 2,54 & 1,58 \\
\hline 354 & 3,46 & 1,69 & 2,05 & 1,59 \\
\hline 356 & 2,96 & 1,70 & 1,55 & 1,60 \\
\hline 358 & 2,47 & 1,71 & 1,06 & 1,61 \\
\hline 360 & 1,98 & 1,72 & 0,00 & 1,62 \\
\hline 362 & 1,48 & 1,73 & 0,00 & 1,62 \\
\hline 364 & 0,00 & 1,74 & 0,00 & 1,62 \\
\hline
\end{tabular}


Simulaçöes A e B - Evolução do nível d'água na trincheira - Solo 1

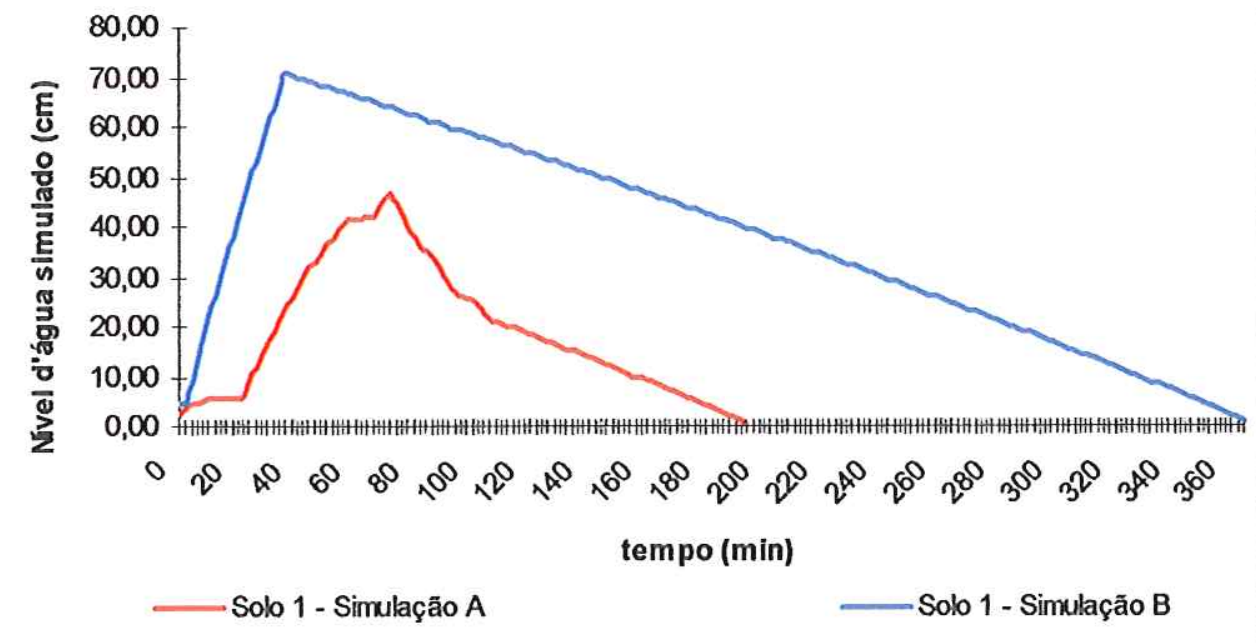

Figura 5.31 - Evolução do nível d'água na trincheira, Simulações A e B - Solo 1

Simulações A e B - Evolução do nível d'água na trincheira - Solo 2

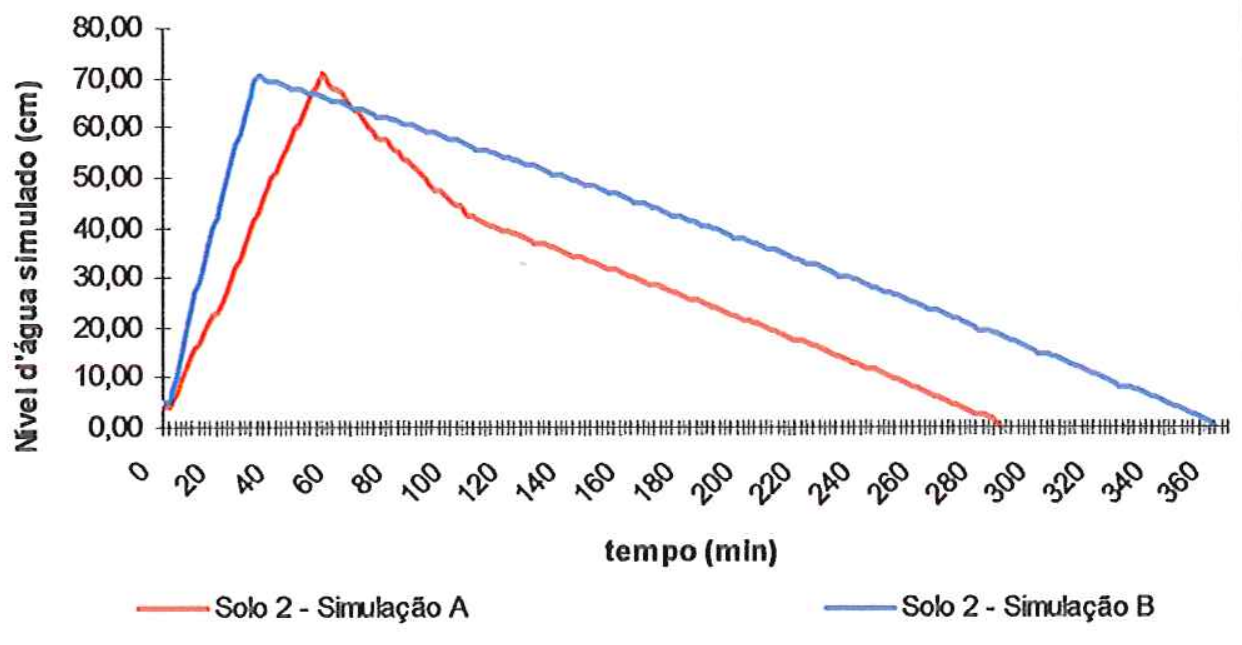

Figura 5.32 - Evolução do nivel d'água na trincheira, Simulações A e B - Solo 2

Conforme pode ser observado na Tabela 5.12, o resulado da simulação B revelou que foi atingida a lâmina d'água máxima, no Solo 1, aos 36 minutos, e, no Solo 2, aos 32 minutos. A simulação $\mathrm{B}$ para os dois solos cessou devido à lâmina máxima ter sido alcançada, e não devido ao volume total de alimentação ser atingido.

O tempo em que a altura máxima de água no interior da trincheira foi atingida, nos Solos 1 e 2, partindo da condição de saturação total do perfil, foi de, aproximadamente, metade do tempo em que o mesmo ocorreu na simulação $\mathrm{A}$, conforme pode ser observado nas Figuras 5.31 e 5.32. O tempo para finalizar a fase de recessão, para o Solo 1, foi de 366 
minutos, e, para o Solo 2, de 360 minutos. O volume total infiltrado no Solo 1 foi de 1,60 $\mathrm{m}^{3}$, e, no Solo 2 , de $1,63 \mathrm{~m}^{3}$. Os dois solos se comportaram de maneira muito semelhante na simulação saturada.

Pode-se estimar a precipitação que gera o volume de $1,70 \mathrm{~m}^{3}$ durante o intervalo de 35 minutos, que é o tempo médio em que as trincheiras nos Solos 1 e 2 atingiram nível máximo na simulação saturada. Considerando um lote de área $250 \mathrm{~m}^{2}$, com $60 \%$ de ocupação, gerando uma área impermeável de $150 \mathrm{~m}^{2}$, obtém-se que o volume de $1,70 \mathrm{~m}^{3}$ equivale a uma lâmina d'água de $11,33 \mathrm{~mm}$ sobre a área impermeável, ou $0,32 \mathrm{~mm} / \mathrm{min}$ $(19,4 \mathrm{~mm} / \mathrm{h})$ nos 35 minutos de alimentação. A partir da equação de chuva de São Carlos (Equação 3.2), e considerando um período de retorno de 2 anos, obtém-se a intensidade de precipitação de $45,3 \mathrm{~mm} / \mathrm{h}$, ou $26 \mathrm{~mm}$ em 35 minutos. Sendo assim, nas condições de saturação total do perfil, as trincheiras nos Solos 1 e 2 se revelaram capazes de absorver cerca de um terço do volume de chuva a elas aduzido.

As Figuras 5.33 e 5.34 ilustram o desenvolvimento do perfil de umidade fornecido pela simulação B para os Solos 1 e 2, respectivamente.

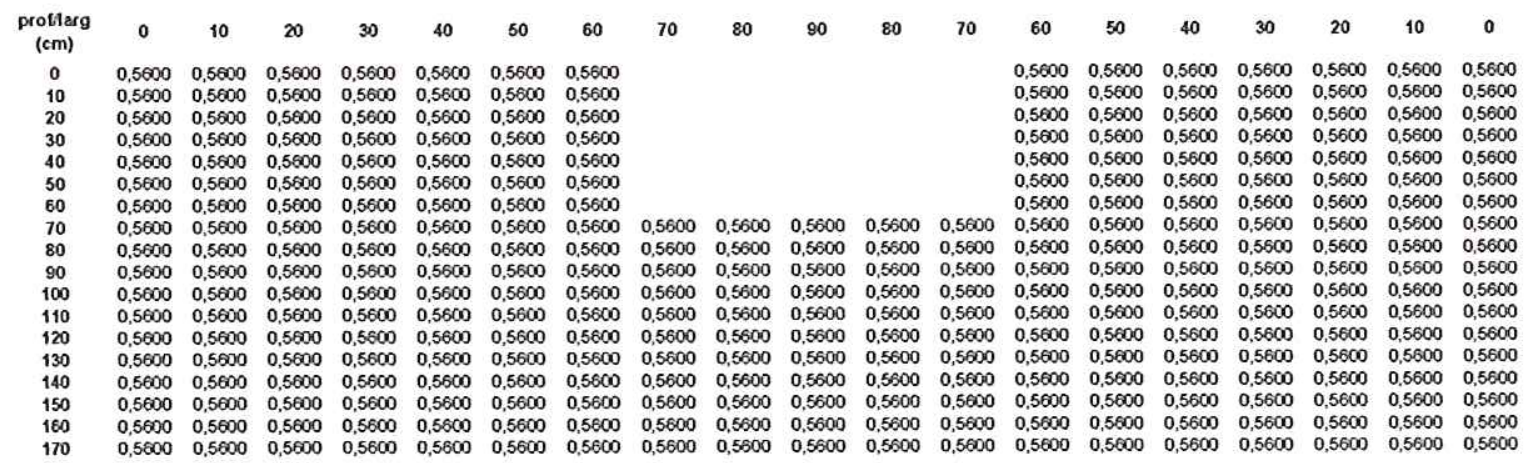

Figura 5.33a - Solo 1 - Simulação B: Perfil de umidlade antes da irrigação

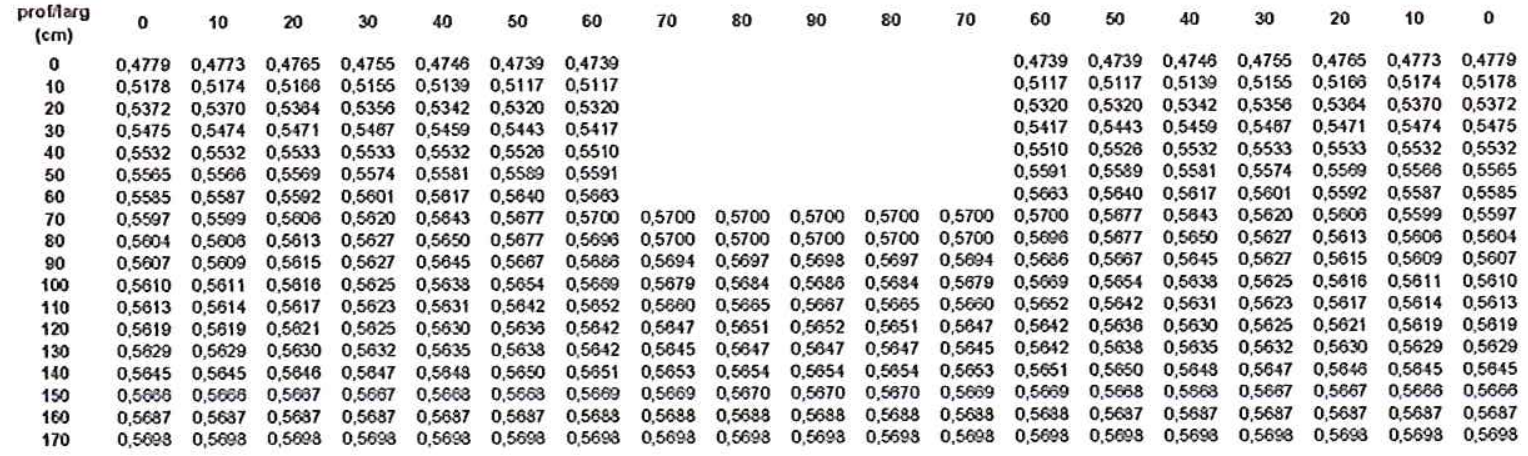

Figura 5.33b - Solo 1 - Simulação B: Perfil de umidade no instante $t=2$ min da fase de alimentação 


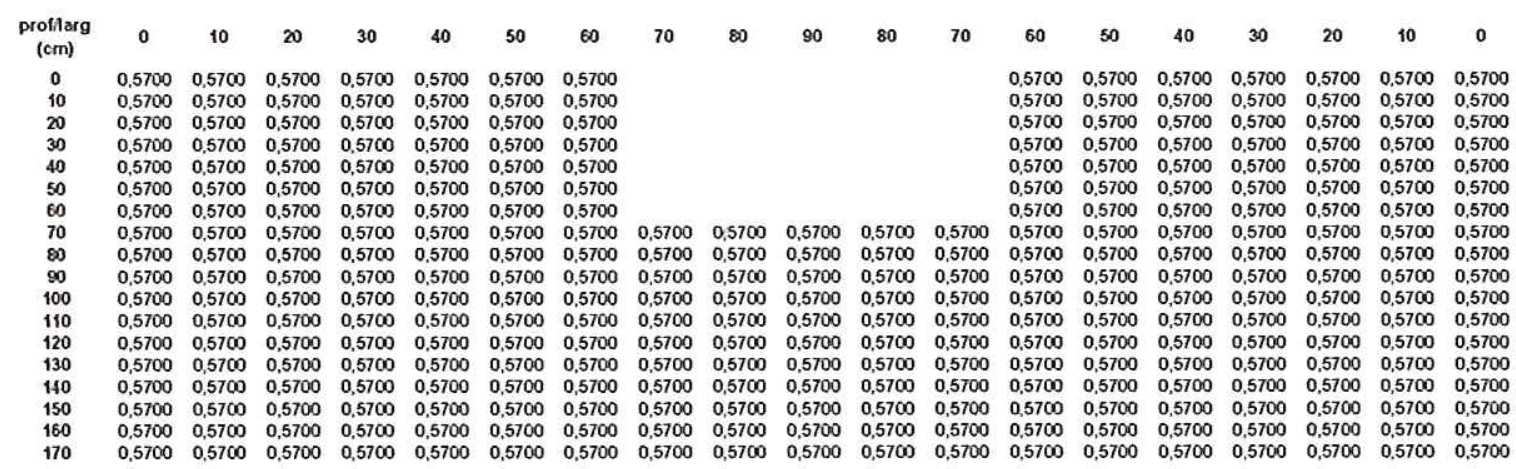

Figura 5.33c - Solo 1 - Simulação B: Perfil de umidade no instante $t=36$ min da fase de alimentação $\equiv$ instante $t=0$ da fase de recessão (NA máximo)

\begin{tabular}{|c|c|c|c|c|c|c|c|c|c|c|c|c|c|c|c|c|c|c|c|}
\hline $\begin{array}{c}\text { proflarg } \\
\text { (cm) }\end{array}$ & 0 & 10 & 20 & 30 & 40 & 50 & 60 & 70 & 80 & 90 & 80 & 70 & 60 & 50 & 40 & 30 & 20 & 10 & 0 \\
\hline 0 & 0.2579 & 2579 & 0,2578 & 2578 & 0,2578 & 0,2578 & 0,2578 & & & & & & 0.2578 & 0.257 & 0.2578 & 0.2578 & 0,2578 & 0.2579 & 0,2579 \\
\hline 10 & 0.2827 & 0.2824 & 0,2822 & 0,2819 & 0,2817 & 0,2314 & 0,2814 & & & & & & 0.2814 & 0,2814 & 0.2817 & 0,2819 & 0,2822 & 0,2824 & 2. \\
\hline 20 & 0,3122 & 0,3118 & 0,3114 & 0,3110 & 0,3107 & 0,3103 & 0,3103 & & & & & & 0,3100 & 0.3103 & 0,3107 & 0,3110 & 0.3114 & 0,3118 & 0.3122 \\
\hline 30 & 0,3507 & 0.3502 & 0.3497 & 0,3493 & 0,3488 & 0,3483 & 0,3479 & & & & & & 0,3479 & 0,3483 & 0.3488 & 0.3493 & 0,3497 & 0,3502 & 0,3507 \\
\hline 40 & 0,4032 & 0,4023 & 0,4023 & 0,4018 & 0,4013 & 0,4003 & 0,4003 & & & & & & 0,4003 & 0,4008 & 0,4013 & 0,4018 & 0,4023 & 0,4023 & 0,4032 \\
\hline so & 0,4634 & 0,4636 & 0,4637 & 0,4636 & 0,4634 & 0,4630 & 0.4626 & & & & & & 0,4626 & 0,4630 & 0,4634 & 0,4636 & 0,4637 & 0,4633 & 0,4634 \\
\hline 60 & 0.5107 & 0,5125 & 0,5147 & 0,5163 & 0.5184 & 0,5194 & 0,5196 & & & & & & 0,5196 & 0,5184 & 0.5184 & 0,5168 & 0,5147 & 0,5125 & 0,5107 \\
\hline 70 & 0.5489 & 6506 & 0.5533 & 0,5577 & 0,5620 & 0,5663 & 0,5697 & 70 & 0.570 & 570 & $57 c$ & 57 & 0,5697 & 0,5663 & 0,5620 & 0,5577 & 0,5538 & 0,5505 & 0.5489 \\
\hline 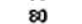 & 0.5566 & 0,5574 & 0,5593 & 0,5625 & 0,5655 & 0.5681 & 0,5697 & 0,5700 & 0,5700 & 0.5700 & 0,5700 & 0,5700 & 0,5697 & 0,5681 & 0,6655 & 0,5625 & 0,5590 & 0,5574 & 0,5568 \\
\hline 90 & 6617 & 0.5622 & 0,5636 & 0,5654 & 0.5673 & 0.5688 & 0,5696 & 0,5699 & 0.5700 & 0,5700 & 0,5700 & 0,5699 & 0,56966 & 0,5688 & 0,5673 & 0.5654 & 0,5636 & 0.5622 & 0,5617 \\
\hline 100 & 0,5650 & 0.5653 & 0,5661 & 0,5672 & 0,5683 & 0,5691 & 0,5696 & 0,5699 & 0,5699 & 0,5700 & & 0,5609 & 0,5696 & 0,5691 & 0,5683 & 0,5672 & 0,5661 & 0,5653 & 0,5650 \\
\hline 110 & 0.5672 & 0,5673 & 0.5678 & 0,5684 & 0,5690 & 0,5694 & 0,5697 & 0,5699 & 0,5699 & 0,5699 & 0,5699 & 0,5099 & 0,5697 & 0,5694 & 0,5690 & 0,5684 & 0,5678 & 0,5673 & 0,5672 \\
\hline 120 & 685 & 0,5683 & 0.568 & 0.5691 & 0,5694 & 0.5696 & 0,5698 & 0,5699 & 0,5699 & 0,5699 & 0,5699 & 0,5099 & 0,5693 & 0,5606 & 0,5694 & 0.5691 & 0,5688 & 0,5653 & 0,5635 \\
\hline 130 & 0,5693 & 0,5693 & 0.5694 & 0,5696 & 0.5697 & 0,5698 & 0,5699 & 0,5699 & 0,5699 & 0,5700 & 0,5699 & 0,5699 & 0,5699 & 0,5698 & 0.5697 & 0,5695 & 0,5694 & 0,5693 & 0,5093 \\
\hline 140 & 0.5697 & 0.5697 & 0,5693 & 0,5698 & 0,5699 & 0,5699 & 0,5999 & 0,5700 & 0,5700 & 0,5700 & 5700 & 0,5700 & 0,5699 & $0,5 \odot 99$ & 0,5699 & 0,5693 & 0,5693 & 0,5697 & 0,5697 \\
\hline 150 & & 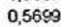 & 0,50 & 0,5699 & 0,5700 & & 0,5700 & 0.5700 & 0,5700 & 0,5700 & 5700 & 0,5700 & 0,5700 & 0.5700 & 0,5700 & 05699 & 0,5699 & 0,5699 & 9 \\
\hline 160 & 700 & 5700 & 0,5700 & 0,5700 & 0,5700 & 0,5700 & 0,5700 & 0,5700 & 0,5700 & 0,5700 & 0,5700 & 0,5700 & 0,5700 & 0,5700 & 0,5700 & 0,5700 & 0,5700 & 0,5700 & 0,5700 \\
\hline 170 & 5700 & 5700 & 5700 & 0.5700 & 0.5700 & 0.5700 & 0.5700 & 0.5700 & 0,5700 & 0,5700 & 0,5700 & 0,5700 & 0,5700 & 0,5700 & 0,5700 & 0.5700 & 0,5700 & 0,5700 & 0,5700 \\
\hline
\end{tabular}

Figura 5.33d - Solo 1 - Simulação B: Perfil de umidade no instante $t=366$ min da fase de recessão $\equiv$ instante $\mathrm{t}=0$ da fase de redistribução $(\mathrm{NA}=\mathbf{0})$

\begin{tabular}{|c|c|c|c|c|c|c|c|c|c|c|c|c|c|c|c|c|c|c|c|}
\hline $\begin{array}{l}\text { rollarg } \\
\text { (cm) }\end{array}$ & 0 & 10 & 20 & 30 & 40 & 50 & 6 & 70 & 80 & 90 & 80 & 70 & 60 & 50 & 40 & 30 & 20 & 10 & 0 \\
\hline 0 & 2571 & 2571 & 2571 & 257 & 0. & 0 & 0,25 & & & & & & 0.2570 & 0,2570 & 0.2571 & 0.2571 & 0,2571 & 0,2571 & 25 \\
\hline 10 & 3146 & 3146 & 0,3146 & 3145 & 0,3146 & 0,3146 & 0,3146 & & & & & & 0,3145 & 0,3146 & 0,3146 & 0.3146 & 0,3146 & 3146 & 16 \\
\hline 20 & 1938 & 3933 & 3838 & 3833 & 0,3837 & 3937 & 0,3837 & & & & & & 0,3837 & 0,3837 & 0,3337 & 0,3833 & 0,3838 & 0.3838 & 3838 \\
\hline 30 & 575 & 4574 & 4574 & 4574 & 0.4574 & 0.4574 & 0.4571 & & & & & & 0,4571 & 0.4574 & 0,4574 & 0,4574 & 0,4574 & 0,4574 & \\
\hline 40 & & & 4 & 20 & 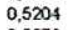 & 4 & 0.52 & & & & & & & & & & 24 & & \\
\hline so & 579 & 5579 & 0,5579 & 5579 & 0,5579 & 0,5578 & 0,5578 & & & & & & 78 & 0,5578 & 0,5579 & 0,5579 & 0,5579 & 79 & 79 \\
\hline 60 & 695 & 6695 & 0,5695 & 5695 & 0.5605 & 0.5695 & 0,5695 & & & & & & 35 & 0,5 & 0,5695 & 0,5695 & 0,5695 & 0,5695 & 5695 \\
\hline 70 & & 0 & 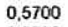 & 0 & & & & 5623 & & & & & & & & & 00 & $\infty$ & 5700 \\
\hline$\infty 0$ & 700 & 5700 & 0.5700 & 0.570 & 0.5700 & 0.5700 & 0.5700 & 0,5673 & 0.5597 & 55563 & 5597 & 0,5673 & 0,5700 & 0,5700 & 0,5700 & 0,5700 & 0,5700 & 0,5700 & .5700 \\
\hline & & 0 & 0,570 & 0. & & 0 & 0,5 & 0 & & & & 35 & 8 & 0,5 & 0,5 & & 0.5700 & 0,5 & 5700 \\
\hline & & & & & & & & & & & & & & & & & & & \\
\hline 110 & 700 & 5700 & 0,5700 & 0,5700 & 0,5700 & 0,5699 & 0,5693 & 0,5695 & 0,5691 & 0,5689 & 5691 & 0,5695 & 0,5698 & 0,5699 & & & 50 & 0,5 & \\
\hline & & & & 0 & & & & & & & & & & 0,5099 & & & 00 & $\infty$ & \\
\hline 130 & & & & & & & & 0 & & & & 5698 & & & & & & & \\
\hline 1 & 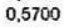 & & & & & & & 056 & 9 & & & & 0,5700 & & & & .5700 & 5700 & 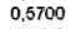 \\
\hline & & & & & & & & & & & & & & & & & & & \\
\hline 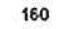 & 5 & o & 0,5700 & 0 . & 0,57 & 0,5700 & 0,5700 & 0, & & & & & & & & & & & \\
\hline & 0,5700 & 700 & 0.5700 & 5700 & 0,5700 & 0,5700 & 0,5700 & 0,5700 & 0,5700 & 0,5700 & 0.5700 & 0,5700 & 0,5700 & 0,5700 & 0,5700 & 0,5700 & 0,5700 & 0,5700 & $0,5 / 6$ \\
\hline
\end{tabular}

Figura 5.33e - Solo 1 - Simulação B: Perfil de umidade no instante $t=20 \mathrm{~min}$ da fase de redistribuição

\begin{tabular}{|c|c|c|c|c|c|c|c|c|c|c|c|c|c|c|c|c|c|c|c|}
\hline $\begin{array}{c}\text { protharg } \\
\text { (cm) }\end{array}$ & 0 & 10 & 20 & 30 & 40 & 50 & 60 & 70 & $\infty$ & 90 & 80 & 70 & 60 & 50 & 40 & 30 & 20 & 10 & 0 \\
\hline 0 & 0.2571 & 2571 & 0,2571 & 0,2571 & 0,2571 & 0,2570 & 0,2570 & & & & & & 0,2570 & 0,2570 & 0,2571 & 0.2571 & 0.2571 & 0,2571 & 0,2571 \\
\hline 10 & 0,3147 & 0,3147 & 0,3147 & 0,3147 & 0,3146 & 0,3146 & 0,3146 & & & & & & 0,3146 & 0,3148 & 0,3148 & 0,3147 & 0,3147 & 0,3147 & 0,3147 \\
\hline 20 & 0,3839 & 0,3839 & 0,3839 & 0,3839 & 0,3839 & 0,3838 & 0,3838 & & & & & & 0.3838 & 0,3838 & 0,3839 & 0,3839 & 0,3839 & 0,3839 & 0,3839 \\
\hline 30 & 0,4576 & 0,4578 & 0,4576 & 0,4576 & 0,4576 & 0.4576 & 0,4575 & & & & & & 0,4575 & 0,4576 & 0,4576 & 0,4576 & 0,4576 & 0,4578 & 0,4576 \\
\hline 40 & 0,5203 & 0,5203 & 0,5206 & 0,5206 & 0,5205 & 0.5205 & 0,5205 & & & & & & 0,5206 & 0,5205 & 0,5205 & 0,5206 & 0,5206 & 0,5203 & 0,5206 \\
\hline 50 & 0,5579 & 0,5579 & 0,5579 & 0,5579 & 0,5579 & 0,5579 & 0,5579 & & & & & & 0,5579 & 0,5579 & 0,5579 & 0.5579 & 0.5679 & 0.5579 & 0,5579 \\
\hline$\omega$ & 0,5095 & 0,5695 & 0,5695 & 0,5695 & 0,5695 & 0,5695 & 0,5695 & & & & & & 0.5695 & 0,5695 & 0,5695 & 0,5605 & 0,5695 & 0,5695 & 0,5095 \\
\hline 70 & 0,5700 & 0,5700 & 0,5700 & 0,5700 & 0,5700 & 0,5700 & 0,5700 & 0,5814 & .5393 & 5288 & 5356 & .5614 & 0,5700 & 0,5700 & 0,5700 & 0,5700 & 0,5700 & 0,5700 & 0,5700 \\
\hline$\infty$ & 0,5700 & 0,5700 & 0,5700 & 0,5700 & 0,5700 & 0,5700 & 0,5700 & 0,5673 & 0,5600 & 0,5559 & 5600 & 5873 & 0,5 & 0,5700 & 0,5700 & 0.5700 & 0,5700 & 0,5700 & 0,5700 \\
\hline 90 & 0.5700 & 0.5700 & 0,5700 & 0,5700 & 0,5700 & 0,5700 & 0,5608 & 0,5686 & 0,5661 & 0,5647 & 0,5661 & 0,5686 & 0,5698 & 0,5700 & 0,5700 & 0,5700 & 0,5700 & 0,5700 & 0,5700 \\
\hline 100 & 0,5700 & 0.57 & 0,57 & 0,5700 & 0.5700 & 0.5700 & 0,5098 & 0,5692 & 0.5682 & 0,5678 & 5582 & 0,5692 & 0,5698 & 0,5700 & 0,5700 & 0.5700 & 0.5700 & 0,5700 & 0.5700 \\
\hline 110 & 0,5700 & 0,5700 & 0,5700 & 0,5700 & 0,5700 & 0,5699 & 0,5603 & 0,5695 & 0,5691 & 0,5000 & 0,5691 & 0,5005 & 0,5698 & 0,5699 & 0,5700 & 0,5700 & 0,5700 & 0,5700 & 0,5700 \\
\hline 120 & 0.5700 & 0,5700 & 0,5700 & 0.5700 & 0,5700 & 0,5699 & 0,5698 & 0,5697 & 0,5696 & 0,5695 & 0,5693 & 0,5697 & 0,5698 & 0,5699 & 0,5700 & 0.5700 & 0,5700 & 0,5700 & 0,5700 \\
\hline 130 & 0,5700 & 0.5700 & 0,5700 & 0,5700 & 0,5700 & 0,5699 & 0,5699 & 0,5699 & 0.5 & 0,5 & & 0,5899 & 0,5699 & 0,5699 & & 0,5700 & 0,5700 & 0,5700 & 0,5700 \\
\hline 140 & 0,5700 & 0.5700 & 0.5700 & 0,5700 & 0,5700 & 0,5700 & 0,5700 & 0,5699 & 0,5699 & 0,5699 & 0,5609 & 0,5699 & 0,5700 & 0,5700 & 0,5700 & 0,5700 & 0,5700 & 0.5700 & 0,5700 \\
\hline 150 & 0,5700 & 0,5700 & 0,5700 & 0,5700 & 0,5700 & 0,5700 & 0,5700 & 0,5700 & 0,5700 & 0,5700 & 0,5700 & & & 0,5700 & & & 0,5700 & 0.5700 & \\
\hline 160 & & . & 0,57 & 0.5 & & 0,5 & 0,5700 & & 0 & & & & & & & & & & \\
\hline & & & & & & & & & & & 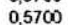 & 0 & 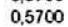 & & 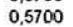 & & 05700 & 05700 & \\
\hline
\end{tabular}

Figura 5.33f - Solo 1 - Simulação B: Perfil de umidade no instante $t=1$ h da fase de redistribuição 


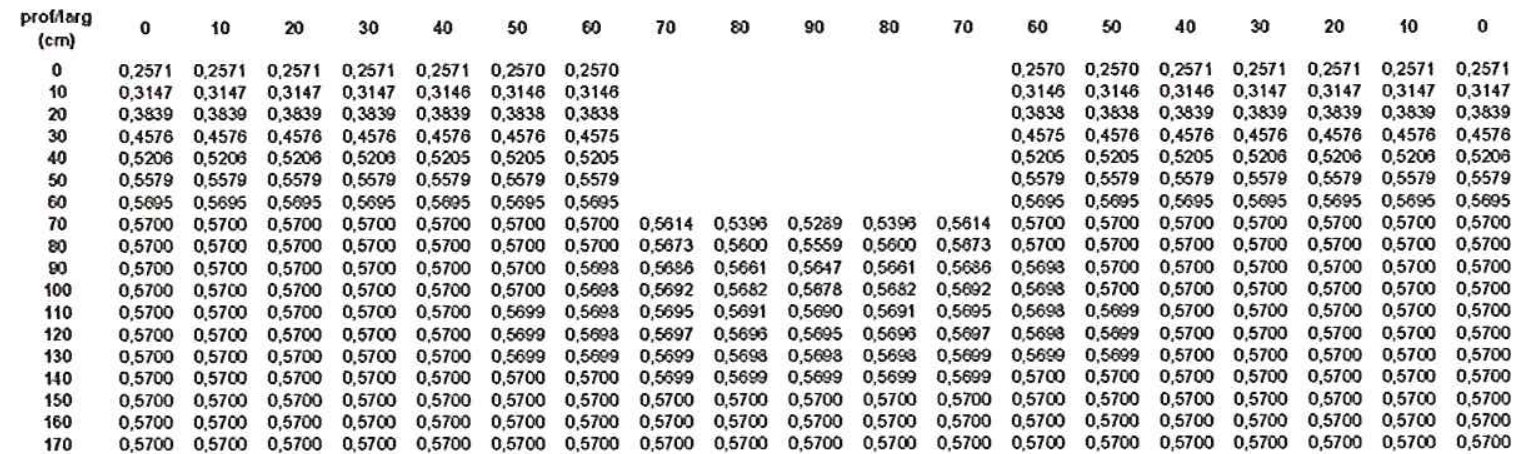

Figura 5. 33g - Solo 1 - Simulação B: Perfil de umidade no instante $t=2 \mathrm{~h}$ da fase de redistribuição

\begin{tabular}{|c|c|c|c|c|c|c|c|c|c|c|c|c|c|c|c|c|c|c|c|}
\hline $\begin{array}{l}\text { rolharg } \\
\text { (cm) }\end{array}$ & 0 & 10 & 20 & 30 & 40 & 50 & 60 & 70 & $\infty$ & 90 & 80 & 70 & 60 & 50 & 40 & 30 & 20 & 10 & 0 \\
\hline 0 & 0.2571 & 0.2571 & 0.2571 & 0,2571 & 0,2571 & 0,2570 & 0,2570 & & & & & & 0.2570 & 0,2570 & 0,2571 & 0,2571 & 0,2571 & 0.2571 & 0,2571 \\
\hline 10 & 0,3147 & 0,3147 & 0,3147 & 0,3147 & 0,3146 & 0,3146 & 0,3146 & & & & & & 0.3146 & 0,3146 & 0,3146 & 0,3147 & 0,3147 & 0,3147 & 0,3147 \\
\hline 20 & 0,3839 & 0.3839 & 0,3839 & 0,3839 & 0.3839 & 0,3838 & 0,3838 & & & & & & 0,3838 & 0,3838 & 0,3839 & 0,3839 & 0,3939 & 0,3839 & 0,3839 \\
\hline 30 & 0,4576 & 0,4576 & 0,4576 & 0,4576 & 0,4576 & 0.4576 & 0,4575 & & & & & & 0,4575 & 0,4576 & 0,4576 & 0,4576 & 0.4576 & 0,4576 & 0,4578 \\
\hline 40 & 0,52086 & $\begin{array}{l}0,45206 \\
0,520\end{array}$ & 0,5206 & 0,5203 & $\begin{array}{l}0,5205 \\
0,525\end{array}$ & 0,5205 & 0,5205 & & & & & & 0,5206 & 0,5205 & 0,5205 & 0,5206 & 0,5206 & 0,5206 & 0,5206 \\
\hline 50 & 0,5579 & 0.5579 & 0.5579 & 0,5579 & 0,5579 & 0.5579 & 0.5579 & & & & & & 0,5579 & 0,5579 & 0,5579 & 0,5579 & 0,5579 & 0,5579 & 0,5579 \\
\hline 60 & 0,5695 & 0,5696 & 0,5695 & 0,5695 & 0,5695 & 0,5695 & 0,5695 & & & & & & 0.5695 & 0.5695 & 0,5695 & 0.5695 & 0,5695 & 0,5695 & 0,5695 \\
\hline 70 & 0,5700 & 0,5700 & 0,5700 & 0,5700 & 0.5700 & 0.5700 & 0,5700 & 0,5614 & 0.5396 & 5289 & 396 & 5614 & 0,5700 & 0.5700 & 0,5700 & 0,5700 & 0,5700 & 0,5700 & 0,5700 \\
\hline 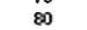 & 0,5700 & 0,5700 & 0,5700 & 0,5700 & 0.5700 & 0,5700 & 0,5700 & 0,5673 & 0,5601 & 0,5559 & 5601 & 0,5673 & 0,5700 & 0,5700 & 0,5700 & 0,5700 & 0,5700 & 0,5700 & 0,5700 \\
\hline 90 & 0,5700 & 0,5700 & 0,5700 & 0,5700 & 0.5700 & 0,5700 & 0,5608 & 0.5686 & 0,5661 & 0.5647 & 0,5661 & 0,5686 & 0,5693 & 0.5700 & 0,5700 & 0,5700 & 0,5700 & 0,5700 & 0,5700 \\
\hline 100 & 0,5700 & 0,5700 & 0,5700 & 0,5700 & 0,5700 & 0,5700 & 0,5609 & 0,5692 & 0,5682 & 0,5678 & 0,5682 & 0,5692 & 0,5683 & 0,5700 & 0,5700 & 0,5700 & 0,5700 & 0,5700 & 0,5700 \\
\hline 110 & 0,5700 & 0,5700 & 0,5700 & 0,5700 & 0,5700 & 0,5699 & 0,5693 & 0,5695 & 0,5691 & 0,5600 & 0,5691 & 0,5695 & 0.5698 & 0,5699 & 0,5700 & 0,5700 & 0,5700 & 0,5700 & 0,5700 \\
\hline 120 & 0,5700 & 0.5700 & 0.5700 & 0,5700 & 0.5700 & 0,5699 & 0,5998 & 0,5697 & 0,5695 & 0,5995 & 0,5696 & 0,5697 & 0,5693 & 0.5699 & 0,5700 & 0,5700 & 0,5700 & 0,5700 & 0,5700 \\
\hline 130 & 0,5700 & 0.5700 & 0,5700 & 0,5700 & 0.5700 & 0,5699 & 0,5609 & 0,5699 & 0,5693 & 0,5893 & 0,5693 & 0,5699 & 0,5699 & 0,5699 & 0,5700 & 0.5700 & 0,5700 & 0,5700 & 0,5700 \\
\hline 140 & 0,5700 & 0.5700 & 0,5700 & 0,5700 & 0,5700 & 0,5700 & 0,5700 & 0,5699 & 0.565 & 0,5699 & 0,5699 & 0.5699 & 0,5700 & 0,5700 & 0,5700 & 0,5700 & 0,5700 & 0,5700 & 0.5700 \\
\hline 150 & 0,5700 & 0,5700 & 0,5700 & 0,5700 & 0,5700 & 0,5700 & 0,5700 & 0.5700 & 0,5700 & 0,5700 & 0.5700 & 0,5700 & 0,5700 & 0,5700 & 0,5700 & 0,5700 & 0,5700 & 0,5700 & 0.5700 \\
\hline 160 & 0,5700 & 0,5700 & 0570 & 0,5700 & 0,5700 & 0,5700 & 0,5700 & 0,5700 & 05700 & 0,5700 & 0.5700 & 0,5700 & 0.5700 & & 05 & 0,5700 & 0,5700 & 0,5700 & 0.5700 \\
\hline 170 & 0,5700 & 5700 & 5700 & 0,5700 & 0,5700 & 0.5700 & 0,5700 & 5700 & 0,5700 & 0.5700 & 0,5700 & 0,5700 & 0.5700 & 0,5700 & 0,5700 & 0,5700 & 0,5700 & 0,5700 & 0,5700 \\
\hline
\end{tabular}

Figura 5. 33h - Solo 1 - Simulação B: Perfil de umidade no instante $t=3 \mathrm{~h}$ da fase de redistribuição

\begin{tabular}{|c|c|c|c|c|c|c|c|c|c|c|c|c|c|c|c|c|c|c|c|}
\hline $\begin{array}{c}\text { proftharg } \\
\text { (cm) }\end{array}$ & 0 & 10 & 20 & 30 & 40 & 50 & 60 & 70 & ఐ & 90 & 80 & 70 & 60 & so & 40 & 30 & 20 & 10 & 0 \\
\hline 0 & 0,2571 & 0,2571 & 0,2571 & 0,2571 & 0,2571 & 0,2570 & 0,2570 & & & & & & 0,2570 & 0,2570 & 2571 & 2571 & 0,2571 & 0,2571 & 0,2571 \\
\hline 10 & 3147 & 0,3147 & 0,3147 & 0,3147 & 0,3146 & 0,3146 & 0.3146 & & & & & & 0,3146 & 0,3146 & 0,3146 & 0.3147 & 0,3147 & 0,3147 & 0,3147 \\
\hline 20 & 0,3839 & 0,3939 & 0,3839 & 0,3939 & 0,3839 & 0,3938 & 0,3838 & & & & & & 0,3838 & 0,3838 & 0,3839 & 0,3839 & 0,3839 & 0,3839 & 0,3839 \\
\hline 30 & 0,4576 & 0,4576 & 0,4576 & 0,4576 & 0,4576 & 0,4576 & 0,4575 & & & & & & 0,4575 & 0.4576 & 0,4576 & 0,4576 & 0,4576 & 0,4576 & 0,4576 \\
\hline 40 & 5206 & 0,5203 & 0,5203 & 0,5203 & 0.5205 & 0,5205 & 0,5205 & & & & & & 0.5205 & 0,5205 & 0,5205 & 0,5206 & 0,5206 & 0,5206 & 0,5206 \\
\hline so & 5579 & 0.5579 & 0.5579 & 0,5579 & 0,5579 & 0,5579 & 0,5579 & & & & & & 0,5579 & 0,5579 & 0.5679 & 0,5579 & 0,5579 & 0,5578 & 0,5579 \\
\hline 60 & 5 & 0,5695 & 0,5695 & 0,5695 & 0,5695 & 0,5695 & 0,5695 & & & & & & 0,5696 & 0,5695 & 0,5695 & 0,5695 & 0,5695 & 0,5696 & 0,5695 \\
\hline 70 & .5700 & 0,5700 & 0.5700 & 0,5700 & 0,5700 & 0,5700 & 0,5700 & 0,5614 & 0,5398 & 0,5269 & 0,5395 & 0,5614 & 0.5700 & 0,5700 & 0,5700 & 0,5700 & 0,5700 & 0,5700 & 0,5700 \\
\hline ఐ & 700 & 5700 & 0,5700 & 0,5700 & 0.5700 & 0,5700 & 0,5700 & 0,5673 & 0.5601 & .5559 & 0,5601 & 5673 & 0,5700 & 0,5700 & 0,5700 & 0.5700 & 0,5700 & 0.5700 & 0,5700 \\
\hline 90 & 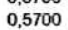 & 0,5700 & 0,5700 & 0,5700 & 0.5700 & 0,5700 & 0,5693 & & 0,5661 & 0,5647 & 0,5661 & & & & & 0,5700 & & 0.5700 & 0,5700 \\
\hline 100 & 5700 & 0,5700 & 0,5700 & 0,5700 & 0,5700 & 0,5700 & 0,5698 & 0,5692 & 0,5682 & 0,5678 & 0,5682 & 0,5692 & 0,5698 & 0,5700 & 0,5700 & 0,5700 & 0,5700 & 0,5700 & 0,5700 \\
\hline 110 & 5700 & 0.5700 & 0,5700 & 0.5700 & 0,5700 & 0,5699 & 0,5693 & 0,5695 & 0,5691 & 0,5090 & 0,5691 & 0,5605 & 0,5698 & 0,5099 & 0,5700 & 0,5700 & 0,5700 & 0,5700 & 0,5700 \\
\hline 120 & 700 & 0.5700 & 0.5700 & 0,5700 & 0.5700 & 0,5699 & 0,5003 & 0,56 & 0,5693 & 0,5695 & 0,56 & & & & 0,5700 & 0,5700 & 00 & 0,5700 & 0,5700 \\
\hline 130 & 700 & 5700 & .5700 & 0,5700 & 0,5700 & 0,6699 & 0,5699 & 0,5699 & 0,5693 & 0,5693 & 0,5693 & 5699 & 0,5699 & 0,5699 & 0.5700 & 0,5700 & 0,5700 & 0,5700 & 0,5700 \\
\hline & 10 & 5700 & 5700 & 0.57 & 0,57 & 0,5700 & 0.5700 & 0,5699 & 0.5699 & 0,5699 & 0,5699 & 0.5699 & 0,5700 & 0,5700 & 0,5700 & 0,5700 & 0,5700 & 0,5700 & 0,5700 \\
\hline 150 & 700 & 5700 & 5700 & 0,5700 & 0,5700 & 0.5700 & 0.5700 & 0.5700 & 0.5700 & 0 & 0.5 & & $\infty$ & & 0.5 & 0. & 00 & 0.5700 & 0,5700 \\
\hline 160 & 700 & 5700 & 5700 & & & 5700 & & (1) & 0 & & & & $\infty$ & 00 & 0 & & & 1.5700 & 0,5700 \\
\hline 170 & 00 & $\infty$ & 00 & & 00 & 700 & & 700 & 700 & 700 & 700 & 700 & 5700 & 5700 & 0.5700 & 0,5700 & .5700 & 5700 & 0,570 \\
\hline
\end{tabular}

Figura 5. 33i - Solo 1 - Simulação B: Perfil de umidade no instante $t=4$ h da fase de redistribuição

\begin{tabular}{|c|c|c|c|c|c|c|c|c|c|c|c|c|c|c|c|c|c|c|c|}
\hline $\begin{array}{c}\text { prot/larg } \\
\text { (cm) }\end{array}$ & 0 & 10 & 20 & 30 & 40 & 50 & 60 & 70 & $\infty$ & 90 & 80 & 70 & 60 & 50 & 40 & 30 & 20 & 10 & 0 \\
\hline 0 & 0,2571 & 0.2571 & 0,2571 & 0.2571 & 0,2571 & 0,2570 & 0,2570 & & & & & & 0.2570 & 0,2570 & 0,2571 & 0.2571 & 0,2571 & 0,2571 & 0.2571 \\
\hline 10 & 0,3147 & 0,3147 & 0,3147 & 0,3147 & 0,3146 & 0,3146 & 0,3146 & & & & & & 0,3146 & 0,3146 & 0.3146 & 0,3147 & 0,3147 & 0.3147 & 0,3147 \\
\hline 20 & 0,3839 & 0,3839 & 0,3839 & 0,3939 & 0,3839 & 0,3938 & 0,3838 & & & & & & 0,3838 & 0,3838 & 0,3839 & 0,3839 & 0.3839 & 0,3839 & 0,3839 \\
\hline 30 & 0,4576 & 0,4576 & 0,4576 & 0.4578 & 0,4576 & 0,4576 & 0,4576 & & & & & & 0,4576 & 0,4576 & 0,4576 & 0,4576 & 0.4576 & 0,4576 & 0,4576 \\
\hline 40 & 0,5200 & 0,5206 & 0,5206 & 0,5206 & 0,5205 & 0,5205 & 0,5205 & & & & & & 0,5205 & 0,5205 & 0,5205 & 0,5200 & 0,5203 & 0,5206 & 0,5206 \\
\hline so & 0,5579 & 0,5579 & 0,5579 & 0,5579 & 0,5579 & 0,5579 & 0,557 & & & & & & 0.5579 & 0,5579 & 0,5579 & 0.5579 & 0,5579 & 0,5579 & 0,5578 \\
\hline$\infty$ & 0,5605 & 0,5695 & 0,5605 & 0,5695 & 0,5605 & 0,5695 & 0,5095 & & & & & & 0.5695 & 0.5695 & 0,5695 & 0,5695 & 0.5695 & 0,5695 & 0,5695 \\
\hline 70 & 0,5700 & 0.5700 & 0,5700 & 0,5700 & 0,5700 & 0.5700 & 0,5700 & 0,5314 & 5396 & 5289 & 0,5396 & 5614 & 0,5700 & 0,5700 & 0.5700 & 0,5700 & 0.5700 & 0,5700 & 0,5700 \\
\hline 80 & 0,5700 & 0,5700 & 0,5700 & 0.5700 & 0,5700 & 0.5700 & 0,5700 & 0,5673 & 5601 & 0,5559 & 0,5601 & 0,5673 & 0,5700 & 0,5700 & 0,5700 & 0,5700 & 0,5700 & 0,5700 & 0,5700 \\
\hline 90 & 0,5700 & 0.5700 & 0,5700 & 0,5700 & 0,5700 & 0,5700 & 0,5698 & 0,5683 & 0,5661 & 0,5647 & 0,5661 & 0.5686 & 0,5693 & 0,5700 & 0,5700 & 0,5700 & 0,5700 & 0,5700 & 0,5700 \\
\hline 100 & 0,5700 & 0,5700 & 0,5700 & 0,5700 & 0,5700 & 0,5700 & 0,5603 & 0,5692 & 0,5682 & 0,5678 & 0,5682 & 0,5692 & 0,5693 & 0,5700 & 0,5700 & 0,5700 & 0.5700 & 0,5700 & 0,5700 \\
\hline 110 & 0,5700 & 0,5700 & 0,5700 & 0.5700 & 0.5700 & 0,5699 & 0,5693 & 0,5695 & 0.5691 & 0,5600 & 0,5691 & 0,5695 & 0,5698 & 0.5699 & 0,5700 & 0,5700 & 0,5700 & 0,5700 & 0,5700 \\
\hline 120 & 0,5700 & 0,5700 & 0,5700 & 0.5700 & 0,5700 & 0.5699 & 0,5693 & 0,5697 & 0,5693 & 0,5605 & 0,5693 & 0,5697 & 0.5693 & 0,5699 & 0,5700 & 0.5700 & 0,5700 & 0,5700 & 0,5700 \\
\hline 130 & 10 & 0,5700 & 0.5700 & 0,5700 & 0.5700 & 0,5700 & 0,5099 & 0.5 & 0.5693 & 0,5698 & & 0,5699 & 0,5699 & 0,5700 & 0,5700 & 0,5700 & 0,5700 & 0,5700 & 0,5700 \\
\hline 140 & 0,5700 & 0,5700 & 0,5700 & 0.5700 & 0,5700 & 0,5700 & 0,5700 & 0,5699 & 0,5699 & 0,5099 & 0,5699 & 0,5699 & 0.5700 & 0,5700 & 0,5700 & 0.5700 & 0,5700 & 0.5700 & 0,5700 \\
\hline 150 & 0.5700 & 0,5700 & 0,5700 & 0,5700 & 0,5700 & 0,5700 & 0.5700 & 0,5700 & 0,5700 & 0,5700 & 0,5700 & 0,5700 & 0,5700 & 0,5700 & 0,5700 & 0,5700 & 0,5700 & 0,5700 & 0,5700 \\
\hline 160 & 0 & 0,57 & 0,5 & 0,5 & & & 0,5 & & & 0,57 & 0 & 0 & 0 & 0.5700 & 0 & 0,5700 & 0,5700 & 0 & 0.5700 \\
\hline 170 & 0,5700 & 0,5700 & 0,5700 & 0,5700 & 0,5700 & 0,5700 & 0,5700 & 0.5700 & 0,5700 & 0,5700 & 0,5700 & 0,5700 & 0,5700 & 0,5700 & 0,5700 & 0,5700 & 0,5700 & 0,5700 & 0,5700 \\
\hline
\end{tabular}

Figura 5. 33j - Solo 1 - Simulação B: Perfil de umidade no instante $t=5 \mathrm{~h}$ da fase de redistribuição 


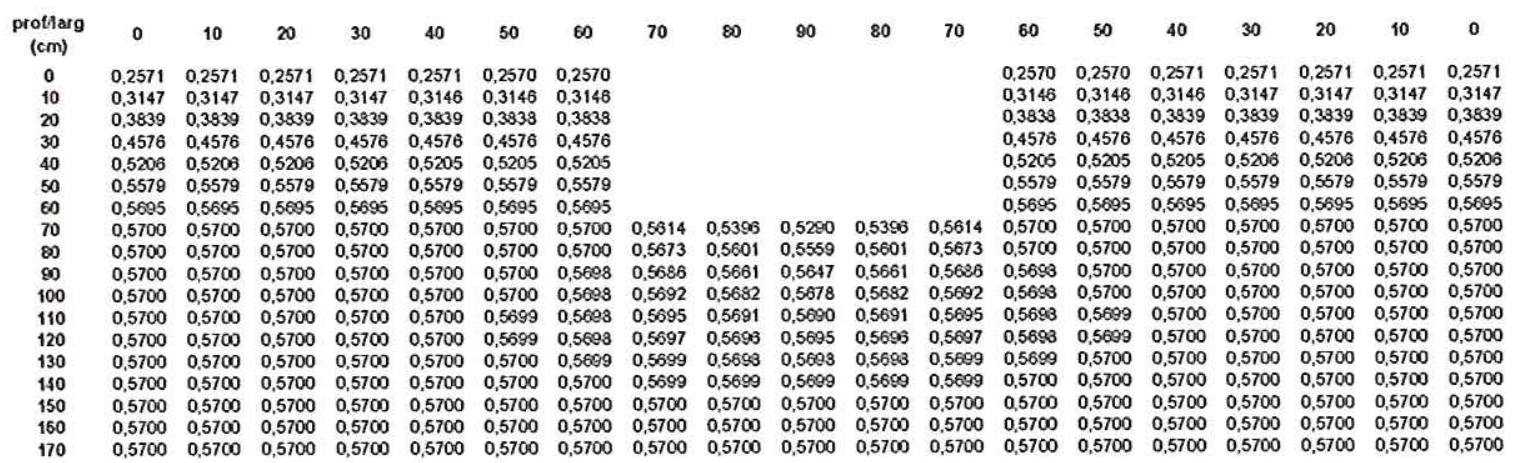

Figura 5. 33k - Solo 1 - Simulação B: Perfil de umidade no instante $t=6 \mathrm{~h}$ da fase de redistribuição

\begin{tabular}{|c|c|c|c|c|c|c|c|c|c|c|c|c|c|c|c|c|c|c|c|}
\hline $\begin{array}{l}\text { rofharg } \\
\text { (cm) }\end{array}$ & 0 & 10 & 20 & 30 & 40 & 50 & 60 & 70 & $\$ 0$ & 90 & 80 & 70 & 60 & 50 & 40 & 30 & 20 & 10 & 0 \\
\hline 0 & 0,2571 & 2571 & 2571 & 0,2571 & 0.2571 & 0.2570 & 0,2570 & & & & & & 0,2570 & 0.2570 & 0,2 & 1 & 1 & .2571 & 0,2571 \\
\hline 10 & 147 & 147 & 147 & 147 & 0,3146 & 0,3146 & 31 & & & & & & & & & 0,3147 & 147 & & \\
\hline 20 & 0,3839 & 1839 & 3839 & 0,3839 & 0,3839 & 0,3838 & 383 & & & & & & & 0,3838 & 0,3839 & 0,3839 & 339 & 0,3839 & 0,3839 \\
\hline 30 & 0,4576 & 1576 & 0,4576 & 0,4576 & 0,4576 & 0,4576 & 0457 & & & & & & 6 & 0,4576 & 0,4576 & 0,4576 & 76 & 0,4576 & 0,4576 \\
\hline 40 & 206 & 2003 & 0,5206 & 0,5206 & 0,5205 & 0,52 & 0,52 & & & & & & & & & & 06 & 03 & 06 \\
\hline 50 & 5579 & 5579 & 557 & 0,5579 & 5579 & 0.5579 & 55 & & & & & & & 0,5579 & 0,5 & 0,5 & & & 0,5579 \\
\hline 60 & 0. & 6605 & 0.58 & 0 & & 56 & 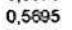 & & & & & & & 5 & 5 & 5 & 25 & 95 & 0.5695 \\
\hline 70 & 0,5700 & 7700 & 0,57 & 0,57 & 0,5700 & 0,5700 & 0,570 & 5614 & 0,5397 & 0,5291 & 0,5397 & 0,5614 & & & 0 & 0 & & & 0,5700 \\
\hline 80 & 0 & 0 & b & 0,5700 & 0,57 & 0.57 & 0 & 3 & 1 & 0 & 0 & 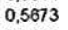 & 0.5 & 0,5 & 0,5700 & 0,5700 & 0,5700 & 0,5700 & 0,5700 \\
\hline 90 & & & & & & & & & & & & & & & 0 & & & $\infty 0$ & 0.5700 \\
\hline 100 & 5700 & 7700 & 0,570 & 0,5700 & 0,5700 & 0,5700 & 8 & 0,56 & 5683 & 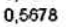 & & & & & & & & & 0.5700 \\
\hline & 0 & 0 & 0 & & 0,57 & & 0,5 & & & 0 , & 0 . & 0,5 & 0,5 & 0,5 & 0,5700 & 0,5 & 0,5700 & 0,5700 & 0,5700 \\
\hline & & & & & & & & & & & & & & & & & & & 0.5700 \\
\hline 130 & 0 & . & 0 & 0,5 & & & & & & & & & & & & & 0,5700 & 0,5 & 700 \\
\hline 14 & & & & & & & & 0, & 0 & 0.5 & 0. & & & & & & & & 700 \\
\hline 150 & & & 0,57 & 0,5 & & 0,5 & & 0,5 & & & & & & & & & & & \\
\hline 160 & & & & & & & & & & & & & 0,5 & 0.5 & 0,5700 & 0,5 & 0,5700 & 0,5700 & 0 \\
\hline & & & & & & & & & & & & .5700 & 0,5700 & 0.5700 & 0,5700 & 0.5700 & 0,5700 & 0,5700 & 0,570 \\
\hline
\end{tabular}

Figura 5. 33l - Solo 1 - Simulação B: Perfil de umidade no instante $t=12 \mathrm{~h}$ da fase de redistribuição

\begin{tabular}{|c|c|c|c|c|c|c|c|c|c|c|c|c|c|c|c|c|c|c|c|}
\hline $\begin{array}{l}\text { profilarg } \\
\text { (cm) }\end{array}$ & 0 & 10 & 20 & 30 & 40 & 50 & 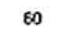 & 70 & $\varnothing 0$ & 90 & 80 & 70 & 60 & 50 & 40 & 30 & 20 & 10 & 0 \\
\hline 0 & 0,2571 & 0,2571 & 0.2571 & 0,2571 & 0,2571 & 0,2571 & 0.2571 & & & & & & 0.2571 & 0,2571 & 0,2571 & 0,2571 & 0,2571 & 0,2571 & 0,2571 \\
\hline 10 & 0,3147 & 0,3147 & 0,3147 & 0.3147 & 0,3146 & 0,3146 & 0,3146 & & & & & & 0,3146 & 0,3146 & 0,3146 & 0,3147 & 0,3147 & 0.3147 & 0,3147 \\
\hline 20 & 0,3839 & 0,3839 & 0,3839 & 0,3839 & 0,3839 & 0,3839 & 0,3839 & & & & & & 0.3839 & 0,3839 & 0,3839 & 0,3839 & 0,3839 & 0,3839 & 0,3839 \\
\hline 30 & 0,4576 & 0,4576 & 0,4576 & 0,4578 & 0,4576 & 0.4576 & 0,4576 & & & & & & 0,4576 & 0,4576 & 0.4576 & 0,4576 & 0,4576 & 0,4576 & 0,4576 \\
\hline 40 & 0.5206 & 0,5203 & 0,5203 & 0,5203 & 0,5205 & 0,5205 & 0,5205 & & & & & & 0,5206 & 0.5205 & 0,5205 & 0,5203 & 0,5206 & 0,5203 & 0,5206 \\
\hline 50 & 0,5579 & 0,5579 & 0,5579 & 0,5579 & 0,5579 & 0,5579 & 0,5579 & & & & & & 0,5579 & 0,5579 & 0,5579 & 0,5579 & 0,5579 & 0,5579 & 0,5579 \\
\hline$\infty$ & 0,5095 & 0,5695 & 0,5695 & 0,5696 & 0,5695 & 0,5695 & 0,5695 & & & & & & 0,5695 & 0,5695 & 0,5695 & 0,5695 & 0,5695 & 0,5695 & 0,5695 \\
\hline 70 & 0.5700 & 0,5700 & 0,5700 & 0,5700 & 0.5700 & 0,5700 & 0,5700 & 0,5614 & 0.5393 & 93 & 5393 & 5614 & 0,5700 & 0,5700 & 0,5700 & 0,5700 & 0,5700 & 0,5700 & 0,5700 \\
\hline ఐ & 0,5700 & 0,5700 & 0,5700 & 0,5700 & 0,5700 & 0,5700 & 0.5700 & 0,5674 & 0,5602 & 5562 & 0.5602 & 0,5674 & 0,5700 & 0,5700 & 0,5700 & 0,5700 & 0,5700 & 0,5700 & 0,5700 \\
\hline 90 & 0,5700 & 0,5700 & 0,5700 & 0,5700 & 0,5700 & 0,5700 & 0,5693 & 0,5685 & 0.5662 & 0,5649 & 0,5662 & 0,5686 & 0,5693 & 0,5700 & 0,5700 & 0,5700 & 0,5700 & 0.5700 & 0,5700 \\
\hline 100 & 0,5700 & 0,5700 & 0,5700 & 0,5700 & 0,5700 & 0,5700 & 0,5608 & 0.5692 & 0,5683 & 0,5679 & 0.5683 & 0,5692 & 0,5693 & 0,5700 & 0,5700 & 0,5700 & 0,5700 & 0,5700 & 0,5700 \\
\hline 110 & 0,5700 & 0,5700 & 0,5700 & 0,5700 & 0,5700 & 0,5699 & 0,5893 & 0,5695 & 0,5592 & 0,5 & 0,5692 & 0,5605 & 0.5693 & 0,5699 & 0,5700 & 0,5700 & 0,5700 & 0,5700 & 0,5700 \\
\hline 120 & 0.5700 & 0,5700 & 0,5700 & 0,5700 & 0,5700 & 0,5699 & 0,5699 & 0,5697 & 0,5696 & 0,5695 & 0,5696 & 0,5697 & 0,5699 & 0,5699 & 0,5700 & 0,5700 & 0,5700 & 0,5700 & 0,5700 \\
\hline 130 & 0,5700 & 0.570 & 0,57 & 0.57 & 0,5700 & 0.5700 & 0,5699 & 0,5699 & 0,5693 & & 0,5693 & 0,5699 & 0,5699 & 0,5700 & 0,5700 & 0,5700 & 0.5700 & 0.5700 & 0,5700 \\
\hline 140 & 0,5700 & 0,5700 & 0,5700 & 0,5700 & 0,5700 & 0,5700 & 0,5700 & 0,5699 & 0,5699 & 0.5 & 0,5699 & 0,5699 & 0,5700 & 0,5700 & 0,5700 & 0,5700 & 0,5700 & 0,5700 & 0,5700 \\
\hline 150 & 0.5700 & 0,5700 & 0,5700 & 0,5700 & 0,5700 & 0,5700 & 0.5700 & 0,5700 & 0,5700 & 0,5700 & 0,5700 & 0,5700 & 0,5700 & 0,5700 & 0,5700 & 0,5700 & 0,5700 & 0,5700 & 0,5700 \\
\hline 160 & 0.5700 & 0,5700 & 0.5700 & 0,5700 & 0.5700 & 0,5 & 0.5700 & & 0,5700 & & 0.5700 & 0.5700 & 0,5700 & 0.5700 & 0.5700 & 0.5700 & 0,5700 & & 05700 \\
\hline 170 & 0.5700 & 0.5700 & 0,5700 & 0,5700 & 0,5700 & 0,5700 & 0,5700 & 0.5700 & 0,5700 & 0,5700 & 0,5700 & 0,5700 & 0,5700 & 0,5700 & 0,5700 & 0,5700 & 0,5700 & 0,5700 & 0,570 \\
\hline
\end{tabular}

Figura 5. 33m - Solo 1 - Simulação B: Perfil de umidade no instante $t=24 \mathrm{~h}$ da fase de redistribuição

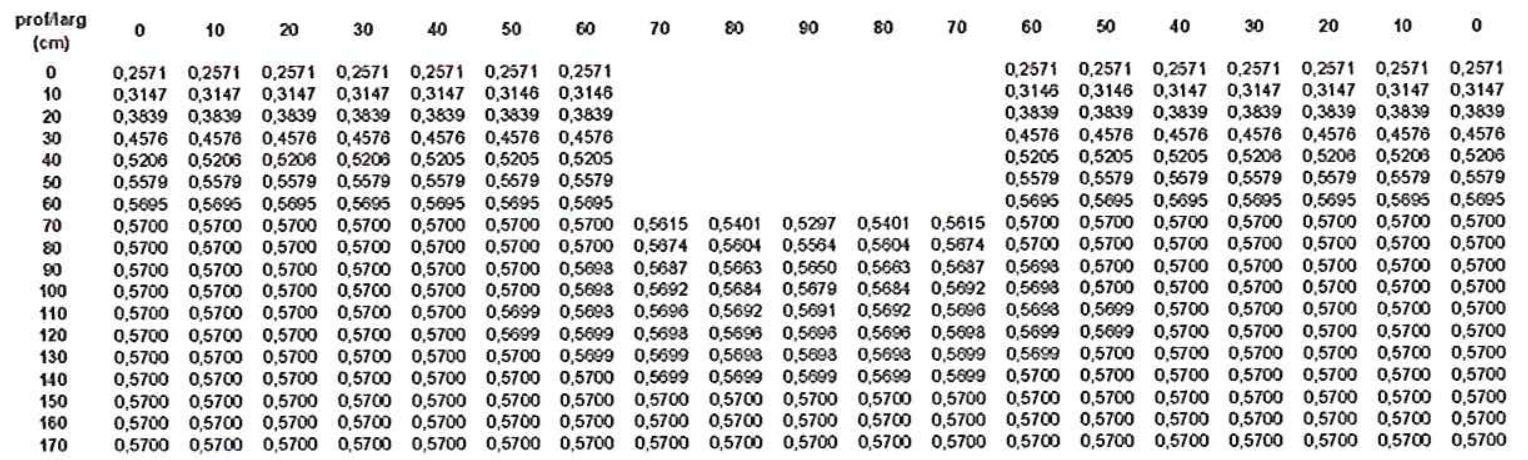

Figura 5. 33n - Solo 1 - Simulação B: Perfil de umidade no instante $t=48 \mathrm{~h}$ da fase de redistribuição 


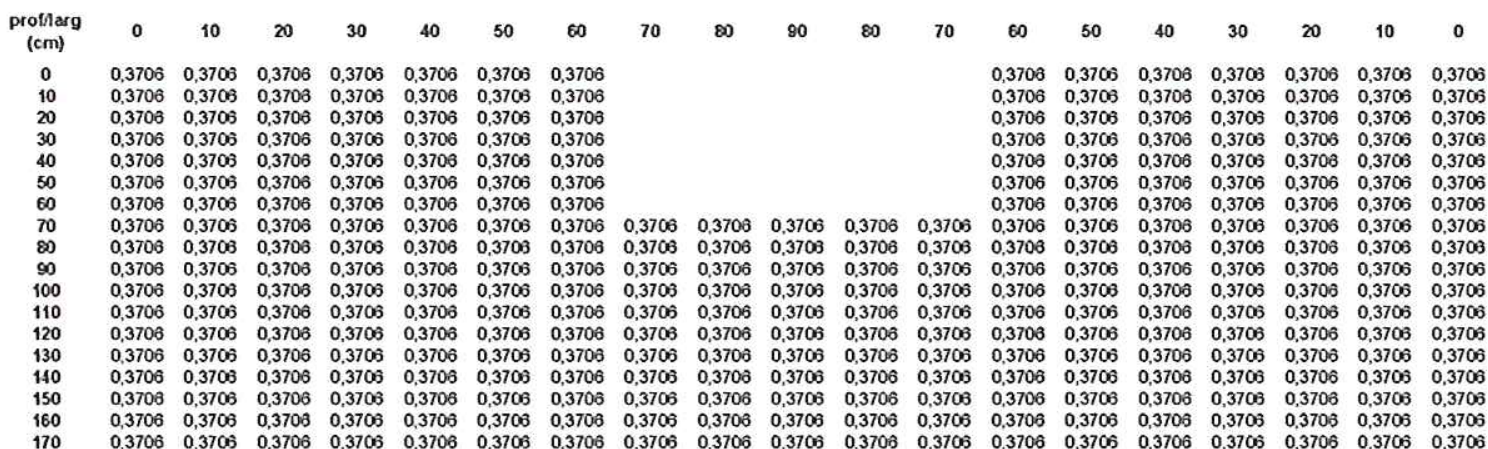

Figura 5.34a - Solo 2 - Simulação B: Perfil de umidade antes da irrigação

\begin{tabular}{|c|c|c|c|c|c|c|c|c|c|c|c|c|c|c|c|c|c|c|c|}
\hline tharg & 0 & 10 & 20 & 30 & 40 & 50 & 60 & 70 & $\infty$ & 90 & ఐ & 70 & 60 & 50 & 40 & 30 & 20 & 10 & 0 \\
\hline 0 & 3348 & 3347 & 0,3347 & 0,3347 & 0,3347 & 0,3348 & 0,3348 & & & & & & 0,3348 & 0,3348 & 0,3347 & 0,3347 & 0,3347 & 0,3347 & 0,3348 \\
\hline 10 & 3621 & 3621 & 0,3621 & 3621 & 0,3621 & 0,3621 & 0.3621 & & & & & & 0,3 & 0,3021 & 3621 & 0.3621 & 3621 & 21 & $\hat{5} 21$ \\
\hline 20 & 3701 & 0,3701 & 0,3701 & 0,3701 & 0,3701 & 0,3700 & 0,3700 & & & & & & 0,3700 & 0,3700 & 0,3701 & 3701 & 3701 & 0,3701 & 0,3701 \\
\hline 30 & 3706 & 0,3706 & 0,3706 & 0,3706 & 0,3706 & 0,3706 & 0.3486 & & & & & & 0.3486 & 0,3706 & 0,3706 & 0,3703 & 0,3706 & 0,3706 & 0,3706 \\
\hline 40 & 706 & 0,3705 & 0,3706 & 0,3706 & 0,3706 & 0,3706 & 0,3575 & & & & & & 0,3575 & 0,3705 & 0,3706 & 0,3706 & 0,3706 & 0,3706 & 0,3706 \\
\hline 50 & & 3706 & 1 & 0,3706 & & & & & & & & & & & & & & & \\
\hline 60 & 3706 & 0,3706 & 0,3706 & 0,3706 & 0,3706 & 0,3703 & 0,3469 & & & & & & 3469 & 0,3703 & 0,3706 & 0,3706 & 3706 & 1706 & 3706 \\
\hline 7 & 3706 & 3705 & 0,3706 & 0,3706 & 0,3706 & 0,3703 & 0,3720 & 3720 & 0,3720 & 0,3720 & 3720 & 3720 & 0.3 & 0,3703 & 0,3706 & 0,3 & 06 & 0,3 & 0,3706 \\
\hline$\infty$ & 6 & 0,3706 & 0 & 0,3703 & 0,3700 & 0,3707 & 0 & 3720 & 0,3720 & 0,3720 & 0,3720 & .3720 & 0,3 & 0,3 & 0,3 & 0,3 & 0,3 & 0.3 & 0,3706 \\
\hline 9 & & 3706 & & & & 0,37 & & & 03720 & 03720 & & & & & & & & & \\
\hline 100 & 706 & 0,3703 & 0,3706 & 0,3706 & 0,3708 & 0,3703 & 0,3707 & 3713 & 0,3714 & 0,3714 & 0,3714 & 0,3713 & 0.3707 & 0,3703 & 0,3706 & 0,3703 & 0,3 & 0,3 & 0,3706 \\
\hline & 3706 & 3700 & 0,37 & 0 & 0,37 & 0,37 & & & 0 & 0,3703 & 0,37 & 66 & & & & & & & 0,3706 \\
\hline & b & 0,3706 & 0,3706 & 0 & 0,3 & 0,3705 & 0,3706 & 0,3706 & 0,3706 & 0,3706 & 0,3706 & 7706 & 0 & 0,3705 & 0,3 & 0,3706 & 0,3 & 0,3 & 3706 \\
\hline 130 & 6 & 0,3706 & 0 & 0,3706 & 0,3706 & 0,3705 & 0,37 & 3706 & 03706 & 0,3703 & 0,3 & 0700 & & & & & & & 3705 \\
\hline & 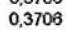 & $\infty$ & 0 & 0 & 0,3 & 0 & 0 & 66 & 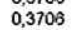 & 0 & 0 & 6 & & 0 & & 6 & 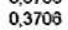 & & s \\
\hline 150 & & 8 & & & & & & & & & & & & & 0 & & & 06 & 706 \\
\hline 160 & & 106 & 06 & 706 & a & 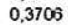 & 3706 & 0 & 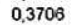 & 705 & & 706 & 1 & 0,3703 & 0,3703 & os & 06 & 3706 & 3706 \\
\hline 1 & 707 & 3707 & 3707 & 0,3707 & 0,3707 & 0,3707 & 3707 & 0,3777 & 0,3707 & 0,3707 & 3707 & 0,3707 & 0.3707 & 0.3707 & 0,3707 & 0.3707 & 0,3707 & 0,3707 & 0,37 \\
\hline
\end{tabular}

Figura 5. 34b - Solo 2 - Simulação B: Perfil de umidade no instante $t=2$ min da fase de alimentação

\begin{tabular}{|c|c|c|c|c|c|c|c|c|c|c|c|c|c|c|c|c|c|c|c|}
\hline h h & 0 & 10 & 20 & 30 & 40 & 50 & 60 & 70 & $\infty$ & 80 & ఐ & 70 & 60 & 50 & 40 & 30 & 20 & 10 & 0 \\
\hline 0 & 3106 & 0,3106 & 0,3107 & 0,3114 & 0.3720 & 0,3720 & 0,3720 & & & & & & 0,3720 & 0,3720 & 0,3720 & 0,3114 & 0,3107 & 0,3106 & 0,3106 \\
\hline 10 & 3373 & 0,3373 & 0,3373 & 0,3424 & 0.3720 & 0.3720 & 0.3720 & & & & & & 0.3720 & 0,3720 & 0,3720 & 0,3424 & 0,3373 & 0,3373 & 0,3373 \\
\hline 2 & 1464 & 3464 & 0,3462 & 3720 & 0,3720 & 0,3720 & 372 & & & & & & 0,3720 & 0,3720 & 0,3720 & 0,3720 & 3462 & 3464 & \\
\hline 30 & 3513 & 0,3513 & 0,3636 & 0,3720 & 0,3720 & 0,3720 & 37 & & & & & & 0 & 20 & 0 & 20 & 3636 & 13 & 3513 \\
\hline 40 & 3545 & 0,3542 & 0,3720 & 0,3720 & 0,3720 & 0,3720 & 0,3720 & & & & & & 0,3720 & 0,3720 & 0,3720 & 0,3720 & 3720 & 0,3542 & 0,3545 \\
\hline 50 & 532 & 0,3720 & 0,3720 & 0,3720 & 0,3720 & 0,3720 & 0,3720 & & & & & & 0,3720 & 0,3720 & 0,3720 & 0,3720 & 0,3720 & 0,3 & 0,3582 \\
\hline & & 3700 & 0,3720 & 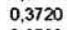 & 0. & 3720 & 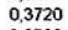 & & & & & & & & & & & & \\
\hline 7 & 3601 & 0,3707 & 0,3720 & 0,3720 & 0,3720 & 0,3720 & 0,3720 & 0 & 0 & 20 & 0 & 20 & 0,3720 & 0,3720 & 0.3720 & 0,3720 & 3720 & 0,3707 & 0,3691 \\
\hline 8 & 2772 & 0,3720 & 0,3720 & 0,3720 & 0,3720 & 0,3720 & 0,3720 & 3720 & 0,3720 & 0,3720 & 0,3720 & 3720 & 0,3720 & 0,3 & 0,3720 & 0,3 & 0,3 & 0,3 & 0,2772 \\
\hline 90 & 720 & 3720 & 0,3720 & 0,3720 & 0,3720 & 0,3720 & 0 & 3720 & 0 & 0,3720 & 0,372 & 20 & & & & & & & 0,3720 \\
\hline 100 & 720 & 3720 & 0,3720 & 0,3720 & 0,37 & 0,3720 & 0 & 0 & 0,3720 & 0,3720 & 0,3 & to & & & & & & & 3720 \\
\hline 110 & 720 & 0,3720 & 0,3720 & 0,3720 & 0,3720 & 0,3720 & 0,3720 & 3720 & 0,3720 & 0,3720 & 0,3720 & 0,3720 & 0.3720 & 0,3 & 0,3720 & 0,3 & 0.3720 & 0,3720 & 0,3720 \\
\hline & 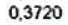 & 0 & 0 & 0 & 0,3 & & & & & 0,37 & & & & & & & & & 0,3720 \\
\hline 13 & U & 0 & 0 & 0. & 0,3 & 0,3720 & 0 & $\infty$ & 0,3720 & 0,3720 & 0,3 & 0,3720 & 0,3 & 0,3 & 0,3 & 0. & 0,3 & 0, & 3720 \\
\hline 140 & 3720 & 0,3720 & 0 & 0,37 & 0,37 & 0,3720 & 0 & 0,3 & 20 & 0,37 & & & & & & & & & \\
\hline & 0,37 & 037 & 0 & 0 & 0,3 & 0,3 & 0 & 20 & 0 & 0 & 0 & 0 & & & 20 & & & & $x$ \\
\hline 160 & 20 & 31 & 0,37 & 0,3720 & 0,3720 & 0,3720 & 0,37 & 0,3720 & 0,3720 & 0,3720 & 0,37 & 0,3720 & 0,3 & 0, & 0,3 & 0,3 & 0,3720 & 0 & 0,3720 \\
\hline 170 & 0,3720 & 0,3720 & 0.3720 & 0,3720 & 03720 & 03720 & 03720 & 0,3720 & 0.3720 & 0,3720 & 0,3720 & 03720 & 03720 & 0,3720 & 0,3720 & 0,3720 & 0.3720 & 0,3720 & 0,3720 \\
\hline
\end{tabular}

Figura 5. 34c - Solo 2 - Simulação B: Perfil de umidade no instante $t=32$ min da fase de alimentação $\equiv$ instante $t=0$ da fase de recessão (NA máximo)

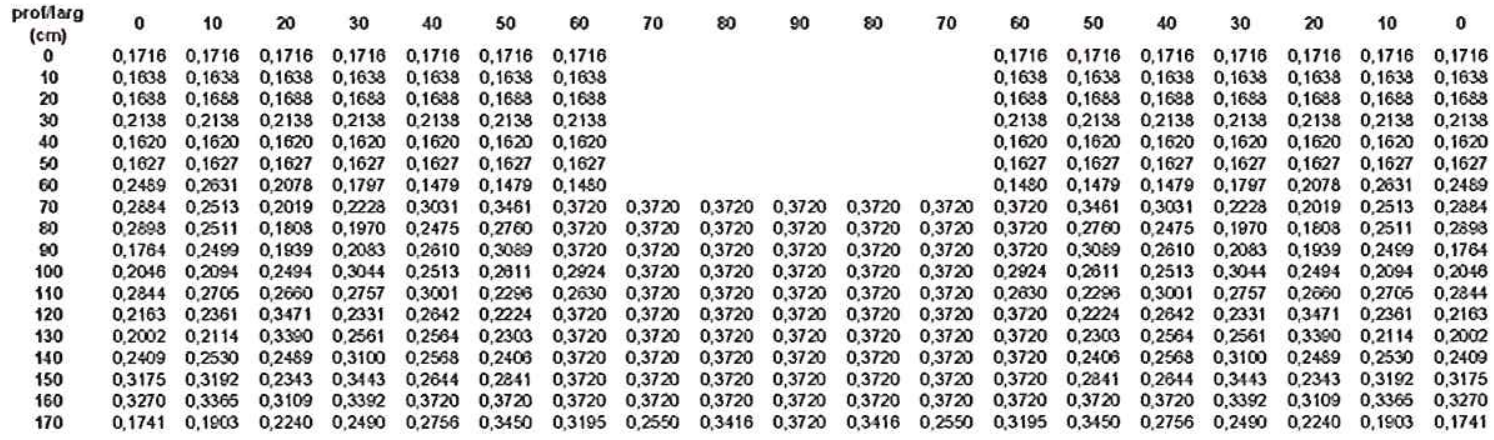

Figura 5. 34d - Solo 2 - Simulação B: Perfil de umidade no instante $t=360$ min da fase de recessão $\equiv$ instante $\mathrm{t}=\mathbf{0}$ da fase de redistribução $(\mathrm{NA}=\mathbf{0})$ 


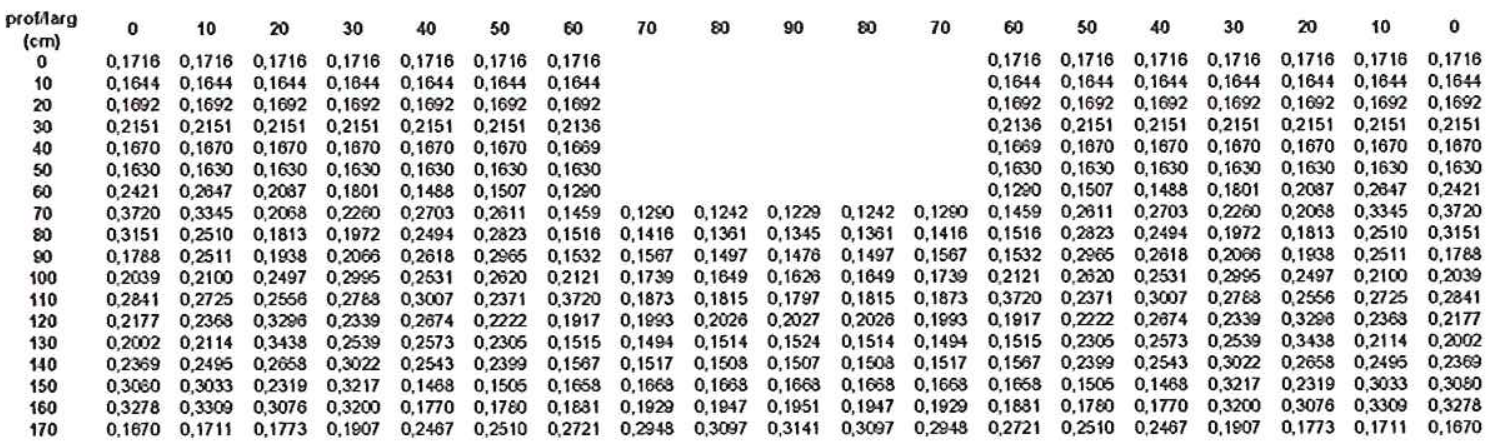

Figura 5. 34e - Solo 2 - Simulação $B$ : Perfil de umidade no instante $t=20$ min da fase de redistribuição

\begin{tabular}{|c|c|c|c|c|c|c|c|c|c|c|c|c|c|c|c|c|c|c|c|}
\hline $\begin{array}{l}\text { rothlarg } \\
\text { (cmi }\end{array}$ & 0 & 10 & 20 & 30 & 40 & 50 & $\infty$ & 70 & ஜ & 90 & 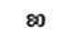 & 70 & 60 & 50 & 40 & 30 & 20 & 10 & 0 \\
\hline 0 & 0,1715 & 0,1715 & 0,1715 & 0,1715 & 0,1715 & 0,1715 & 0,1715 & & & & & & 0,1715 & 0,1715 & 0,1715 & 0.1715 & 0,1715 & 0,1715 & 0,1715 \\
\hline 10 & 1649 & 1649 & 1649 & 1649 & 0,1649 & 0.1649 & 0.1649 & & & & & & 0.1649 & 0,1649 & 0,1649 & 0,1649 & 0,1649 & 0,1649 & 0,1649 \\
\hline 20 & 1695 & 1696 & 0,1605 & 0,1696 & 0,1605 & 0,1695 & 0,1695 & & & & & & 0,1695 & 0,1696 & 0,1695 & 0,1695 & 0,1695 & 0,1695 & 0,1695 \\
\hline 30 & 2166 & 0,2166 & 0,2166 & 0,2163 & 0,2166 & 0,2163 & 0.2136 & & & & & & 0,2136 & 0,2166 & 0,2168 & 0,2163 & 0,2166 & 0,2165 & 0,2160 \\
\hline 40 & 1721 & 0.1721 & 0,1721 & 0,1721 & 0,1721 & 0,1721 & 0.171 & & & & & & 0,1714 & 0,1721 & 0,1721 & 0,1721 & 0,1721 & 0,1721 & 0,172 \\
\hline so & 1634 & 1634 & 0,1635 & 0,1635 & 0,1635 & 0,1635 & 0,1635 & & & & & & & 0,1635 & 0,1635 & 0,1635 & 0,1635 & 0,1634 & 0,163 \\
\hline 6 & 307 & 2533 & 0,2097 & 1805 & 0,1493 & 0,1511 & 0,1295 & & & & & & 95 & 0,1511 & 0,1493 & 0,1805 & 97 & 33 & 0,2307 \\
\hline 7 & 3720 & 0,3720 & 0,2126 & 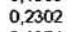 & 14 & 0,2551 & 0.1459 & & & 120 & 124 & & 9 & 51 & & & & & 3720 \\
\hline$a$ & 7720 & 3720 & 0,1819 & 0,1974 & 0.2497 & 0,2783 & 0,1516 & 1416 & 0,1361 & 0,1345 & 0,1361 & 0,1416 & 0,1516 & 0,2798 & 0,2497 & 0.1974 & 0,1819 & 0,3720 & 0,3720 \\
\hline$\alpha$ & 720 & 24 & 0,1938 & 0 & 0 & 0,2 & 0.1 & 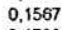 & 77 & 0,1476 & 0.1 & 37 & 0,1 & & 0.2 & & 0.1 & 24 & 0.3720 \\
\hline & & 0,210 & & 0 & 0 & 0,20 & 0,1 & 19 & 9 & 0.1625 & 0,1649 & & 0,1 & & & & 0,2 & 0,2 & 32 \\
\hline 110 & 2838 & 0,2740 & 0,2521 & 0,2814 & 0,3002 & 0,2403 & 0,1731 & 1873 & 0,1815 & 0,1797 & 0,1815 & 0.1 & 0,1731 & 0.2 & & & & & 0,2838 \\
\hline & & 23 & 033 & & 0,27 & 0,20 & & 83 & 28 & 0,2027 & 0,2026 & 3 & 20 & 0 & & & 0,3 & 0,2377 & 0.2190 \\
\hline $13 \mathrm{C}$ & 2 & 0.211 & 8 & 0 & 0 & 0,230 & 0,3 & 1494 & & & & & & & & & & & \\
\hline $14 C$ & & 0,2477 & 2831 & 2994 & 0,2539 & 0,2394 & & & 1503 & 0,1507 & 0,1508 & 0,1517 & 0,1567 & 0,2394 & 0,2539 & 0 & 0,2 & $0,24 \pi$ & 0,234 \\
\hline 150 & 897 & 02927 & 2304 & 0 & 0,1475 & & 01 & & & & & & & & & & & & \\
\hline & & & & & & & & & & & & & & & & & & & \\
\hline 170 & 0.1659 & 0,1667 & 0,1654 & 0.1685 & 0,1853 & 0,1875 & 0,1838 & 0,2123 & 0,2229 & 0,2259 & 0,2229 & 0,2129 & 0,1988 & 0.1875 & 0,1853 & 0,1685 & 0,1654 & 0,1667 & 0,165 \\
\hline
\end{tabular}

Figura 5. $34 \mathrm{f}$ - Solo 2 - Simulação B: Perfil de umidade no instante $t=1 \mathrm{~h}$ da fase de redistribuição

\begin{tabular}{|c|c|c|c|c|c|c|c|c|c|c|c|c|c|c|c|c|c|c|c|}
\hline rolfarg & 0 & 10 & 20 & 30 & 40 & 50 & 60 & 70 & \$0 & 90 & 80 & 70 & 60 & 50 & 40 & 30 & 20 & 10 & 0 \\
\hline & 0.1715 & 1715 & 0,1715 & 0,1715 & 0,1715 & 0,1715 & 0,1715 & & & & & & 0,1715 & 0,1715 & 0,1715 & 0.1715 & 0.1715 & 0.1715 & 0,1715 \\
\hline 10 & 0,1667 & 1657 & 0,1657 & 0,1657 & 0,1657 & 0,1657 & 0,1657 & & & & & & 0,1657 & 0,1657 & 0,1657 & 0,1657 & 0,1657 & 0,1657 & 0,1657 \\
\hline 20 & 701 & 1701 & 1701 & 0.1701 & 1701 & 0.1701 & 0.170 & & & & & & 1701 & 0,1701 & 0,1701 & 0,1701 & 0,1701 & 0,1701 & 0,1701 \\
\hline 30 & 0,2189 & 2189 & 0,2189 & 0.2189 & 0,2189 & 0.2189 & 0,21 & & & & & & 11 & 0,2189 & 0. & 89 & 89 & 69 & 2189 \\
\hline 40 & 0,18001 & 0,1801 & 0,1801 & 0,1801 & 0,1801 & 0,1801 & 0,1782 & & & & & & 82 & 0,1 & 0,1 & 0,1 & 0.1 & 01 & 0,1801 \\
\hline 5 & 644 & 1643 & 1644 & 0,1645 & 0,1645 & 0.1645 & 0,1644 & & & & & & 0,1644 & 0,1645 & & 0,1645 & 0,1644 & 0,1643 & 0,1644 \\
\hline 6 & 2161 & 0.2257 & 2114 & 1 & 0 & 0,1518 & 0,13 & & & & & & 03 & 0,1518 & 0,1 & 0,1811 & 14 & 0,2257 & 0,2161 \\
\hline 7 & 3720 & 0,3720 & 0,3720 & 0,2331 & 0.2412 & 0,2450 & 0,1460 & 0,1290 & 2 & 9 & 0,1242 & 0,1290 & 1460 & 0,2490 & 0,2 & & & & 3720 \\
\hline$\approx$ & 72 & 3720 & 5 & 0,1821 & 0,1824 & 0,2767 & 0.1515 & 1416 & 1361 & 0,1345 & 0,1301 & 0,1416 & 0,1515 & 0,2767 & 0,1824 & 0,1821 & 0,1845 & 0,3720 & 0,3720 \\
\hline & 0 & 0 & 0 & 2 & 0 & 0,28 & 0, & & 7 & 0 & 0 . & & 35 & & & & 38 & & 0,3720 \\
\hline 10 & & & & & & & & & & & & & & & & & & & 0,3720 \\
\hline 11 & 720 & 3720 & 3 & 0 & 0,2994 & 0,2432 & 0,1598 & 0,1 & 0,1815 & 0,1797 & 0,1815 & 0,1873 & 0,1598 & 0,2432 & 0,2 & 0,2851 & 0.2 & & 0,3720 \\
\hline & & 0.23 & & & & & & & & & & & & & & & & & 0,3720 \\
\hline & 2 & 0.21 & 0 & 0 & 0 & 0.23 & 0.2 & 0 & 6 & 0 . & & 0,1 & 3 & & & & & & \\
\hline $14 C$ & 2315 & 0,2461 & 3017 & 0 & & 0,2383 & & & & & & & 0,3720 & 0,2386 & & & 17 & 0.2461 & 0.2315 \\
\hline 170 & (1) & 0,2820 & 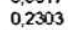 & 0,3102 & 0,1485 & 年 1516 & 0,3720 & 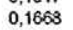 & 0,1665 & 0,1667 & 0,1668 & & & 0,1516 & & & & & 2876 \\
\hline 160 & & 0,31 & 0,28 & & & & & & & & & & & & & & & & \\
\hline 170 & 0,1651 & 0,1649 & 0,1634 & 0,1639 & 0.1633 & 0.1635 & 0,1644 & 0,1658 & 0,1672 & 0,1676 & 0,1672 & 0,1658 & 0,1644 & 0,1635 & 0,1633 & 0,1639 & 0,1634 & 0,1649 & 0.1651 \\
\hline
\end{tabular}

Figura 5. 34g - Solo 2 - Simulação B: Perfil de umidade no instante $t=2 \mathrm{~h}$ da fase de redistribuição

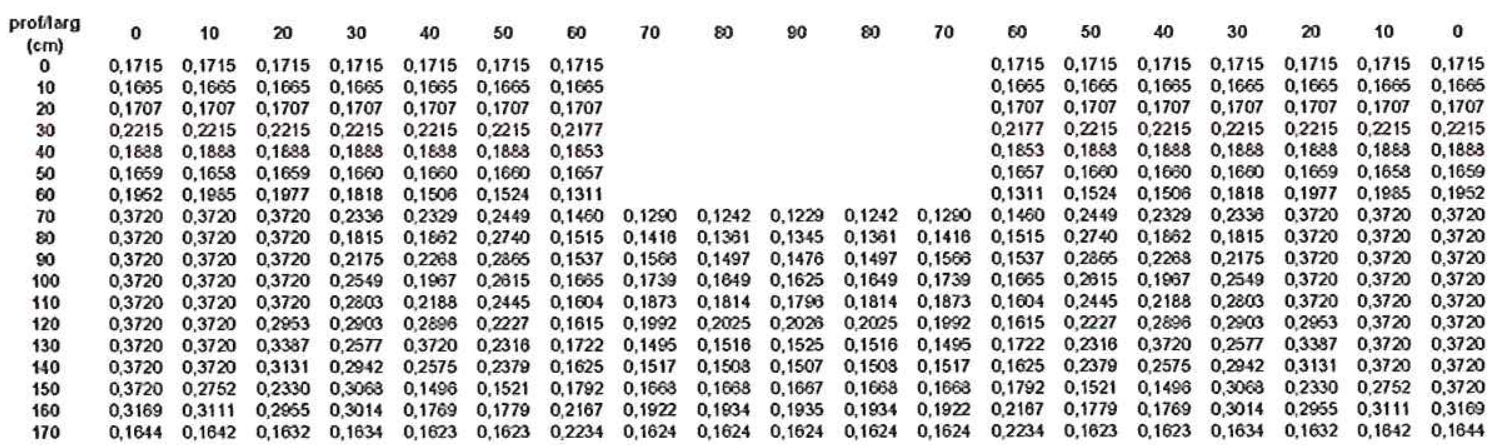

Figura 5. 34h - Solo 2 - Simulação B: Perfil de umidade no instante $t=3 \mathrm{~h}$ da fase de redistribuição 


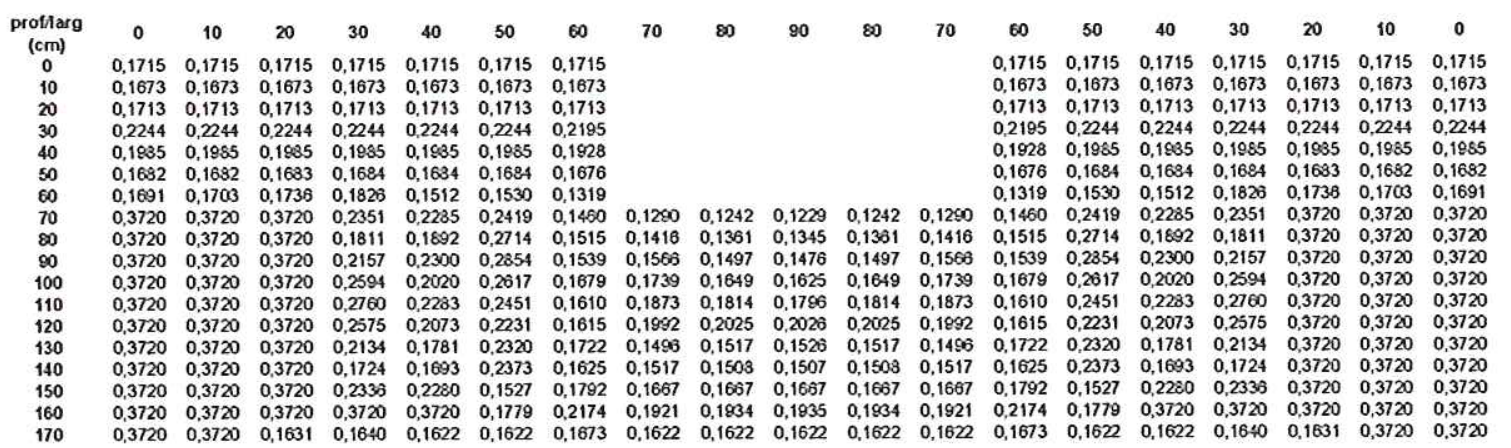

Figura 5. 34i - Solo 2 - Simulação B: Perfil de umidade no instante $t=4$ h da fase de redistribuição

\begin{tabular}{|c|c|c|c|c|c|c|c|c|c|c|c|c|c|c|c|c|c|c|c|}
\hline $\begin{array}{r}\text { rotharg } \\
\text { (cm) }\end{array}$ & 0 & 10 & 20 & 30 & 40 & 50 & 60 & 70 & $\infty$ & 90 & $\infty 0$ & 70 & 60 & 50 & 40 & 30 & 20 & 10 & 0 \\
\hline 0 & 0,1715 &, 1715 & 0,1715 & 0,1715 & 0,1715 & 0,1715 & 0,1715 & & & & & & 0,1715 & 0,1715 & 0,1715 & 0,1715 & 0,1715 & 0,1715 & 0,1715 \\
\hline 10 & 1681 & 1681 & 1681 & 0,1681 & 1631 & 0,1681 & 0,1681 & & & & & & 0,1681 & 0,1681 & 0,1681 & 0,1681 & 0,1631 & 0,1681 & 0,168 \\
\hline 20 &, 1720 & .1720 & 0,1720 & 0,1720 & 0,1720 & 0,1720 & 0,1720 & & & & & & 720 & 0.1720 & 0,1720 & 0,1720 & 0.1720 & 1720 & 1720 \\
\hline 30 & 0,2278 & 0,278 & 0,2278 & 0,2278 & 0,2278 & 0,2278 & 0.223 & & & & & & 2238 & 0,2278 & 0,2278 & 0,278 & 0,2278 & 0.2278 & 0,2278 \\
\hline 40 & 0,2100 & 0,2100 & 0,2100 & 0,2100 & 0,2100 & 0,2100 & 0,201 & & & & & & 0,2017 & 0,2100 & 0,2100 & 0,2100 & 0,2100 & 0,2100 & 0,2100 \\
\hline 50 & 1722 & 1721 & 0,1723 & 0,1723 & 0,1723 & 0.1723 & 0,1704 & & & & & & & & 0,1723 & 0,1723 & 0, & 0,1721 & 0,1722 \\
\hline 60 & 607 & 0,1614 & 1577 & 3 & 0 & 0,1538 & 0,1329 & & & & & & 29 & 0,1 & 0,1520 & 0,1693 & 0,1577 & 0,1614 & 0,1607 \\
\hline 70 & 0,1846 & 0,2025 & 0,2482 & 0,3720 & 0,2256 & 0,2398 & 0,1461 & 0,1290 & 0.124 & 120 & 0,1242 & & 0,1 & 0,2 & 0,2256 & 0,3720 & 0.2482 & 125 & 0,1846 \\
\hline$\approx$ & 1869 & 0,1951 & 0,2317 & 0,3720 & 0,1915 & 0,2690 & 0,1515 & 0,1416 & 1361 & 0,1345 & 0.1361 & 0,1416 & 0,1515 & 0,2690 & 0,1915 & 0,3720 & 0.2317 & 51 & 1809 \\
\hline & 2186 & 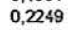 & 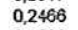 & . & 0 & & 0,1 & 0,15 & 7 & & 0 & & & & & 0,2 & 66 & 49 & 0,2196 \\
\hline 10 & 2013 & 0,2046 & 0,1990 & 0.17 & 0,20 & 0,20 & 0,1691 & & 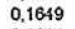 & & & & 1601 & 0,2 & 0,2 & 0 & 0 . & 0.2 & 2013 \\
\hline 110 & 1730 & 0.1732 & 0,1732 & 0,1757 & 0.2333 & 0,2454 & 0,1615 & 0,1873 & 0,1814 & 0,1796 & 0,1814 & 0,1873 & 0,1615 & 0.2 & 0.2333 & 0,1757 & 0,1 & 32 & 730 \\
\hline 120 & 2 & 0.18 & 8 & 0,1 & 0,2 & 0,2 & 0,1616 & 0,1992 & 0,2024 & 0,2 & 0,2024 & 0,1 & 0,1616 & 0,2 & 0,2159 & 0,1056 & 0,1 & & 0,1932 \\
\hline 13 & 307 & 0,2311 & 0,2318 & 0,2 & 0 & 0.2324 & 0,1722 & 0,14 & 0,15 & 0,1 & 0,1 & & 0,1 & & & & & & \\
\hline 140 & 3720 & 0,3720 & 0,3720 & 03 & & 0,2363 & 0,1625 & 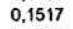 & 0,1503 & 0,1507 & 0,1508 & & 0,1625 & 0,2363 & 0.1738 & 0,3 & 0,3720 & 0,3720 & 0,3720 \\
\hline 15 & & 0,3 & & 0.3 & 0. & 30 & 0,1791 & 0 . & 0,16 & & & & & & & & & & 3720 \\
\hline 160 & 3720 & 0,3720 & 0,3720 & 0,17 & 0,15 & 0,1 & 0,21 & 0,1 & & & & & & & & & & & 03720 \\
\hline 170 & 0,3720 & 0,3720 & 0.3720 & 0,1693 & 0,1934 & 0,1622 & 0,1624 & 0,1622 & 0,1622 & 0,1622 & 0,1622 & 0,1622 & 0,1624 & 0,162 & 0,1964 & 0,1693 & 0,3720 & 0,3720 & 0,3720 \\
\hline
\end{tabular}

Figura 5. 34j - Solo 2 - Simulação B: Perfil de umidade no instante $t=5 \mathrm{~h}$ da fase de redistribuição

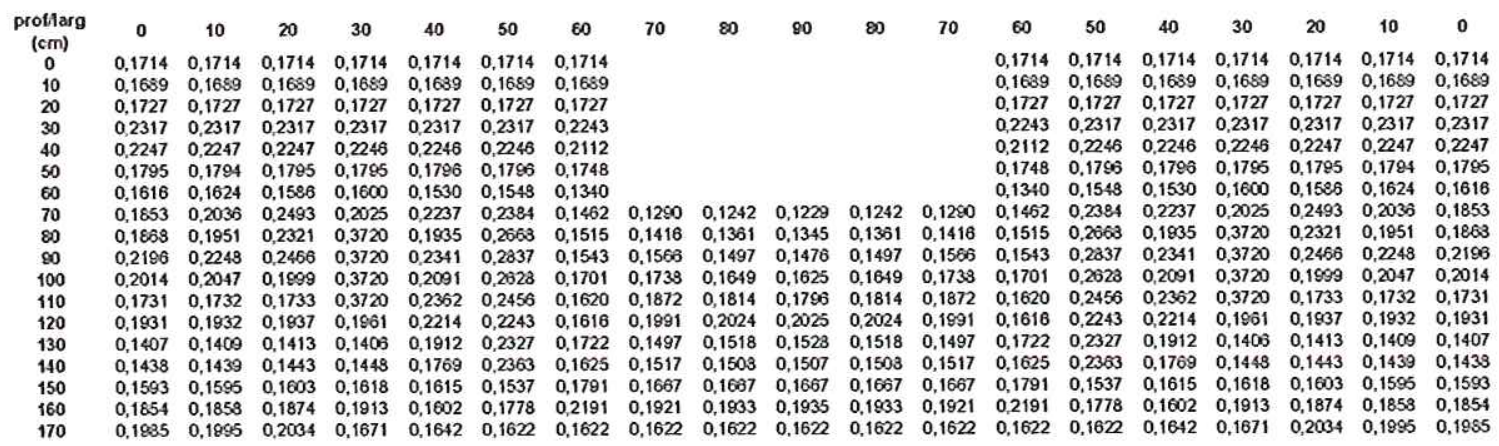

Figura 5. 34k - Solo 2 - Simulação B: Perfil de umidade no instante $t=6 \mathrm{~h}$ da fase de redistribuição

A simulação B para os solos 1 e 2 revelou que, ao final da fase de alimentação, todo o perfil de umidade estava saturado, tanto no Solo 1 quanto no Solo 2, conforme pode ser observado nas figuras $5.33 \mathrm{c}$ e $5.34 \mathrm{c}$. Nas Figuras $5.27 \mathrm{c}$ e $5.28 \mathrm{c}$, em que se observa os perfis de umidade no instante final da fase de alimentação, fornecidos pela Simulação A, para os Solos 1 e 2, observa-se que o perfil não se encontrava totalmente saturado, como na simulação B, apenas a parte inferior do domínio apresentou valores de saturação.

Ao final da fase de recessão, que, na simulação B ocorreu aos 366 minutos para o Solo 1 e 360 minutos para o Solo 2, a parte inferior do domínio, logo abaixo do fundo da trincheira, em ambos os solos, ainda se encontrava saturada, enquanto que os demais pontos da malha já encontravam-se parcialmente drenados. Neste instante do processo de infiltração, os dois solos apresentaram comportamento semelhante nas simulações A e B, conforme pode ser observado nas figuras $5.27 \mathrm{~d}$ e $5.33 \mathrm{~d}$ (Solo 1) e $5.28 \mathrm{~d}$ e $5.34 \mathrm{~d}$ (Solo 2 ). 
Nos instantes seguintes da redistribuição, os Solos1 e 2 apresentaram comportamento distinto com relação à rapidez do processo de dreangem. Nas figuras $5.33 \mathrm{e}-\mathrm{k}$ e $5.34 \mathrm{e}-\mathrm{k}$ observa-se que, nas primeiras horas da redistribuição, o Solo 1 apresentou valores de umidade bem inferiores aos do início da alimentação, enquanto que, no Solo 2, o perfil ainda se encontrava muito próximo da saturação. Este resultado era esperado, devido à maior retenção de água do Solo 1 . O Solo 1 permaneceu praticamente saturado ainda nos instantes 12, 24 e 48 horas após o início da alimentação, conforme pode ser observado nas Figuras 5.33 1-n.

Como considerações finais, especialmente em relação aos resultados da simulação, pode-se comentar alguns aspectos peculiares ao estudo realizado, e que, provavelmente, contribuiram para os resultados obtidos, tais como:

- A multimodalidade na distribuição dos diâmetros dos poros dos Solos 1 e 2, como fonte de incerteza associaca ao modelo de retenção de Van Genuchten;

- Os caminhos preferenciais comumente encontrados em ensaios de infiltração, e não previstos nos modelos ajustados;

- O efeito da histerese, considerado nulo na modelagem. Embora as curvas de retenção dos Solos 1 e 2 tenham sido obtidas por processo de drenagem, e os ensaios de campo terem sido realizados também na drenagem, as variações na forma da curva no processo reverso, não previstas no modelo e facilmente constatadas em laboratório, aliadas às condições iniciais em que se realizaram os ensaios, podem influenciar o ajuste das curvas;

- A precisão do equipamento utilizado para a medição da umidade, no caso, sonda de nêutrons. As incertezas associadas à calibração do equipamento estão relacionadas: à representatividade do ponto de amostragem; ao ajuste linear das contagens registradas ao teor de umidade do solo; à própria natureza estocástica das iterações radioativas, que permanecem, embora minimizadas pelo critério da contagem padrão. 


\section{MODELO COMPUTACIONAL PARA SIMULAÇÃO DA INFILTRAÇÃO BIDIMENSIONAL EM TORNO DE TRINCHEIRAS DE INFILTRAÇÃO ESTRUTURA E MANUAL DE INSTRUÇÕES}

\subsection{Introdução}

Para a simulação do processo de infiltração em torno de trincheiras, foi adapado o software BIDISUL, desenvolvido na Universidade Técnica de Lisboa, pelo Prof. Dr. Manuel Tabuada ${ }^{1}$. Este software foi escrito em linguagem Fortran, originalmente na versão 77, e nos foi enviado pelo autor em forma de código fonte por escrito.

Ao transcrever o código para o Fortran 90, embora o programa compilasse sem erros, apresentou problemas de execução. A fim de averiguar as possíveis causas de falha, algumas alterações foram feitas no código fonte original. Estas alterações, descritas a seguir, restringiram-se, em sua maior parte, a organizar o código, originalmente estruturado em coluna única, em seções adentadas e sub-rotinas, de modo a proporcionar melhor compreensão da estrutura do programa. Apenas uma alteração foi feita com relação ao modelo, a qual consistiu em adotar o ajuste de condutividade hidráulica não saturada proposto por van Genuchten, no lugar do ajuste polinomial assumido no modelo original. As alterações realizadas no modelo BidiSul foram:

1) Adentar o programa para melhor visualizar as estruturas e comandos;

2) Organizá-lo em sub-rotinas para facilitar o acompanhamento da execução;

3) Criar uma sub-rotina para a leitura de dados, com a função de organizar em um único arquivo de entrada as variáveis que, no código original, eram inseridas manualmente;

4) Criar arquivos de saída para armazenar as variáveis calculadas em cada sub rotina, a cada intervalo de tempo, a fim de acompanhar os resultados parciais obtidos em cada etapa da execução. A relação desses arquivos, bem como sua descrição detalhada, é apresentada mais adiante.

\footnotetext{
${ }^{1}$ Manuel Tabuada - Departamento de Engenharia Rural, Instituto Superior de Agronomia, Universidade Técnica de Lisboa. E-mail: mantabuada@isa.utl.pt
} 
5) Inserir comentários no programa, acerca da função de cada sub-rotina, bem como quais são as variáveis de entrada e saída de cada uma, de modo a facilitar a compreensão da estrutura do código por parte de novos usuários;

6) Alterar a função $\mathrm{k}(\theta)=\mathrm{A}^{*} \theta^{\mathrm{B}}$ para $K(\theta)=K_{0} \omega^{t}\left[1-\left(1-\omega^{\frac{1}{4}}\right)^{n}\right]^{2}$, modelo de condutividade hidráulica proposto por van Genuchten, mais compatível com o modelo adotado para a curva de retenção. No mais, todas as equações do modelo Bidisul original foram mantidas.

\subsection{Estrutura do programa}

O programa é estruturado de maneira a seguir as seguintes funções:

Calcular, por meio da equação de Richards' bidimensional, a umidade volumétrica e o volume infiltrado a cada intervalo de tempo, durante o processo de irrigação em um sulco de seção trapezoidal, ao redor de sua seção transversal. A adaptação da seção de trapezoidal para retangular é meramente geométrica, e está relacionada à variável CANG, que armazena o valor do coeficiente angular da inclinação do talude, dada pela $\operatorname{tg}(\alpha)$, em que $\alpha$ é o ângulo de inclinação.

A equação de Richards' bidimensional foi discretizada (Equação 4.17) e linearizada (Equação 4.18) conforme descrito no Capítulo 4 e em Tabuada et. al., 1995. A solução do sistema de equações lineares é feita pelo processo de interações Gauss Seidel, em que:

$[\mathrm{M}(\mathrm{ij})]^{*}[\mathrm{~N}(\mathrm{i})]=[\mathrm{S}(\mathrm{i})]$

$\mathrm{Ou}$, conforme a nomenclatura adotada no modelo,

$\mathrm{HM}(\mathrm{ij}) * \mathrm{H} 1(\mathrm{i})=0$

Neste modelo, a matriz HM(ij) armazena os valores da matriz de incidência M(ij) mais os valores da variáveis dependentes do vetor solução $S(i)$, na última coluna. Esta matriz, HM(ij), possui dimensões NPN1xNPN2, em que NPN2=NPN1+1. O vetor H1(i) armazena os valores das variáveis independentes $\mathrm{h}(\mathrm{ij})$, a cada iteração.

O processo de infiltração é dividido nas seguintes fases:

Instante $\mathbf{t}=\mathbf{0}$, início da irrigação, caracterizado pelas condições iniciais do solo.

Fase 1, ou fase de alimentação, em que a água é abastecida ao sulco, e a lâmina d'água é crescente.

Fase 2, ou fase de recessão, iniciando no momento em que cessa a alimentação, e a lâmina d'água passa a diminuir (esvaziar o sulco), até zerar.

Fase 3, ou redistribuição, em que já não há água no interior do sulco, e esta se movimenta no interior do domínio, até voltar novamente às condições iniciais. 
A diferença entre as três fases, do ponto de vista do modelo, consiste na variação das condições de contorno nos limites do domínio, as quais foram apresentadas na Tabela 4.1.

A estrutura do programa é detalhada a seguir. O código fonte compõe o ANEXO 3.

1) Leitura de dados

Realizada pela Sub-Rotina ReadData.

- Um arquivo de extensão .DAT, cujo nome possui cinco caracteres, e é fornecido ao programa pelo usuário, armazena os valores de potencial mátrico da primeira coluna do domínio (valores de pressão de suç̧ão, com sinais negativos).

- O arquivo DADOS.DAT possui as informações de:

- geometria do sulco e dados sobre o ensaio que será simulado. Estas informações são armazenadas pelas variáveis NTC, NTL, NCS, NCF, NLS, CANG, NVEZES, INCR, ACTIV, NZDREN, LCOMP, Q, TTREG e TEMPO, as quais serão explicadas mais detalhadamente adiante.

- parâmetros das equações do modelo: equação de Van Genuchten $\left(\theta_{\mathrm{s}}, \theta_{\mathrm{r}}\right.$, $\alpha, \beta)$ e equação de condutividade hidráulica não saturada $(\mathrm{Ko}, \gamma)$

- dados da discretização do domínio e do tempo $(\Delta \mathrm{x}, \Delta \mathrm{z}$ e $\Delta \mathrm{t})$.

2) Montagem do perfil de potencial mátrico h(ij)

Realizada no Programa Principal.

A cada ponto da malha, é atribuído o valor de potencial h(ij) igual ao valor $h(i, 1)$;

3) Cálculo dos valores de umidade volumétrica em cada ponto da malha, no instante inicial.

Realizada pela Sub-Rotina SoilMoistContF0

Através da equação de Van Genuchten, são calculados os valores de umidade inicial $\theta \mathrm{I}(\mathrm{ij})$, a partir dos valores de potencial mátrico inicial hI(ij), fornecidos pelo usuário.

4) Cálculo dos coeficientes da matriz de incidência HM(ij)

Sub-Rotina IncidFase0

Nesta rotina são calculados os coeficientes AIJ(ij), BIJ(ij), DIJ(ij), EIJ(ij), FIJ(ij) e GIJ(ij), descritos pelas Equações 4.19 a 4.24, para o instante inicial. Estes são os coeficientes de linearização da equação da equação do modelo.

\section{5) Cálculo da altura da lâmina d'água}

Sub-Rotina WaterLevel 
A partir dos valores de vazão, tempo e geometria do sulco, é calculada a altura da lâmina d'água abastecida até o instante t. Este valor é armazenado na variável LAG.

6) Cálculo do número de linhas com e sem água no interior da trincheira Programa Principal

Calcula-se a altura da lâmina d'água em linhas, e armazena-se o valor na variável NLSCA. A variável NLSSA armazena o número de linhas da trincheira sem água.

7) Cálculo do número de elementos da matriz de incidência, NPN1 e NPN2 Programa Principal

8) Montagem da matriz de incidência HM(ij), com inclusão dos termos dependentes na última coluna

Sub-Rotina AssembleMatF1

Esta rotina monta a matriz de incidência HM(ij) durante a Fase 1.

9) Montagem do vetor H1(i) com os termos independentes h(ij)

Sub-Rotina AssembleVectF1

Esta rotina atribui valores às variáveis independentes $h(i j)$, durante a Fase 1 . No primeiro instante, $\mathrm{t}=0$, estes valores são os próprios valores de potencial fornecidos pelo usuário. Nos instantes seguintes, são os valores calculados no processo Gauss Seidel.

10) Processo iterativo de Gauss Seidel para solução do sistema de equações lineares

Sub-Rotina gSeidel

Esta rotina calcula os valores das variáveis independentes $h(i j)$.

11) Determinação dos valores de umidade volumétrica $\theta(i j)$

\section{Sub-Rotina SoilMoistContF1}

Esta rotina calcula, a partir da equação de Van Genuchten, os valores de umidade volumétrica em cada ponto da malha, durante a Fase 1. Para tanto, ela se utiliza dos valores recém calculados de potencial $\mathrm{h}(\mathrm{ij})$, a cada intervalo de tempo.

\section{2) Passagem para o próximo passo temporal, $T=T+\Delta T$}

Programa Principal

\section{3) Cálculo do volume infiltrado até 0 instante $T$}

\section{Sub-Rotina WaterVolumeF1}

Esta rotina calcula o teor de umidade de cada malha do domínio, e, a seguir, multiplica pelo volume da malha, para obter o volume de água no domínio. Este valor é armazenado na variável VOL. Em seguida, ele multiplica este valor por 2, para obter o volume infiltrado em todo o entorno da seção transversal do sulco, uma vez que o mesmo 
foi dividido em 2 e adotada a condição de simetria para solução computacional. O volume infiltrado total, em ambos os lados da trincheira, é armazenado na variável VOL1.

\section{4) Cálculo do incremento de linhas no domínio}

Sub-Rotina IncrLinesF1

Esta é uma etapa do programa original, mantida no programa atual. Ela é responsável por aumentar gradativamente o número de linhas no domínio, à medida que a frente de molhamento se aproxima das camadas mais inferiores do solo. A variável ACTIV armazena o valor da diferença entre os h's de dois instantes consecutivos que irá ativar o aumento do número de linhas do perfil. As variáveis INCR e NVEZES armazenam, respectivamente, os valores do incremento de linhas a cada ativação, e do número de vezes que o perfil será aumentado.

Esta rotina se justifica por reduzir o tempo de processamento do programa, uma vez que elimina cálculos desnecessários de linhas da malha que ainda não sofreram variações significativas de umidade. Esta redução de tempo possui significado relevante no contexto em que o programa original foi desenvolvido, devido às limitações de capacidade de armazenamento e rapidez de processamento dos micros existentes. No entanto, em se tratando de malhas pequenas, e/ou considerando a rapidez dos processadores de que se dispõe atualmente, ela deixa de possuir tal relevância. Apesar disso, não foi eliminada do programa, a fím de não descaracterizar o modelo original, uma vez que, para que esta rotina não seja executada, basta adotar, na entrada de dados do programa, um valor alto para ACTIV, superior às diferenças observadas entre h's consecutivos Neste caso, a rotina não é ativada, e a malha é calculada toda de uma vez, considerando todo o domínio.

\section{5) Passagem para o próximo cálculo}

Programa Principal

Nesta etapa, através da verificação da variável LCICL, o programa encaminha a seqüência de cálculos para permanecer na Fase 1 ou iniciar a Fase 2, que começa na linha 377. Esta variável, iniciada com valor 1, deverá ter seu valor alterado para 2 dentro da rotina WaterLevel, quando o nível d'água, expresso pela variável LAG, assumir valor superior à altura da lâmina d'água durante a fase de alimentação, fornecida pelo usuário, no arquivo de entrada de dados, e armazenada na variável HTEMPALI.

\section{6) Cálculo dos coeficientes da matriz de incidência}

\section{Sub-Rotina IncidFase1}

Tal como no passo 4, são calculados os coeficientes da matriz de incidência: AIJ(ij), BIJ(ij), EIJ(ij), FIJ(ij), DIJ(ij) e GIJ(ij). Estes coeficientes, são função da 
condutividade hidráulica não saturada, expressa pela variável KAPA(ij). Esta, por sua vez, é função da umidade no instante considerado, e, se no passo 4, os coeficientes foram calculados com base na umidade inicial $\theta \mathrm{I}$, fornecida pelo usuário, agora eles são calculados com base na umidade $\theta$ calculada na rotina SoilMoistContF1.

\section{7) Anulação dos elementos da matriz de incidência HM(ij)}

Programa Principal

O programa zera os valores dos elementos da matriz de incidência, para dar seqüência à próxima etapa. Caso o programa permaneça na Fase 1, o que é verificado pela variável HTEMPALI, um GOTO o encaminha para a linha 222, em que é chamada a rotina WaterLevel. A partir daí, são repetidos os passos 5 a 15, até que LAG seja maior que HTEMPALI, e o programa inicie a Fase 2.

\section{8) Cálculo dos coeficientes da matriz de incidência}

Sub-Rotina IncidFase2

São calculados os coeficientes da matriz HM(ij), considerando as condições de contorno da a fase 2 .

19) Anulação dos elementos da matriz de incidência HM(ij)

Programa Principal

Idem ao passo 17.

20) São repetidos os passos 8 a 14 para a Fase 2

Sub-Rotinas: AssembleMatF2, AssembleVectF2, gSeidel, SoilMoistContF2, WaterVolumeF2, e IncrLinesF2.

21) Verificação da permanência na Fase 2 ou mudança para a Fase 3

Programa Principal

Através da verificação da variável LAG. Caso ela assuma valor menor que $0.1 \mathrm{~cm}$, a seqüência de cálculos é encaminhada para a Fase 3, com início na linha 1006.

Se permanecer na fase 2, serão repetidos os passos 18 a 20.

Se for encaminhado para a Fase 3, o Programa Principal zera a matriz de incidência e dá seqüência ao passo 22 .

22) Cálculo dos coeficientes da matriz de incidência

Sub-Rotina IncidFase3

23) São repetidos os passos 8 a 14 para a Fase 3.

Sub-Rotinas: AssembleMatF3, AssembleVectF3, gSeidel, SoilMoistContF3, WaterVolumeF3, e IncrLinesF3. 


\section{Programa Principal}

$\mathrm{O}$ programa é encerrado com base na verificação da variável $\mathrm{T}$ com relação à variável TTREG, o que ocorre na linha 389. A variável TTREG armazena o valor do intervalo de tempo total de irrigação. Caso T supere este valor, o programa é encerrado.

\subsection{Arquivos de saída}

O programa apresenta resultados distribuídos em arquivos de extensão .DAT e .LIS, que possuem, no código fonte, Status OLD, o que significa que devem ser criados pelo usuário e estar salvos no mesmo diretório do programa executável. São eles:

- [Nome com cinco caracteres].DAT - armazena os valores iniciais de potencial mátrico HI(ij)

- [Nome com cinco caracteres].LIS - irá armazenar os resultados do programa. Este é o único arquivo de saída do código fonte original. Os demais foram inseridos como alterações, de modo a acompanhar os resultados gerados pelo programa em cada passo da execução.

- HI.dat - irá armazenar os valores de h(ij) no instante inicial.

- Matricpot.dat - irá armazenar os valores de h(ij) a cada intervalo de tempo.

- CIJ.DAT - irá armazenar os valores da variável C(ij), derivada da função de VanGenuchten, em relação à umidade, a cada intervalo de tempo.

- Hydrconduc.DAT - irá armazenar os valores de condutividade hidráulica, expressos pela variável KAPA(ij) a cada intervalo de tempo.

- Soilmoist.DAT - irá armazenar os valores de umidade $\theta \mathrm{I}(\mathrm{ij})$ e $\theta(\mathrm{ij})$, a cada intervalo de tempo.

- Coeficients.DAT - irá armazenar os valores dos coeficientes da matriz de incidência: AIJ(ij), BIJ(ij), EIJ(ij), FIJ(ij), DIJ(ij) e GIJ(ij), a cada intervalo de tempo.

- Halt.DAT - irá armazenar os valores de lâmina d'água, expressos pela variável LAG, a cada intervalo de tempo.

- HM.DAT - irá armazenar a matriz de incidência em cada instante.

- H1.DAT - irá armazenar o vetor com as incógnitas em cada instante.

Além destes arquivos de saída, há outros, com Status NEW, que não necessitam ser criados pelo usuário, pois o são pelo próprio programa, e devem ser apagados a cada execução. Estes arquivos são os MATRIZ(NUMERO).DAT - gerados pelas rotinas WaterVolume. 


\subsection{Informações necessárias para a simulação da infiltração em trincheiras:}

Para simular o processo de infiltração no entorno da seção transversal de trincheiras de infiltração, em suas três fases, são necessários conhecimentos prévios sobre a física do solo que se vai estudar, especialmente suas propriedades de infiltração e condições de umidade:

- A curva de retenção do solo, $\phi m=f(\theta)$;

- A condutividade hidráulica do solo em função do grau de saturação $k(\theta)$;

- As condições iniciais de umidade do solo na região em torno da seção transversal da trincheira.

\section{Curva de retenção do solo}

O modelo trabalha com a Equação de Van Gemuchten (1980), apresentada no Capítulo 3 e descrita pela equação 3.23 :

$$
\theta=\theta_{r}+\frac{\left(\theta_{s}-\theta_{r}\right)}{\left[1+\left(\alpha_{v} \cdot \phi_{m}\right)^{n}\right]^{m}}
$$

\section{Condutividade hidráulica não saturada}

Trata-se da curva de condutividade hidráulica em função do teor de umidade do solo. $\mathrm{O}$ modelo original de Tabuada et al. (1994) trabalha com a relação de condutividade hidráulica em função da umidade dada pela Equação 6.1:

$$
K(\theta)=A \cdot \theta^{B}
$$

O modelo adaptado utiliza-se da relação proposta por Van Genuchten (1980) a partir do modelo de Mualem (1976, apud Libardi, 2000), apresentado no Capítulo 5 e descrito pela Equação 5.1:

$$
K(\theta)=K_{0} \omega^{l}\left[1-\left(1-\omega^{\frac{1}{m}}\right)^{m}\right]^{2}
$$

em que:

$$
\omega=\frac{\theta-\theta_{r}}{\theta-\theta_{r}}
$$

$l=0,5$ para solos de textura média a arenosa.

\section{Condições iniciais de umidade}

São obtidas em campo, com sonda de nêutrons. Podem ser estimativas iniciais, baseadas em simulações anteriores, para prever cenários que têm como ponto de partida 
uma determinada chuva anterior, para fins de estudo do comportamento da trincheira em situações de chuvas sucessivas.

\subsection{Alimentação do modelo}

\section{Variáveis de entrada}

Para a correta inserção de dados no modelo, é necessário conhecer o significado físico de suas variáveis de entrada. Baseado nas Figuras 4.28 e 4.29, que apresentam as malhas de pontos no domínio da seção transversal da trincheira em duas geometrias diferentes, adota-se a seguinte nomenclatura:

$\mathrm{NTC}=$ número total de colunas da malha

NTL = número total de linhas

NCS = número de colunas à superfície, ou seja, fora da trincheira.

$\mathrm{NCF}=$ número de colunas no fundo da trincheira

$\mathrm{NL}=$ profundidade da trincheira, em linhas

CANG $=$ tangente do ângulo de inclinação do talude. É muito importante ressaltar o seguinte: o domínio é discretizado em elementos retangulares de dimensões $\Delta \mathrm{x}$ e $\Delta \mathrm{z}$. $\mathrm{O}$ modelo é concebido de maneira tal que, ao longo da inclinação do talude, esses elementos se tornam triângulos retângulos de base $\Delta x$ e altura $\Delta z$. Deste modo, o talude da trincheira deve possuir inclinação tal que, necessariamente, gere esses triângulos. Neste trabalho, por exemplo, foi utilizada uma malha de dimensões $\Delta x=1,25 \mathrm{~cm} \mathrm{e} \Delta \mathrm{z}=10 \mathrm{~cm}$, de modo que o ângulo de inclinação foi de $83^{\circ}$, ou seja, a inclinação do talude deve ser igual à inclinação da diagonal dos elementos retangulares da malha, e não simplesmente escolhida sem critério, sob risco de ocasionar inconsistência nos cálculos, ou mesmo erros de execução do programa.

NVEZES, INCR e ACTIV, conforme explicado anteriormente, utilizadas pelas subrotinas IncrLines.

TETA-S, TETA-R, ALFA e BETA

São os parâmetros de ajuste da curva de retenção pela equação de Van Gemuchten (1980) (Equação 1): umidade de saturação $\theta_{\mathrm{s}}$, umidade residual $\theta_{\mathrm{r}}, \alpha$ e $n$, respectivamente.

\section{CKS}

Parâmetro de ajuste da curva de condutividade hidráulica não saturada, pela Equação (6.2): $\mathrm{K}_{0}$. 
Valores em $\mathrm{cm}$ dos espaçamentos da malha na horizontal $(\Delta \mathrm{x})$ e na vertical $(\Delta \mathrm{z})$. e valor, em segundos do intervalo de tempo $\Delta \mathrm{t}$ considerado para a discretização.

\section{NZDREN}

Variável original NZRAD do modelo de irrigação, que indica a profundidade da camada de raízes da cultura irrigada. No modelo de infiltração, foi substituída pela variável NZDREN, ou profundidade da camada de solo sob ação direta da drenagem da trincheira. Esta profundidade será utilizada como referência para o cálculo do volume drenado e armazenado na região de domínio da trincheira.

$\mathrm{LCOMP}=$ comprimento da trincheira, $\mathrm{em} \mathrm{cm}$.

$\mathrm{Q}=$ vazão de alimentação à trincheira, $\mathrm{em} \mathrm{cm}^{3} / \mathrm{s}$

HTEMPALI = altura da lâmina d'água durante o tempo de alimentação, em $\mathrm{cm}$. Esta variável considera a possibilidade da trincheira manter um nível d' água constante durante a fase de alimentação, após o enchimento da trincheira.

TTREG = tempo total de irrigação ou alimentação, em segundos.

TEMPO = intervalo de tempo para traçado das eqüipotenciais, em segundos. É o intervalo de tempo entre os perfis que se deseja obter como saída do modelo.

\subsection{Geração dos arquivos de entrada}

$O$ arquivo principal de entrada deve ter o formato [*5.DAT], e estar localizado no mesmo diretório do arquivo executável.

Este arquivo de entrada consta de um vetor com uma coluna e tantas linhas quantas forem as linhas da malha. Ele é formado pelos valores de sucção matricial iniciais, anteriores à irrigação. As casas decimais devem ser separadas por ponto [ . ] e os valores devem ser expressos com o sinal negativo.

O modelo assume que os valores de umidade inicial em todas as colunas da malha são iguais aos da primeira, de modo que o vetor de entrada deve ser formado por estes valores. Para efeitos práticos, pode-se adotar o valor médio das umidades de cada linha da malha. Feito isso, converte-se os valores de umidade para sucção matricial, por meio do modelo de Van Genuchten. Exemplo de arquivo de entrada: SOLO1.DAT 


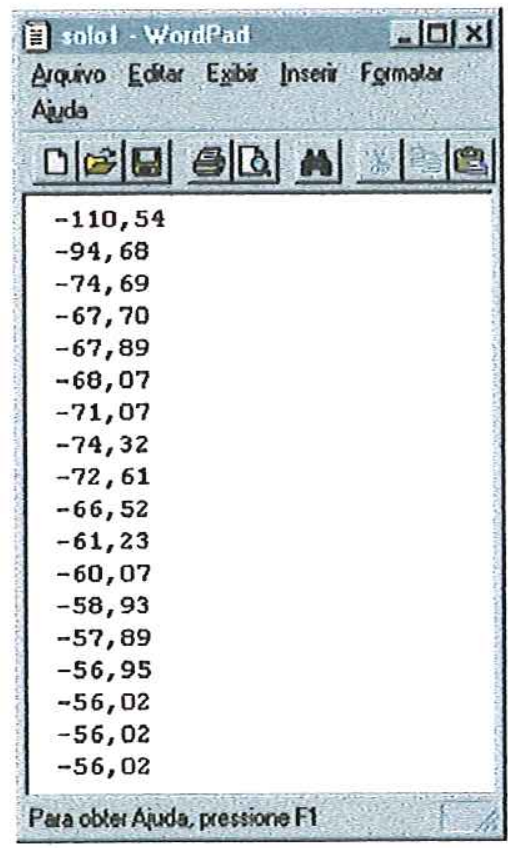

Figura 6.1 - Arquivo de entrada com os valores iniciais de sucção matricial.

$\mathrm{O}$ arquivo com as variáveis de entrada, chama-se Dados.DAT, e segue as especificações de formato descritas na Sub-rotina ReadData.

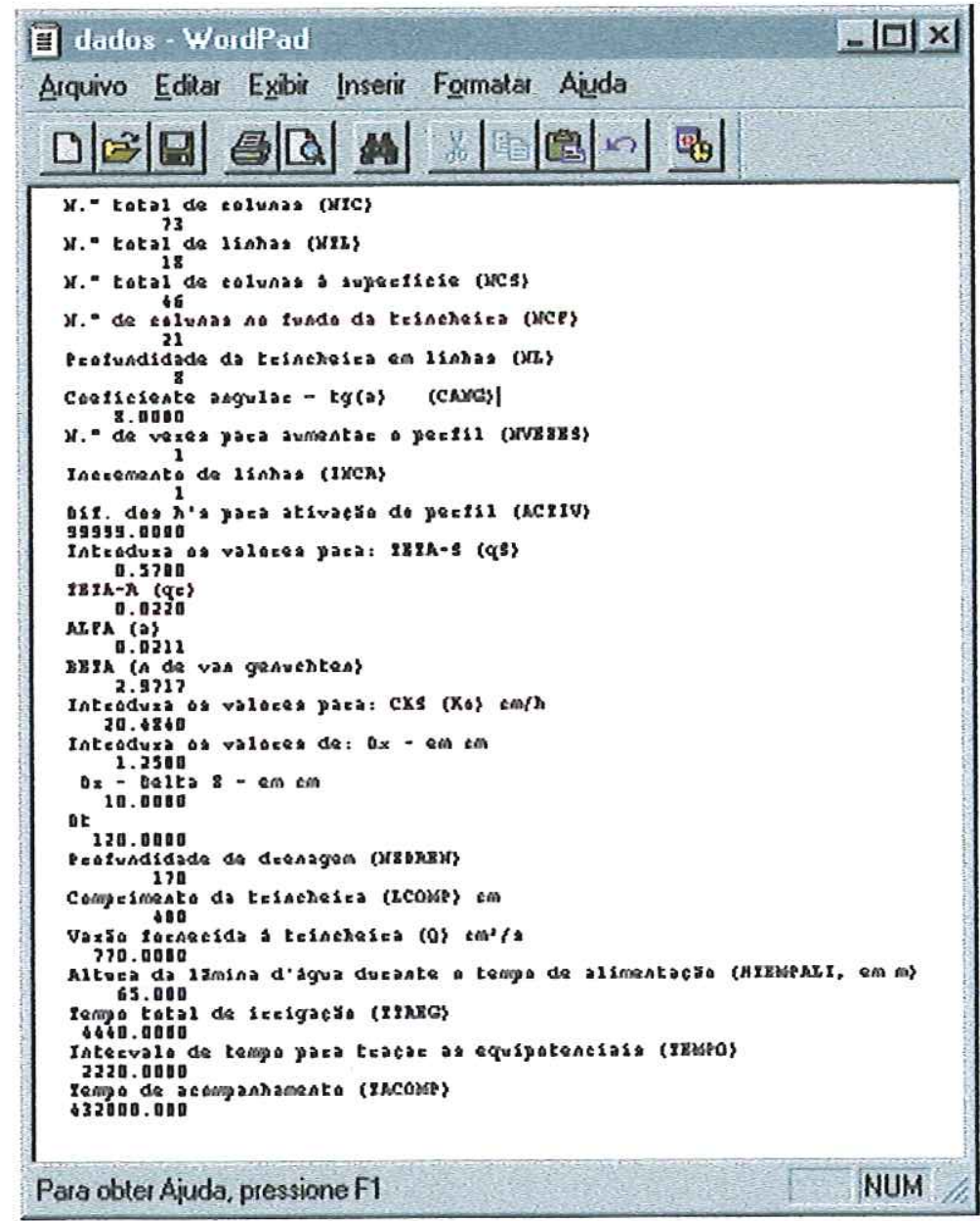

Figura 6.2 - Arquivo de dados com as variáveis de entrada do modelo. 


\subsection{Geração do arquivo de saída}

O programa possui os arquivos de saída listados na seção 6.3. O código do programa assume, para estes arquivos, STATUS OLD, de modo que o usuário deve criar os arquivos em branco no WORDPAD ou no BLOCO DE NOTAS, e salvá-los com os respectivos nomes e extensões (especificados em 6.3), antes de rodar o programa.

Durante a execução do programa, são gravados, nestes arquivos, os valores das variáveis como umidade e potencial mátrico para todo o domínio, em cada instante, bem como lâmina d'água e volume infiltrado, em forma de matriz.

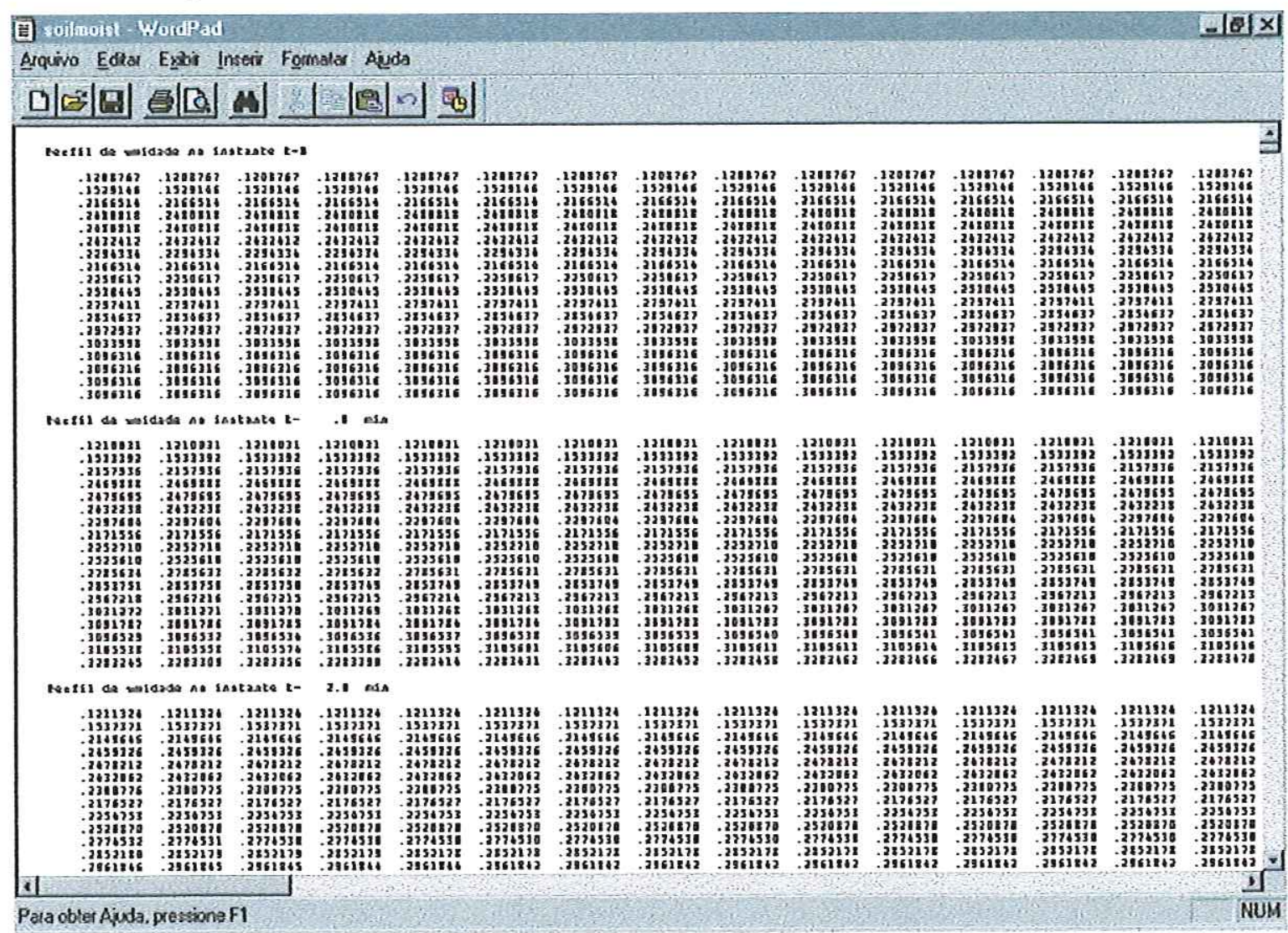

Figura 6.3 - Exemplo de arquivo de saída - SOILMOIST.DAT 


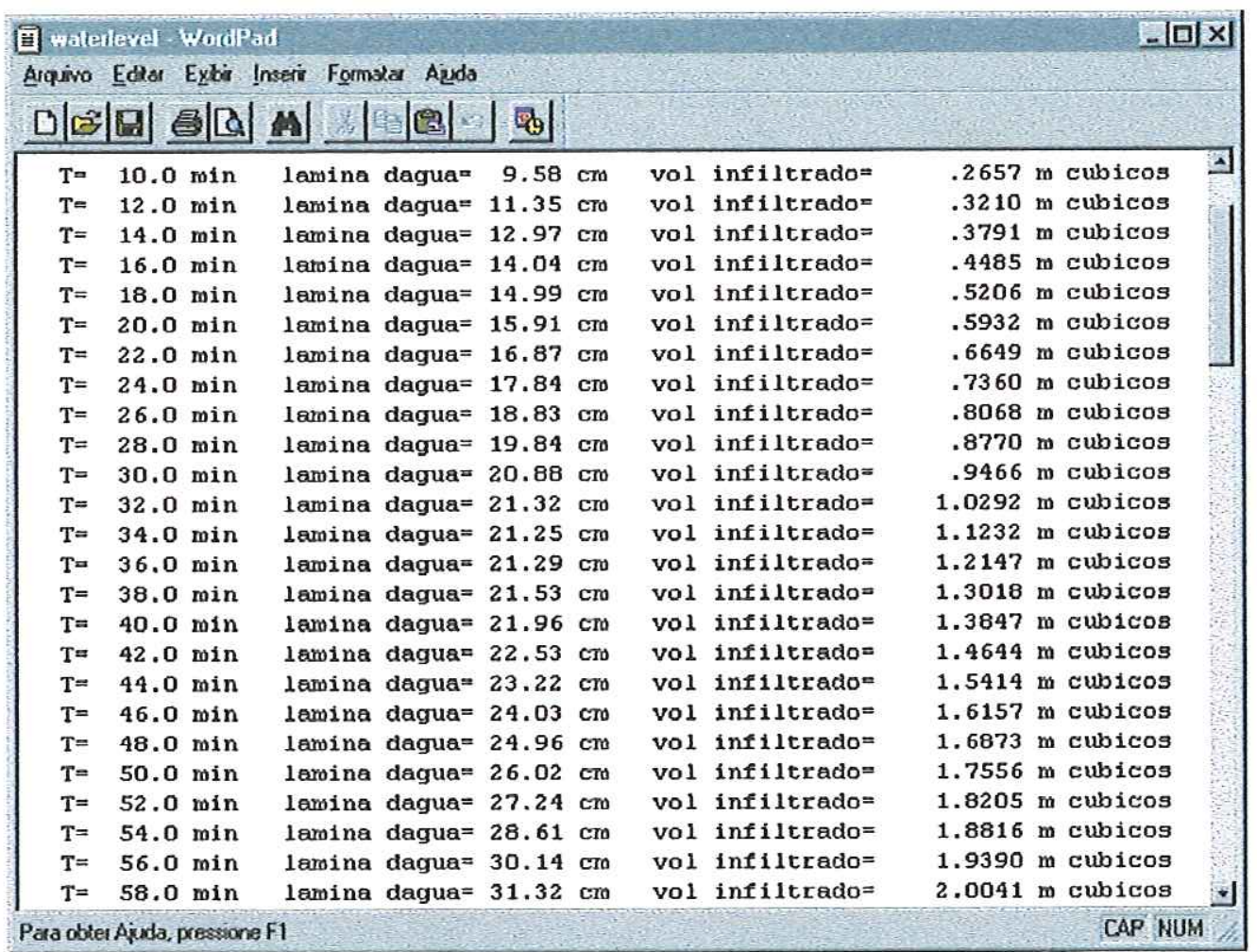

Figura 6.4 - Exemplo de arquivo de saída - WATERLEVEL.DAT 


\section{DIMENSIONAMENTO DE TRINCHEIRAS DE INFILTRAÇÃO}

Conforme foi apresentado no Capítulo 3, Jonasson (1984, apud Mikkelsen e Jacobsen, 1993; Mikkelsen et al., 1996) propôs, para o dimensionamento de trincheiras de infiltração, o rain envelope method, baseado no balanço de massa, segundo o qual o volume de armazenamento da trincheira $\left(\mathrm{V}_{\mathrm{t}}\right)$ deve ser igual ao volume de água precipitado sobre a área de contribuição $\left(\mathrm{V}_{\text {prec }}\right)$, durante o período de tempo considerado, subtraído do volume de água infiltrado durante o mesmo período $\left(v_{\text {inf }}\right)$.

$$
V_{t}=V_{\text {prec }}-V_{\text {inf }}
$$

Originalmente, o método propõe que a vazão de infiltração seja obtida a partir da formulação de Darcy para escoamento em solo saturado. Esta hipótese subestima a capacidade de infiltração da trincheira, uma vez que considera que a taxa de infiltração do solo é constante e igual à taxa de infiltração na condição de saturação.

A metodologia de dimensionamento de trincheiras de infiltração proposta neste trabalho baseia-se também no balanço de massa no interior da trincheira, em que, o volume a ser armazenado é igual ao volume de entrada, proveniente da precipitação, subtraído do volume da saída, através da infilltração. Para a estimativa do volume infiltrado, propõe-se que seja considerada a variação da taxa de infiltração no tempo.

A determinação das dimensões da trincheira depende, portanto, de que sejam conhecidos, além da área de contribuição geradora do escoamento superficial, dois aspectos relacionados:

a) as características de chuva locais, e

b) as propriedades de infiltração do solo e sua variação no tempo.

Para a estimativa da capacidade de infiltração do solo, são aplicadas duas metodologias.

A primeira, mais simplificada, baseia-se na equação de Philip para infiltração horizontal, e, assim, como o rain envelope method, proposto por Jonasson (1984, apud 
Mikkelsen et al. 1996), considera a condição de colmatação do fundo da trincheira, em que a infiltração ocorre somente na área lateral da estrutura.

A segunda metodologia utiliza o modelo de Richard's para prever, não apenas os volumes infiltrados a cada instante, mas também os valores de umidade em cada ponto da malha ao redor da seção transversal da trincheira, ou seja, como ocorre a redistribuição da água no solo.

O segundo método é mais elaborado, e requer o conhecimento da curva de retenção e a relação da condutividade hidráulica em função da umidade do solo. Estas são propriedades bastante específicas, que só podem ser obtidas a partir de experimentos em laboratório e campo, o que torna difícil sua aplicação direta. Além disso, não são propriedades de fácil correlação entre solos distintos.

No entanto, o método apresenta a vantagem de ser mais preciso, e permitir que sejam traçados cenários baseados em condições iniciais específicas de umidade do solo, as quais podem ser alteradas em função de diferentes estações do ano, chuvas sucessivas, etc. Isto pode ser muito útil quando se pretende prever o comportamento de um sistema descentralizado de estruturas de infiltração de águas pluviais a ser implantado em grande escala, como em loteamentos inteiros.

A seguir, são apresentadas as duas metodologias.

\subsection{Volume de projeto $\left(V_{p}\right)$}

O volume de projeto é o volume precipitado sobre a área de contribuição do escoamento superficial para a trincheira de infiltração. Ele é função, portanto, da intensidade e tempo de precipitação e da área de drenagem.

$$
V_{p}=3,6 \cdot 10^{-6} i \cdot 60 t \cdot A_{d}
$$

em que:

$V_{p}=$ volume de projeto, $\mathrm{em}^{3}$

$i=$ intensidade de precipitação, $\mathrm{em} \mathrm{mm} / \mathrm{h}$

$t=$ tempo de precipitação, em $s$

$A_{d}=$ área de drenagem conectada à trincheira de infiltração, em $\mathrm{m}^{2}$

A intensidade de precipitação é obtida a partir da curva de intensidade-duraçãofreqüência local (curva idf), da forma: 


$$
i=\frac{a \cdot T^{b}}{(t+c)^{d}}
$$

em que:

$i=$ intensidade de precipitação, $\mathrm{em} \mathrm{mm} / \mathrm{h}$,

$T=$ periodo de retorno, em anos,

$t=$ duração da precipitação, em mimutos, $e$

$a, b, c$ e d são parâmetros ajustados empiricamente.

O método considera que a forma de alimentação da trincheira baseia-se em conduzir à estrutura de infiltração as águas precipitadas sobre o telhado. Deste modo, a área de drenagem $A_{d}$, ou área efetiva de contribuição do escoamento superficial para a trincheira, é estimada com base nas dimensões e na taxa de ocupação do lote.

\subsection{Volume infiltrado (Vinf)}

Nesta etapa do dimensionamento reside a diversidade entre as duas metodologias apresentadas, que serão discutidas a seguir:

\subsubsection{Método A - Baseado no modelo horizontal de infiltração de Philip}

Apesar do processo de infiltração em trincheiras ser multidimensional, uma análise pelo modelo de infiltração horizontal de Philip, apresentado no Capítulo 3 e descrito pelas equações 3.31 e 3.32 , em que a taxa de infiltração decai com o tempo, fornece um meio de dimensionar o volume da estrutura considerando a vazão de infiltração correspondente ao tempo de precipitação.

$$
\begin{aligned}
& i=\frac{C}{2 \sqrt{t}} \\
& I=C \sqrt{t} \\
& V_{\mathrm{inf}}(t)=I(t) \cdot A_{\mathrm{inf}}
\end{aligned}
$$

em que:

$V_{\text {inf }}=$ volume infiltrado até $o$ instante $t, \mathrm{em} \mathrm{m}^{3}$;

$I=$ infiltração acumulada até o instante $t, \mathrm{em} \mathrm{m}^{3} / \mathrm{m}^{2}, e$

$A_{\text {inf }}=$ área efetiva de infiltração, em $\mathrm{m}^{2}$. 
O ajuste ao modelo é obtido experimentalmente. Para os solos 1 e 2, a calibração ao foi realizada conforme metodologia descrita no Capítulo 4, cujo ajuste está apresentado no Capítulo 5, Tabela 5.8 e Figuras 5.12 e 5.13.

O uso da taxa de infiltração conforme obtida por ajustes de dados experimentais ao modelo de Philip produz uma estimativa subestimada do volume infiltrado, tendo em vista que, durante a operação da trincheiras de infiltração, não necessariamente ocorre a colmatação total do fundo. A área de infiltração é estimada considerando-se as hipóteses assumidas por Jonasson (1984, apud Mikkelsen e Jacobsen, 1993; Mikkelsen et al., 1996), segundo as quais:

a) a área superficial da base é totalmente colmatada após algum tempo de operação da trincheira;

b) a superfície lateral de infiltração nas extremidades da trincheira é desprezível, e,

c) a infiltração ocorre, portanto, somente na superficie lateral ao longo do comprimento da trincheira, e o nível d'água médio é igual a $1 \frac{1}{2} \mathrm{H}$, em que $\mathrm{H}$ é a altura útil da trincheira.

Obtém-se que a área efetiva de infiltração $\left(\mathrm{A}_{\text {inf }}\right)$ é dada por:

$$
A_{\text {inf }}=2 \cdot L \cdot \frac{H}{2}=L H
$$

\subsubsection{Método B - Baseado no modelo bidimensional de Richards'}

O volume infiltrado após um determinado tempo de operação da trincheira é calculado com o auxílio do modelo de infiltração apresentado. $O$ arquivo de saída WATERLEVEL.DAT fornece os valores de volume infiltrado acumulado em cada instante, durante e após a irrigação.

\subsection{Volume efetivo de armazenamento (Va,ef)}

$V_{a, e f}=\phi \cdot V_{t}$

em que

$\phi=$ porosidade da brita utilizada para o enchimento da trincheira.

Assim, o volume efetivo de armazenamento da trincheira de infiltração deve ser igual a:

$$
V_{a, e f}=\left(3,6 \cdot 10^{-6} i \cdot 60 t \cdot A_{d}\right)-(I \cdot L \cdot H)
$$


em que:

$i=$ intensidade de precipitação, em $\mathrm{mm} / \mathrm{h}$;

$t=$ tempo, em $s$

$A_{d}=$ área de drenagem da trincheira, em $\mathrm{m}^{2}$;

$I=$ infiltração acumulada até o instante $t$, $\mathrm{em} \mathrm{m}^{3} / \mathrm{m}^{2}$;

$A_{\text {inf }}=$ área efetiva de infiltração $=L . H\left(\mathrm{~m}^{2}\right)$.

Ou seja, o volume de armazenamento da trincheira de infiltração é o volume precipitado sobre a área de contribuição, atenuado pela capacidade de infiltração da trincheira.

Considerando a porosidade da brita, de acordo com a Equação 7.7, o volume da trincheira deve ser igual a:

$$
V_{t}=\frac{\left[\left(i \cdot t \cdot A_{d}\right)-(I \cdot L \cdot H)\right]}{\phi}
$$

Desta forma, o dimensionamento é um processo iterativo, em que se considera a área disponível para implantação da trincheira e o volume precipitado.

\subsection{Exemplo de dimensionamento para os Solos 1 e 2}

Supondo os seguintes dados de projeto: lote padrão de $15 \times 20 \mathrm{~m}^{2}$, com taxa de ocupação de $60 \%$, e, portanto, área impermeável geradora de escoamento superficial de $180 \mathrm{~m}^{2}$.

Para a cidade de São Carlos, segundo Barbassa (1991), a curva idf assume o seguinte ajuste:

$$
i=\frac{1519 \cdot T^{0,236}}{(t+16)^{0,935}}
$$

Considerando-se uma chuva de 20 minutos (1200 s), com período de retorno de 1 ano, tem-se $\mathrm{i}=53 \mathrm{~mm} / \mathrm{h}(\mathrm{i}=1,472 \mathrm{E}-5 \mathrm{~m} / \mathrm{s})$, que, sobre uma área de $180 \mathrm{~m}^{2}$, gera um volume precipitado $\mathrm{V}_{\text {prec }}=3,20 \mathrm{~m}^{3}$.

A brita 3 comercial fornece porosidade de aproximadamente $45 \%$.

De acordo com o ajuste à ao modelo de Philip, apresentado na Tabela 5.8, a infiltração acumulada em 20 minutos no Solo 1 é $\mathrm{I}=0,1978 \mathrm{~m}^{3} / \mathrm{m}^{2}$, e, no Solo $2, \mathrm{I}=0,2418 \mathrm{~m}^{3} / \mathrm{m}^{2}$.

As dimensões da trincheira são: B (largura), H (profundidade) e L (comprimento). O processo de dimensionamento consiste de adotar valores iniciais para $\mathrm{H} \mathrm{e} \mathrm{L}$, para o cálculo 
do lado direito da Equação 9, e, por esta equação, obter o valor de B, verificar a viabilidade construtiva e refazer os cálculos, se necessário, adotando novos valores para $\mathrm{H} \mathrm{e} \mathrm{L.}$

Atribuindo, inicialmente, valores de $\mathrm{H}$ e L iguais a $1,00 \mathrm{~m}$ e $5,00 \mathrm{~m}$, respectivamente, a Equação 7.8 conduz a $V_{t 1}=4,87 \mathrm{~m}^{3}$ para o Solo 1 , o que implica em $B_{1}=0,98 \mathrm{~m}$, e $V_{12}=$ $4,37 \mathrm{~m}^{3}$ para o Solo 2 , fornecendo $\mathrm{B}_{2}=0,88 \mathrm{~m}$.

Ou seja, no Solo 1, uma trincheira de $0,98 \times 1,00 \times 5,00 \mathrm{~m}^{3}$, e, no Solo 2 , uma trincheira de $0,88 \times 1,00 \times 5,00 \mathrm{~m}^{3}(\mathrm{BxHxL})$, preenchidas com brita 3 , de porosidade $45 \%$, são capazes de atender, partindo da condição seca, uma chuva de 1 ano de período de retorno. Por não serem dimensões práticas em engenharia, as larguras obtidas podem ser arredondadas para números inteiros próximos.

\subsection{Estimativa de custos de implantação}

A análise de custos de implantação é o passo seguinte, e deve ser feita, preferencialmente, considerando a implantação do sistema como um todo, o que diminui os custos em relação à implantação em um único lote. Os custos envolvidos diretamente são: escavação de terra, brita de preenchimento, dispositivos hidráulicos (tubos, conexões, calhas), manta geotêxtil e mão-de-obra. A Tabela 7.1 apresenta uma estimativa dos custos diretos, para a implantação de uma trincheira de infiltração isolada, de dimensões $0,90 \times 1,00 \times 5,00 \mathrm{~m}^{3}$.

Tabela 7.1 - Estimativa de custos diretos de implantação de uma trincheira de infiltração

\begin{tabular}{|c|c|c|c|c|}
\hline Item & Unidade & Quantidade & Custo unitário R\$ & Custo total R\$ \\
\hline Brita 3 & $\mathrm{m}^{3}$ & 4,5 & 35,00 & 157,50 \\
\hline Escavação de solo & $\mathrm{m}^{3}$ & 4,5 & 16,70 & 75,15 \\
\hline Carga de terra & $\mathrm{m}^{3}$ & 4,5 & 10,62 & 47,79 \\
\hline Transporte de terra & $\mathrm{m}^{3}$ & 4,5 & 7,13 & 32,09 \\
\hline Manta geotêxtil & $\mathrm{m}^{2}$ & 11,8 & 2,30 & 27,14 \\
\hline MDO servente/ajudante & dia & 1 & 25,00 & 25,00 \\
\hline Tubos e conexões & & & & 30,00 \\
\hline & & & Total: & 394,67 \\
\hline
\end{tabular}

A estimativa apresentada na Tabela 7.1 refere-se aos custos diretos de implantação de uma unidade de trincheira de infiltração em um lote urbano. A implantação de um sistema de infiltração de águas pluviais em um loteamento requer estudos mais elaborados sobre os custos envolvidos indiretamente, há tais como: estudos iniciais da bacia, programas de incentivo, elaboração de manuais de projeto, monitoramento do sistema, físcalização e gerenciamento do funcionamento das trincheiras. 


\section{ESTIMATIVA DA REDUÇÃO DO ESCOAMENTO SUPERFICIAL EM UMA MICRO BACIA PELO USO DE TRINCHEIRAS DE INFILTRAÇÃO}

O efeito do uso de trincheiras de infiltração de águas pluviais no hidrograma de cheia da bacia só pode ser precisamente avaliado considerando-se as propriedades hidráulicas do solo, a função de transformação chuva-vazão da área de drenagem e as condições exatas de operação e manutenção das trincheiras.

No entanto, para fins de prognóstico, pode-se fazer uma avaliação simplificada, utilizando-se o método racional e as condições ideais de operação das instalações de infiltração.

Considere-se o esquema representativo de uma micro bacia hidrográfica, compreendida por quarteirões residenciais, ilustrada na Figura 8.1. Trata-se de uma micro bacia hidrográfica urbana, composta por 12 quarteirões residenciais, em que o sentido do escoamento é indicado pelas setas, convergindo para um único ponto localizado no limite inferior direito da planta. 


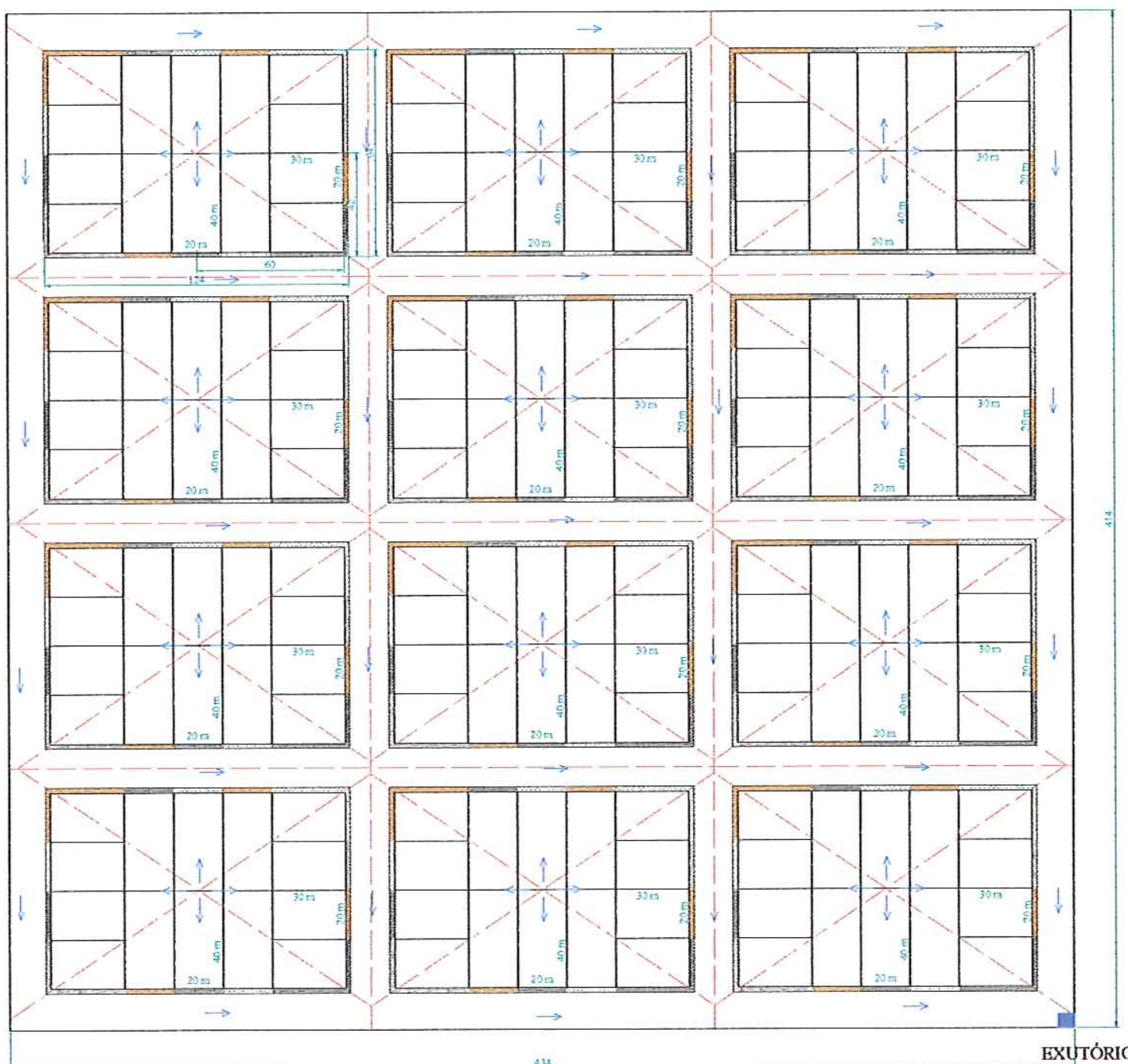

EXUTÓRIO

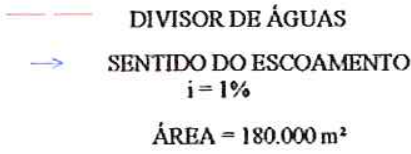

Figura 8.1 - Esquema representativo do escoamento superficial em uma microbacia urbana.

A área total da bacia é de $180.000 \mathrm{~m}^{2}$, dos quais $125.000 \mathrm{~m}^{2}$ (aproximadamente $70 \%$ ) são compostos por lotes, e o restante, por ruas pavimentadas.

A estimativa da redução do escoamento superficial proporcionada pelo uso de trincheiras na micro bacia ilustrada é apresentada em duas etapas:

A - estimativa da vazão gerada em cada lote, para um determinado período de retorno e chuva de projeto;

B - estimativa da vazão infiltrada por um sistema descentralizado de trincheiras de infiltração nos lotes. 


\section{A) Estimativa da vazão de escoamento superficia}

O cálculo estimado da vazão de escoamento no exutório da bacia, para uma dada chuva de projeto, é feito pelo método racional:

$\mathrm{Q}=0,278 \mathrm{CiA}$

em que:

$Q=$ vazão de escoamento, $\mathrm{m}^{3} / \mathrm{s}$

$C=$ coeficiente de escoamento superficial (Tabela 8.1)

$i=$ intensidade de precipitação, $\mathrm{mm} / \mathrm{h}$

$A=$ Área da bacia, $\mathrm{km}^{2}$

A Tabela 8.1 apresenta os valores do coeficiente de escoamento superficial "C", do método racional, adotados pela Prefeitura Municipal de São Paulo (Wilken, 1978, Apud Bidone e Tucci, 1995).

Tabela 8.1 - Valores do coeficiente de escoamento superficial C adotados pela Prefeitura Municipal de São Paulo Fonte: Wilken, 1978 apud Bidone e Tucci, 1995.

\begin{tabular}{|l|c|}
\hline \multicolumn{1}{|c|}{ Zonas } & C \\
\hline $\begin{array}{l}\text { Edificação muito densa: } \\
\text { Partes centrais, densamente construídas, de uma } \\
\text { cidade com ruas e calçadas pavimentadas. }\end{array}$ & $0,70-0,95$ \\
\hline $\begin{array}{l}\text { Edificação não muio densa: } \\
\text { Partes adjacentes ao centro, de menor densidade de } \\
\text { habitações, mas com ruas e calçadas pavimentadas. }\end{array}$ & $0,60-0,70$ \\
\hline $\begin{array}{l}\text { Edificações com poucas superfícies livres: } \\
\text { Partes residenciais, com ruas macadamizadas ou } \\
\text { pavimentadas. }\end{array}$ & $0,50-0,60$ \\
\hline $\begin{array}{l}\text { Edificações com muitas superficies livres: } \\
\text { Partes residenciais, com ruas maçadamizadas ou } \\
\text { pavimentadas. }\end{array}$ & $0,25-0,50$ \\
\hline $\begin{array}{l}\text { Subúrbios com alguma edificação: } \\
\text { Partes de arrebaldes e subúrbios com pequena } \\
\text { densidade de construção. }\end{array}$ & $0,10-0,25$ \\
\hline $\begin{array}{l}\text { Matas, parques e campos de esporte: } \\
\text { Partes rurais, áreas verdes, superícies arborizadas, } \\
\text { parques ajardinados, campos de esporte sem } \\
\text { pavimentação. }\end{array}$ & $0,05-0,20$ \\
\hline
\end{tabular}

Além do coeficiente de escoamento superficial, é necessário estimar a intensidade de precipitação, o que pode ser feito por meio da curva idf, em que o período de retorno considerado em projetos de micro drenagem varia de 2 a 10 anos. A Equação 3.2, representa a curva idf de São Carlos - SP. 
$i=\frac{1519 \cdot T^{0,236}}{(t+16)^{0,935}}$

em que:

$i=$ intensidade de precipitação, em $\mathrm{mm} / \mathrm{h}$,

$T=$ periodo de retorno, em anos,

$t=$ duração da precipitação, em mimutos, $e$

$a, b, c$ e d são parâmetros ajustados empiricamente

De acordo com a proposta do método racional, a duração da precipitação máxima de projeto é igual ao tempo de concentração da bacia. Admite-se que a bacia seja pequena para que essa condição aconteça, pois a duração é inversamente proporcional à intensidade, conforme salientam Bidone e Tucci, 1995, que sugerem, para o cálculo do tempo de concentração da bacia o seguinte equacionamento:

A velocidade das superfícies é obtida com base na Equação 8.2:

$v=k \cdot S^{0,5}$

em que:

$v=$ velocidade, $\mathrm{em} \mathrm{m} / \mathrm{s}$;

$k=$ coeficiente estimado de acordo com a Tabela 8.2;

$S=$ declividade da superfície, em \%.

O tempo de concentração é calculado por:

$t_{c}=\sum_{i=1}^{n} \frac{L_{i}}{v_{i}}$

em que:

$L_{i}=$ comprimento do trecho

$v_{i}=$ velocidade no trecho

Tabela 8.2 - Valores do coeficiente k (SCS, 1975)

\begin{tabular}{|l|c|}
\hline \multicolumn{1}{|c|}{ Uso da terra e regime de escoamento } & k \\
\hline Floresta com muita folhagem no solo & 0,076 \\
\hline Área com pouco cultivo; terraceamento & 0,152 \\
\hline Pasto ou grama baixa & 0,213 \\
\hline
\end{tabular}




\begin{tabular}{|l|c|}
\hline \multicolumn{1}{|c|}{ Uso da terra e regime de escoamento } & k \\
\hline Áreas cultivadas & 0,274 \\
\hline Solo quase nu sem cultivo & 0,305 \\
\hline Caminhos de escoamento em grama, pasto & 0,457 \\
\hline Superfície pavimentada; pequenas vossorocas de nascentes & 0,610 \\
\hline
\end{tabular}

O cálculo do tempo de concentração feito por este método, para bacias muito pequenas, como um único lote urbano, gera valores muito pequenos, e, conseqüentemente, intensidades muito altas. Por este motivo, adotou-se um tempo de concentração de 10 minutos para determinar a curva idf.

$$
i=\frac{1519 \cdot T^{0,236}}{(10+16)^{0,935}}=72,2 \cdot T^{0,236}
$$

Para $\mathrm{T}=2$ anos, a intensidade de precipitação é:

$\mathrm{i}=72,2 \times 5^{0,236}=85,0 \mathrm{~mm} / \mathrm{h}$

Para $\mathrm{T}=5$ anos, a intensidade de precipitação é:

$\mathrm{i}=72,2 \times 5^{0,236}=105,6 \mathrm{~mm} / \mathrm{h}$

De acordo com o método racional, e considerando que:

Área de contribuição $=700 \mathrm{~m}^{2}$ (área média dos lotes) $=7 \times 10^{-4} \mathrm{~km}^{2}$

$\mathrm{C}=0,70$ (adotado, Tabela 8.1)

Tem-se:

Para $\mathrm{T}=2$ anos

$Q=0,278 \cdot(0,70) \cdot(85,0) \cdot\left(7 \cdot 10^{-4}\right)=1,16 \times 10^{-2} \mathrm{~m}^{3} / \mathrm{s}=11,61 / \mathrm{s}$

Para $\mathrm{T}=5$ anos

$Q=0,278 \cdot(0,70) \cdot(105,6) \cdot\left(7 \cdot 10^{-4}\right)=1,43 \times 10^{-2} \mathrm{~m}^{3} / \mathrm{s}=14,3 \mathrm{l} / \mathrm{s}$

\section{B) Estimativa da reduç̃o no escoamento superficial com o uso de trincheiras:}

A estimativa de redução do escoamento superficial, considerando que cada um dos lotes possua uma trincheira de infiltração, é feita através do balanço hídrico no lote, da seguinte forma:

$\mathrm{V}_{\mathrm{e}}=\mathrm{V}_{\mathrm{a}}-\mathrm{V}_{\mathrm{i}}$

em que: 
$V_{e}=$ volume escoado, $m^{3}$

$V_{a}=$ volume afluente, $m^{3}$

$V_{i}=$ volume infiltrado, $\mathrm{m}^{3}$

\section{Volume afluente:}

$\mathrm{O}$ volume afluente é calculado com base na vazão de escoamento, estimada no item A, pelo método racional, e no tempo de precipitação.

Para $\mathrm{T}=2$ anos

$$
V_{a}=Q \cdot t=0,0116 m^{3} / s \cdot 600 s=6,96 m^{3}
$$

Para $\mathrm{T}=5$ anos

$$
V_{a}=Q \cdot t=0,0143 m^{3} / s \cdot 600 s=8,58 m^{3}
$$

\section{Volume infiltrado:}

Estimativa com base no ajuste do modelo de Philip (Equações 3.31 e 3.32) para os Solos 1 e 2:

Solo 1: $\mathrm{I}=\mathrm{Ct}^{1 / 2}=0,00571 \times 600^{1 / 2}=0,14 \mathrm{~m}^{3} / \mathrm{m}^{2}$

Solo 2 : $\mathrm{I}=\mathrm{Ct}^{1 / 2}=0,00698 \times 600^{1 / 2}=0,17 \mathrm{~m}^{3} / \mathrm{m}^{2}$

Conforme as equações 7.4 e 7.5 :

$\mathrm{V}_{\mathrm{i}}=\mathrm{I} \times \mathrm{A}_{\mathrm{inf}}=\mathrm{I} \times 2 \mathrm{LH}$ (supondo a condição de fundo totalmente colmatado)

Para uma trincheira de dimensões $B=0,7 \mathrm{~m}, \mathrm{~L}=10,0 \mathrm{~m}$ e $\mathrm{H}=1,0 \mathrm{~m}$, tem-se, para os solos 1 e 2, a seguinte estimativa de volume infiltrado:

Solo 1: $\mathrm{V}_{\mathrm{i}}=\mathrm{I} \times \mathrm{A}_{\mathrm{inf}}=\mathrm{I} \times 2 \mathrm{LH}=0,14 \times 2 \times 10 \times 1=2,8 \mathrm{~m}^{3}$

Solo $2: \mathrm{Vi}=\mathrm{I} \times \mathrm{A}_{\mathrm{inf}}=\mathrm{I} \times 2 \mathrm{LH}=0,17 \times 2 \times 10 \times 1=3,4 \mathrm{~m}^{3}$

Ao volume infiltrado, soma-se o volume de armazenamento da trincheira, para obter o volume retido total:

Solo 1: $2,8 \mathrm{~m}^{3}+(0,7 \times 10,0 \times 1,0) \times 45 \%=5,95 \mathrm{~m}^{3}$

Solo 2: $3,4 \mathrm{~m}^{3}+(0,7 \times 10,0 \times 1,0) \times 45 \%=6,55 \mathrm{~m}^{3}$

O que corresponde, para um período de retorno de 2 anos, a uma redução de $85,0 \%$ do escoamento superficial no lote, no caso do Solo1, e 94,0 \% no caso do Solo 2. Para o período de retorno de 5 anos, os resultados conduzem a uma redução de $69,0 \%$ no volume de escoamento superficial gerado pelo lote no Solo 1 , e $76,3 \%$ no Solo 2.

O escoamento superficial gerado no lote corresponde a, aproximadamente, $70 \%$ do total gerado em toda a bacia, se for assumida a hipótese simplificadora de homogeneidade de distribuição das parcelas de áreas impermeabilizadas no loteamento todo. Sendo assim, 
o efeito do uso das trincheiras nos lotes, na redução do escoamento superficial em toda a bacia, é de:

Solo 1: $59,5 \%$ para $\mathrm{T}=2$ anos; $48,3 \%$ para $\mathrm{T}=5$ anos.

Solo 2 : $65,8 \%$ para $\mathrm{T}=2$ anos; $53,4 \%$ para $\mathrm{T}=5$ anos.

Esta é a estimativa de redução do escoamento superficial na bacia, devida somente ao uso de trincheiras nos lotes. Técnicas complementares, tais como valas de infiltração em pátios e estacionamentos e calçadas e pavimentos permeáveis nas vias de menor tráfego, podem otimizar a eficiência do sistema de drenagem do loteamento, como um todo. 


\section{CONCLUSÕES E RECOMENDAÇÕES}

O presente trabalho foi conduzido de modo a atender aos objetivos propostos no Capítulo 2. A partir dos resultados obtidos nos experimentos de campo e laboratório e na simulação numérica, pode-se formular algumas conclusões, bem como apresentar propostas para trabalhos futuros.

\subsection{Escolha de dois solos de propriedades hidráulicas distintas e realização de ensaios de campo e laboratório para sua caracterização}

Os Solos 1 e 2 foram escolhidos com o intuito de estudar o comportamento hidráulico das trincheiras em situações propícia e contrária à infiltração. Além disso, por questões de viabilidade prática de execução dos experimentos de campo, procurou-se escolher áreas experimentais localizadas nas proximidades da Escola de Engenharia de São Carlos EESC. No interior do Campus em São Carlos a textura do solo tende a arenosa, e sofre pouca variação nos diversos setores do Campus, de modo que apenas uma área experimental foi instalada neste local. A outra área escolhida pertence também à EESC, mas em uma unidade distante 30 kilômetros da sede, na cidade de Itirapina, às margens da Represa do Broa, onde funciona o Centro de Recursos Hídricos e Ecologia Aplicada CRHEA, da USP São Carlos. Neste local, foi encontrado o solo que mais se aproximou de possuir propriedades distintas do solo do interior do campus. O solo do CRHEA foi denominado Solo 1, e o do interior do Campus na cidade, Solo 2.

Apesar do Solo 1 possuir maior teor de argila e silte que o Solo 2, ele não chega a ser classificado como uma argila; na verdade, os dois solos são arenosos, sendo o Solo 1 menos arenoso, e o Solo 2, mais arenoso. Estes solos permitiram a análise diferenciada das condições de operação das trincheiras. No entanto, ainda permanece uma lacuna a ser preenchida, que é o estudo experimental de trincheiras em condições mais adversas à infiltração, ou seja, em um solo com baixa condutividade hidráulica, da ordem de $10^{-5}$ $\mathrm{cm} / \mathrm{s}$. No entanto, ainda há necessidade de analisar as características de anisotropia local e 
de heterogeneidade textural de ambos solos, em especial quando a condutividade hidráulica é menor. Para isso, recomenda-se futuros estudos experimentais de trincheiras em condições mais adversas à infiltração, com solos com baixa condutividade hidráulica, da ordem de $10^{-5} \mathrm{~cm} / \mathrm{s}$.

A condutividade hidráulica dos dois solos estudados neste trabalho é da ordem de grandeza de $10^{-3} \mathrm{~cm} / \mathrm{s}$.

É desejável que, em trabalhos futuros, sejam buscadas as condições ideais de caracterização dos solos para aplicação de equacionamento disponível na literatura que trata de solos homogêneos. Uma forma eficiente de avaliação desta propriedade é a determinação da curva de retenção do solo, pois, através dela, pode-se obter uma estimativa da distribução dos diâmetros dos poros. Solos "ideais", além de se ajustarem melhor aos modelos de retenção disponíveis na literatura, permitem também melhor calibração dos equipamentos de campo, entre eles a sonda de nêutrons.

\subsection{Realização de experimentos de infiltração em trincheiras para quantificar a variação do volume infiltrado e o desenvolvimento do campo de umidade}

A metodologia utiliazada para a condução dos ensaios com trincheiras de infiltração revelou-se adequada à observação dos dados de interesse. O sitema de transdutores de pressão forneceu valores precisos de lâmina d'água e sua variação no tempo, permitindo o ajuste ao modelo horizontal de infiltração de Philip. A sonda de nêutrons permitiu o acompanhamento instantâneo do perfil de umidade no entorno da seção transversal da trincheira, sem a necessidade de deformação da amostra pelo método gravimétrico convencional.

Os resultados observados permitiram o conhecimento do padrão de comportamento das trincheiras de infiltração para os dois solos estudados, revelando pequena diferença na capacidade de drenagem de ambos. Pode-se concluir que são resultados favoráveis no sentido de confirmar a viabilidade do uso de trincheiras como ferramentas para a redução do escoamento superficial, uma vez que os volumes infiltrados e perfis de umidade observados foram condizentes com a expectativa de boa percolação e redistribuição da água no solo necessária à sua utilização como recurso de armazenamento e disposição das águas pluviais em alternativa ao sistema convencional de drenagem urbana.

Os ensaios com trincheiras experimentais realizados neste trabalho foram conduzidos de modo a avaliar as propriedades hidráulicas das mesmas, em condições préestabelecidas, com volumes aplicados controlados. Para a avaliação da eficiência das 
trincheiras na redução do escoamento superficial, com base em dados experimentais, recomenda-se, em trabalhos futuros, que se proceda a instalação de trincheiras em condições reais de operação, em lotes urbanos, conectadas ao telhado por meio de calhas, preenchidas com brita e revestidas com manta geotêxtil. Deste modo, poder-se-ia, ao longo de um determinado período hidrológico de observação, avaliar, não somente os volumes infiltrados e perfis de umidade, mas também o desgaste da trincheira, a possível perda de eficiência por colmatação, os volumes excedentes encaminhados para a rede de drenagem convencional, e o comportamento em resposta a eventos de chuva sucessivos.

Outro aspecto a ser estudado com relação às trincheiras de infiltração, e que pode ser incorporado em trabalhos futuros e estudos mais detalhados, é a sua utilização como meio de recarga do aqüífero. Esta seria uma vantagem adicional do uso de trincheiras, considerando a importância deste fator, especialmente em bacias que utilizam as águas subterrâneas como principal fonte de abastecimento.

\subsection{Modelagem do fenômeno bidimensional de infiltração em torno de trincheiras e comparação entre os resultados experimentais e numéricos}

A adaptação do modelo de Tabuada et al (1995) para o estudo de trincheiras, formulado originalmente para sulcos de irrigação, foi feita conforme descrito no item 6.1. Os resulados obtidos para as simulações A subestimaram a capacidade de infiltração do solo, especialmente na fase de redistribuição.

Estes resultados podem se dever à forma escalonada da curva de retenção. Os parâmetros da curva de van Genuchten utilizados foram os apresentados na Tabela 5.2 e Figuras 5.3 e 5.4, que são ajustados para todos os pontos observados, e não possuem a mesma precisão do ajuste escalonado, de natureza bimodal de poros em um solo heterogêneo, que não foi introduzida na simulação numérica. A curva de van Genuchten é, juntamente com a equação de Richards', a base do modelo computacional, e divergências no seu ajuste em relação aos dados observados podem conduzir a estimativas também divergentes dos volumes infiltrados e perfis de umidade ao longo do processo de infiltração simulado, em relação ao observado.

Para a simulação B, iniciada em condição de saturação total do perfil, os resultados revelaram que, mesmo partindo de condições saturadas de umidade do solo, as trincheiras são capazes de infiltrar o volume de água equivalente a $40 \%$ de uma precipitação de 25 min e período de retorno de 2 anos, para a cidade de São Carlos, em um lote padrão de 250 
$\mathrm{m}^{2}$ com $60 \%$ de área impermeável. Este é um bom resultado, considerando a condição inicial desfavorável e a propensão do modelo a gerar dados subestimados de infiltração.

Em termos de simulação numérica, as propostas para trabalhos futuros podem ser direcionadas em dois sentidos: incorporar o efeito escalonado das curvas de retenção no modelo computacional, e ampliar a aplicação do software, não somente para prever volumes infiltrados, mas para dimensionar sistemas de infiltração, baseando-se nas considerações do capítulo 7.

Em termos de simulação numérica, as propostas para trabalhos futuros podem ser direcionadas em três sentidos: (1) incorporar o efeito escalonado de solos heterogêneos das curvas de retenção no modelo computacional, (2) ampliar a aplicação do software aqui disponibilizado e (3) avaliação do grau de incertezas das estimativas. Estas premissas são necessárias tanto para prever volumes infiltrados, como também para dimensionar sistemas de infiltração, baseando-se nas considerações do capítulo 7 .

\subsection{Proposta de uma metodologia de dimensionamento de trincheiras de infiltração}

As metodologias apresentadas no capítulo 7 para o dimensionamento de trincheiras de infiltração baseiam-se em dois modelos de infiltração distintos. O primeiro, de Philip, oferece a possibilidade de uma estimativa simples dos volumes infiltrados, e não requer detalhes muito específicos a respeito da dinâmica da água no solo para ser aplicado. O segundo, de Richards', é mais preciso que o primeiro, mas requer conhecimento profundo das propriedades hidráulicas do solo.

Ambos podem ser aplicados em conjunto, como ferramentas no auxílio à decisão nas fases de prognóstico e de projeto de sistemas de infiltração, uma vez que a metodologia de dimensionamento em si é simples, baseada apenas no balanço hídrico na trincheira.

Maiores estudos na área de dimensionamento devem ser conduzidos no sentido de avaliar a viabilidade prática da implantação de sistemas de trincheiras em loteamentos, incluindo principalmente os custos. Com relação a este ítem em particular, os estudos necessários estão relacionados aos custos indiretos, citados na seção 7.5 , e na "popularização" dos métodos e materiais construtivos. 


\subsection{Estimativa simplificada da redução no hidrograma da bacia proporcionada pelo uso de trincheiras de infiltração}

A avaliação feita no capítulo 8 , sobre a redução no hidrograma de cheia de uma micro bacia urbana pelo uso de trincheiras, apesar de simplificada pela utilização do método racional na determinação das vazões, e pela equação de Philip no cálculo dos volumes infiltrados, pode fornecer uma estimativa aproximada da redução no escoamento superficial.

O estudo revelou, considerando os dois tipos de solo estudados no trabalho, reduções da ordem de 85 a $95 \%$ no escoamento superficial gerado no lote, para o período de retorno de 2 anos, e de 70 a $80 \%$ para o período de retorno de 5 anos. A estimativa de redução no escoamento gerado pela bacia como um todo, devido ao uso de trincheiras nos lotes, foi da ordem de 60 a $65 \%$ para 2 anos, e 48 a $53 \%$ para 5 anos.

Esta margem de eficiência pode ser otimizada por meio da aplicação conjunta com outras técnicas de redução do hidrograma de cheia, e por estudos mais elaborados sobre a relação custo $\mathrm{x}$ benefício de sistemas de infiltração de águas de chuva.

Este trabalho se propôs a estudar o tema "trincheiras de infiltração" em alguns de seus principais aspectos, tais como o seu comportamento hidráulico, e métodos de dimensionamento e avaliação da efíciência quando aplicadas em bacias urbanas. Um variado leque de possibilidades se abre com relação aos estudos futuros sobre este tema, e alguns deles foram apresentados nesta seção. Recomenda-se que estas avaliações sejam aprimoradas em condições locais em bacias da região de São Carlos e que sejam incorporadas como tecnologias na escala de lote que favoreçam o gerenciamento integrado em bacias urbanas visando o Plano Diretor respectivo.

Recomenda-se que projetos em andamento, p.ex. "Experimento Piloto de Gerenciamento Integrado de Bacias Urbanas para o Plano Diretor de São Carlos", CTHIDRO FINEP 01.02.0086.00, com interveniência do DAEE/SP continuem e aprimorem esta tecnologia de trincheiras de infiltração em pesquisas futuras. 


\section{REFERÊNCIAS BIBLIOGRÁFICAS}

AKAGAWA, Y.; MATSUMOTO, Y.; ZAIZEN, M. (1997). The inspection of actual runoff control facilities five years after construction. Water Science and Technology, vol. 36, n. ${ }^{\circ} 8-9$, p. 373-377.

ALFAKIH, E.; BARRAUD, S.; MARTINELLI, I. (1999). A study of stormwater infiltration system feasibility and design. Water Science and Technology, vol. 39, n. ${ }^{\circ}$ 2, p. 225-231.

ANDOH, R.Y.G.; DECLERCK, C. (1997). A cost effective approach to stormwater management? Source control and distributed storage. Water Science and Technology, vol. 36, n. ${ }^{\circ} 8-9$, p. 307-311.

ARAÚJO, P.R.; GOLDENFUM, J.A.; TUCCI, C.E.M. Avaliação experimental de pavimentos permeáveis no controle da geração de escoamento superficial. In:XIII Simpósio Brasileiro de Recursos Hidricos, Belo Horizonte, 1999. Anais.

BARBASSA, A. P. (1991). Simulação do efeito de urbanização sobre a drenagem pluvial na cidade de São Carlos - SP. EESC - UUSP, 1991, 327p., Tese (doutorado em hidráulica e saneamento) - Departamento de Hidráulica e Saneamento.

BARNER, W.L. (1999). Comparison of stormwater management in a karst terrane in Springfield, Missouri - case histories. Engineering Geology, vol. 52, p. 105-112.

BARRAUD, S.; AZZOUT, Y.; CRES, F.N. E CHOCAT, B. (1999). Selection aid of alternative techniques in urban storm drainage - proposition of an expert system. Water Science and Technology, Vol. 39, n. ${ }^{\circ} 34$, p. 241-248.

BARRAUD, S.; GAUTIER, A.; BARDIN, J.P.; RIOU, V. (1999). The impact of intentional stormwater infiltration on soil and groundwater. Water Science and Technology, vol. 39, n. ${ }^{\circ}$, p. 185-192.

BIDONE, F.; TUCCI, C.E.M. (1995). Microdrenagem. em Drenagem Urbana, ABRH, ed. da UFRGS, Capítulo 3.

BRAGA, B.; TUCCI, C.E.M. E TOZZI, M., org. (1998). Drenagem Urbana - Gerenciamento Simulação e Controle, ABRH, editora da Universidade Federal do Rio Grande do Sul, 203 p. 
COOMBES, P.J.; ARGUE, J.R.; KUCZERA, G. (1999). Figtree Place: a case study in water sensitive urbana development (WSUD). Urban Water, vol. 1, p. 335-343.

COOMBES, P.J.; KUCZERA, G.; KALMA, J.D.; ARGUE, J.R. (2002). An evaluation of the benefits of source control measures at the regional scale. Urban Water, vol. 4, p. 307-320.

CORDEIRO NETO, O.M. (2004). Gerenciamento do saneamento em comunidades organizadas, Técnicas de minimização da drenagem de águas pluviais. Notas de aula. Universidade de Brasilia.

CRUZ, M.A.S,; TUCCI, C.E.M.; SILVEIRA, A.L.L. (1998). Controle do escoamento com detenção em lotes urbanos. Revista Brasileira de Recursos Hídricos, vol. 3, n. ${ }^{\circ} 4$, out.

ELLIS, J.B.; DEUTSCH, T.C.; MOUCHEL, J.M.; SCHOLES, L.; REVITT, M.D. (2004). Multicriteria decision approaches to support sustainable drainge options for the treatment of highway and urban runorr. Sciende of the Total Environment. /no prelo/.

ELLIS, J.B.; JACOBSEN, T.H. (1996). Urban drainage impacts on receiving waters. Journal of Hydraulic Research, vol. 34, n. ${ }^{\circ}$ 6, p. 771-783.

ELLIS, J. B.; MARSALEK, J. (1996). Overview of urban drainage: environmental impacts and concerns, means of mitigation and implementations policies. Journal of Hydraulic Research, vol. 34, n. ${ }^{\circ} 6$, p. $723-731$.

FERGUSON, B.K. (1995). Store-water infiltration for peak-flow control. Journal of Irrigation and Drainage Engineering, nov./dec., p. 463-466.

FUJITA, S. (1997). Measures to promote stormwater infiltration. Water Science and Technology, vol. 36, n. ${ }^{\circ} 8-9$, p. 289-293.

GEDOLF, G.; JACOBSEN, P.; FUJITA, S. (1994). Urban stormwater infiltration perspectives. Water Science and Technology, vol. 29, n. ${ }^{\circ} 1-2$, p. 245-254.

VAN GENUTCHEN, M.T. (1980). A closed-form equation for predicting the hydraulic conductivity of untaturated soils. Soil Science Society of America, vol. 44, p. 892-898.

GROTEHUMANN, D.; KHELIL, A.; SIEKER, F.; UHL, M. (1994). Alternative urban drainage concept and design. Water Science and Technology, vol. 29, n. ${ }^{\circ} 1-2$, p. 277-282.

HAVERKAMP, R.; VAUCLIN, M., VACHAUD, G. (1984). Error analysis inestimating soil water content from neutron probe measurements: 1. local standpoint. Soil Science, vol. 137, n. ${ }^{\circ}$ 2, p. 78-90.

HUHN, V.; STECKER, A.; (1997). Alternative stormwater management concept for urban and suburban areas. Water Science and Technology, vol. 36, n. ${ }^{\circ}$ 8-9, p. 295-300.

LAWRENCE, A. I.; MARSALEK, J., ELliS, J. B.; URBONAS, B. (1996). Stormwater detention and BMPs. Journal of Hydraulic Research, vol. 34, n. ${ }^{\circ}$ 6, p. $799-813$. 
LIBARDI, P. L. (2000) Dinâmica da água no solo 2.ed. Departamento de Ciências Exatas da Escola Superior de Agricultura Luiz de Queiroz (ESALQ), Universidade de São Paulo (USP), Piracicaba-SP.

LIBARDI, P.L.; REICHARDT, D.R.; NIELSEN, D.R.; BIGGAR, J.W. (1980). Simple field methods for estimating soil hydraulic conductivity. Soil Science Society of American, vol. 44, p. 3-7.

MAKROPOULOS, C.; BUTLER, D.; MAKSIMOVIC, C. (1999). Gis supported evaluation of source control applicability in urban areas. Water Science and Technology, vol. $39, \mathrm{n}^{\circ}$ 9, p. 243-252.

MEHLER, R.; OSTROWXKI, M.W.; (1999). Comparison of the efficiency of best stormwater management practices in urban drainage systems. Water Science and Technology, vol. 39, n. 9, p. $269-276$.

MENDIONDO, E. M. (2001). Contribuições da análise de incertezas para a recuperação ambiental de bacias através da abordagem interdisciplinar de Geobiohidrologia, Tese (Doutorado), IPHUFRGS, Porto Alegre, 287p+anexos.

MIKKELSEN, P.S.; JACOBSEN, P. (1993). Stormwater infiltration design based on rainfall statistics and soil hydraulics. Proc. ASCE International Symposium on Engineering Hydrology, San Francisco, California, July 25-30, pp. 653-658.

MIKKELSEN, P. S.; JACOBSEN, P.; FUJITA, S. (1996). Infiltration practice for control of urban stormwater. Journal of Hydraulic Research, vol. 34, n. ${ }^{\circ}$ 6, p. 827-840.

MIKKELSEN, P.S.; HÄFLIGER, M.; OCHS, M.; JACOBSEN, P.; TJELL, J.C.; BOLLER, M. (1997). Pollution of Soil and Groundwater from infiltration of highly contaminated stormwater - a case study. Water Science and Technology, vol. 36, n. ${ }^{\circ} 8-9$, p. 325-330.

MUALEM, Y. (1976). A new model for predicting the hydraulic conductivity of unsaturated porous media. Wat. Res. Res., v.12, n.6, p.773-870.

OTTO, S.L.R. E ALCAIDE, M. (2001). Utilização do método TDR-Tensiômetro na obtenção da curva de retenção da água no solo. Revista Brasileira de Engenharia Agrícola e Ambiental, vol. $5, n^{\circ} 2, p .265-269$.

PORTO, R. M. (1989). Atenuação de Vazões de Pico em Bacias de Detenção. Revista Brasileira de Engenharia, vol. 7, n. ${ }^{\circ}$ 2, p.05-18.

PORTO, R. L. L. (1995). Escoamento superficial direto. em Drenagem Urbana, ABRH, ed. da UFRGS, Capítulo 4.

PRATT, C. J. (1999). Use of permeable, reservoir pavement constructions for stormwater treatment and storage for re-use. Water Science and Technology, vol. 39, n. ${ }^{\circ}$ 5, p. 145-151. 
SHORT, D.; DAWES, W.R.; WHITE, I. (1995). The practicability of using Richards' equation for general purpose soil-water dynamics models. Environment International, vol. 21, n. ${ }^{\circ} 5$, p. 723-730, set.

SIEKER, F. (1998). On-site stormwater management as an alternative to conventional sewer systems: a new concept spreading in germany. Water Science and Technology, vol. $38, \mathrm{n} .{ }^{\circ} 10$, p. 65-71.

SIEKER, F. E KLEIN, M. (1998). Best management pratices for stormwater-runoff with alternative methods in a large urban catchment in berlin, germany. Water Science and Technology, vol. 38, n. ${ }^{\circ}$ 10, p. $91-97$.

SOTO, M.A.F. (1999). Estudo da condutividade hidráulica em solos não saturados. Dissertação (Mestrado) - Departamento de Geotecnia, Escola de Engenharia de São Carlos, Universidade de São Paulo.

SOTO, M.A.F. (2004). Comparação entre métodos de imposição e de controle de sucção em ensaios com solos não saturados. Tese (Doutorado) - Departamento de Geotecnia, Escola de Engenharia de São Carlos, Universidade de São Paulo

SOUZA, V.C.B. (2002). Estudo experimental de trincheiras de infiltração no controle do escoamento superficial (Doutorado) - Instituto de Pesquisas Hidráulicas, Universidade Federal do Rio Grande do Sul.

TABUAdA, M. A., Rego, Z. J. C., VACHAUd, G. E PEREIRA, L. S. (1995). Twodimensional infiltration under furrow irrigation: modelling, its validation and applications. Agricultural Water Management, vol. 27, n. ${ }^{\circ}$ 8-9, p. 105-123.

TUCCI, C.E.M. (1995). Inundações urbanas. em Drenagem Urbana, ABRH, ed. da UFRGS, Capítulo 1.

TUCCI, C.E.M. E GENZ, F. (1995). Controle do impacto da urbanização. em Drenagem Urbana, ABRH, ed. da UFRGS, Capítulo 7.

VELDKAMP, R.G.; HERMANN, T.; COLANDINI, V.; TERWEL, L.; GEDOLF, G.D. (1997). A decision network for urban water management. Water Science and Technology, vol. 36, n. ${ }^{\circ} 8-9$, pp. 111-115.

WADA, Y.; MIURA, H.; TADA, R.; KODAKA, Y. (1997). Evaluation of an improvement in runoff control by means of a construction of an infiltration sewer pipe under a porous asphalt pavement. Water Science and Technology, vol. 36, n. ${ }^{\circ}$ 8-9, p. 397-402.

WARNAARS, E.; LARSEN, A.V.; JACOBSEN, P. E MIKKELSEN, P. S. (1999). Hydrologic behaviour of stormwater infiltration in a central urban area during $2 \frac{3 / 4}{4}$ years of operation. Water Science and Technology Technology, vol. 39, n. ${ }^{\circ}$ 2, p. 217-224. 
ANEXO I

RELATÓRIO DE ANÁLISE DE SEGURANÇA RADIOLÓGICA DO LABORATÓRIO DE HIDRÁULICA AMBIENTAL 


\section{LABORATÓRIO DE HIIDRÁULICA AMBIIENTAL}

CRHEA - CENTRO DE RECURSOS HÍDRICOS E ECOLOGIA APLIDADA ESCOLA DE ENGENHARIA DE SÃO CARLOS - USP 


\section{INTRODUÇÃO}

$\mathrm{O}$ presente relatório tem por objetivo o credenciamento, junto à $\mathrm{CNEN}$, do Laboratório de Hidráulica Ambiental do CRHEA - Centro de Recursos Hídricos e Ecologia Aplicada, da Escola de Engenharia de São Carlos - USP, de modo a viabilizar, em suas atividades de pesquisa, o uso de fontes radioativas seladas.

Neste laboratório são desenvolvidas pesquisas diversas nas áreas de dinâmica dos fluidos, hidráulica e recursos hídricos, entre as quais destacam-se as abaixo mencionadas, nas quais o uso da radiação tem se revelado de grande utilidade na obtenção de dados precisos e rápidos, sem provocar intervenção nos fenômenos observados ou nas amostras analisadas. Alguns dos experimentos realizados são:

Determinação do perfil de umidade e densidade do solo: A medida da umidade do solo é comumente feita em laboratório, via método gravimétrico, com o uso de uma estufa e uma balança, na qual se pesa a amostra de solo com a umidade natural e após secagem; calcula-se, então, através da diferença entre as duas, a massa de água existente. No entanto, uma vez feita esta determinação, torna-se inviável estimar novamente a umidade da mesma porção de solo, uma vez que este foi removido e deformado. Quando se deseja acompanhar a variação da umidade em um processo de infiltração, é necessária uma ferramenta para observação do processo transiente em um determinado ponto ou perfil de solo. Ultimamente a física dos solos vem contando com o uso de técnicas radioativas na quantificação de diversas variáveis envolvidas no processo de movimento da água em meios porosos. Estas técnicas consistem, basicamente em medir a atenuação de um feixe radioativo incidente sobre a amostra. Por apresentarem características adequadas ao estudo da dinâmica da água no solo, os radioisótopos Césio-137 e Amerício-241 vêm sendo utilizados com freqüência em tais medidas. Para tanto, lança-se mão de um equipamento conhecido como "sonda de nêutrons", que possui as vantagens de operar a grandes profundidades, fornecer respostas imediatas sem a necessidade de análises de laboratório, sem destruir as características estruturais do solo, possibilitando repetidas medições no mesmo ponto. As especificações técnicas deste equipamento serão detalhadas mais adiante. Determinação da Concentração de Âr ou Outras Substâncias em Fluidos: Em estudos hidráulicos, ou na dinâmica dos fluidos em geral, é comum a necessidade de determinar a concentração de uma substância no fluido em movimento. Mais uma vez, a medição em 
laboratório, pelos métodos tradicionais de coleta e análise de amostras, compromete a confiabilidade das medidas, tanto durante amostragem, por provocar interferência no escoamento, como também na análise, por ser uma medida pontual, não representativa das condições reais de concentração no fluido. Novamente, encontrou-se nas técnicas radioativas a solução para o problema de determinar a concentração em condições de medição externas ao escoamento, e, portanto, não interferindo no mesmo. Analogamente ao processo de determinação do perfil de umidade do solo, a metodologia consiste na medida da atenuação de um feixe de radiação gama, ao atravessar o escoamento em estudo. No caso do laboratório do CRHEA, utiliza-se um sistema composto por uma fonte de Césio -137 e um detetor, cujos detalhes de projeto serão especificados adiante.

\section{CLASSIFICAÇÃO DA INSTALAÇÃO RADIOATIVA (CONFORME NORMA CNEN-NE 6.02)}

O Laboratório de Hidráulica Ambiental enquadra-se, de acordo com sua área de atividade e fontes radioativas utilizadas, no item 4.1.3. da norma CNEN-NE 6.02:

Grupo III - Instalações que utilizam fontes seladas para fins outros que não os citados em 4.1.1 e 4.1.2.

De acordo com esta classificação, faz-se necessária a obtenção, junto à CNEN, de duas autorizações:

- para aquisição de material radioativo;

- para operação. 
3. PROJETO FÍSICO DO LABORATÓRIO E ÁREAS RESTRITAS 


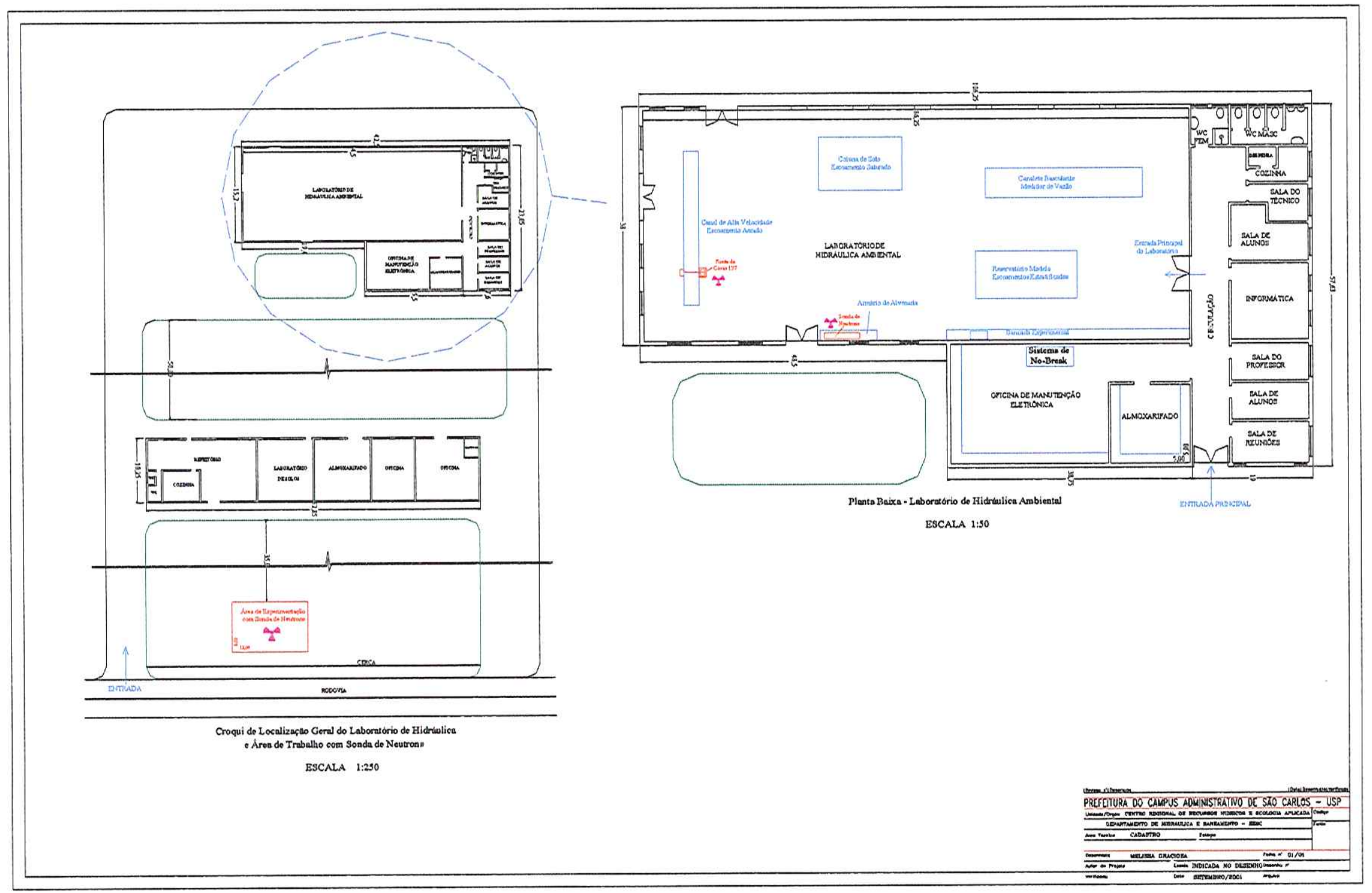




\section{EQUIPAMENTOS E FONTES DE RADIAÇÃO}

\subsection{Sistema de Emissão/Deteç̧ão de Radiação Gama (Fonte de Césio-137)}

O Laboratório de Hidráulica Ambiental conta com um sistema de medição da concentração em fluidos por absorção de radiação gama, projetado e construído pela equipe do próprio laboratório, em 1980.

Trata-se, basicamente, de uma fonte de $\mathrm{Cs}-137$, com $300 \mathrm{mCi}$ de atividade inicial em 01/1980. O material radioativo está inserido em uma cápsula de aço, mantida dentro de uma proteção de chumbo, a qual é dotada de um dispositivo de abertura que permite a saída do feixe colimado. Alinhado ao colimador de saída, o sistema possui um detetor de cristal de cintilação de iodeto de Sódio de $2,5 \mathrm{~cm}$ de diâmetro por $2,5 \mathrm{~cm}$ de espessura, ativado com $1 \%$ de iodeto de Tálio. Este cristal fíca acoplado a um tubo fotomultiplicador, gerando impulsos que são analisados e contados em um sistema monocanal. A blindagem de chumbo em torno da cápsula é de $12,5 \mathrm{~cm}$, em qualquer direção. A figura 4.1. ilustra o sistema descrito.

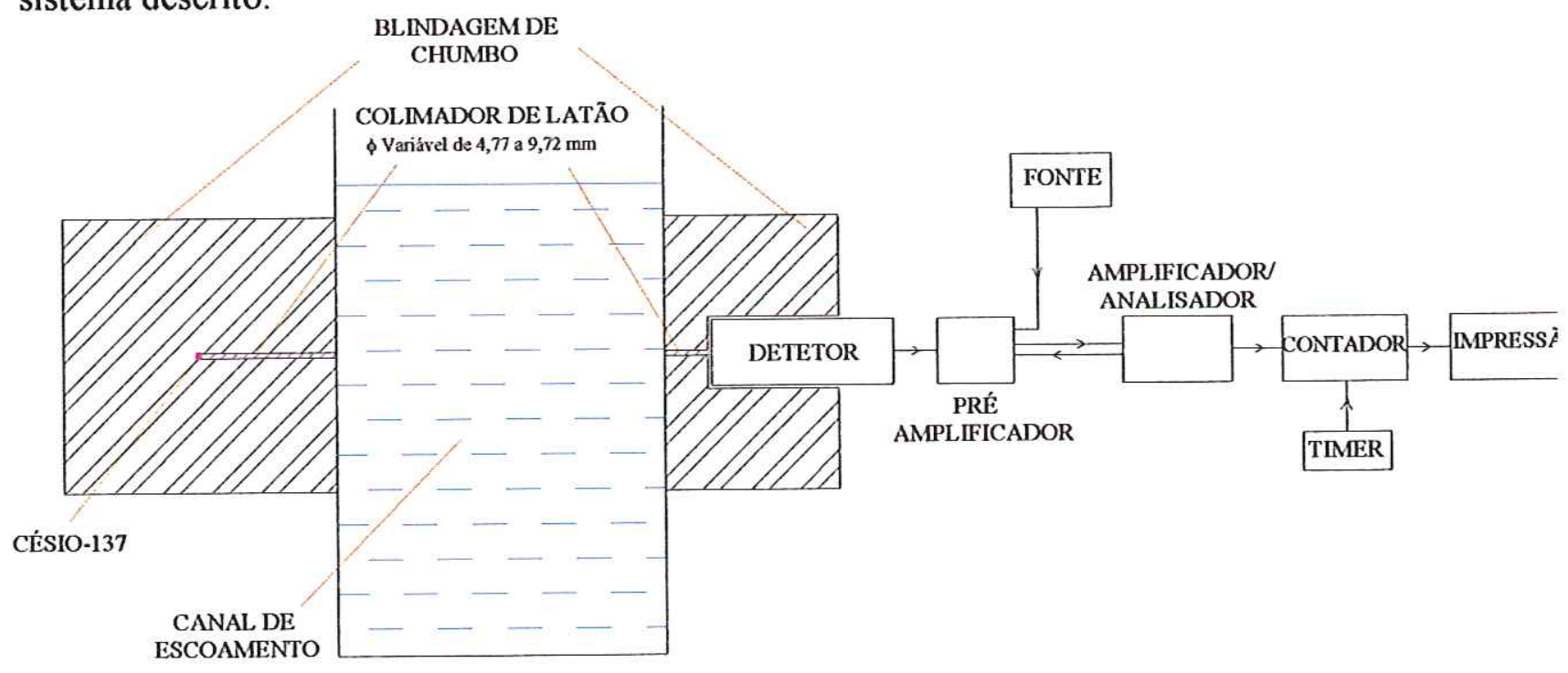

Figura 4.1 - Esquema geral de funcionamento do sistema emissor/detetor de radiação gama. 

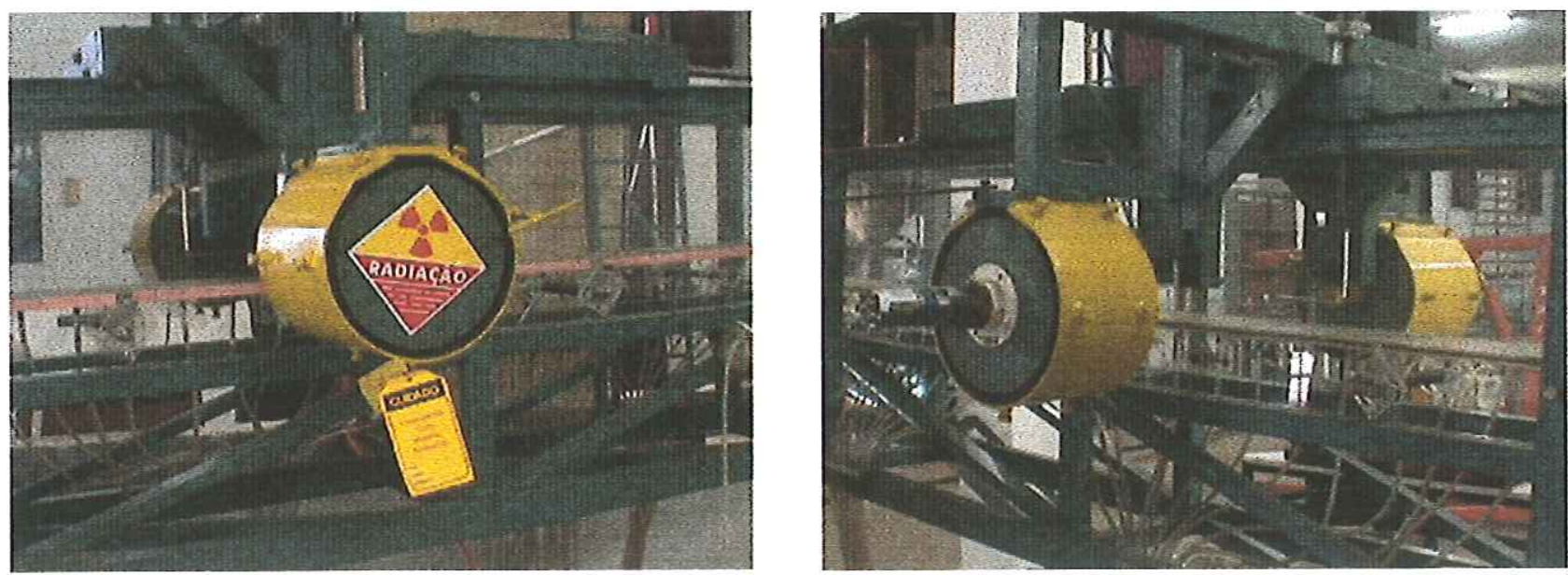

Figuras 4.2. e 4.3.. - Fotografias do sistema instalado no canal de experimentação hidráulica.

Ressaltamos que todas as pessoas diretamente envolvidas com o uso do equipamento acima (técnico do laboratório e alunos de pós graduação) são submetidos a dosimetria constante, sendo que os valores registrados mensalmente nos dosímetros encontram-se sempre abaixo do nível registro de $0,2 \mathrm{mSv}$.

\subsection{Sonda de Nêutrons}

O Laboratório de Hidráulica Ambiental do CRHEA possui uma sonda de nêutrons para a determinação da umidade do solo em condições de campo. Este equipamento consiste de uma fonte radioativa, um detetor, um circuito eleltrônico para amplificação de sinais conectado a um mostrador digital e um tubo de acesso instalado no solo. Para a medição, o equipamento é posicionado sobre o tubo instalado verticalmente no solo, no interior do qual insere-se a sonda até a profundidade desejada, por meio de um cabo que faz a interligação entre a fonte radioativa e os componentes eletrônicos. O princípio de funcionamento do equipamento é baseado na propriedade de moderação de nêutrons rápidos pela água presente no solo. A fonte radioativa, constituída por uma cápsula de Amerício-241:Berílio, emite nêutrons rápidos, que ao colidir com os núcleos de átomos de hidrogênio presentes no solo, tornam-se lentos, ou termalizados. Por não possuir carga elétrica, os nêutrons não podem ser detectados diretamente; mas podem ser absorvidos pelo núcleo dos átomos de um gás (Boro Trifluorídrico ou Hélio-3), o qual torna-se um emissor de fótons, que por sua vez podem ser facilmente detectados por um dispositivo eletrônico adequado. Os pulsos elétricos gerados são conduzidos à superfície, ampliados e 
apresentados no mostrador em forma de contagem. A umidade do solo é obtida com o emprego de uma curva de calibração que expressa a relação entre contagens e umidade volumétrica, sendo definida para cada tipo de solo. Abaixo, fotografias do equipamento.
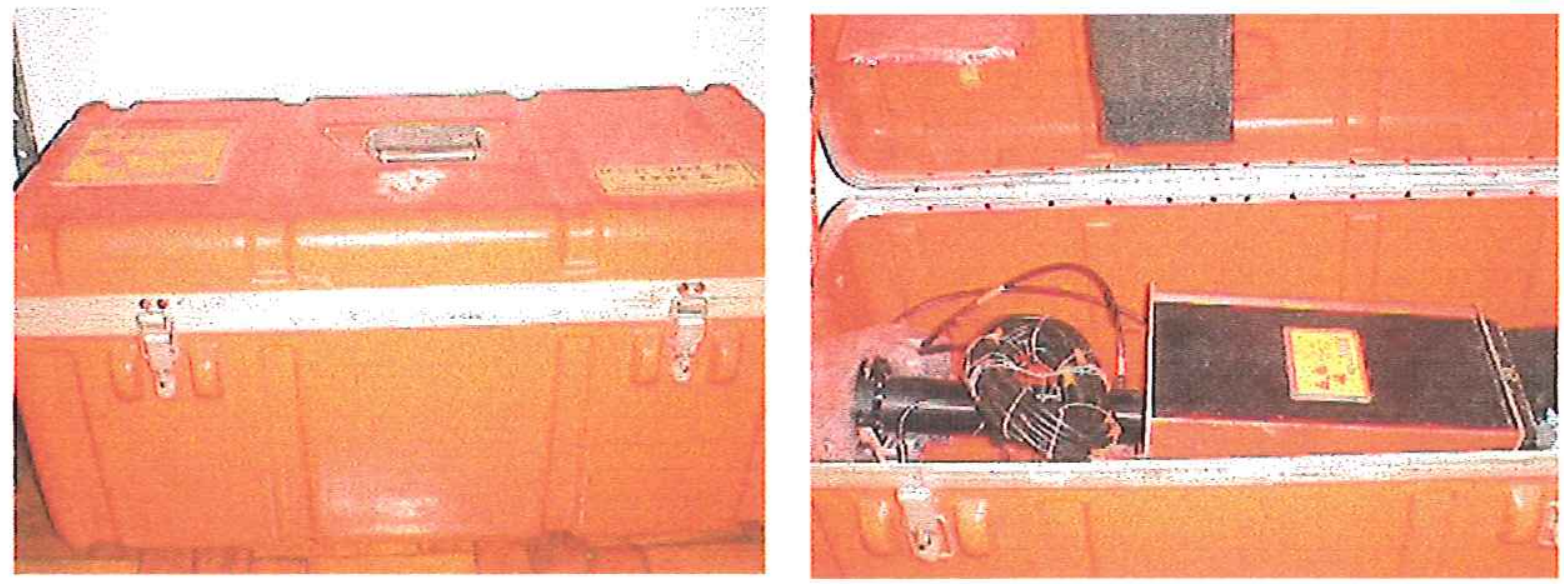

Figuras 4.4. e 4.5. - Sonda de nêutrons no interior da caixa de proteção.

A atividade inicial da fonte radioativa da sonda acima era de 10 mCi de Cs-137 em 12/06/83, com energia de $662 \mathrm{KeV}$, e $50 \mathrm{mCi}$ de Am-241:Be em 01/09/84, com energia de $60 \mathrm{KeV}$.

Os responsáveis pela operação do equipamento possuem curso de radioproteção no uso de fontes radioativas.

\section{PLANO DE OPERAÇÕES}

\subsection{Controles Administrativos}

O responsável pela radioproteção do laboratório, Prof. Dr. Fazal Hussain Chaudhry, vem executando as seguintes tarefas:

- implementar e orientar os procedimentos de radioproteção;

- garantir exposições tão baixas quanto razoavelmente exeq6uíveis;

- elaborar e manter atualizadas as instruções operacionais e de emergência;

- treinar o pessoal envolvido com as atividades do laboratório.

\subsection{Condução das Operações}


A tabela abaixo traz a relação de todos os atuais usuários do Laboratório de Hidráulica Ambiental, com suas respectivas funções:

\begin{tabular}{|l|c|c|}
\hline \multicolumn{1}{|c|}{ NOME } & FUNÇÃO & FORMAÇÃO \\
\hline Harry Edmar Schulz & Professor Titular & Doutorado \\
\hline Fazal Hussain Chaudhry & Professor Titular & Doutorado \\
\hline Osni Aparecido Rizato & Técnico & $2 .^{\circ} \mathrm{Grau}$ \\
\hline Selma Vargas da Silva & Aluna pós-graduação & Doutoranda \\
\hline Alberto Carlos M. Lima & Aluno pós-graduação & Doutorando \\
\hline Melissa C. P. Graciosa & Aluna pós-graduação & Mestranda \\
\hline
\end{tabular}

As seguintes instruções gerais, relativas à segurança no trabalho com as fontes, são transmitidas por escrito, a todos os usuários:

- Usar dosímetro durante todo o tempo em que estiver executando trabalhos com as fontes radioativas;

- Planejar toda a seqüência de passos do trabalho a ser realizado, de modo a minimizar o tempo de exposição;

- Sempre que possível, fazer uma simulação do experimento a ser realizado, antes de trabalhar efetivamente com a fonte, providenciando antecipadamente todo o material a ser utilizado no experimento;

- Manter a Sonda de Nêutrons guardada na caixa protetora, dentro do armário específico para esse fim, trancado, durante todo o tempo em que não estiverem sendo realizadas medições;

- Não permitir a aproximação de indivíduos estranhos ao experimento quando estiverem sendo utilizadas as fontes radioativas.

\subsection{Programa de Treinamento e Procedimentos de Radioproteção Adotados}

A principal medida de radioproteção adotada, consiste da restrição ao acesso às áreas onde se utiliza os equipamentos radioativos. O laboratório permanece trancado, sendo que o acesso é permitido somente aos alunos de pós-graduação que nele desenvolvem atividades 
de pesquisa, aos professores responsáveis e ao técnico. Todas as portas do laboratório possuem sinalização de radioatividade.

A sonda de nêutrons é um equipamento de utilização em experimentações de campo nas imediações do laboratório; quando não está em uso, permanece guardada no interior do laboratório, em um armário de alvenaria trancado e sinalizado.

Todo novo usuário do laboratório será informado da existência e utilidade das fontes existentes, bem como dos procedimentos de utilização e proteção radiológica a elas pertinentes. A instituição oferece, periodicamente, cursos de radioproteção, e os usuários dos equipamentos radioativos são convidados a freqüentá-los. Atualmente, todos os usuários possuem certificados recentes de participação nestes cursos.

O laboratório é mantido trancado durante todo o tempo em que não está em atividade, e possui sistema de alarme. No entanto, a CNEN será imediatamente comunicada sobre qualquer ocorrência comprometedora, tais como roubo ou avaria das fontes.

O pessoal interno é treinado para o controle de pequenos incêndios que porventura venham a ocorrer, embora não se utilize substâncias inflamáveis nas atividades normais do laboratório. Em caso de ocorrência de incêndio de maiores proporções, o corpo de bombeiros será acionado e comunicado sobre a existência e a localização das fontes radioativas.
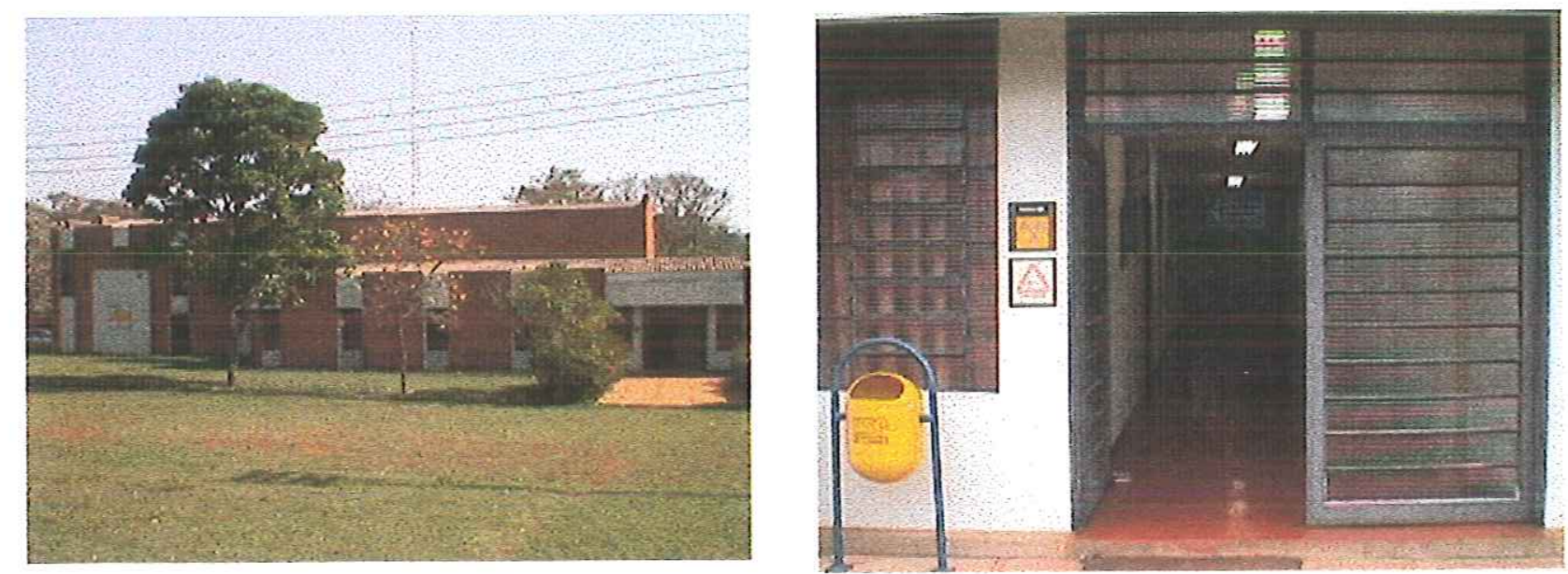

Figuras 5.1 e 5.2 - Vista geral e da entrada do setor do CRHEA onde está instalado o Laboratório de Hidráulica Ambiental. 

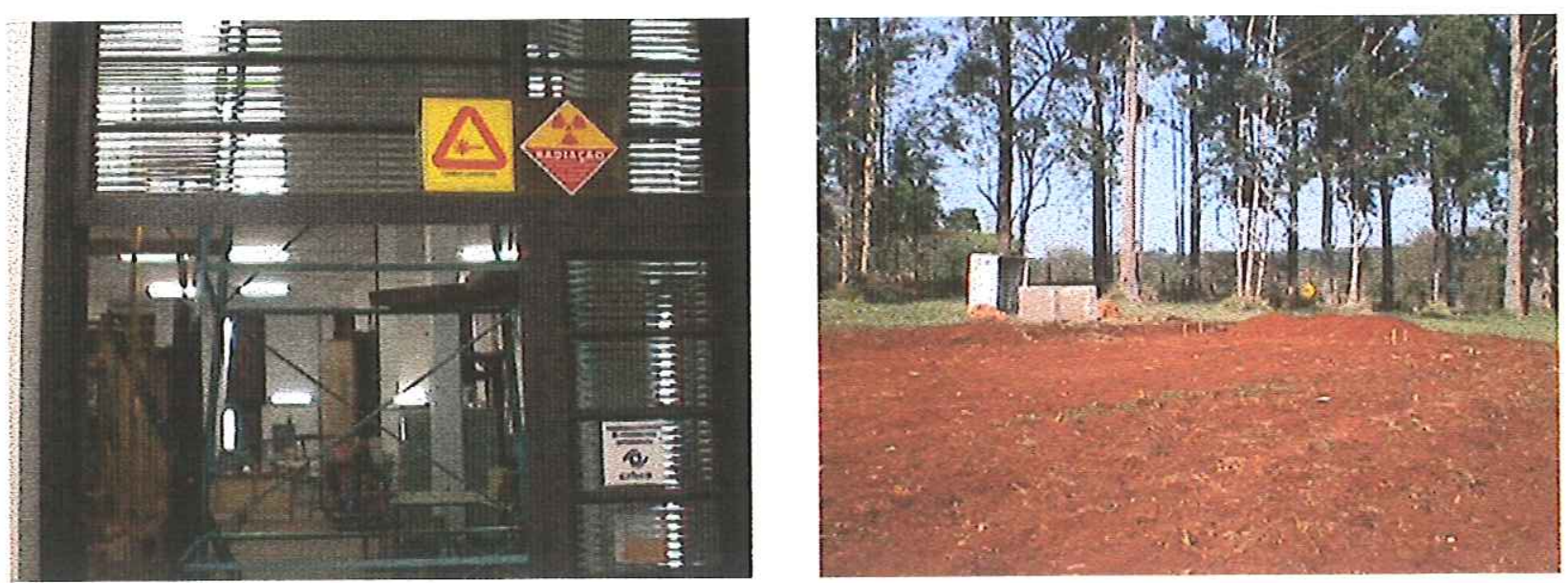

Figuras 5.3. e 5.4. - Principal porta de acesso do Laboratório de Hidráulica; Área de estudo do solo e utilização da sonda de nêutrons, a $100 \mathrm{~m}$ do laboratório.

\section{GERENCIA DE REJEITOS}

Devido à própria natureza das fontes radioativas existentes - fontes seladas - não há geração de rejeitos radioativos. Estes só existirão quando da desativação das instalações do laboratório, e consistirão dos próprios equipamentos existentes. Nesta ocasião, serão seguidos todos os procedimentos de retirada de operação constantes do item 13 da norma CNEN NE 6.02. e outros quantos forem pertinentes ao encaminhamento adequado das fontes a serem desativadas. 
ANEXO II

REGISTRO PESSOAL, JUNTO À CNEN, PARA OPRERÇÃO DE MATERIAL RADIOATIVO E REGISTTRO DO LABORATÓRIO DE HIDRÁULICA AMBIENTAL 
Oficio n $1716 / 2002$ - CORAD/CNEN

Rio de Janeiro, 08 de julho de 2002

Sisdoc- $11057 / 02,3785 / 02,1034 / 02$

\section{Assunto: Registro para aplicaçăo em pesquisa}

Prezada(a) Senhor(a),

Vimos pela presente informar que foi concedido a V.Sa., um registro para uso de pequenas quantidades de radioisótopos na área de aplicaçäo em pesquisa, registro: AP-0971, por terem sido cumpridos os requisitos contidos na Norma CNEN-NN-6.01 publicada no D.0.U de 16 de oulubro de 1997.

Este registro é válido por 05 (cinco) anos, a partir da presente data, devendo a revalidaçäo ser requerida com 01 (um) mês de antecedencia, mediante formulàrio proprio, disponivel em nosso site www.cnen.gov.br.

Outrossim, esclarecemos que o registro para uso näo implica necessariamente na autorizaçāo para aquisição de radioisótopos, conforme previsto na Norma CNEN-NE6.02 , sendo apenas um dos pré-requisitos exigidos.

Outros pré-requisitos detalhados nas Normas especificas também devem ser atendidos de forma a permitir que a CNEN autorize a aquisiçăo diretamente à entidade juridica à qual V.S.a. encontra-se vinculado.

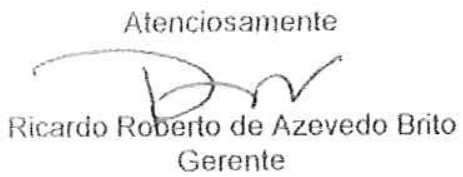

Coordenaçäo de Instalaçōes Radiativas

Ilmo(a). Sr.(a).

MEI ISCA CRICTINA PFRFIRA GRACINGA

Av. Trabalhador Säo-cartense, 400 - Centro

Săo Carlos - SP

$13566-590$ 
(ivedic $9812 m 2$

Rio de Janciro. 31 de julho de $2900 ?$

Assumto : Registro

Informamos que cssa cntidade csta registrada nesta Coordenaçio de Instalaçöes Radiativas (CORAD). com os semintes dados:

Ares: l'esquisa

Processo on (0) 28x/2(10)2 Matricula: 14072

Especialidade: Laboratorio de Pesquisa de Pequeno Porte

Prohissional Responsivel : Fazal Hussain Chaudhry

Radioisotopos e Quantidades: ${ }^{137} \mathrm{Cs}-310 \mathrm{mCi}$, ${ }^{21} \mathrm{Am}-\mathrm{Be}-50 \mathrm{mCi}$

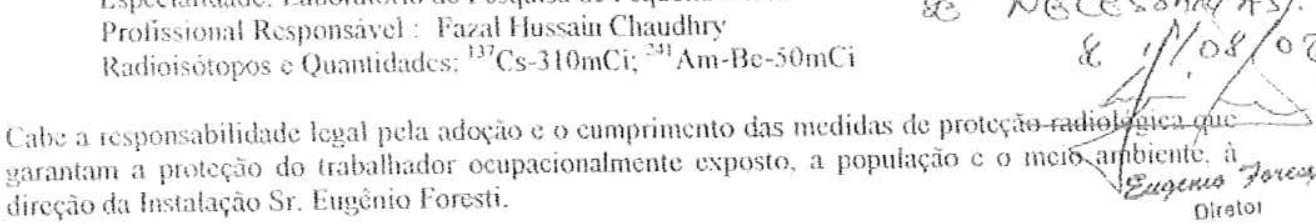

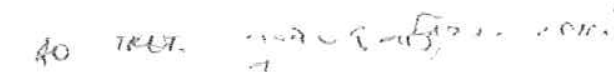

O năo cumprimento dos requisitos estabelecidos tanto no Plano de Radioproteçào como nas Normas da CNLN podera acarretar o cancelamento do Registro.

Quando a cntidade ja tiver submetido o Plano de Radioproteçào, porém pleitear a aquisiçào de umá fonte de radiação cujo uso nảo esteja previsto no Plano original, deve ser submetida complementaça sob forma de revisaio dos aspectos cspecificos de segurança radiológica para a nova prática.

Quando howver qualquer modiftcaçâo nas condiçóes expostas neste documento, deverá ser solicitada a Alteração de Registro, mediante requerimento próprio (SCRA), disponivel em www cnen.gov. br.

Quando as atividades com material radioativo forem encerradas esse laboratorio deverá solicitar o Cancelamento de Registro mediante requerimento proprio (SCRA), disponivel en wivenengov. br.

Atenciosamente.

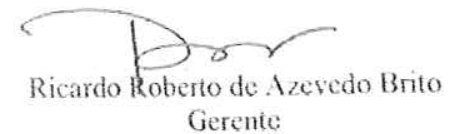

Coordenaçăo de Instalaçōes Radiativas

\{im Si. Eugenio Foresti

(6)

OGIA APLICADA - CRHEA - 14072 f $1001.288 / 021$

ta Trabalhador São Carlense, 400 - Centro

590 - Sào Carlos - SP 
ANEXO III

CÓDIGO FONTE DO MODELO DE INFILTRAÇÃO 


\section{PROGRAMA PRINCIPAL}

PROGRAM BIDISUL

This program calculates the soil moisture profile around the section of a short

irrigation furrow, during and after the irrigation process. It gives information

on the position of the wetting front in the soil with time, thus allowing the

quantification of the water stored in the root zone. It was developed by Tabuada

M.A. et al, in 1995, and published on the paper "Two-dimensional infiltration unde furrow irrigation: modelling, its validation and applications", at Agricultural Water Management 27, 105-123.

The program uses the two-dimensional Richards' equation.

The function $\mathrm{h}=\mathrm{f}(\mathrm{theta})$, where $\mathrm{h}$ is the matric potential and theta is the soil

moisture content, is gaven by Van Genuchte equation.

The function $k=f(t h e t a)$, where $k$ is the hydraulic conductivity and theta is the soil moisture content, is gaven by the exponencial equation $k=k 0^{*} \exp \left(g a a^{*}\right.$ (theta-thetas)) where ko is the saturated hydraulic conductivity, thetas is the saturated moisture, and gama is a parameter empirically adjusted.

The infiltration process is divided in three distict fases:

The Fase 1 means the advance and supply fases, occurring when water is supplied into the furrow.

The Fase 2 means the recession fase, occurring when water infiltrates, after cut-off.

The Fase 3 means the redistribution fase, occurring when water moves in the soil after
The faster infiltration ended.

It's cosidered that: water and soil are incompressible, the soil is homogeneous and isotropic, the hysteresis is not considered.

The time interval between two consecutive isopotential lines heve to be the same that the interval since the irrigations begining, when $t=0$, untill the end of Fase 1.

The input of this software is two files: the first one contains the initial values of the matrical potencial $h$ for the first column of the domain; the second one contais the values of the variables that are read in the subroutine ReadData, and it es called the values of the variables that are read in the subroutine ReadData, and it es called
dados.dat. Both have status "old", so they must exists before running the program, at the same directory of the .exe file.

The output of this software is the file containing the values of the soil moisture content in each node of the domain, at each instant of the process, as well the file halt.dat containig the infiltrated volumes at each time intervals. Both have status "old", so they must exists before running the program, at the same directory of the .exe file.

REAL KAPA $(200,200)$, LAG,LPR

C INTEGER FLAG INTEGER FLAGTEST

COMMON /bisimul/ il, im

DIMENSION HI(200,200), TETAI $(200,200), C(200,200), H(200,200)$,

${ }^{*} \operatorname{AIJ}(200,200), \operatorname{BIJ}(200,200), \operatorname{DIJ}(200,200), \operatorname{EIJ}(200,200)$,

*FIJ $(200,200)$, GIJ $(200,200)$, HM $(2000,2000), \mathrm{H} 1(2000)$.

*TETA $(200,200), X(200), Y(200)$

CHARACTER FIC $1 * 5$, FICH1 19, FIC2 $2 * 5$, FICH2 29 , NUMERO $(400) * 3$, NOMEFI* 13

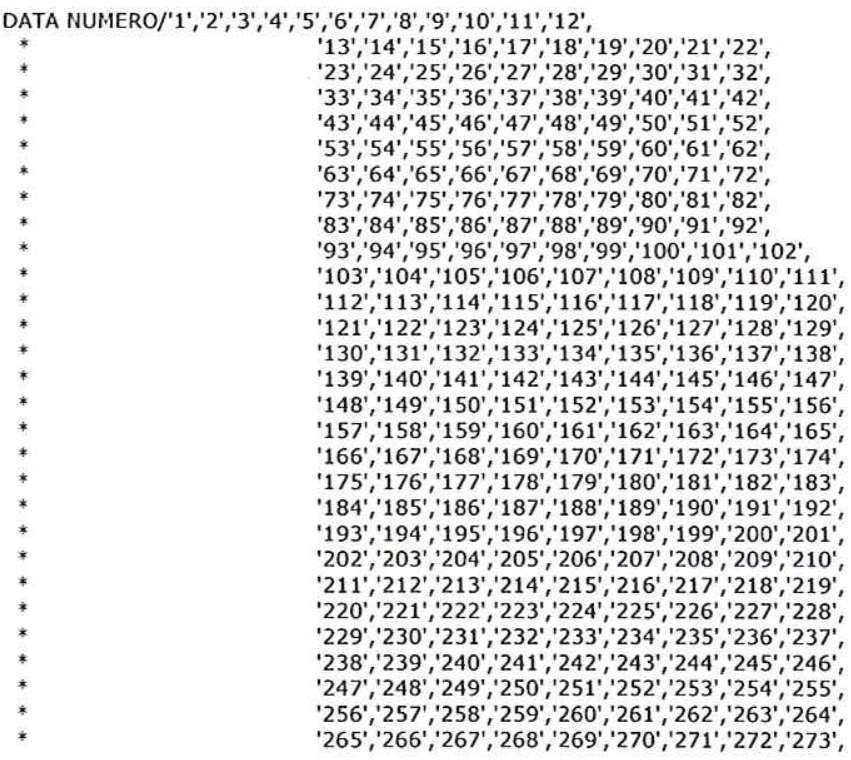




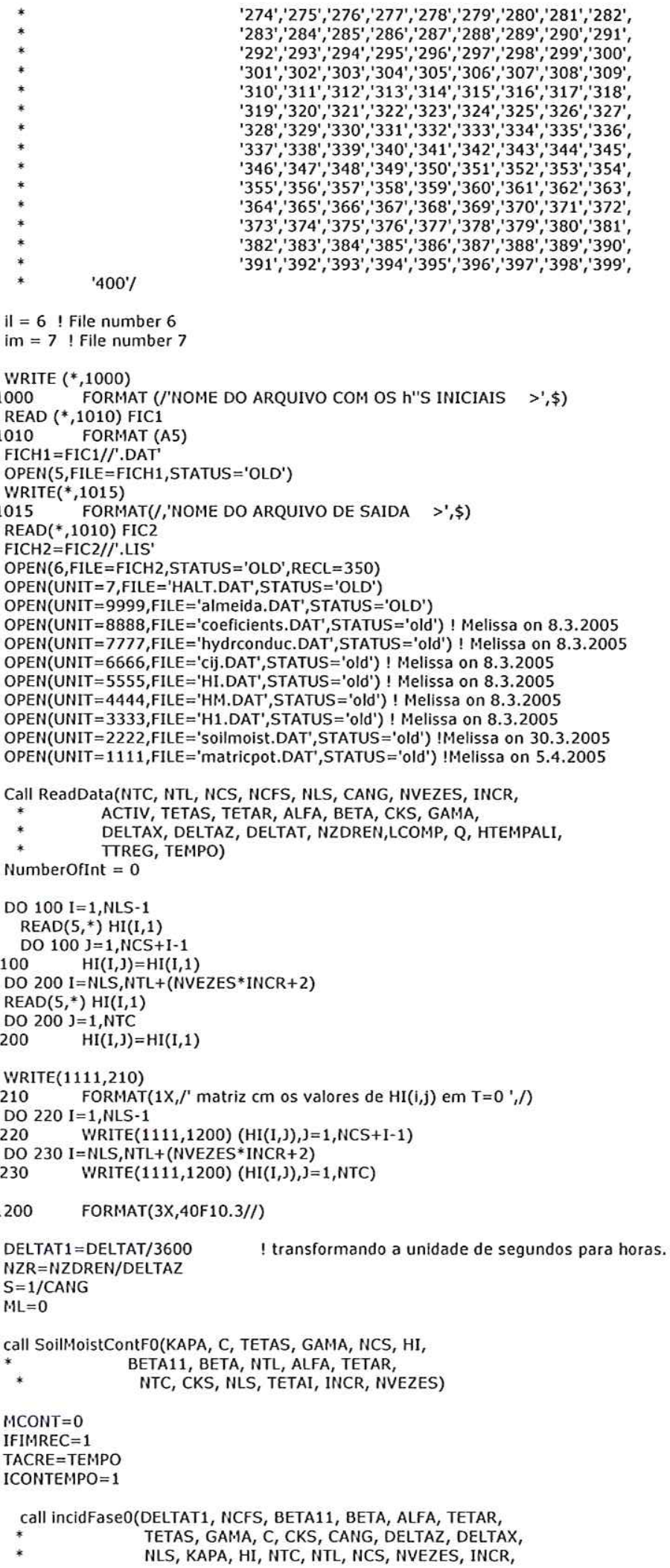




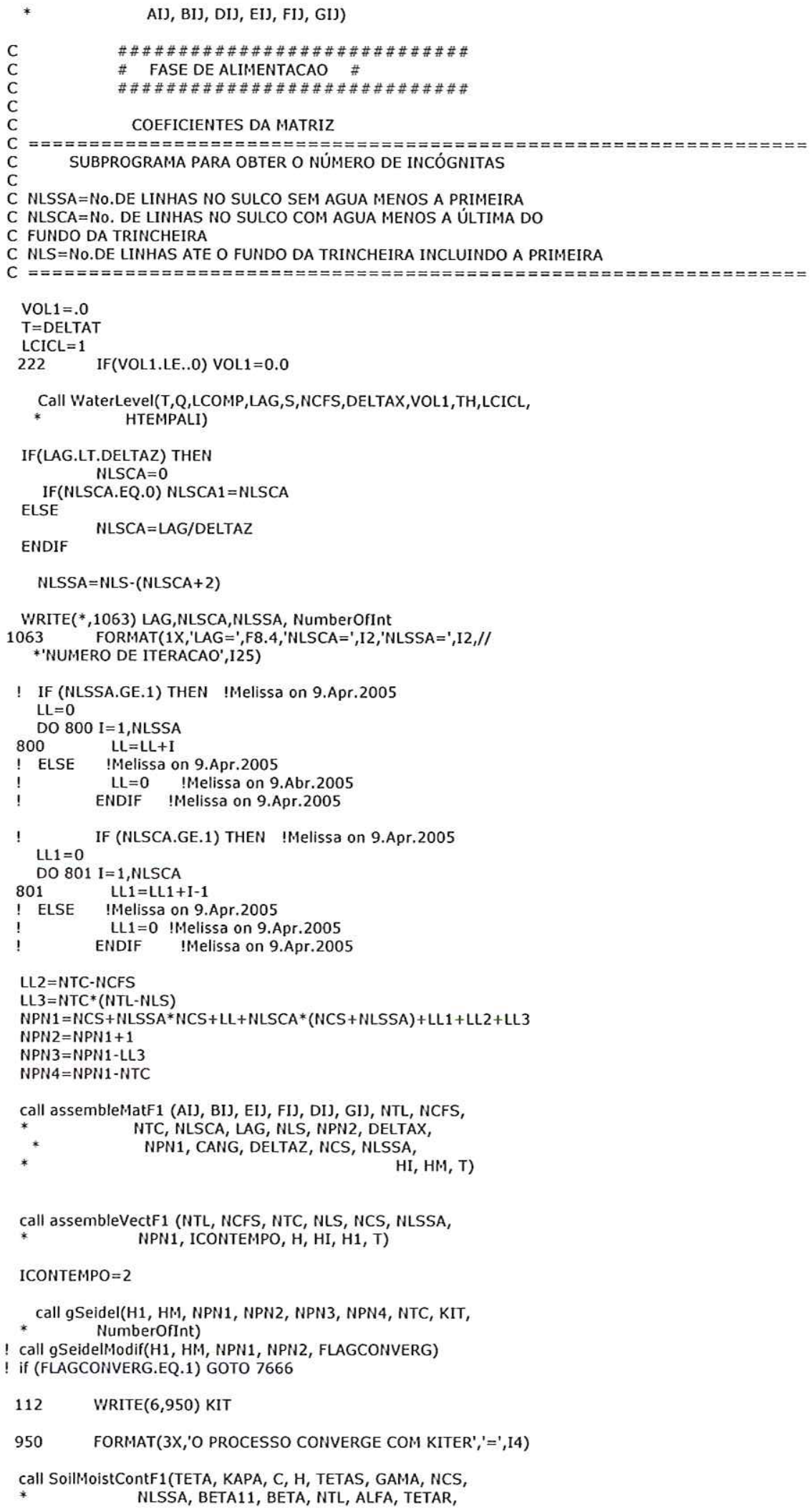




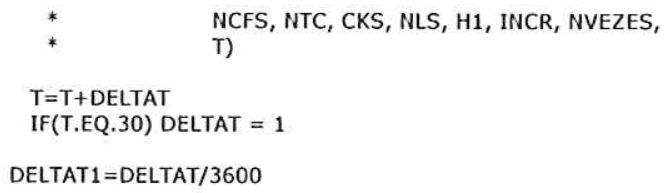

call WaterVolumeF1(NLSSA, TACRE, HTEMPALI, LAG, NTL, LCOMP,

* DELTAZ, DELTAX, T, NCFS, TETAS, NLS, NCS,

* NTC, $X, Y$, NOMEFI, NUMGRO, TETAI, $H, H I$

ML, TEMPO, TETA, VOL1, NTC1, DIF, VOL)

call IncrLinesF1 (HM, NCS, NLS, NCFS, NLSCA, NLSSA, GAMA,

* CKS, BETA11, BETA, ALFA, TETAR, TETAS, C,

NTS, INCR, ACTIV, H, HI, TETA, KAPA, DIF,

NTL, NPN1, NPN2, NPN3, NPN4)

IF(LCICL.EQ.2) GOTO 377

call incidFase1(DELTAT1, NCFS, BETA11, BETA, ALFA, TETAR, H,

* TETAS, GAMA, C, CKS, CANG, DELTAZ, NLSSA,

* DELTAX, NLS, KAPA, HI, NTC, NTL, NCS, AIJ,

BIJ, DIJ, EIJ, FIJ, GIJ, NVEZES, INCR, T)

DO $74455 \mathrm{I}=1, \mathrm{NPN} 3$

DO $74455 \mathrm{~J}=1, \mathrm{I}+\mathrm{NTC}$

$74455 \quad H M(1,3)=0$

DO $74466 \mathrm{I}=\mathrm{NPN} 3+1$,NPN 4

DO 74466 J $=I-N T C, I+N T C$

$74466 \quad H M(I, J)=0$

DO $74477 \mathrm{I}=\mathrm{NPN} 4+1$,NPN1

$\begin{array}{ll} & \text { DO } 74477 \mathrm{~J}=1-N T C, N P N 1 \\ \operatorname{HM}(I, J)=0\end{array}$

DO $74488 \mathrm{I}=1$, NPN 1

$74488 \quad H M(I, N P N 2)=0$

$\mathrm{LCONT}=\mathrm{LCONT}+1$

IF(LAG.LE.HTEMPALI.OR.LCICL.EQ.1) GOTO 222

1066 call assemblematF2 (AI), BI), EI), FI), DIJ, GI), NTL, NCFS,

* NTC, NLSCA, LAG, NLS, NPN2, DELTAX, T,

* NPN1)

CANG, DELTAZ, NCS, NLSSA, HI, LPR, HM,

call assembleVectF2 (NTL, NCFS, NTC, NLS, NCS, NLSSA

* NLSCA, H, H1, NPN1, T)

call gSeidel(H1, HM, NPN1, NPN2, NPN3, NPN4, NTC, KIT,

* NumberOfInt)

!call gSeidelModif(H1, HM, NPN1, NPN2, FLAGCONVERG)

!if (FLAGCONVERG.EQ.1) GOTO 7666

8112

WRITE $(6,1950)$ KIT

1950

FORMAT(3X,'O PROCESSO CONVERGE COM KITER','=',I4)

call SoilmoistContF2(TETA, KAPA, C, H, TETAS, GAMA, NCS,

* NLSSA, BETA11, BETA, NTL, ALFA, TETAR,

* NCFS, NTC, CKS, NLS, H1, INCR, NVEZES,

* T, DELTAZ, LAG, NLSCA, NPN1, NPN2,

NPN3, NPN4, HM)

call WaterVolumeF2(TETA, DELTAT, TETAS, NTL, NLSSA,

* NCS, NLS, DELTAZ, DELTAX, NCFS,

CANG, TACRE, LCOMP, $X, Y$, NOMEFI,

NUMERO, TETAI, H, HI, LAG, ML, NTC,

TEMPO, VOL1, DIF, T, DELTAT1, NTC2,

T2, VOLR, VOL)

call IncrLinesF2 (HM, NCS, NLS, NCFS, NLSCA, NLSSA, GAMA

* CKS, BETA11, BETA, ALFA, TETAR, TETAS, C,

* NTC, INCR, ACTIV, H, HI, TETA, KAPA, DIF,

NTL, NPN1, NPN2, NPN3, NPN4)

IF(LAG.LE.0.1) GOTO 1006

! AQUI COMEÇA A FASE 2

377 call incidFase2(DELTAT1, NCFS, BETA11, BETA, ALFA, TETAR, H, 


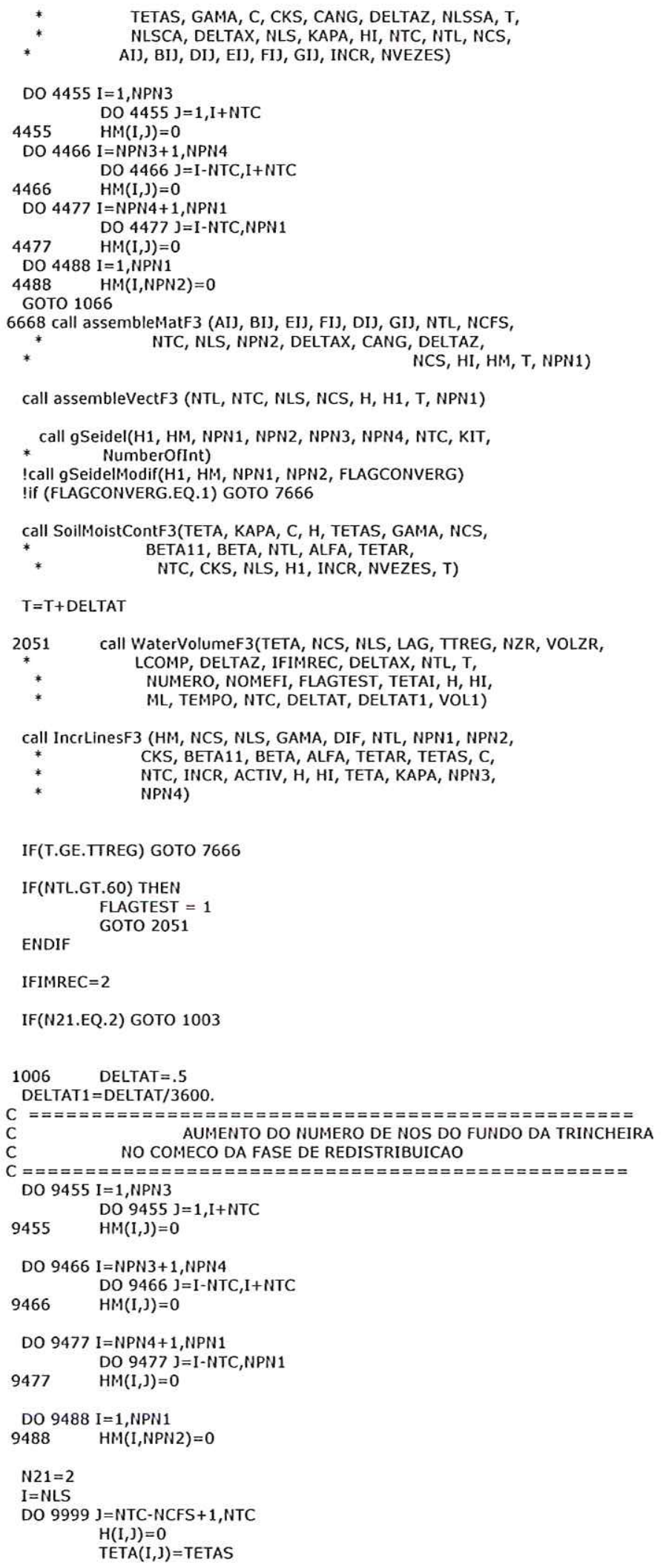




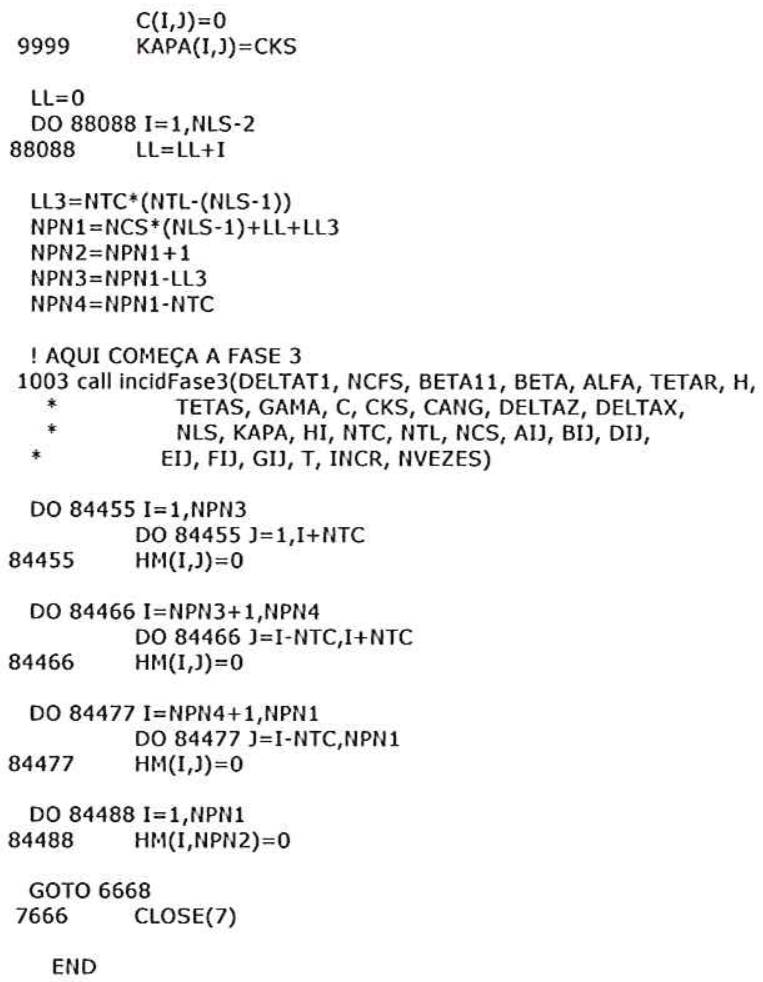

\section{SUB-ROTINA READDATA}

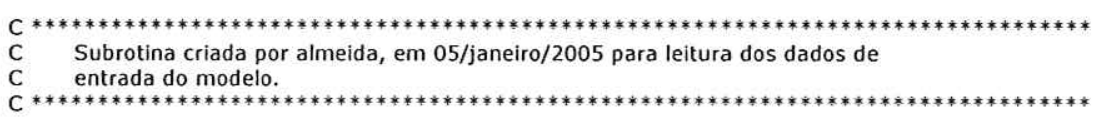

SubRoutine ReadData(NTC, NTL, NCS, NCFS, NLS, CANG,NVEZES,INCR,

$*$
$*$ ACTIV, TETAS, TETAR, ALFA, BETA, CKS, GAMA,

* $\quad$ DELTAX, DELTAZ, DELTAT,

open (unit $=100$, file $=$ 'dados.dat',STATUS $=$ 'OLD')

2000 format(i12)

2001 format(1i10)

2002 format(f10.4)

$$
\begin{aligned}
& \operatorname{read}(100,2000) \\
& \operatorname{read}(100,2000) \\
& \operatorname{read}(100,2000) \\
& \operatorname{read}(100,2000) \\
& \operatorname{read}(100,2000) \\
& \operatorname{read}(100,2000) \\
& \operatorname{read}(100,2000) \\
& \operatorname{read}(100,2000) \\
& \operatorname{read}(100,2000) \\
& \operatorname{read}(100,2000) \\
& \operatorname{read}(100,2000) \\
& \operatorname{read}(100,2002) \text { CANG } \\
& \operatorname{read}(100,2000)
\end{aligned}
$$

Aqui ele introduz variáveis que servem para aumentar o número de linhas do domínio

com base em uma variação de potencial na última linha, definida pelo usuário, através da

variável ACTIV, em $\mathrm{mH} 2 \mathrm{O}$ (ou $\mathrm{cmH2O}$, ainda tem que conferir).

As variáveis NVEZES e INCR definem, respectivamente, quantas vezes o perfil será aumentado

e quantas linhas de cada vez. Isso para ele só ter que calcular as linhas da malha que a

frente de molhamento já tiver atingido.

São atribuídos a todos os nós da malha os valores de umidade da

primeira coluna

$\operatorname{read}(100,2000)$ NVEZES

$\operatorname{read}(100,2000)$ 


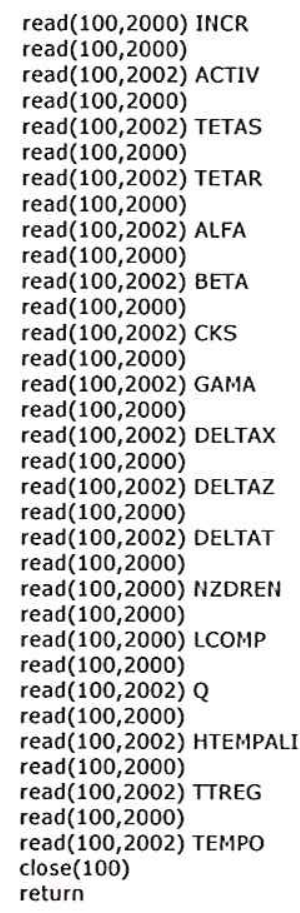

END

C SubRoutine WriteData(NTC, NTL, NCS, NCFS, NLS, CANG, NVEZES,INCR,

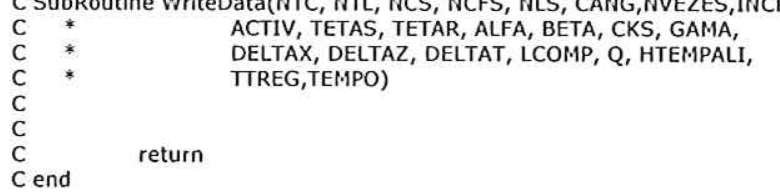

\section{SUB-ROTINA SOILMOISTCONTF0}

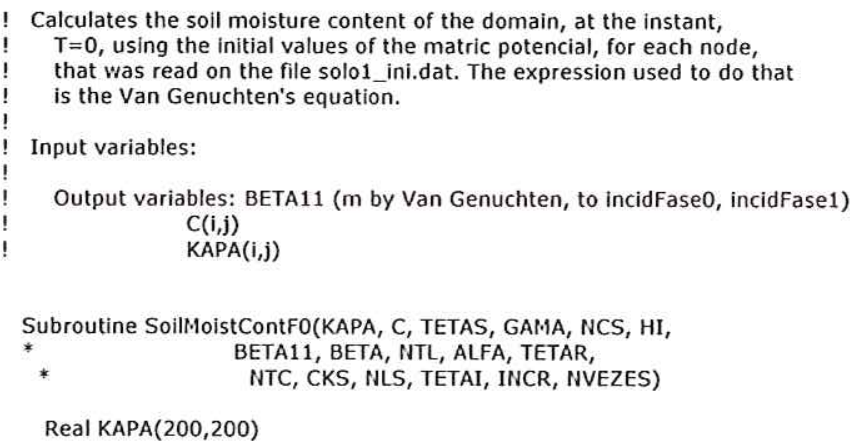




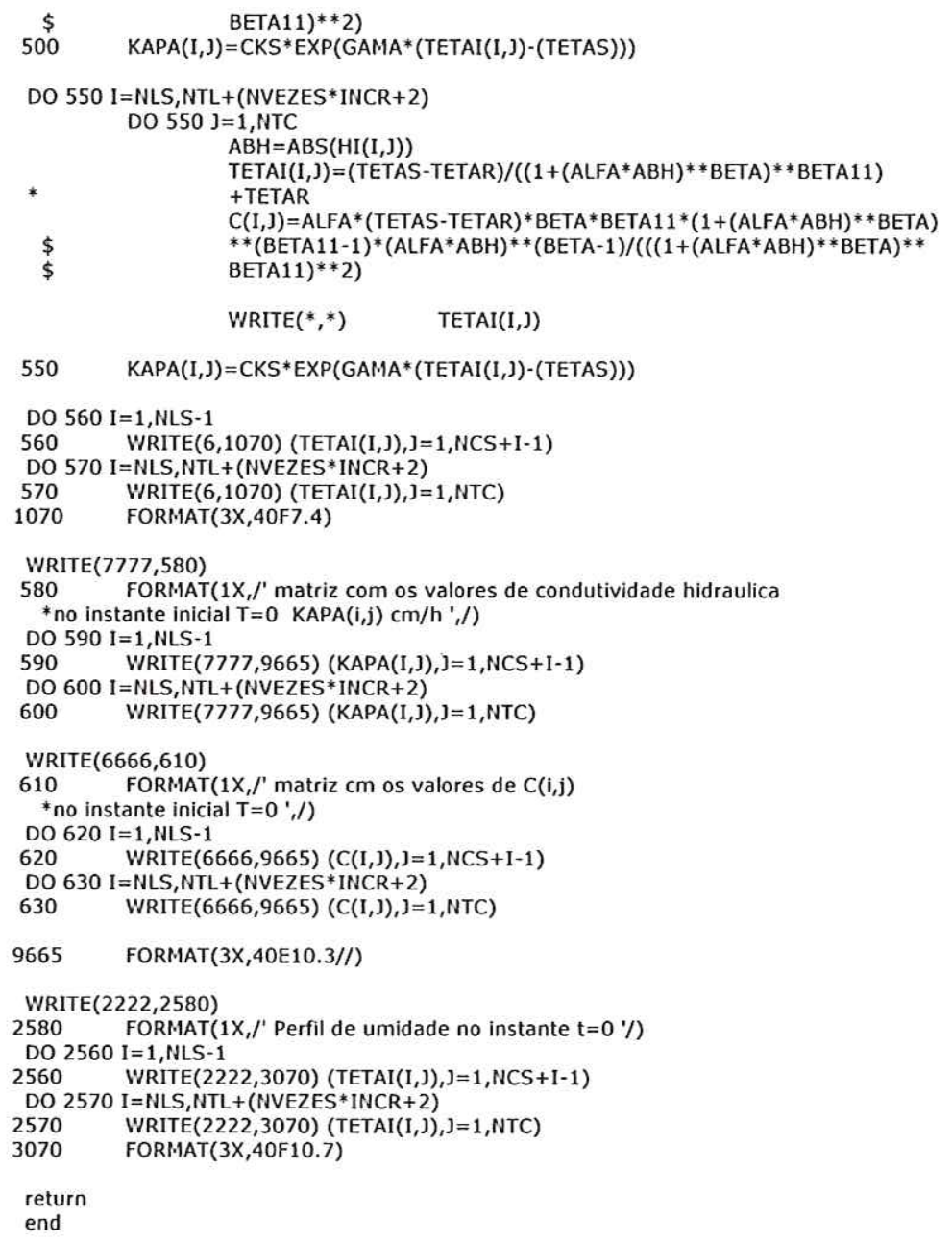

\section{SUB-ROTINA INCIDF0}

! Determining the coeficients of the Incidence Matrix,

Aij, Bij, Dij, Eij, Fij and Gij, for the Fase 0, according to the I equation 4 of Tabuada et. al (1995), that is the discretization of two-dimensional Richards' Equation.

The Fase 0 means the initial instant $T=0$, before the irrigation begining.

Input variables: NLS, NCS, NTL, NTC, NCFS, DELTAX, DELTAZ, CANG, CKS, GAMA,

TETAS, TETAR, ALFA, BETA (from input file dados.dat)

$\mathrm{HI}(\mathrm{i}, \mathrm{j})$ (initial values of matric potential, from Bidisul)

$\operatorname{KAPA}(i, j)$ (from SoilmoistContF0)

BETA11 ( $m$ by Van Genuchten, from SoillioistContF0)

$C(i, j)$ (derivation of Van Genuchten equation, from SoilmoisContFo)

DELTAT1 (DELTAT in hours, from Bidisul)

Output variables: AIJ, BIJ, EIJ, FI), DIJ, GIJ (coeficients of incidence matrix, to assembleMatF1)

Subroutine incidFase0(DELTAT1, NCFS, BETA11, BETA, ALFA, TETAR,

* TETAS, GAMA, C, CKS, CANG, DELTAZ, DELTAX,

* NLS, KAPA, HI, NTC, NTL, NCS, NVEZES, INCR,

AI), BI], DIJ, EI, FIJ, GIJ)

REAL KAPA $(200,200)$

Dimension $\operatorname{AIJ}(200,200), \operatorname{BIJ}(200,200), \operatorname{DIJ}(200,200), \operatorname{EIJ}(200,200)$,

* $\quad \mathrm{FIJ}(200,200), \mathrm{GI}(200,200), \mathrm{C}(200,200), \mathrm{HI}(200,200)$ 


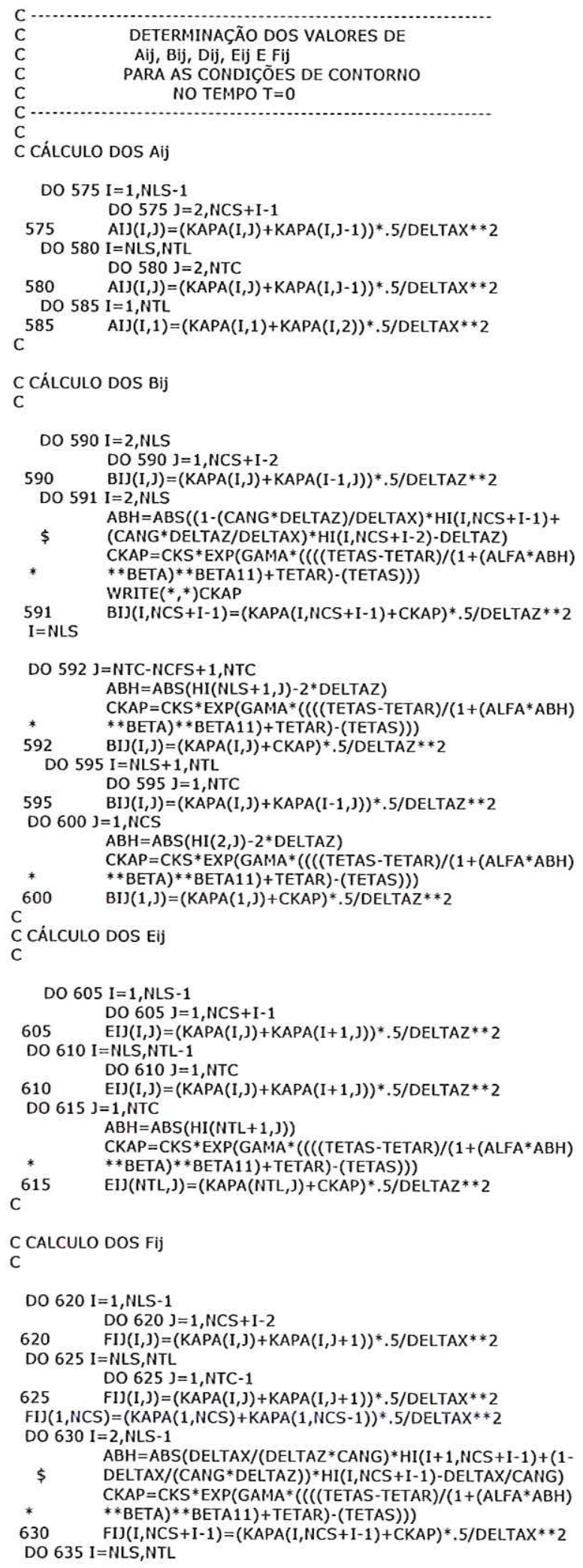




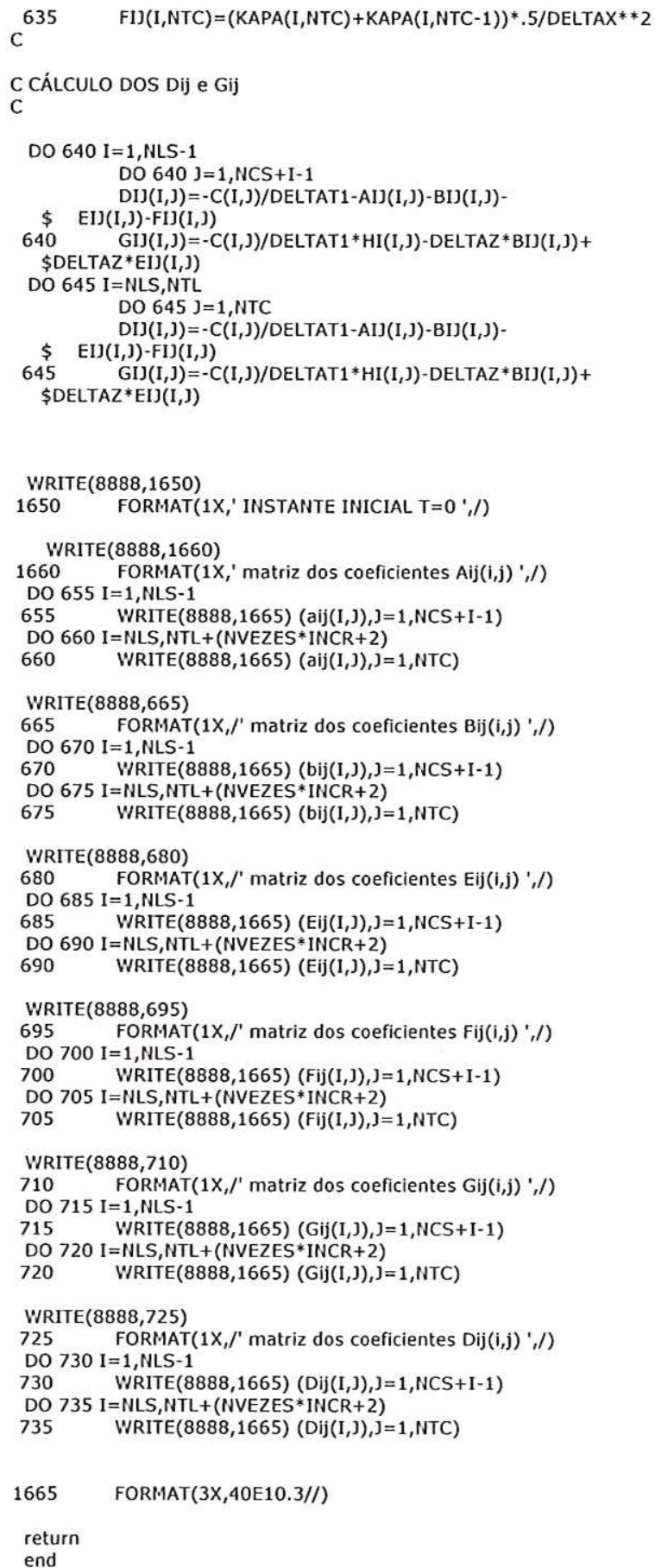

\section{SUB-ROTINA WATERLEVEL}




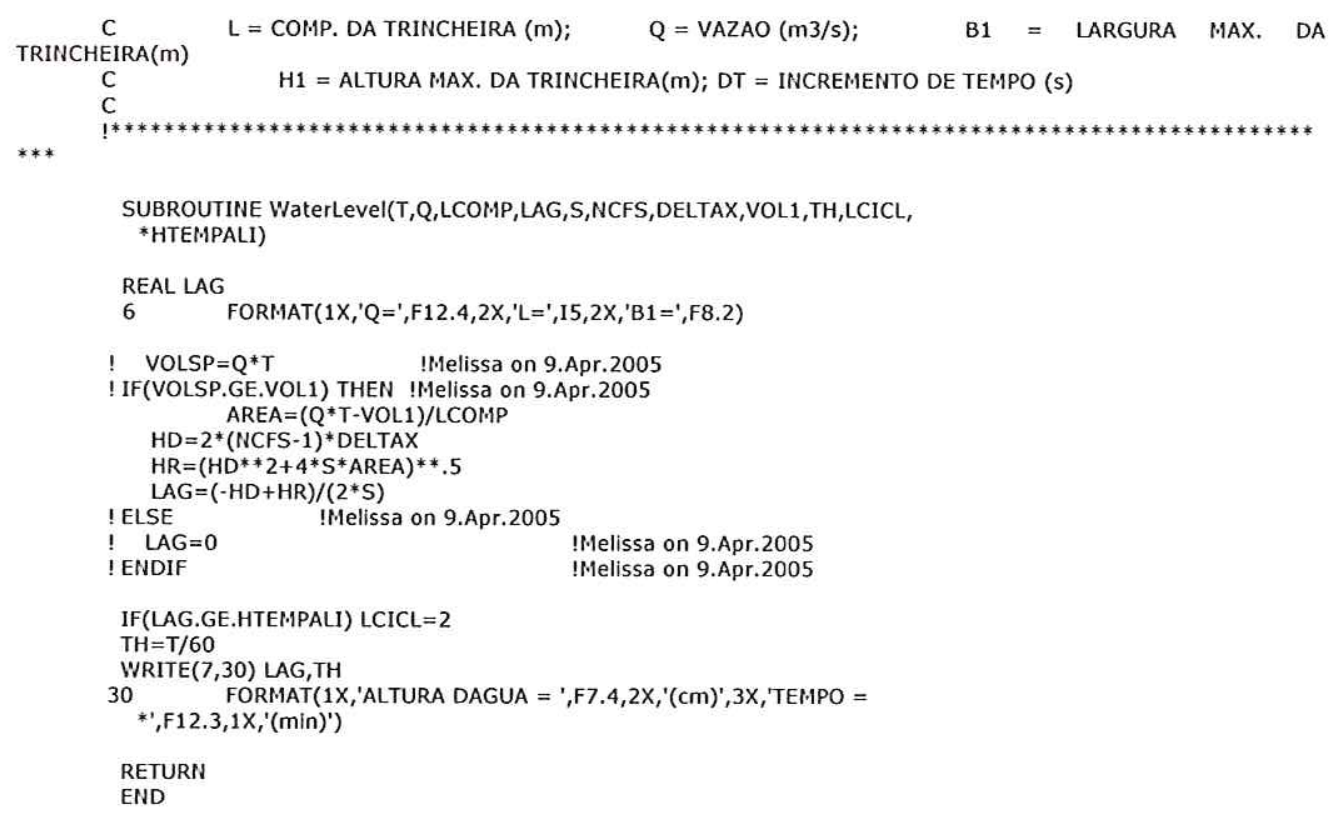

\section{SUB-ROTINA ASSEMBLEMATF1}

! Construction of the incidence matrix for Fase 1, using the coeficients ! that was calculated on incidfase1.

The output of this subroutine is the incidence matrix $H M(i, j)$.

Subroutine assembleMatF1 (AI), BI), EI), FIJ, DI), GIJ, NTL, NCFS,

* NTC, NLSCA, LAG, NLS, NPN2, DELTAX,

$*$
$*$

REAL LAG

Dimension AIJ $(200,200), \operatorname{BIJ}(200,200), \operatorname{DIJ}(200,200), \operatorname{EIJ}(200,200)$,

* $\operatorname{FIJ}(200,200), \operatorname{GIJ}(200,200), \operatorname{HI}(200,200), \operatorname{HM}(2000,2000)$

$\mathrm{L}=0$

DO $700 \mathrm{I}=1, \mathrm{NLSSA}+1$

DO $700 \mathrm{~J}=1, \mathrm{NCS}+\mathrm{I}-1$

$\mathrm{L}=\mathrm{L}+1$

IF(I.NE.1) THEN

IF(J.EQ.NCS+I-1) THEN

$\mathrm{HM}(\mathrm{L}, \mathrm{L}-1)=\mathrm{AIJ}(\mathrm{I}, \mathrm{J})+\mathrm{BI} \mathrm{J}(\mathrm{I}, \mathrm{J}) *$ DELTAZ*CANG/DELTAX

$\$$

$H M(L, L)=D I J(I, J)+(1-$ CANG*DELTAZ/DELTAX $)$ ${ }^{*} \mathrm{BIJ}(\mathrm{I}, \mathrm{J})+\left(1-\mathrm{DELTAX} /(\right.$ CANG*DELTAZ $){ }^{*} \mathrm{FIJ}(\mathrm{I}, \mathrm{J})$

$\$$ $H M(L, L+N C S+I-1)=E I J(I, J)+F I J(I, J) * D E L T A X /$

$\$$

(DIJ $(\mathrm{I}, \mathrm{J})+($ DELTAX/CANG $) * F I J(I, J)$

+ DELTAZ*BIJ $(I, J)$

$$
\begin{aligned}
& \multicolumn{1}{c}{\text { ELSE }} \\
& \text { IF(J.NE.1)THEN } \\
& H M(L, L-1)=A I J(I, J) \\
& H M(L, L)=D I J(I, J) \\
& H M(L, L+1)=F I J(I, J) \\
& H M(L, L+N C S+I-1)=E I)(I, J) \\
& H M(L, N P N 2)=G I(I, J)
\end{aligned}
$$

$H M(L, L-(N C S+I-2))=B I(I, J)$ 


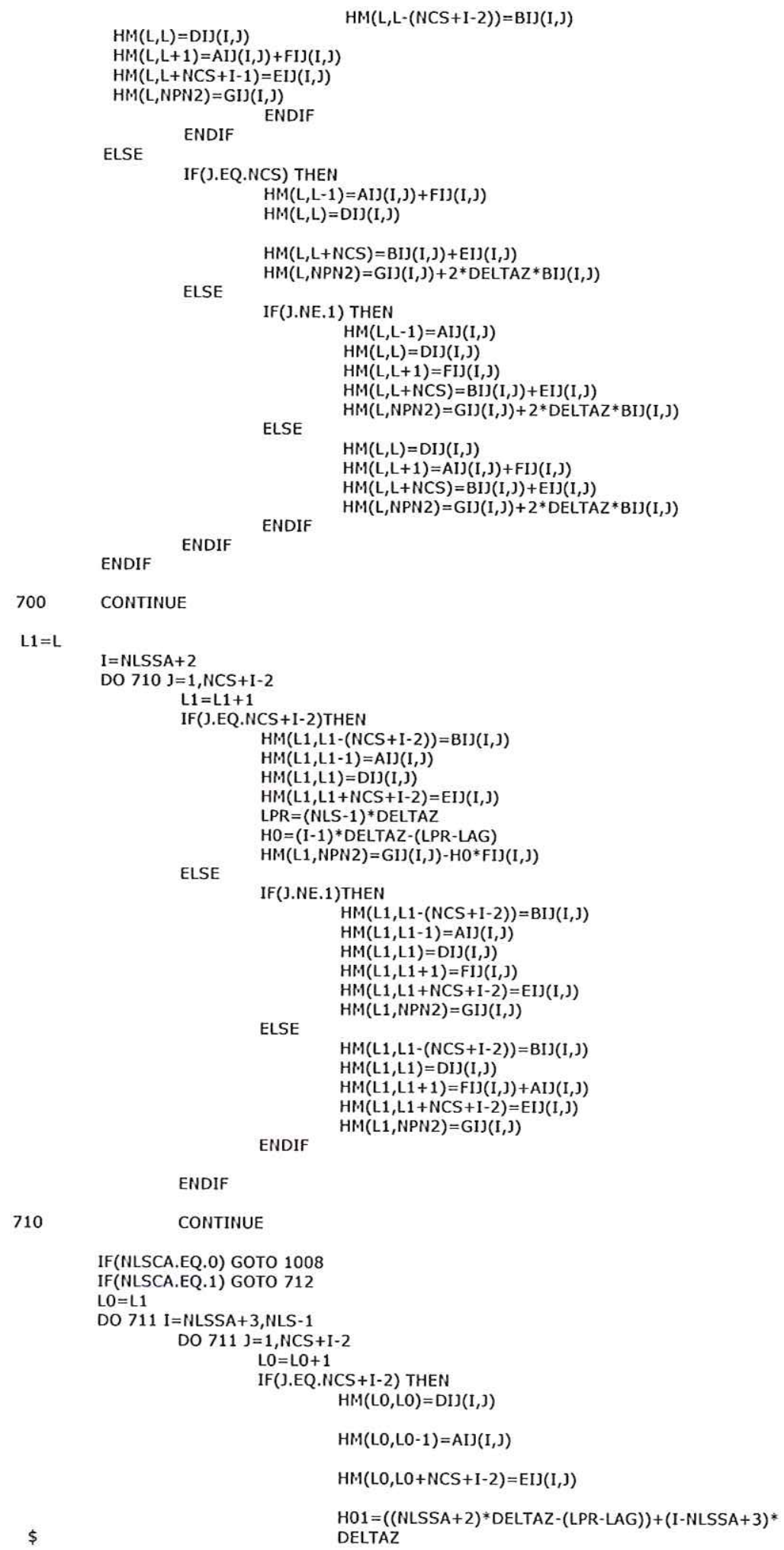

CONTINUE

IF(NLSCA.EQ.0) GOTO 1008 IF(NLSCA.EQ.1) GOTO 712

$H M(L O, N P N 2)=G I J(I, J)-H 01 * F I J(I, J)-(H 01-D E L T A Z) *$ 
$\$$

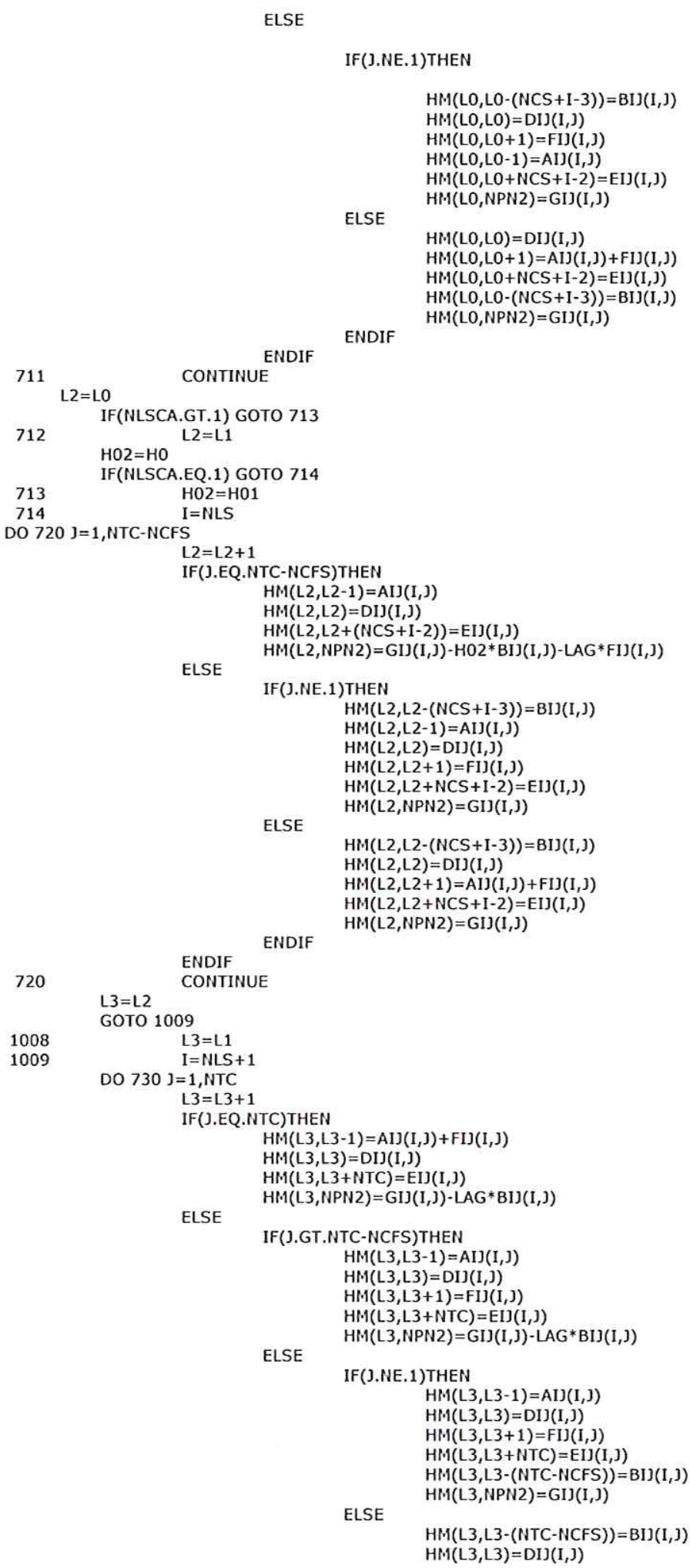

ELSE

IF(J.NE.1)THEN

$(\mathrm{L}, \mathrm{LO}-(\mathrm{NCS}+\mathrm{I}-3))=\mathrm{BIJ}(\mathrm{I}, \mathrm{J})$

$H M(L 0, L 0)=D I J(1, J)$

$\mathrm{HM}(\mathrm{L}, \mathrm{L}, \mathrm{L}+1)=\mathrm{FIJ}(\mathrm{I}, \mathrm{J})$

$H M(L 0, L 0-1)=A I J(I, J)$

$H M(L 0, L 0+N C S+I-2)=E I J(I, J)$

$H M(L O, N P N 2)=G I J(I, J)$

ELSE

$H M(L 0, L 0)=D I J(I, J)$

$H M(L 0, L 0+1)=A I J(I, J)+F I J(I, J)$

$H M(L 0, L 0+N C S+I-2)=E D(I, J)$

$H M(L O, L O-(N C S+I-3))=B I J(I, J)$

ENDIF $\operatorname{HM}(L 0, N P N 2)=\operatorname{GI}(I, J)$

$\operatorname{BIJ}(\mathrm{I}, \mathrm{J})$ 


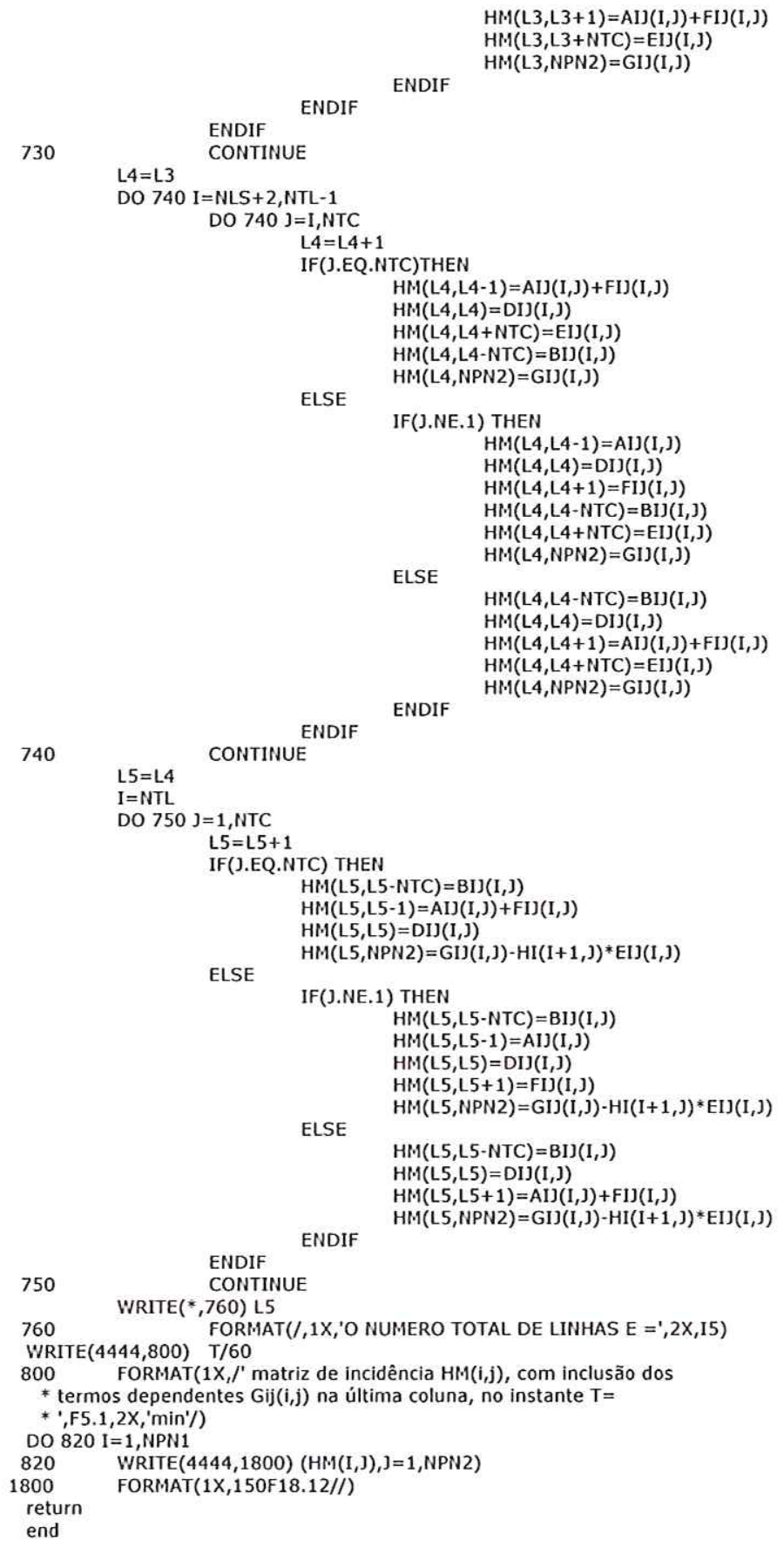

\section{SUB-ROTINA ASSEMBLEVECTF1}

! Construction of the vector with the initial values of

! the matric potentials for each node $(i, j)$ for Fase 1

! The output of this subroutine is the vector $\mathrm{H} 1$ (i).

Subroutine assembleVectF1 (NTL, NCFS, NTC, NLS, NCS, NLSSA,

* NPN1, ICONTEMPO, $\mathrm{H}, \mathrm{HI}, \mathrm{H} 1, \mathrm{~T}$ )

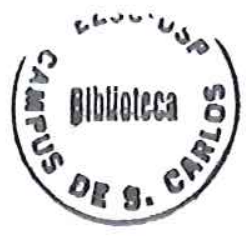


Dimension $H(200,200), H I(200,200), H 1(2000)$

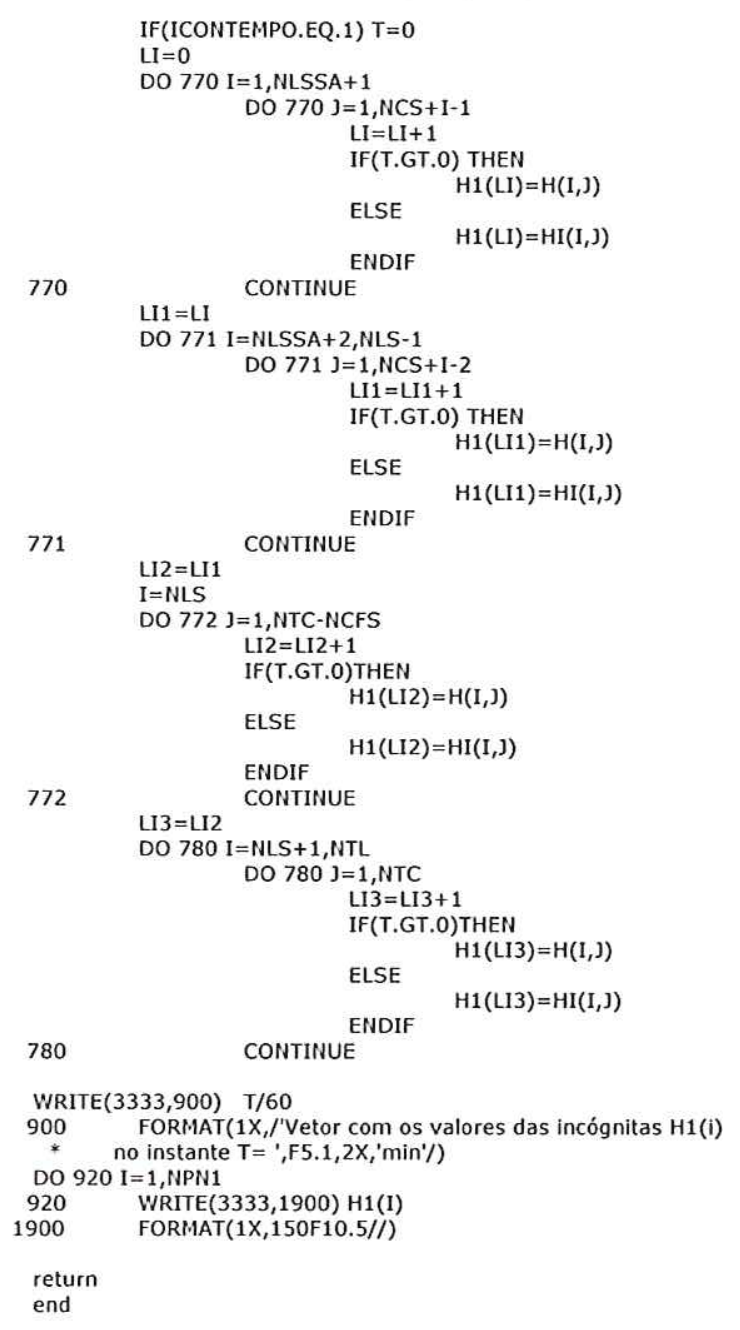

\section{SUB-ROTINA GSEIDEL}

1 Gauss Seidel for Fases 1, 2 and 3.

Routine for solution of the linear system consisting of the Richard's equation

for calculate the water volume infiltrated in a infiltration trenche.

The incidence matrix HM(NPN1,NPN2) is assembled on assemblematF1. It's coeficients are calculated on incidfase1.

The vector containing the independent terms H1(NPN1) is assembled on assembleVectF1

! The Fase1 (one) means the advance and supply fases, occurring when water is

! applied into the trenche.

! The Fase 2 (two) means the recession fase, occurring when water infiltrates after

! cut-off.

! The Fase 3 (three) means the redistribution fase, occurring when water moves in the

! soil after infiltration ended.

! The maximum number of iteractions is gaven by NMITER. The maximum value of the Gauss

! Seidel residual is represented by ERADM.

! The output of this subroutine is the vector $\mathrm{H} 1$ (i). 


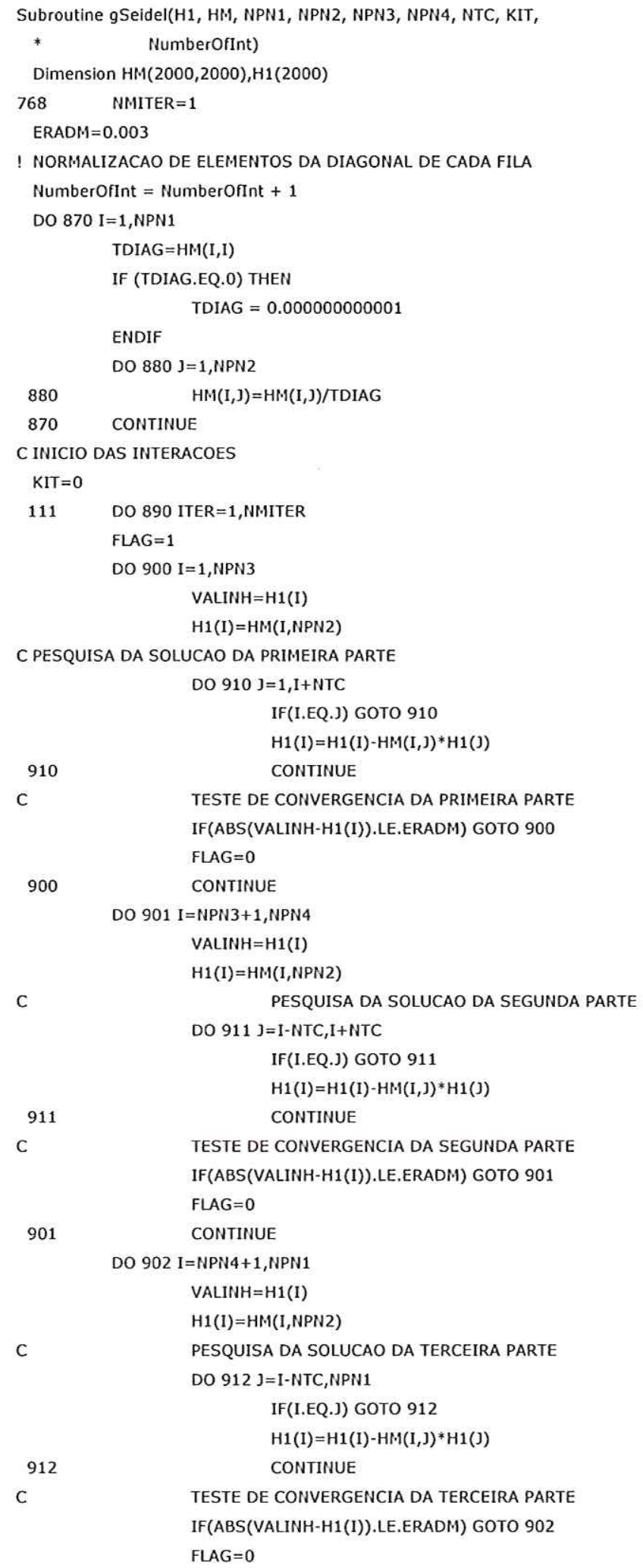




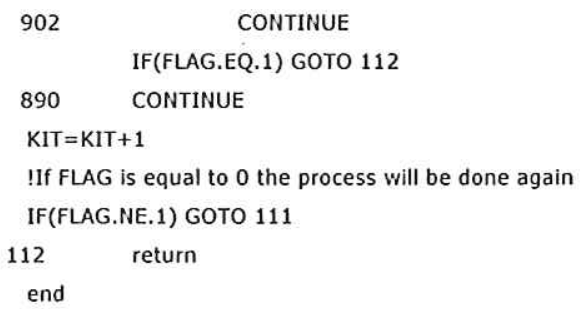

\section{SUB-ROTINA SOILMOISTCONTF1}

G Calculates the soil moisture content of the domain, during the Fase 1,
G using the values of the matric potencial, for each node, that was
G calculated on the subroutine gSeidel. The expression used to do that

$\mathrm{G}$ is the Van Genuchten's equation.

Subroutine SoilmoistContF1(TETA, KAPA, C, H, TETAS, GAMA, NCS,

* NLSSA, BETA11, BETA, NTL, ALFA, TETAR,

* $\quad$ NCFS, NTC, CKS, NLS, H1, INCR, NVEZES,

Real KAPA $(200,200)$

Dimension $\operatorname{TETA}(200,200), \mathrm{C}(200,200), \mathrm{H}(200,200), \mathrm{H} 1(2000)$

$\mathrm{L} .01=0$

DO $501 \mathrm{I}=1, \mathrm{NLSSA}+1$

$\begin{aligned} \text { DO } 501 \mathrm{~J} & =1, \mathrm{NCS}+\mathrm{I}-1 \\ \mathrm{LO} 1 & =\mathrm{LO} 1+1\end{aligned}$

$\mathrm{LO} 1=\mathrm{LO} 1+1$
$\mathrm{H}(\mathrm{I}, \mathrm{J})=\mathrm{H} 1(\mathrm{LO} 1)$

If the matric potencial $\mathrm{H}$ has a positive value, the program

! considers that the soil moisture is equal to the saturation

moisture, and the hydraulic conductivity is maximum. Else, it

calculates the soil moisture and the hydraulic conductivity

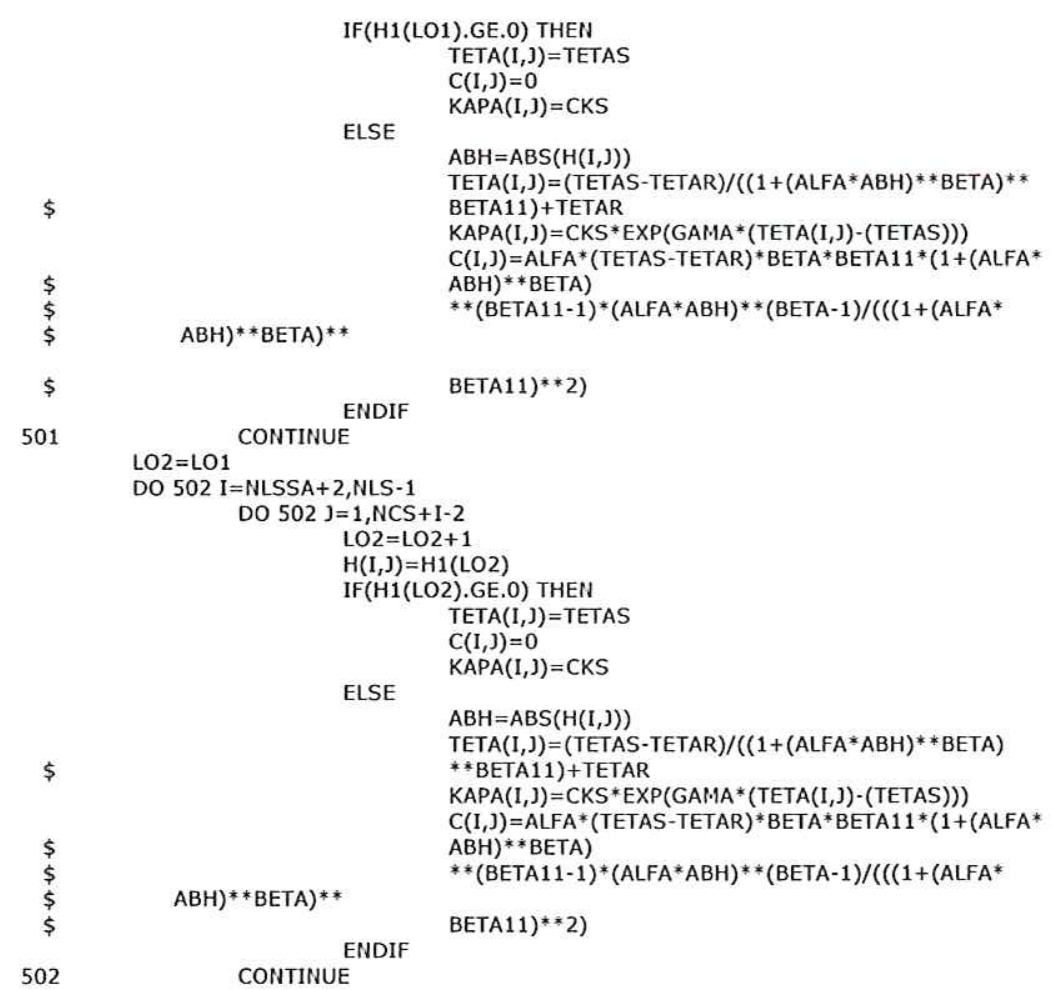




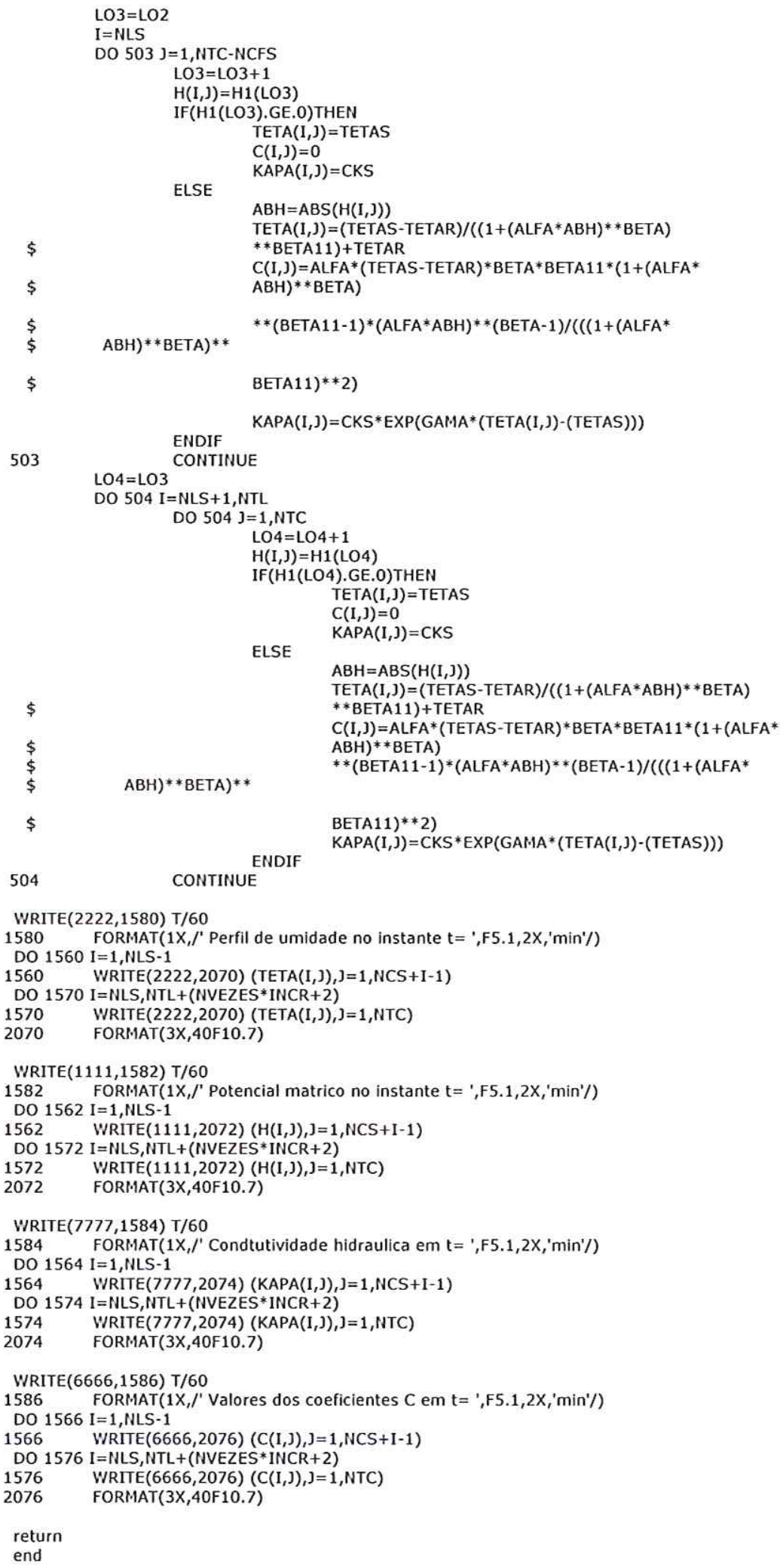




\section{SUB-ROTINA WATERVOLUMEF1}

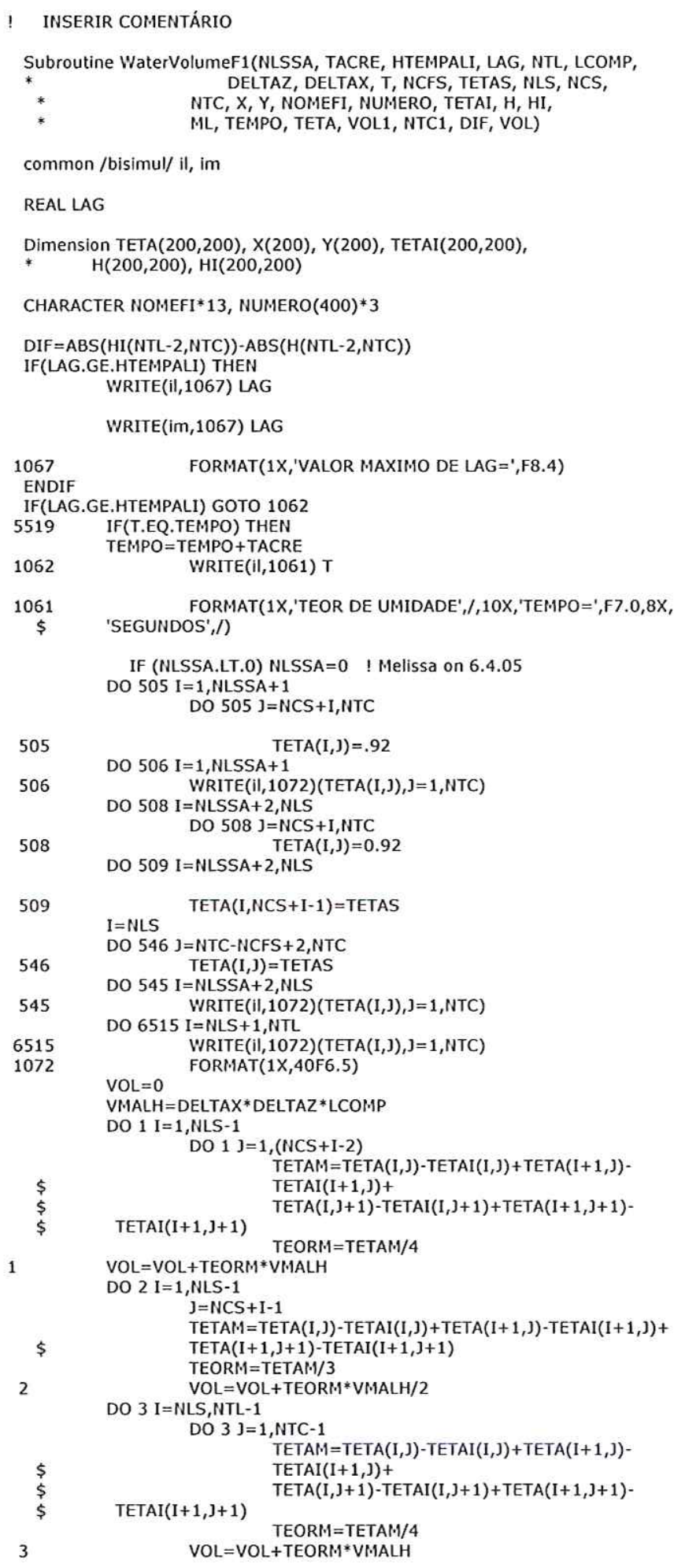




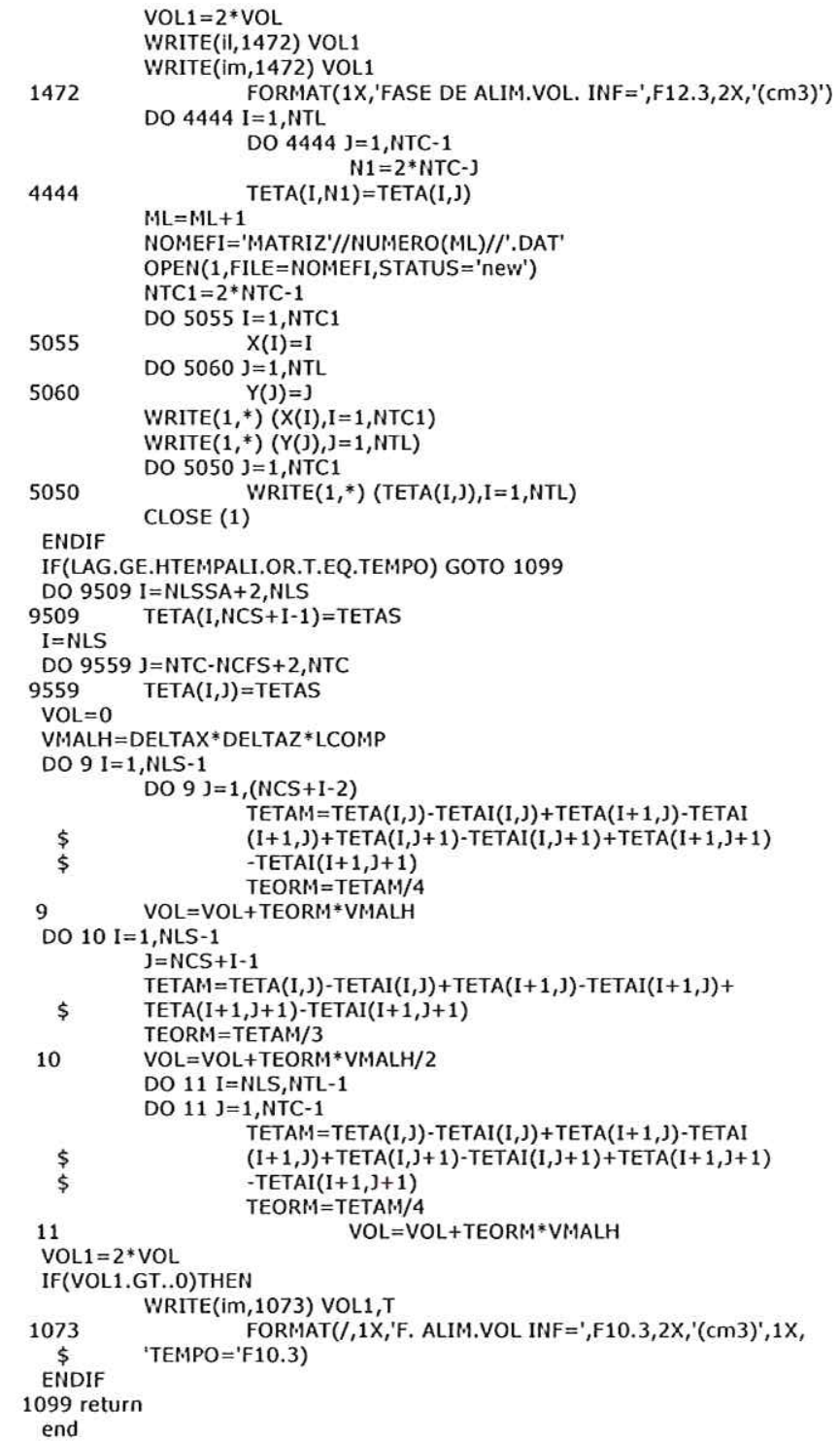

\section{SUB-ROTINA INCRLINESF1}

$G$ Increasing the number of lines of the domain, using the variables

G ACTIV, NVEZES and INCR, for Fase 1.

$G$ The variable ACTIV sets the diference of matric potential, at the

$G$ last line, that is necessary to activate the profile

$G$ The variable NVEZES sets the number of times that the profile will

$G$ be activated

$\mathrm{G}$ The variable INCR sets the number of lines increased each time

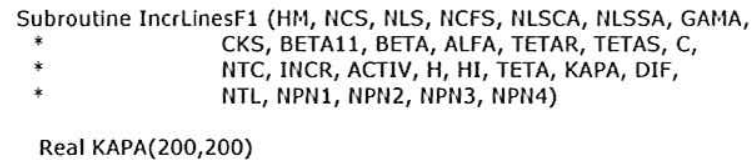

Dimension HM(2000,2000), H(200,200), $\operatorname{HI}(200,200), \operatorname{TETA}(200,200)$,

* $\quad$ C $(200,200)$ 


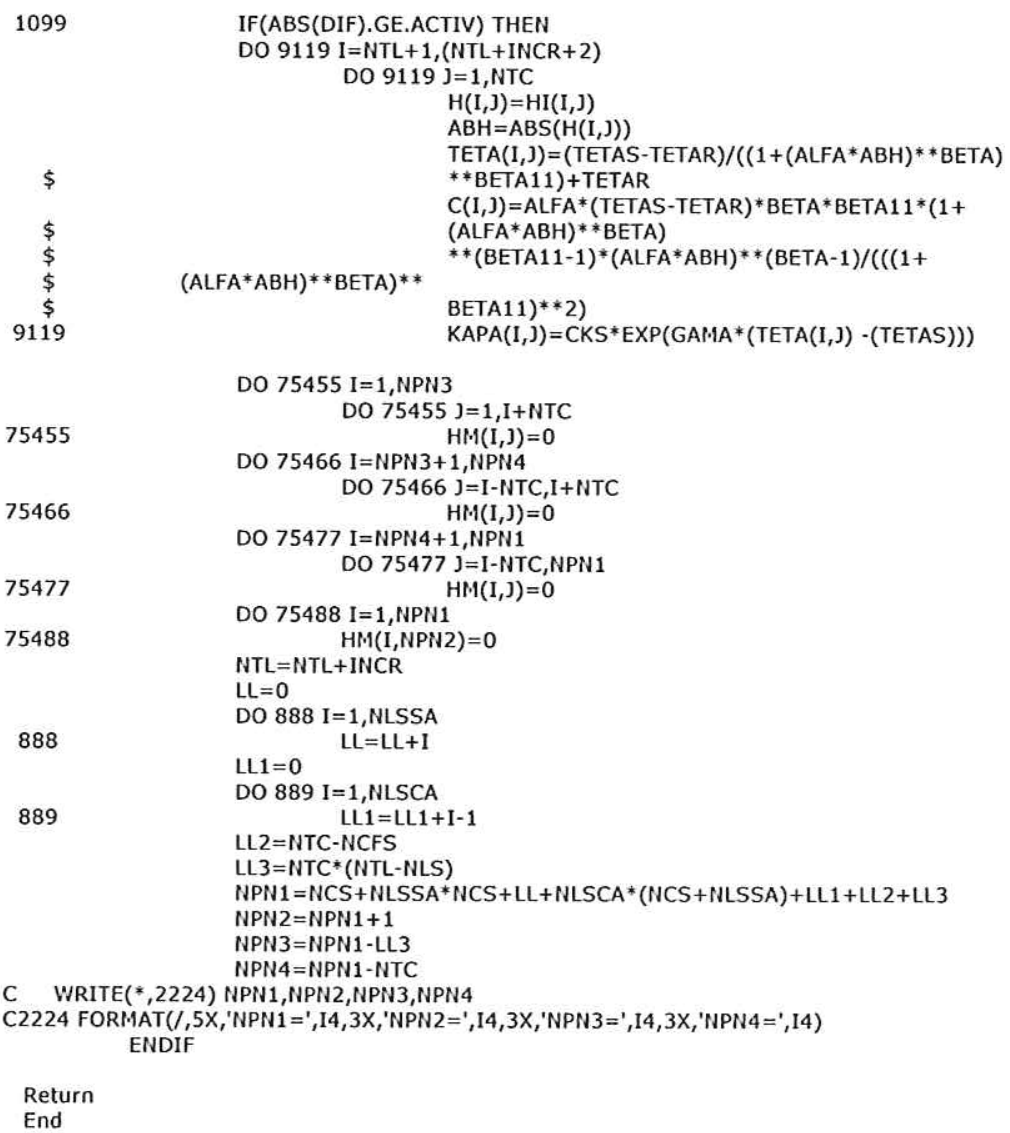

\section{SUB-ROTINA INCIDFASE1}

Determining the coeficients of the Incidence Matrix,

Aij, Bij, Dij, Eij, Fij and Gij, for the Fase 1, according to the

equation 4 of Tabuada et. al (1995), that is the discretization of

two-dimensional Richards' Equation.

The Fase 1 (one) means the advance and supply fases, occurring when water is supplied into the trenche.

Input variables: NLS, NCS, NTL, NTC, NCFS, DELTAX, DELTAZ, CANG, CKS, GAMA TETAS, TETAR, ALFA, BETA (from input file dados.dat)

NLSSA (number of lines without water inside the furrow, from Bidisul)

$H(i, j)$ (values of matric potential, from SoilmoistContF1)

$\mathrm{HI}(\mathrm{i}, \mathrm{j})$ (initial values of matric potential, from Bidisul)

KAPA $(i, j)$ (from SoilmoistContF 1 )

BETA11 ( $m$ de Van Genuchten, from Soill-loistContF1)

$C(i, j)$ (derivation of Van Genuchten equation, from Soilm-ioisContF1)

DELTAT1 (DELTAT in hours, from Bidisul)

Output variables: AIJ, BIJ, EIJ, FIJ, DIJ, GIJ (coeficients of the incidence matrix,

to assembleMatF2)

Subroutine incidFase1(DELTAT1, NCFS, BETA11, BETA, ALFA, TETAR, $H$, 3665TETAS, GAMA, C, CKS, CANG, DELTAZ, NLSSA 3665DELTAX, NLS, KAPA, HI, NTC, NTL, NCS, AIJ, 3665BI, DI), EI, FI, GI, NVEZES, INCR, T)

\section{REAL KAPA $(200,200)$}

Dimension $\operatorname{AIJ}(200,200), \operatorname{BIJ}(200,200), \operatorname{DIJ}(200,200), \operatorname{EIJ}(200,200)$, $3665 \mathrm{FIJ}(200,200), \mathrm{GI}(200,200), \mathrm{H}(200,200)$, $\mathrm{HI}(200,200)$ $3665 C(200,200)$ 


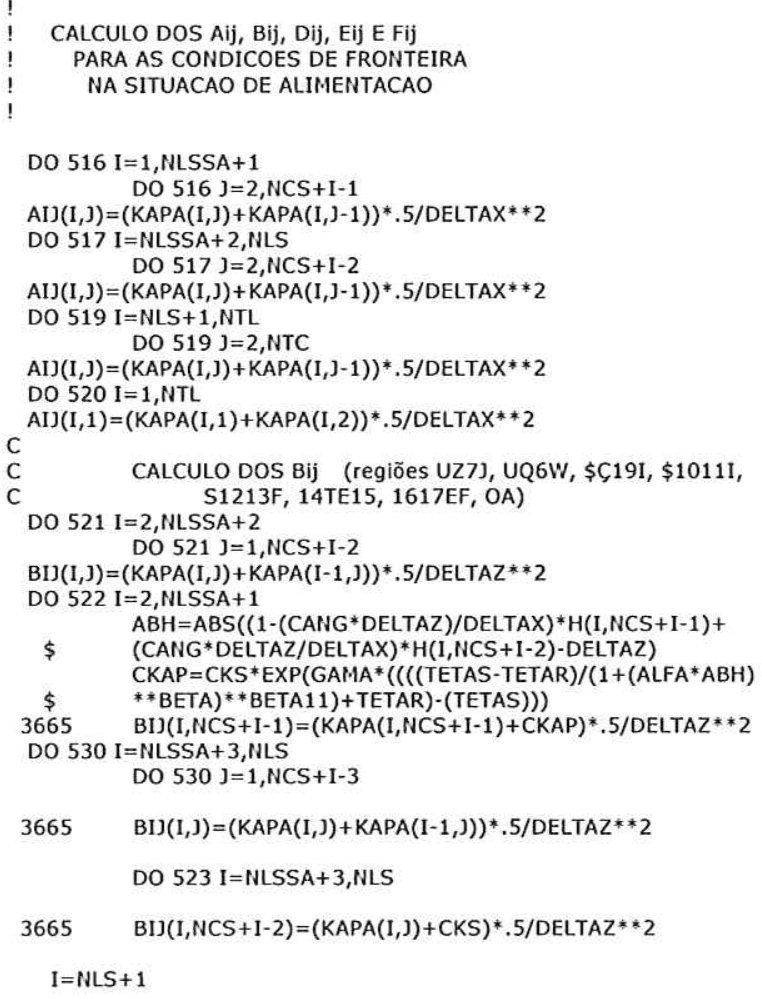




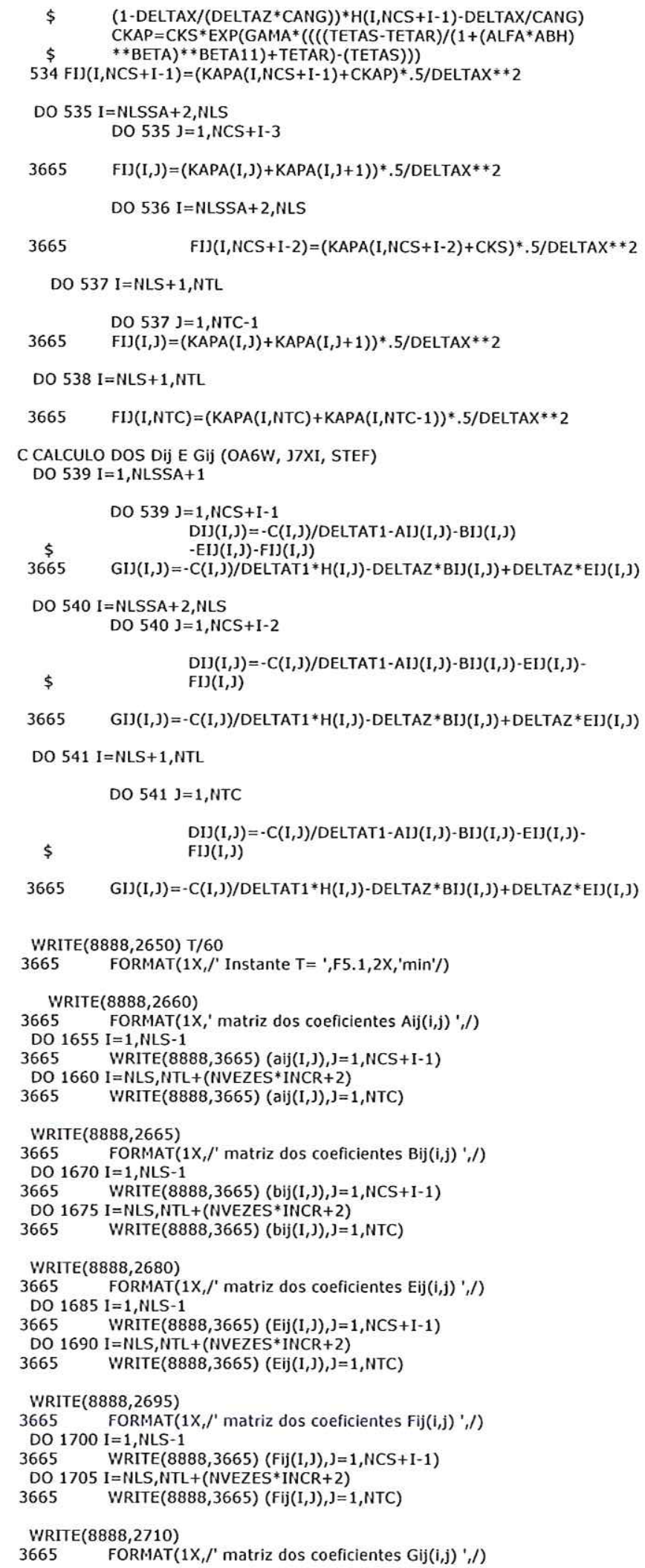




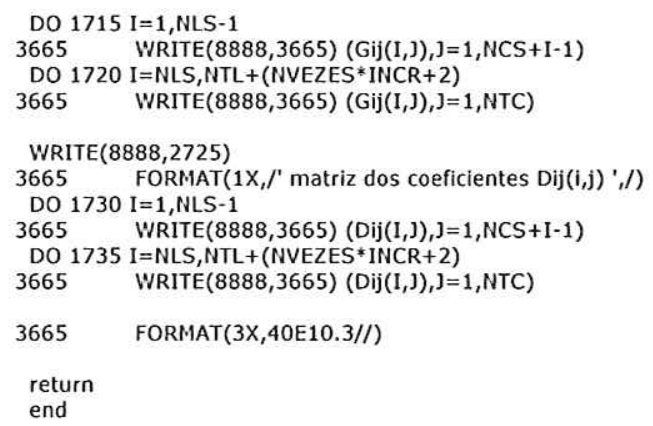

\section{SUB-ROTINA ASSEMBLEMATF2}

! Construction of the incidence matrix for Fase 2, using the coeficients that was calculated on incidfase 2

The output of this subroutine is the incidence matrix $\mathrm{HM}(\mathrm{i}, \mathrm{j})$.

Subroutine assembleMatF2 (AI), BI), EI), FIJ, DI), GI), NTL, NCFS,

$*$
$*$

Dimension $\operatorname{AIJ}(200,200), 8 \mathrm{BJ}(200,200), \operatorname{DIJ}(200,200), \operatorname{EIJ}(200,200)$,

* FIJ $(200,200), \mathrm{GIJ}(200,200), \mathrm{HI}(200,200), \mathrm{HM}(2000,2000)$

REAL LAG, LPR

$\mathrm{L}=0$

DO $707 \mathrm{I}=1$, NLSSA +1

DO $707 \mathrm{~J}=1, \mathrm{NCS}+\mathrm{I}-1$

$\mathrm{L}=\mathrm{L}+1$

IF(I.NE.1)THEN ! Primeira e terceira geometrias IF(J.EQ.NCS+I-1)THEN

$\$$

$\$$

$\$$

$\$$

$\mathrm{HM}(\mathrm{L}, \mathrm{L}-1)=\mathrm{AIJ}(\mathrm{I}, \mathrm{J})+\mathrm{BIJ}(\mathrm{I}, \mathrm{J}) * \operatorname{DELTAZ} *$

CANG/DELTAX

$H M(L, L)=\operatorname{DIJ}(I, J)+(1-\text { CANG*DELTAZ/DELTAX })^{*}$

$\mathrm{HM}(\mathrm{L}, \mathrm{L})=$
$\mathrm{BIJ}(\mathrm{I}, \mathrm{J})+$

$(1-$ DELTAX $/($ CANG*DELTAZ))*FIJ $(\mathrm{I}, \mathrm{J})$

$H M(L, L+N C S+I-1)=E I J(I, J)+F I J(I, J) *$

DELTAX/(DELTAZ*CANG)

$H M(L, N P N 2)=G I J(I, J)+(D E L T A X / C A N G) * F I J(I, J)+$

ELSE

$\operatorname{DELTAZ*BIJ}(I, J)$

IF(J.NE.1)THEN

$H M(L, L-(N C S+I-2))=B I J(I, J)$

$\operatorname{HM}(\mathrm{L}, \mathrm{L}-1)=\mathrm{AIJ}(\mathrm{I}, \mathrm{J})$

$\operatorname{HM}(\mathrm{L}, \mathrm{L})=\operatorname{DIJ}(\mathrm{I}, \mathrm{J})$

$H M(L, L+1)=F I J(I, J)$

$H M(L, L+N C S+I-1)=E I J(I, J)$

$H M(L, N P N 2)=G I J(I, J)$

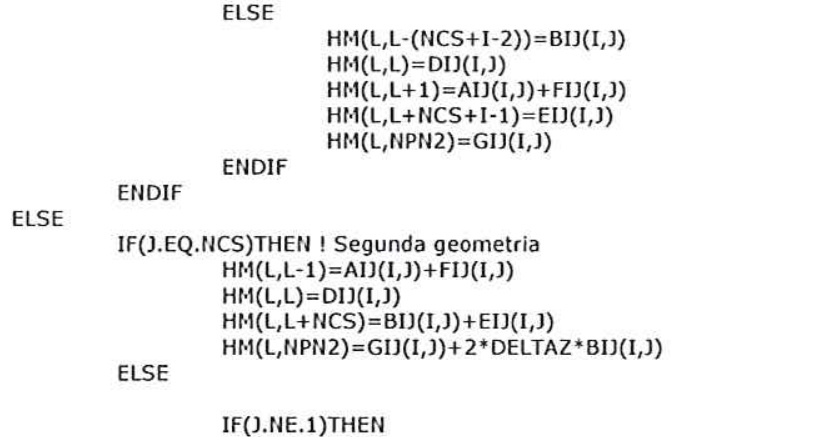

ELSE 


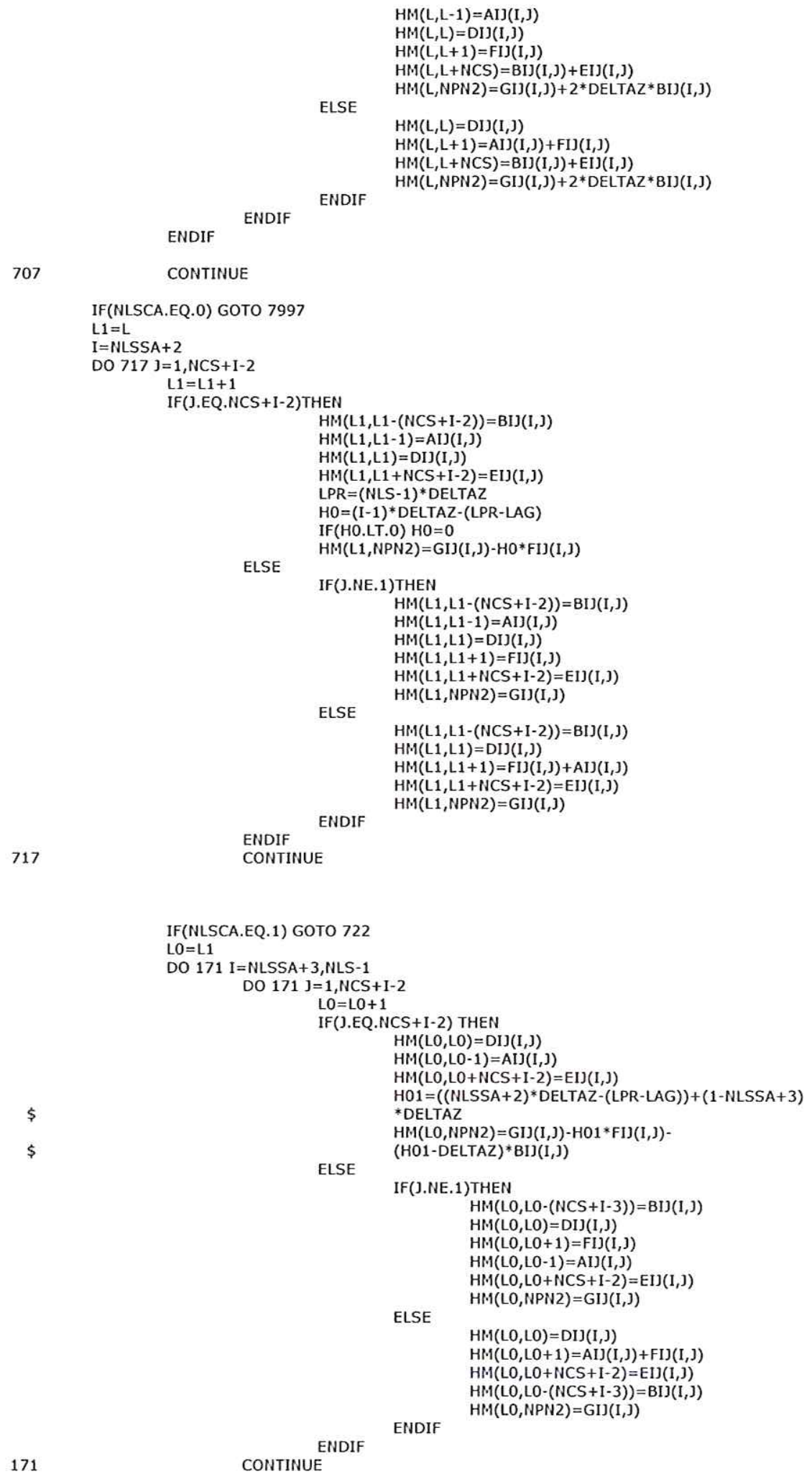


$\mathrm{L} 2=\mathrm{L} 0$

IF(NLSCA.GT.1) GOTO 733

$\mathrm{HO2}=\mathrm{HO}$

$\mathrm{L} 2=\mathrm{L} 1$

IF(NLSCA.EQ.1) GOTO 744

$\mathrm{H} 02=\mathrm{H} 0$
$\mathrm{I}=\mathrm{NLS}$

44

DO $729 \mathrm{~J}=1$,NTC-NCFS

$\mathrm{L} 2=\mathrm{L} 2+1$

IF(J.EQ.NTC-NCFS)THEN

$\mathrm{HM}(\mathrm{L} 2, \mathrm{~L} 2-1)=\mathrm{AIJ}(\mathrm{I}, \mathrm{J})$

$H M(L 2, L 2+(N C S+I-2))=E I J(I, J)$

ELSE

$\operatorname{HM}(\mathrm{L} 2, \mathrm{NPN} 2)=\mathrm{GIJ}(\mathrm{I}, \mathrm{J})-\mathrm{H} 02^{*} \mathrm{BIJ}(\mathrm{I}, \mathrm{J})-\mathrm{LAG}^{*} \mathrm{FIJ}(\mathrm{I}, \mathrm{J})$

IF(J.NE.1) THEN

$\mathrm{HM}(\mathrm{L} 2, \mathrm{~L} 2-(\mathrm{NCS}+\mathrm{I}-3))=\mathrm{BU}(\mathrm{I}, \mathrm{J})$

$\mathrm{HM}(\mathrm{L} 2, \mathrm{~L} 2-1)=\operatorname{AIJ}(\mathrm{I}, \mathrm{J})$

$\operatorname{HM}(L 2, L 2)=D I J(I, J)$

$H M(L 2, L 2+1)=F I J(I, J)$

$H M(L 2, L 2+N C S+I-2)=E I J(I, J)$

ELSE

$\mathrm{HM}(\mathrm{L} 2, \mathrm{NPN} 2)=\mathrm{GI}(\mathrm{I}, \mathrm{J})$

$\mathrm{HM}(\mathrm{L} 2, \mathrm{~L} 2-(\mathrm{NCS}+\mathrm{I}-3))=\mathrm{BIJ}(\mathrm{I}, \mathrm{J})$

$H M(L 2, L 2)=D I J(I, J)$

$\operatorname{HM}(L 2, L 2+1)=A I J(I, J)+F I J(I, J)$

$H M(L 2, L 2+N C S+I-2)=E I(I, J)$

ENDIF

$H M(L 2, N P N 2)=G I J(I, J)$

729

ENDIF

GOTO 7998

7997

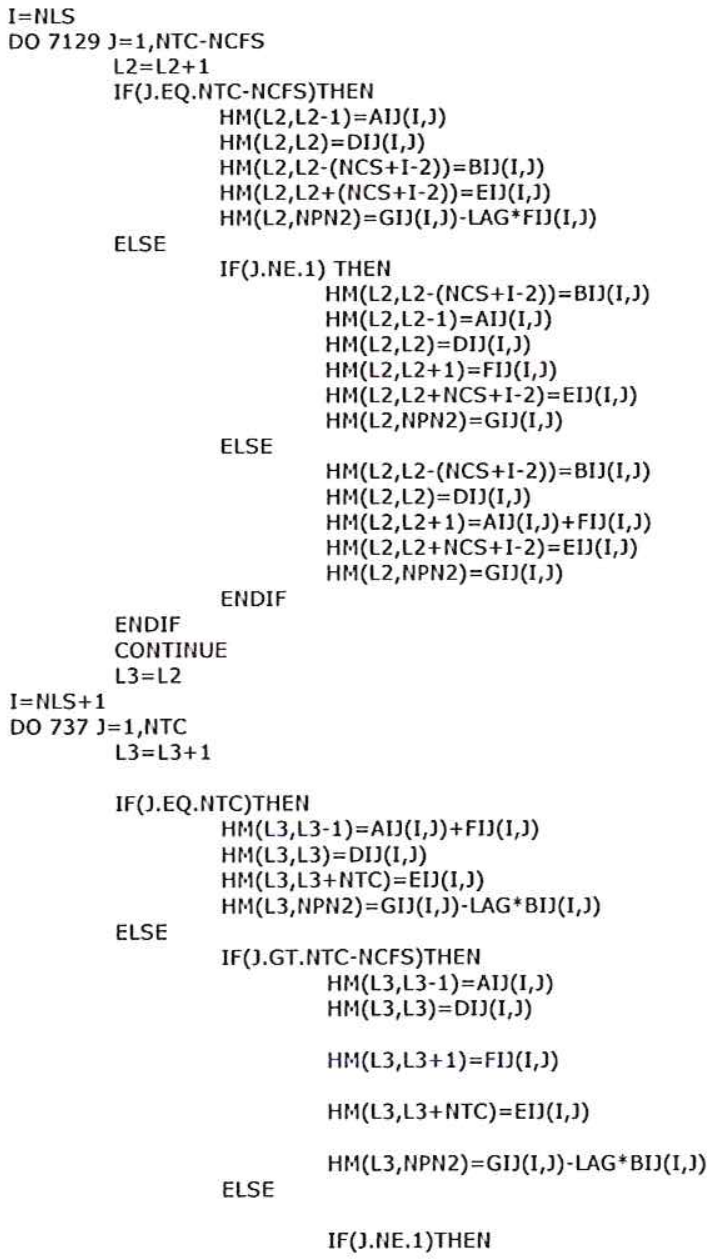

IF(J.NE.1)THEN 
$\operatorname{HM}(L 3, L 3-1)=A I J(I, J)$

$\operatorname{HM}(\mathrm{L} 3, \mathrm{~L} 3)=\mathrm{DIJ}(\mathrm{I}, \mathrm{J})$

$\operatorname{HM}(L 3, L 3+1)=F I(I, J)$

$H M(L 3, L 3+N T C)=E I J(I, J)$

$H M(L 3, L 3-(N T C-N C F S))=B D(I, J)$

ELSE

$\mathrm{HM}(\mathrm{L} 3, \mathrm{NPN} 2)=\mathrm{GI}(1, \mathrm{~J})$

$\mathrm{HM}(\mathrm{L3}, \mathrm{L} 3-(\mathrm{NTC}-\mathrm{NCFS}))=\mathrm{BI}(\mathrm{I}, \mathrm{J})$

$\operatorname{HM}(\mathrm{L} 3, \mathrm{~L} 3)=\mathrm{DIJ}(\mathrm{I}, \mathrm{J})$

$H \cdot M(L 3, L 3+1)=A I J(I, J)+F I J(I, J)$

$\operatorname{HM}(\mathrm{L} 3, \mathrm{~L} 3+\mathrm{NTC})=\mathrm{EI}(\mathrm{I}, \mathrm{J})$

ENDIF

$H M(L 3, N P N 2)=G I J(I, J)$

ENDIF

ENDIF

737

CONTINUE

$\mathrm{L} 4=\mathrm{L} 3$

DO 747 I=NLS+2,NTL-

DO $747 \mathrm{~J}=1$, NTC

$\mathrm{L} 4=\mathrm{L} 4+1$

IF(J.EQ.NTC)THEN

$H M(L 4, L 4-1)=A I J(I, J)+F I J(I, J)$

$\operatorname{HM}(\mathrm{L} 4, \mathrm{~L} 4)=\mathrm{DIJ}(\mathrm{I}, \mathrm{J})$

$\operatorname{HM}(\mathrm{L} 4, \mathrm{~L} 4+\mathrm{NTC})=\mathrm{EIJ}(\mathrm{I}, \mathrm{J})$

$\operatorname{HM}(L 4, \mathrm{~L} 4-\mathrm{NTC})=\mathrm{BI}(\mathrm{I}, \mathrm{J})$

ELSE

$(L 4, N P N 2)=G I J(I, J)$

IF(J.NE.1)THEN

$\mathrm{HM}(\mathrm{L} 4, \mathrm{~L} 4-1)=\mathrm{AI}(\mathrm{I}, \mathrm{J})$

$\operatorname{HM}(L 4, L 4)=D I J(I, J)$

$\mathrm{HM}(L 4, L 4+1)=F \mathrm{~J}(\mathrm{I}, \mathrm{J})$

$\mathrm{HM}(\mathrm{L} 4, \mathrm{~L} 4-\mathrm{NTC})=\mathrm{BI}(\mathrm{I}, \mathrm{J})$

$\operatorname{HM}(\mathrm{L} 4, \mathrm{~L} 4+\mathrm{NTC})=\mathrm{EI}(\mathrm{I}, \mathrm{J})$

ELSE

$\operatorname{HM}(L 4, L 4-N T C)=B I J(I, J)$

$\operatorname{HM}(\mathrm{L} 4, \mathrm{~L} 4)=\mathrm{DIJ}(\mathrm{I}, \mathrm{J})$

$\mathrm{HM}(L 4, \mathrm{~L} 4+1)=\mathrm{AIJ}(\mathrm{I}, \mathrm{J})+\mathrm{FIJ}(\mathrm{I}, \mathrm{J})$

$\operatorname{HM}(L 4, L 4+N T C)=E I(I, J)$

ENDIF

HM(L4,NPN2) $=\mathrm{GIJ}(\mathrm{I}, \mathrm{J})$

747

CONTINUE

ENDI

$\mathrm{L} 5=\mathrm{L} 4$

$\mathrm{I}=\mathrm{NTL}$

DO $757 \mathrm{~J}=1$, NTC

$\mathrm{L} 5=\mathrm{L} 5+1$

IF(J.EQ.NTC)THEN

$\mathrm{HM}(\mathrm{L} 5, \mathrm{~L} 5-\mathrm{NTC})=\mathrm{BIJ}(\mathrm{I}, \mathrm{J})$

$\mathrm{HM}(\mathrm{L} 5, \mathrm{~L} 5-1)=\mathrm{AI}(\mathrm{I}, \mathrm{J})+\mathrm{FIJ}(\mathrm{I}, \mathrm{J})$

$\mathrm{HM}(\mathrm{LS}, \mathrm{LS})=\mathrm{DIJ}(\mathrm{I}, \mathrm{J})$

ELSE

IF(J.NE.1) THEN

HM $(L S, L 5-N T C)=B I(1, J)$

$\mathrm{HM}(\mathrm{L} 5, \mathrm{~L} 5-1)=\mathrm{AIJ}(\mathrm{I}, \mathrm{J})$

HM $(L 5, L 5)=\operatorname{DIJ}(1, J)$

$\mathrm{HM}(\mathrm{LS}, \mathrm{LS}+1)=\mathrm{FIJ}(\mathrm{I}, \mathrm{J})$

ELSE HM(LS,NPN2) $=\mathrm{GI}(\mathrm{I}, \mathrm{J})-\mathrm{HI}(\mathrm{I}+1, \mathrm{~J}) * \mathrm{EIJ}(\mathrm{I}, \mathrm{J})$

$\mathrm{HM}(\mathrm{LS}, \mathrm{L} 5-\mathrm{NTC})=\mathrm{BIJ}(\mathrm{I}, \mathrm{J})$

$H M(L 5, L 5)=D I J(1, J)$

HM $(L 5, L 5+1)=A D(I, J)+F I J(I, J)$

ENDIF

$\mathrm{HM} \cdot(\mathrm{L} 5, \mathrm{NPN} 2)=\mathrm{GIJ}(1, \mathrm{~J})-\mathrm{HI}(\mathrm{I}+1, \mathrm{~J}) * \mathrm{EI}(\mathrm{I}, \mathrm{J})$

ENDIF

757

CONTINUE

C

WRITE $(*, 769)$ L5

C769

FORMAT( $/, 1 X$,'O NUMERO TOTAL DE LINHAS E $=$ ',2X,I5)

WRITE $(4444,1800)$ T/60

1800 FORMAT(1X,/' matriz de incidência $\mathrm{HM}(\mathrm{i}, \mathrm{j})$, com inclusão dos

* termos dependentes $\mathrm{Gij}(\mathrm{i}, \mathrm{j})$ na última coluna, no instante $\mathrm{T}=$ 


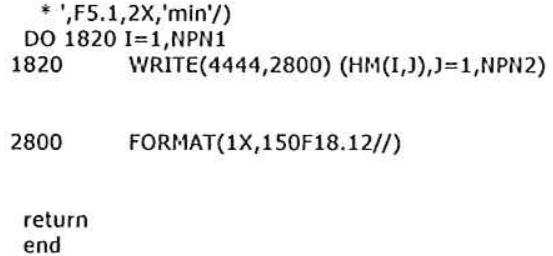

\section{SUB-ROTINA ASSEMBLEVECTF2}

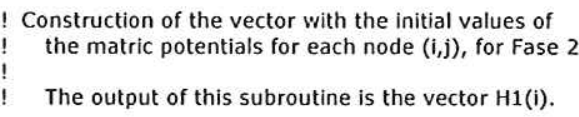

7780

$H 1(L I 3)=H(I, J)$

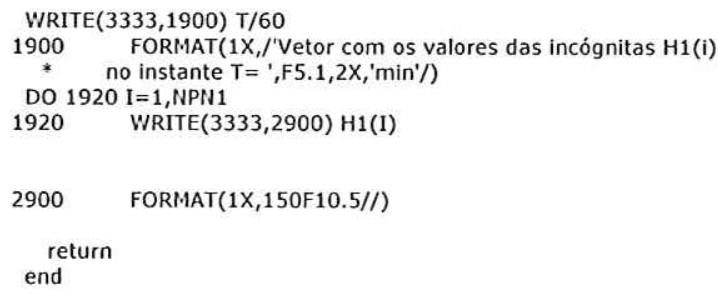

\section{SUB-ROTINA SOILMOISTCONTF2}

G Calculates the soil moisture content of the domain, during the Fase 2 , G using the values of the matric potencial, for each node, that was

$G$ calculated on the subroutine 9 Seidel. The expression used to do that

$\mathrm{G}$ is the Van Genuchten's equation.

Subroutine SoilmoistContF2(TETA, KAPA, C, H, TETAS, GAMA, NCS,

*
$*$
NCSSA, BETA11, BETA, NTL, ALFA, TETAR, 


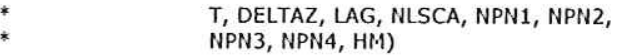

$\mathrm{LO} 1=0$

DO $5501 \mathrm{I}=1$, NLSSA +1

DO $5501 \mathrm{~J}=1, \mathrm{NCS}+\mathrm{I}-1$

$\mathrm{LO} 1=\mathrm{LO} 1+1$

$H(I, J)=H 1(L O 1)$

If the matric potencial $\mathrm{H}$ has a positive value, the program

! considers that the soil moisture is equal to the saturation

moisture, and the hydraulic conductivity is maximum. Else, it

calculates the soil moisture and the hydraulic conductivity

IF(H1(LO1).GE.0) THEN

$\operatorname{TETA}(\mathrm{I}, \mathrm{J})=\operatorname{TETAS}$

$C(I, J)=0$

$\operatorname{KAPA}(I, J)=C K S$

ELSE

$\mathrm{ABH}=\mathrm{ABS}(\mathrm{H}(\mathrm{I}, \mathrm{J}))$

$\$$

$\$$

$\$$

$\$$

$\$$

1502

1001
$\operatorname{TETA}(\mathrm{I}, \mathrm{J})=($ TETAS $-\mathrm{TETAR}) /((1+($ ALFA*ABH $)$

**BETA)**BETA11)+TETAR

$C(I, J)=A L F A *(T E T A S-T E T A R) * B E T A * B E T A 11 *(1+$

(ALFA*ABH)**BETA)

$* *(B E T A 11-1) *\left(A L F A^{*} A B H\right) * *(B E T A-1)$ /

$(((1+(A L F A * A B H) * * B E T A) * *$

BETA11)**2)

ENDIF

$\operatorname{KAPA}(I, J)=\operatorname{CKS} * \operatorname{EXP}(\operatorname{GAMA} *(\operatorname{TETA}(I, J)-(\operatorname{TETAS})))$

CONTINUE

IF(NLSCA.EQ.0) GOTO 2714

$\mathrm{LO} 2=\mathrm{LO} 1$

DO $1502 \mathrm{I}=\mathrm{NLSSA}+2$,NLS- 1

DO $1502 \mathrm{~J}=1, \mathrm{NCS}+\mathrm{I}-2$

$\mathrm{LO} 2=\mathrm{LO} 2+1$

$H(I, J)=H 1(L O 2)$

IF(H1(LO2).GE.0) THEN

$\operatorname{TETA}(I, J)=\operatorname{TETAS}$

$\mathrm{C}(\mathrm{I}, \mathrm{J})=0$

ELSE

$\operatorname{KAPA}(1, \mathrm{~J})=\mathrm{CKS}$

$A B H=A B S(H(I, J))$

$\operatorname{TETA}(I, J)=($ TETAS - TETAR $) /((1+($ ALFA*ABH $)$ **BETA)**BETA11)+TETAR

$C(I, J)=A L F A *($ TETAS - TETAR $) * B E T A * B E T A 11 *(1+$ $($ ALFA*ABH)**BETA)

** $(B E T A 11-1) *($ ALFA*ABH $) * *(B E T A-1) /(((1+$

(ALFA*ABH)**BETA)**

BETA11)**2)

ENDIF

$\operatorname{KAPA}(I, J)=\operatorname{CKS} * \operatorname{EXP}(\operatorname{GAMA} *(\operatorname{TETA}(I, J)-(\operatorname{TETAS})))$

CONTINUE

DO $1001 \mathrm{I}=\mathrm{NLSSA}+2, N \mathrm{NS}-1$

$\operatorname{TETA}(\mathrm{I}, \mathrm{NCS}+\mathrm{I}-1)=$ TETAS 
$\mathrm{LO} 3=\mathrm{LO} 2$

GOTO 2715

2714

C
C
C
C
C

2715

77455

77466

77477

77488

C

C2223

7999

$\$$

$\$$

$\$$

3503

$\mathrm{I}=\mathrm{NLS}$

DO 1002 J =NTC-NCFS +1 , NTC

$\mathrm{LO} 3=\mathrm{LO} 1$

$R=L A G / N L S C A$

IF(R.LT.DELTAZ) THEN

$N L S S A=N L S S A+1$

NLSCA $=$ NLSCA -1

$\mathrm{I}=\mathrm{NLSSA}+1$

DO $77455 \mathrm{I}=1, \mathrm{NPN} 3$

NPN2 $=N P N 2+1$

$N P N 3=N P N 3+1$

NPN4 $=$ NPN4 +1

,I4,3X,'NPN4 =', I4

ENDIF $\quad I=N$ LS

DO $3503 \mathrm{~J}=1$, NTC-NCFS

$\mathrm{LO} 3=\mathrm{LO} 3+1$

$\mathrm{H}(\mathrm{I}, \mathrm{J})=\mathrm{H} 1(\mathrm{LO} 3)$

$C(I, J)=0$

ELSE

ENDIF

CONTINUE
TESTE PARA DETECTAR QUANDO UN NO FICA SEM AGUA NA FASE DE RECESSAO

AUMENTO DO N. DE LINHAS SEM AGUA AUMENTO DE $H(\mathrm{I}, \mathrm{J})$ E DE NPN1 E NPN2

IF(NLSCA.EQ.0) GOTO 7999

$\mathrm{H}(\mathrm{NLSSA}+1, \mathrm{NCS}+\mathrm{I}-1)=0$

TETA $($ NLSSA +1, NCS $+1-1)=$ TETAS

$\mathrm{C}(\mathrm{NLSSA}+1, \mathrm{NCS}+\mathrm{I}-1)=0$

KAPA(NLSSA $+1, N C S+I-1)=C K S$

DO $77455 \mathrm{~J}=1, \mathrm{I}+\mathrm{NTC}$

DO $77466 \mathrm{I}=\mathrm{NPN} 3+1$, NPN 4

DO $77466 \mathrm{~J}=\mathrm{I}-\mathrm{NTC}, \mathrm{I}+\mathrm{NTC}$

$H M(I, J)=0$

DO 77477 ] =I-NTC,NPN1

DO 77488 I=1,NPN1

$$
\operatorname{HM}(I, J)=0
$$

NPN1 $=$ NPN $1+1$, NPN2 $)=0$

WRITE $(*, 2223)$ NPN1,NPN2,NPN3,NPN4

IF(H1(LO3).GE.0) THEN

$\operatorname{TETA}(I, J)=\operatorname{TETAS}$

$\operatorname{KAPA}(I, J)=C K S$

$\mathrm{ABH}=\mathrm{ABS}(\mathrm{H}(\mathrm{I}, \mathrm{J}))$

TETA $(I, J)=($ TETAS - TETAR $) /((1+($ ALFA*ABH $) * * B E T A)$ **BETA11)+TETAR

$C(I, J)=A L F *(T E T A S-T E T A R) * B E T A * B E T A 11 *(1+$ $\left.\left(A L F{ }^{*} A B H\right) * * B E T A\right)$

**(BETA11-1)*(ALFA*ABH)**(BETA-1) $/(((1+($ ALFA

*ABH)**BETA)**

BETA11)**2)

$\operatorname{KAPA}(I, J)=\operatorname{CKS}^{*} \operatorname{EXP}(\operatorname{GAMA} *(\operatorname{TETA}(I, J)-(\operatorname{TETAS})))$

$\operatorname{TETA}(\mathrm{I}, \mathrm{J})=\operatorname{TETAS}$ 


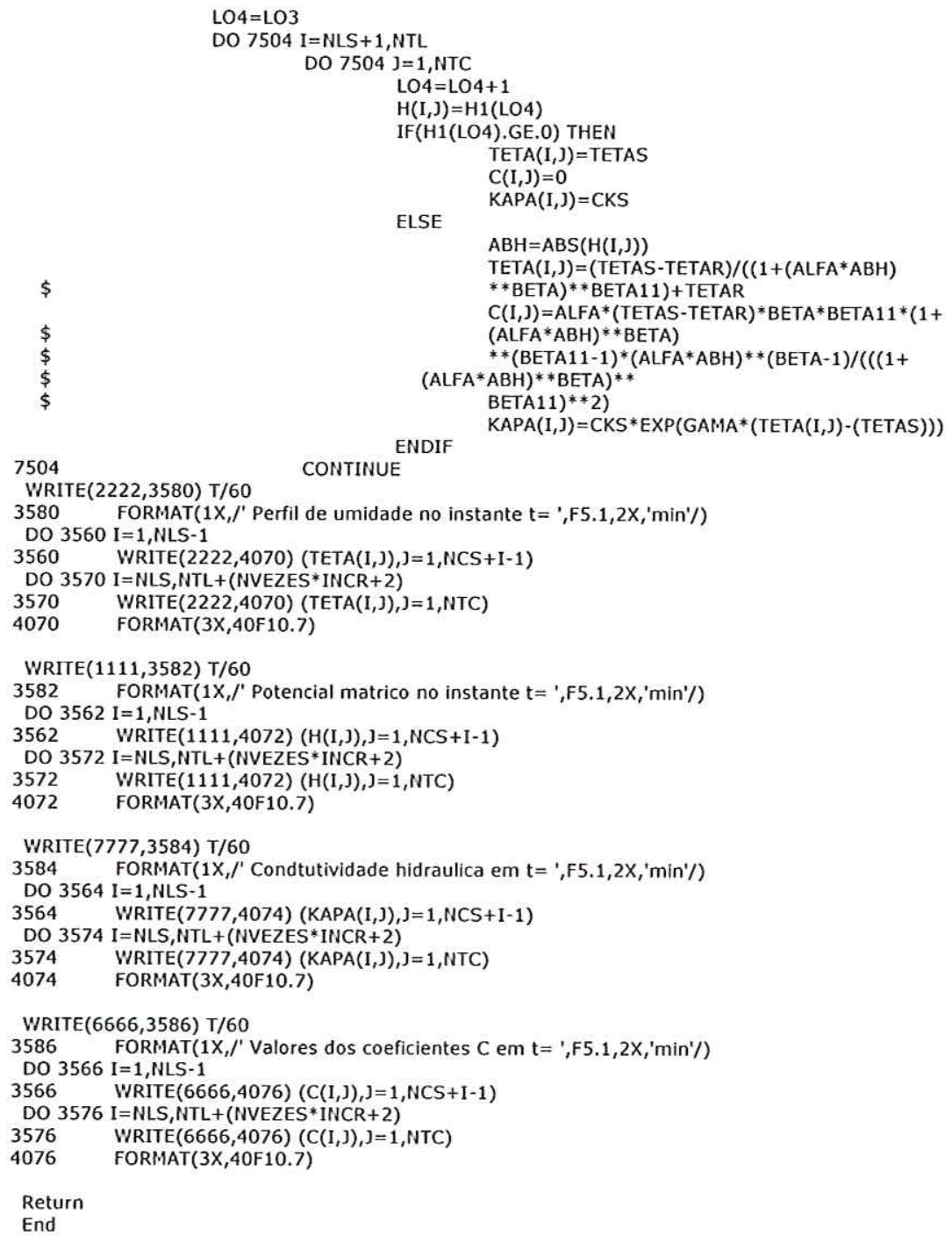

\section{SUB-ROTINA WATERVOLUMEF2}

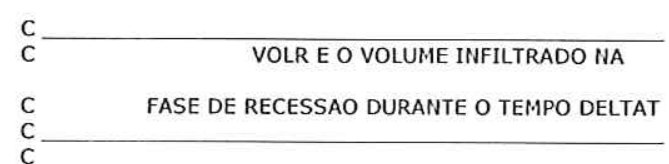
Subroutine WaterVolumef2(TETA, DELTAT, TETAS, NTL, NLSSA
* NCS, NLS, DELTAZ, DELTÁ, NCFS,
CANG, TACRE, LCOMP, $X, Y$, NOMEFI,
NUMERO, TETAI, H, HI, LAG, ML, NTC,
TEMPO, VOL1, DIF, T, DELTAT1, NTC2,
$T 2$, VOLR, VOL)

common /bisimul/ il, im

REAL LAG

Dimension $\operatorname{TeTA}(200,200), X(200), Y(200), \operatorname{TETAI}(200,200)$, 


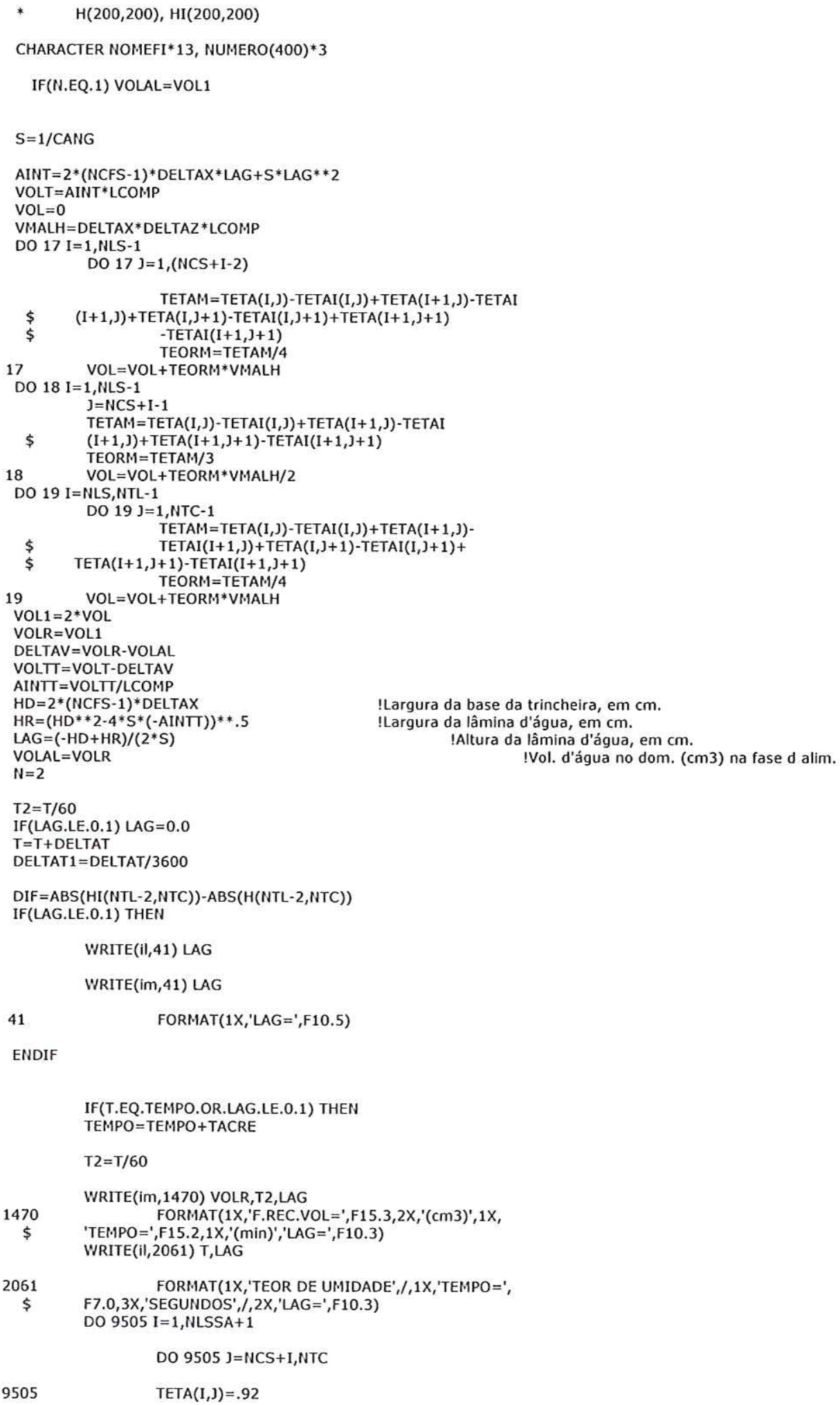


DO $6506 \mathrm{I}=1, \mathrm{NLSSA}+1$

6506 WRITE(il, 2072)(TETA(I,J), J=1,NTC)

DO $6508 \mathrm{I}=\mathrm{NLSSA}+2, \mathrm{NLS}$ DO $6508 \mathrm{~J}=\mathrm{NCS}+\mathrm{I}, \mathrm{NTC}$

6508 $\operatorname{TETA}(\mathrm{I}, \mathrm{J})=0.92$

DO $1509 \mathrm{I}=$ NLSSA +2 NLS

1509

$\mathrm{I}=\mathrm{NLS}$ $\operatorname{TETA}(\mathrm{I}, \mathrm{NCS}+\mathrm{I}-1)=$ TETAS

DO 9546 J =NTC-NCFS +2 , NTC

$\begin{array}{cc}9546 & \operatorname{TETA}(\mathrm{I}, \mathrm{J})=\text { TETAS } \\ 2545 & \text { DO } 2545 \mathrm{I}=\mathrm{NLSSA}+2, \mathrm{NLS} \\ & \text { WRITE }(\mathrm{il}, 2072)(\operatorname{TETA}(\mathrm{I}, \mathrm{J}), \mathrm{J}=1, \mathrm{NTC}) \\ & \text { DO } 7515 \mathrm{I}=\mathrm{NLS}+1, \mathrm{NTL}\end{array}$

DO $7515 \mathrm{I}=\mathrm{NLS}+1, \mathrm{NTL}$

$\begin{array}{ll}7515 & \text { WRITE(il, 2072)(TETA(I, J), J=1, NTC) } \\ 2072 & \text { FORMAT }(1 X, 40 \mathrm{~F} 6.5)\end{array}$

DO $4445 \mathrm{I}=1, \mathrm{NTL}$

DO $4445 \mathrm{~J}=1$, NTC- 1

4445

N2 $=2 *$ NTC- $]$

$M L=M L+1$

$M L=M L+1$

NOMEFI ='MATRIZ'//NUMERO $(M L) / /$ '.DAT

OPEN $(1$, FILE $=$ NOMEFI,STATUS $=$ 'new'

NTC $2=2 *$ NTC -1

5057

$X(I)=I$

DO $3060 \mathrm{~J}=1, \mathrm{NTL}$

$3060 \quad Y(J)=3$

WRITE $(1, *)(X(I), I=1, N T C 2)$

WRITE $(1, *)(Y(J), J=1, N T L)$

5056

WRITE $(1, *)(\operatorname{TETA}(I, J), I=1, N T L)$

ENDIF

Return

End

\section{SUB-ROTINA INCRLINESF2}

G Increasing the number of lines of the domain, using the variables ACTIV, NVEZES and INCR, for Fase 2.

The variable ACTIV sets the diference of matric potential, at the

last line, that is necessary to activate the profile

The variable NVEZES sets the number of times that the profile will

G be activated

G The variable INCR sets the number of lines increased each time

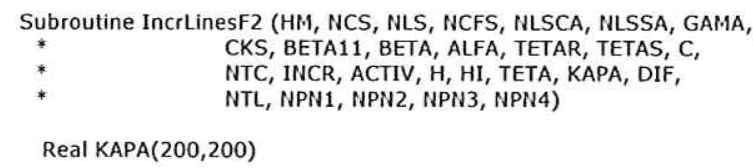

Dimension HM(2000,2000), H(200,200), HI(200,200), $\operatorname{TETA}(200,200)$,

* $\quad C(200,200)$

IF(ABS(DIF).GE.ACTIV) THEN

DO $97119 \mathrm{I}=\mathrm{NTL}+1,(\mathrm{NTL}+\mathrm{INCR}+2)$

DO $97119 \mathrm{~J}=1$, NTC

$\mathrm{H}(\mathrm{I}, \mathrm{J})=\mathrm{HI}(\mathrm{I}, \mathrm{J})$

$A B H=A B S(H(I, J))$

$\$$

**BETA $)^{* * B E T A 11)+T E T A R}$

$C(I, J)=A L F A *($ TETAS - TETAR $) * B E T A * B E T A 11 *(1+$

(ALFA*ABH)**BETA)

$* *(B E T A 11-1) *($ ALFA*ABH $) * *(B E T A-1) /(((1+$

(ALFA*ABH)**BETA)**

BETA11)**2)

97119

$\operatorname{KAPA}(I, J)=C K S * \operatorname{EXP}(G A M A *(\operatorname{TETA}(I, J)-(\operatorname{TETAS})))$ 
DO $71455 \mathrm{I}=1$, NPN3

DO $71455 \mathrm{~J}=1, \mathrm{I}+\mathrm{NTC}$

71455

$\operatorname{HM}(\mathrm{I}, \mathrm{J})=0$

DO $71466 \mathrm{I}=\mathrm{NPN} 3+1, \mathrm{NPN} 4$

DO $71466 \mathrm{~J}=\mathrm{I}-\mathrm{NTC}, \mathrm{I}+\mathrm{NTC}$

71466

$\operatorname{HM}(1, j)=0$

DO $71477 \mathrm{I}=$ NPN4 +1 , NPN 1

DO 71477 J=I-NTC,NPN1

71477

$\operatorname{HM}(I, J)=0$

DO 71488 I=1,NPN1

71488

$\operatorname{HM}(I, N P N 2)=0$

$N T L=N T L+I N C R$

$\mathrm{LL}=0$

DO $9888 \mathrm{I}=1$, NLSSA

9888

$\mathrm{LL} 1=0$

$\mathrm{LL}=\mathrm{LL}+\mathrm{I}$

9889

DO $9889 \mathrm{I}=1$, NLSCA

$\mathrm{LL2}=\mathrm{NTC}-\mathrm{NCFS}$

$\mathrm{LL}=N \mathrm{NTC}^{*}(\mathrm{NTL}-\mathrm{NLS})$

$N P N 1=N C S+N L S S *^{*} N C S+L L+N L S C A *(N C S+N L S S A)+L L 1+L L 2+L L 3$

$N P N 2=N P N 1+1$

NPN3 $=$ NPN1 $1-\mathrm{LL} 3$

NPN4 $=$ NPN $1-$ NTC

C

WRITE $(*, 9224)$ NPN1,NPN2,NPN3,NPN4

$\begin{aligned} & \text { C9224 } \\ & C \$\end{aligned} \quad, 14,3 X, ' N P N 4=', 14$

FORMAT $\left(/, 5 X, ' N P N 1=', 14,3 X\right.$, 'NPN2 $^{2}=1,14,3 X, ' N P N 3=$

ENDIF

Return

End

\section{SUB-ROTINA INCIDFASE2}

Determining the coeficients of the Incidence Matrix,

Aij, Bij, Dij, Eij, Fij and Gij, for the Fase 2, according to the

equation 4 of Tabuada et. al (1995), that is the discretization of

two-dimensional Richards' Equation.

The Fase 2 (two) means the recession fase, occurring when

water infiltrates, after cut-off.

Input variables: NLS, NCS, NTL, NTC, NCFS, DELTAX, DELTAZ, CANG, CKS, GAMA,

TETAS, TETAR, ALFA, BETA (from input file dados.dat)

NLSSA (number of lines without water inside the furrow, from Bidisul)

NLSCA (number of lines with water inside the forrow, from Bidisul)

$\mathrm{H}(\mathrm{i}, \mathrm{j})$ (values of matric potential, from Soill-4oistContF2)

$\mathrm{HI}(i, j)$ (initial values of matric potential, from Bidisul)

$\operatorname{KAPA}(i, j)$ (from SoilmoistContF2)

BETA11 ( $m$ de Van Genuchten, from SoilmoistContF2)

$C(i, j)$ (derivation of Van Genuchten equation, from SoilmoisContF2)

DELTAT1 (DELTAT in hours, from Bidisul)

Output variables: AIJ, BIJ, EIJ, FIJ, DIJ, GIJ (coeficients of the incidence matrix, to assembleMatF3)

Subroutine incidFase2(DELTAT1, NCFS, BETA11, BETA, ALFA, TETAR, H

* TETAS, GAMA, C, CKS, CANG, DELTAZ, NLSSA, T,

* NLSCA, DELTAX, NLS, KAPA, HI, NTC, NTL, NCS,

REAL KAPA $(200,200)$

Dimension AIJ $(200,200), \mathrm{BIJ}(200,200), \mathrm{DIJ}(200,200), \mathrm{H}(200,200)$,

* $\operatorname{EIJ}(200,200), \mathrm{FI}(200,200), \mathrm{GI}(200,200), \mathrm{C}(200,200)$,

$\mathrm{HI}(200,200)$

$\mathrm{C}=$

C = CALCULO DOS Aij, Bij, Dij, Eij E Fij =

$=$ PARA AS CONDICOES DE FRONTEIRA =

NA SITUACAO DE RECESSAO 


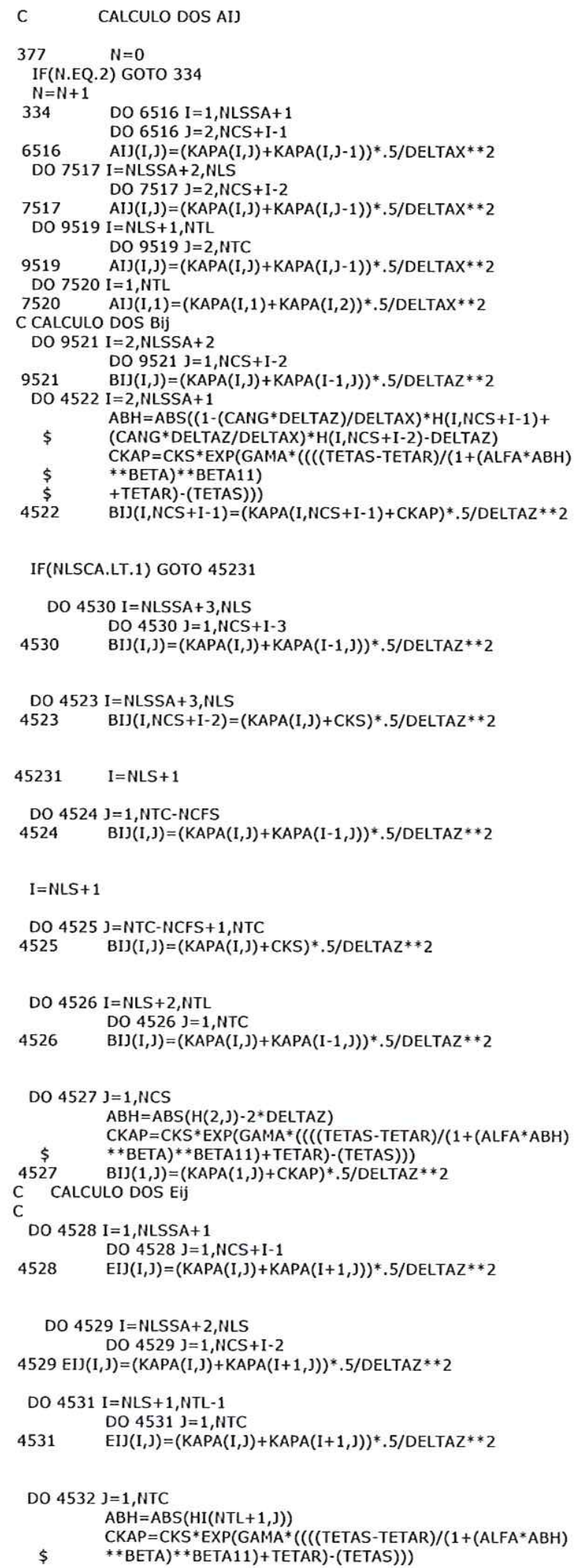




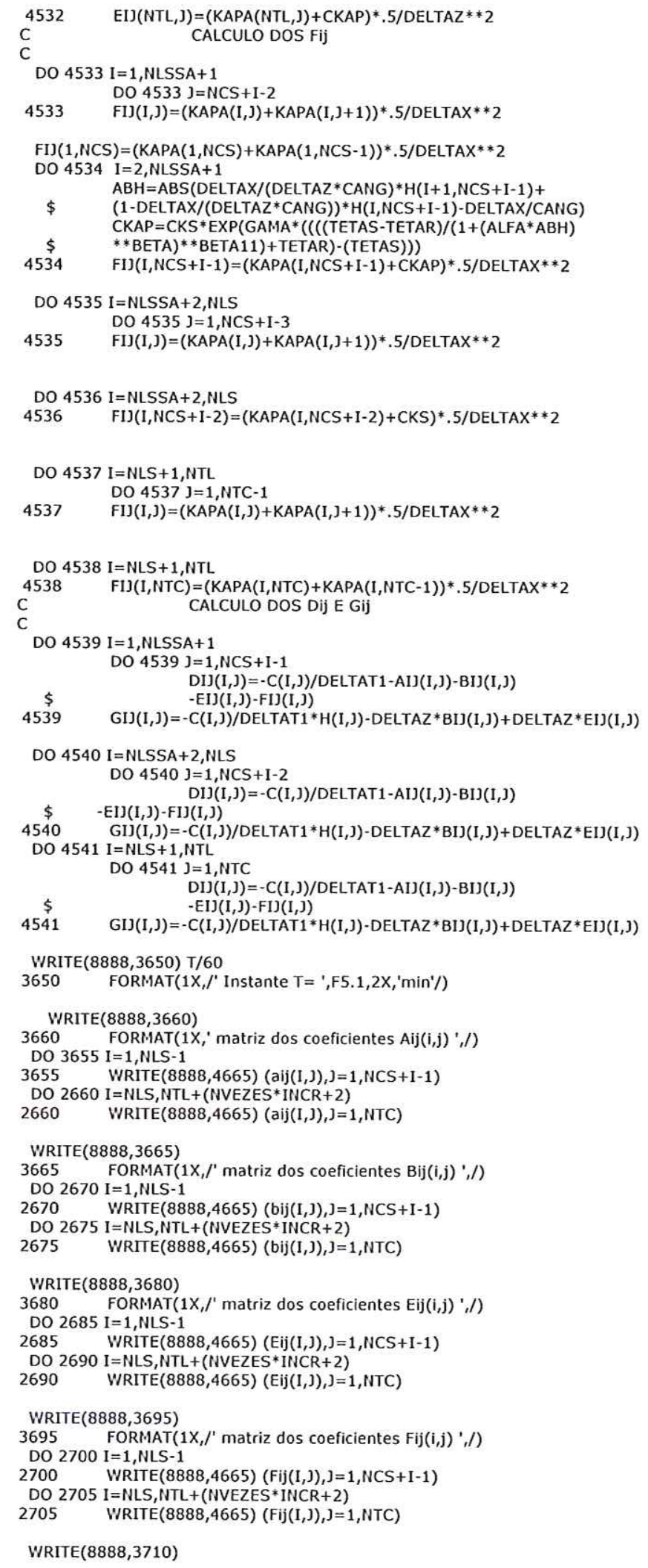




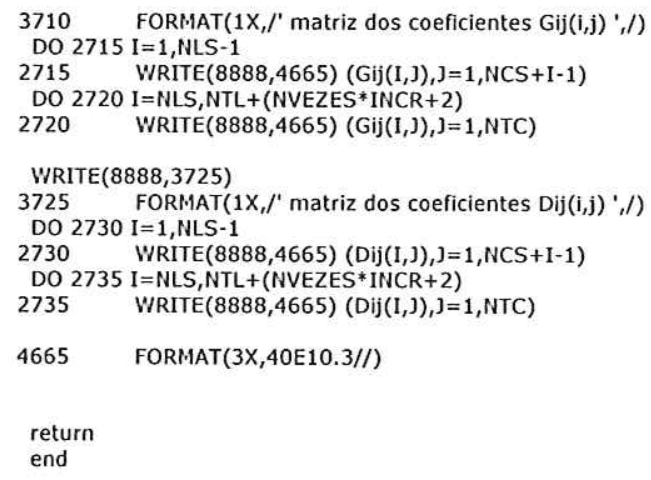

\section{SUB-ROTINA ASSEMBLEMATF3}

! Construction of the incidence matrix for Fase 3, using the coeficients that was calculated on incidfase 3

! The output of this subroutine is the incidence matrix $\operatorname{HM}(i, j)$.

Subroutine assemblematF3 (AI), BIJ, EIJ, FI), DI), GI), NTL, NCFS,

* NTC, NLS, NPN2, DELTAX, CANG, DELTAZ, NCS, HI, HM, T, NPN1)

Dimension $\operatorname{AIJ}(200,200), \operatorname{BIJ}(200,200), \operatorname{DIJ}(200,200), \operatorname{EIJ}(200,200)$, * FIJ $(200,200), \mathrm{GI}(200,200), \mathrm{HI}(200,200), \operatorname{HM}(2000,2000)$

6668 $\mathrm{L}=0$
DO $777 \mathrm{I}=1, \mathrm{NLS}-1$

DO $777 \mathrm{~J}=1, \mathrm{NCS}+\mathrm{I}-1$ $\mathrm{L}=\mathrm{L}+1$
IF(I.NE.1)THEN

$\$$
IF(J.EQ.NCS+I-1)THEN

$\operatorname{HMM}(\mathrm{L}, \mathrm{L}-1)=\mathrm{AIJ}(\mathrm{I}, \mathrm{J})+\mathrm{BIJ}(\mathrm{I}, \mathrm{J}) * \mathrm{DELTAZ}$

*CANG/DELTAX
$H M(L, L)=$ DI $(I, J)+(1-$ CANG*DELTAZ/DELTAX $)$ *BIJ $(\mathrm{I}, \mathrm{J})+($ (1-DELTAX/(CANG*DELTAZ)) *FI $(\mathrm{I}, \mathrm{J})$

$\mathrm{HM}(\mathrm{L}, \mathrm{L}+\mathrm{NCS}+\mathrm{I}-1)=\mathrm{EIJ}(\mathrm{I}, \mathrm{J})+\mathrm{FIJ}(\mathrm{I}, \mathrm{J})$

*DELTAX/(DELTAZ*CANG)

HM $(L, N P N 2)=G I J(I, J)+(D E L T A X / C A N G)$

*FIJ $(\mathrm{I}, \mathrm{J})+\operatorname{DELTAZ} * \mathrm{BIJ}(\mathrm{I}, \mathrm{J})$

ELSE

IF(J.NE.1)THEN

$\mathrm{HM}(\mathrm{L}, \mathrm{L}-(\mathrm{NCS}+\mathrm{I}-2))=\mathrm{BI}(\mathrm{I}, \mathrm{J})$

$\mathrm{HM}(\mathrm{L}, \mathrm{L}-1)=\mathrm{AIJ}(\mathrm{I}, \mathrm{J})$

$H M(L, L)=D I J(I, J)$

$\mathrm{HM}(\mathrm{L}, \mathrm{L}+1)=\mathrm{FIJ}(\mathrm{I}, \mathrm{J})$

$H M(L, L+N C S+1-1)=E I J(I, J)$

$H M(L, N P N 2)=G I J(I, J)$

ELSE

$H M(L, L-(N C S+I-2))=B I J(I, J)$

$\operatorname{HM}(\mathrm{L}, \mathrm{L})=\mathrm{DIJ}(\mathrm{I}, \mathrm{J})$

$\mathrm{HM}(\mathrm{L}, \mathrm{L}+1)=\mathrm{AIJ}(\mathrm{I}, \mathrm{J})+\mathrm{FIJ}(\mathrm{I}, \mathrm{J})$

$H M(L, L+N C S+I-1)=E[J(I, J)$

ENDIF

$\mathrm{HM}(\mathrm{L}, \mathrm{NPN} 2)=\mathrm{GI}(\mathrm{I}, \mathrm{J})$

ENDIF

ELSE

IF(J.EQ.NCS)THEN

$H M(L, L-1)=A I J(I, J)+F I J(I, J)$

$\mathrm{HM}(\mathrm{L}, \mathrm{L})=\mathrm{DI}(\mathrm{I}, \mathrm{J})$

$H M(L, L+N C S)=B I J(I, J)+E I J(I, J)$

$H M(L, N P N 2)=G I J(I, J)+2 * \operatorname{DELTAZ} * B I J(I, J)$

ELSE

IF(J.NE.1)THEN 
$\operatorname{HM}(\mathrm{L}, \mathrm{L}-1)=\mathrm{AIJ}(\mathrm{I}, \mathrm{J})$

$H \cdot M(L, L)=D I J(I, J)$

$H M(L, L+1)=F I)(I, J)$

$H M(L, L+N C S)=B I(I, J)+E I J(I, J)$

$\operatorname{HM}(L, N P N 2)=G I J(I, J)+2 * D E L T A Z$

$* B I J(I, J)$

ELSE

$H M(L, L)=D I J(I, J)$

$H M(L, L+1)=A I J(I, J)+F I J(I, J)$

$H M \cdot(L, L+N C S)=B I J(I, J)+E I J(I, J)$

$H M(L, N P N 2)=G I J(1, J)+2 * D E L T A Z$

$\$$

*BIJ $(I, J)$

777

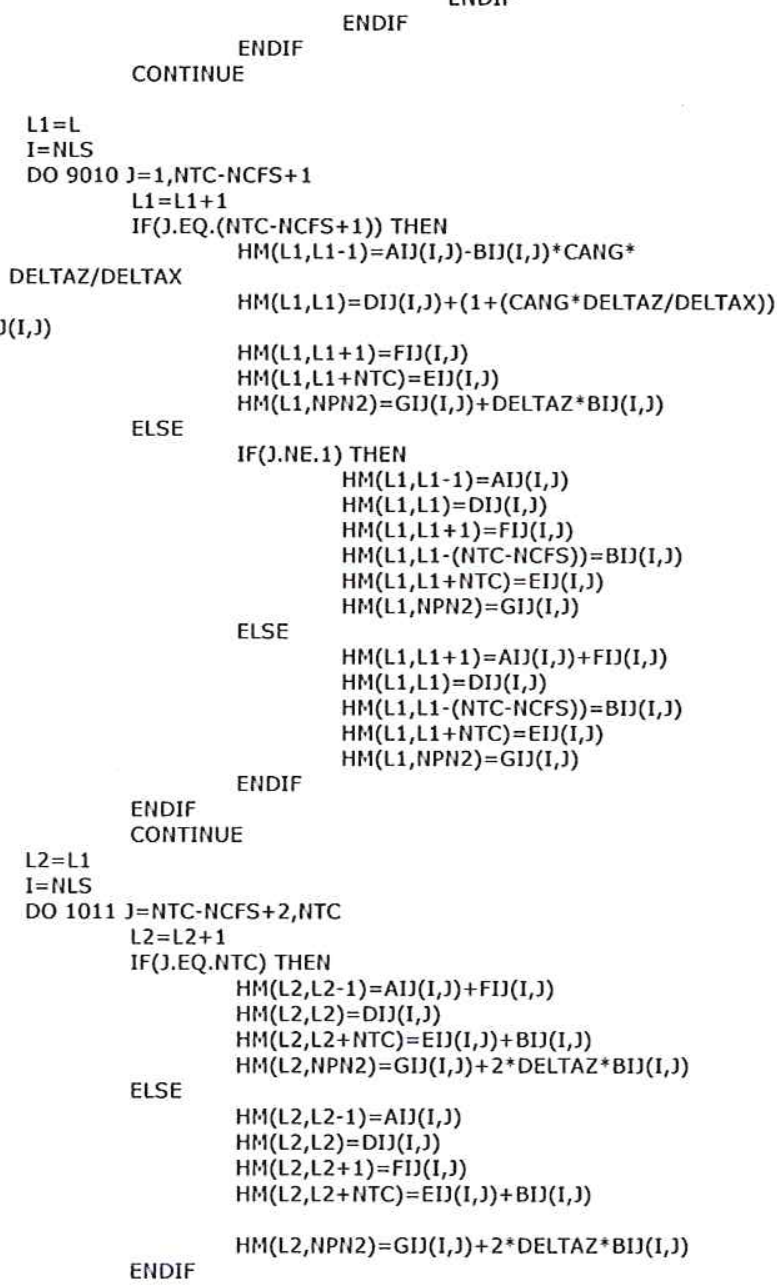
CONTINUE

CONTINUE 


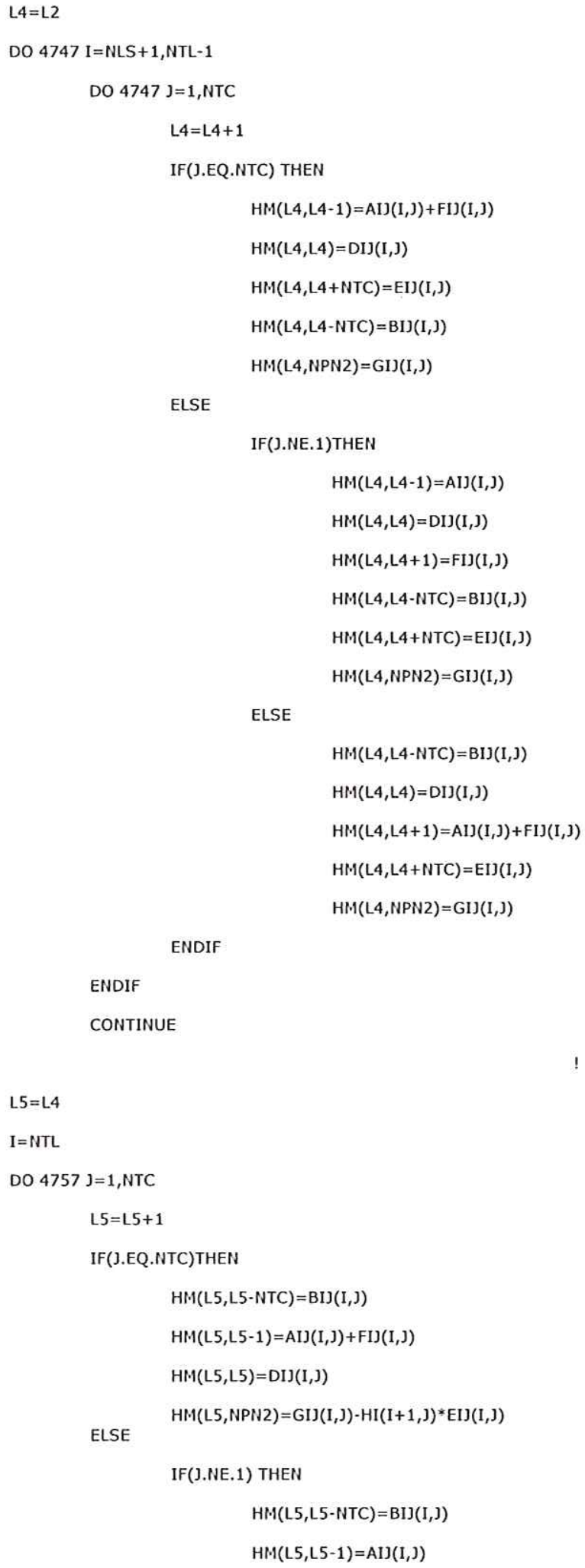




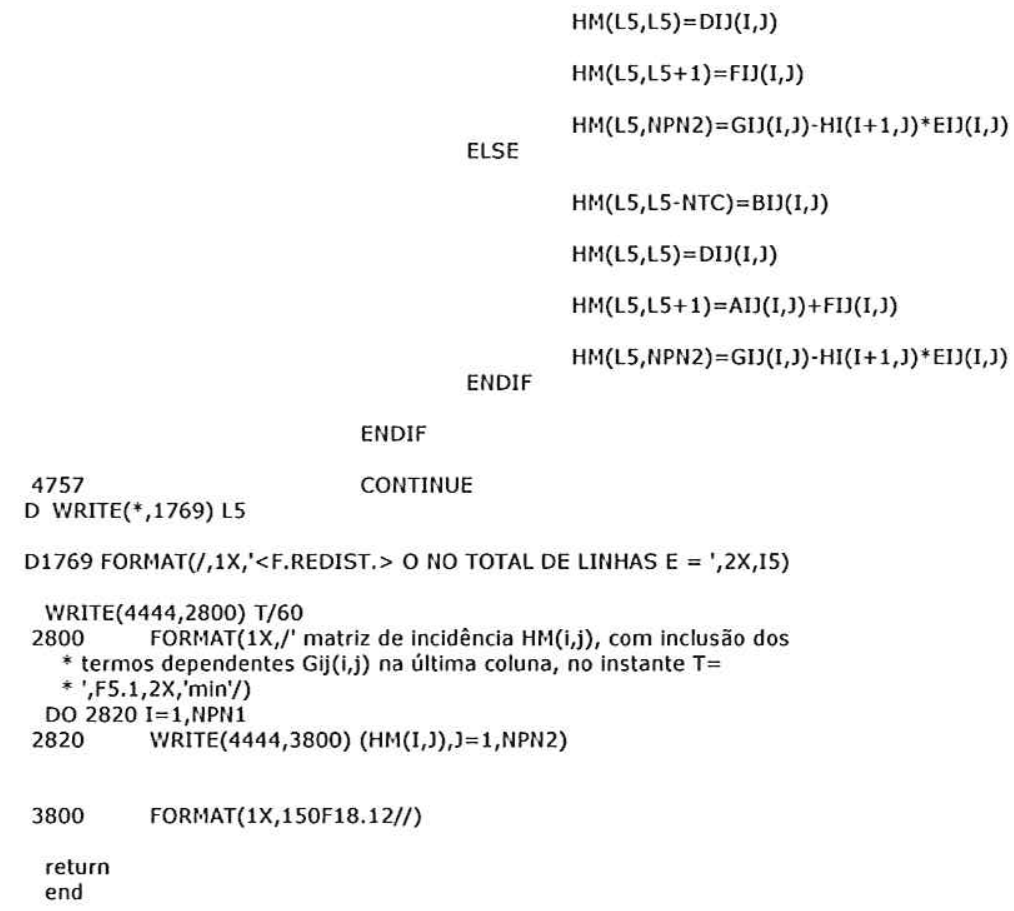

\section{SUB-ROTINA ASSEMBLEVECTF3}

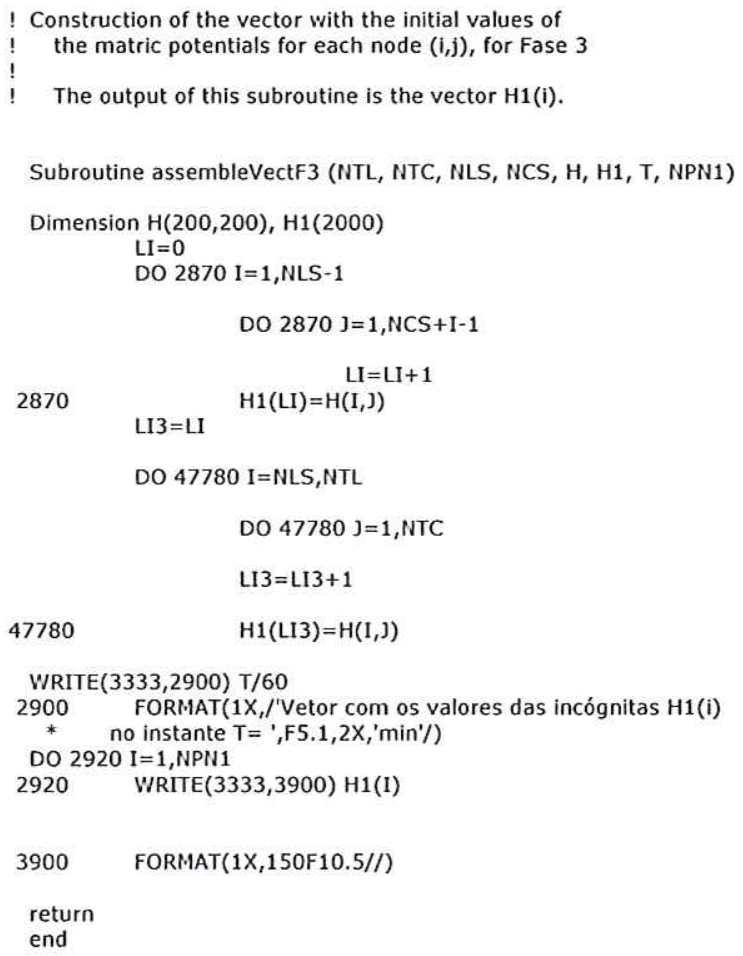

\section{SUB-ROTINA WATERVOLUMEF3}




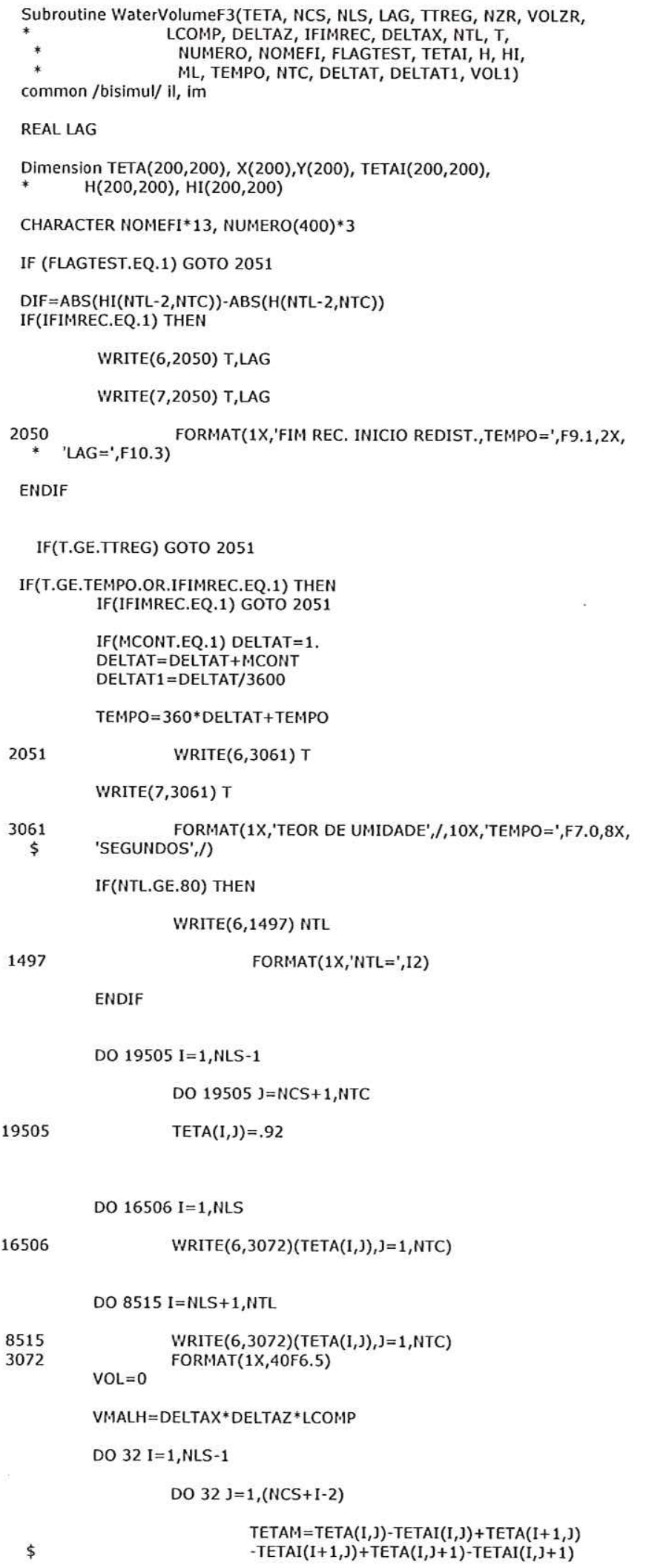




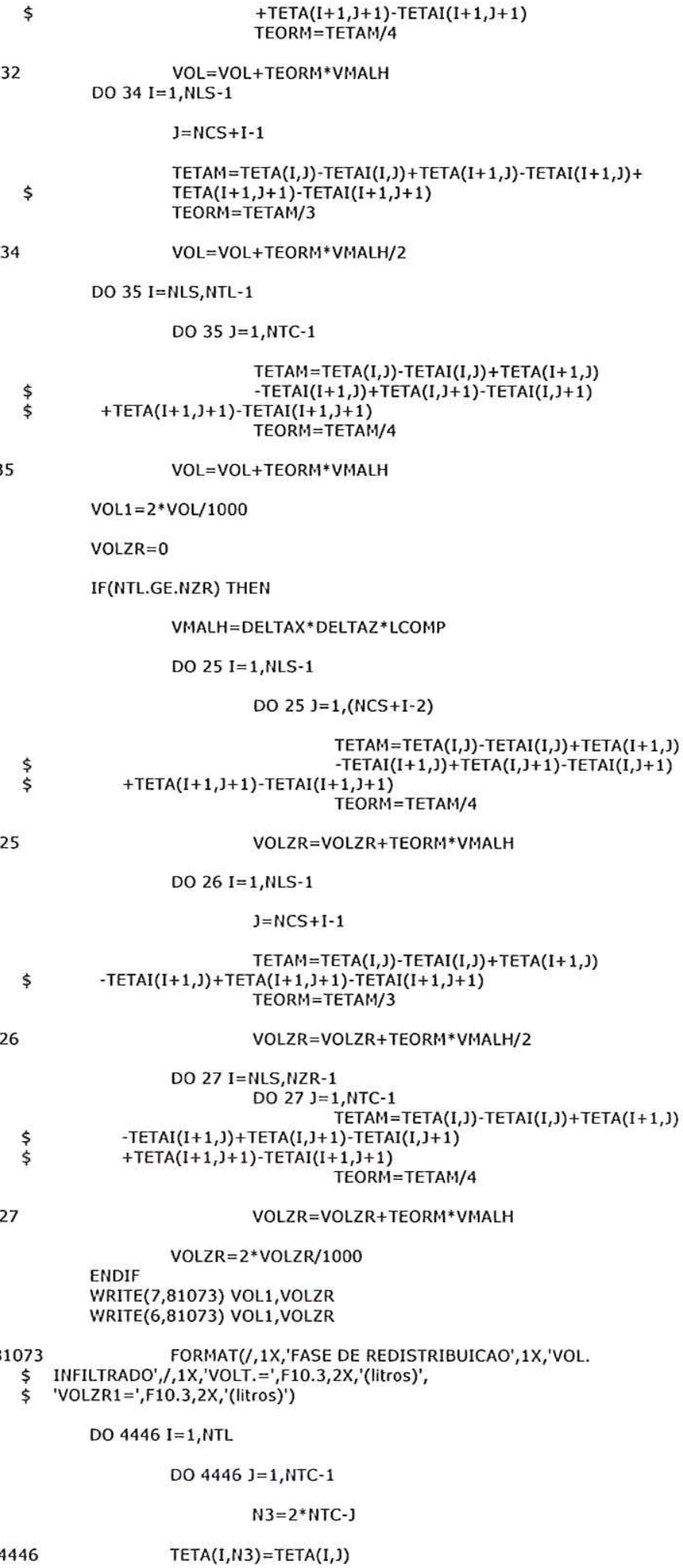




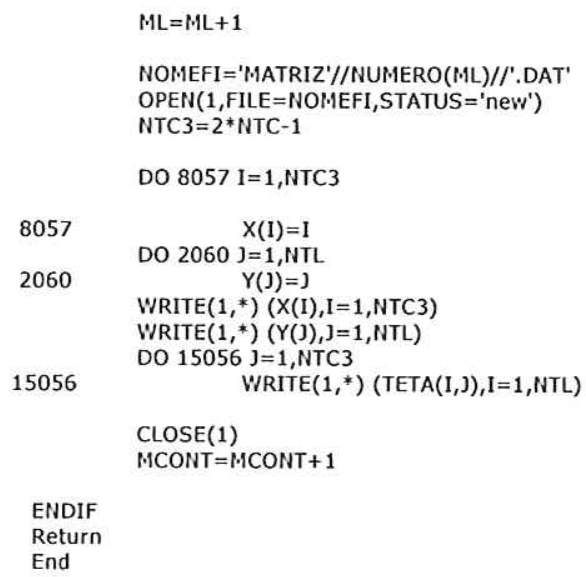

\section{SUB-ROTINA INCRLINESF3}

G Increasing the number of lines of the domain, using the variables G ACTIV, NVEZES and INCR, for Fase 1.

$G$ The variable ACTIV sets the diference of matric potential, at the

G last line, that is necessary to activate the profile

$G$ The variable NVEZES sets the number of times that the profile will

$\mathrm{G}$ be activated

$G$ The variable INCR sets the number of lines increased each time

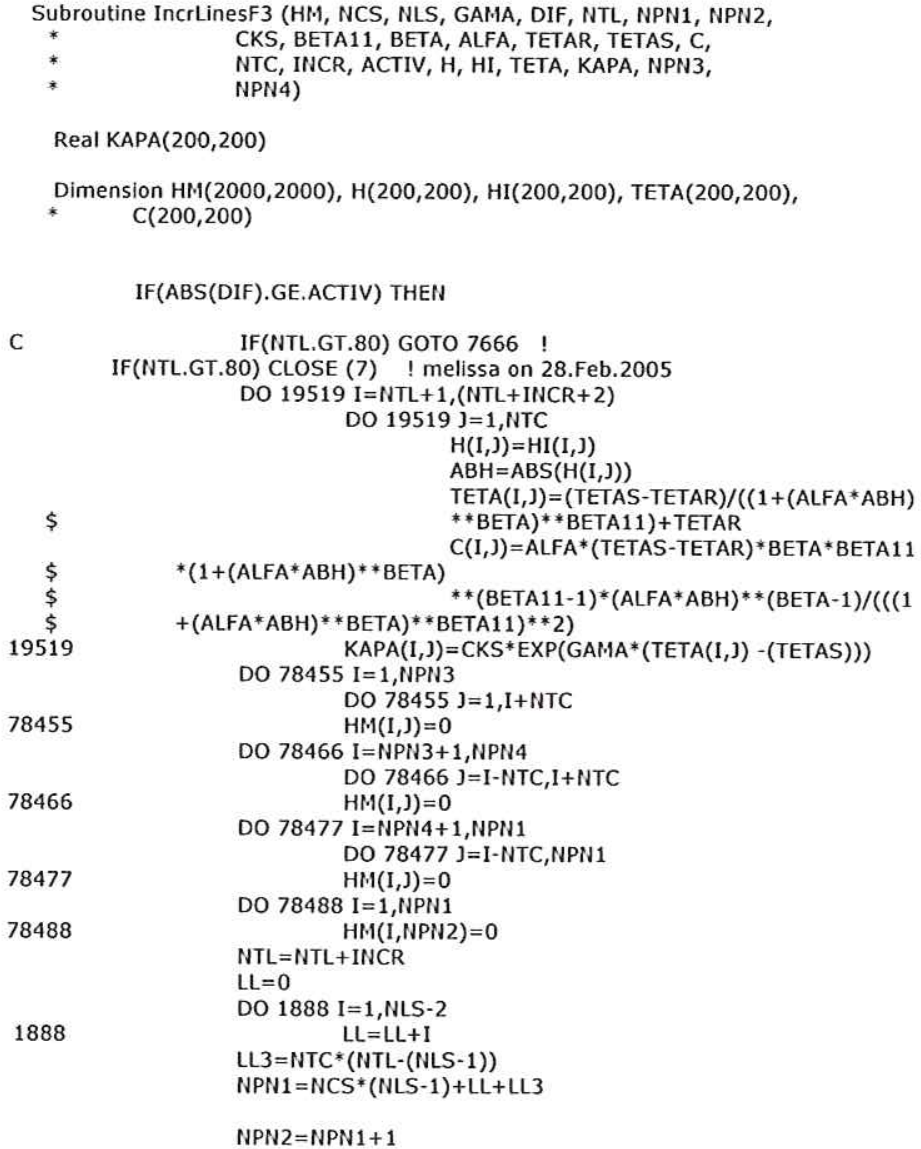

78488 


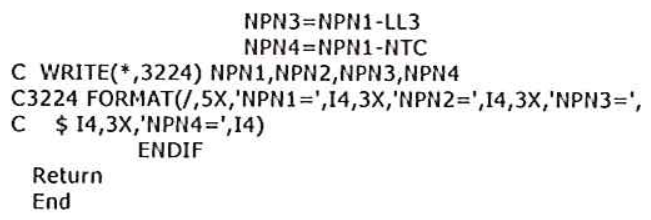

\section{SUB-ROTINA INCIDFASE3}

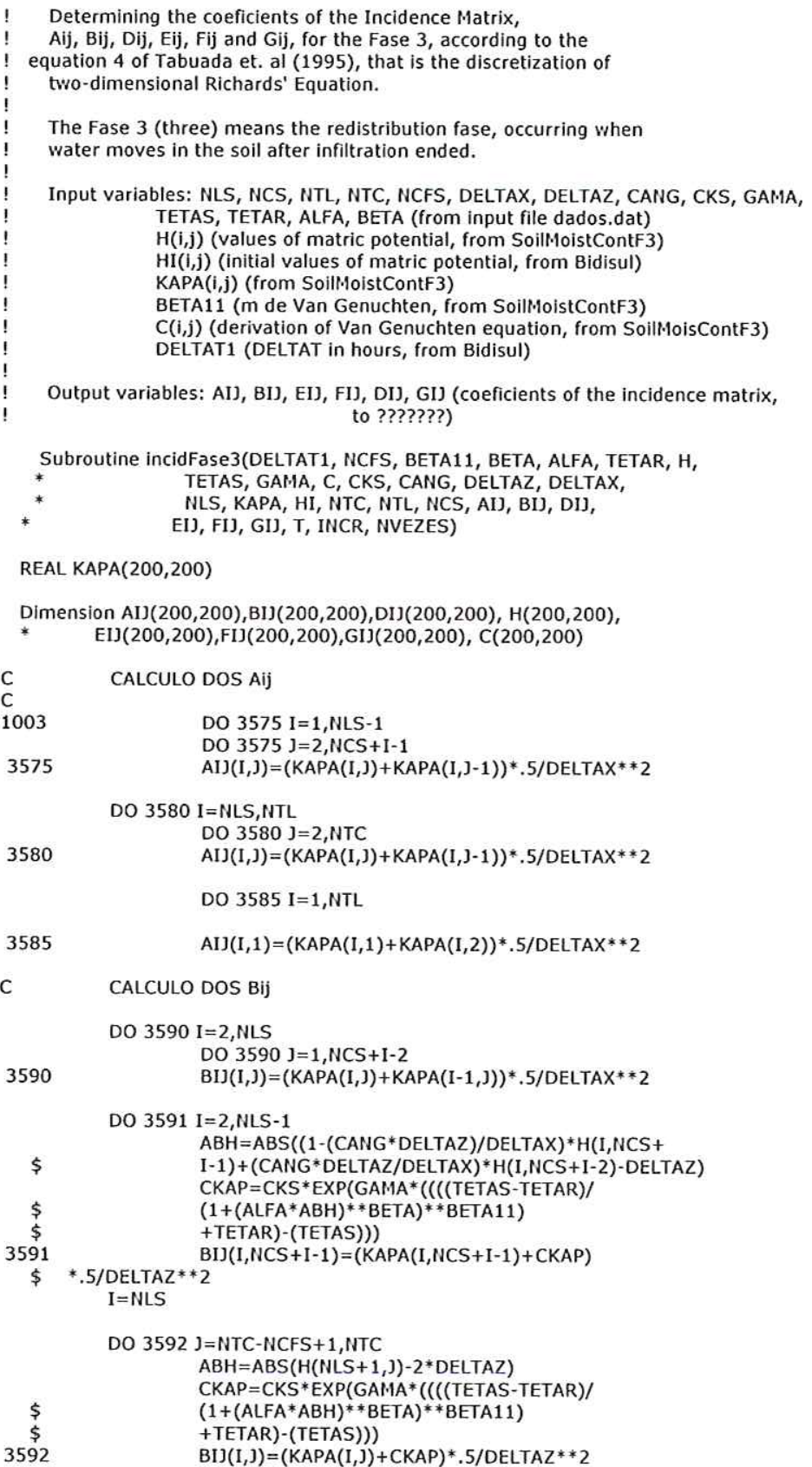

DO $3595 \mathrm{I}=\mathrm{NLS}+1$, NTL 


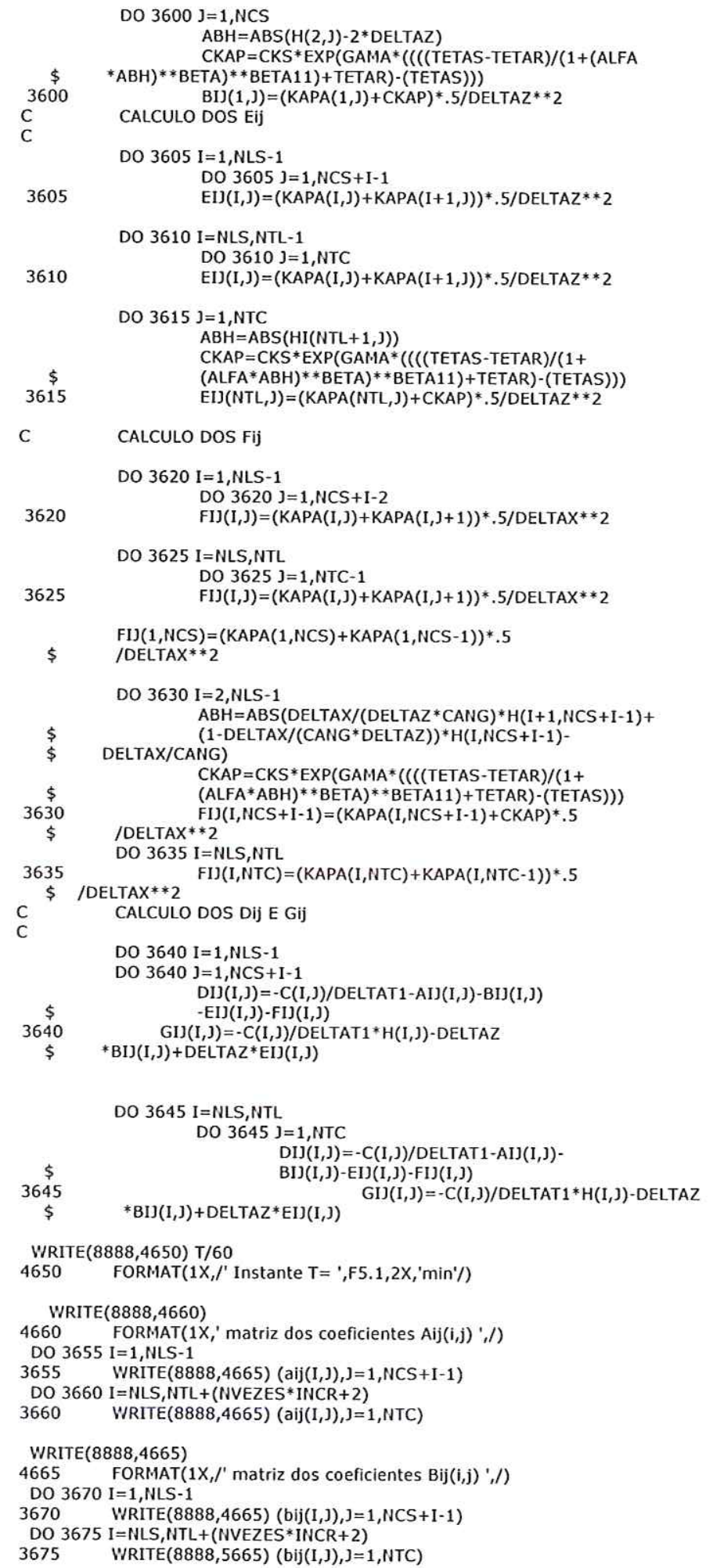




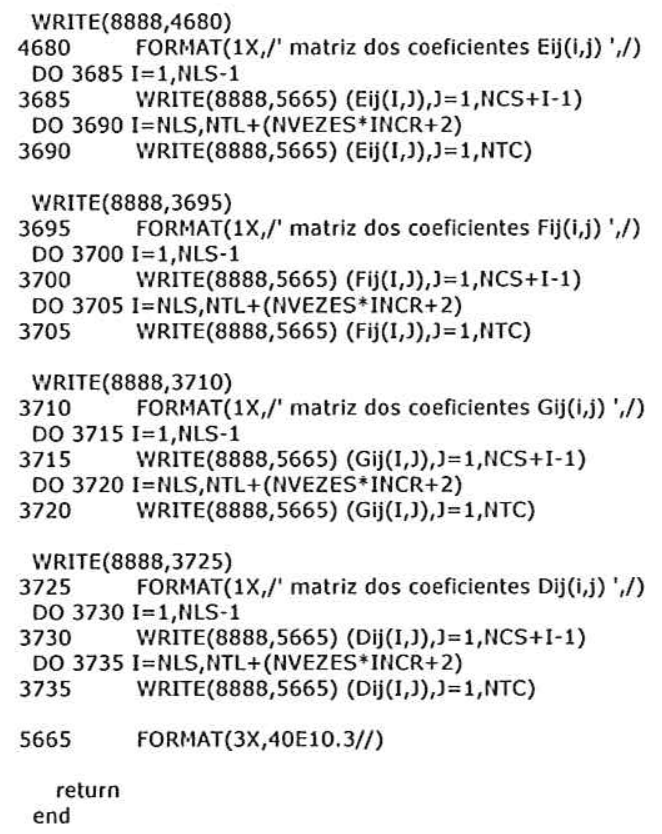

